Universidad Politécnica de Madrid

Escuela Técnica Superior de Arquitectura

\title{
TESIS
}

Influencia del microclima de proximidad frente a datos climáticos de referencia.

Aplicación en la zona climática D: el caso de Zaragoza

\author{
AUTOR \\ Ricardo Tendero Caballero, arquitecto \\ DIRECTORES \\ Margarita de Luxán García de Diego \\ César Bedoya Frutos
}


2 de 406 
A María, Ana y Miguel

su cariño tras mis ausencias,

ha sido mi mayor estímulo 
4 de 406 


\section{ÍNDICE GENERAL}

RESUMEN

ABSTRAT

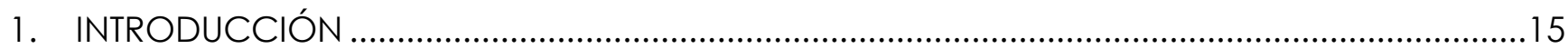

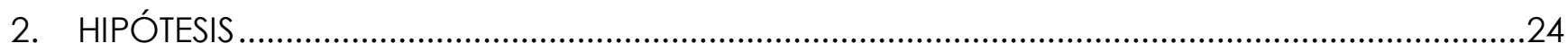

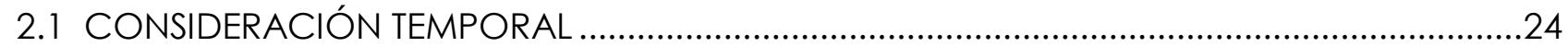

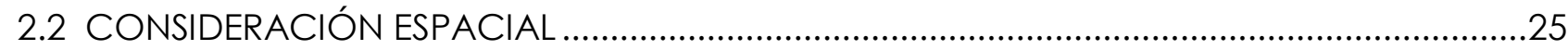

2.3 CONSIDERACIÓN DEL POTENCIAL DE MEJORA …............................................................25

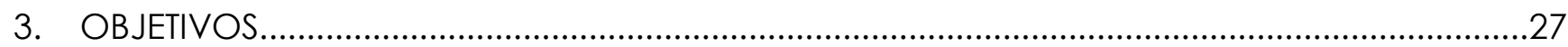

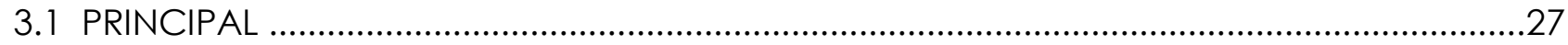

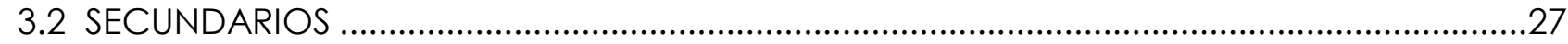

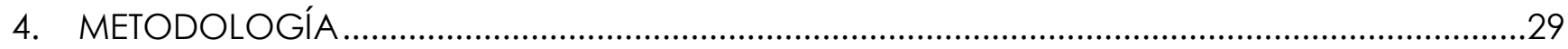

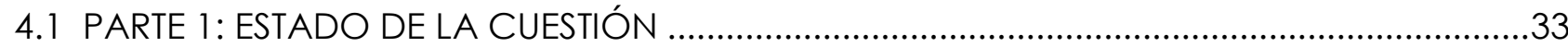

4.2 PARTE 2: RECOGIDA Y TRATAMIENTO DE LOS DATOS. ...................................................33

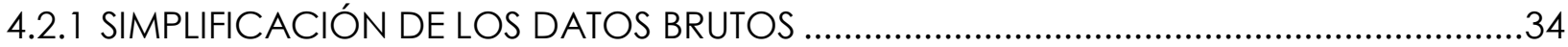

4.2.2 ELECCIÓN DE VALORES Y PERIODOS RELEVANTES Y RELLENO DE

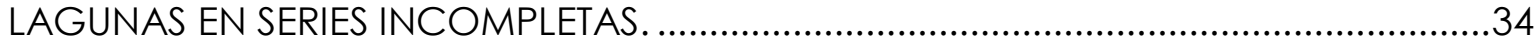

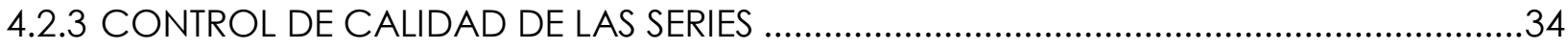

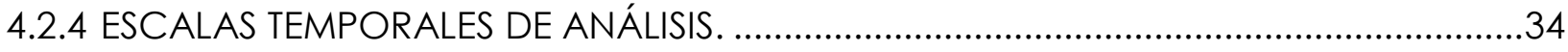

4.2.5 PRESTACIONES (EXIGENCIAS) PARA UN USO CONFORTABLE DE

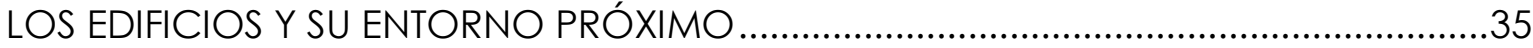

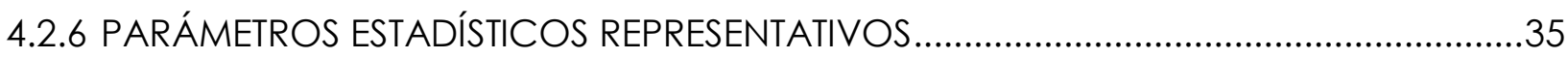

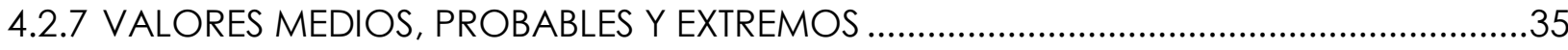

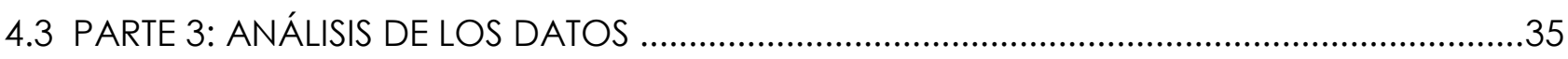

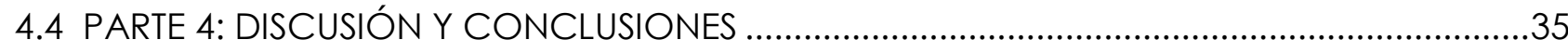

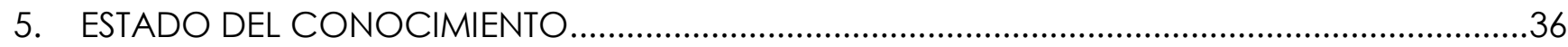

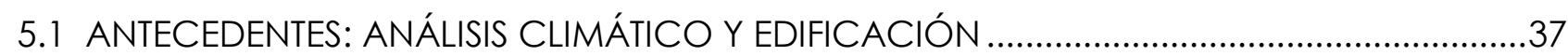

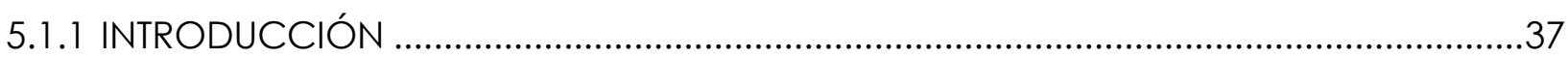

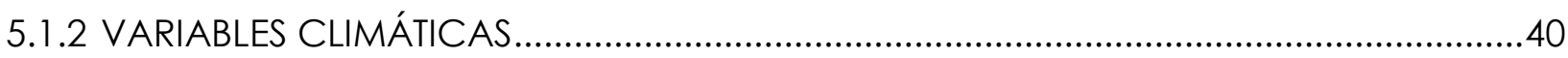

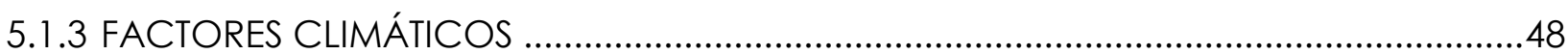

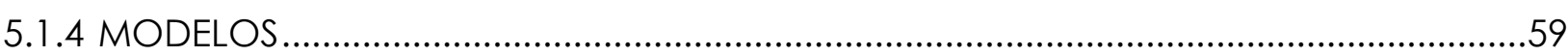

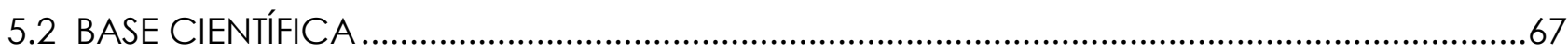

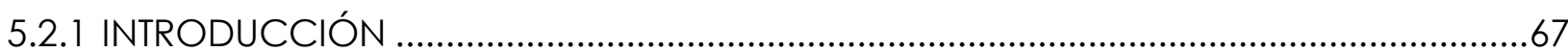

5.2.2 INFLUENCIA DEL CLIMA EN EL BALANCE DE FLUJO TÉRMICO DE LOS EDIFICIOS

5.2.3 FUENTES DE INFORMACIÓN SOBRE BASES CLIMATOLÓGICAS EN EDIFICACIÓN

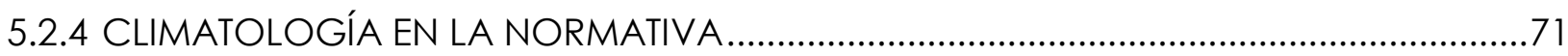

5.2.5 REGIONALIZACIÓN NORMATIVA DEL CLIMA EN EDIFICACIÓN .................................73 
5.2.6 FACTORES QUE INFLUYEN EN LA TEMPERATURA CORPORAL

ENTORNO A LOS EDIFICIOS.

5.2.7 CONDICIONES HIGROTÉRMICAS ADECUADAS ENTORNO A LOS

EDIFICIOS. DIAGRAMAS DE CONFORT.

5.2.8 CAPACIDAD PARA REGULAR LAS CONDICIONES

HIGROTÉRMICAS DEL EDIFICIO PARA UNA COMODIDAD

TÉRMICA

6. ANÁLISIS TEÓRICO

6.1 CARACTERIZACIÓN

6.1.1 RELACIÓN ENTRE LA RADIACIÓN Y LA TEMPERATURA

6.1.2 RELACIÓN ENTRE HUMEDAD Y TEMPERATURA .85

6.1.3 RELACIÓN ENTRE VIENTO Y TEMPERATURA .86

6.2 ÁMBITO ESPACIAL Y TEMPORAL DEL ESTUDIO REALIZADO .87

6.2.1 ESCALA ESPACIAL .87

6.2.2 ESCALA TEMPORAL .92

6.3 TIPOS DE SERIES CLIMÁTICAS Y PARÁMETROS SIGNIFICATIVOS. .95

6.3.1 EL CLIMA EN LA LEGISLACIÓN APLICADA A EDIFICACIÓN .98

6.3.2 ESTUDIOS DE CASO

6.4 CLIMA REGISTRADO EN LA ESTACIONES METEOROLÓGICAS SITUADAS EN LA ZONA CLIMÁTICA D3

6.4.1 FUENTES DE INFORMACIÓN CLIMÁTICA LOCAL .124

6.4.2 VALORES REPRESENTATIVOS DEL ESTADO TÉRMICO LOCAL 126

6.4.3 OBSERVACIONES GENERALES SOBRE EL ESTADO TÉRMICO LOCAL 127

6.5 MICROCLIMA URBANO: VALORES TÉRMICOS EN ZONAS URBANAS.

6.6 MICROCLIMA DE PROXIMIDAD: VALORES TÉRMICOS EN EL ENTORNO

PRÓXIMO DE UN EDIFICIO.

6.6.1 MICROCLIMA DE PROXIMIDAD EN ZARAGOZA CENTRO: SAN

PABLO-B. BOGGIERO

6.7 PROCEDIMIENTOS DIGITALES DE ESTIMACIÓN DE LA DEMANDA

7. RESULTADOS

7.1 CLIMAS DE REFERENCIA PARA ZONA CLIMÁTICA D3.

7.1.1 TEMPERATURA .134

7.1.2 HUMEDAD RELATIVA .146

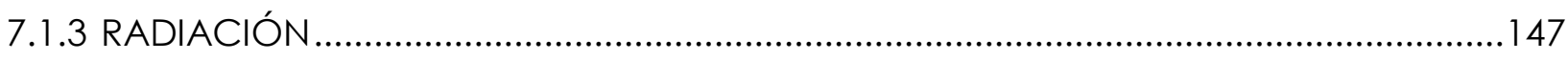

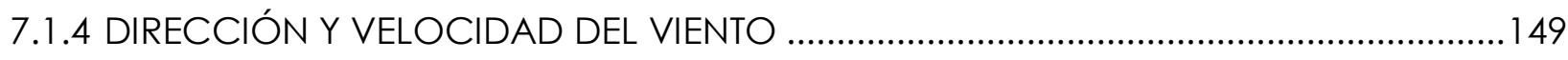

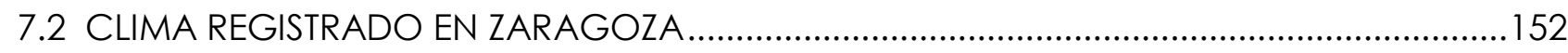

7.2.1 SECUENCIAS DE 40 AÑOS (1973-2012) PARA ZARAGOZA ......................................152

7.2.2 SECUENCIAS COMPARADAS DE SECUENCIAS TÉRMICAS DECENALES EN ZARAGOZA 
7.3 COMPARACION ENTRE ESTACIONES METEOROLÓGICAS PRÓXIMAS

EN ZARAGOZA 164

7.3.1 ESTACIÓN METEOROLÓGICA DEL AEROPUERTO DE ZARAGOZA .............................166

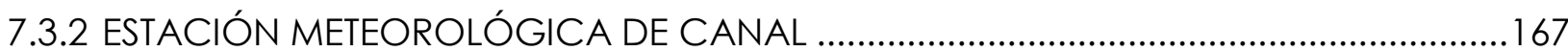

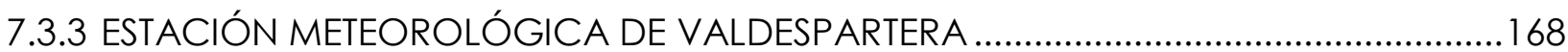

7.4 ESTUDIO COMPARADO DE LAS SECUENCIAS TÉRMICAS EN CLIMAS REGISTRADOS Y DE REFERENCIA

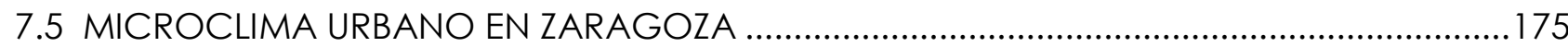

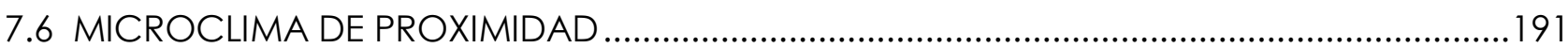

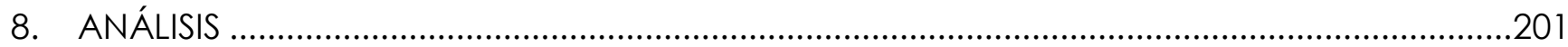

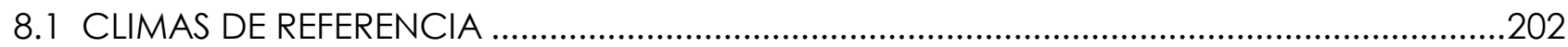

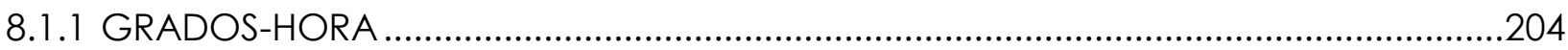

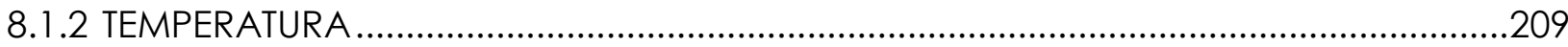

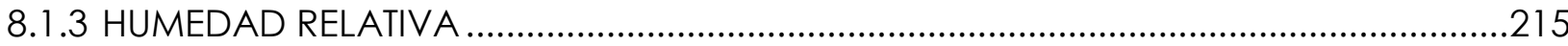

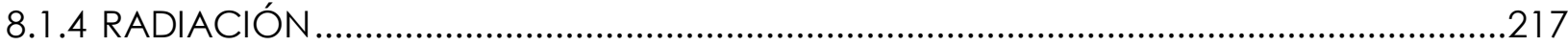

8.1.5 DIRECCIÓN Y VELOCIDAD DEL VIENTO _..................................................................219

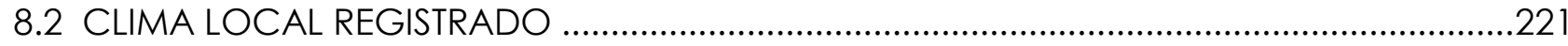

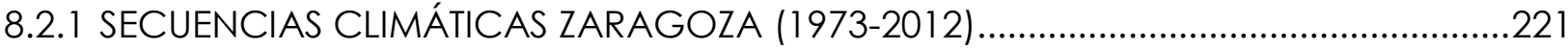

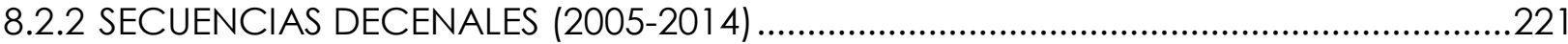

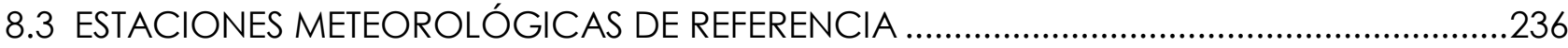

8.3.1 DISTRIBUCIÓN TEMPORAL Y VALORES ANUALES ACUMULADOS

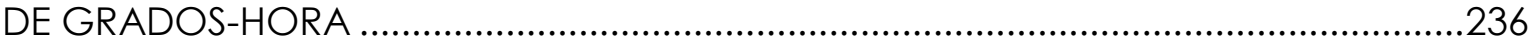

8.3.2 COMPARACIÓN ENTRE LOS VALORES DIARIOS DE TEMPERATURA

MÁXIMA, MÍNIMA, MEDIA Y OSCILACIÓN TÉRMICA

8.3.3 TEMPERATURAS HORARIAS EN PERIODOS DIARIOS ..............................................261

8.3.4 COMPENDIO DEL ANÁLISIS COMPARADO ENTRE ESTACIONES .............................275

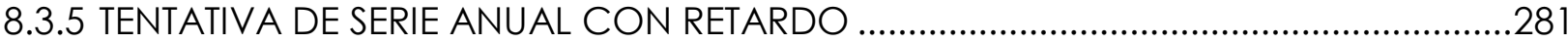

8.3.6 SERIES TÉRMICAS MENSUALES Y CADA TRES MESES ..............................................283

8.3.7 SERIES EN PERIODOS EN LOS QUE SE MANTIENE LA TENDENCIA ............................284

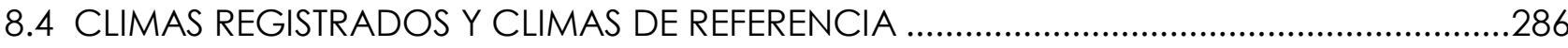

8.4.1 LÍMITE DE USO DE LOS VALORES CLIMÁTICOS MEDIOS ............................................290

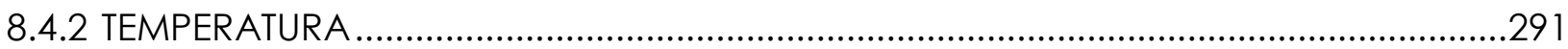

8.4.3 COMPARACIÓN ENTRE EL CLIMA DE REFERENCIA Y LOS

VALORES MEDIOS DE LA DÉCADA 2005 A 2014....................................................293

8.4.4 ANÁLISIS DE LAS SECUENCIAS TÉRMICAS REGISTRADAS Y DE REFERENCIA

8.5 ESTACIONES METEOROLÓGICAS DE REFERENCIA Y ESTACIONES

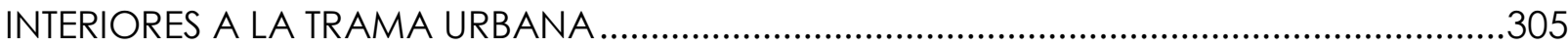

8.5.1 SECUENCIAS COMPARADAS ENTRE ESTACIÓN METEOROLÓGICA

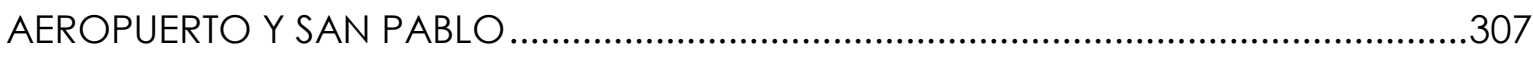

8.6 ESTUDIO COMPARADO DE SECUENCIAS TÉRMICAS ......................................................309 
8.7 MICROCLIMA DE PROXIMIDAD

8.7.1 PATIO DE LUCES INTERIOR AL EDIFICIO Y ESTACIÓN METEOROLÓGICA DE AEROPUERTO.

8.8 PROCEDIMIENTO DE ANÁLISIS CLIMÁTICO APLICADO ..................................................333

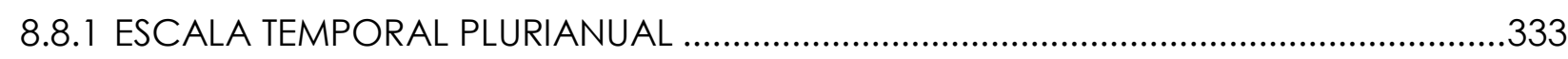

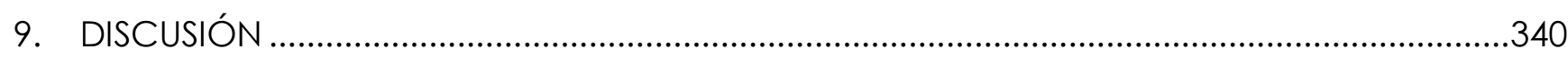

9.1 CLIMA REGISTRADO EN ESTACIONES METEOROLÓGICAS ............................................341

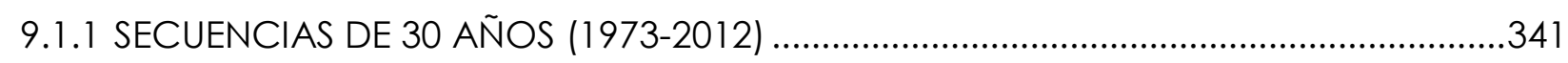

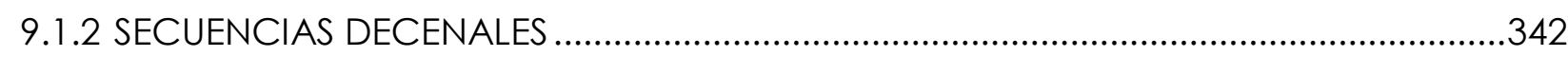

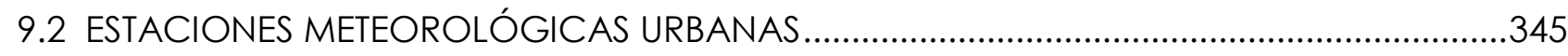

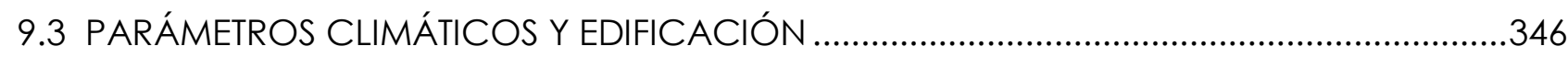

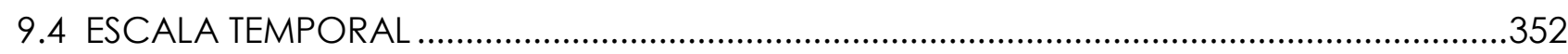

9.4.1 FRANJAS DE HOMOGENEIDAD TÉRMICA ANUALES ................................................352

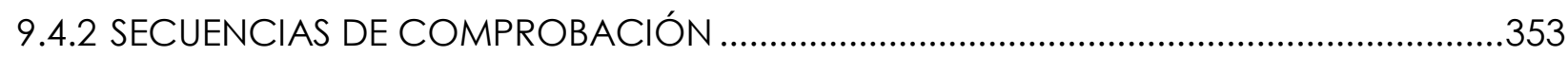

9.4.3 DURACIÓN DE LAS SECUENCIAS DE COMPROBACIÓN ...........................................356

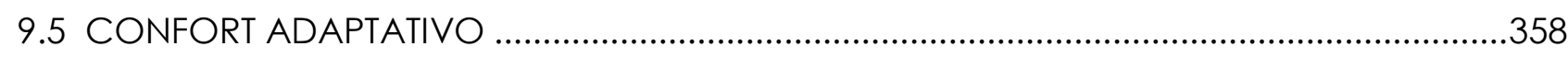

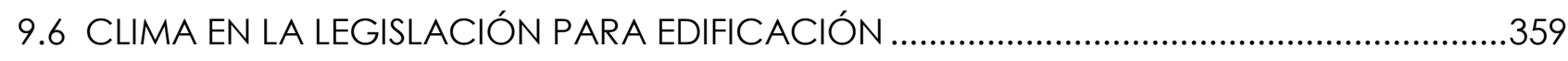

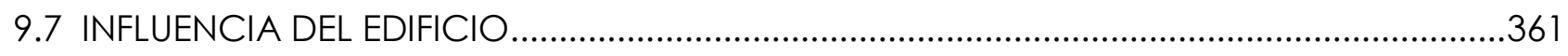

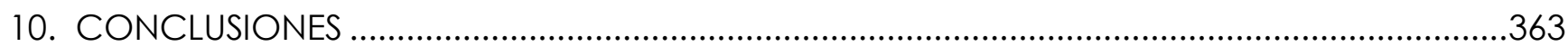

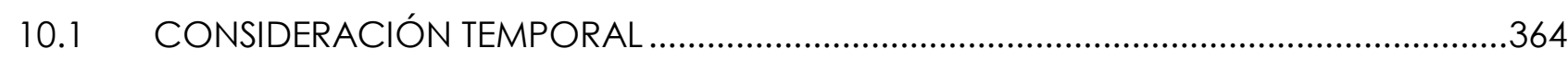

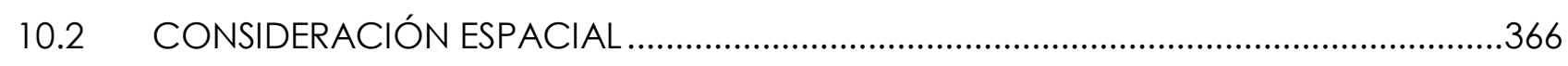

10.3 CONSIDERACIÓN DEL POTENCIAL DE MEJORA .......................................................368

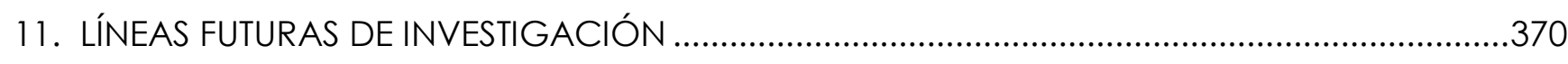

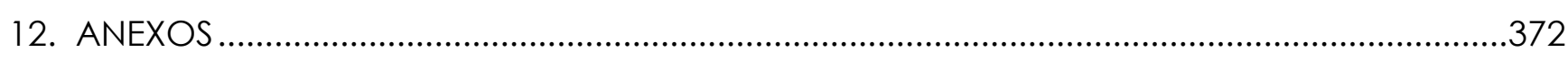

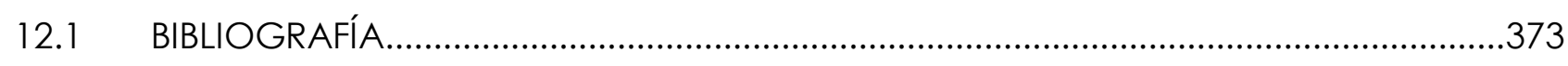

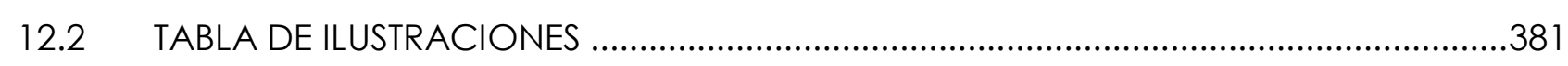

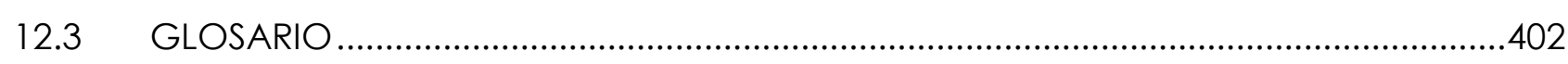




\section{Agradecimientos}

A mis padres su confianza sin reservas en mi criterio para encontrar mi vocación.

A mis directores por su paciencia en este largo proceso, por su comprensión de mis limitaciones, y por aportar su punto de vista honesto e inteligente. Las conversaciones mantenidas han sido siempre enriquecedoras en lo académico y en lo personal.

A Margarita por descubrirme una visión de la arquitectura que me acompaña ya más de tres décadas y por su visión, siempre optimista y positiva, aportando siempre una salida a cualquier encrucijada.

A César por su rigor, su generosidad y por estar siempre ahí con su mejor disposición.

A mi hermano Javier, siempre atento a lo importante, y cuya lectura inteligente del texto final me ha permitido revisarlo desde la lógica de una mente a la que nada le es ajeno y que ha visto más allá de lo explícito.

A mis hermanas cuyo aliento siempre he sentido independientemente de la distancia que nos separase.

A Tristán, atento a responder mis dudas de joven investigador desde su madurez, verle crecer me aporta confianza en un futuro mejor.

A mis compañeros en la universidad, por su interés, sus palabras de ánimo, su ayuda y, sobretodo, por haber podido sentir su compañía en todo este proceso. Especialmente aquellos con los que he compartido despacho y con los que he visto cambiar la escuela a la que hemos dedicado nuestra vida académica durante estos años. A los más próximos, Mercedes, Goyo, Pilar, Antonio, Natalia, Inmaculada y Bárbara, y a tantos otros que siempre han estado atentos a que no cejase en el empeño y con los que me he permitido compartir las luces y las sombras del proceso.

A la Universidad de Costa Rica, que me han alojado en un periodo crítico del proceso. A profesores como Emily, Andrea, Olman, Jaime, Jaqueline, Javier, George, Rudy, Rodolfo o Laura. A Oki y al resto del personal administrativo. A Suhra y Wajiha Sasa, por invitarme a participar de su rica vida personal y familiar, que me hizo sentir como en casa. A todos los que han brindado su apoyo, me han ayudado a solventar mis dudas y me han aportado una visión vitalista y renovadora de la vida académica y de su responsabilidad en la sociedad.

A Eugenia Solís, vital, esforzada, entrañable y generosa con su tiempo y su afecto, sin ella y Federico la experiencia en Costa Rica no habría sido posible.

A Isidro de Villota, que está en el origen de esta tesis, siempre próximo y entrañable, que me ha animado, incluso en su ausencia, a terminar este proceso.

Iniciar una canónica actividad investigadora, después de tres décadas de dedicación a la docencia y al trabajo profesional me ha permitido sentir la emoción de volver a empezar. Muchas gracias a todos, especialmente a los que no menciono explicitamente,' por vuestra ayuda, estímulo y compañía. 
10 de 406 


\section{RESUMEN}

Los parámetros empleados para realizar las clasificaciones climáticas no permiten, por sí solos, ni la definición de la arquitectura más apropiada para un determinado lugar, ni la de sus componentes, por ello es necesario definir el entorno climático que permitirá establecer las estrategias de diseño adecuadas, que se denominará como microclima de proximidad (MP).

Para definir el MP se tienen en cuenta las series climáticas en el entorno próximo al edificio, los climas de referencia y las series climáticas obtenidas en las estaciones meteorológicas cercanas, estableciendo una estimación de la cuantía y, en caso de ser posible, de la naturaleza y de las distorsiones que sufren las temperaturas por la influencia del edificio.

Mediante un método basado en la elaboración, comparación y análisis de series térmicas, se definen las escalas temporal y espacial de las secuencias térmicas a emplear en la estimación del balance termodinámico de los edificios.

Entre las cuestiones relacionadas con la escala temporal está definir la duración adecuada de las secuencias térmicas históricas que deben ser consideradas para realizar la estimación del balance termodinámico de la edificación.

Otra actividad relacionada con la escala temporal está enfocada a definir los intervalos de registro de las series térmicas. En este sentido se establece la duración apropiada de estos intervalos en función de si el edificio dispone de un sistema de climatización y el tipo de este.

La escala espacial se plantea con el objetivo cualitativo de establecer la influencia de la localización en las determinaciones climáticas en entornos edificados, especialmente en las zonas exteriores próximas a su perímetro y en las que quedan compartimentadas por él. En la práctica, esto supone poner de manifiesto la variedad de MP existentes en el entorno del edificio y su importancia para establecer su balance termodinámico.

De una parte mediante la elaboración de series climáticas, principalmente térmicas, que permiten describir las condiciones en un determinado lugar y de otra parte mediante la comparación de las series obtenidas y el análisis de estos resultados se demuestra la influencia de la localización en las secuencias térmicas registradas. Estas diferencias justifican el empleo de MP para una determinación más precisa del balance higrotérmico de los edificios con su entorno.

También en esta escala espacial se desarrollan las directrices para la elaboración de las series térmicas que permitan describir el entorno higrotérmico del edificio. Definiendo las condiciones anuales típicas a las que se enfrentan los edificios y que son de aplicación a una zona climática determinada y a los climas de referencia empleados para describir el entorno climático.

Para la aplicación del clima en el diseño arquitectónico se establece un procedimiento para establecer en cada lugar las franjas de homogeneidad térmica anuales (FHTA) o periodos en los que las condiciones térmicas exteriores tienen una respuesta unívoca en los edificios.

A partir de estos periodos se define el criterio para establecer las secuencias térmicas de comprobación de la respuesta mediante el empleo de procedimientos digitales, comúnmente empleados en la certificación y auditoría energética, y en la operación de sistemas de climatización. 
12 de 406 


\begin{abstract}
ABSTRAT
The parameters used to classify the climates allow, by themselves, neither the definition of the most appropriate architecture in a certain place, nor that of its components. For that reason, it's necessary to define the climatic environment that will allow to establish the appropriate design strategies, which will be named Proximity Microclimate (PM).
\end{abstract}

The PM will be defined taking into account the climatic series in the building's environment, the reference climates and the climatic series obtained in the nearest meteorological stations, establishing an estimation of the amount and, where possible, the nature and distortions of the temperatures as influenced by the building.

The temporal and spatial scales of the thermic sequences to be applied when estimating the thermodynamic balance of buildings will be defined through a method based in the elaboration, comparison and analysis of thermic series.

Among the matters related to the temporal scale is the need to define the adequate duration for the historical thermic sequences that must be considered when estimating the thermodynamic balance of the building.

Another activity related to the temporal scale focuses on the register intervals. The appropriate duration of these intervals depends on whether the building has a climatization system, as well as on its type.

The spatial scale serves the cualitative purpose of establishing the influence of location on the climatic determinations in edified environments, especially in the exterior zones close to its perimeter and which are compartimentalized by it. In practice, this involves proving the variety of existent Proximity Microclimates in the building's environment as well as their importance when establishing its thermodynamic balance.

Partly by elaborating climatic series, mainly thermic, that allow to describe the conditions in a particular place, and partly by comparing those series and analyzing the comparison, the influence of location in the building's close environment is made manifest. These differences justify the use of PM for the more accurate determination of the hygrothermic balance of the buildings with their environment.

The spatial scale also serves to establish the directives that will help elaborate the thermic series that will describe the building's hygrothermic environment. This description will define the typical annual conditions which buildings face and which are applicable both to a determined climatic zone and to the reference climates used to describe the climatic environment.

For the application of climate in arquitectonical design, the procedure for delimiting thermic homogeneity stripes (FHTA) are used. FHTA are periods in which the external thermic conditions present a univocal answer to the building.

Starting at those periods, a criteria is defined for establishing the thermic sequences meant to test the answer through digital procedures commonly employed in energy audition and certification, and in the operation of climatization systems. 
14 de 406 


\section{INTRODUCCIÓN}

Existe unanimidad en considerar el clima como el resultado de la integración de los flujos energéticos solares con cinco elementos terrestres interdependientes, como son la atmósfera, los océanos, la criosfera, la biosfera y la superficie terrestre en un sistema dinámico y

EL CLIMA COMO BALANCE TÉRMICO GLOBAL

Este sistema se caracteriza por el carácter selectivo frente a la radiación solar de la atmósfera que, especialmente debido al vapor de agua y al dióxido de carbono que contiene, mantiene la temperatura en el rango en que son viables los ciclos biológicos actuales, dando lugar al denominado efecto invernadero natural.

En este contexto, la temperatura de equilibrio media observada en la tierra está entre $14^{\circ} \mathrm{C}$ y $15^{\circ} \mathrm{C}$, mientras que sin la colaboración de la atmósfera estaría en valores mucho menores, según distintos autores entre $-18^{\circ} \mathrm{C}$ y $-20^{\circ} \mathrm{C}$ (VVAA 1992, XXXIV) (Lashof 1989, 213-242).

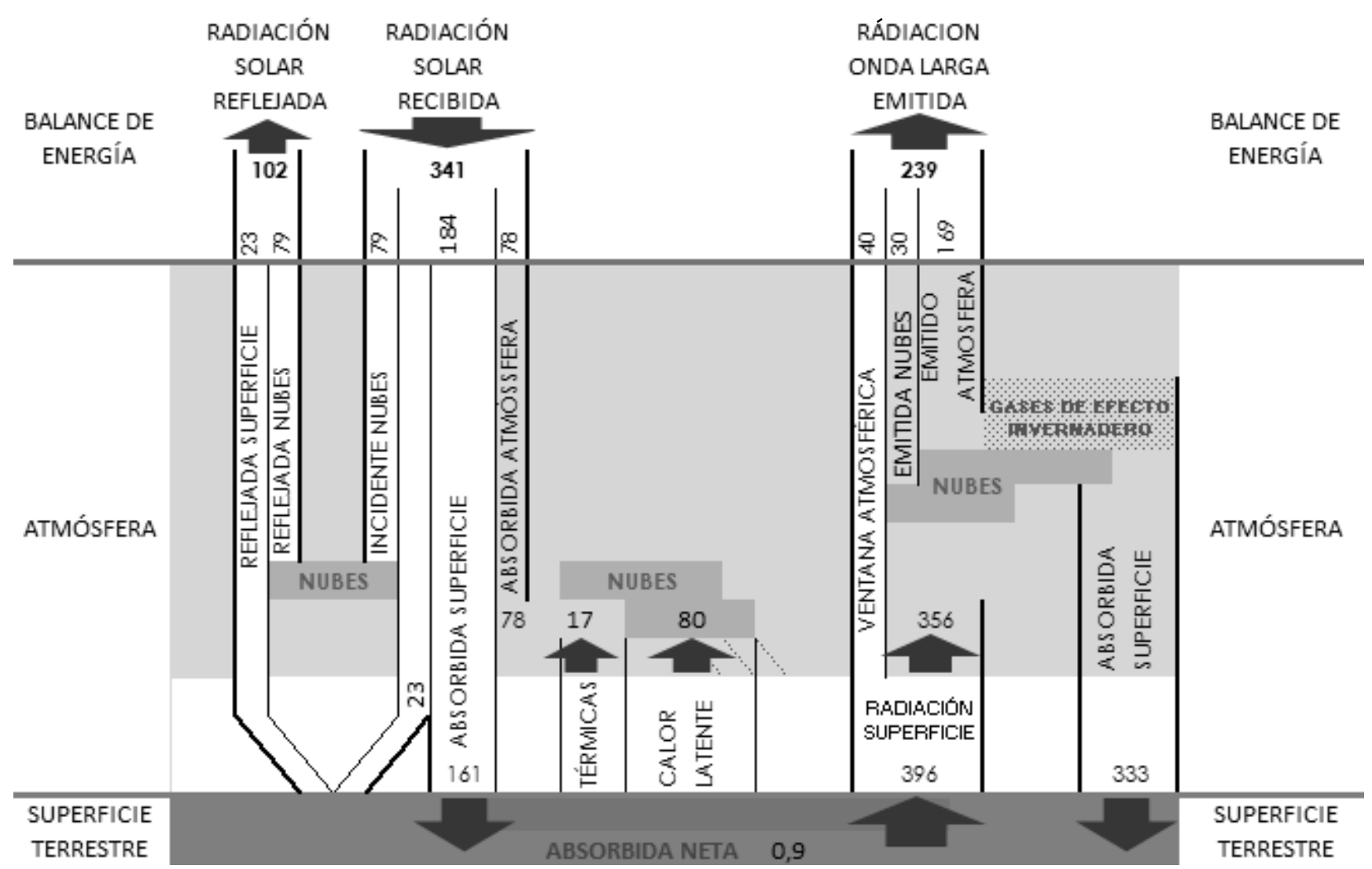

FIG 1-1 BALANCE TERRESTRE DE FLUJOS ENERGÉTICOS MEDIOS (Wm²) (Elaboración propia, según distintos autores)

Son conocidos (Dines, 1917) los aspectos básicos del balance global medio de la radiación incidente en la parte alta de la atmósfera (TOA, por sus siglas en inglés: "Top of the atmosphere") y el frágil equilibrio entre la radiación solar absorbida (ASR por sus siglas en inglés: "Absorbed Solar Radiation") y la radiación de onda larga saliente (OLR, por sus siglas en inglés: "Outgoing Longwave radiation") (Manabe, 1961). Sobre una estimación media de 341 W.m-2, incidentes en las capas altas de la atmósfera la absorción neta en la superficie terrestre no supone más de un $0,27 \%$ de dicha cantidad (FIG 1-1).
RADIACIÓN SOLAR:

TOA TOP of the atmosphere

ASR Absorbed solar radiation

OLR Outgoing longware radiation 
Este flujo de energía, su transformación y su almacenamiento, han sido objeto de amplio estudio y actualmente existe un notable conocimiento de los procesos. La cuantificación del balance de energía total, que compone este flujo, en términos de transporte y de almacenamiento (Fasullo \& Trenberth, 2008) dista mucho de ser la visión cotidiana de los intercambios de energía que se producen en nuestro entorno, donde se observa una gran heterogeneidad en la distribución de las temperaturas ambientales en el tiempo y en el espacio. La estimación teórica de sus cuantías exige aplicar los estudios y las simulaciones al balance global para distintos supuestos, periodos y regiones.

Por razones astronómicas y planetarias, como son la forma y dimensión de la tierra y sus movimientos de traslación y rotación, y geográficas como son el relieve, los materiales, la posición en el planeta o la distancia a grandes masas de agua o hielo se producen variaciones locales y temporales de los climas. Estos factores que influyen en la formación de los climas y que se interrelacionaran entre sí son los llamados factores climáticos.

Las diferencias geográficas, estacionales y entre el día y la noche son las que provocan los cambios atmosféricos que distribuyen el agua, el aire y la energía por toda la tierra, en forma de calor interno, de calor latente y de energía cinética (Trenberth y Stepaniak, 2004).

En función del balance de energía total los climas pueden ser exógenos o endógenos. Este concepto también sería de aplicación a los balances temporales, circunscritos a periodos largos, como son las estaciones, o cortos, como son los días.

Desde el punto de vista geográfico la respuesta frente a los flujos solares es muy diferente para las zonas terrestres y marítimas $y$, desde el punto de vista temporal, muy diferente entre los distintos periodos del año, como son los meses o las estaciones, según puede observarse en los balances energéticos recogidos por Fasullo \& Trenberth en «The Annual Cycle of the Energy Budget. Part I: Global Mean and Land-Ocean Exchangesı (Fasullo \& Trenberth, 2008) (FIG 1-2).
EL BALANCE TÉRMICO GLOBAL SE SINGULARIZA EN FUNCIÓN DEL

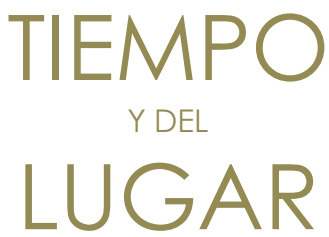




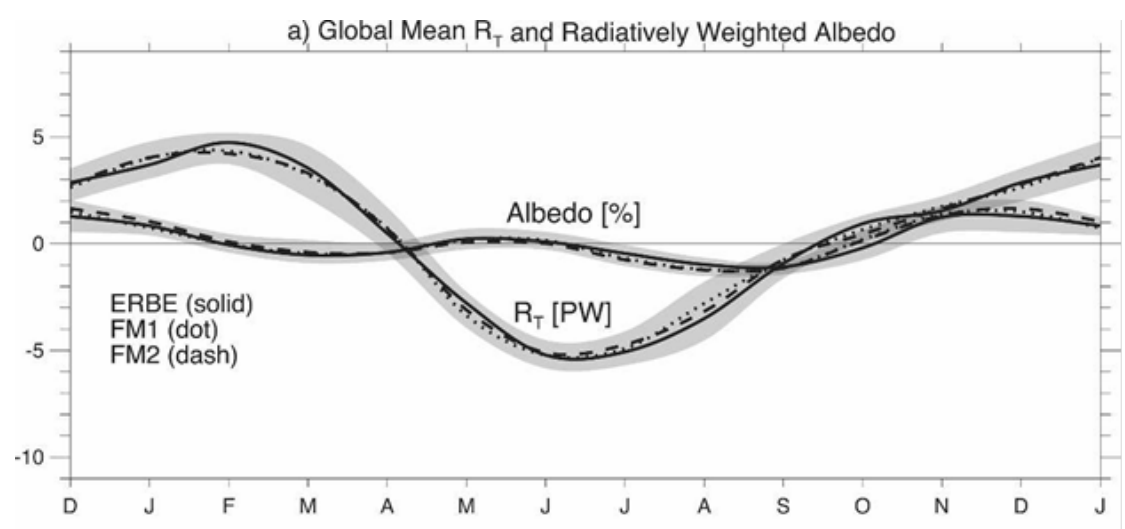

b) Global Ocean Means

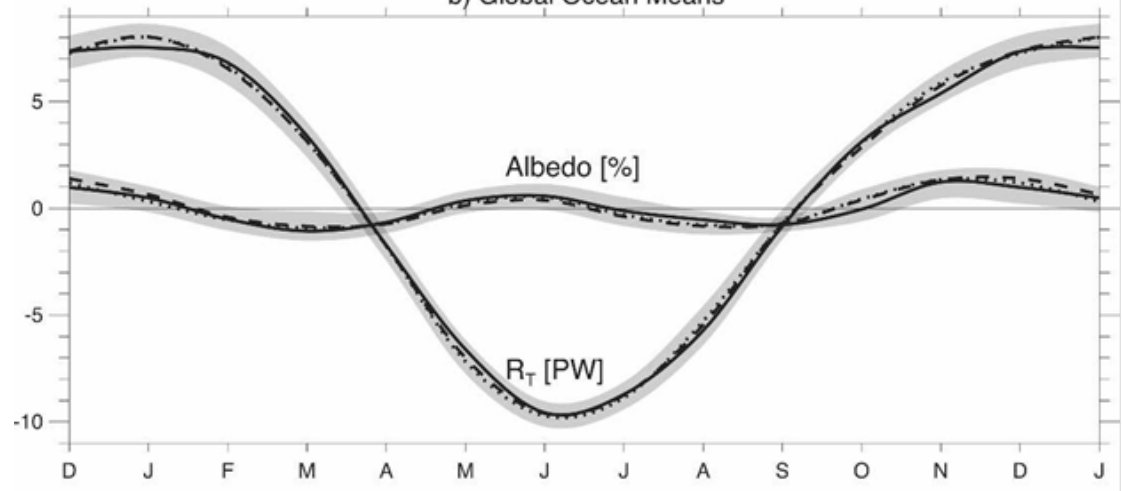

c) Global Land Means

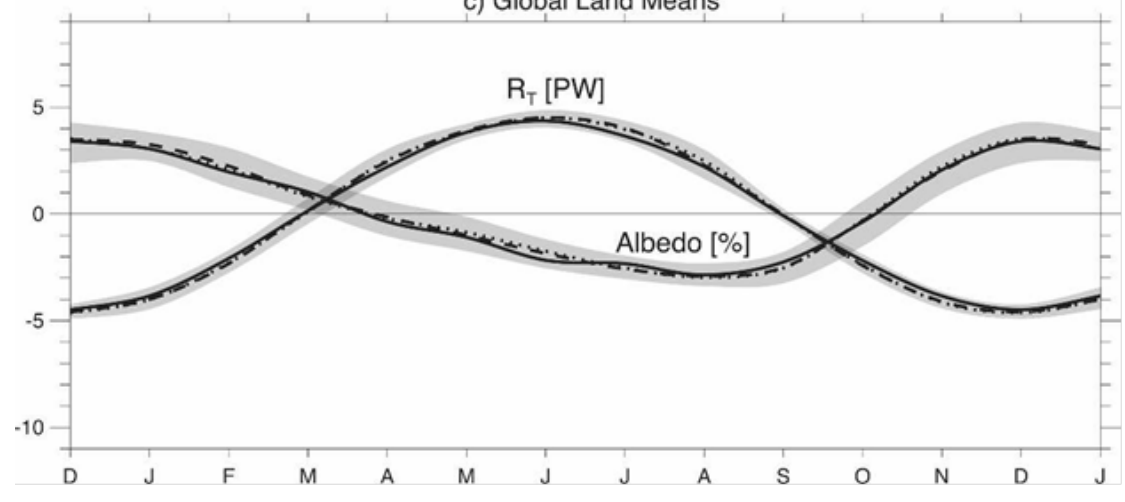

FIG 1-2 BALANCE EMISIVO EN FUNCIÓN LA NATURALEZA DE LA SUPERFICIE TERRESTRE FASULLO, J. T.. \& TRENBERTH, K, E. (2008) "The Annual Cycle of the Energy Budget. Part I: Global Mean and Land-Ocean Exchanges", Journal of Climate, vol. 21, pp. fig 3

Esta interesante visión sintética sugiere distinguir entre aquellas regiones donde la temperatura de equilibrio es superior a la media y aquéllas en las que es inferior.

También debemos concluir que las regiones templadas se caracterizan por sus grandes diferencias en función del periodo considerado y por una oscilación térmica muy significativa a lo largo del año.

Una distribución en grandes regiones climáticas puede hacerse en función de la posición relativa entre el sol y la tierra, y simplificarse considerando el paralelo en que se encuentran y la influencia de las grandes masas de agua. Este criterio permite distinguir entre una región ecuatorial donde la ganancia de energía es siempre mayor que la cesión, las zonas polares, donde siempre es mayor la cesión de energía, y las zonas comprendidas en el entorno de los equinoccios, donde este 
balance difiere en función de la estación climática, comportándose como exógenas y endógenas a lo largo de un ciclo anual.

Esta elemental clasificación tiene su interés para uno de los propósitos que nos ocupa que es el observar la evolución de las condiciones higrotérmicas de en el entorno próximo de los edificios construidos en localizaciones afectadas por climas templados donde las ganancias térmicas superan a las pérdidas o permanecen en equilibrio, ya que este factor determinará las estrategias de diseño a considerar en la prescripción arquitectónica.

La percepción del clima y su afección a la edificación son el resultado de una relación dinámica entre el clima y los edificios, con implicaciones a largo plazo, en el total de la vida útil de los edificios, así como en la sensación instantánea de sus usuarios, tanto en su interior como en su entorno próximo.

Las consideraciones temporales a lo largo de un ciclo anual, que permiten conocer los balances globales de los edificios, deben ser complementados con análisis instantáneos, ya que entre el día y la noche se manifiesta una gran diferencia en la energía recibida, haciendo patente la influencia de la capacidad térmica local, de modo que cuando la energía acumulada y la velocidad de transferencia de esta energía al ambiente son altas pueden mantenerse las temperaturas en rangos más estrechos, aunque durante el día se produzcan las ganancias y por la noche las pérdidas, como sucede en los litorales templados, mientras que cuando son bajas la variación de la temperatura entre la noche y el día es mucho mayor, como sucede en los climas continentales y que tiene sus valores extremos en los desiertos cálidos.

Por otra parte, esta circunstancia hace patente la importancia de discretizar la respuesta de los edificios para ciclos diarios, a cuyas alternancias térmicas tienen que responder $y$, en función de su capacidad térmica, considerar varios ciclos diarios completos para caracterizar su balance de energía.

La adaptación de la metodología a los objetivos que se pretenden en la caracterización de estos procesos de interacción entre el clima y los edificios exige una revisión para su aplicación a campos tan diversos como pueden ser la estimación del clima futuro, la predicción meteorológica o el establecimiento de unas condiciones de cálculo para aspectos tecnológicos, la predicción de la pluviometría sobre una cuenca para establecer la medidas de prevención de riesgos, las especies y condiciones para una explotación más adecuada de la producción vegetal o la estimación de las condiciones bajo las que una edificación y sus equipamientos habrán de conseguir condiciones confortables para sus usuarios.

Las singularidades o anomalías locales adquieren una gran importancia para el análisis de las condiciones en las que se encuentran y a las que responden los edificios. Por ello la estimación de las condiciones climáticas, elaborada desde las clasificaciones con un ámbito geográfico muy amplio y su necesaria búsqueda de invariantes comunes, descartando las condiciones estadísticamente poco relevantes, para conseguir una imagen poco distorsionada de los procesos comunes a una región, no contempla en muchas ocasiones las zonas urbanas, bien por su singularidad geográfica, al estar situadas en localizaciones 
singulares dentro de su región climática, bien por la transformación que los edificios y su agregación provocan en el entorno natural en el que se sitúan. En este contexto ya se ha consolidado como un microclima más el microclima urbano, denominado muy expresivamente como isla de calor en la bibliografía consultada (FIG 1-3 y 1-4).

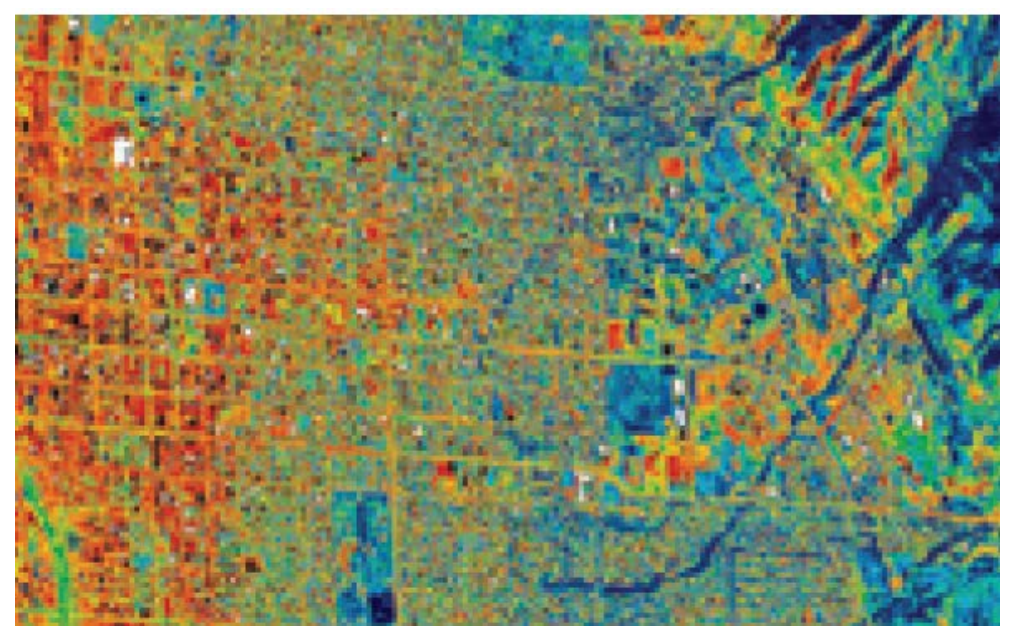

FIG 1-3 IMAGEN INFRARROJA DE LA SUPERFICIE URBANA: ISLA DE CALOR. JUlio 1998 Salt Lake City, Utah. USA. NASA/Marshall Space Flight Center (Wong, 2008)

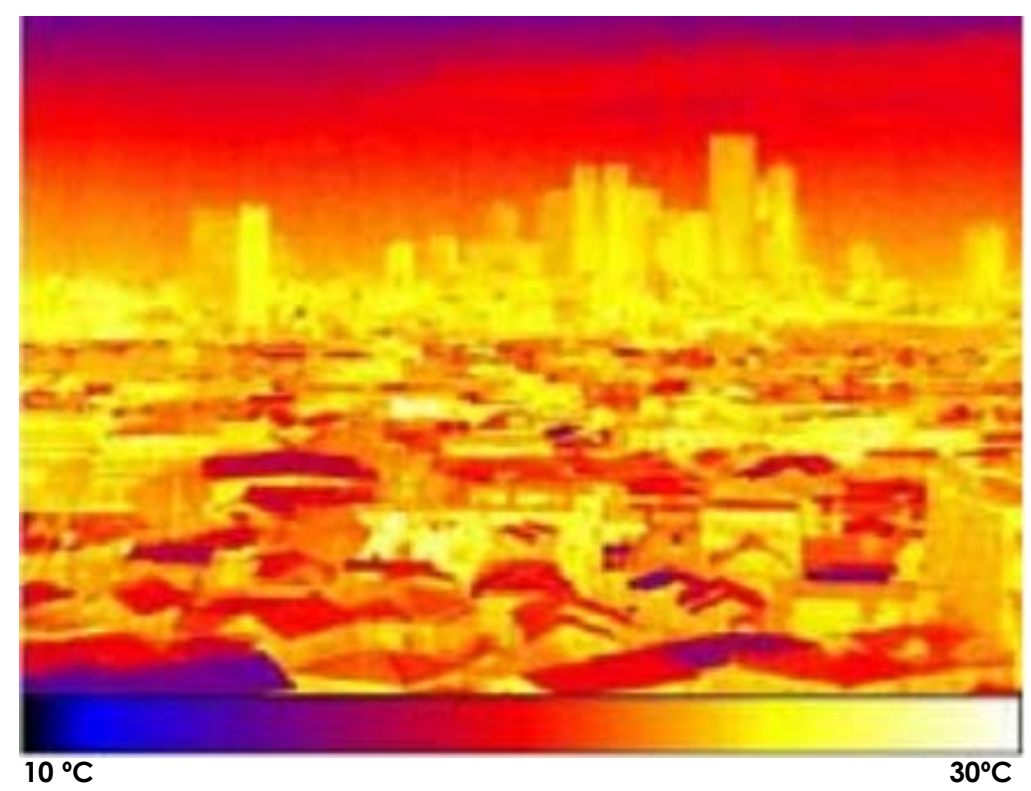

FIG 1-4 IMAGEN INFRARROJA DEL PERFIL URBANO: ISLA DE CALOR. Concentración de oficinas, Shinjuku, Tokyo. Japan. (Voogt, 2002)

La naturaleza del edificio, diseñado para modificar las condiciones higrotérmicas existentes, su agregación en conjuntos construidos más complejos que ellos mismos y su dimensión, mucho menor que las regiones para las que se definen los climas, hace que la singularidad climática urbana tenga cualidades específicas (FIG 1-5).
ISLA DE CALOR
NECESIDAD DE CARACTERIZAR LOS CLIMAS EN FUNCIÓN DE LA REACCIÓN DEL EDIFICIO 


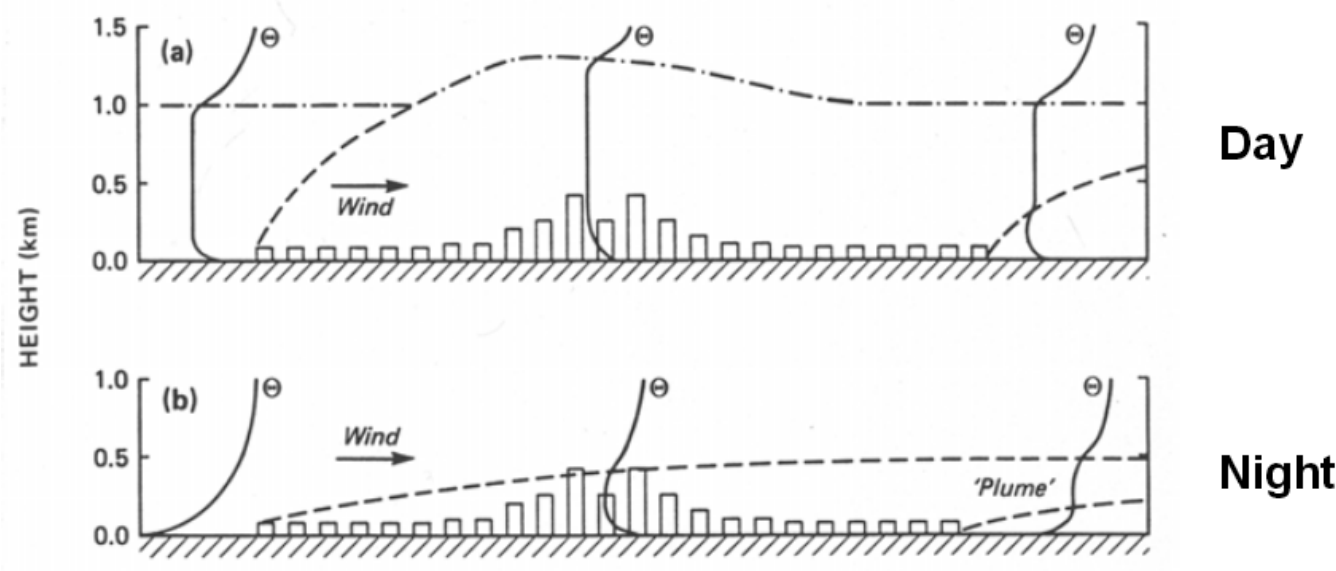

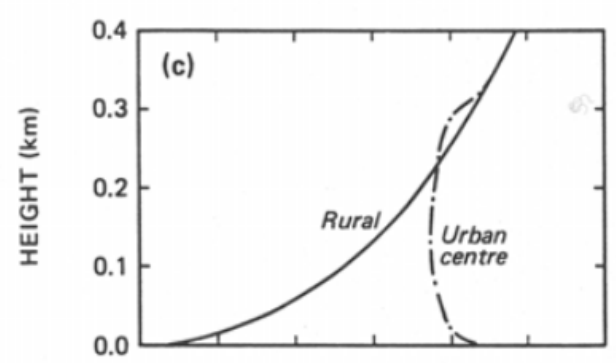

$\Theta$

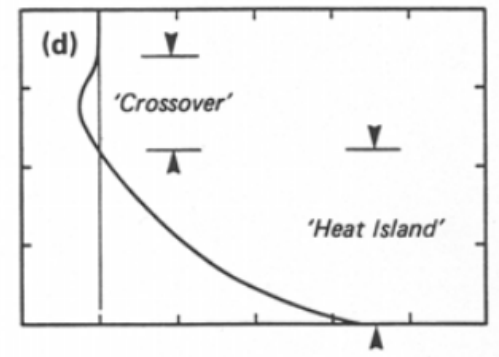

$\Delta \Theta_{\mathrm{u}-\mathrm{r}}$

FIG 1-5 ISOTERMAS: ANÁLISIS TEÓRICO DE LA CAPA LÍMITE DE LAS ISLAS DE CALOR. Capa límite de las Islas de calor. Oke, T.R., 1982

Esta circunstancia refuerza la opción elegida de realizar los estudios mediante un modelo muestral, que se promociona por la agregación y posterior síntesis, siempre sujeta a revisiones, de estudios de caso, frente a modelos que aborden esta complejidad desde el "todo a la parte", como promueve la epistemología clásica.

Una parte sustancial del esfuerzo se concentra en encontrar caracterizaciones del clima singularizadas para las interrelaciones con la edificación en general y el bienestar higrotérmico en sus estancias.

En definitiva, el clima considerado para simular la reacción de los edificios y la respuesta de cada una de las estancias de este es determinante para los resultados finales. Representar correctamente el clima local es imprescindible para una estimación precisa del balance termodinámico del edificio.

APROXIMACIÓN

INDUCTIVA:

EVOLUCIONANDO DESDE LA PARTE AL TODO
VER ANEXOS 01 y 02 BALANCE TERMODINÁMICO MEDIANTE ENERGY PLUS Y DESIGNBUILDER 1 y 2 
La interdependencia entre la meteorología y la actividad humana está en el origen de nuestra evolución. Así, la protección estimula la búsqueda de soluciones y la exposición estimula la producción y el desarrollo.

Su predicción y su modificación es clave para el progreso y el desarrollo humano. Así se clasifican las variables atmosféricas homogéneas formando climas, entendidos como sucesiones temporales sintéticas de magnitudes y variaciones de valores atmosféricos, para una localización espacial determinada.

El conocimiento del clima ha permitido desde la exploración del planeta al aprovechamiento de los recursos y será determinante para un desarrollo sostenible. Para hacer posible que las viviendas colaboren con un desarrollo sostenible, destinando menos recursos para su climatización, no es suficiente con un mejor conocimiento de las edificaciones, sino que, al ser una actividad modal, es necesario que esta formación del conocimiento se materialice en actividades y participe de los principios que subyacen en el desarrollo sostenible, que en una primera aproximación se pueden esquematizar como de causalidad, universalidad, equidad, autonomía y participación.

El conocimiento del clima y su consideración en la vida cotidiana y en la consecución del bienestar doméstico es la mejor forma de mejorar la respuesta de los edificios (Tendero, 2016), aunque probablemente sería conveniente hablar de un "reconocimiento", dada la importancia que ha tenido en el pasado reciente, al menos en el entorno rural. Su evolución, asociada a la redefinición del bienestar y de como conseguirlo por parte de cada residente, sería el complemento necesario para que los esfuerzos sean eficaces.

Si la posición del residente es pasiva y soporta el clima, la adaptación exigirá la adopción de medidas o estrategias que acomoden los espacios habitados al clima exterior y conseguir así una ambiente confortable. Si, por el contrario, es activa se ocupará de la modificación del clima próximo al hábitat o creación de microclimas, de disponer del arropamiento adecuado a cada actividad y ubicación, de actuar sobre los equipamientos que permiten sectorizar el edificio que habita, exponerlo o protegerlo del sol o el viento, en función de sus necesidades, para facilitar su aclimatación pasiva.

Puesto que la acción humana está cambiando el clima y esto nos afectase gravemente, la actitud basada en cubrir necesidades de bienestar local de un modo sostenible se extiende a la búsqueda de soluciones, considerando la afección a un entorno global.

Esta demanda es el mayor reclamo para que técnicos, operadores, suministradores y demás profesionales comprometidos con la consecución de este bienestar colaboren en el proceso. La colaboración pasiva a demanda del residente debe complementarse con el desarrollo de tecnología y procedimientos que retomen la necesidad de una climatización de bajo impacto medioambiental.

En una descripción simplificada la consecución de un desarrollo sostenible según el principio de causalidad antes aludido debe establecer las acciones que satisfacen las necesidades. La búsqueda de 
la comodidad, especialmente en ambientes interiores o semi-interiores, exige considerar qué condiciones higrotérmicas son las apropiadas para el desarrollo de cada actividad y si están adaptadas a los individuos que las habrán de percibir.

El principio de causalidad exige que la toma de decisiones siga una cadena sostenible que se inicia en las necesidades que habrán de ser satisfechas, en este caso la climatización de los espacios en los que se desarrollan actividades, y en las condiciones del entorno, o condiciones atmosféricas adyacentes. El estudio de las características del edificio analizado, si está ya construido, o la estimación de su comportamiento previsto cuando es solo un proyecto, corregirá las condiciones atmosféricas, generalmente suavizando sus oscilaciones en las zonas menos expuestas e incrementando la temperatura ambiente en las zonas soleadas, especialmente si el soleamiento llega al interior a través de vidrios. La modificación de la compartimentación, las aberturas, la humedad o la regulación del soleamiento, entre otras soluciones bioclimáticas pasivas, permite correcciones de los valores higrotérmicos interiores. Una vez alcanzadas las máximas capacidades pasivas del edificio, las correcciones mediante tecnologías activas con mayor impacto medioambiental entrarán en acción, para facilitar las condiciones higrotérmicas y su adaptación al usuario.

Comienza, por tanto, la cadena causal en un conocimiento del clima local a través de los valores atmosféricos percibidos.

El principio de universalidad por su parte hace necesaria la capacidad del sistema de climatización de adaptarse al conocimiento y a la capacidad socio-económica de cada individuo que hará uso del edificio.

El principio de participación se apoya en la transparencia y en la información adaptada a cada uno de los agentes y permitirá al usuario ser consciente de la repercusión económica, social y medio ambiental de sus decisiones.

El principio de equidad se apoya en la corresponsabilidad de todos los agentes en el proceso y la convergencia en la reducción del impacto medioambiental para la satisfacción de sus necesidades.

Solo con los principios enunciados es posible que se aplique el principio de autonomía, entendida como capacidad de elegir, y no como autosuficiencia, que permitirá a cada usuario elegir la opción más adecuada a sus condiciones y su propósito.

Descartar cualquier solución generalista y promover el estudio local de las condiciones atmosféricas permite la formación de conocimiento local, facilita el establecimiento de personal técnico y de operarios con conocimientos aplicados y permite un máximo aprovechamiento del potencial local. 


\begin{tabular}{|l|c|c|}
\hline \multicolumn{2}{|c|}{ PRINCIPIOS PARA UN DESARROLLO SOSTENIBLE } \\
\hline \multicolumn{2}{|c|}{ PRINCIPIOS BÁSICOS } & \multicolumn{1}{c|}{ CONCEPTOS RELACIONADOS } \\
\hline 1 & UNIVERSALIDAD & $\begin{array}{l}\text { Principio de CORRESPONSABILIDAD } \\
\text { Principio de CONVERGENCIA }\end{array}$ \\
\hline 2 & EQUIDAD & $\begin{array}{l}\text { Principio de TRANSPARENCIA } \\
\text { Derecho a la INFORMACIÓN }\end{array}$ \\
\hline 3 & PARTICIPACIÓN & $\begin{array}{l}\text { Principio de LOCALIZACIÓN } \\
\text { Principio de DIVERSIDAD }\end{array}$ \\
\hline 4 & AUTONOMÍA & $\begin{array}{l}\text { Acción y Medidas Preventivas } \\
\text { Principio de PRECAUCIÓN }\end{array}$ \\
\hline 5 & CAUSALIDAD & \\
\hline
\end{tabular}

FIG 1-6 PRINCIPIOS BÁSICOS PARA UN DESARROLLO SOSTENIBLE Y CONCEPTOS RELACIONADOS. (Tendero, 2010)

En todo el documento, aun afectando sólo al conocimiento de las condiciones térmicas próximas al edificio relevantes para el diseño, la construcción y el uso de los edificios, subyace la necesidad de implementar soluciones que sigan los principios de universalidad, equidad, participación, autonomía y causalidad, para que sus logros se materialicen en un desarrollo sostenible.

\section{CONTENIDO}

Este documento esta ordenado en cuatro partes. La primera hace referencia a la oportunidad del tema, a la motivación del autor, a los objetivos y a la metodología empleada en su desarrollo, también se hace una breve reseña del estado de la cuestión y del análisis teórico de los temas que se abordarán en el documento.

La segunda parte recoge una recopilación de los registros y de las series climáticas contemplados,

La tercera incluye el tratamiento de los datos y su análisis.

En la cuarta parte se plantea una discusión sobre la aplicación en edificación del análisis realizado y las conclusiones.

El documento se completa con los cuadros de figuras, acrónimos, un breve glosario y la bibliografía, así como los anexos con la documentación complementaria al texto que se ha considerado que no es fundamental para la comprensión del texto, pero que puede complementarlo y facilitar la comprensión de algunos aspectos abordados. 


\section{HIPÓTESIS}

Los parámetros empleados para realizar las clasificaciones climáticas no permiten, por sí solos, ni la definición de la arquitectura más apropiada en un determinado lugar, ni la de sus componentes (OLGYAY, 1998). A este fin, tampoco son determinantes los valores estadísticos más probables del clima, ni siquiera cuando están expresados por sus quintiles o sus percentiles.

Otros procesos que estiman la acumulación de demandas energéticas, mediante herramientas como son, por ejemplo, los grados-día, o los grados -hora en distintas bases, tampoco caracterizan completamente las condiciones climáticas en su aplicación al diseño de edificios. Se hace necesario pues encontrar una descripción del clima eficaz, para ser aplicada a la determinación de la respuesta de la edificación y en ella deben considerarse aspectos temporales, espaciales y de reacción $u$ operacionales. Previamente a la definición de los aspectos cualitativos y cuantitativos más significativos del clima para su aplicación en edificación, y especialmente cuando se trata de definir su balance térmico con el exterior, se debe establecer una correcta descripción de los valores climáticos en el entorno próximo del edificio.

\subsection{CONSIDERACIÓN TEMPORAL}

Es necesario definir la periodicidad en que deben considerarse las secuencias térmicas en edificación, no siendo representativas, a priori, periodicidades anuales, estacionales, mensuales o diarias, al estar su influencia en función de la capacidad de reacción del edificio objeto de estudio.

Los periodos en que se establecen los valores estadísticos, como son las medianas o los promedios, y los valores extremos, como son las máximas y las mínimas, $u$ otros valores representativos para caracterizar un estado higrotérmico concreto de la vida de un edificio, también estarán influidos por el edificio y su capacidad de reacción.

A estos efectos, la unidad temporal comúnmente utilizada es horaria, como demuestra que las bases de datos climáticos a las que se ha tenido acceso mantengan este intervalo. Se considera que es un intervalo apropiado, tanto a efectos prácticos, como por la precisión de los resultados a los efectos de caracterizar la respuesta del edificio, especialmente cuando no se considera la acción puntual de sistemas de climatización forzada.

Para la obtención de valores estadísticos o extremos se han considerado secuencias con un mínimo 10 años de duración y ocasionalmente se han considerado también series más largas, en concreto las que disponen de registros de 30 años de duración, y más cortas, con una extensión de sólo varios años.

Para la definición del estado térmico del edificio se deben considerar secuencias de varios días definidas por sus valores horarios, considerando la trayectoria previa que siguen las series térmicas, Para edificios convencionales, estos periodos pueden oscilar entre 3 y 9 días.
EL ESTUDO DEL BALANCE TÉRMICO, ENTRE EL EDIFICO Y SU ENTORNO REQUIERE DESCRIBIR SERIES TÉRMICAS ESPECÍFICAS EN EL ENTONO PRÓXIMO DEL EDIFICIO,
LAS CONSIDERACIONES TEMPORALES SE CENTRAN EN:

1. INTERVALO DE MEDIDA

2. DURACION DE LAS SERIES TÉRMICAS REPRESENTTIVAS DE UN ESTADO TÉRMICO. 


\subsection{CONSIDERACIÓN ESPACIAL}

Los parámetros más característicos empleados para describir un clima local se obtienen, normalmente, en estaciones meteorológicas, en las que pueden hacerse anotaciones precisas de los valores climáticos. También se utilizan para este fin estaciones meteorológicas virtuales que aportan datos meteorológicos por interpolación ponderada a partir de otras estaciones.

La diferencia entre los valores registrados en entornos urbanos difiere de los obtenidos en las estaciones meteorológicas, siendo estas diferencias significativas al analizar el balance termodinámico, entre el edificio y el ambiente térmico.

Por otra parte, estos valores difieren de los que realmente se pueden observar en las cercanías de los edificios una vez construidos, donde se modifican en función de factores como son las condiciones de su entorno o la exposición al sol o al viento.

Por lo que se considera de interés establecer la relación entre los valores registrados en una estación meteorológica y los observados en entornos urbanos y en el entorno próximo al edificio, con el objeto de iniciar la definición de patrones de correlación térmica para su aplicación en edificación.

Una parte significativa de la reflexión sobre la posición de las observaciones climáticas se realiza sobre la consideración de que los valores registrados en el entorno próximo al edificio se manifiestan grandes diferencias con respecto a las registradas en estaciones meteorológicas próximas, las estaciones urbanas y los climas sintéticos elaborados para describir la influencia del clima en la edificación.

En concreto las secuencias térmicas en ciclos diarios, de varios días, estacionales o anuales en varias zonas del entorno próximo al edificio manifiestan diferencias significativas entre sí y con los climas de referencia $\circ$ el tiempo atmosférico registrado en estaciones meteorológicas próximas.

En función, por ejemplo, de su exposición, su orientación o su forma estas diferencias sugieren considerar para el estudio de los flujos energéticos del edificio unas condiciones térmicas exteriores diferentes en función de las condiciones existentes en el entorno de la zona del edificio considerada.

Estas condiciones se denominan como temperatura de proximidad y es uno de los componentes del microclima de proximidad, o microclima inducido por el edificio.

\subsection{CONSIDERACIÓN DEL POTENCIAL DE MEJORA}

Las condiciones climáticas se perciben en los edificios en función de factores que dependen de su construcción y su diseño, siendo su capacidad para acumular, disipar o aportar energía un componente fundamental para la aclimatación de sus ambientes interiores y periféricos.

LA CAPACIDAD DE ACUMULAR, DISIPAR O DE APORTAR ENERGÍA DEL EDIFICIO INFLUYE EN EL MICROCLIMA DE PROXIMIDAD 
Esta circunstancia se comprueba a través de la observación de los procesos combinados de retardo y amortiguación térmica debidos a la interacción del edificio con las condiciones exteriores.

La influencia de la radiación solar, de la ventilación natural, del incremento de la humedad o de la presencia de grandes masas térmicas permite ser utilizada para aproximar el ambiente térmico local a las condiciones de comodidad térmicas requeridas por un espacio arquitectónico, en una primera, y complementaria, pre-aclimatación pasiva. (Givoni, 1996)

Un mejor conocimiento de la respuesta del edificio al clima circundante (reactividad), es determinante para establecer las demandas de energía complementaria y la forma en la que la operación de los sistemas pasivos afecta a su balance higrotérmico. 


\section{OBJETIVOS}

\subsection{PRINCIPAL}

Establecer la pertinencia y la singularidad del microclima de proximidad para definir el ambiente térmico exterior a la edificación.

Teniendo en cuenta las series climáticas en el entorno próximo al edificio, los climas de referencia y las series climáticas obtenidas en las estaciones meteorológicas próximas, estableciendo una estimación de la cuantía y, en caso de ser posible, de su naturaleza y de las distorsiones que sufren las temperaturas por la influencia del edificio, definiendo estas condiciones térmicas junto al edificio como parte del microclima de proximidad (MP) y estableciendo las consideraciones que se deben tener en cuenta para definir los valores higrotérmicos para que permitan, en una localización determinada, una adecuada estimación de la respuesta al clima de los edificios.

Esto debe permitir avanzar una propuesta para establecer una relación entre las condiciones higrotérmicas junto al edificio, que denominaremos como microclima de proximidad (MP) y las condiciones atmosféricas observadas en un entorno próximo en un determinado momento, en aras a mejorar el conocimiento de la influencia del clima en la edificación.

\subsection{SECUNDARIOS}

La consecución del objetivo establecido se apoya en la realización de actividades operativas que, en sí mismas, constituyen objetivos que denominaremos como secundarios.

Mediante un método basado en la elaboración, comparación y análisis de series, se cumplimenta el objetivo de definir la escala temporal y espacial adecuada para las series empleadas y las consideraciones a tener en cuenta para formar las series adecuadas a la simulación del comportamiento térmico de la edificación.

Estos objetivos secundarios se materializan en cuatro actividades, dos relativas a la escala temporal y una a la escala espacial.

Entre las relacionadas con la escala temporal está definir la duración adecuada de las secuencias térmicas históricas que deben ser consideradas para realizar la estimación del balance termodinámico de la edificación. Lo cual se realiza mediante el estudio de los valores registrados en las estaciones meteorológicas de referencia locales que pueden aportar información sobre las condiciones climáticas en las que se encuentra un edificio.

Otra actividad relacionada con la escala temporal está enfocada a los intervalos de registro o descripción empleados en las series térmicas. En este sentido se establece la duración apropiada de estos intervalos en función de si el edificio dispone de un sistema de climatización y el tipo de este.

La escala espacial se plantea con el objetivo cualitativo de establecer la influencia de la localización en las determinaciones climáticas en entornos edificados, especialmente en las zonas exteriores próximas a su
ESTABLECER LA SINGULARIDAD Y PERTINENCIA DEL MICROCILMA DE PROXIMIDAD PARA DEFINIR

EL AMBIENTE TÉRMICO EXTERIOR A LA EDIFICACIÓN

\section{OBJETIVOS SECUNDARIOS}

ESCALA TEMPORAL

ESTABLECER LA DURACIÓN ADECUADA DE LAS SERIES HISTÓRICAS PARA SER CONSIDERADAS EN EDIFICACIÓN

DEFINIR EL INTERVALO MÁS ADECUADO EN FUNCIÓN DE LOS SISTEMAS DE CLIMATIZACIÓN

ESCALA ESPACIAL 
perímetro y en las que quedan compartimentadas por él. En la práctica, esto supone poner de manifiesto la variedad de microclimas de proximidad existentes en el entorno del edificio y su importancia para establecer su balance termodinámico.

De una parte mediante la elaboración de series temporales climáticas, principalmente térmicas, que permitan describir las condiciones en un determinado lugar y de otra parte mediante la comparación de las series obtenidas y el análisis de estos resultados de estas comparaciones se demuestra la influencia de la localización en el entorno próximo del edificio en las secuencias térmicas registradas. Estas diferencias justifican el empleo de microclimas de proximidad para una determinación más precisa del balance higrotérmico de los edificios con su entorno

También en la escala espacial se establecen las directrices para la elaboración de las series térmicas que permiten describir el entorno higrotérmico del edificio. Aplicando un proceso de definición de las condiciones anvales típicas a las que se enfrentan los edificios y que son de aplicación a una zona climática determinada y a los climas de referencia empleados para describir el entorno climático.
ESTABLECER LA INFLUENCIA

DE LA LOCALIZACIÓN EN

LOS VALORES TÉRMICOS

REGISTRADOS. MICROCLIMA

DE PROXIMIDAD

DEFINIR DIRECTRICES PARA ELABORAR SERIES TÉRMICAS PARA SIMULACIÓN DEL

BALANCE TERMODINÁMICO DEL EDIFICIO 


\section{METODOLOGÍA}

El método con que se plantea el análisis de las condiciones climáticas y su aplicación a un mejor diseño de los edificios, de sus sistemas y de su entorno próximo se ha establecido atendiendo a las secuencias de diseño y la intervención en ella de que se considera para el diseño y operación de los sistemas.

Las secuencias, en general, parten del clima para, mediante estrategias de diseño, conseguir unas condiciones confortables en el interior de los edificios. Se describen tres secuencias significativas, dos de diseño, una sin considerar equipos para aportar o disipar energía al interior y otra con ellos, y una secuencia de operación.

La primera secuencia establece las previsiones de respuesta del edificio al clima a partir de parámetros estimados. Mediante procesos inducidos o iterativos se estima la mejor forma de cumplir los objetivos, definiendo las estrategias y, a partir de ellas, el diseño arquitectónico y los sistemas constructivos. Cuando la actuación es de rehabilitación la arquitectura es una condición para la definición de las estrategias mientras que en actuaciones de nueva planta las estrategias precederán a la arquitectura. Este proceso conduce a la estimación de las previsiones de bienestar, en un proceso iterativo que permitirá elegir entre distintas opciones (FIG. 4-1).

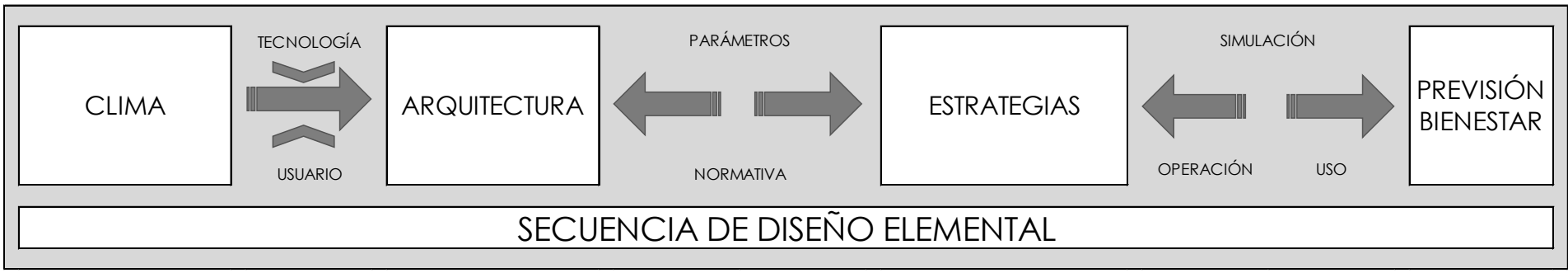

FIG 4-1 Secuencia de diseño de edificios en relación con su adaptación al clima

La evolución de la arquitectura doméstica se apoya en conseguir el bienestar para cada usuario, con un patrón de usos determinado, y empleando la tecnología disponible, entendida como el compendio de la tradición, la cultura, las costumbres, el conocimiento y la capacidad tecnológica de ponerlos en uso.

Este proceso es viable en climas benignos, donde puede promoverse mediante la arquitectura y unas prácticas adecuadas una combinación de temperatura, humedad, el ventilación y radiación que procuren unas condiciones de bienestar higrotérmico.

Para el resto de los climas es preciso emplear energía para alcanzar condiciones de bienestar higrotérmico. Esta energía se canaliza a través de equipos y sistemas que la transformen y canalizan para modificar las condiciones térmicas, de velocidad del aire o de humedad, que influirán en el bienestar. Estos equipos y sistemas procurarán bienestar a costa de energía, que, a su vez, podrá ser gratuita o comercial, renovable o no renovable, etc.

La consideración de equipos en la secuencia de diseño modifica los parámetros estimados de salida siendo necesario incorporar el consumo estimado o demanda de energía que sería necesario aportar a los equipos (FIG. 4.2). 


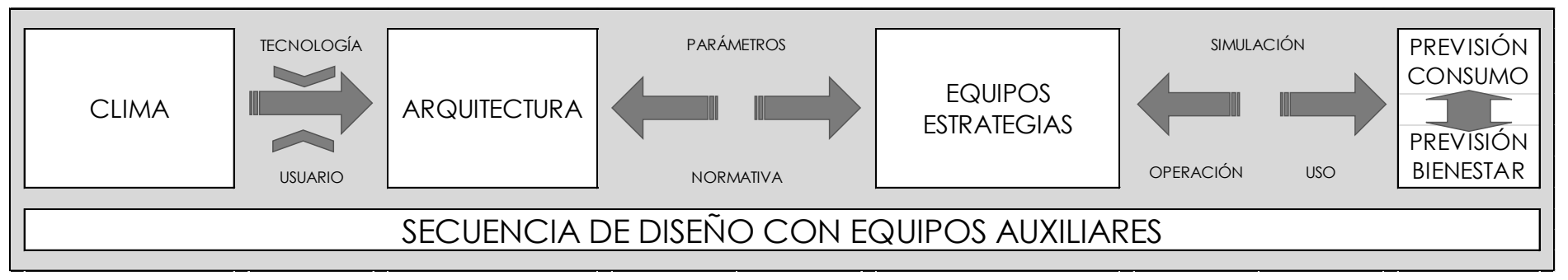

FIG 4-2 Secuencia de diseño de sistemas formados por edificios y equipos para su adaptación al clima

Por un elemental sentido práctico se considerarán consumos los producidos por aquellas fracciones de energía comercial empleadas en conseguir el bienestar, mientras que se consideran ganancias el conjunto de las energías gratuitas que recibe el sistema. Estos consumos pueden expresarse en función del objetivo del estudio en unidades de energía, económicas, emisiones, impactos medioambientales, etc.

Una tercera secuencia se produce cuando entran en servicio los equipos que aportan o detraen energía en un momento y lugar determinado, con las condiciones reales se busca el bienestar higrotérmico. Las condiciones las definen el tiempo atmosférico, las condiciones y parámetros de operación y el estado de los equipos y los edificios. El resultado de esta secuencia son los consumos reales. No está exenta esta secuencia de la previsión que puede establecerse a partir de la estimación del tiempo atmosférico, los usos, las condiciones de operación y el rendimiento de los equipos. El resultado sería la estimación del coste económico, emisiones o consumo energético, que puede contrastarse posteriormente con los valores reales (FIG 4.3).

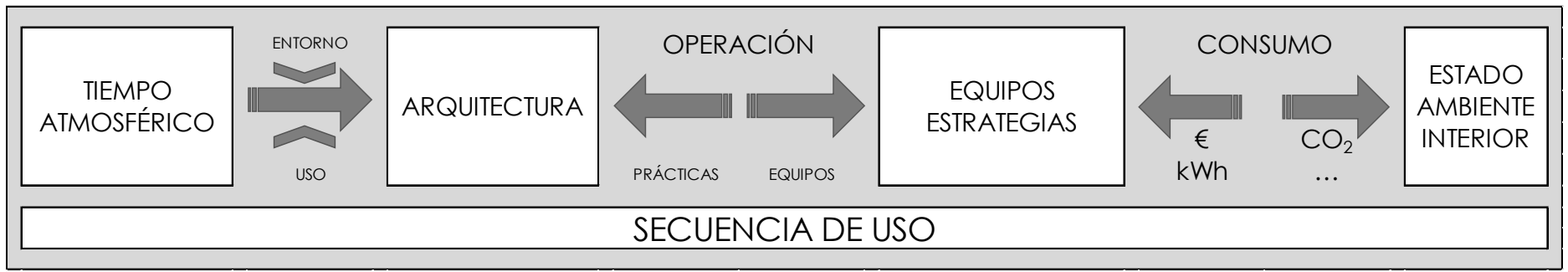

FIG 4-3 Secuencia de operación del edifico y los equipos durante su vida útil

Las relaciones entre el clima y los medios necesarios para conseguir condiciones de bienestar se manifiestan de este modo como las operaciones necesarias para que el conjunto formado por la arquitectura, los equipos y las estrategias empleadas procuren unas condiciones higrotérmicas confortables al ambiente interior.

Las dos primeras secuencias están destinadas a la prescripción arquitectónica y al establecimiento de la demanda estimada, la tercera, en cambio, a establecer las condiciones de operación y la gestión apropiada, como confluencia del consumo y el bienestar.

La aplicación independiente de estas secuencias, pone en evidencia importantes diferencias entre las estimaciones y los consumos reales en el ámbito residencial. (Taylor, 2013, pág.19).

La estructura propuesta parte de considerar diversas bases de datos climáticos, el registro "in situ" de los valores climáticos y su posterior análisis y comparación. Para ello será preciso realizar un tratamiento de los datos que permita este análisis comparado. 
Así mismo, será preciso tener en cuenta la singularidad climática que supone el entorno urbano y sus conjuntos de edificios.

La influencia mutua de los parámetros climáticos y su evolución en el entorno próximo al edificio, se resuelve proponiendo la definición de unas condiciones específicas para el entorno próximo al edificio, diferenciada para sus distintas orientaciones y espacio los distintos espacios con los que limita o compartimenta, o microclima de proximidad.

La simulación del estado higrotérmico y del consumo en distintos supuestos mediante herramientas informáticas, así como el estudio y la aplicación a diversos estudios de caso.

La organización de la metodología se inicia, por tanto, en una primera instancia en la recopilación de valores de clima existentes y en la obtención de datos sobre el terreno, para su estudio comparado y posterior elaboración de las conclusiones. Para la elaboración de esta metodología se han considerado las prácticas convencionales en meteorología (Fernández García, 1996), adaptándolas a las necesidades de la edificación.

La primera fase se apoya en la información existente en diversos bancos de datos, casi todos ellos de la Agencia Nacional de Meteorología, procedente de la reorganización del Servicio Meteorológico Nacional (SMN) español (RD 186/2008), denominado posteriormente como Instituto Nacional de Meteorología (INM) (RD 2229/1978), procedentes ambos del Instituto Central de Meteorología (RD de 12 de agosto de 1887).

La base documental de la meteorología en España se forma con registros históricos de más de 30 años que, tras un proceso estadístico y analítico, son la fuente de información más precisa de las consultadas.

Las bases de datos internacionales también recogen informaciones locales integrándolas en modelos mayores. En nuestro entorno las actividades de los servicios nacionales de meteorología españoles y portugueses permiten la elaboración de un atlas climático común para toda la península ibérica (VVAA, 2011) y, en un orden diferente, de datos meteorológicos locales que son la base necesaria para la instruir modelos climáticos que simulan el clima pasado más antiguo (paleo-clima) y de la variabilidad climática tanto a nivel regional (AR4 en la región euroatlántica, NAO en el atlántico norte, SCAND en Escandinavia, EA en la región este-atlántica, EA/WR en el atlántico oriental y la Rusia occidental) como en un re-análisis de mayor envergadura (ERA-40 del Centro Europeo de Predicción a medio plazo (Uppala, 2005) o NCEP/NCAR, desarrollado en USA (Kalay, 1996)).

Otro tipo de información es la que muestra el comportamiento medio horario que permite reproducir las condiciones estimadas durante el periodo de un año. Entre otras se han considerado las bases de datos formadas para la aplicación de programas de simulación del comportamiento de los edificios y, entre ellas, se ha elegido la que se aplica por defecto en el programa de simulación EnergyPlus desarrollado por el U.S. Department of Energy de Estados Unidos, al estar presente en muchos de los programas desarrollados por terceros (OPENSSTUDIO, CYPECAD MEP, DesignBuilder, ECOTEC,...). Estas bases de datos están accesibles en el citado U.S. Department of Energy, a través del enlace 
En él se recogen los datos climáticos de distintas ciudades españolas, normalmente la red de estaciones meteorológicas (SWEC) situadas en los aeropuertos.

También se han considerado las bases de datos aportadas para la aplicación de la normativa vigente, actualmente recogidas en la información anexa al Código Técnico de la Edificación (CTE), como "Documento descriptivo de climas de referencia" publicado por la Secretaría de Estado de Infraestructuras, Transporte y Vivienda de la Dirección General de Arquitectura, Vivienda y Suelo del Ministerio de Fomento en septiembre de 2013, y sus correspondientes archivos de datos para cada uno de las zonas climáticas que se incluyen en la aplicación del Código Técnico de la Edificación.

Se considera igualmente la edición de datos de provincias y zonas climáticas por parte del Ministerio de Industria y Energía, que pueden consultarse en:

http://www.minetad.gob.es/energia/desarrollo/EficienciaEnergetica/CertificacionEnergeti ca/DocumentosReconocidos/Paginas/documentosreconocidos.aspx (consultado por última vez el 30 de marzo de 2017)

Por último se han recogido datos mediante equipos de medida propios dispuestos en diversas ubicaciones del interior y el exterior de edificios situados en Zaragoza y en otras ciudades de España..

En general los valores así obtenidos y los existentes en bases de datos han seguido un proceso de elaboración que puede esquematizarse en dos fases, una de tratamiento y otra de discusión, en el que se pueden distinguir tres fases, una de tratamiento de los datos, otra de comparación y análisis y, por último, otra de discusión que permita comprender su relevancia para un área concreta.

De una parte la elaboración de series temporales climáticas, principalmente térmicas, que permitan describir las condiciones en un determinado lugar, de otra parte la comparación de las series obtenidas y, por último, se analizan los resultados de estas comparaciones.

Aplicándose este proceso a los distintos climas de referencia elaborados para la definición de las condiciones anuales típicas a las que se enfrentan los edificios y que son de aplicación a una zona climática determinada,

También se aplican a los valores obtenidos de las estaciones meteorológicas de referencia locales, que pueden aportar información sobre las condiciones climáticas en las que se encuentra un edificio. Este proceso se propone para series temporales largas, constituyendo también un objetivo secundario definir la duración significativa para estas series.

Además de las series, tanto de registros como de estimaciones, obtenidas de fuentes de información públicas se ha realizado la toma de datos en varias localizaciones, de las que se ha elegido, aunque ocasionalmente se empleen otras referencias geográficas, la situada en el centro urbano de Zaragoza. Esta toma de datos afecta a la obtención de valores 
climáticos en general e higrotérmicos en particular en el entorno próximo del edificio.

Esquemáticamente, el método empleado, se muestra en los siguientes apartados de este documento.

\subsection{PARTE 1: ESTADO DE LA CUESTIÓN}

La experiencia acumulada en este área, el marco normativo, los principios climáticos y las relaciones cruzadas entre los distintos parámetros del clima y su relación con la edificación, ocupan la primera parte que se aborda entre el capítulo 1 y el 5.

\subsection{PARTE 2: RECOGIDA Y TRATAMIENTO DE LOS DATOS.}

La mayor parte de los datos corresponden a los registrados por las entidades responsables del conocimiento climático, fundamentalmente por la Agencia Estatal de Meteorología (AEMET) a través de los registros de sus sedes localizadas cerca de las zonas de trabajo.

Estos valores se complementan con los obtenidos en el interior de las zonas urbanas donde se focaliza el estudio, tratados e incluidos en bases de datos comparables.

Estos registros se realizan mediante un equipo inalámbrico según el esquema descrito en la figura, y cuyos datos están recogidos en el anexo:

\section{EQUIPOS DE TOMA DE DATOS}

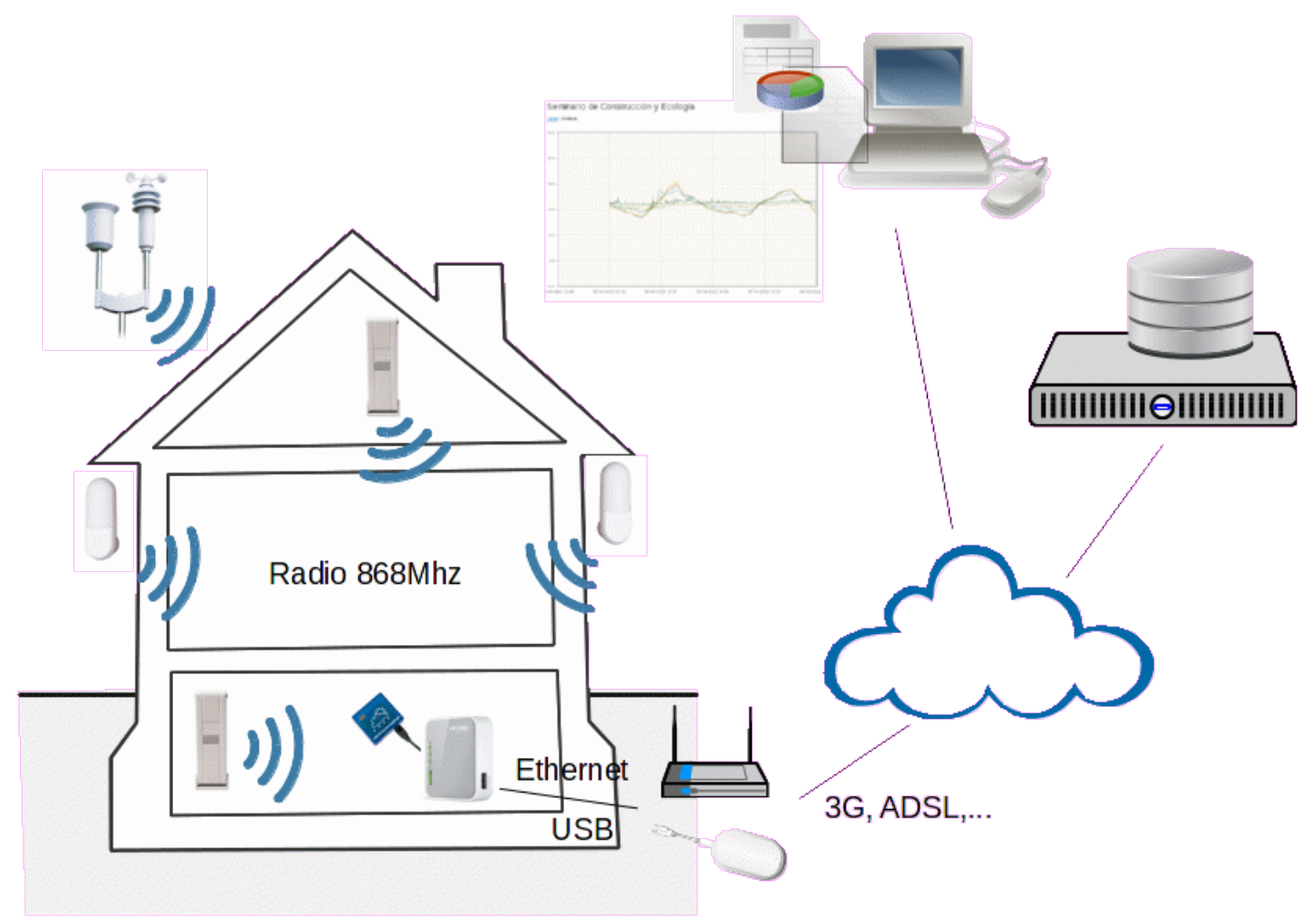

FIG 4-4 ESQUEMA DE MEDIOS A TRAVÉS DE LOS QUE SE TRANSFIERE EL CALOR DE LA ATMÓSFERA AL CUERPO HUMANO (Elaboración propia) 
Para ello se procede a realizar los procesos de simplificación, selección y clasificación que se describen a continuación.

\subsubsection{SIMPLIFICACIÓN DE LOS DATOS BRUTOS}

Las series recogen los datos de forma indiscriminada recogiendo parámetros diferentes y temporalizaciones muy variadas.

La simplificación ha consistido en ordenar las variables en secuencias temporales adecuadas al objetivo previsto.

La secuencia temporal se ha establecido en una hora, aunque cuando estos procesos son menores de un día también se han considerado intervalos menores.

\subsubsection{ELECCIÓN DE VALORES Y PERIODOS RELEVANTES Y RELLENO DE} LAGUNAS EN SERIES INCOMPLETAS.

La amplitud de los datos obtenidos exige una selección y transformación posterior en variables adecuadas, como son la temperatura del aire, la humedad relativa, la radiación, difusa y directa incidente sobre un plano horizontal, y la velocidad y dirección del viento.

Las series procedentes de análisis solventes efectuados por entidades especializadas, como son los valores normales para series temporales de 10 a 30 años de AEMET o los valores promedio recogidos por la normativa para la simulación del comportamiento térmico de los edificios, recogidos en el CTE o en el RITE, están ya ordenados por horas e incluyen, entre otros, los que se han considerado más apropiados.

Las series obtenidas mediante estaciones meteorológicas portátiles, con recogida de datos mediante envío remoto o por retirada periódica, pueden presentar severas discontinuidades por lo que la consideración de periodos comunes y la forma de estimación de estos valores es especialmente importante.

\subsubsection{CONTROL DE CALIDAD DE LAS SERIES}

Los parámetros para evaluar esta calidad se basan en la longitud de la muestra, entendida como el número de años de los que proceden los valores climáticos; está muy relacionada con el margen de error siendo este mayor cuando disminuye el número de años o aumenta la desviación, el tamaño de la muestra

De un modo general se admiten 5, 10, 30 o 50 años como duraciones adecuadas, aunque su determinación es necesario hacerla en función del error que se está dispuesto a asumir.

\subsubsection{ESCALAS TEMPORALES DE ANÁLISIS.}

Las escalas temporales que se analizarán son muy variadas, la imposibilidad de disponer de secuencias homogéneas de larga duración ha determinado el uso de series anuales y decenales para los datos obtenidos en observatorios oficiales y desde varios días hasta más de cuatro años para los obtenidos dentro de este trabajo. 


\subsubsection{PRESTACIONES (EXIGENCIAS) PARA UN USO CONFORTABLE DE LOS} EDIFICIOS Y SU ENTORNO PRÓXIMO

No todos los parámetros tienen aplicación en igual medida para el estudio propuesto por lo que, en síntesis, se han considerado prioritarios aquéllos que permiten definir el estado del clima y su evolución durante un periodo determinado en función de la capacidad de reacción de la edificación y de su entorno. De este modo se establecen las medidas que informan sobre la centralidad (media, mediana,...) y las que lo hacen sobre la dispersión (cuartiles, oscilaciones,...)

\subsubsection{PARÁMETROS ESTADÍSTICOS REPRESENTATIVOS}

Entre los parámetros estadísticos representativos se consideran especialmente las medias y las desviaciones.

\subsubsection{VALORES MEDIOS, PROBABLES Y EXTREMOS}

Los valores recogidos en las series térmicas estudiadas son, en muchas ocasiones, valores medios (anuales, diarios $u$ horarios), y en otras puramente estadísticos y que, expresados en valores horarios, reflejan el estado térmico estimado o probable en una determinada zona climática.

Por último, se analizan series térmicas con valores extremos, máximos o mínimos absolutos, durante un determinado periodo.

\subsection{PARTE 3: ANÁLISIS DE LOS DATOS}

Exploración de diversos procedimientos de análisis de la relación entre clima y edificación.

\subsection{PARTE 4: DISCUSIÓN Y CONCLUSIONES}

La discusión incluye información sobre la relevancia para la edificación de las condiciones higrotérmicas

La conclusión, por su parte, recoge las condiciones para establecer las secuencias térmicas que describen el clima local para su aplicación a la edificación.

También se incluyen unas líneas de investigación futuras deducidas a partir de los trabajos realizados.

El documento se completa con la bibliografía, un breve glosario, los acrónimos y el índice de figuras y se completa con anexos que complementan la información aportada y no se han considerado imprescindibles para el seguimiento del texto. 


\section{ESTADO DEL CONOCIMIENTO}

El rango de temperaturas que admite una menor variación es el que corresponde al interior corporal, pudiéndose afirmar que sus condiciones de confort son muy restrictivas. Por ello, existen a su alrededor barreras biológicas, como la piel, y antrópicas, como el arropamiento, que contribuyen a ampliar notablemente el rango de temperaturas confortables. Los elementos constructivos y los sistemas del edificio realizan una acción similar, contribuyendo a ampliar el rango térmico atmosférico en el que es posible disfrutar de condiciones de confort.

Cada edificio es, por tanto, un recurso para adaptar las condiciones interiores a las demandas de los usuarios en un entorno climático determinado y tendrá un comportamiento diferente en función de su forma y la disposición y naturaleza de sus componentes (FIG 5.1).

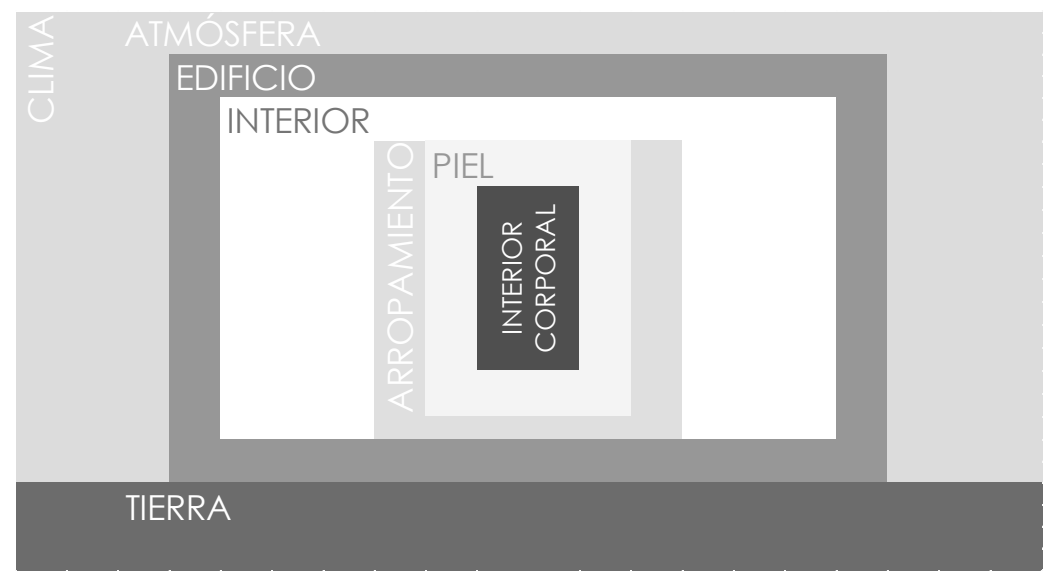

FIG 5-1 ESQUEMA DE MEDIOS A TRAVÉS DE LOS QUE SE TRANSFIERE EL CALOR DE LA ATMÓSFERA AL CUERPO HUMANO (Elaboración propia)

El balance termodinámico entre ambientes interiores y exteriores se realiza, por tanto, situando al edificio entre el clima local exterior (clima local) y el usuario y sus demandas de bienestar.

Las decisiones que permiten ambientes térmicamente confortables son abordadas por distintas tecnologías y ciencias, en una estructura multidisciplinar (FIG 5.2).

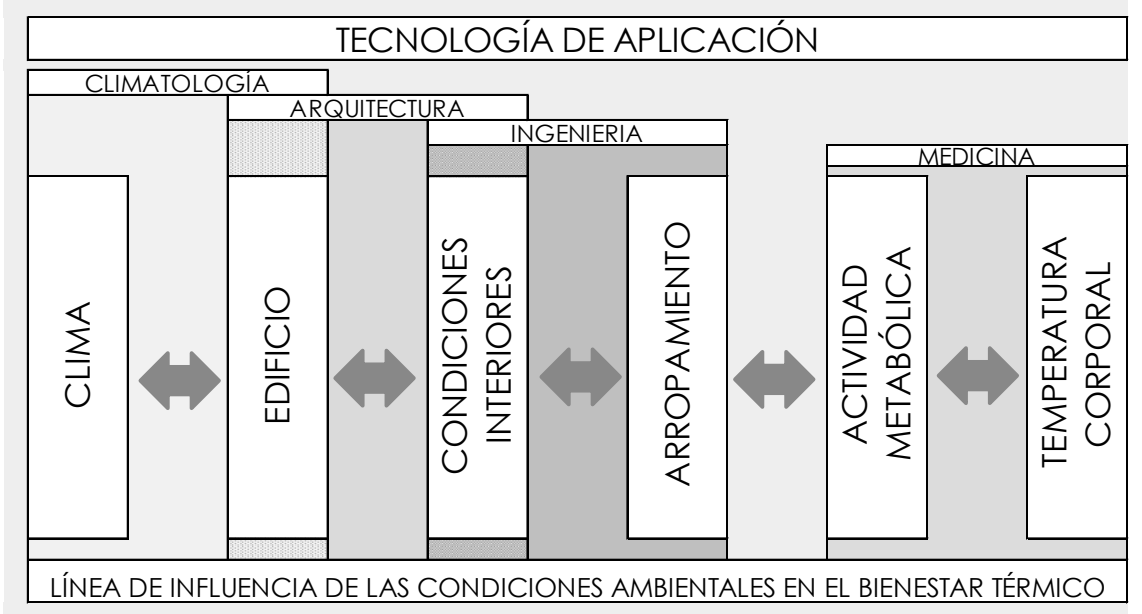

FIG5-2 tECNOLOGÍAS Y CIENCIAS DE APLICACIÓN AL BIENESTAR TÉRMICO (Elaboración propia). 


\subsection{ANTECEDENTES: ANÁLISIS CLIMÁTICO Y EDIFICACIÓN}

\subsubsection{INTRODUCCIÓN}

Si la manifestación que se percibe en cada momento de las condiciones atmosféricas es el tiempo atmosférico o el estado en cada momento de la atmósfera, el clima hace referencia a la percepción de un pasado reciente y a la estimación de un futuro probable, considerando los ciclos periódicos (estacionales, díanoche,...) o los ciclos ocasionales (viento, nubosidad,...), expresado en variables como pueden ser la radiación, la lluvia, la temperatura o la humedad.

La percepción de las condiciones atmosféricas que se tiene en un lugar y durante un periodo de tiempo corto; el denominado tiempo atmosférico, condiciona la forma en que se puede conseguir el bienestar higrotérmico en ese lugar y en ese momento. El tiempo atmosférico es variable, y la edificación tiene la vocación de permanencia. Esto hace que se considere para el diseño de la edificación un compendio de los valores estadísticos de las condiciones atmosféricas, a los que se hace referencia como condiciones climáticas locales, y que, frecuentemente puede identificarse en la forma de los edificios y en su ordenación.

La predicción del tiempo atmosférico en un determinado lugar es el resultado del desarrollo de la meteorología.

La predicción atmosférica hace referencia a la interpretación de sucesos periódicos, como pueden ser los amaneceres húmedos y fríos o la variación de la radiación, en una zona y momentos determinados $u$ ocasionales, como el cambio de dirección del viento o la acumulación de nubes en una cumbre.

El clima, en cambio, se ha considerado siempre como un agregado de condiciones atmosféricas, asociadas a una región.

La rápida evolución en el registro de datos comparables de las condiciones climáticas en un momento dado ha permitido la reciente evolución de la climatología como ciencia.

La previsión del tiempo influye en edificación al determinar protocolos de operación eficiente de los sistemas, precauciones de mantenimiento o la programación de actividades, mientras que el clima permitirá, por ejemplo, la estimación de los rendimientos globales.

La climatología recoge el tiempo medio para un determinado lugar en un periodo suficientemente significativo (Fernández García, 1996, pág. 15).

Esta definición es concurrente con la que lo considera como el conjunto de condiciones atmosféricas o de valores promedio de las condiciones atmosféricas a lo largo de un periodo suficientemente largo aplicados a una determinada región geográfica (Yáñez, 2008, pág.173) o el conjunto de fenómenos que caracterizan el estado medio de la atmósfera en un punto de la corteza terrestre. Así definido también es denominado como climatología analítica. 
Para explicar y describir el ambiente atmosférico será preciso recurrir a la climatología dinámica y a la climatología sinóptica, que se engloban en la denominada climatología sintética. A través de ella podemos establecer semejanzas y diferencias entre el ambiente atmosférico de diversos lugares, significándolos como zonas climáticas.

Para el diseño de los sistemas precisos para adaptarse a las condiciones del entorno o el diseño de los espacios capaces de enfrentarse a las situaciones extremas razonablemente previsibles se diseñan climas de referencia, que son frecuentemente incorporados a las exigencias que habrá de seguir el diseño para el cumplimiento de una determinada normativa (RITE,2007) (CTE,2007). Por ello se les denominará como climas normativos o climas de referencia.

Así como en la climatología analítica el clima define con precisión el estado históricamente medio de la atmósfera en un lugar, la climatología sintética o física describe e intenta explicar la sucesión de fenómenos que dan lugar al tiempo atmosférico en un momento y un lugar. El ambiente estadístico o de valores medios solo define y explica parcialmente el proceso, siendo preciso complementarlo en el ambiente sintético que define y explica la secuencia de fenómenos que afectan al bienestar local o instantáneo. La aplicación de la climatología a la prescripción arquitectónica da lugar a los climas de referencia o normativos.

La zonificación climática se realiza mediante la asignación de un comportamiento similar a las zonas en las que se producen valores similares, es decir, los situados entre dos umbrales de varios parámetros diferentes. Las clasificaciones no son ajenas a su finalidad última, como es, por ejemplo, la capacidad de producción agrícola o ganadera, los biotopos que se alojan en cada clima e incluso la facilidad de aclimatación de los seres humanos.

Entre ellas puede destacarse las de A.N. Strahler y KoopenGeiger, por agrupar en zonas o regiones climáticas aquellos lugares con condiciones similares para las actividades productivas y su potencial uso residencial.

La edificación pasa a ser una parte importante del clima a partir de los estudios que asocian las zonas urbanizadas con modificaciones causales de los parámetros del clima, considerándose una región del clima, normalmente denominada como clima o microclima urbano (GOLDREICH, 1995) (HONGLI, 2005) o, más recientemente, como isla de calor.

Se ha podido corroborar la intensa relación entre el clima y la vitalidad humana (VVAA, 2011):

- El clima influye, junto a la edad y la alimentación, en la salud.

- La influencia del clima en la salud está en función de las personas y sus circunstancias y de la alternancia de periodos fríos y cálidos.
- SINTÉTICA

DINÁMICA

SINÓPTICA

- DE REFERENCIA (NORMATIVOS)

ZONIFICACIÓN

CLIMÁTICA

CLIMA Y VITALIDAD HUMANA 
- El clima influye y determina las actividades humanas en todos los sectores socioeconómicos y culturales.

El clima influye en nuestras costumbres y en el modo en que vivimos (Miller, 1957). Su persistencia obliga a considerarlo como un invariante (Racine, 1985) y su modificación, aun sucediendo en periodos muy largos, supone perjuicios a la salud humana y afecta a la productividad y a las posibilidades de desarrollo (BM, 1992), corroborando esta afirmación informes recientes aplicados a zonas concretas, donde se anticipa una previsible modificación drástica del entorno natural, rural y urbano y su repercusión en la salud (BM, 2013).

La capacidad de transformación y adaptación al clima por parte del hombre es la más intensa y eficaz de las existentes en el mundo animal. Ésta es, sin duda, una de las cualidades que le han permitido su proliferación como especie. Las relaciones entre la física, la medicina y la climatología para conseguir el bienestar humano son el principal objetivo de la bioclimatología, siendo el diseño en planificación urbana y en arquitectura campos en los que se desarrollan aplicaciones de esta ciencia.

La arquitectura, que tiene a las fuerzas de la naturaleza como uno de sus factores básicos a considerar, habrá de considerar la climatología como una de las disciplinas científicas que se han de tener en cuenta para su definición constructiva.

Se mantiene, por tanto, una referencia circular entre el edificio y su entorno y el clima, ya que el edificio recibe la acción del tiempo atmosférico y se diseña para conseguir el bienestar en un determinado clima $y$, a su vez, influye en las condiciones climáticas de su entorno (Page, F.K. 1975).

Está muy documentada la relación del clima con la edificación y la ordenación del territorio. Tanto los estudios y tratados históricos como los análisis de las edificaciones tradicionales o los más recientes textos académicos que tienen como objetivo la didáctica de la arquitectura o el urbanismo recogen esta relación. La utilidad práctica de seguir unos criterios que atiendan a las exigencias del clima para diseñar y ejecutar los edificios, y así evitar sus inconvenientes y potenciar sus ventajas, se ve reflejada abundantemente en la bibliografía sobre edificación, poniendo en evidencia la interdependencia entre las formas, los usos y los tipos de edificios y sistemas constructivos y el balance energético en un determinado clima. Este proceso se manifiesta tanto a través de su decantación en el acervo cultural de sus habitantes (LUXAN, 2013) como de su aplicación a los análisis y procesos tecnológicos para su implantación.

La adaptación al clima de su entorno ha sido históricamente una de las preocupaciones de la arquitectura. Tanto en las referencias antiguas (Vitruvio, S. I a.c. ) o (Alberti, 1485), como modernas (Le Corbusier, 1953), puede comprobarse esta relación y la importancia que se confiere en la arquitectura al clima donde se ubicará.

El emplazamiento en el que se realizan los estudios de caso es la
CLIMA

PLANIFICACIÓN URBANA Y

ARQUITECTURA

RFERENCIA CIRCULAR ENTRE CLIMA Y EDIFICACIÓN

CLIMA Y ARQUITECTURA 
península ibérica, que se caracteriza por gran heterogeneidad climática, dada su posición latitudinal, su orografía y la circulación general de las masas de aire cálido y frio que le afectan (AEMET, 2011). Dentro de ellas se prestará especial atención a las zonas que se podrían denominar como moderadas, por no estar entre las más extremas.

\subsubsection{VARIABLES CLIMÁTICAS}

La caracterización del tiempo atmosférico se realiza mediante variables que permitan cuantificar sus manifestaciones, ya se observen mediante la percepción directa o mediante instrumentos que registren condiciones atmosféricas de las que pueden deducirse. Estas variables se emplean para la definición del clima y los umbrales que permiten clasificarlos.

Existe un amplio consenso sobre las variables climáticas que describen el clima y cómo, a su vez, estas variables son influidas por diversos factores climáticos. Su consideración, por tanto, es importante para lograr unas condiciones de bienestar en edificación. Por otra parte, los factores climáticos sufren fuertes modificaciones en presencia de los edificios y los entornos urbanos o fuertemente antropizados (Page, 1975).

Se han tenido en cuenta la temperatura, la humedad, la radiación y el viento, como los valores o parámetros más significativos para un análisis climático que tenga como finalidad la toma de decisiones en edificación residencial (Aritzmendi, 2002).

El carácter sistémico del clima hace que todas sus variables estén relacionadas entre sí, pudiendo ser, en muchos casos, unas reflejo de otras y siempre unas consecuencia de las otras (Serra, 2002).

Del mismo modo este carácter sistémico del clima hace que estas variables sean, simultáneamente causa, efecto e indicador de estado, en una referencia circular.

También denominadas como propiedades físicas de la atmósfera recogen todos aquellos parámetros que aunque se encuentren permanentemente en ella se modifican tanto cíclica como evolutiva u ocasionalmente.

Los objetivos buscados sugieren poner énfasis en la determinación de secuencias y su frecuencia para establecer las condiciones típicas y singulares a los que tendrá que enfrentarse el edificio para alcanzar las prestaciones requeridas.

Sus valores instantáneos constituyen el tiempo atmosférico y sus secuencias estadísticas los climas. Estas estadísticas tienen diferente periodicidad, desde las máximas y mínimas diarias a los valores horarios, pasando por diversas fracciones de las series temporales.

Permiten la definición de periodos tipo, días, semanas u otra secuencia, de máximos o de mínimos para diversos periodos climáticos en cada región. 
La frecuencia con la que se relaciona la temperatura con las condiciones adecuadas y los umbrales límite para el desarrollo de la actividad biológica hacen que se considere la temperatura como el parámetro más significativo para establecer las condiciones de bienestar, aunque para ello se utilice como indicador el formado como agregado de distintas variables.

El exponente más directo de las condiciones térmicas del ambiente es la temperatura del aire, una de las condiciones básicas para la habitabilidad del planeta, estableciendo los umbrales que precisan las diferentes estrategias de supervivencia y desarrollo de los seres vivos. Esta evidencia se hace patente en los procesos de formación y evolución del clima, siendo igualmente consecuencia de este, en una referencia también circular o recíproca.

Las series anuales, a partir de las que se determinan los climas en su conjunto, se ha considerado que no permiten una descripción correcta del entorno para los objetivos buscados. Por ello se han elaborado varias estimaciones de las fracciones temporales significativas, frente a la respuesta del edificio en un determinado clima, y se establecen los valores que describan la evolución diaria, estacional y las series donde la temperatura se incrementa y en las que decrece.

Este fraccionamiento temporal se aleja de las estaciones convencionales, de algo más de noventa y un días de duración, ya que no se ajustan a un comportamiento climático significativo. Para evitar la simplificación de ajustar a una asignación temporal prefijada las condiciones climáticas se ha decidido establecer otra denominación que permita que tanto el comienzo como la duración de estos periodos puedan asociarse a las condiciones atmosféricas en un determinado lugar y circunstancia, antes que a una asignación automática al calendario. Por ello se ha preferido la denominación periodo cálido (verano), frío (invierno) o de evolución fría cuando transcurre entre el periodo cálido y el frio (otoño) y de transición cálida cuando lo hace desde el periodo frío al cálido (primavera). Las temporalizaciones realizadas se hacen para que, eludiendo los análisis estacionarios, se consideren otras opciones dinámicas para hacer visible la relación entre las variables climáticas y su evolución y la sensación de comodidad térmica.

A su vez la descripción que se ha considerado de aplicación debe considerar dentro de cada periodo, secuencias más frías, más cálidas o medias (en un gradiente de grises de claros a oscuros respectivamente) (FIG. 5.2).

También puede observarse la evolución de los valores máximos, mínimos o medios en estos periodos y, a su vez, tanto los valores mínimos como los máximos podrán ser los mínimos absolutos o la media de los valores mínimos en un determinado periodo.

La dispersión aporta un nuevo parámetro que, ya venga dado por la oscilación térmica, por la desviación estándar o por cualquier otro valor, nos aportará un factor muy importante para establecer el potencial de las estrategias de adaptación a estas situaciones,
DISTRIBUCIÓN TEMPORAL EN PERIODOS:

\section{- CÁLIDOS \\ - DE EVOLUCIÓN FRÍA - FRÍOS \\ - DE EVOLUCIÓN CÁLIDA}


promoviendo, dificultando o evitando los intercambios entre el interior y el exterior.

\begin{tabular}{|c|c|c|c|c|c|c|c|c|c|c|c|c|c|c|c|c|c|c|}
\hline \multirow{3}{*}{\multicolumn{2}{|c|}{$\begin{array}{c}\text { PERIODO } \\
\text { VALOR RELATIVO }\end{array}$}} & \multicolumn{4}{|c|}{ DIARIO } & \multicolumn{4}{|c|}{ SERIE CRECIENTE } & \multicolumn{4}{|c|}{ SERIE DECRECIENTE } & \multicolumn{4}{|c|}{ ESTACIONAL } & $\overrightarrow{4}$ \\
\hline & & \multirow{2}{*}{ CÁLIDO } & \multicolumn{2}{|c|}{ TRANSICIÓN } & \multirow[b]{2}{*}{ FRIO } & \multirow[b]{2}{*}{ CÁLIDO } & \multicolumn{2}{|c|}{ TRANSICIÓN } & \multirow[b]{2}{*}{ FRIO } & \multirow[b]{2}{*}{ CÁLIDO } & \multicolumn{2}{|c|}{ TRANSICIÓN } & \multirow[b]{2}{*}{ FRIO } & \multirow[b]{2}{*}{ CÁLIDO } & \multicolumn{2}{|c|}{ TRANSICIÓN } & \multirow[b]{2}{*}{ FRIO } & $\vec{z}$ \\
\hline & & & $\begin{array}{l}\text { CÁLIDO } \\
\text { A FRIO }\end{array}$ & $\begin{array}{l}\text { FRíO } \\
\text { CÁLID }\end{array}$ & & & $\begin{array}{l}\text { CÁLIDO } \\
\text { A FRIO }\end{array}$ & $\begin{array}{l}\text { FRÍO A } \\
\text { CÁLLIDO }\end{array}$ & & & $\begin{array}{l}\text { CÁLIDO } \\
\text { A FRIO }\end{array}$ & $\begin{array}{l}\text { FRÍO A } \\
\text { CÁLIDO }\end{array}$ & & & $\begin{array}{l}\text { CÁLIDO } \\
\text { A FRIO }\end{array}$ & $\begin{array}{l}\text { FRÍO A } \\
\text { CÁLIDO }\end{array}$ & & \\
\hline \multirow{2}{*}{ MÁXIMAS } & MEDIA & & & & & & & & & & & & & & & & & \\
\hline & ABSOLUTA & & & & & & & & & & & & & & & & & \\
\hline \multirow{2}{*}{ CENTRALIDAD } & MEDIANA & & & & & & & & & & & & & & & & & \\
\hline & PROMEDIO & & & & & & & & & & & & & & & & & \\
\hline \multirow{2}{*}{ MÍNIMA } & MEDIA & & & & & & & & & & & & & & & & & \\
\hline & ABSOLUTA & & & & & & & & & & & & & & & & & \\
\hline \multirow{2}{*}{ DISPERSIÓN } & OSCILACIÓN & & & & & & & & & & & & & & & & & \\
\hline & $\begin{array}{l}\text { DEVIACIÓN } \\
\text { STANDARD }\end{array}$ & & & & & & & & & & & & & & & & & \\
\hline & & & & & & & & & & & & & & & & & & \\
\hline
\end{tabular}

FIG 5-2 ESQUEMA DE LAS ESCALAS TEMPORALES PARA VALORES DE TEMPERATURA SIGNIFICATIVOS (Elaboración propia)

Un criterio para el dimensionamiento de las estaciones térmicas es la consideración el de establecer límites a los periodos en una serie continua de días en los que se superen o alcancen valores máximos o mínimos de temperatura $(\theta)$ por encima o por debajo de un determinado percentil $(P)$ durante un tiempo determinado (López de la Franca, 2012) (Frich, 2002), que pueden enunciarse, en función como:

periodo de transición al calor:

Última vez que durante 6 días consecutivos, la media diaria climática de la $\theta_{\text {mín }}>P_{25}$ de la media diaria del ciclo anual de 30 años de la $\theta_{\text {mín. }}$ Antes del máximo diario anual climático de la $\theta_{\text {mín. }}$

periodo cálido

Primera vez que durante 6 días consecutivos, la media diaria climática de la $\theta_{\text {máx }}>P_{75}$ de la media diaria del ciclo anual de 30 años de $\theta_{\text {máx. }}$ Antes del máximo anual de la $\Theta_{\text {máx. }}$

periodo frío

Primera vez que durante 6 días consecutivos la media diaria climática de la $\theta_{\text {mín }}<P_{25}$ de la media diaria del ciclo anual de 30 años de la $\theta_{\text {mín. }}$ Después del máximo diario anual climático de la $\theta_{\text {mín. }}$

periodo de transición al frío

Última vez que durante 6 días consecutivos, la media diaria climática de la $\theta_{\text {máx }}>P_{25}$ de la media diaria del ciclo anual de

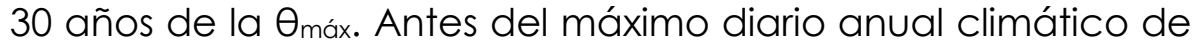
la $\theta_{\text {máx. }}$ 
Donde:

$\begin{array}{ll}\Theta_{\text {min }} & \text { Temperatura mínima } \\ \Theta_{\text {máx }} & \text { Temperatura máxima } \\ P_{25} & \text { Percentil vigésimo quinto } \\ P_{75} & \text { Percentil septuagésimo quinto }\end{array}$

HUMEDAD

La presencia de agua, tanto en forma líquida, de vapor o de hielo, en la atmósfera determina su estado y su evolución, promoviendo fenómenos como son los meteoros e influyendo en sus propiedades térmicas, como son su transparencia o su capacidad para acumular calor.

El bienestar se apoya en la presencia de agua, tanto por sus propiedades evaporativas y su capacidad para la transferencia térmica por cambio de fase, como por su influencia directa sobre las capacidades orgánicas.

Las series climátológicas consultadas aportan ocasionalmente la temperatura de rocío como uno de los valores significativos del clima, aduciéndose errores máximos estimados de un $5 \%$ entre las humedades absolutas y las relativas; el amplio tramo de humedades confortables, estimado como mínimo entre el $30 \%$ y el $70 \%$ y la alta tolerancia a variaciones ocasionales de estos valores hace este error poco significativo en este caso.

Cuando las series aportan la temperatura de bulbo seco y la temperatura de rocío se ha considerado más fácil deducir la humedad relativa, para armonizar las series, ya que junto a la temperatura, la radiación y la velocidad y dirección del aire se ha considerado uno de los valores significativos para definir el clima y el estado del tiempo atmosférico en un determinado lugar.

Para hacerlo puede considerarse el uso de ábacos como el de la figura(FIG. 5.3), aunque se ha calculado mediante la ecuación:

$$
H R=100 *\left[\frac{\left(112-0,1^{*} \theta+\theta_{d}\right)}{\left(112+0,9^{*} \theta\right)}\right]^{2}
$$

Donde:

$\begin{array}{ll}\text { HR } & \text { Humedad relativa } \\ \theta_{d} & \text { Temperatura de rocío } \\ \theta & \text { Temperatura de bulbo seco }\end{array}$




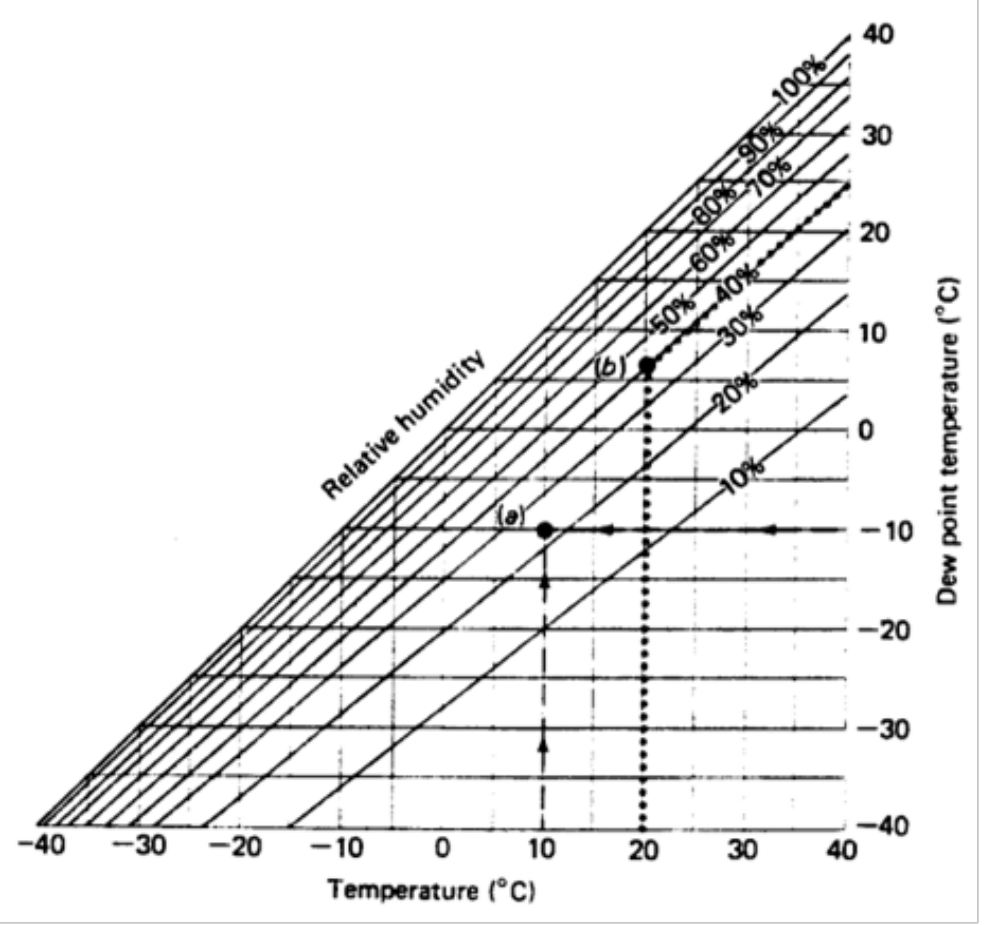

FIG 5-3 Gráfico para establecer la humedad relativa a partir de las temperaturas de bulbo seco y de rocío

\section{MOVIMIENTO DEL AIRE}

La circulación del aire es otro de los factores más influyentes en la evolución del tiempo atmosférico y de las condiciones meteorológicas. Su dirección, intensidad y frecuencia, afectan a la transferencia térmica, por procesos de convección, en relación a su temperatura y la de los objetos del entorno. Su influencia en la edificación se manifiesta en la eficacia de la ventilación, en el aumento de infiltraciones y en la velocidad de las trasferencias de calor (convección). El bienestar está condicionado por la velocidad del aire y la temperatura en la que se producen las transferencias térmicas en el entorno del sujeto.

Su cuantificación es compleja ya que se requiere establecer simultáneamente la dirección, la velocidad y el periodo en que se producen. Normalmente se establecen para valores máximos (rachas) y valores medios, siendo a menudo importante establecer los periodos de calma. Los datos se recogen normalmente en gráficos (rosa de los vientos) o en tablas anuales, estacionales o mensuales.

\section{RADIACIÓN}

La fuente energética casi única del planeta es la radiación procedente del sol. Por ello es muy importante conocer la forma en la que ésta se transfiere al aire, al agua, a la tierra o a los objetos. La naturaleza de la radiación hace que sus diferentes longitudes de onda y poder calorífico les afecten térmicamente de diferente forma. A su vez, la energía acumulada en el planeta es emitida amplificando la existente o retardándola.

Se ha considerado la radiación incidente sobre la edificación 
como un parámetro del que se deducen fácilmente la existencia de otros fenómenos como la nubosidad, la duración de los días o la transparencia de la atmósfera, con los que mantiene una fuerte correlación.

Así el factor o índice de nubosidad que cuantifica la existencia o ausencia de nubes, también descrita como la fracción de la bóveda celeste cubierta por las nubes se establece en valores iguales o inferiores a 0,2 para días despejados y si es igual o superior a 0,8 se considera un día nuboso.

Si se suma la incertidumbre en la determinación instantánea a la que aporta su promedio a lo largo del tiempo parece más fácil y eficiente considerar la radiación incidente y la difusa conjuntamente en la radiación global para establecer la influencia en la edificación, reduciendo así los errores acumulados.

La intensidad de la radiación es diferente según la inclinación de las superficies receptoras y las diferentes orientaciones. Los datos pueden ser recopilados como acumulación total en el año, por estaciones, meses o días, o establecer los valores en periodos más breves, como puede ser por hora. Los valores pueden ser el resultado de las mediciones realizadas o formarse a partir de ellos como valores normales o medios o responder a simulaciones 0 interpolaciones basadas en datos o en estimaciones.

La energía procedente del sol es una constante en las variables climáticas y puede considerarse constante al nivel exterior de la atmosfera. Su valor es el de la constante solar: $1.367 \mathrm{~W}^{*} \mathrm{~m}^{-2}$, que equivale, aproximadamente, a $2(1,96) \mathrm{cal}^{*} \mathrm{~min}^{-1} * \mathrm{~cm}^{-2}$ en un plano perpendicular a la línea más corta que une el sol y la tierra desde el lugar considerado.

Esta radiación se recibe en distintas longitudes de onda. Los espectros que inciden en la superficie terrestre y las construcciones se clasifican, en función de si se pueden o no percibir por medio de la vista directa, en ultravioleta, visible e infrarrojo. Su magnitud dependerá de la transparencia de la atmosfera y de las obstrucciones que se puedan percibir. Son comunes las representaciones gráficas de la longitud de onda (abscisas) y flujo de calor (ordenadas), pudiendo observarse la importancia de las fracciones visibles e infrarrojas próximas a las visibles para el transporte de calor.

En la práctica esto supone que la radiación sin discriminarse por la longitud de onda en la que se recibe aporta un dato poco preciso para considerar balances termodínámicos ya que la cantidad de calor que transporta en las diferentes longitudes de onda es diferente, y un dato unificado de radiación solo será un indicador de la energía que realmente está llegando al edificio, al filtrarse por la atmósfera, incluyendo las partículas, sustancias o compuestos que están disueltos en ella, o los elementos interpuestos entre el edificio y el sol. 


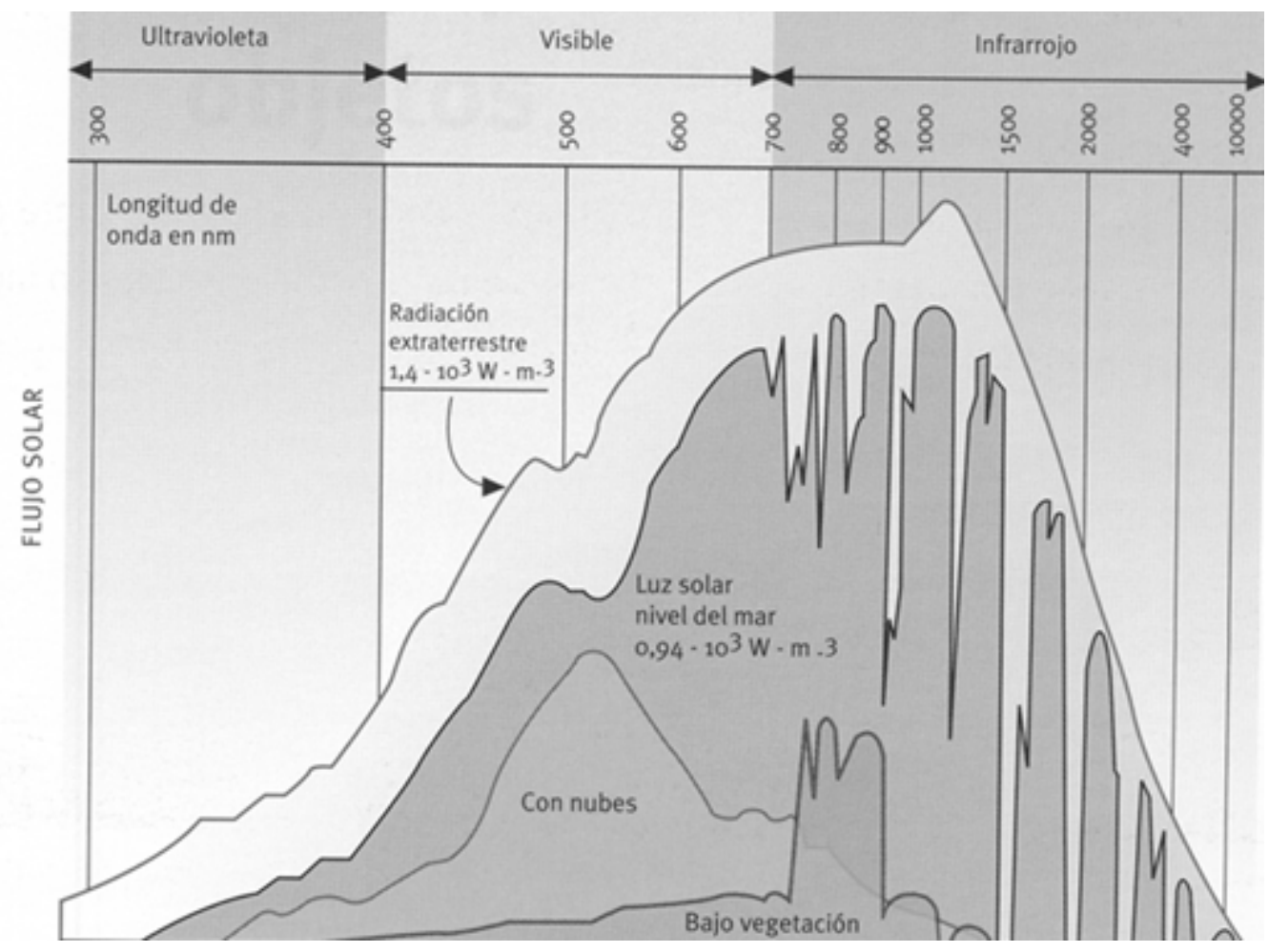

FIG 5-4 DISTRIBUCIÓN DE LA RADIACION SOLAR. VVAA. IDAE. Pag. 15-16

La influencia de la radiación en el interior de los edificios es necesario considerarla simultáneamente a la iluminación natural, ya que ésta colabora notablemente en el bienestar interior de los edificios y es muy importante para establecer la demanda energética en las viviendas. La dificultad estriba en que su presencia es una fuente de calor que debe considerarse al evaluar el balance térmico en edificación, favoreciendo el confort en los periodos fríos y colaborando con el sobrecalentamiento en los periodos cálidos.

Por ello es importante asociar al estudio las demandas de luz solar para un uso confortable de los edificios y establecer así su incidencia en la aportación de energía.

La medición y los registros de series significativas de la radiación incidente es, en la práctica, poco frecuente en los observatorios existentes, por lo que muy frecuentemente se sustituye este valor por la radiación teórica recibida, aplicándole el valor de la insolación que sí es un parámetro muy extendido.

La distribución de la radiación a lo largo del año y el día puede verse en un ejemplo aplicado a una de las localizaciones que servirá como estudio de caso, según los datos recogidos por AEMET en su estación de la Base aérea de Zaragoza (FIG.5.5) 


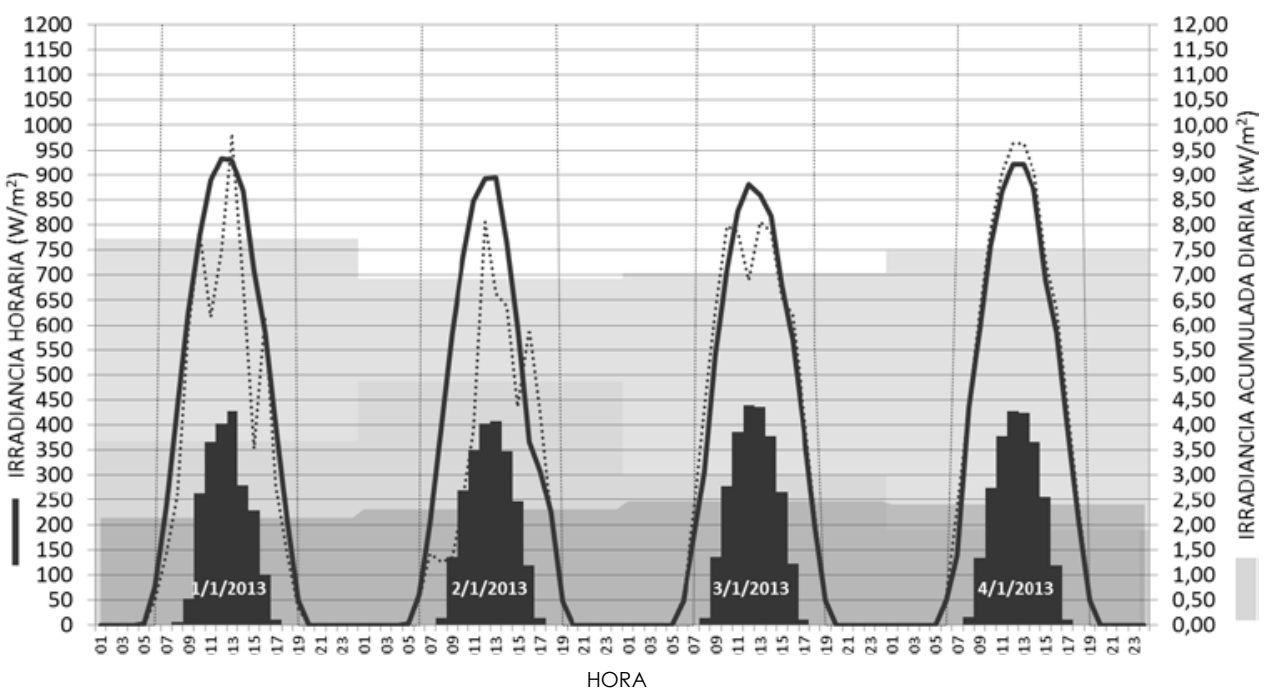

FIG 5-5 IRRADIANCIA GLOBAL ACUMULADA $\left(\mathrm{kW} / \mathrm{m}^{2}\right)$ Y POR HORA (W/ $\left.\mathrm{m}^{2}\right)$ PARA ZARAGOZA DEL 1 AL 4 DE ENERO DEL AÑO 2013 (AEMET y Elaboración propia)

\section{FENÓMENOS METEOROLÓGICOS}

No existe una definición única para este concepto aunque sí un cierto consenso sobre su significado, incluyéndose aquellos acontecimientos naturales relacionados con la variabilidad del clima.

A este grupo pertenecen las precipitaciones, que se cuantifican en tiempo o volumen, e incluyen la lluvia, el granizo o las nevadas, debiéndose considerar también el carácter súbito, la diferencia de temperatura entre la precipitación y el ambiente o su singularidad temporal, climática o de intensidad. Igualmente las tormentas de fuerte componente eléctrico, con sus connotaciones de descarga sobre el territorio y sus efectos visuales, acústicos, de precipitaciones y de vientos, las formaciones hídricas en la atmósfera como son las nubes o las nieblas, o las deposiciones de agua sobre la tierra o las plantas (rocío, escarcha,...), así como los relacionados con el viento, como son los vórtices (huracanes, tifones, ciclones, tornados, trombas marinas, tolvaneras, tubas o los vórtices de racha), los vientos intensos lineales asociados a las tormentas (reventón, frente de racha, o reventón cálido) o los vientos de ladera y otros como los aludes, o las avalanchas, las inundaciones, riadas o crecidas, las sequías o las heladas. Entre ellos se encuentran los fenómenos meteorológicos singulares, descritos como aquéllos que son locales, poco frecuentes, de intensidad significativa y con capacidad de provocar un alto impacto social, (AEMET, 2013). También podrían incluirse los de naturaleza óptica como el arco iris o las auroras boreales.

No todos son de interés por su influencia en la edificación por lo que se consideran básicamente los relacionados con el viento, y que se incluyen es este apartado y la nubosidad que se puede inducir desde el conocimiento de la radiación incidente directa y difusa. 
Aunque se suele utilizar para definir el clima también la pluviometría, desde el punto de vista de su influencia en la edificación puede ser suficiente la información que tenemos de ella a través de la humedad, el viento y la radiación directa, que como ya se ha visto está muy relacionada con la nubosidad.

\subsubsection{FACTORES CLIMÁTICOS}

Los climas están definidos en función del objetivo final de la clasificación y, más allá de ésta, de la finalidad práctica que la justifica.

Por ello enunciar los factores que se consideran significativos para establecer los modelos de estudio, ya implica realizar una elección y una aplicación al objetivo buscado.

Está acreditada la influencia de factores geográficos como la topografía, la orientación o la proximidad de aguas superficiales, biológicos como la presencia de vegetación o arbolado, y otros factores asociados a las edificaciones existentes y a la contaminación, que se han agrupado, para el ámbito que se estudia, como factores de urbanidad.

La topografía influye de manera determinante en las condiciones térmicas de un lugar, pudiéndose subdividir en sub-factores entre los que están la altitud, la clinometría o las formaciones topográficas.

La orientación influye en la facilidad para que se produzcan heladas o precipitaciones en forma de nieve, eleva o no el riesgo de precipitación y de condensaciones en forma de bancos de neblina, las precipitaciones de rocío y escarcha, y es determinante en posibles obstrucciones a la radiación y en la velocidad del viento.

La clinometría y la orientación de las pendientes influyen en la exposición a la radiación incidente.

Las formaciones geográficas influyen en las temperaturas, el viento, la radiación o la humedad. Las formaciones en valle, por ejemplo, favorecen la creación y retención de masas de aire frío y bancos de neblina, con unas temperaturas medias más bajas que en los alrededores.

Otros factores que no tienen tanta duración en el tiempo y pueden considerarse como coyunturales; son la vegetación, la temperatura de la superficie marina, la actividad volcánica o la actividad solar.

La presencia de vegetación influye en evitar la concentración de aire frío en las proximidades de las superficies cubiertas por ella, evitando las pérdidas de calor en periodos fríos, así como la transferencia térmica por convección frente a la acción del viento. Las plantaciones de árboles y arbustos en el edificio y en su entorno influyen en el clima circundante. tanto por el aumento del rozamiento y la consiguiente disminución de la velocidad del aire como por la desviación de los flujos. 
También para refrigerar el entorno próximo al edifico puede ser de utilidad la vegetación; mediante la evaporación, la humectación o el sombreamiento, por ejemplo consigue evitar la incidencia solar directa y la acumulación de calor en las superficies y favoreciéndose la reducción de la temperatura. La reacción de la vegetación frente a la radiación en forma de absorción, reflejo o emisión, unida a la evaporación provoca una acumulación de energía que puede estimarse en $4200 \mathrm{kcal} / \mathrm{m} 2$ durante una estación. La temperatura de las superficies manifiesta valores más templados por el efecto de la vegetación; una superficie de hierba la reduce entre $5^{\circ} \mathrm{C}$ y $8^{\circ} \mathrm{C}$ en días soleados de verano, y en las zonas en sombra, se estima en casi $3^{\circ} \mathrm{C}$ la reducción de temperatura, por ejemplo, bajo un árbol al mediodía. (Olgyay, 1998).

La conversión del dióxido de carbono en oxígeno o la retención de partículas sólidas son dos de las funciones más significativas de la vegetación para contribuir a una mejor calidad del aire.

Las zonas muy construidas tienden a elevar las temperaturas, probablemente por ser la mayoría de los materiales que las forman energéticamente absorbentes (Landsberg, 1950), y no es despreciable la influencia de los flujos de calor no deseados o la contaminación. Las modificaciones microclimáticas inducidas por el entorno del edificio han sido ampliamente estudiadas por el grupo de termotecnia de la Universidad de Sevilla (Sánchez, 2002)

La cuantificación de esta influencia ha permitido observar, pr ejemplo, temperaturas en zonas asfaltadas de $51^{\circ} \mathrm{C}$ para unas temperaturas ambientales de $37^{\circ} \mathrm{C}$ y diferencias de $4^{\circ} \mathrm{C}$ en distancias de pocos kilómetros 0 de $6^{\circ} \mathrm{C}$ entre el centro y la periferia, concretamente en Washington D.C. Para entender estas diferencias en su contexto puede considerarse que una variación similar en la temperatura media similar, $5^{\circ} \mathrm{C}$, es la que se produce en los Estados Unidos de Norteamérica en un cambio de de $9^{\circ}$ (OLGYAY, 1998)

La contaminación influye en la radiación reduciendo sus valores globales entre un $10 \%$ y un $30 \%$. Esta influencia no es proporcional al tipo de radiación considerada, manifestándose por ejemplo, en reducciones de la radiación directa en un $40 \%$ y aumentando por otra parte la radiación difusa.

Influye mucho en la recepción de radiación la orientación de calles y edificios, así como la posición en altura de la zona del edificio que se está considerando. También es frecuente el sombreamiento de unos edificios sobre otros (VVAA, 2011).

El viento en un entorno urbano, puede manifestarse encajonado en las calles con velocidades mayores, acelerándose en los bordes de los edificios, esquinas, coronaciones o cornisas, o puede ser bloqueado por los edificios cambiando de dirección y generando turbulencias y reducciones de velocidad por el rozamiento con las superficies construidas y con la vegetación. (VVAA, 2011 pág. 33)

Cuando estos factores provocan temperaturas menores que las de su entorno, colaboran con la disipación de energía, y cuando son
- ANTRÓPICOS (ZONAS CONSTRUIDAS) 
mayores la incrementan, Esta circunstancia aplicada a la edificación puede contribuir a su acondicionamiento higrotérmico.

Para que esta influencia contribuya a una mejor climatización de los edificios es importante que, o bien se localicen donde las condiciones climáticas son más favorables o bien se modifique el entorno para potenciar los factores climáticos que colaboran más eficazmente con esta climatización. La primera es la solución tradicional de la construcción popular o vernácula y la segunda establece la directriz fundamental de la adecuación de espacios urbanos a través de disciplinas como el paisajismo o el urbanismo.

Los factores climáticos que generalmente se recogen son aquellas singularidades, circunstancias y procesos que afectan a la formación del clima y se tienen en cuenta para la definición del tiempo atmosférico, que, en definitiva, será el que afecte a los edificios y a sus usuarios.

Su interés principal reside en que además de definir el clima, dentro de un determinado clima son los catalizadores de los diferentes comportamientos meteorológicos y de las variaciones en las propiedades y condiciones en relación a la edificación.

Los factores climáticos tienen una clara repercusión en la edificación dentro de lo que se ha venido denominando como análisis bioclimático aplicado a la arquitectura y a el urbanismo (OLGYAY, 1998). Se ha optado por agruparlos en función de aspectos geográficos como la latitud, la continentalidad, la altitud, la naturaleza de la superficie de la tierra, la orientación, la estructura geomorfológica, la orografía o la clinometría, coyunturales como la variación en la temperatura del mar, la actividad solar, las emanaciones volcánicas o el factor de cobertura y sistémicos, como la acción humana combinada con la natural para formar unidades paisajísticas o paisajes construidos, o bien para modificar las condiciones de la atmósfera local o globalmente.

A su vez estos factores están interrelacionados entre sí en lo que se viene denominando como referencias circulares y que están en la raíz de la necesidad de afrontar complejos procesos iterativos o dinámicos frente a los más convencionales y sencillos sistemas estacionarios, para establecer la relación entre el clima y la edificación. 


\section{A. FACTORES GEOGRÁFICOS}

\section{Al Latitud}

La latitud se mide angularmente en grados minutos y segundos. En la zona objeto de estudio se mantienen aproximadamente entre $30^{\circ}$ y $60^{\circ}$ de latitud norte.

Afecta a algunos componentes fundamentales del clima, como son la inclinación e intensidad del soleamiento y el movimiento de las masas de aire.

La incidencia del sol está condicionada por su posición relativa. Esta posición cambia a lo largo del día y de las estaciones en ciclos temporales, que se repiten secuencialmente con comportamientos análogos para una determinada localización. Esto determina diferentes ángulos de incidencia e intensidades, cuya determinación teórica puede hacerse en función de su posición con respecto al plano del ecuador. Aquí sólo se considerarán las inclinaciones que suceden en latitudes medias con una fuerte variación estacional en la incidencia solar, frente a las latitudes extremas con inclinaciones más constantes y que en latitudes altas presenta bajas inclinaciones solares y en las bajas presenta una incidencia muy vertical.

La circulación general de la atmósfera está su vez influida por los movimientos ascendentes provocados por el calentamiento de la tierra y de las masas de agua, y por la rotación del planeta y está muy relacionada con la latitud que determina la dirección, continuidad e intensidad de los vientos predominantes. Las corrientes térmicas provocan una elevación de las masas de aire en el ecuador y bajadas en los polos, con dirección norte en capas altas y sur en capas bajas en el hemisferio norte, vientos de rotación con dirección NE en la proximidad del ecuador hasta $30^{\circ} \mathrm{LN}$, SW entre $30^{\circ} \mathrm{LN}$ y $60^{\circ} \mathrm{LN}$ y NE y las turbulencias de fricción entre estos dos regímenes.

A2 Altitud

La altura que alcanzan los accidentes geográficos, y en algunas ocasiones la pendiente con la que lo hacen, provoca que se desplacen las masas de aire hacia arriba enfriándolas, o las mantienen en sus laderas, provocando fenómenos higrotérmicos de gran importancia para el clima local

Las ubicaciones a mayor altitud tienen una menor temperatura del aire y una mayor radiación solar generalmente.

La temperatura del aire disminuye en muchas ocasiones entre $0,5^{\circ} \mathrm{C}$ y $1^{\circ} \mathrm{C}$ cada $100 \mathrm{~m}$. de altitud, en función de su humedad, por lo que las ganancias y pérdidas de calor son mayores, siendo determinante la orientación y exposición a la radiación solar y al viento de las laderas para establecer estos gradientes

La altitud manifiesta un gradiente de temperatura bastante regular para una determinada región y orientación, lo que justifica que se hayan definido climas relacionados con la configuración topológica, como son el de montaña o los de las grandes depresiones interiores bajo el nivel del mar. 
Este gradiente de temperatura ha motivado las correcciones propuestas en la legislación a las condiciones climáticas, factor este que se ha introducido como un indicador del clima en la normativa en vigor mediante una asignación de variación climática por la diferencia de altitud entre dos puntos. Estas modificaciones afectan básicamente a las temperaturas y a la radiación solar incidente y quedan expresadas al agruparse como zonas climáticas.

De esta forma se proponen correcciones a la asignación de zona climática en función de la altitud, generando, en la práctica, una asignación por regiones climáticas ajena a la distribución administrativa por provincias y capitales de provincia.

Tabla B.1.- Zonas climáticas de la Península Ibérica

\begin{tabular}{|c|c|c|c|c|c|c|c|c|c|c|c|c|c|c|c|c|c|c|}
\hline \multicolumn{19}{|c|}{ Zonas climáticas Península Ibérica } \\
\hline Capital & z.c. & Altitud & A4 & A3 & A2 & A1 & 84 & B3 & B2 & B1 & C4 & C3 & $\mathrm{C} 2$ & C1 & D3 & $\mathrm{D} 2$ & D1 & E1 \\
\hline Albacete & D3 & 677 & & & & & & & & & & $h<450$ & & & $h<950$ & & & $h \geq 950$ \\
\hline Alicante/Alacant & $B 4$ & 7 & & & & & $h<250$ & & & & & $h<700$ & & & $h \geq 700$ & & & \\
\hline Almeria & A4 & 0 & $h<100$ & & & & $h<250$ & $h<400$ & & & & $h<800$ & & & $h=8000$ & & & \\
\hline Ávila & E1 & 1054 & & & & & & & & & & & & & & $h<550$ & $h<850$ & $h=850$ \\
\hline Badajoz & $\mathrm{C} 4$ & 168 & & & & & & & & & $h<400$ & $h<450$ & & & $h \geq 450$ & & & \\
\hline Barcelona & C2 & 1 & & & & & & & & & & & $h<250$ & & & $h<450$ & $h<750$ & $h=750$ \\
\hline Bilbao/Bilbo & $\mathrm{C} 1$ & 214 & & & & & & & & & & & & $h<250$ & & & $h \geq 250$ & \\
\hline Burgos & E1 & 861 & & & & & & & & & & & & & & & $h<600$ & $h \geq 600$ \\
\hline Cáceres & $\mathrm{C} 4$ & 385 & & & & & & & & & $h<600$ & & & & $h<1050$ & & & $h \geq 1050$ \\
\hline Cádiz & $A 3$ & 0 & & $h<150$ & & & & $h<450$ & & & & $h<600$ & $h<850$ & & & $h \geq 850$ & & \\
\hline Castellón/Castelló & B3 & 18 & & & & & & $h<50$ & & & & $h<500$ & & & $h<600$ & $h<1000$ & & $h \geq 1000$ \\
\hline Ceuta & B3 & 0 & & & & & & $h<50$ & & & & & & & & & & \\
\hline Ciudad Real & D3 & 630 & & & & & & & & & $h<450$ & $h<500$ & & & $h \geq 500$ & & & \\
\hline Córdoba & B4 & 113 & & & & & $h<150$ & & & & $h<550$ & & & & $h \geq 550$ & & & \\
\hline Coruña, La/ A Coruña & C1 & 0 & & & & & & & & & & & & $h<200$ & & & $h \geq 200$ & \\
\hline Cuenca & $\mathrm{D} 2$ & 975 & & & & & & & & & & & & & $h<800$ & $h<1050$ & & $h=1050$ \\
\hline Gerona/Girona & D2 & 143 & & & & & & & & & & & $h<100$ & & & $h<600$ & & $h \geq 600$ \\
\hline Granada & C3 & 754 & $h<50$ & & & & $h<350$ & & & & $h<600$ & $h<800$ & & & $h<1300$ & & & $h=1300$ \\
\hline Guadalajara & D3 & 708 & & & & & & & & & & & & & $h<950$ & $h<1000$ & & $h \geq 1000$ \\
\hline Huelva & A4 & 50 & $h<50$ & & & & $h<150$ & $h<350$ & & & & $h<800$ & & & $h=800$ & & & \\
\hline Huesca & D2 & 432 & & & & & & & & & & $h<200$ & & & $h<400$ & $h<700$ & & $h=700$ \\
\hline Jaén & $\mathrm{C} 4$ & 436 & & & & & $h<350$ & & & & $h<750$ & & & & $h<1250$ & & & $h=1250$ \\
\hline León & E1 & 346 & & & & & & & & & & & & & & & & $h<1250$ \\
\hline Lérida/Lleida & D3 & 131 & & & & & & & & & & $h<100$ & & & $h<600$ & & & $h \geq 600$ \\
\hline Logroño & D2 & 379 & & & & & & & & & & & $h<200$ & & & $h<700$ & & $h=700$ \\
\hline Lugo & $\mathrm{D} 1$ & 412 & & & & & & & & & & & & & & & $h<500$ & $h \geq 500$ \\
\hline Madrid & D3 & 589 & & & & & & & & & & $h<500$ & & & $h<950$ & $h<1000$ & & $h \geq 1000$ \\
\hline Málaga & $A_{3}$ & 0 & & & & & & $h<300$ & & & & $h<700$ & & & $h \geq 700$ & & & \\
\hline Melilla & $A 3$ & 130 & & & & & & & & & & & & & & & & \\
\hline Murcia & B3 & 25 & & & & & & $h<100$ & & & & $h<550$ & & & $h \geq 550$ & & & \\
\hline Orense/Ourense & $\mathrm{D} 2$ & 327 & & & & & & & & & & $h<150$ & $h<300$ & & & $h<800$ & & $h=800$ \\
\hline Oviedo & D1 & 214 & & & & & & & & & & & & $h<50$ & & & $h<550$ & $h=550$ \\
\hline Palencia & $\mathrm{D} 1$ & 722 & & & & & & & & & & & & & & & $h<800$ & $h=800$ \\
\hline Palma de Mallorca & $B 3$ & 1 & & & & & & $h<250$ & & & & $h \geq 250$ & & & & & & \\
\hline Pamplona/Iruña & $\mathrm{D} 1$ & 456 & & & & & & & & & & & $h<100$ & & & $h<300$ & $h<600$ & $h=600$ \\
\hline Pontevedra & $\mathrm{C} 1$ & 77 & & & & & & & & & & & & $h<350$ & & & $h \geq 350$ & \\
\hline Salamanca & D2 & 770 & & & & & & & & & & & & & & $h<800$ & & $h=800$ \\
\hline San Sebastián/Donostia & $\mathrm{D} 1$ & 5 & & & & & & & & & & & & & & & $h<400$ & $h \geq 400$ \\
\hline Santander & $\mathrm{C1}$ & 1 & & & & & & & & & & & & $h<150$ & & & $h<650$ & $h \geq 650$ \\
\hline Segovia & $\mathrm{D} 2$ & 1013 & & & & & & & & & & & & & & $h<1000$ & & $h \geq 1000$ \\
\hline Sevilla & B4 & 9 & & & & & $h<200$ & & & & $h \geq 200$ & & & & & & & \\
\hline Soria & E1 & 984 & & & & & & & & & & & & & & $h<750$ & $h<800$ & $h \geq 800$ \\
\hline Tarragona & 83 & 1 & & & & & & $h<50$ & & & & $h<500$ & & & $h \geq 500$ & & & \\
\hline Tervel & $\mathrm{D} 2$ & 995 & & & & & & & & & & $h<450$ & $h<500$ & & & $h<1000$ & & $h \geq 1000$ \\
\hline Toledo & $\mathrm{C} 4$ & 445 & & & & & & & & & $h<500$ & & & & $h \geq 500$ & & & \\
\hline Valencia/Valéncia & B3 & 8 & & & & & & $h<50$ & & & & $h<500$ & & & & $h<950$ & & $h \geq 950$ \\
\hline Valladolid & $\mathrm{D} 2$ & 704 & & & & & & & & & & & & & & $h<800$ & & $h=800$ \\
\hline Vitoria/Gasteiz & D1 & 512 & & & & & & & & & & & & & & & $h<500$ & $h=500$ \\
\hline Zamora & D2 & 617 & & & & & & & & & & & & & & $h<800$ & & $h=800$ \\
\hline Zaragoza & D3 & 207 & & & & & & & & & & $h<200$ & & & $h<650$ & & & $h \geq 650$ \\
\hline Capital & z.c. & Altitud & A4 & A3 & A2 & A1 & 84 & B3 & $B 2$ & B1 & C4 & C3 & $\mathrm{C} 2$ & C1 & D3 & D2 & D1 & E1 \\
\hline
\end{tabular}

FIG 5-6 ZONAS CLIMÁtICAS. APÉNDICE B. TABLA BI (CTE DB-HE MF, 2013) 
A3 Continentalidad

Se manifiesta en el tiempo de respuesta ante las variaciones de la radiación solar, que es más lenta en la proximidad de grandes masas de agua, o zona litoral, y más rápida al alejarse de ellas. Este también denominado factor de continentalidad, se incrementa con la distancia pero también con la interposición de barreras montañosas.

Esta resistencia a la modificación de la temperatura tiene también influencia en profundidad, afectando a un máximo de 20 metros de profundidad, aunque sólo es significativa para las latitudes consideradas a profundidades menores a un metro.

En la práctica, la proximidad a las grandes masas de agua reduce la oscilación higrotérmica, manteniendo la temperatura y la humedad más homogénea y constante. Mediante desplazamientos de aire constantes, normalmente en ciclos diarios, se amortiguan el efecto del soleamiento sobre la tierra y las construcciones, la acumulación de calor en periodos cálidos y la disipación en periodos fríos.

Podría afirmarse que las grandes masas de agua permiten desplazamientos de materia y energía que mantienen más homogénea su temperatura y que, cuando hay un gran espesor de agua sobre la tierra, la temperatura apenas se ve afectada por las oscilaciones térmicas estacionales y diarias por el efecto de su gran inercia térmica.

A4 Naturaleza de la superficie de la tierra

Las superficies inorgánicas y la presencia de cubiertas vegetales en el terreno, colaboran con el clima local a través de procesos como la absorción del calor y su conservación, la retención de agua, el albedo o el apantallamiento total o parcial del viento.

La naturaleza de la superficie de la tierra, su color, composición y estructura influye en su calentamiento. El hecho de tratarse de superficies de cultivo, bosques y zonas arboladas o superficies artificiales de asfalto o edificadas provoca fenómenos de calentamiento distintos.

Si las superficies son inorgánicas, ya estén edificadas o sea la tierra expuesta, el calentamiento y enfriamiento será intenso, la absorción del agua de lluvia será lenta y las escorrentías superficiales, en el caso de tierra, irán alterando lenta pero inexorablemente su constitución. La diferencia de color de estas superficies también influirá en su mayor o menor calentamiento.

\section{A5 Orientación}

Tanto el terreno natural como las construcciones provocan sombras o se orientan en la dirección de la incidencia de la radiación solar, con lo que resultan más o menos afectadas por la transferencia de calor que lleva asociada.

La variación de la inclinación de la radiación solar con la latitud y la estación, así como la variación de su intensidad en función de la 
cantidad de atmósfera que habrá de atravesar, dependiendo de la hora del día, hace que se considere que las laderas y edificios orientados al sur van a recibir más calor y los orientados al norte menos; los orientados al este recibirán calor al inicio del día y los orientados al oeste al final del mismo.

Que la dirección de la radiación solar sea más vertical en verano y más inclinado en invierno influye en la capacidad de ocultación o soleamiento, en presencia de viseras o voladizos.

A6 Orografía y clinometría

La orografía fragmenta el clima al re-direccionar los vientos y modifica el tiempo de insolación, provocando modificaciones higrotérmicas.

Las formaciones montañosas generan el ascenso de las masas de aire húmedo, dando lugar a la formación y depósito de agua líquida, bloquean los vientos dominantes, incrementando la velocidad en las aristas y creando remansos en zonas alejados de ellas y, en zonas encajonadas, retienen el aire frío y húmedo en los terrenos más bajas y provocando la aceleración del viento en su dirección.

Conocidos son los procesos de sobrecalentamiento en las laderas a sotavento que vienen causados por el descenso de aire que ha perdido humedad al enfriarse en su ascenso previo hacia las cumbres y que al descender aporta la energía latente que ha tomado del agua.

La clinometría Influye en la capacidad de captación y en el balance hídrico, ya que la pendiente determina la retención de agua y de los sólidos permeables facilitándola en los terrenos superficiales y modificando el ángulo de incidencia solar. Estas condiciones se ven muy afectadas por el factor de cobertura.

Las pendientes, en función de la dirección predominante de los vientos, influyen en la capacidad de convección y de transferencia de energía del viento.

\section{A7 Estructura geomorfológica}

Las condiciones climáticas en valles, abrigos rocosos, cimas o laderas modifican las generales de su entorno estableciendo variantes que se repiten y pueden, incluso, ser equivalentes aun estando situadas en regiones de climas diferentes.

Las obstrucciones, cuando tienen una gran entidad pueden modificar el clima, en función de las magnitudes relativas de los accidentes geográficos, según su proximidad y pueden suponer obstáculos para la radiación y/o la ventilación, como ya se ha comentado cuando se ha hecho referencia a la orientación.

Las cualidades superficiales del terreno en el entorno del edificio pueden favorecer o dificultar la reflexión de los rayos solares (albedo) y sus cualidades para retener o drenar el agua recibida afectarán a la humedad ambiental y a la vegetación que pueda soportar. 
La inercia térmica del terreno y el agua que pueda contener puede ser utilizada para aclimatar el edificio e influir en él, reduciendo la influencia de las oscilaciones térmicas.

La influencia del suelo natural suele esquematizarse en función de su naturaleza y la del suelo artificial por su composición, capacidad de absorción de agua, permeabilidad y color. La influencia de la naturaleza del terreno en el edificio puede esquematizarse según la siguiente clasificación (CIEMAT, 1989):

a) Terrenos silíceos: Albedo medio bajo y menor incidencia en la radiación; humedad baja y alta inercia térmica en el contacto del edificio con el terreno.

b) Terrenos calcáreos: Albedo alto y mayor incidencia en la radiación, humedad baja e inercia térmica menor en el contacto del edificio con el terreno.

c) Terrenos arcillosos: Albedo medio o bajo y menor incidencia en la radiación, humedad alta con variaciones e inercia térmica relativamente elevada en el contacto del edificio con el terreno.

d) Terreno de areniscas: Albedo alto y mayor incidencia en la radiación, humedad baja e inercia térmica media en el contacto del edificio con el terreno.

e) Terrenos volcánicos: Albedo bajo y poca incidencia en la radiación, humedad baja dependiendo del substrato, inercia térmica alta en el contacto con el edificio con el terreno si su densidad es elevada.

\section{A. FACTORES COYUNTURALES}

B1 Variación de la temperatura del mar

Aunque en una primera lectura la temperatura de mares y océanos influye estabilizando el clima, su temperatura no es homogénea y afecta cíclicamente a los climas, modificándolos sustancialmente.

Su influencia en los climas es muy grande dada la gran superficie que en la tierra está cubierta de agua. Denominado también como factor marítimo tiene influencia en los litorales templando su temperatura.

La desigual de temperatura de la superficie del mar, aunque más estable que las de los continentes, hace que a igual latitud se produzcan grandes diferencias entre unos continentes y otros. Asimismo provoca el desplazamiento de grandes masas de agua con temperaturas más cálidas que el ambiente y puesto que el agua fría está siempre más profunda, hasta alcanzar los $4^{\circ} \mathrm{C}$ refresca las zonas de la que procede.

La temperatura superficial, ya sea del agua o de la tierra, es uno de los componentes determinantes de la temperatura del aire que entra en contacto con ella y, a su vez, cuando el aire cambia de temperatura con el de su entorno provoca su desplazamiento a veces agrupado en grandes masas. 
La importancia práctica de esta influencia es la creación de microclimas que modifican las condiciones meteorológicas que se producirían en función exclusivamente de parámetros como la longitud y la latitud ya mencionados. Dado que las zonas más afectadas por estos efectos son las costas de Europa del norte, por influencia de la corriente del golfo, con climas más cálidos que los observados en el mismo paralelo en el continente americano, o los efectos de la corriente del niño en el norte de Suramérica, no se considera un factor determinante en el entorno que es aquí objeto de estudio.

\section{B2 Actividad solar}

Actualmente se ha relacionado la actividad solar con fenómenos meteorológicos terrestres, observándose también la influencia de las tormentas solares.

Está actividad manifiesta una cierta estabilidad en periodos largos de tiempo, lo que no hace presagiar que en periodos históricos próximos se puedan producir modificaciones tendenciales 0 sustantivas en la radiación solar, aún cuando es previsible su influjo en más que probables anomalías meteorológicas futuras, como seguramente lo haya sido en el pasado.

\section{B3 Emanaciones volcánicas}

Tanto la atmósfera como las precipitaciones modifican con su composición química el clima. Los casos más notables se refieren a las grandes emanaciones de partículas sólidas en suspensión que, aun siendo de origen natural (erupciones volcánicas, polvo en suspensión, ...), modifican la filtración de la radiación solar y acumulan calor entre otros efectos, dando lugar a cambios significativos del clima durante periodos breves, desde el punto de vista histórico, y con una distribución espacial limitada.

\section{B4 Factor de cobertura}

En las zonas cubiertas de vegetación, debido a la capacidad de ésta para mantener estable su temperatura, las variaciones de día y noche son mucho menores, produciéndose una absorción correcta del agua de lluvia para su acumulación en los acuíferos subterráneos generando un equilibrio hídrico permanente; también conocido como factor de cobertura o calidad superficial, e influye en el equilibrio higrotérmico, también está condicionado por el color, composición y naturaleza de la superficie terrestre y su cobertura.

La existencia de masas vegetales promueve la retención de agua en el suelo y la creación de materia orgánica, moderando los efectos del clima. El sombreamiento del suelo, es el caso de las especies de hoja caduca estacional, evitando su sobrecalentamiento. La permeabilidad y capacidad de retención hídrica del suelo favorece la presencia de masas de agua templadas y una mayor humedad ambiental. El color de las superficies inorgánicas, así como su naturaleza, influye en su capacidad para captar energía. 
La sustitución de los bosques por zonas de cultivo o para la ganadería, y la transformación de éstas en zonas urbanizadas han provocado la alteración irremediable del clima de muchos lugares.

La radiación solar se ve afectada por las grandes masas de vegetación, tanto ofreciendo pantallas a la radiación directa como absorbiendo parte del espectro, modificando sus calidades, lo cual sucede en mayor medida con árboles de hoja caduca que con las coníferas, por ejemplo. La persistencia de hojas también influye en la captación invernal y en la protección estival.

Con respecto a la humedad, especialmente las especies frondosas, colaboran a mantenerla a través de su alta evapotranspiración.

La dirección e intensidad de los vientos igualmente se ve afectada por las masas densas y orientadas de vegetación.

La protección vegetal de los edificios, por estos motivos, es una práctica ya muy extendida.

\section{B. FACTORES ANTRÓPICOS}

C1. Unidades paisajísticas

La fauna y la flora desarrollada en amplias zonas generada a partir del clima o por la acción humana (agrícola, ganadera, minera,...), y sus correspondientes ecosistemas, colaboran en la formación del clima.

En este grupo se incluyen los tipos de paisajes generados por el clima del lugar; desierto, tundra, estepa, los bosques, etc.

C2. Paisajes construidos

Conocidas como islas térmicas en la actualidad las ciudades tienen su propio clima, inducido en parte por la construcción y en parte por la ausencia del medio natural al que ésta sustituye.

Muchos materiales de construcción, como son la grava, el ladrillo, el granito, el asfalto o el hormigón, tienen una alta inercia térmica, lo que hace que ya estén situados en los edificios o en los pavimentos, colaboren en la acumulación de calor durante los periodos en que permanecen soleados y que lo emitan en los periodos nocturnos, cuando la temperatura ambiente es menor. Si están situados en lugares al abrigo o a modo de solanas permiten mejorar las condiciones de calor invernales aunque también dificultan la disipación del calor estival diurno.

Los colores oscuros favorecen esta acumulación de calor.

Tanto la existencia de construcciones alineadas como la distancia entre ellas pueden formar pantallas que dificulten o canalicen el aire y que eviten el asoleo de otras construcciones o del suelo, influyendo, por tanto, en la iluminación, la radiación incidente y la ventilación. La forma de las tramas urbanas es determinante para la formación de estas alineaciones; si coinciden con los vientos dominantes favorecen los intercambios, refrescando en general el 
entorno de los edificios, y si los dificultan, mejoran el calentamiento.

La orientación de los edificios según alineaciones Norte-Sur expone sus fachadas al este y al oeste, favoreciendo el calentamiento en verano sin mejorarlo en invierno. En cambio si es Este-Oeste la radiación incidente será mayor en invierno y menor en verano, especialmente si se dispone de aleros o salientes en la fachada.

La densidad de construcciones y una alta relación entre la altura y la distancia entre edificios intensifica estos efectos y colabora a formar un clima local que se viene denominado genéricamente como isla de calor, una cuyas características, la dificultad en realizar intercambios, es su cualidad más notoria (Luxán, pág. 59 a 61).

\section{C3. Emanaciones}

Las emanaciones antropogénicas, como puede ser el smog o la polución urbana, modifican la composición de la atmósfera y con ella su comportamiento frente a muchos fenómenos meteorológicos. La helada, la lluvia o su transparencia a la radiación solar quedan modificadas por la presencia de compuestos ajenos a los habituales. La presencia de agentes oxidantes o irritantes, ácidos o nocivos tiene, además, una gran influencia en la adopción de estrategias adecuadas para la corrección higrotérmica del ambiente.

\section{C4. Vertidos}

La presencia de vertidos, además de modificar la composición química del entorno, puede modificar su temperatura o su humedad (Luxán, pág. 59 a 61). 


\subsubsection{MODELOS}

La relación entre arquitectura, ordenación del territorio y clima ha generado, en analogía a lo ya desarrollado para diferentes ecosistemas naturales o sistemas antrópicos de aprovechamiento forestal o agropecuario, el establecimiento de modelos que permitan un análisis que afecte a diversas escalas climáticas, ya sean estas escalas temporales o espaciales (Martín, 1999).

Las escalas temporales hacen referencia a la duración del periodo en que el modelo se aplica y el rango temporal durante el que es adecuado emplearlo. Para este análisis no se consideran las escalas históricas o paleoclimáticas y sí, parcialmente, las escalas seculares, donde disponemos de registros de un centenar de años de duración y que han permitido observar los cambios en el clima urbano durante este periodo y asociarlos a las modificaciones en la densidad y amplitud de los diferentes medios de producción.

Más recientemente, las medidas instantáneas de temperatura con series precisas y coordinadas durante un periodo mínimo permiten ver la evolución de estas temperaturas y asociarlas a la composición del aire o a la climatología periférica. El periodo normal para obtener datos significativos es de 30 años aunque ocasionalmente se consideran periodos más cortos, entre los que 10 años es el periodo mínimo.

Las escalas secular e instantánea están basadas actualmente en fuentes directas procedentes de estaciones de observación meteorológica existentes en superficie y, recientemente, en altura, realizadas mediante sensores remotos instalados en satélites o aviones.

La escala geográfica de las clasificaciones climáticas oscila entre unos centenares de metros y muchos kilómetros cuadrados, dependiendo de su objetivo y de la precisión requerida.

Una vez caracterizado el clima se podrá iniciar su estudio y aplicación en función del área tecnológica en la que influye. Una clasificación muy frecuente es la realizada según índices desarrollados para que los recursos, las limitaciones y los riesgos a que da lugar puedan ser homogéneos en cada una de las zonas definidas por ellos.

De este modo mediante el tratamiento estadístico de los datos obtenidos se establecen las características básicas del clima a escala espacial y temporal (Cuadrat, 2006).

\section{ESCALA ESPACIAL}

La escala espacial se materializa en regiones climáticas que a su vez están condicionadas por la utilidad que se pretende, eligiendo los factores y umbrales que las definen en función de ellas. Así se construyen los mapas agropecuarios, bioclimáticos o, por ejemplo, los de Köppen-Geiger, (Köppen, 1884), asociados a la distribución de las especies, y particularmente de los seres humanos, en función del clima, con múltiples aplicaciones posteriores como puede ser la propagación de virus o enfermedades (Brugger, 2013). 
En el análisis espacial de los climas es común diferenciar cuatro escalas: macroclimática, mesoclimática, clima local y microclimática. Cada una aporta información específica para estudios de diferente naturaleza y permiten por tanto distintos niveles de generalización. Su naturaleza es comprensiva, estando incluidas las de menor escala en las más amplias. La asignación a las normales climáticas, entendidas como una estadística simple de sus valores máximos, mínimos o medios, no determina por sí misma la caracterización del clima, siendo preciso considerar también la variabilidad y la frecuencia (Cuadrat, 2006) (Martín, 1999).

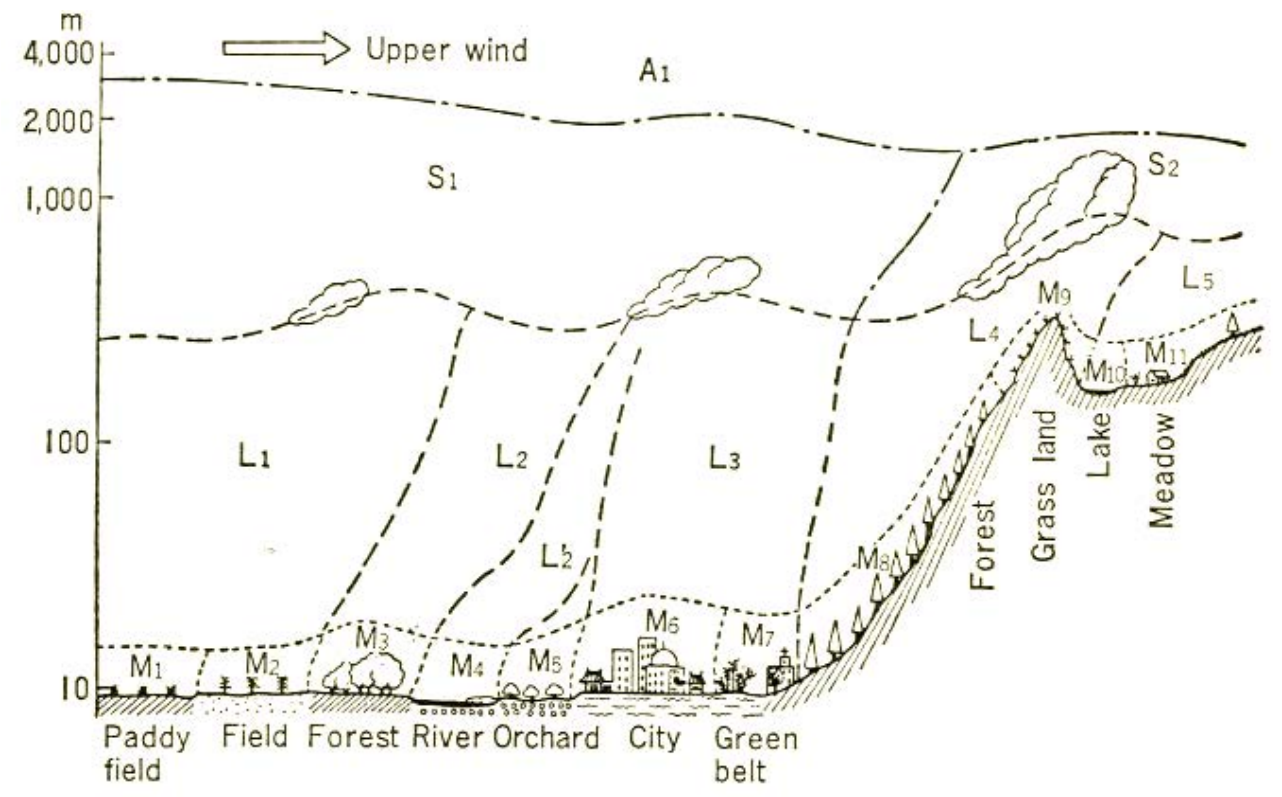

FIG5-3 ESQUEMA DE LA DISTRIBUCIÓN ESPACIAL DE LAS ESCALAS CLIMÁTICAS: M1M11: MICROCLIMA, L1-L5: CLIMA LOCAL, S1-S2, MESOCLIMA y A1: MACROCLIMA (Yoshino, 1961)

Tampoco pueden considerarse las variables atmosféricas como parámetros fijos ya que su ponderación y los valores que se les asignan, cambian con el propósito de la clasificación.

En cualquier caso la clasificación climática exige establecer umbrales significativos determinados específicamente para cada área, en nuestro caso relacionados con la edificación residencial. De este modo se observa en la diferencia entre los umbrales que se consideran confortables para cada una de las variables climáticas y los umbrales que se establecen para las variables con que se define el tiempo atmosférico.

Los valores disponibles están localizados en las zonas donde las actividades son muy sensibles a la climatología, como sucede por ejemplo en los aeropuertos, o donde el clima puede ser la causa de modificaciones sustanciales en las condiciones de uso, explotación o riesgo, como pueden ser las estaciones de esquí o las cuencas fluviales.

La influencia urbana ha demostrado que en el entorno de los edificios existen condiciones peculiares, cuyo conjunto se ha denominado como clima local urbano. 
Para establecer las similitudes en el clima urbano se han comparado los valores climáticos en diversas localizaciones obteniendo correlaciones que facilitan la consideración de condiciones de contorno más ajustadas a la realidad.

Una regionalización peculiar es la realizada para la aplicación de la normativa y así fijar los requisitos y exigencias mínimas recogidas en el ordenamiento regional o local.

Las condiciones con que se definen los climas y las regiones climáticas son, básicamente, la temperatura, la humedad y la radiación en las distintas estaciones o meses, variabilidad de los valores meteorológicos $y$, ocasionalmente, los distintos climas regionales que se pueden establecer en ellos.

La zona de trabajo en que se desarrolla el presente estudio está incluida en el clima templado, y, dentro de él, en el clima regional mediterráneo.

La clasificación espacial empleada y el ámbito de estudio puede esquematizarse como:

\section{A1 MACROCLIMA}

Es el orden de clasificación más amplio. Pretende establecer climas bien diferenciados geográficamente, de miles de kilómetros cuadrados de superficie, y que comparten una circulación general atmosférica, como puede ser un continente o incluso los cinturones zonales que se perfilan alrededor de todo el planeta. Su interés es muy limitado para actuaciones concretas en edificación ya que los parámetros empleados tienen un alto nivel de abstracción y están formados a su vez por zonas con cualidades climáticas que pueden llegar a ser muy diferentes de las del entorno global en que se encuentran.

La zona objeto de estudio está situada en el macroclima templado, entendiendo como tal aquel que cumple las siguientes condiciones:

- La temperatura media del mes más frío es menor de $18^{\circ} \mathrm{C}$ y mayor de $-3^{\circ} \mathrm{C}$ (Gil, 1999, pág. 343.)

- En general son los que experimentan con mayor nitidez las variaciones estacionales, en coincidencia con las cuatro estaciones meteorológicas (Gil, 1999, pág. 343)

- La diversidad es uno de sus rasgos geográficos significativos, por lo que pueden distinguirse muchas variedades de climas regionales (Gil, 1999, pág. 343)

\section{A2 MESOCLIMAS}

También denominados como climas regionales, con dimensiones lineales que varían entre $200 \mathrm{~km}$ y $2.000 \mathrm{~km}$ y están definidos por influencias a gran escala y a menudo exteriores a la región, consecuencia de los factores geográficos. 
La zona objeto de estudio está situada en el mesoclima templado mediterráneo, que, aunque se producen grandes contrastes por tratarse de un clima regional templado, mantiene algunas características comunes. Se agrupa bajo la nomenclatura " $C$ " en la clasificación de Köppen-Geiger. Debe distinguirse de los muy próximos geográficamente pero distintos climas regionales oceánicos o semioceánicos (Gil, 1999, pág. 347-348).

Se entiende como tal el que cumple las siguientes condiciones:

Pluviometría

Con valores mínimos de $250 \mathrm{~mm} / \mathrm{m}^{2}$ y año (semiáridos) (Gil, 1999, pág. 347 y 348), valores medios entre 400 y $900 \mathrm{~mm} / \mathrm{m}^{2}$ y año concentrados en el semestre invernal, con picos en las épocas equinocciales. En particular las otoñales se producen en cortos periodos de tiempo, provocando fuertes escorrentías superficiales. Con valores máximos en 24 horas de una intensidad similar a los valores anuales medios, como es el caso de Jávea, con 871 mm/m² en 24h (2-10-57)(Gil, 1999, pág. 347 y 348). En general, la pluviometría presenta una gran irregularidad interanual (Gil, 1999, pág. 347 y 348)

Temperatura

Los valores medios de enero están entre $6^{\circ} \mathrm{C}$ y $12^{\circ} \mathrm{C}$; Aunque con ocasionales olas de frio (Gil, 1999, pág. 347 y 348). Los valores medios de julio están entre $21^{\circ} \mathrm{C}$ y $27^{\circ} \mathrm{C}$ (Gil, 1999, pág. 347 y 348). Los valores medios anuales están entre $16^{\circ} \mathrm{C}$ a $18^{\circ} \mathrm{C}$ con amplitudes que no exceden de $16^{\circ} \mathrm{C}$, y de la mitad en zonas costeras (Gil, 1999 pág. 347 y 348)

Radiación

Inviernos con abundancia de días despejados y muchas horas de sol anuales, aproximadamente 3000 (Gil, 1999, pág. 347 y 348)

Verano cálidos en las zonas costeras, por el efecto de la brisa marina, y tórridos en el interior (Gil, 1999, pág. 347 y 348).

Vientos

Importantes circulaciones locales de vientos y brisas que refrescan el ambiente en verano y provocan malestar en invierno. Son denominaciones habituales: Levante, Poniente, Mistral, Cierzo, Tramontana, Siroco, ... (Gil, 1999, pág. 347 y 348).

\section{C5. CLIMAS LOCALES}

Permiten diferenciar en cada clima regional, unidades climáticas bastante diferentes entre sí. Sus rasgos meteorológicos están muy ligados a las condiciones locales, como pueden ser las ciudades, los valles o los bosques. Su extensión espacial suele alcanzar en sentido horizontal de $100 \mathrm{~m}$ a $10.000 \mathrm{~m}$ y verticalmente hasta unos $100 \mathrm{~m}$.

Se ha circunscrito el estudio a la zona definida, en función de su severidad climática de verano e invierno según el Código Técnico 
de la Edificación español (CTE), como D3. Dentro de esta zona climática se encuentra Zaragoza, donde se sitúa el caso de estudio.

\section{A3 MICROCLIMAS}

Los microclimas se segregan del clima local cuando la clasificación climática se aplica a la capa de aire contigua a la superficie terrestre y se circunscrbe a lugares pequeños. Son áreas bien delimitadas y muchas veces confinadas, como pueden ser calles, parques urbanos, una cueva, etc., donde la naturaleza de los elementos meteorológicos está condicionada fundamentalmente por los factores del entorno inmediato mucho más que por los factores locales o regionales. Su estudio implica el uso de instrumentos específicos para registrar los pequeños cambios ambientales en condiciones muy localizadas y con una evolución que puede ser muy rápida, observándose que se producen singularidades climáticas muy acusadas. Estas diferencias no se producen necesariamente en superficie, siendo a veces más significativa la variación térmica en vertical; de modo que, con frecuencia, las diferencias de temperatura entre la cabeza y los pies de una persona son más importantes para su aplicación en edificación que los registrados horizontalmente a lo largo de cientos de kilómetros.

Los condicionantes más comunes para la aparición de un microclima en una región climática determinada son la topografía del terreno, especialmente manifestada por la altitud y el relieve, la vegetación, los vientos dominantes y la humedad.

Este conjunto de factores pueden agruparse en patrones prefijados, que, aun con distintos valores climáticos, subdividen una región climática. Como ejemplo pueden citarse los microclimas siguientes:

- MICROCLIMA DE VALLE

- MICROCIMA DE VERTIENTE NORTE (UMBRÍA)

- MICROCLIMA DE VERTIENTE SUR (SOLANA)

- MICROCLIMA DE ALTURA

- microclima litoral MEDIterRáneO

- MICROCLIMA LITORAL ATLÁNTICO

- micRoClima CONTINENTAL

- MICROCLIMA URBANO

Obsérvese cómo pueden aplicarse dos o más microclimas a una localización. En localizaciones urbanas, por ejemplo, pueden hacerse distinciones también por la altitud y por una configuración de valle o de continentalidad.

Se han observado los datos correspondientes a diversas zonas de Zaragoza que representan diversos microclimas urbanos, aunque al estar situada la zona de estudio en el valle del rio Ebro, de gran caudal y longitud, su microclima predominante es el de valle continental. 


\section{A4 MICROCLIMA DE PROXIMIDAD}

La necesidad de identificar las singularidades fuertemente afectadas por elementos naturales o artificiales dentro de un microclima, como son las construcciones urbanas, justifica la definición del microclima de proximidad, para hacer referencia a la afección de los sistemas naturales o construidos sobre las condiciones climáticas.

Esta última escala se caracteriza por la influencia mutua y la repercusión de los sistemas naturales y construidos en las condiciones ambientales, así como su variación con la definición de los espacios arquitectónicos y su entorno próximo. En esta escala tiene sentido la ubicación de las dependencias de los edificios y la de estos en relación al entorno natural y edificado en el sentido empleado en la teoría arquitectónica sobre el emplazamiento desde una perspectiva bioclimática (Olgyay, 1998), ya se aplique al urbanismo o al edificio.

En el entorno del edificio se han considerado sus distintas envolventes observando los valores de temperatura en cada una de ellas.

EN DIVERSAS DISPOSICIONES:

- EN PATIO DE LUCES

- ORIENTACIÓN NORTE A PATIO INTERIOR

- ORIENTACIÓN NORTE A CALLE

- ORIENTACIÓN SUR A PATIO INTERIOR

- ORIENTACIÓN SUR A CALLE 


\section{ESCALA TEMPORAL}

Se refiere a la distribución de los valores climáticos en la secuencia de ciclos periódicos, ya sean días, estaciones, años o series de éstos.

Su medida viene dada en cada punto del planeta por la división del ciclo diario en 24 fracciones horarias, donde las $12 \mathrm{~h}$ del día coincidirán con la máxima altitud solar. Esta convención hace que la asignación horaria sea diferente en cada punto de cada paralelo terrestre.

Para facilitar la coordinación horaria entre localizaciones distintas se conviene la división del planeta en franjas de norte a sur en la dirección de los meridianos con una longitud de 24 unidades de $15^{\circ}$, hasta completar la superficie terrestre, y donde asignan horas sucesivas, en lo que se denomina como Tiempo Universal Coordinado (por sus siglas en inglés UTC) establecido en 1884 en la Conferencia Internacional sobre el primer meridiano por Sandford Fleming.

Otra forma de establecer la hora en estos husos es haciendo referencia a la línea internacional de cambio de fecha en el meridiano $180^{\circ}$, reflejando la diferencia horaria con respecto al meridiano de Greenwich o Greenwich Mean Time (GMT), donde los husos se denominan por esta diferencia como GMT $\pm \mathrm{H}$, contabilizando $\mathrm{H}$ como una unidad por cada fracción de $15^{\circ}$ de longitud que se recorre avanzando hacia el este desde el meridiano de Greenwich.

Una mención especial merecen las horas oficiales, donde los estados corrigen la hora arbitrariamente en su legislación, muy a menudo coordinando la hora oficial con la de otras regiones. En España está regulada oficialmente y existe una fuerte discusión sobre su oportunidad (Gámez, 2008)(Planesas, 2013). En la zona central europea se aplica el Central European Time (CET), también conocido como el Middle European Time donde se aplica una compensación de tiempo, UTC +1. Por su parte el CET que pretende un mejor aprovechamiento de la luz solar establece una corrección durante el periodo estival a UTC +2 .

Esta decisión se apoya en Directivas Europeas (D 2000/84/CE O D $97 / 44 / C E$ ) y en la normativa nacional (O 7/3/1940 y RD 236/2002) estableciéndose en los últimos domingos de marzo y de octubre su inicio y su final.

Estas consideraciones son de especial interés al realizar comparaciones o utilizar para formar series climáticas diversas fuentes con diferente criterio en la consideración de la asignación horaria.

Esto ha motivado la corrección de los datos obtenidos "in situ" con relojes ajustados a la hora oficial y los datos en tiempo real (UTC) a los que se ajustan los aportados por las agencias meteorológicas.

Además de los ciclos horarios se han considerado diferentes unidades de trabajo. como el propio año natural donde se 
producen secuencias comparables de series térmicas, con una duración de 365 días.

La serie temporal mínima considerada para obtener valores que permitan la caracterización de los climas se ha considerado de 10 años.

De este modo se puede observar una evolución diferente de los distintos climas, tanto entre sí como en el territorio donde cada uno se aplica.

La modificación planetaria de la temperatura del mar, las precipitaciones o la radiación incidente sobre la superficie de la tierra se vienen reconociendo como causantes de una importante evolución acrecentada en los últimos años por la acción humana tanto agropecuaria, como urbanizadora o fruto de la realización de grandes infraestructuras, de las que serian un buen ejemplo las iniciativas para la gestión del agua ya sea para embalsarla, drenarla o extraerla.

Esta evolución analizada a través de modelos climáticos globales permite estimaciones de la modificación de los climas en sus diferentes escalas espaciales. 


\subsubsection{INTRODUCCIÓN}

La climatología no tiene un desarrollo como ciencia moderna, hasta bien entrado el siglo XX, a pesar de ello en se ha consolidado como una ciencia de la tierra, en un principio enclavada dentro de la geografía (Ptolomeo, S. II), pero actualmente puede considerarse más afín a las ciencias físicas o medioambientales. Esto hace que la terminología y los conceptos empleados en la documentación consultada sean en ocasiones poco claros e incluso contradictorios.

Aún así se ha observado una cierta unanimidad en considerar que la información básica para el estudio del clima precisa de series de observaciones climáticas con las que se forman las series climáticas.

Estas series de datos climáticas siempre son una fracción de una población infinita de datos en continua evolución, su análisis requiere una aproximación estadística previa mediante parámetros de centralidad y dispersión o las frecuencias acumuladas o relativas de cada uno de los valores de la serie.

Al estar el estudio realizado centrado en los valores térmicos y no en el total de los parámetros climáticos, se han considerado las relaciones termodinámicas que están en la base de la interdependencia energética entre el edificio y el clima.

\subsubsection{INFLUENCIA DEL CLIMA EN EL BALANCE DE FLUJO TÉRMICO DE LOS EDIFICIOS}

El flujo de calor que se establece entre el edificio, o más concretamente los espacios que este contiene, y el ambiente, se realiza por procesos de conducción, como puede ser el producido hacia otros edificios o el terreno, y por convección y radiación hacia el ambiente exterior a través del aire.

Estos procesos dependen por tanto de su envolvente, expresada a través de su magnitud, generalmente la superficie de contacto (A), y por sus cualidades, como pueden ser la conductividad, la densidad, el calor específico, la emisividad o la transmisión superficial.

En concreto la influencia de cada una de las formas que se reconocen convencionalmente para el intercambio de calor puede expresarse como:

1. La conducción sigue la Ley de Fourier, que en su expresión vectorial más sencilla puede expresarse como:

$$
\Phi=-k_{d} \cdot \nabla \theta
$$

Siendo: 
Ф Flujo de calor por unidad de tiempo (W.m-2)

$\mathrm{Kd} \quad$ Constante de proporcionalidad de conducción (W. $\left.\mathrm{m}^{-1} \cdot \mathrm{K}^{-1}\right)$. Asimilable a la conductividad $(\lambda)$

$\nabla \ominus \quad$ Gradiente de energía (K. $\left.\mathrm{m}^{-1}\right)$

2. La transferencia de calor por convección sigue la ley de enfriamiento de Newton

$$
\Phi=k_{v}\left(\theta_{1}-\theta_{2}\right)
$$

Siendo:

$\Phi \quad$ Flujo de calor (W.m-2)

Kv Constante de proporcionalidad de convección (W. $\mathrm{m}^{-2} \cdot \mathrm{K}^{-1}$ ) Asimilable a el coeficiente de película o de transmisión superficial (h)

$\theta_{1} \quad$ Temperatura interior $(K)$

$\Theta_{2}$ Temperatura ambiente (K)

3. La transferencia de calor por radiación se rige por la ley de Stefan-Boltzmann

$$
\Phi=k_{r} \quad \theta_{s E^{4}}
$$

Siendo:

Ф Flujo de calor (W. $\left.\mathrm{m}^{-2}\right)$

$\mathrm{K}_{\mathrm{r}} \quad$ Constante de proporcionalidad de radiación (W. $\mathrm{m}^{-2} \cdot \mathrm{K}^{-4}$ ) Asimilable a la constante de Stefan-Boltzman $(\sigma)$ por la emisividad (६).

$\theta_{s E} \quad$ Temperatura superficial de la envolvente hacia el interior

4. Esto permite considerar, para los objetivos planteados, que el flujo de calor por unidad de área, puede expresarse como:

$$
\Phi=k_{c}\left(\theta_{1}-\theta_{2}\right)+k_{r} \theta_{2 s} 4
$$

Siendo:

Ф Flujo de calor (W . $\mathrm{m}^{-2}$ )

Kc Constante de proporcionalidad compilada (W. $\mathrm{m}^{-2} \cdot \mathrm{K}^{-1}$ ) 
$\theta_{1} \quad$ Temperatura interior $(K)$

$\Theta_{2}$ Temperatura ambiente (K)

$\mathrm{kr} \quad$ Constante de proporcionalidad de radiación (W. $\mathrm{m}^{-2} \cdot \mathrm{K}^{-4}$ ) Asimilable a la constante de Stefan-Boltzman $(\sigma)$ por la emisividad (६).

$\theta_{2 s} \quad$ Temperatura superficial de la envolvente hacia el interior

Por lo tanto, el flujo para una estancia dada estará en función de un conjunto de parámetros constantes dependientes de la envolvente definida por la disposición, proporción, forma y cualidades de los elementos constructivos que la conforman y sus materiales constituyentes, incluyendo sus eventuales cualidades de cambio de fase, estos valores se expresan en la ecuación compendiada (4) como $\mathrm{K}_{\mathrm{x}}$.

Por otra parte las condiciones exteriores, que pueden simplificarse como viento, radiación incidente, temperatura y humedad, son variables estocásticas que ofrecen diferentes escenarios en función de sus combinaciones.

Su participación en el flujo térmico del edificio y el exterior se produce a través de los términos térmicos de la ecuación compendiada (4) que se refieren a las temperaturas interiores (ya sea expresadas como temperatura de la superficie interior o como temperatura del aire interior) y la temperatura exterior.

La complejidad de la caracterización climática puede analizarse segregando su influencia en el edificio. Las condiciones de viento y la radiación manifiestan una gran heterogeneidad, mientras que la temperatura del aire y su humedad están relacionadas entre sí, presentando patrones diarios y estacionales relativamente regulares, en las zonas de estudio.

La simplificación realizada compilando la influencia climática en la temperatura, tiene limitaciones muy importantes para el análisis del problema, ya que la presencia de agua líquida en los paramentos, la velocidad, humedad, temperatura y dirección del viento o la radiación solar directa y su distribución aleatoria hace muy compleja su integración en un análisis de comportamiento del edificio en el ambiente. Aún así el análisis del balance térmico puede realizarse por la agregación de la influencia de las distintas variables sobre el edificio.

Se ha optado por analizar el flujo térmico, considerando las diferencias de temperatura, independientemente del resto de los factores, dada la posibilidad de afectar los valores obtenidos por la aplicación sucesiva de la influencia de los distintos parámetros o combinaciones.

Parece, por tanto, estar justificado disponer de valores de temperatura que caractericen correctamente los ambientes en los que se ubican los edificios. 


\subsubsection{FUENTES DE INFORMACIÓN SOBRE BASES CLIMATOLÓGICAS EN EDIFICACIÓN}

La información relativa al clima procede en su mayoría del análisis estadístico de situaciones pasadas. Estas series climáticas se depuran para obtener en una primera instancia valores medios, máximos y condiciones de cálculo.

Las fuentes estadísticas y las recopilaciones que se emplearán son:

Valores medios

La climatología y la meteorología se sustentan sobre series de valores históricos, que son actualizados y revisados con los valores presentes. De esta forma las variables climáticas tienen una dimensión pretérita recogiendo series bien acotadas en el tiempo y futura haciendo previsiones o indicando tendencias de evolución de sus valores para cada ubicación.

Efemérides y valores singulares

Con cierta regularidad se presentan anomalías atmosféricas de gran interés para establecer los riesgos asociados al territorio, combinadas con las singularidades locales están en procesos naturales de avalanchas, riadas, arrastres, desprendimientos, y otras manifestaciones indirectas del estado atmosférico.

Valores aplicados al cálculo científico o técnico.

La aplicación a lo cotidiano de este conocimiento del clima pasado se manifiesta en establecer las condiciones de entorno meteorológico en el que se desarrollan las actividades humanas. Tanto será de utilidad para establecer la probabilidad de que prosperen actividades agropecuarias como las solicitaciones a las que estarán sometidas las infraestructuras o las condiciones extremas y medias a las que tendrán que responder los edificios para procurar el bienestar a sus usuarios. 


\subsubsection{CLIMATOLOGÍA EN LA NORMATIVA}

El objetivo de incorporar las clasificaciones climáticas a la normativa de edificación está relacionado con el desempeño energético, estando, desde el punto de vista legislativo, regulatorio y de control, distribuidas las responsabilidades entre diversas entidades en función de los ámbitos geográficos. Así, puede observarse la concurrencia de entidades locales, regionales, nacionales y europeas.

\section{AMBITO EUROPEO}

La motivación y la exigencia primera de regulación parte de la máxima institución europea (Directivas 2002/91/CE y 2010/31/UE), permitiendo establecer por parte de los países miembros una metodología y unas exigencias propias, lo que genera una gran diversidad en su transposición (García-Hooghuis, 2013).

En una primera aproximación la regulación establece las características que deben cumplir los edificios para que se alcancen unas determinadas condiciones interiores frente a unas determinadas condiciones exteriores.

La aplicación de la normativa en nuestro ordenamiento ha supuesto la implantación de unos requisitos mínimos más exigentes (García-Hooghuis, 2013) a las prestaciones de habitabilidad ya reguladas (LOE, 1999), con criterios de mejora en la eficiencia energética de los edificios aplicados a una reducción efectiva del consumo (Dyrbøl, 2010, García-Hooghuis, 2013).

La legislación europea promueve la implantación de sistemas de certificación energética de los edificios y los estado miembros pueden elegir para su cálculo entre dos tendencias bien marcadas para hacer una aplicación más acorde con sus necesidades:

"The comparison of the calculated (asset) rating for energy certification with the measured (operational) rating is a matter of weighing advantages and disadvantages for each of the methods and selecting the most appropriate method for the a c tual situation in the Member States (MS)" (EU, 2011 pág. II-5)

Esta clasificación mediante el cálculo (informada) permite establecer una estimación de demanda futura ajena al usuario y a sus condiciones de uso, a la ejecución del edificio, a una operación eficiente y a la capacidad de adaptación futura de la edificación a las circunstancias del usuario, a la mejora de su operación o la implantación de nuevas tecnologías. Por otra parte exige la creación de un clima de referencia o normativo que permita aplicar estas estimaciones a un entorno climatológico verosímil. Para ello debe tener la capacidad de adaptarse a las diferentes posibilidades de exposición al sol o al viento y a diversas localizaciones geográficas.

La certificación energética de edificios tiene la gran ventaja de estar asociada al proyecto, ser previa a la ejecución, y ser impuesta. Por tanto, aporta en el inicio del proceso de construcción del edificio la capacidad de anticipar unos 
resultados finales estimados y comparables que facilitan la supervisión y delega en los agentes del mercado de construcción la responsabilidad de la correcta ejecución.

Por otra parte, la certificación basada en el consumo real (operativa) sería la única certificación que permitiría incluir el desempeño real de las previsiones de diseño, la construcción, el uso y la operación, y al disponer de datos reales de consumo, permitiría la evolución a lo largo del tiempo y la correlación entre las estadísticas de consumo energético y los edificios para sancionar o estimular las iniciativas y conductas en función de valores y de objetivos contrastables.

Tiene la dificultad de que exigiría una evaluación continua, primero de la propuesta arquitectónica y sus instalaciones energéticas y después de la operación de este sistema a lo largo del tiempo para la que actualmente no existe una estructura de seguimiento y control realmente operativa, con las limitaciones impuestas por una adecuada habitabilidad, por ejemplo en temperatura o humedad.

El clima de referencia o normativo elaborado para la estimación del consumo futuro podría ajustarse al clima real para establecer los patrones de control y, a su vez, el clima sintético podría ser modificado para ajustarlo a la realidad en su escala espacial y temporal.

La expresión gráfica de las diferencias entre ambos sistemas de certificación, por otra parte conciliables en una solución escalonada, puede observarse en el siguiente cuadro:

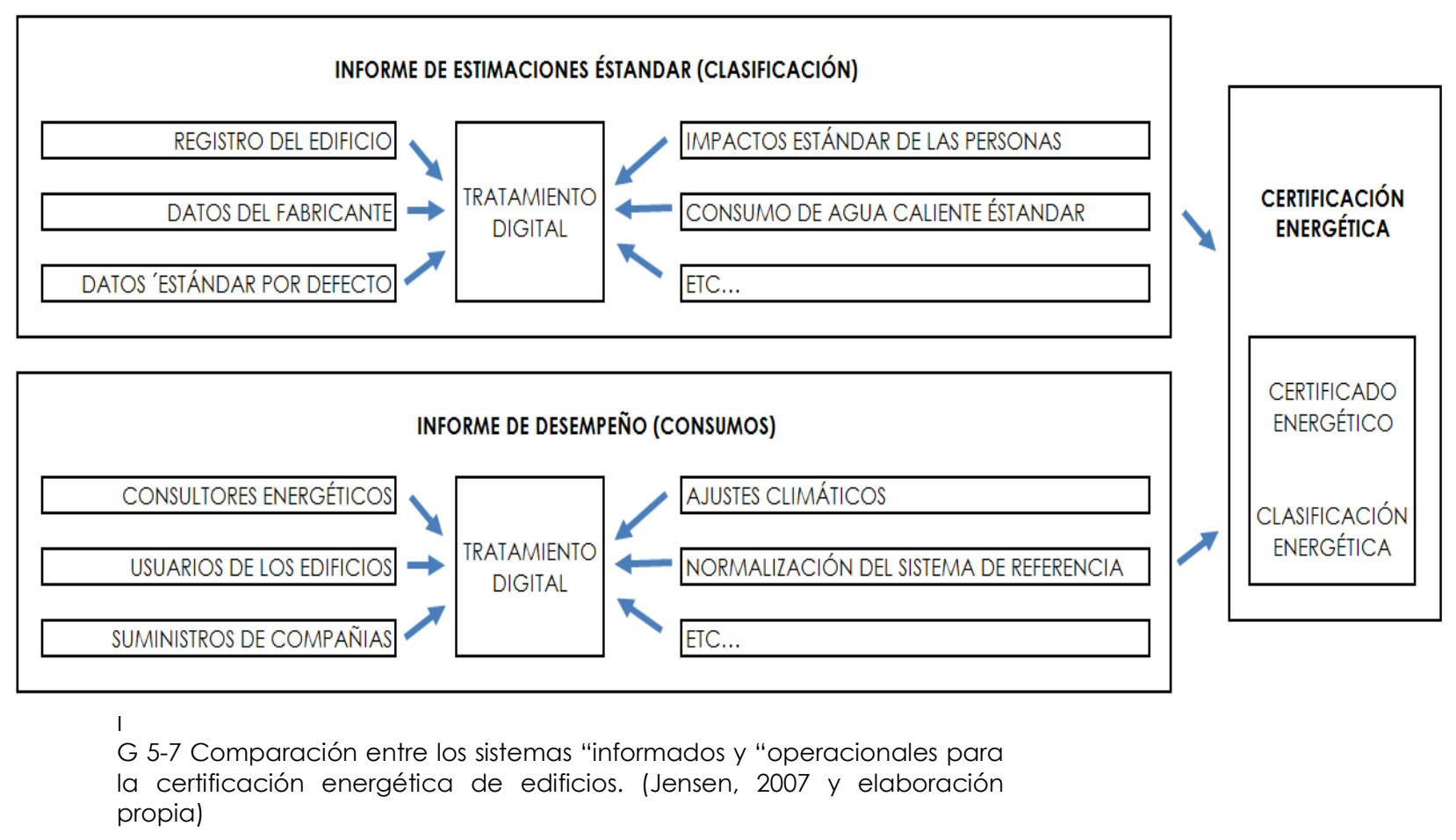

El sistema informado es el adoptado en nuestra legislación, con lo que, a pesar del cambio de una normativa prescriptiva a prestacional, existe una cierta continuidad ya que la prestación es solo estimada, no medida, y permite una asignación directa de 
prestaciones estimadas a los productos y por ende inducir una prescripción asociada a la prestación demandada.

Las exigencias básicas a las que se aplica el clima están descritas en el artículo 15 de la LOE y se refieren al ahorro de energía. En el contexto del artículo se entiende que se refiere al ahorro en la energía estimada para mantener en condiciones de confort y habitabilidad las estancias en los edificios. Este valor se ha denominado abreviadamente como demanda.

Esta exigencia se desglosa en dos, una relativa a las envolventes (HEl) a las que se exige una limitación de la demanda basada en factores climáticos, como son el clima de la localidad, régimen de verano y de invierno, y que podrían considerarse como solicitaciones externas, y otras referidas al uso y a las cualidades del edificio, como son el aislamiento térmico, la inercia térmica, la permeabilidad al aire y la exposición a la radiación solar o sus cualidades constructivas con una referencia expresa a los puentes térmicos. También se realizan referencias expresas al balance higrotérmico, como la limitación de condensaciones superficiales e intersticiales.

Otra exigencia se refiere al rendimiento de las instalaciones térmicas (HE2) cuyos equipos y rendimiento habrán de ser apropiadas para proporcionar el bienestar térmico de sus ocupantes (RITE).

Para la aplicación de los climas de referencia o normativos elaborados es preciso considerar que su objetivo es, parafraseando al CTE, representar las acciones del clima sobre el comportamiento térmico del edificio y su demanda energética (estimada) (CTE DB-HE, 2013, pág. 17 y 18).

El cálculo de las estimaciones se hará, por tanto, considerándolas solicitaciones exteriores basadas en una clasificación en zonas climáticas y en unos climas de referencia, en los que se considera la temperatura y la radiación solar, asociados a ellas y aportados por el legislador mediante valores tabulados (CTE DB-HE APÉNDICE $B$, 2013) o mediante documentos reconocidos que habrán de elaborar las diferentes regiones administrativas.

Esta normalización del clima se realiza a nivel nacional asignado localmente en función de la provincia y de la altitud sobre el nivel del mar.

\subsubsection{REGIONALIZACIÓN NORMATIVA DEL CLIMA EN EDIFICACIÓN}

La afortunada inclusión del clima entre las exigencias y prestaciones a satisfacer con los edificios en nuestra legislación propone, en la práctica, una nueva distribución espacial del clima definiendo, con precisión suficiente para realizar las estimaciones de su desempeño tecnológico, nuevas divisiones territoriales en los climas.

La consideración de estos climas diseñados para servir de entorno físico de las tecnologías que se aplicarán en el edificio, debe hacerse entendiendo que cualquier edificio estará sometido a una 
legislación europea, nacional, regional y local, no necesariamente idénticas.

La legislación que habrá de ser aplicada al diseño del edificio tiene diversas fuentes y organismos de control. La iniciativa europea alimenta las directivas que serán posteriormente transpuestas en los distintos estados. El resto de las fuentes de las que emanan estas legislaciones en el ámbito de estudio se promueven, en la práctica, por parte de las instituciones de gobierno: las del estado, las de las regiones y las de las entidades locales, y son aprobadas por las entidades legislativas que han elegido estos gobiernos. Las procedentes de ámbitos nacionales y regionales disponen, por lo general, de estructuras similares $y$, aunque con diferentes funciones y una clara jerarquía legal, ambas escalas espaciales incluyen dos sectores de gobierno: las entidades gestoras de la arquitectura y la ordenación territorial y las de la industria y la energía.

La intensidad con la que las entidades regulan y vigilan su cumplimiento es mayor en las entidades locales y tienen como última instancia a las entidades nacionales, pasando por la acción regional que puede dimensionar su protagonismo de formas diferentes.

En la práctica, el seguimiento y acreditación del cumplimiento de esta regulación está en las áreas local, vía licencia de primera ocupación o de actividad, y regional, a través del registro y para la ejecución en segunda instancia, como pueden ser recursos, inspecciones, sanciones o exenciones.

Esto hace que cualquier estudio deba ser planteado teniendo en cuenta localizaciones concretas, aunque su planteamiento pretenda ser aplicado más ampliamente dentro del área definida.

Por ello se han epigrafíado y ordenado los datos en estudios de caso en capítulos independientes, ya que, aunque su objetivo es dar soporte a los contenidos generales, no son más que una parte de la realidad a la que éstos se aplican y no pueden argumentarse como demostraciones, sino sólo como líneas de trabajo para, una vez aplicadas a otras localizaciones, ratificar o matizar las observaciones realizadas. 


\subsubsection{FACTORES QUE INFLUYEN EN LA TEMPERATURA CORPORAL ENTORNO A LOS EDIFICIOS}

La temperatura corporal en los ambientes interiores y exteriores está afectada, por la actividad metabólica y por las características del espacio, entendido en un sentido amplio:

- Temperatura ambiente

- Temperatura de las superficies (verticales, techos, vegetación y suelos)

- Arropamiento

- Velocidad del aire

- Ventilación (renovaciones)

- Estratificación de la temperatura en vertical

- Diferencia de temperatura en horizontal

- Distancia a los paramentos

- Humedad ambiente

- Presencia de agua líquida

Para tener en cuenta estos factores en la caracterización de los espacios interiores se han diseñado índices que, mediante la agrupación de distintos valores y parámetros con un sistema de determinación por observación directa, ofrezcan una imagen del espacio interior que permita su comparación y estudio en relación con la comodidad de las personas que los ocupan.

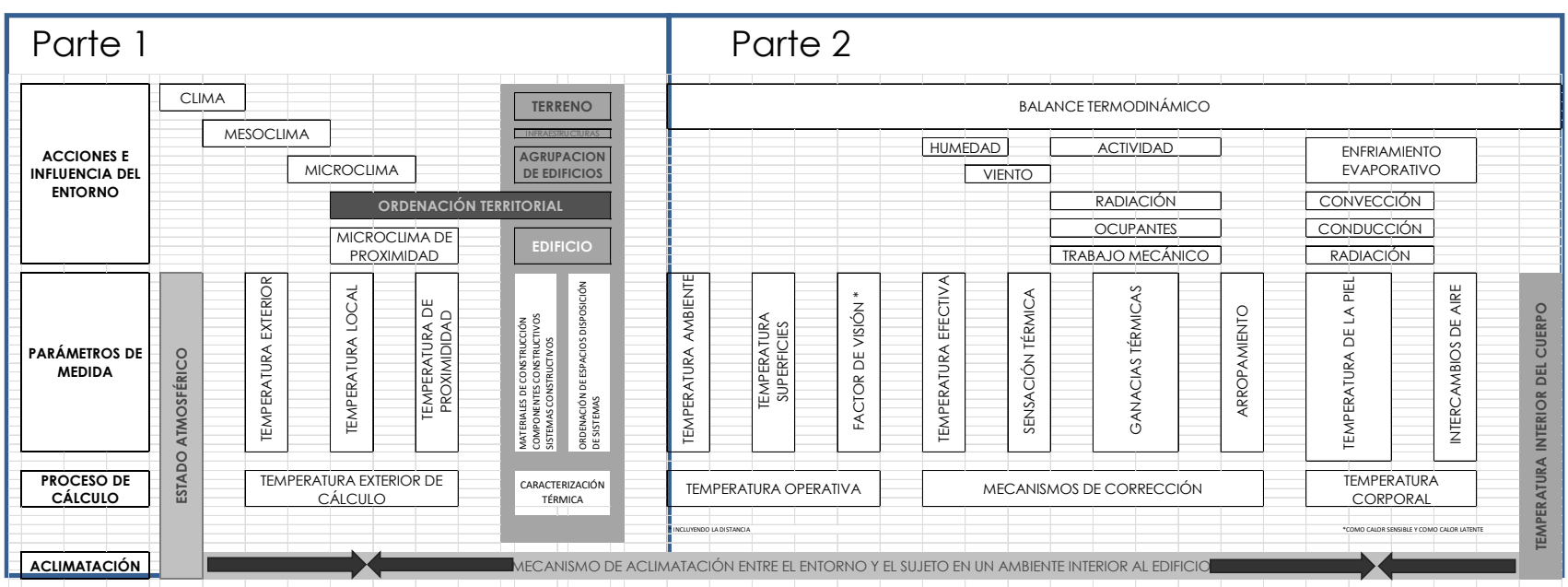

FIG 5-8 Esquema de la relación entre los climas y su aplicación en diferentes ámbitos espaciales. Balance termodinámico y Parámetros térmicos. (Elaboración propia) 


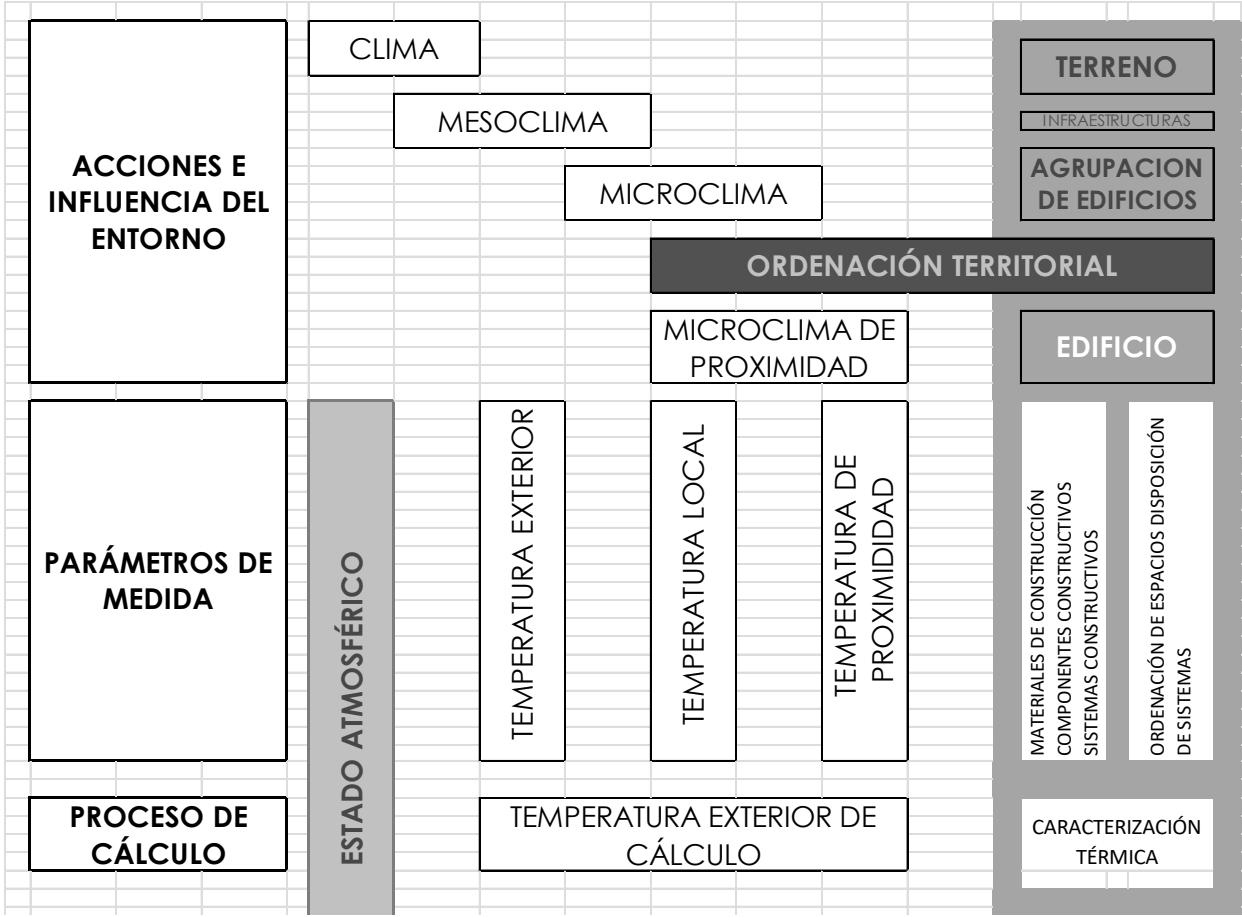

FIG 5-9 Esquema de la relación entre los climas y las temperaturas que aportan (Elaboración propia)

Entre los valores que se utilizan para su determinación se encuentran los datos empíricos directos como los obtenidos del termómetro de bulbo seco, del termómetro de bulbo húmedo, del termómetro de globo o los termómetros de superficie y aquellos otros valores indirectos que se obtienen de tablas, correlaciones o ecuaciones a partir de ellos, como son por ejemplo los parámetros de humedad del aire (humedad relativa, presión de vapor, déficit de saturación y otros). En general, para un entorno dado todos los parámetros higrotérmicos están fuertemente correlacionados por lo que permiten caracterizar el ambiente con un reducido número de ellos.

La concreta determinación de las condiciones de bienestar higrotérmico en un interior, recogida en la norma EN ISO 7730 : 2006, establecido como proporción de personas satisfechas considerando que determinadas variables se mantienen en un intervalo determinado, permite una aplicación concreta de las variables consideradas, simplificándolas para establecer unas condiciones viables para ser controladas y medidas.

Para ello la normalización recurre a la estadística y a la definición de un porcentaje límite de personas insatisfechas en un determinado estado higrotérmico, que varía en función de la calidad del ambiente $(<6 \%,<10 \%$ y $<15 \%$ para las categorías $A, B$ y $C$, respectivamente). Es un proceso que busca satisfacer las condiciones de comodidad térmica de un porcentaje determinado de los usuarios, mediante una estimación de su probabilidad, manteniendo fijos parámetros como el arropamiento, la velocidad del viento o la actividad (met). 


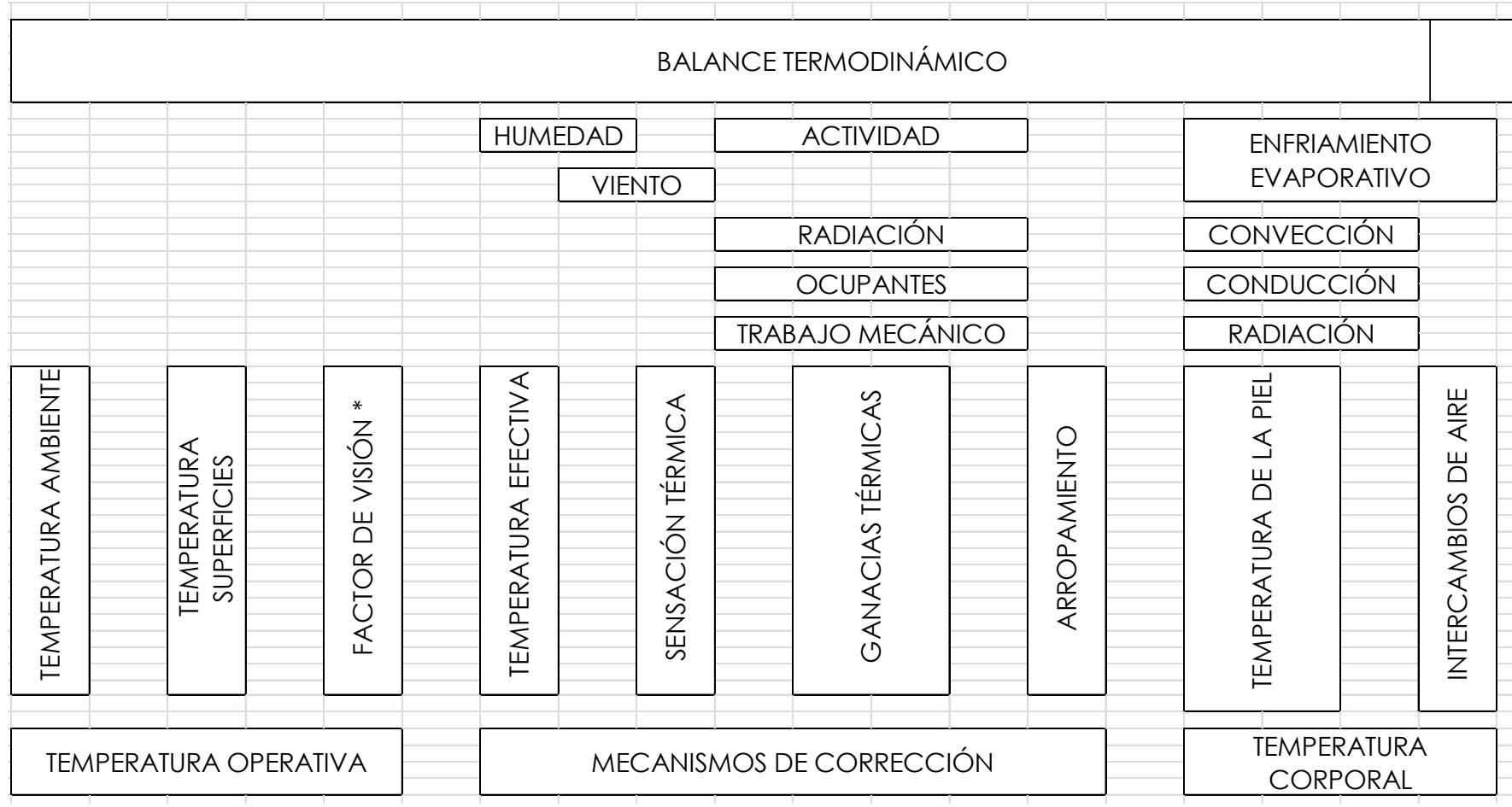

FIG 5-10 EJEMPLO DE LIMITACIONES TÉRMICAS DE CONFORT ADAPTATIVO APLICADO CONDICIONES HIGROTÉRMICAS ADECUADAS PARA EL INTERIOR DE LOS EDIFICIOS. DIAGRAMAS DE CONFORT 
Las condiciones de confort no pueden ser definidas de un modo universal y están sujetas a una fuerte controversia, aunque sus valores difieren en la práctica muy poco de unos a otros autores, siendo la influencia del arropamiento, el metabolismo de los individuos o la actividad, mayor que las diferencias entre estas consideraciones.

En estas condiciones parece lícito recurrir a definiciones gráficas que, si bien carecen de la precisión de las determinaciones analíticas, permiten una visión de conjunto del problema y facilitan la búsqueda de sus eventuales soluciones.

Varios sistemas gráficos o diagramas relacionan el confort con parámetros como la temperatura de bulbo seco, la humedad relativa, el viento, la radiación e incluso temperaturas de bulbo húmedo, temperaturas efectivas o humedades absolutas.

Estos diagramas representan las zonas de confort y permiten buscar los recursos que compensen valores climáticos o ambientales como pueden ser la radiación, la exposición al viento o por el contrario, la protección solar y el abrigo a los vientos.

Son de especial interés las regiones del diagrama en las que se utilizan unos parámetros climáticos para compensar otros, mostrando correcciones al disconfort afectando la temperatura por la velocidad del viento, la radiación o la inercia térmica.

En el diagrama de Giboni, por ejemplo, sobre un diagrama psicomético se establece una temperatura de bulbo seco de confort entre el $20 \%$ y el $75 \%$ de humedad relativa y con temperaturas entre 21 y $26^{\circ} \mathrm{C}$ si la humedad es menor del $50 \%$, a humedades mayores les hace corresponder temperaturas cada vez menores hasta alcanzar los $24^{\circ} \mathrm{C}$ cuando la humedad es del 75\% (Givoni, 1969)

Otros autores establecen esta zona entre el $40 \%$ y el $70 \%$ de humedad relativa, con temperaturas de bulbo seco entre $19^{\circ} \mathrm{C}$ y $24^{\circ} \mathrm{C}$ con una humedad relativa del $40 \%$ y entre $18^{\circ} \mathrm{C}$ y $22,5^{\circ} \mathrm{C}$ con un 70\% de humedad relativa. (Sargent y Tromp, 1964).

Estos diagramas de confort adolecen de algunas posibilidades de intervención, frecuentes e históricamente relevantes, en las que se hace participar un conjunto de factores ambientales relacionados con el territorio o la ordenación urbana, modificando sustancialmente las posibilidades de intercambios energéticos, iluminación y ventilación. Entre estos factores se documentan y reconocen tanto la formación de pantallas $u$ ocultaciones al viento $o$ al sol mediante construcciones o vegetación como la consideración del conjunto construido como un todo en función de su densidad, altura de las construcciones, dirección y continuidad de la trama, relación entre altura y superficie expuesta de las construcciones y entre este factor de forma y los espacios vacíos, ya sean estos calles, plazas o patios (Luxán, pág. 63). 
Del mismo modo las soluciones que se adoptan no hacen referencia a la acción combinada ni a las sinergias que pueden producirse cuando se emplean sistemas complejos como pueden ser los canales subterráneos para el precalentamiento o la refrigeración o los sistemas geotérmicos de baja entalpía o los procesos de refrigeración adiabática (Heeger, pág. 23 y 24)

La consideración de zonas de confort adaptativo amplían las posibilidades de estos sistemas al permitir establecer zonas de confort variables.

\section{ZARAGOZA AEROPUERTO}

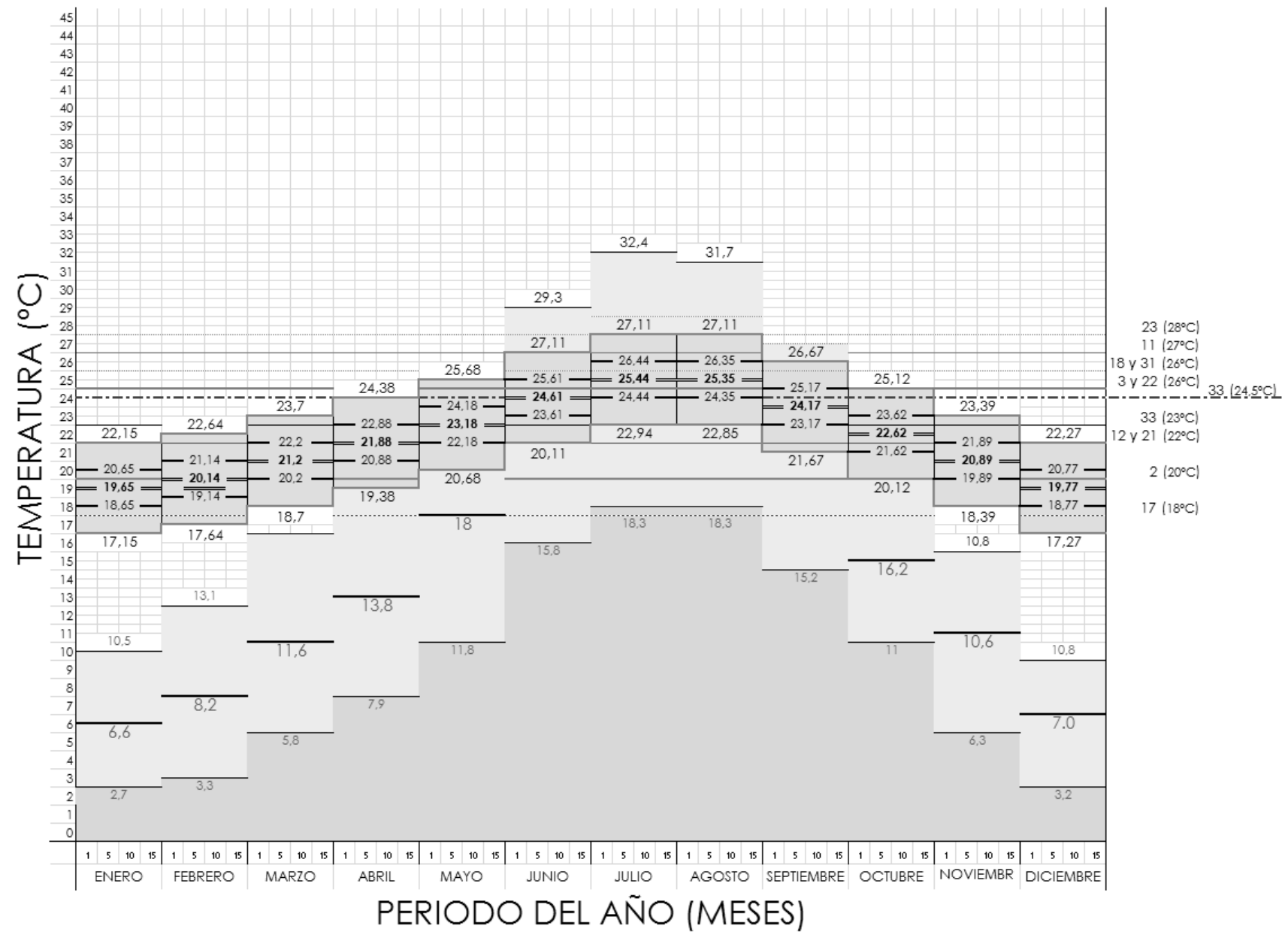

FIG 5-11 EJEMPLO DE LA ESQUEMA DE LA DISTRIBUCIÓN TEMPORAL DE LAS TEMPERATURAS DE CONFORT ADAPTATIVO CON LAS TEMPERATURAS MÁXIMAS MÍNIMAS Y MEDIAS EN EL AEROPUERTO DE ZARAGOZA (Elaboración propia) 


\subsubsection{CAPACIDAD PARA REGULAR LAS CONDICIONES HIGROTÉRMICAS}

DEL EDIFICIO PARA UNA COMODIDAD TÉRMICA

Así como la climatología analítica define con precisión el estado históricamente medio de la atmósfera en un lugar y la climatología sintética o física describe e intenta explicar la sucesión de fenómenos que dan lugar al tiempo atmosférico en un momento y un lugar, el ambiente estadístico o de valores medios sólo define y explica parcialmente el proceso, siendo preciso complementarlo formando climas de referencia o normativos que definan las condiciones para el diseño de edificios y equipos e incluso con la estimación de consumos más probables a medio plazo.

La representación de las condiciones climáticas de contorno que permitan definir y explicar la secuencia de fenómenos que afectan al bienestar local o instantáneo en el edificio están peor definidas, ya que no puede realizarse a través de los valores estadísticos, por su sesgo a eliminar los valores extremos, ni con los climas de referencia, por no recoger toda la casuística local. 


\section{ANÁLISIS TEÓRICO}

\subsection{CARACTERIZACIÓN}

Se considera que la sensación térmica percibida por una persona en un clima templado está definida fundamentalmente por la temperatura $(\theta)$, la humedad $(H)$, la velocidad del viento (V) y la radiación (R).

A su vez estos valores pueden determinarse como valores medios (subíndice "m"), medias de las máximas, medias de las mínimas, máximas absolutas o mínimas absolutas, en periodos temporales horarios, diarios, semanales, mensuales, estacionales o anuales.

De este modo se puede, por ejemplo, caracterizar un clima o unas condiciones higrotérmicas, estimar las demandas energéticas para la aclimatación de los espacios o la potencia de los equipos necesarios para satisfacer esta demanda y dado que su influencia en el bienestar se produce en cada momento se ha optado por considerar sólo los valores horarios, siempre que no existan grandes oscilaciones térmicas durante este periodo, para así dar una idea más cabal de la sensación que tendrían los ocupantes del espacio interior o interior analizado.

Por otra parte se observa una amortiguación y un desfase en las temperaturas interiores, así como una gran influencia en estos valores de la ventilación, la forma y la disposición y características ópticas y térmicas de los elementos practicables, cuya protección y orientación determinan su influencia en la ventilación, la humedad, la radiación y el viento en el interior de los edificios.

Las variables asociadas con el ambiente interior pueden ser medidas en el interior de los espacios (subíndice "a") o en las superficies que lo circundan, normalmente diferenciadas según la posición con respecto al usuario y denominadas de pared (subíndice "p") cuando son paramentos sensiblemente verticales, de suelo (subíndice "s") cuando están situados bajo los sujetos o de techo (subíndice "t") cuando están sobre los sujetos. Estos valores superficiales se aplican afectándolos por el ángulo con el que resultan térmicamente visibles desde la posición del sujeto y por la distancia a la que estas superficies se encuentran del mismo, traduciendo la influencia de las superficies, por tanto, a vectores de energía en coordenadas polares.

Cada uno de estos parámetros está condicionado por diversos factores que, en ámbitos urbanos, adquieren unas connotaciones que han permitido definir un microclima específico o de proximidad donde pueden modificarse notablemente según la localización dentro del núcleo urbano, tanto en sus coordenadas horizontales como en función de la altura sobre el suelo. Es muy notoria la diferencia de estos valores, climáticos en general y térmicos en particular, según se determinen en una estación meteorológica ajena a esta naturaleza urbana o en las diversas localizaciones insertas en ella.

Por ello tiene sentido considerar tres niveles básicos de datos, unos destinados a describir el clima, formados por series con registros muy fiables tomados durante periodos de tiempo suficientemente largos, que son reducidos a sus valores medios, y sus variaciones para conocer su 
probabilidad, y otros dos más vinculados al lugar concreto en que se ubica el edificio

La primera serie, con valores climáticos generales, estaría formada por series formadas estadísticamente que representan el entorno climático y sirven de contexto para realizar simulaciones y para la definición de los sistemas y elementos constructivos de los edificios. Esta serie puede provenir directamente de los valores de la estación meteorológica más próxima o de los valores estimados de estaciones virtuales configuradas por ponderación con los datos de estaciones meteorológicas próximas, considerando los factores de modificación del clima. Podemos considerar esta primera serie como de referencia, continua y local.

Otra segunda serie vendría dada por los valores observados en el entorno del edificio. Mientras los valores anteriores pueden elegirse en función de la calidad de las estaciones de referencia (duración y continuidad de las series y calibración de los equipos, por ejemplo), en este caso es más aconsejable disponer de series cortas, más relacionadas con la secuencia de producción del edificio o la rehabilitación y asociadas a las fases previas de diseño, por lo que las series tendrán una duración frecuentemente menor de un año y sólo muy ocasionalmente tendrían una duración de tres o cinco años, por ejemplo. Por otra parte, el seguimiento y obtención de los valores no es frecuente que permita la obtención de valores continuos de calidad por lo que puede estar formada por la suma de series discontinuas, donde la selección de los periodos adquiere una gran importancia. Esta temperatura que podemos denominar como temperatura del lugar o local, formará una serie, o varias, discontinuas y microclimáticas.

Una tercera serie vinculada a localizaciones singulares en las proximidades del edificio, haría hincapié en la influencia del edificio y de su entorno en las condiciones climáticas en su derredor. Indicará por tanto la influencia de orientaciones, protecciones, alturas o exposición a las condiciones térmicas en el contorno del edificio. Es la temperatura que se ha denominado como temperatura junto al paramento. Esta última serie climática será muy frecuentemente discontinua y de proximidad, entendiendo como microclima de proximidad aquel influido directamente por el edificio y su entorno más inmediato y que, por tanto, presenta más facilidad para ser modificado por las actuaciones a realizar. 


\subsubsection{RELACIÓN ENTRE LA RADIACIÓN Y LA TEMPERATURA}

La radiación aporta energía a los edificios en forma discontinua, proporcional a su superficie expuesta y en función de su ángulo de visión. Esta energía aporta calor a los paramentos y al aire interior.

Las elaboración de los datos disponibles (PGVIS, 2012) permite observar para las localizaciones en las que se ubican los estudios de caso que se producen ciertas correlaciones, por otra parte concurrentes con las que se recogen en otras fuentes bibliográficas.

- La irradiación y la temperatura diurnas medias mensuales máximas se producen semanas después del solsticio de verano y las temperaturas mínimas semanas después del solsticio de invierno.

- La irradiación aumenta de forma no lineal. Los incrementos son mayores cerca de los periodos más fríos y menos en los más cálidos, mientras que las temperaturas, en cambio, sí experimentan incrementos y decrementos más homogéneos a lo largo del año.

- La irradiación disminuye más lentamente que las temperaturas una vez alcanzados sus valores máximos.

- La temperatura en un día medio de cualquier mes tiene su máximo varias horas después de que la irradiación haya alcanzado el suyo, siendo esta diferencia ligeramente mayor en verano que en invierno.

- La intensidad de la radiación influye mucho en la temperatura. Las temperaturas medias diurnas pueden ser superiores a las de confort en varios meses mientras que las medias nocturnas siempre están por debajo de los valores de confort.

- La irradiación directa es susceptible de aportar energía calorífica los meses en los que las temperaturas diurnas están por debajo de las de bienestar, siendo estos meses más que aquellos en los que las temperaturas diurnas superan las de confort.

- Las temperaturas medias horarias diurnas superiores varios meses a las de bienestar convencional, durante las horas centrales del día en los que la irradiación sigue aportando calor.

Esta influencia de la radiación solar en la temperatura tiene importancia como recurso para mejorar las condiciones de habitabilidad higrotérmica y como obstáculo para el bienestar interior en función de cómo incida sobre el edificio y del estado térmico en el que éste se encuentre.

A modo de ejemplo se presentan las conclusiones para un caso de estudio en el centro urbano de Zaragoza. Si se superponen las gráficas de temperatura (en azul) con sus valores medios y horarios y de radiación solar expresada por la irradiancia global horaria 
para un día medio del mes, y el total mensual, se observa como estas observaciones se concretan en:

- La irradiación y las temperaturas diurnas medias mensuales máximas se producen entre los meses de julio y agosto y las mínimas entre los meses de diciembre y enero.

- La irradiación aumenta durante 7 meses en una forma no lineal con incrementos mayores al principio para mantenerse en los meses de máximas, mientras que las temperaturas medias diurnas aumentan muy lentamente de forma casi lineal.

- La irradiación disminuye durante 5 meses de una forma casi lineal, mientras que esta disminución casi lineal de la temperatura se produce a lo largo de 4 meses.

- La temperatura en un día medio de cualquier mes tiene su máximo varias horas después de que la irradiación haya alcanzado el suyo, siendo esta diferencia ligeramente mayor en los periodos cálidos que en los periodos fríos.

- Las temperaturas medias diurnas están por encima de los valores convencionales de confort durante las horas centrales durante 5 meses pero en ningún caso lo están durante todo el día manteniéndose las medias nocturnas siempre por debajo de ellas.

- La irradiación directa durante 7 u 8 meses al año es susceptible de aportar calor mientras las temperaturas están por debajo de la zona de bienestar convencional.

- La irradiación directa durante los meses más cálidos es susceptible de aportar calor durante las horas centrales del día, siendo las temperaturas medias horarias diurnas superiores a las de la zona de bienestar convencional. 


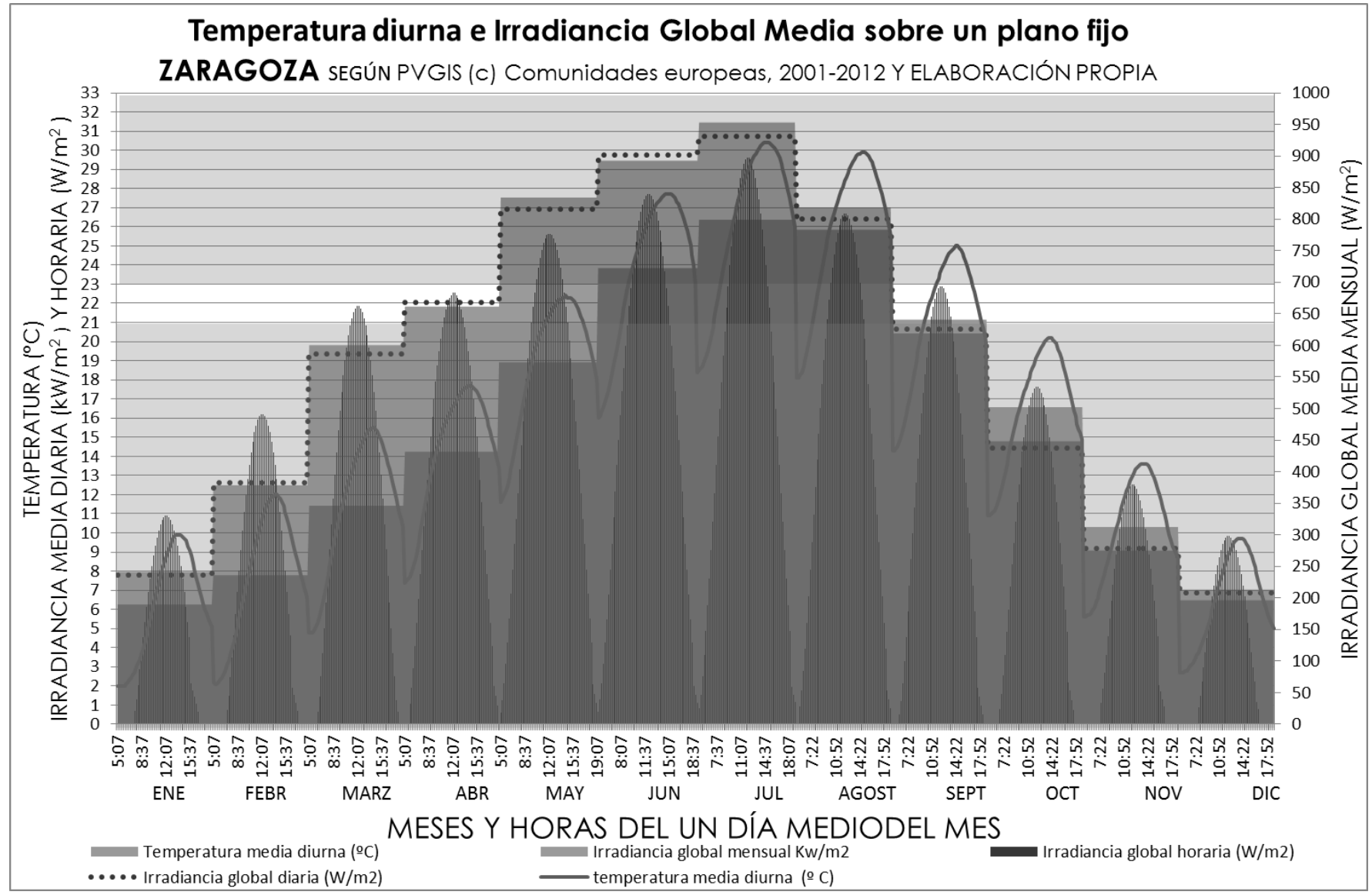

FIG 6-1 Relación entre temperatura e irradiación, con zona de bienestar convencional para ZARAGOZA. (Elaboración propia partir de los datos de PGVIS, 2012)

\subsubsection{RELACIÓN ENTRE HUMEDAD Y TEMPERATURA}

Las correlaciones más evidentes entre humedad y temperatura tienen que ver con la disminución de las humedades relativas ante los aumentos de la temperatura y el proceso inverso, ya que no precisa modificar la cantidad de agua contenida en la atmósfera. La presencia de meteoros hidrológicos como son la nubosidad, la lluvia o la niebla, están acompañados de reducciones de temperatura en periodos fríos y de aumentos en periodos cálidos.

En los casos estudiados la cantidad de agua en el aire varia relativamente poco y las diferencias de humedad suceden acompañadas de meteoros hidrológicos. 


\subsubsection{RELACIÓN ENTRE VIENTO Y TEMPERATURA}

Lo vientos aportan un mayor intercambio de energía y por lo general incrementan la sensación de calor cuando las temperaturas son muy altas y la de frio cuando son bajas. En periodos templados reducen la sensación de calor.

Será en los periodos anteriores y posteriores al solsticio de verano, cuando las temperaturas son cálidas, los momentos en los que el viento, favoreciendo la convección. permitirá reducir la sensación de calor, siempre que la temperatura del aire no sea superior a la del ambiente y que la humedad relativa no supere el $80 \%$. También en estos periodos, los vientos nocturnos, más fríos, colaborarán muy eficazmente a reducir la temperatura de los edificios y los elementos urbanos.

En los periodos más fríos, especialmente si las máximas son inferiores a las temperaturas de confort, el viento colaborará con este disconfort, especialmente si su temperatura es inferior a la temperatura ambiente. 


\section{2 ÁMBITO ESPACIAL Y TEMPORAL DEL ESTUDIO REALIZADO}

Las secuencias climáticas de referencia o normativas, así como los valores característicos medios o extremos para un determinado periodo, no permiten analizar con eficacia la respuesta del edificio al clima.

La definición de un modelo experimental que mejore la previsión de la respuesta estimada del edificio ante el clima sería de gran utilidad para el análisis de la arquitectura $y$, muy especialmente, de la arquitectura bioclimática.

\subsubsection{ESCALA ESPACIAL}

Este modelo debe permitir identificar los periodos del año homogéneos en relación a la temperatura interior que se produciría en un edificio sin aportación ni sustracción artificial de energía y su frecuencia a lo largo del año.

Para ello se han considerado las temperaturas del microclima urbano y de proximidad y la del interior de los espacios sin climatizar.

Este modelo parte de la observación de las temperaturas horarias en secuencias rítmicas entre máximos y mínimos diarios y otras secuencias en las que los valores se manifiestan como crecientes y decrecientes en varios días consecutivos., con muy breves periodos en los que no se modifican.

La aplicación a la edificación hace necesario considerar la relación con las temperaturas confortables en el interior de los edificios.

A. LOCALIZACIÓN DE LAS ESTACIONES METEOROLÓGICAS DE REFERENCIA

Los rasgos característicos que pueden percibirse tras la observación en estaciones meteorológicas ofrecen una imagen precisa de los valores térmicos del entorno de éstas. Las diferencias con los valores de otras estaciones meteorológicas próximas, podrían ser un indicador de la diferencia que habría entre los valores de la estación meteorológica más próxima al edificio objeto de estudio y los que se producirán él.

Para ver la magnitud real de estas diferencias se han considerado dos localidades situadas en la misma zona climática, con varios observatorios meteorológicos próximos y con una condiciones de densidad y amplitud suficientes como para poder detectar si existen diferencias significativas entre sus registros. La ciudad elegida ha sido Zaragoza. En el caso de Zaragoza, se puede disponer de los valores registrados en un pequeño radio, en el entorno de $7 \mathrm{~km}$.

Se busca un patrón para la evolución térmica en los observatorios tanto en un periodo anual que permita asignar a una estación un valor deducido del obtenido por las otras dos y sin incorporar otros parámetros que influyen en la temperatura se estudiarán también 
periodos más cortos para buscar patrones y observar su precisión en periodos menores.

Las estaciones meteorológicas se describen por su indicador meteorológico y su longitud, latitud y altitud, de forma que permita su ubicación geográfica con precisión.

Se ha considerado representativo recoger en los estudios datos sobre la localización en distintas escalas de estas estaciones meteorológicas, de forma que se pueda observar la distancia entre ellas y la relación con las zonas construidas y los accidentes geográficos mediante cartografía e imágenes aéreas

Las temperaturas horarias consideradas se producen en una lectura realizada en las horas enteras.

\section{B. CLIMA LOCAL}

La región climática en la que se ubican los edificios sólo puede ser considerada para la estimación de su respuesta al clima afectándola por las características del entorno próximo, formando lo que se han denominado como microclimas.

En el ámbito de estudio que se propone la región climática se ha identificado con la zona climática definida para la aplicación de las exigencias prestacionales en la normativa de aplicación a la edificación.

La gran variedad climática en la península ibérica hace muy prolijo el análisis de todos los tipos, por lo que se circunscribirá al que se ha denominado en el Código Técnico de la Edificación (CTE, 2006) como zona climática D3.

Esta clasificación climática incluye diferentes microclimas, por lo que se ha elegido una ubicación donde éstos se manifiestan en variaciones significativas con respecto al clima descrito para la zona climática genérica. Así se se considera Zaragoza, situada en la rivera de un rio caudaloso.

Dentro de estas localizaciones se estudian ubicaciones que, en general, se pueden considerar incluidas en un microclima urbano.

\section{MICROCLIMA URBANO}

La observación del clima local en la zona de influencia urbana hace patente la dualidad entre la similitud en la evolución de sus valores y sus diferencias con respecto al clima local de la zona. Mientras que una visión comparada del territorio identifica el clima como homogéneo, la observación cotidiana y las costumbres de sus habitantes en el uso de la ciudad hacen que sus diferentes zonas se frecuenten más o menos en función del periodo del año, del día o de la actividad.

Solanas, umbrías, corredores ventosos o al abrigo, zonas más húmedas o secas se distribuyen en función de la conjunción de factores análogos a los descritos para la formación de microclimas pero que ahora están insertos dentro de otro microclima. 
Las estaciones meteorológicas próximas a los núcleos urbanos permiten observar estos patrones que, siguiendo las denominaciones clásicas, podrían corresponderse con un microclima urbano.

Las diferencias entre los valores obtenidos en las estaciones no suelen ser significativas para el objetivo que se pretende, ya que tienen valores análogos. Tanto sus oscilaciones térmicas diarias, como los periodos de máximas y mínimas y las temperaturas se producen en periodos similares y son de duración también similar. Otros parámetros como la humedad y el viento tienen patrones muy parecidos y la radiación apenas presenta diferencias.

Aun así, estas diferencias tienen consecuencias en el comportamiento higrotérmico del edificio y en su potencial de climatización pasiva.

Las insignificantes diferencias en una escala geográfica son percibidas por sus usuarios como importantes al afectar a su bienestar instantáneo.

Se considera que para esta caracterización del clima en función de la percepción a escala humana en lo que afecta al bienestar y a las edificaciones son importantes valores como la temperatura media, máxima y mínima diaria y por lo tanto la oscilación térmica, combinados con la radiación, el viento y la humedad en estos periodos.

La evolución de estos valores en función de la escala temporal se considera durante un año, ya que en este periodo se repetirán cíclicamente, si no los valores si las tendencias generales, aún con marcadas tendencias temporales en función de la amplitud del periodo considerado.

Estos valores cíclicos y sensiblemente recurrentes se agrupan a su vez en periodos con comportamientos análogos que se denominan como estaciones. Así, verano, otoño, invierno y primavera identifican tanto ciclos biológicos como climáticos.

Pero es importante para nuestro objetivo considerar que la transición entre estaciones está en su propia naturaleza y en cómo cada periodo transita hacia el siguiente. Más allá de poder ser considerados como homogéneos por mantener sus valores, es más correcto caracterizarlos por la evolución de estos valores; su observación siempre manifiesta una tendencia, más que un estado.

Cuando estas tendencias son continuas y evolucionan lentamente permiten una adaptación de metabolísmo, de las costumbres, el arropamiento, la programación de las actividades lo que facilita la sensación de bienestar y se reducen las afecciones a la salud humana.

Las secuencias con altibajos causan el efecto contrario y provocan efectos sobre la salud y el bienestar tanto más acusados cuanto mayor es esta diferencia en la tendencia. 
La evolución de los valores climáticos en un día ofrece una secuencia también cíclica que, siempre que nos mantenemos en climas templados continentales, manifiesta temperaturas máximas en el entorno del inicio del declive solar, mínimas en las primeras horas del día y unas oscilaciones relativamente altas. La presencia de viento, radiación o la aportación de agua a la atmósfera completa la percepción del clima a lo largo del día.

Estos valores diarios comparados ofrecen unas correlaciones aparentemente desordenadas, lo cual, sugiere que la relación entre ellos en distintas localizaciones está influida por la evolución del clima, manifestándose con retardo o amortiguado. Se ha considerado esta reacción como fruto de las variaciones de inercia térmica en las distintas ubicaciones de las zonas urbanas puesto que los edificios y la urbanización en general exponen al clima una gran cantidad de materiales de construcción y alojan actividades que disipan al ambiente grandes cantidades de calor.

Así, se puede definir el clima en un lugar determinado por una secuencia de días o por una sucesión de periodos o estaciones o según unas tendencias de evolución distribuidas a lo largo de un año.

Para los objetivos previstos dada la importancia de la percepción en cada momento de los valores térmicos absolutos con influencia en el metabolismo, y de los relativos con influencia en la capacidad de adaptación, se han considerado dos secuencias de estudio. Por una parte los días tipo y por otra las secuencias de varios días, distribuidas a lo largo del año.

\section{MICROCLIMA DE PROXIMIDAD}

Un comportamiento climático análogo al observado en el microclima local se puede observar en el entorno próximo del edificio. Lo que aquí se define como microclima de proximidad está directamente condicionado por la influencia de las construcciones, las diferencias climáticas nacen con el edificio y los valores dependen de su diseño, construcción y uso.

Las manifestaciones más evidentes hacen referencia a las zonas expuestas al sol y las sombreadas, y a las que están expuestas o no al viento.

El diseño del edificio puede hacer que zonas en principio expuestas al sol estén protegidas de su acción directa y que las expuestas al viento queden en remanso.

La naturaleza de la construcción, que manifiestan los materiales y su disposición en los sistemas constructivos del edificio, identificada por sus valores higrotérmicos según sea su capacidad de acumular, transmitir o repeler el calor o la humedad, colabora con el diseño en que el conjunto del edificio a su vez acumule, transmita o repela el calor y la humedad modificando el microclima a su alrededor.

Se podría simplificar la definición del microclima de proximidad identificándolo con la evolución de los valores climáticos en cada uno de los espacios contiguos al edificio. 
La evidencia de la influencia de los entornos urbanos en el clima local, se manifiesta con más intensidad en el entorno próximo del edificio, en parte por la gran variación de su exposición al viento, muy influyente en la convección, y por la radiación, y no es ajeno a la producción de calor por parte de los sistemas activos para el transporte o la climatización.

E. CONDICIONES HIGROTÉRMICAS EN EL EDIFICIO

Los espacios interiores del edificio reflejan, matizados por su naturaleza constructiva y el diseño de los espacios, las condiciones climáticas exteriores y amortiguan o exacerban sus valores.

Los factores que influyen en esta corrección de las temperaturas son la inercia térmica de los elementos constructivos que circundan los espacios y su localización, la ventilación, la radiación entrante y la humedad, estando todos ellos relacionados entre si con influencias mutuas. 


\subsubsection{ESCALA TEMPORAL}

\section{A. DISCRETIZACIÓN DE LOS DATOS}

Se han elegido secuencias de temperaturas horarias, análogamente a las secuencias suministradas como climas de apoyo a la normativa en vigor y a las recomendaciones internaciones.

Los valores horarios están en Tiempo Universal Coordinado (UTC) y los valores de temperatura son los obtenidos en la hora de referencia, de forma que la temperatura indicada a una hora determinada es el valor registrado a esta hora. Obsérvese que los valores indicados para una hora determinada en las series térmicas de referencia, la temperatura es la convenida para el momento central del periodo horario para el que se define. Al no tener sentido la comparación puntual entre los valores estimados y los valores registrados a una hora determinada no se plantea ningún conflicto significativo.

Sin embargo, la contabilidad del número de días o franjas horarias en las que se producen determinados rangos de temperaturas si pueden ofrecer datos diferentes en función de la forma de asignar las temperaturas a los periodos horarios, por lo que deben considerase 25 valores horarios en un día para establecer los valores medios diarios o la asignación de los días a los rangos establecidos.

En ocasiones, durante una hora se registran varios valores, recogiendo la temperatura frecuentemente cada 10 o 20 minutos. En este caso se establece la temperatura horaria a partir del valor promedio o la mediana de las temperaturas registradas durante este periodo.

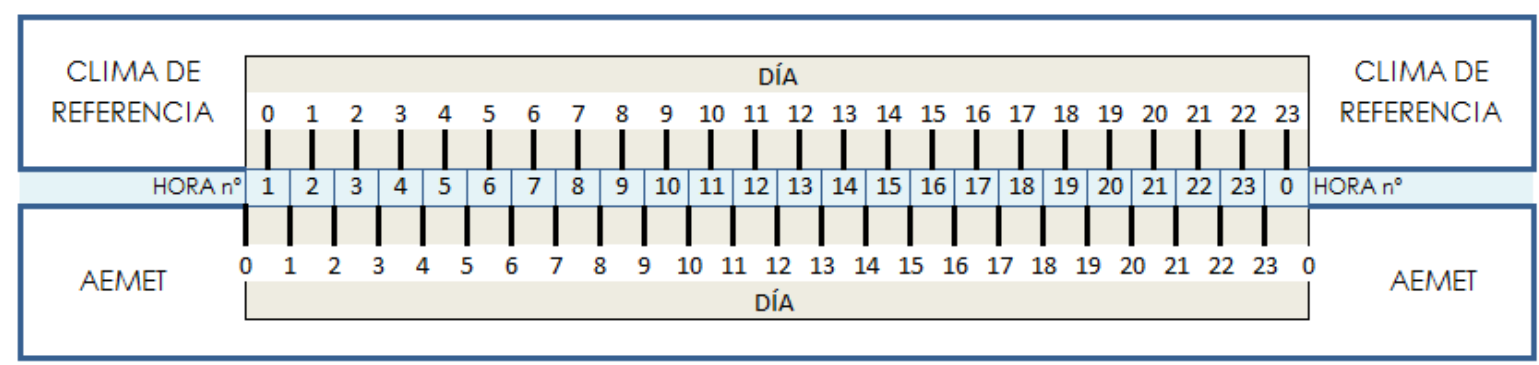

FIG 6-2 RELACIÓN ENTRE LOS PERIODOS HORARIOS DEL DÍA Y LA ASIGNACIÓN DE TEMPERATURAS A CADA PERIODO EN LOS CLIMAS DE REFERENCIA Y EN LOS ARCHIVOS DE AEMET. (ELABORACIÓN PROPIA)

En general las series térmicas obtenidas requieren ser armonizadas al emplearse valores horarios tanto en Tiempo Universal Coordinado (UTC), como en Hora Media de Greenwich (GTM) y horas oficiales corregidas por el horario de verano (Daylight saving time (DST)).

También pueden encontrarse distintos formatos y tipos de presentación que han requerido elaborar cuadros que faciliten la comparación entre las temperaturas horarias. 


\section{B. PERIODOS CONSIDERADOS EN LOS ESTUDIOS DE CASO}

Se realiza la comparación en un ciclo anual completo para establecer las diferencias de conjunto entre las estaciones y posteriormente se seleccionan aquellos periodos significativos por manifestar diferencias mayores entre ellas y considerar importante su influencia en la edificación.

Los datos comparables entre las estaciones datan, en muchos casos, sólo desde 2013 y en ocasiones las estaciones meteorológicas de referencia disponen de registros discontinuos. Al ser necesario observar un ciclo anual, se ha optado por comparar las estaciones meteorológicas con registros suficientes desde el año 2004.

Para comparar los datos obtenidos en las estaciones meteorológicas se ha procedido a la observación comparada de los valores absolutos y medios anvales determinados a partir de valores horarios, los grados-hora $(\mathrm{GH})$ en diferentes bases, percentiles y periodos en que se producen las superaciones de umbrales.

\section{SERIES CLIMÁTICAS PARA LA EDIFICACIÓN}

La aplicación del clima a la edificación será tanto más eficaz cuanto más directa sea la influencia de las series climáticas en las condiciones higrotérmicas interiores a los edificios y en el bienestar higrotérmico.

Para ello se ha procedido a estudiar la relación entre las condiciones climáticas exteriores y las interiores, en espacios no climatizados, como indicador de la reacción de los edificios a las condiciones exteriores, la cual podrá ser utilizada para establecer la influencia del clima en cada periodo.

Por otra parte, para su aplicación al bienestar higrotérmico, es imprescindible asegurar que las oscilaciones de los valores climáticos no superan los umbrales entre los que éste se mantiene. Por ello se ha elegido una escala temporal horaria en la que no es frecuente que se manifiesten fuertes oscilaciones y que concuerda con las bases de datos empleadas para la simulación higrotérmica y la justificación del cumplimiento de la normativa.

Los valores horarios reflejan variaciones relativamente pequeñas que al ser consideradas para periodos mayores se incrementan progresivamente. Por ejemplo, cuando se compara un clima de referencia, como es el correspondiente a la zona climática D3 del CTE, con la realidad en un periodo de 10 años (2005 a 2014), se observa que los valores medios son muy similares en todos los periodos observados mientras que sí se producen variaciones significativas en las máximas (9\%), mínimas (30\%) y en las oscilaciones térmicas (26\%).

La conjunción de la influencia en el edificio y su definición horaria y su análisis pormenorizado justifica la elección de periodos su análisis pormenorizado justifica la eleco
significativos para la que deben considerarse: 
1. El valor absoluto de los datos climáticos obtenidos tanto exteriores como interiores.

2. La estación climática en la que estos valores se producen.

3. La relación de los valores absolutos con los anteriores y posteriores, dentro de cada estación climática.

4. La relación entre la magnitud y la evolución de los valores climáticos interiores y exteriores. 


\subsection{TIPOS DE SERIES CLIMÁTICAS Y PARÁMETROS SIGNIFICATIVOS}

El procedimiento habitual de analizar la respuesta del edificio al clima se apoya en valores climáticos medios o críticos estimados a partir de series temporales suficientemente largas y aplicadas a una escala geográfica amplia.

La facilidad de aplicación por la vía de la clasificación de los climas en un número de tipos o clases reducida donde puedan estar representadas la mayor parte de las condiciones atmosféricas a las que se verán sometidos los edificios presenta múltiples ventajas prácticas, tanto desde el punto de vista del legislador, como de los técnicos que utilizan estos tipos climáticos para el diseño y el dimensionamiento en la edificación de espacios, envolventes o sistemas activos que hagan posible la aclimatación a las condiciones del usuario. Constituyen lo que se ha venido denominando como clima asignado por la normativa a una determinada localización o clima normativo, que también denominaremos como clima de referencia.

Si se busca que la caracterización climática sirva para el diseño de elementos o sistemas del edificio se recurre frecuentemente a la consideración de valores medios, estimados, extremos o significativos (de cálculo) obtenidos de los climas reales a lo largo del año, normalmente representados por sus valores horarios y basados en los datos recogidos por una estación meteorológica próxima o virtual. Estos valores pueden establecerse como máximos, mínimos, medios o extremos en el lugar donde se sitúa o situará el edificio, limitando la imprecisión en la escala geográfica y afectando a una escala temporal tan amplia como requiera el objetivo de la simulación.

Este análisis de la respuesta extendido a todo un año supone un gran esfuerzo, especialmente cuando se comprueba la respuesta de estrategias de diseño diferentes y las diferentes combinaciones que pueden hacerse entre ellas.

Esto sugiere la definición de un número limitado de periodos cuyas condiciones climáticas sirvan para el análisis de la respuesta del edificio de modo que permita ajustar mejor las distintas variables de diseño con una estimación de la respuesta más precisa, sin extender el estudio a todo el año.

La duración de estos periodos estará limitada por la naturaleza dinámica de la respuesta al clima del edificio, por lo que no serán demasiado cortos, y por la homogeneidad de la respuesta dinámica, por lo que tampoco deben ser demasiado largos.

La respuesta dinámica estará más influida por las condiciones precedentes cuanta mayor inercia higrotérmica manifieste el edificio y, por lo tanto, no sólo dependerá del clima sino que, sobre todo, estará condicionado por la forma en la que el edificio esté diseñado y construido. 
Se han considerado edificaciones convencionales en los climas templados de nuestro entorno con construcciones de fábrica de no menos de $100 \mathrm{~kg} / \mathrm{m}^{3}$ ni más de $1000 \mathrm{~kg} / \mathrm{m}^{3}$, lo que hubiera supuesto grandes diferencias con construcciones ligeras, como son las de estructura de madera o perfiles metálicos y paneles ligeros de madera o yeso laminado, en las que pueden darse valores muy inferiores y con las construcciones pesadas, como pueden ser las de cantería o las que tienen mucha superficie de contacto con el terreno natural, con ventilaciones medias y estanqueidades altas.

Los estudios de caso que se consideran pertenecen a obras de fábricas sin superficies en contacto con el terreno natural y con densidades medias.

Aunque el presente trabajo se circunscriba a los aspectos térmicos del clima, en una primera aproximación se revisarán también en cada una de las localizaciones elegidas el viento, la radiación y la humedad.

Los datos correspondientes a las estaciones meteorológicas se complementarán con los obtenidos junto a los edificios.

De este modo se considerarán las gráficas anuales elaboradas para dar una imagen de las condiciones climáticas que afectan más significativamente al edificio:

Viento

Se recoge la velocidad del viento en una zona despejada y en unas condiciones meteorológicas estándar, suficientemente alejada de obstrucciones. Los datos se expresan en $\mathrm{m} / \mathrm{s}$, normalmente en el eje secundario situado a la derecha de los gráficos. Las zonas próximas a los edificios, normalmente tienen fuertes turbulencias que suman a las condiciones comunes a la capa límite las debidas a las obstrucciones que provocan los edificios y el doble efecto de evitar el paso del aire por unas zonas y el de concentrarlo en otras.

\section{Radiación}

Se recoge la radiación en una zona despejada y en unas condiciones meteorológicas estándar, suficientemente alejada de obstrucciones. Los datos se expresan en $\mathrm{W} / \mathrm{m}^{2}$ cuando son horarios mientras que si están acumulados por días, meses o años se hace en $\mathrm{Kw} / \mathrm{m}^{2}$. Cuando se recurre a datos indirectos obtenidos a partir de la radiación teórica estimada, afectada de la ocultación solar, se indica expresamente.

Humedad

Se recoge la humedad relativa en el lugar donde se realiza la determinación, ya sea la estación meteorológica, el entorno próximo al edificio o el interior de los espacios. Los datos se expresan en $\%$. 
Temperatura

Se recoge la temperatura del aire junto a los paramentos a una altura de 1,90 metros aproximadamente en interiores, fundamentalmente para realizar los registros sin afectar a la actividad.

Los valores se recogen en tablas ordenadas por fechas y horas oficiales a partir de los datos horarios, independientemente de la escala temporal de trabajo. Los datos horarios medidos se elaboran como valores medios a partir de los datos recibidos con una periodicidad de 3 minutos aproximadamente.

En general se usan curvas de regresión para indicar la evolución de las series térmicas. Muy pocas veces tiene más utilidad que la meramente informativa pero se ha optado por utilizarlas, indicando su varianza.

En todos los casos se han estudiado las formulaciones que resultan más eficaces al objetivo que se ha propuesto. Por ejemplo, en el caso de la empleada para el día 10-06-2013. Se ha elegido entre diferentes tipos de tendencia o regresión polinómica:

1. OPCIÓN 1: Ecuación polinómica de cuarto orden:

$$
\begin{gathered}
-0,000004 x^{4}-0,005 x^{3}+0,1901 x^{2}-1,4553 x+18,003 \\
\left(R^{2}=0,9850\right)
\end{gathered}
$$

2. OPCIÓN 2: $\quad$ Ecuación polinómica de tercer orden:

$$
\begin{gathered}
-0,0052 x^{3}+0,1932 x^{2}-1,4736 x+18,03 \\
\left(R^{2}=0,9850\right)
\end{gathered}
$$

3. OPCIÓN 3: $\quad$ Ecuación polinómica de segundo orden:

$$
\begin{array}{r}
-0,003 x^{2}+05283 x+13,439 \\
\left(R^{2}=0,8319\right)
\end{array}
$$

4. OPCIÓN 4: $\quad$ Ecuación lineal:

$$
\begin{aligned}
& +0,4541 x+13,761 \\
& \left(R^{2}=0,8305\right)
\end{aligned}
$$

Se opta por la opción 1, por ajustarse mejor a la curva existente. 


\subsubsection{EL CLIMA EN LA LEGISLACIÓN APLICADA A EDIFICACIÓN}

La aplicación del clima a la climatización de la edificación está regulada para garantizar la satisfacción de las demandas energéticas del usuario. Para ello se limita el consumo máximo (CTE $\mathrm{HE}$ 0) y la demanda energética del edificio (CTE-HE 1) se establecen los valores mínimos del rendimiento de las instalaciones y equipos (CTE-HE 2 o RITE) y la aportación que deben hacer las energías renovables (CTE HE 4 y HE 5).

La aplicación de esta regulación se apoya en climas sintéticos de referencia regionalizados en función de las condiciones climáticas en periodos cálidos, denominados como de verano, y periodos fríos, denominados como de invierno.

“ Los edificios dispondrán de una envolvente de características tales que limite adecuadamente la demanda energética necesaria para alcanzar el bienestar témico en función del clima de la localidad, del uso del edificio y del régimen de verano y de inviemo, así como por sus caractenísticas de aislamiento e inercia, permeabilidad al aire y exposición a la radiación solar, reduciendo el riesgo de aparición de humedades de condensación superficiales e intersticiales que puedan pejudicar sus características y tratando adecuadamente los puentes térmic os para limitar las pérdidas o ganancias de calor y evitar problema s higrotérmic os en los mismos."

15.1 Exigencia básica HE 1: Limitación de la demanda energética

“ La determinación de zonas climáticas, para localidades que dispongan de registros climátic os contrastados, se obtendrá a partir del cálculo de las severidades climátic as de inviemo y de vera no para dic haslocalidades."

Apéndice D Zonasclimáticas

D.2 Determinación de la zona climática a partir de registros climátic os

Apartado 1 DBHE

Real Decreto 314/2006 de 17 de marzo (BOE 28-marzo-2006)

La aplicación del clima a la edificación se realiza a través de parámetros significativos. Denominadas como solicitaciones exteriores de cálculo, se establecen como datos climáticos determinantes la temperatura seca, la humedad relativa y la irradiancia solar sobre plano horizontal, haciéndose mención también de otros datos climáticos como son la temperatura efectiva del cielo, la irradiancia solar directa, la irradiancia solar difusa, la humedad específica, el azimut solar y el cénit solar (IDAE, 2015, pág. 7). Así se forman los climas de referencia generados con CLIMED 1.3 a partir de los datos climáticos del Instituto Nacional de Meteorología para cada una de las capitales de provincia, Ceuta y Melilla y los 12 archivos correspondientes a las 12 zonas climáticas que incluyen también la dirección y velocidad del viento (IDAE, 2009, pág. 7 a 9).

Para facilitar la comparación de los valores recogidos en los distintos climas de referencia se han empleado rangos o niveles en función de la influencia de cada uno de los parámetros considerados en la edificación. 


\section{MARCO NORMATIVO}

La edificación en general es una actividad fuertemente regulada por la administración al considerarse la habitabilidad de los edificios una necesidad básica y, por lo tanto, necesitada de protección. Tanto en el ámbito común europeo:

“la creación arquitectónica, la calidad de las construcciones, su inserción armoniosa en el entomo, el respeto de los paisajes naturales y urbanos, así como del patrimonio colectivo y privado, revisten un interés público".

Directiva 85/384/CEE de la Unión Europea

como en el ámbito nacional:

“la necesidad, por una parte,...(ordenar) la construcción de los edificios, y
de superar, por otra, la discrepancia existente entre la legislación vigente y
la realidad por la insuficiente regulación actual del proceso de la
edific ación, así como de establecer el marco general en el que pueda
fomentarse la calidad de los edificios y, por último, el compromiso de fijar las
garantías suficientes a losusuariosfrente a los posibles daños".

Ley 38/1999, de 5 de noviembre, de Ordenación de la Edific ación.

Dentro de esta regulación la respuesta eficiente al clima local de los edificios es uno de los requisitos básicos que afectan a las condiciones de habitabilidad de la edificación frente al clima, focalizándolo hacia el ahorro de energía:

"Ahorro de energía y aislamiento térmico, de forma que se consiga un uso racional de la energía necesaria para la adecuada utilización del edificio"

art. 3. Requisitos bá sic os de la edific ación, apartado 1. Subapartado c Relativosa la habitabilidad número 3. Ley 38/1999, de 5 de noviembre, de Ordenación de la Edificación.

Las exigencias básicas que permiten el cumplimiento de este requisito se regulan en el Código Técnico de la Edificación, en adelante CTE, con una voluntad expresa de armonizar la legislación con las disposiciones de la Unión Europea en esta materia mediante un enfoque basado en prestaciones, frente al enfoque tradicional prescriptivo, en aras a facilitar la inclusión de innovaciones y la apertura a mercados globales de productos de construcción (RD 314, 2006).

Los apartados en los que se recogen estas exigencias son los que abordan el ahorro de energía, denominados como HE, en sus apartados HE 0 sobre la limitación del consumo energético, HE 1 sobre la limitación de la demanda energética, HE 2 sobre el rendimiento de las instalaciones térmicas, también denominado Reglamento de Instalaciones Térmicas de los Edificios, en adelante RITE, en la terminología de la Secretaría de Estado para la Energía, de la Dirección General de Política Energética y Minas del Ministerio de Industria, Energía y Turismo, que elabora los planes de acción estratégica de ahorro y eficiencia energética en España y los planes de fomento de las energías renovables, las exigencias de seguridad de las instalaciones térmicas en los edificios y se ocupa de la armonización en el ámbito del rendimiento de las instalaciones térmicas, así como de la armonización de las disposiciones europeas, como es el caso de la Directiva 2002/91/CE y la Directiva 2010/31/UE del Parlamento Europeo y del Consejo de 19 de mayo de 2010, relativa a la eficiencia energética 
de los edificios, HE 3 sobre eficiencia energética de las instalaciones de iluminación, HE 4 sobre la contribución solar mínima de agua caliente sanitaria y HE 5 sobre contribución fotovoltaica mínima de energía eléctrica.

La naturaleza del objetivo de la exigencia de "ahorro de energía", hace necesarias posteriores aclaraciones en este epígrafe y sus sub-epígrafes, aclarando que se refiere a la consecución de la exigencia de mantener un ambiente higrotérmico adecuado a la naturaleza, condiciones y actividad de los usuarios de los edificios.

También se aplica el concepto de ahorro, y por extensión, el de la necesidad de considerar el clima al estimar las condiciones del edificio para satisfacer la demanda de bienestar higrotérmico, de un modo inclusivo, afectando al proyecto, construcción, uso y mantenimiento.

De estas exigencias energéticas a la edificación se consideran aquellas que colaboran con el bienestar higrotérmico, en concreto expuesta en los apartados HE 0, HE 1 y HE 2, en los que se establece de una forma explícita la consideración de las condiciones climáticas locales para establecer las prestaciones que se exigen al edificio.

Las exigencias básicas se recogen en el DB-HE, del CTE, que se ocupa de asegurar la satisfacción de las necesidades básicas y la superación de los niveles mínimos de calidad propios del requisito básico del ahorro de energía.

Art. 15 sobre la exigencia básica HE 5, apartados 1 al 3

En el documento HE 0 , sobre la caracterización y cuantificación de la exigencia de ahorro de energía, se establece que el consumo energético de los edificios se limitará en función de la zona climática de su localidad de ubicación y del uso previsto.

Art. 2.1 HEO. CTE Orden FOM / 1635/2013 del 10 de septiembre por el que se actualiza el Documento Básico DB-HE (BOE 12-septiembre-2013)

La limitación de la demanda energética, que recoge la exigencia básica HE 1, establece que la envolvente de los edificios deberá diseñarse para alcanzar el bienestar térmico en función del clima de la localidad, y de otras circunstancias, como son el uso del edificio, el régimen de verano y de invierno, las características de aislamiento e inercia, la permeabilidad al aire, la exposición a la radiación solar y limitando la influencia de los puentes térmicos y la posibilidad de condensaciones superficiales e intersticiales.

Art. 15.1 sobre la exigencia básica HE 1: Limitación de la demanda energética.

La regulación del rendimiento de las instalaciones térmicas en el edificio, a que hace referencia la exigencia básica HE 2, se regula en el RITE. Como exigencia técnica de las instalaciones térmicas se establece, entre otras, la obtención de de la calidad térmica del ambiente:

“Calidad térmica del ambiente: las instalaciones témicas permitirán mantener los parámetros que definen el ambiente térmico dentro de un 
intervalo de valores determinados con el fin de mantener unas condiciones a mbientalesconfortables para losusuarios de los edific ios."

art. 11 Bienestare Higiene, Real Decreto 1027/2007, de 20 de julio, porel que se aprueba el

Reglamento de Instalaciones Témicas en los Edificios.

Otra de las exigencias técnicas es la eficiencia energética, empleada en el texto como sinónimo de rendimiento máximo de los equipos de generación de calor y frio, lo que permitirá un menor consumo de energía y la reducción de las emisiones de gases de efecto invernadero, y otros contaminantes atmosféricos. Así mismo se sugiere en el citado Reglamento el empleo de energías renovables y la recuperación de energía. Todo ésto en el contexto de la consecución del rendimiento energético máximo de los equipos en cualquier condición de funcionamiento. El cálculo debe realizarse por algún procedimiento reconocido.

Art. 17 Memoria Técnica, a partado c. sobre el cálculo de la potencia térmica

Alguno de estos procedimientos reconocidos mantienen la caracterización climática definida en el CTE para la severidad climática de invierno, estableciéndose los valores máximos y mínimos en percentiles próximos al $99 \%$ y al $1 \%$ de los valores máximos y mínimos respectivamente.

Guía técnica de condiciones climáticas exteriores de proyecto 2010 ATECYR. IDAE Comentarios al Reglamento de instalaciones témicas en los edificios (RITE-2007) 2007 ATECYR. IDAE

Apart. 2.3 Guía técnica para el diseño y cálculo del a isla miento térmico de conducciones, a paratos y equipos. ATECYR. IDAE

Apart 3, 4 y Anexos Prestaciones medias estacionales de las bombas de calor para producción de calor en edificios. 2014. IDAE Guía técnica de instalaciones de climatización poragua

En su Instrucción Técnica, a partir de ahora IT, número 1.2 sobre la exigencia de eficiencia energética, se indica expresamente la necesidad de considerar los sistemas que sean viables técnica, medioambiental y económicamente, en clara referencia a la definición convencional de desarrollo sostenible, aunque obviando la viabilidad social, en función del clima y de las características del edificio y de su entorno.

El resto de las exigencias básicas, aun considerando valores climáticos para sus determinaciones, no se relacionan directamente con el bienestar higrotérmico, estableciendo las condiciones para el bienestar lumínico (HE 3), y las posibles contribuciones de energías renovables solares a la disponibilidad de energía para agua caliente sanitaria (HE 4) o a la energía eléctrica fotovoltaica (HE 5).

La aplicación del clima a la legislación para la definición de las cualidades de los edificios sigue las directrices generales y las recomendaciones comunes a la Unión europea, por regulación nacional y por los procedimientos regionales y locales.

El marco normativo a que deben someterse las actuaciones en materia de climatización en edificación muestra la complejidad en 
aplicar esta regulación y la posibilidad de la existencia de solapes y de una regulación excesiva.

\section{DIRECTRICES COMUNES EU}<smiles>C1=CC=C1</smiles>

\section{LEGISLACIÓN NACIONAL}

\section{LEGISLACIÓN REGIONAL}

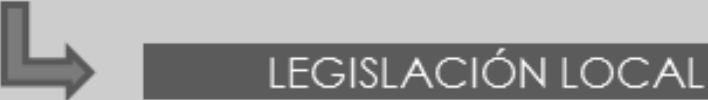

FIG 6-3 ESQUEMA DE LA SECUENCIA DE PRELACIÓN EN LAS REGULACIONES PARA EDIFICACIÓN (ELABORACIÓN PROPIA)

En resumen, el clima es tenido en cuenta en la regulación condicionando la construcción de los edificios de modo que la climatización interior permita satisfacer las necesidades de bienestar manteniendo un ambiente higrotérmico adecuado a las necesidades y demandas de sus usuarios. 


\section{E. APLICACIÓN EN EDIFICACIÓN}

La aplicación de los climas normativos a la edificación se concreta en tres niveles; la limitación de la demanda energética, la configuración y composición del edificio y las necesidades de aportación y disipación de energía para alcanzar unas condiciones confortables en su interior.

\section{El LIMITACIÓN DE LA DEMANDA ENERGÉTICA}

La limitación del consumo energético se aplica a edificios de nueva construcción y a las ampliaciones de edificios existentes y está recogida en la sección HE 0 del CTE.

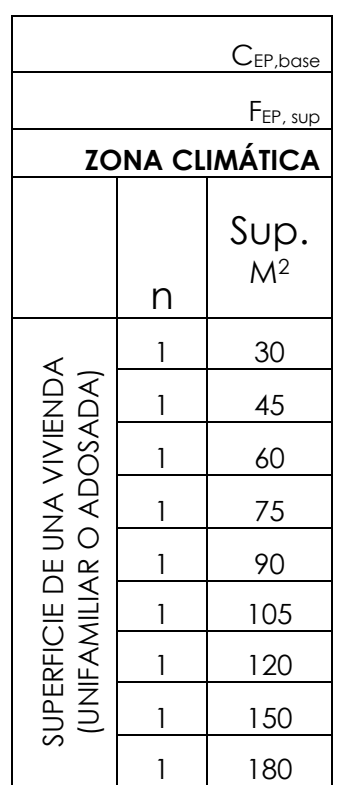

\begin{tabular}{|c|c|c|c|c|c|}
\hline 40 & 40 & 45 & 50 & 60 & 70 \\
\hline 1000 & 1000 & 1000 & 1500 & 3000 & 4000 \\
\hline a & A & B & C & D & E \\
\hline \multicolumn{6}{|c|}{$\begin{array}{c}C_{E P, \lim }=C_{E P, \text { base }}+\left(F_{E P, \text { sup }} / S\right) \\
K W \cdot h / m^{2} \cdot \text { año }\end{array}$} \\
\hline 73,33 & 73,33 & 78,33 & 100,00 & 160,00 & 203,33 \\
\hline 62,22 & 62,22 & 67,22 & 83,33 & 126,67 & 158,89 \\
\hline 56,67 & 56,67 & 61,67 & 75,00 & 110,00 & 136,67 \\
\hline 53,33 & 53,33 & 58,33 & 70,00 & 100,00 & 123,33 \\
\hline 51,11 & 51,11 & 56,11 & 66,67 & 93,33 & 114,44 \\
\hline 49,52 & 49,52 & 54,52 & 64,29 & 88,57 & 108,10 \\
\hline 48,33 & 48,33 & 53,33 & 62,50 & 85,00 & 103,33 \\
\hline 46,67 & 46,67 & 51,67 & 60,00 & 80,00 & 96,67 \\
\hline 45,56 & 45,56 & 50,56 & 58,33 & 76,67 & 92,22 \\
\hline
\end{tabular}

\begin{tabular}{|c|c|c|}
\hline \multirow{15}{*}{ 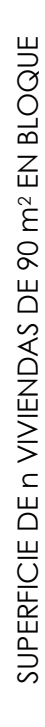 } & 2 & 180 \\
\hline & 4 & 360 \\
\hline & 6 & 540 \\
\hline & 8 & 720 \\
\hline & 10 & 900 \\
\hline & 20 & 1800 \\
\hline & 30 & 2700 \\
\hline & 40 & 3600 \\
\hline & 50 & 4500 \\
\hline & 100 & 9000 \\
\hline & 200 & 18000 \\
\hline & 300 & 27000 \\
\hline & 400 & 36000 \\
\hline & 500 & 45000 \\
\hline & 1000 & 90000 \\
\hline & $A C$ & МÁTICA \\
\hline
\end{tabular}

\begin{tabular}{|cc|cc|c|c|c|}
\hline 45,56 & 45,56 & 50,56 & 58,33 & 76,67 & \multirow{2}{*}{92,22} \\
\cline { 1 - 1 } 42,78 & 42,78 & 47,78 & 54,17 & 68,33 & 81,11 \\
\cline { 1 - 1 } 41,85 & 41,85 & 46,85 & 52,78 & 65,56 & 77,41 \\
41,39 & 41,39 & 46,39 & 52,08 & 64,17 & 75,56 \\
41,11 & 41,11 & 46,11 & 51,67 & 63,33 & 74,44 \\
40,56 & 40,56 & 45,56 & 50,83 & 61,67 & 72,22 \\
40,37 & 40,37 & 45,37 & 50,56 & 61,11 & 71,48 \\
40,28 & 40,28 & 45,28 & 50,42 & 60,83 & 71,11 \\
40,22 & 40,22 & 45,22 & 50,33 & 60,67 & 70,89 \\
40,11 & 40,11 & 45,11 & 50,17 & 60,33 & 70,44 \\
40,06 & 40,06 & 45,06 & 50,08 & 60,17 & 70,22 \\
40,04 & 40,04 & 45,04 & 50,06 & 60,11 & 70,15 \\
40,03 & 40,03 & 45,03 & 50,04 & 60,08 & 70,11 \\
40,02 & 40,02 & 45,02 & 50,03 & 60,07 & 70,09 \\
40,01 & 40,01 & 45,01 & 50,02 & 60,03 & 70,04 \\
\hline \multicolumn{2}{|c|}{ a } & A & B & C & D & E \\
\hline
\end{tabular}

FIG 6-4 DEMANDA ENERGÉTICA MÁXIMA PERMITIDA EN EL CTE SEGÚN LA ZONA CLIMÁTICA DE INVIERNO Y LA SUPERFICIE DEL EDIFICIO (CTE HEO, APARTADO 2.2.1 Y ELABORACIÓN PROPIA)

Se establece así la máxima energía que podrá consumir el edificio teóricamente en un año por cada metro cuadrado de superficie, en función de la zona climática y su superficie total. 
Si los edificios o las viviendas son muy grandes la exigencia de demanda máxima, expresada en $\mathrm{Kw} \cdot \mathrm{h} / \mathrm{m}^{2}$ y año, es mayor.

La demanda máxima permitida en función de la superficie del inmueble considerando la misma zona climática es, por tanto, variable. Para zonas climáticas con menor severidad climática en invierno, como son las zonas $\alpha$, A, B y C, la demanda permitida es menor, reduciéndose a un porcentaje igual o ligeramente inferior a un $50 \%$, mientras que para la zona climática $D$ la demanda se reduce a un $38 \%$ y para la zona climática $\mathrm{E}$ se reduce a un $34 \%$.

Si se comparan las demandas máximas permitidas se observa que cuando las superficies son muy pequeñas $\left(30 \mathrm{~m}^{2}\right)$ la reducción de la exigencia llega a ser de un $38 \%$ en función de la zona climática, mientras que para una vivienda de $90 \mathrm{~m}^{2}$ de superficie la demanda máxima se llega a reducir a un $45 \%$ y a partir de viviendas o edificios con más de $2900 \mathrm{~m}^{2}$ la exigencia es un $57 \%$ para los climas con menor severidad climática de invierno con respecto a los de mayor severidad climática.

La aplicación de estas zonas climáticas a la limitación del consumo energético de energía primaria no renovable, o asimilable a ella en la proporción que se considere, ya esté destinada a climatización, ACS o iluminación, se materializa en incrementos en los valores que la limitan cuando las zonas climáticas se corresponden con zonas más frías. Para las dimensiones habituales en viviendas sociales, y superficies útiles entre 60 y $120 \mathrm{~m}^{2}$ la influencia del clima en esta limitación puede hacer oscilar estos valores entre $50 \mathrm{Kw} \cdot \mathrm{h} / \mathrm{m}^{2}$ y año y $110 \mathrm{Kw} \cdot \mathrm{h} / \mathrm{m}^{2}$ y año, en función del tamaño y, sobretodo, de la zona climática.

El proceso se concreta en la demanda de energía primaria requerida para disponer de una determinada energía final y en las emisiones de $\mathrm{CO}_{2}$ equivalente.

La limitación de demanda en climatización se determina en el apartado 2.2.1.1.1 del HE 1 del CTE y diferencia la demanda de calefacción y la de refrigeración.

La aplicación de estas zonas climáticas a la limitación de la demanda energética de energía útil no renovable destinada sólo a calefacción, se materializa en incrementos en los valores que la limitan cuando las zonas climáticas se corresponden con zonas más frías. Para las dimensiones habituales en viviendas sociales, y superficies útiles entre 60 y $120 \mathrm{~m}^{2}$ la influencia del clima en esta limitación puede hacer oscilar estos valores entre $15 \mathrm{Kw} \cdot \mathrm{h} / \mathrm{m}^{2}$.año y $70 \mathrm{Kw} \cdot \mathrm{h} / \mathrm{m}^{2}$ y año.

La limitación de la demanda energética de energía útil no renovable destinada sólo a refrigeración está entre $15 \mathrm{Kw} \cdot \mathrm{h} / \mathrm{m}^{2}$ y año y $20 \mathrm{Kw} \cdot \mathrm{h} / \mathrm{m}^{2}$ y año, reservándose esta última limitación para las zona más cálida, como es la zona climática de verano 4.

El límite de demanda para calefacción, se determina por un proceso similar al descrito para la energía final total admisible, aunque con cuantías notablemente menores, como puede verse en la tabla adjunta y que también denota una fuerte diferencia 
entre las distintas zonas climáticas, fundamentalmente entre las más cálidas ( $a, A$ y $B$ ) y las más frías ( $C, D$ y E). Estas diferencias se exacerban cuando las viviendas son individuales o adosadas y cuando las superficies son menores; aumentando la exigencia en más de un $300 \%$ en la zona climática de invierno $E$, en un $200 \%$ en la zona climática de invierno D, en más de un $100 \%$ para la zona climática de invierno $C$ y no modificándose en los climas más cálidos ( $a, A$ y B).

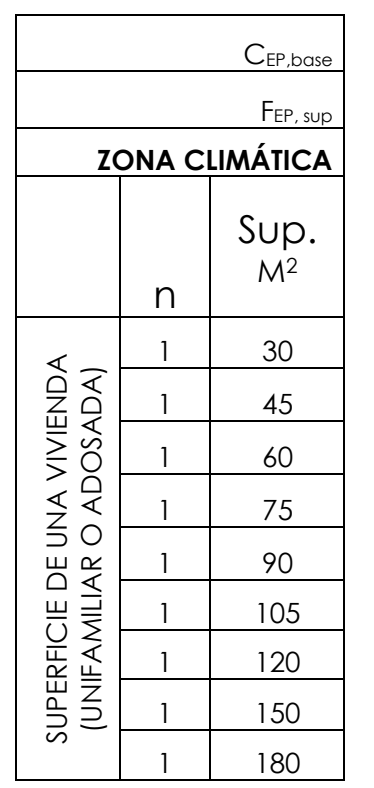

\begin{tabular}{|c|c|c|c|c|c|}
\hline 15 & 15 & 15 & 20 & 27 & 40 \\
\hline 1000 & 1000 & 1000 & 1500 & 3000 & 4000 \\
\hline a & A & B & C & D & E \\
\hline \multicolumn{6}{|c|}{$\begin{array}{c}\mathrm{DCAL}, \mathrm{lim}=\mathrm{D}_{\mathrm{EP}, \mathrm{base}}+\left(\mathrm{F}_{\mathrm{CAL}, \text { sup }} / \mathrm{S}\right) \\
\mathrm{KW} \cdot \mathrm{h} / \mathrm{m}_{2} \cdot \mathrm{Año}\end{array}$} \\
\hline 15,00 & 15,00 & 15,00 & 53,33 & 93,67 & 140,00 \\
\hline 15,00 & 15,00 & 15,00 & 42,22 & 71,44 & 106,67 \\
\hline 15,00 & 15,00 & 15,00 & 36,67 & 60,33 & 90,00 \\
\hline 15,00 & 15,00 & 15,00 & 33,33 & 53,67 & 80,00 \\
\hline 15,00 & 15,00 & 15,00 & 31,11 & 49,22 & 73,33 \\
\hline 15,00 & 15,00 & 15,00 & 29,52 & 46,05 & 68,57 \\
\hline 15,00 & 15,00 & 15,00 & 28,33 & 43,67 & 65,00 \\
\hline 15,00 & 15,00 & 15,00 & 26,67 & 40,33 & 60,00 \\
\hline 15,00 & 15,00 & 15,00 & 25,56 & 38,11 & 56,67 \\
\hline
\end{tabular}

\begin{tabular}{|c|c|c|}
\hline \multirow{15}{*}{ 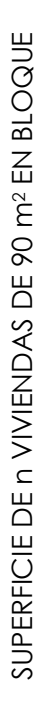 } & 2 & 180 \\
\hline & 4 & 360 \\
\hline & 6 & 540 \\
\hline & 8 & 720 \\
\hline & 10 & 900 \\
\hline & 20 & 1800 \\
\hline & 30 & 2700 \\
\hline & 40 & 3600 \\
\hline & 50 & 4500 \\
\hline & 100 & 9000 \\
\hline & 200 & 18000 \\
\hline & 300 & 27000 \\
\hline & 400 & 36000 \\
\hline & 500 & 45000 \\
\hline & 1000 & 90000 \\
\hline & NAC & MÁTICA \\
\hline
\end{tabular}

\begin{tabular}{|cccc|c|c|c|}
\hline 15,00 & 15,00 & 15,00 & 25,56 & 38,11 & 56,67 \\
& 15,00 & 15,00 & 15,00 & 22,78 & 32,56 & 48,33 \\
15,00 & 15,00 & 15,00 & 21,85 & 30,70 & 45,56 \\
15,00 & 15,00 & 15,00 & 21,39 & 29,78 & 44,17 \\
15,00 & 15,00 & 15,00 & 21,11 & 29,22 & 43,33 \\
15,00 & 15,00 & 15,00 & 20,56 & 28,11 & 41,67 \\
15,00 & 15,00 & 15,00 & 20,37 & 27,74 & 41,11 \\
15,00 & 15,00 & 15,00 & 20,28 & 27,56 & 40,83 \\
15,00 & 15,00 & 15,00 & 20,22 & 27,44 & 40,67 \\
15,00 & 15,00 & 15,00 & 20,11 & 27,22 & 40,33 \\
15,00 & 15,00 & 15,00 & 20,06 & 27,11 & 40,17 \\
15,00 & 15,00 & 15,00 & 20,04 & 27,07 & 40,11 \\
15,00 & 15,00 & 15,00 & 20,03 & 27,06 & 40,08 \\
15,00 & 15,00 & 15,00 & 20,02 & 27,04 & 40,07 \\
15,00 & 15,00 & 15,00 & 20,01 & 27,02 & 40,03 \\
\hline a & A & B & C & D & E \\
\hline
\end{tabular}

FIG 6-5 DEMANDA ENERGÉTICA MÁXIMA PERMITIDA EN EL CTE PARA CALEFACCIÓN SEGÚN LA ZONA CLIMÁTICA DE INVIERNO Y LA SUPERFICIE DEL EDIFICIO (CTE HEl, APARTADO 2.2.1.1 Y ELABORACIÓN PROPIA)

En invierno, para las zonas climáticas más cálidas y edificios pequeños este límite es algo menor de un $20 \%$ del exigido para el total de la energía final. También en invierno para edificios pequeños, en las zonas más frías es aproximadamente un $70 \%$ del total. Esta relación reconoce, como era de esperar, un peso de la demanda en calefacción mayor en los climas más fríos en invierno. 
Cuando el tamaño de los edificios crece esta relación disminuye llegando a ser la máxima demanda permitida para calefacción en invierno en climas más cálidos casi un $40 \%$ de la demanda final permitida para todos los consumos del edificio y en los más fríos de casi un $60 \%$ del total.

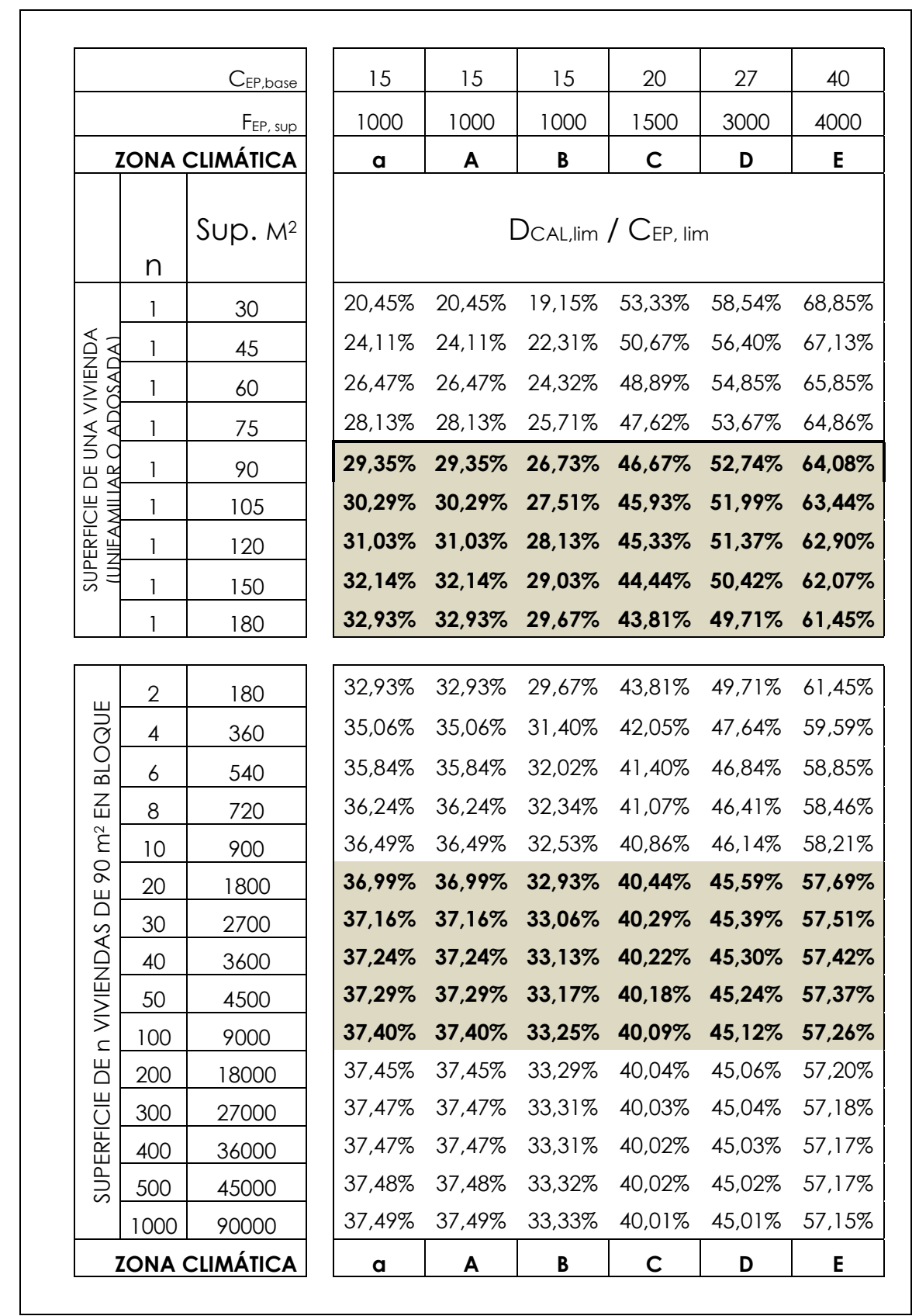

FIG 6-6 RELACIÓN ENTRE LA DEMANDA ENERGÉTICA MÁXIMA PERMITIDA Y LA DEMANDA MÁXIMA PERMITIDA PARA CALEFACCIÓN EN EL CTE SEGÚN LA ZONA CLIMÁTICA DE INVIERNO Y LA SUPERFICIE DEL EDIFICIO (CTE HEI, APARTADO 2.2.1.1 Y ELABORACIÓN PROPIA)

En la tabla de la figura se resalta esta relación en el caso de pequeñas viviendas unifamiliares, donde la relación entre la demanda permitida para calefacción con respecto a la demanda total está en el entorno del $30 \%$ en climas cálidos y entre un $61 \%$ y un $64 \%$ en climas más fríos, es decir más del doble. 
También se muestran estos valores para edificios en bloque usuales en las promociones pequeñas, entre 20 y 100 viviendas, con valores de demanda permitida en calefacción con respecto a la demanda permitida total próxima al $37 \%$ en los climas cálidos y ligeramente superior al $57 \%$ en los climas más fríos.

El cumplimiento de esta exigencia se justifica estimando la demanda y el consumo energético, aportando la administración una herramienta gratuita para realizar esta simulación energética, denominada "Herramienta unificada LIDER-CALENER".

Para realizar la estimación de las demandas en climatización se consideran unas condiciones climáticas definidas por los climas de referencia elaborados para las distintas zonas climáticas, por lo que el cumplimiento efectivo de esta exigencia no sólo dependerá de las cualidades del edificio y de los equipos dispuestos en él, sino también del clima de referencia o normativo elaborado e introducido en la aplicación con la que se sugiere hacer la justificación de su cumplimiento y del patrón de uso predeterminado en la aplicación.

La correcta asignación de los municipios a una determinada zona climática es, por lo tanto, determinante para la estimación de su demanda máxima, aunque más allá de la asignación a una u otra zona climática es de gran interés la configuración concreta que tome el clima de referencia asignado a cada zona climática en el que será simulada la demanda del edificio.

Esto hace necesario el estudio de los climas de referencia para comprobar su adecuación a las condiciones reales existentes en el entorno del edificio en el que se pretende justificar el cumplimiento de no superar la demanda mínima. 


\section{E2 CONFIGURACIÓN Y COMPOSICIÓN DEL EDIFICIO}

También se establecen para el cumplimiento de la exigencia de conseguir una demanda baja de energía en edificación unas limitaciones específicas en las cualidades de los componentes del edificio, descritas en la sección 1 del DB HE, que se concretan en limitar la descompensación de la calidad térmica entre los espacios de la vivienda, la transferencia de calor con el exterior y entre espacios de distinto uso al residencial y la reducción de riesgos de condensación. Estas condiciones se pueden verificar, para cada zona climática comprobando que cada una de las envolventes que se han definido en el edifico, como son los muros, suelos, cubiertas, huecos y las particiones, cumplen con los valores mínimos de transmitancia y permeabilidad al aire.

La zona climática de invierno es el factor fundamental para asignar la limitación de transmitancia térmica en las envolventes del edificio, la permeabilidad al aire de los huecos exteriores y la limitación de la transmitancia térmica en suelos intermedios, medianeras y particiones que separen zonas de uso residencial de zonas de uso común o zonas con otros usos (HE 1, apartado 2.1.1.2).

El procedimiento de justificación de la demanda estimada se realiza comparando el edificio proyectado con un edificio de referencia con la misma forma tamaño, orientación, zonificación interior, uso de cada espacio e iguales obstáculos remotos, con unos parámetros de transmitancia y factor solar de los elementos de la envolvente térmica preestablecidos en función de la zona climática, según se recoge en el apéndice $D$ del HEl del CTE.

En la práctica esto se traduce en exigencias diferentes de transmitancia limite y factor solar modificado límite diferentes para cada zona climática. Como puede verse para la transmitancia de fachadas, cubiertas, suelos y cerramientos opacos en general en la tabla siguiente:

\begin{tabular}{|c|c|c|c|c|c|c|c|}
\hline \multicolumn{3}{|c|}{ ZONA CLIMÁTICA } & $\alpha, \mathrm{A}$ & B & $\mathrm{C}$ & $\mathrm{D}$ & $E$ \\
\hline \multirow{4}{*}{ 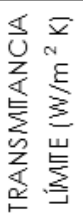 } & MUROS DE FACHADA & \multirow{2}{*}{$\mathrm{U}_{\text {Mlim }}$} & \multirow{2}{*}{0,94} & \multirow{2}{*}{0,82} & \multirow{2}{*}{0,73} & \multirow{2}{*}{0,66} & \multirow{2}{*}{0,57} \\
\hline & CERRAMIENTOS EN CONTACTO CON EL TERRENO & & & & & & \\
\hline & SUELOS (SOBRE ESPACIOS ABIERTOS) & $U_{\text {slim }}$ & 0,53 & 0,52 & 0,50 & 0,49 & 0,48 \\
\hline & CUBIERTAS & $\mathrm{U}_{\text {Clim }}$ & 0,50 & 0,45 & 0,41 & 0,38 & 0,35 \\
\hline
\end{tabular}

FIG 6-7 TRANSMITANCIA LÍMITE EN EL EDIFICIO DE REFERENCIA PARA LA SIMULACIÓN DE DEMANDA MEDIANTE LA HERRAMIENTA PROPUESTA POR EL CTE. (CTE HEI, APENNDICE D2 Y ELABORACIÓN PROPIA)

Esta significa, por ejemplo, que los valores estimados de transmitancia de los elementos constructivos que permiten a un edificio de referencia cumplir las exigencias de demanda se incrementan cuando la zona climática es más fría. También que la influencia en el enfriamiento del edificio es mayor, para las estimaciones realizadas, en cubiertas que en suelos y en muros y cerramientos con el terreno, requiriéndose elementos con casi la mitad de transmitancia térmica en cubiertas que en fachadas o 
cerramientos con el terreno, en todos los climas, aunque con unas reducciones de la transmitancia de un $11 \%$ con cada salto hacia un clima más frío.

Dado que el procedimiento de simulación de la demanda estimada se realiza aplicando un clima de referencia a cada una de las zonas climáticas, se hace patente la importancia de la transferencia de energía por cada una de las envolventes del edificio en relación a la pérdida de energía en periodos fríos.

\begin{tabular}{|c|c|c|c|c|c|c|c|}
\hline \multicolumn{3}{|c|}{ ZONA CLIMÁTICA } & $\alpha, \mathrm{A}$ & $\mathrm{B}$ & $\mathrm{C}$ & $\mathrm{D}$ & $\mathrm{E}$ \\
\hline \multirow{4}{*}{ 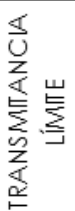 } & MUROS DE FACHADA & \multirow{2}{*}{$\mathrm{U}_{\text {Mlim }}$} & \multirow{2}{*}{$0,00 \%$} & \multirow{2}{*}{$15 \%$} & \multirow{2}{*}{$29 \%$} & \multirow{2}{*}{$42 \%$} & \multirow{2}{*}{$65 \%$} \\
\hline & CERRAMIENTOS EN CONTACTO CON EL TERRENO & & & & & & \\
\hline & SUELOS (SOBRE ESPACIOS ABIERTOS) & $U_{\text {slim }}$ & $0,00 \%$ & $2 \%$ & $6 \%$ & $8 \%$ & $10 \%$ \\
\hline & CUBIERTAS & $\mathrm{U}_{\text {Clim }}$ & $0,00 \%$ & $11 \%$ & $22 \%$ & $32 \%$ & $43 \%$ \\
\hline
\end{tabular}

FIG 6-8 REDUCCIÓN DE LA TRANSMITANCIA LÍMITE EN EL EDIFICIO DE REFERENCIA PARA LA SIMULACIÓN DE DEMANDA MEDIANTE LA HERRAMIENTA PROPUESTA POR EL CTE. (CTE HEI, APENDICE D2 Y ELABORACIÓN PROPIA)

El predimensionado de las soluciones constructivas en uso residencial de los parámetros característicos de la envolvente térmica se puede hacer teniendo en cuenta los valores recogidos en el Apéndice E de la HE 1 del CTE. Para ello es preciso considerar la zona climática de invierno y el tipo de envolvente y, en el caso de los valores para los cerramientos de los huecos, también la captación solar.

Para estimar estos valores se han considerado los puentes térmicos en una proporción semejante al edificio de referencia y edificios de compacidad media, con una superficie de huecos no superior al $15 \%$ de la superficie útil.

Esto significa, en la práctica, que el cumplimento de las condiciones de demanda máxima en calefacción exige adoptar unos valores inferiores de transmitancia en los climas más fríos que los considerados en el edificio de referencia, según se indica en el apéndice E, apartado E2.

Esta reducción se incrementa con la severidad climática de invierno, llegando a ser de entre $338 \%$ al $292 \%$ para los huecos en los climas más fríos y con captaciones solares bajas. Aunque una mejor captación solar puede reducir la minoración de las transmitancias en los huecos y las propuestas de reducción son menores en cubiertas y suelos sobre espacios abiertos, la recomendación es aumentar las exigencias reduciendo en casi todos los casos a más de la mitad las transmitancias recomendadas. 


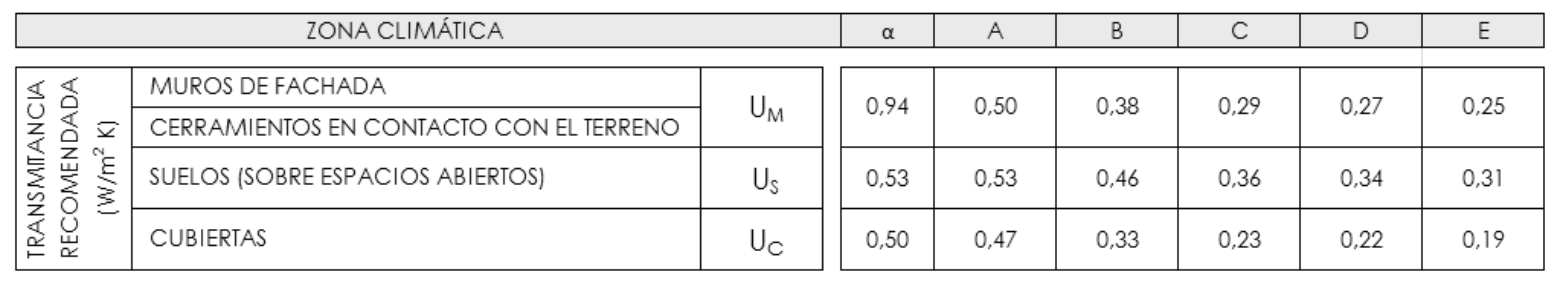

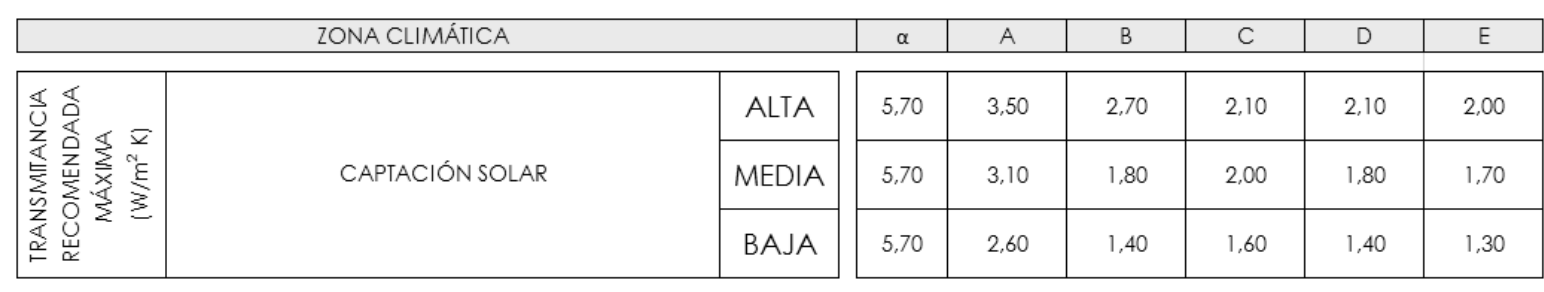

\begin{tabular}{|c|c|c|c|c|c|c|c|c|}
\hline \multicolumn{3}{|c|}{ ZONA CLIMÁTICA } & $\alpha$ & A & B & C & $\mathrm{D}$ & $E$ \\
\hline \multirow{2}{*}{ 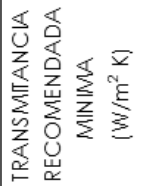 } & \multirow{2}{*}{ CAPTACIÓN SOLAR } & ALTA & 5,50 & 2,60 & 2,10 & 1,90 & 1,80 & 1,90 \\
\hline & & BAJA & 4,70 & 1,80 & 1,40 & 1,20 & 1,20 & 1,20 \\
\hline
\end{tabular}

FIG 6-9 TRANSMITANCIA SUGERIDA PARA PREDIMENSIONADO. (CTE HEI, APENDICE D2 Y ELABORACIÓN PROPIA)

\begin{tabular}{|c|c|c|c|c|c|c|c|c|}
\hline \multicolumn{3}{|c|}{ ZONA CLIMÁTICA } & $\alpha$ & A & B & C & $\mathrm{D}$ & E \\
\hline \multirow{4}{*}{ 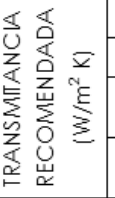 } & MUROS DE FACHADA & \multirow{2}{*}{$\mathrm{U}_{\mathrm{M}}$} & \multirow{2}{*}{$0,00 \%$} & \multirow{2}{*}{$88 \%$} & \multirow{2}{*}{$147 \%$} & \multirow{2}{*}{$224 \%$} & \multirow{2}{*}{$248 \%$} & \multirow{2}{*}{$276 \%$} \\
\hline & CERRAMIENTOS EN CONTACTO CON EL TERRENO & & & & & & & \\
\hline & SUELOS (SOBRE ESPACIOS ABIERTOS) & $U_{S}$ & $0,00 \%$ & $0 \%$ & $15 \%$ & $47 \%$ & $56 \%$ & $71 \%$ \\
\hline & CUBIERTAS & $\mathrm{U}_{\mathrm{C}}$ & $0,00 \%$ & $6 \%$ & $52 \%$ & $117 \%$ & $127 \%$ & $163 \%$ \\
\hline \multicolumn{3}{|c|}{ ZONA CLIMÁTICA } & $\alpha$ & A & B & $\mathrm{C}$ & $\mathrm{D}$ & $\mathrm{E}$ \\
\hline \multirow{3}{*}{ 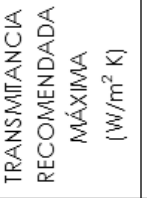 } & \multirow{3}{*}{ CAPTACIÓN SOLAR } & ALTA & $0,00 \%$ & $63 \%$ & $111 \%$ & $171 \%$ & $171 \%$ & $185 \%$ \\
\hline & & MEDIA & $0,00 \%$ & $84 \%$ & $217 \%$ & $185 \%$ & $217 \%$ & $235 \%$ \\
\hline & & BAJA & $0,00 \%$ & $119 \%$ & $307 \%$ & $256 \%$ & $307 \%$ & $338 \%$ \\
\hline \multicolumn{3}{|c|}{ ZONA CLIMÁTICA } & $\alpha$ & A & $\mathrm{B}$ & $\mathrm{C}$ & $\mathrm{D}$ & $E$ \\
\hline \multirow{3}{*}{ 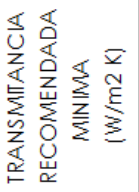 } & \multirow{3}{*}{ CAPTACIÓN SOLAR } & ALTA & $0,00 \%$ & $112 \%$ & $162 \%$ & $189 \%$ & $206 \%$ & $189 \%$ \\
\hline & & MEDIA & $0,00 \%$ & $122 \%$ & $183 \%$ & $219 \%$ & $219 \%$ & $219 \%$ \\
\hline & & BAJA & $0,00 \%$ & $161 \%$ & $236 \%$ & $292 \%$ & $292 \%$ & $292 \%$ \\
\hline
\end{tabular}

FIG 6-10 REDUCCIÓN DE LA TRANSMITANCIA SUGERIDA PARA PREDIMENSIONADO (CTE HEl, APENDICE D2 Y ELABORACIÓN PROPIA)

Con esto se reconoce la importancia de los climas de referencia que se suministran junto a la herramienta de justificación del cumplimiento y lo exigentes que son para climas fríos. 


\section{E3 NECESIDADES DE APORTACIÓN Y DISIPACIÓN DE ENERGÍA}

Para el cumplimiento de la limitación de la demanda será preciso realizar una simulación o estimación de esta demanda. Para hacerlo habrán de considerarse, por un lado, las solicitaciones interiores, como son las cargas térmicas y las condiciones operacionales, como son la ventilación, el perfil de uso y las temperaturas de consigna establecidas. Por otro lado las condiciones exteriores recogen las acciones del clima sobre el edificio.

En este tercer nivel, se establecen las necesidades de aportación o disipación de energía que serán precisas para alcanzar un clima interior confortable. Con ello se determina la cantidad de energía que será preciso emplear para este fin y para estimar costes, emisiones o demandas de energía durante el uso del edificio y, por ende, elegir los sistemas más eficaces para este fin.

Ya se realice con el auxilio de herramientas informáticas o por cálculos directos, el proceso debe equilibrar las entradas y salidas de energía manteniendo la temperatura interior en la temperatura de consigna adecuada para cada uso y para todas las variables de temperatura exterior existentes o para aquéllas que se consideran extremas o probables.

En definitiva la carga térmica total en un recinto o edificio (Q) se obtiene de la siguiente expresión:

$$
Q=Q_{s}+Q_{1}
$$

donde,

$Q_{s}$ es la carga térmica sensible (W);

Qi es la carga térmica latente (W).

Por su parte la carga térmica sensible (Qs) es una agregación de las cargas sensibles procedentes de la radiación solar a través de los huecos, la transmisión y radiación a través de las envolventes exteriores e interiores, la producida por las infiltraciones y a la procedente de las cargas internas:

$$
Q_{s}=Q_{s r}+Q_{s t r}+Q_{s e}+Q_{s i}+Q_{s a}
$$

siendo,

Qsr es el valor de la carga sensible debida a la radiación solar a través de las superficies acristaladas (W);

$Q_{s e}$ es la carga sensible por transmisión y radiación a través de envolventes (W);

$Q_{s t}$ es la carga sensible por transmisión desde los paramentos y huecos interiores (W);

$Q_{\text {si }}$ es la carga sensible transmitida por infiltraciones de aire exterior (W):

$Q_{s a}$ es la carga sensible debida a aportaciones internas (W). 
Salvo el debido a las cargas internas, para conocer estos sumandos es preciso establecer unas temperaturas interiores de consigna o temperaturas interiores de diseño y las temperaturas exteriores que dependerán de los climas de referencia considerados para establecer los consumos y de los valores de temperatura máximos para el dimensionamiento de la instalación y sus equipos.

En este balance influye, por tanto, la capacidad del edificio para captar energía, acumularla y disiparla. 


\section{F. ZONAS CLIMÁTICAS}

Como ya se ha comentado, las zonas climáticas se diseñan en función del concepto denominado por la normativa de aplicación como severidad climática de invierno y de verano, que permite la realización de dos clasificaciones, una para las condiciones climáticas en periodos fríos y otra para las condiciones climáticas en periodos de verano.

Se considera invierno aquella fracción del año natural en que se producen las menores temperaturas, concretada en los meses más fríos, de octubre a mayo. Por su parte, el verano está circunscrito a los cuatro meses más cálidos, desde junio a septiembre, ambos incluidos.

La asignación de las localidades a una determinada zona climática se realiza en función de los grados día en base $20^{\circ} \mathrm{C}$ y a la proporción de horas soleadas para los meses de invierno y de los grados día en base $20^{\circ} \mathrm{C}$ para los meses de verano.

La variabilidad de los datos si es observada en distintos periodos, en las localidades de referencia empleadas, se ha comprobado que es diferente en los periodos fríos, donde no es mayor del $10 \%$, que en los periodos cálidos, en los que supera el 15\%, mientras que los valores medios para varios años igualan aún más los valores reduciendo estas diferencias. por lo que se confirma como un valor con suficiente estabilidad en el tiempo para servir a clasificaciones climáticas.

Esta acción del clima se establece en virtud del clima de referencia asignado a cada zona climática y recogido en la propia norma DB-HE 1.APÉNDICE B, y en documentos reconocidos elaborados por las comunidades autónomas. Estos climas definen las solicitaciones exteriores en términos de temperatura, humedad y radiación solar.

La forma elegida para definir las zonas climáticas afectadas por cada clima de referencia es una distribución administrativa por provincias y por la altitud con respecto al nivel del mar, en cada área geográfica de esta provincia. En la práctica, las viviendas se sitúan mayoritariamente en los núcleos de población $y$, por lo tanto, suele asignarse a cada municipio la zona climática correspondiente a su núcleo de población principal. Aún siendo inexacto sí permite realizar una distribución geográfica orientativa de las zonas climáticas.

Puede observarse que los climas de referencia a nivel del mar son relativamente benignos, mientras que los situados a más altitud se corresponden con altas severidades climáticas de invierno.

Particularmente significativos son aquellas localidades con alta severidad climática de verano e invierno (D3) donde el edificio debe responder a periodos cálidos y periodos fríos muy contrastados. 


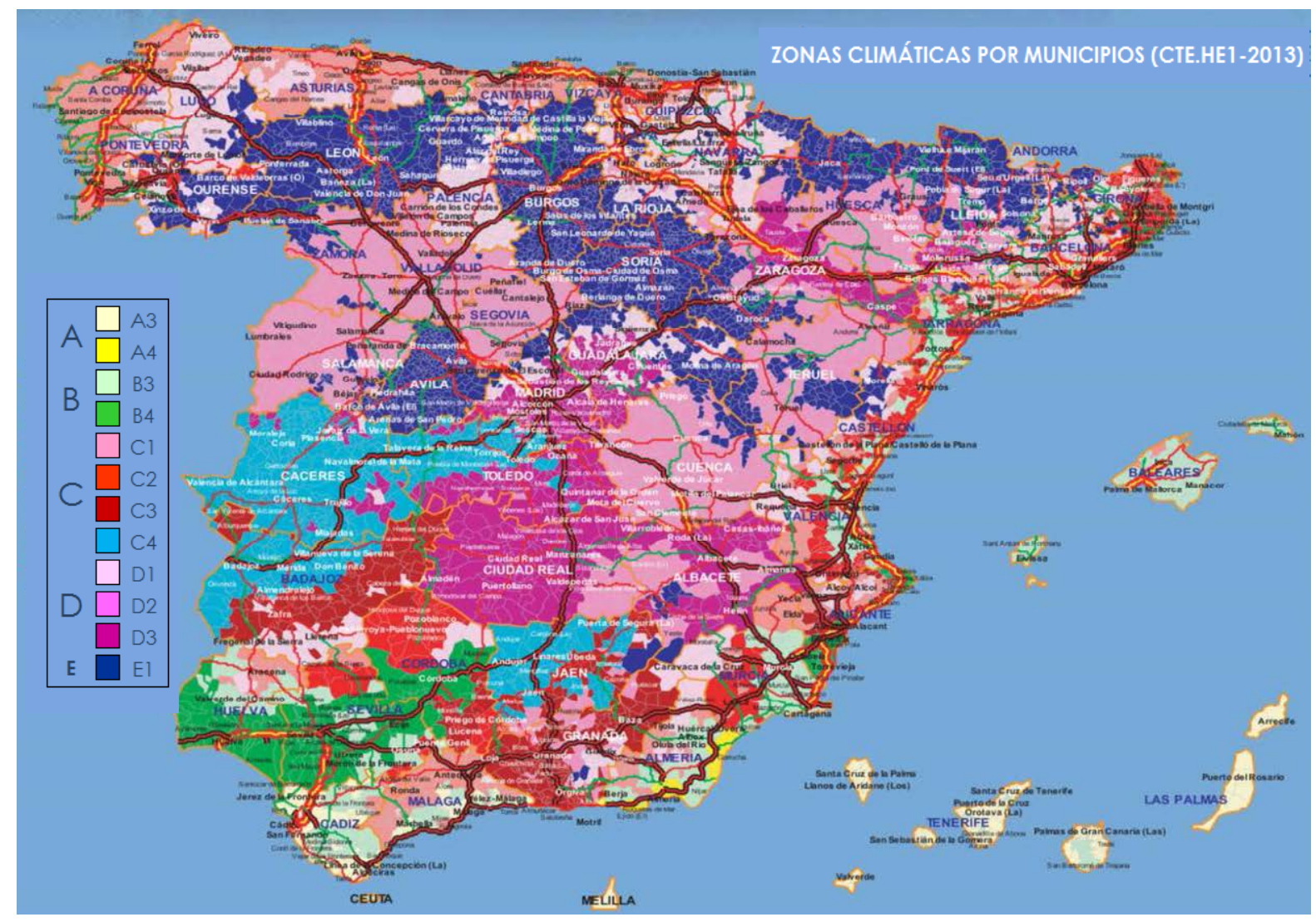

6-11 DISTRIBUCIÓN GEOGRÁFICA DE LAS REGIONES CLIMÁTICAS POR MUNICIPIOS.

(http://www.gasparnoguera.com/wp-content/uploads/2015/03/map_web.jpg

http://www.cmbburgos.es/images/20100311_014252.jpg y elaboración propia)

Se han analizado diversos años climáticos, al existir diversas series de aplicación normativa a una determinada localidad:
CTE_ZG_RITE Clima de referencia aplicable a Zaragoza recogido en las series publicadas para la aplicación del RITE.

CTE_D3_RITE Clima de referencia aplicable a la zona climática D3, recogido en las series publicadas para la aplicación del RITE.

CTE_D3_CTE Clima de referencia aplicable a la zona climática D3, recogido en las series publicadas para la aplicación del CTE.
VALORES

REPRESENTATIVOS DE

LOS CLIMAS

NORMATIVOS:

$\mathrm{GH}$

MÁXIMAS

MÍNIMAS

PROMEDIOS

MEDIANAS

Los climas normativos presentan diferencias significativas que pueden observarse en su representación anual y en los valores estadísticos, como pueden ser medias, máximas o mínimas, y analíticos, como son los grados-hora (GH). 


\section{ZONAS CLIMÁTICAS PARA PERIODOS FRÍOS}

Las zonas climáticas de periodos fríos (invierno) se establecen en función de un indicador adimensional denominado Severidad Climática de Invierno (SCl), que se determina mediante la siguiente expresión:

$$
S C l=a \cdot G D+b \cdot(n / N)+c \cdot G D^{2}+d \cdot(n / N)^{2}+e
$$

donde,

$\left.\left.\begin{array}{ll}\text { GD } & \begin{array}{l}\text { es la suma de los grados-día de invierno en } \\ \text { base } 20 \text { para los meses de invierno (fríos) }\end{array} \\ \mathrm{n} / \mathrm{N} & \begin{array}{l}\text { es la proporción de horas soleadas con } \\ \text { respecto a las máximas posibles en invierno } \\ \text { a }\end{array} \\ \mathrm{b} & -0,0003546 \\ \mathrm{C} & +0,4043 \\ \mathrm{~d} & -0,00000008394 \\ \mathrm{e} & -0,1137\end{array}\right\} \begin{array}{l}\text { Coeficientes de } \\ \text { Regresión }\end{array}\right\}$

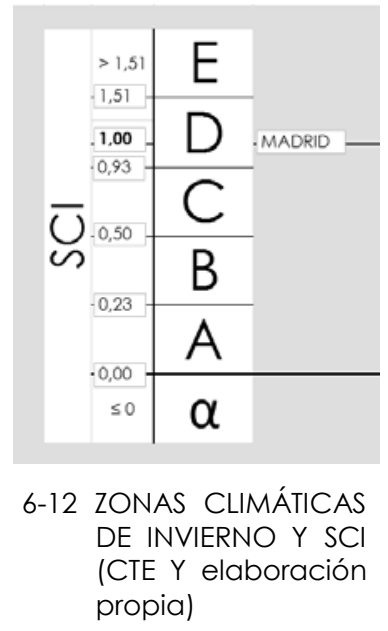

El valor de severidad climática de invierno está diseñado para hacer coincidir los GD de invierno y la relación $\mathrm{n} / \mathrm{N}$ de invierno de Madrid con el valor 1,00.

Estableciendo las distintas zonas climáticas en función de los intervalos de estos valores de SCl. Estos intervalos se identifican con letras $(\alpha, A, B, C, D, E)$.

De forma que se asigna $(\alpha)$ a la zona climática menos fría cuando $\mathrm{SCl} \leq 0$, y (E) a la más fría cuando $\mathrm{SCl}>1,51$, siendo Madrid el clima de referencia, $\mathrm{SCl}=1,00$, correspondiéndole una zona climática de invierno D.

Los valores de grados día en base 20 comprobados entre los meses de octubre a mayo confirman su estabilidad para distintas localizaciones y periodos. En el caso de la figura se aportan los datos para Madrid y Zaragoza, ambos considerados como clima de invierno tipo $D(S C l=1,00)$, en periodos de octubre a mayo entre los años 2010 Y 2015 y en el mismo periodo entre 2014 y 2015. 
MADRID LEMD Madrid/ Barajas, Spain (3.56W,40.47N)

FUENTE: $w$ ww.degreedays.net (using temperature data from www.wunderground.com)

MEDIA OCTUBRE-MAYO DESDE 2010 A 2015

2317 으

OCTUBRE 2014- MAYO 2015

$2277 \stackrel{\circ}{C}$

\section{ZARAGOZA LEZG Zaragoza/Aeropuerto,ES (1.01W,41.66N)}

FUENTE: www.degreedays.net (using temperature data from Www.wunderground.com)

MEDIA OCTUBRE-MAYO DESDE 2010 A $2015 \quad 2153$ ㄷ

OCTUBRE 2014- MAYO 2015

2086 으

6-13 EJEMPLO DE DETERMINACIONES DE LOS GRADOS DIA EN BASE $20^{\circ} \mathrm{C}$ EN MESES FRIOS (UTILIDAD "On line" WwW.DEGREEDAYS.NET Y ELABORACIÓN PROPIA)

\section{ZONAS CLIMÁTICAS PARA PERIODOS CÁLIDOS}

Las zonas climáticas de verano se establecen en función de un indicador adimensional denominado como Severidad Climática de Verano (SCV), que se determina mediante la siguiente expresión:

$$
S C V=a \cdot G D+b \cdot G D^{2}+c
$$

donde

GD es la suma de los grados-día de verano en base 20 para los meses de verano

$\mathrm{n} / \mathrm{N}$ proporción de horas soleadas con respecto a las máximas posibles en verano

a $\quad+0,00299$

b $\quad-0,000000115947$

Coeficientes de Regresión

c $\quad-0,1713$

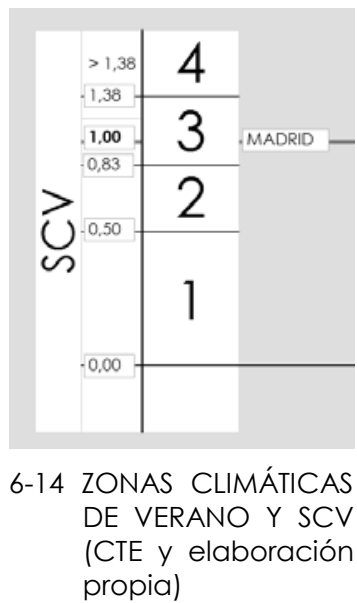

El valor de Severidad Climática de Verano está diseñado para hacer coincidir los GD de verano de Madrid con el valor 1,00.

Estableciendo las distintas zonas climáticas en función de los intervalos de estos valores de SCV. Estos intervalos se identifican con números $(1,2,3,4)$.

De forma que se asigna la zona climática menos cálida (1) cuando SCV $\leq 0,5$ y la más cálida (4) cuando SCV > 1,38, siendo Madrid el clima de referencia, $S C V=1,00$, correspondiéndole una zona climática de verano 3.

Los valores de grados día en base 20 comprobados entre los meses de octubre a mayo confirman su estabilidad para distintas localizaciones y periodos. En el caso de la figura se aportan los datos para Madrid y Zaragoza, ambos considerados como clima de verano tipo $3(S C V=1,00)$, en periodos de junio a septiembre entre los años 2010 Y 2015 y en el mismo periodo en 2015. 
ESTUDIO DE CASO ZONA CLIMÁTICA DE VERANO 3.

\begin{tabular}{|lrr|}
\hline MADRID LEMD Madrid/ Barajas, Spain $(3.56 \mathrm{~W}, 40.47 \mathrm{~N})$ & & \\
FUENTE: $\quad$ www.degreedays.net(Using temperature & data & from \\
Www.wunderground.com) & \\
MEDIA JUNIO-SEPTIEMBRE DESDE 2010 A 2015 & $102^{\circ} \mathrm{C}$ \\
JUNIO - SEPTIEMBRE 2015 & $95^{\circ} \mathrm{C}$ \\
\hline
\end{tabular}

ZARAGOZA LEZG Zaragoza/Aeropuerto,ES (1.01W,41.66N)

FUENTE: $\quad$ www.degreedays.net lusing temperature data from www.wunderground.com)

MEDIA JUNIO-SEPTIEMBRE DESDE 2010 A $2015 \quad 112^{\circ} \mathrm{C}$

JUNIO - SEPTIEMBRE $2015 \quad 81^{\circ} \mathrm{C}$

FIG 6-15 EJEMPLO DE DETERMNACIONES DE LOS GRADOS DIA EN BASE $20^{\circ} \mathrm{C}$ EN MESES CÁLIDOS (UTILIDAD "On line" WwW.DEGREEDAYS.NET Y ELABORACIÓN PROPIA) 
Cada uno de las zonas climáticas dispone de al menos un clima de referencia que materializa las severidades de verano e invierno que le son propias y que permite disponer de un clima de referencia, formado sintéticamente y cuyos valores no se corresponden exactamente con ninguno de los años climáticos concretos o elaborados por valores medios a partir de ellos. Se trata, por tanto, de un clima sintético que recoge los valores climáticos significativos de una anualidad, discriminado en periodos horarios, cuyos valores se aplican como representativos de un determinado clima de referencia.

Estos climas de referencia están incorporados a la base de datos de la "Herramienta de Justificación Integrada LIDER-CALENER", denominada como HULC, y aportada por la administración para ser aplicada en los proyectos de arquitectura residencial.

Estos climas tienen una extensión ".met" y están accesibles en la aplicación para el CTE, del Ministerio de Fomento y según se describe en el "Documento descriptivo de climas de referencia" de septiembre de 2013. Su propósito es definir las solicitaciones exteriores de cálculo para un año tipo a través de parámetros representativos de una determinada zona climática, como son la temperatura, la humedad o la radiación solar.

Su estructura también está descrita en el "Documento descriptivo de climas de referencia" de septiembre de 2013, y se corresponde con un archivo informático con la siguiente información:

Primera línea Cadena de texto identificativa del archivo de datos.

Segunda línea Datos de: latitud, longitud, altitud y longitud de referencia para el cálculo de la hora oficial.

8760 Líneas $\quad$ Datos horarios formados por los campos siguientes:

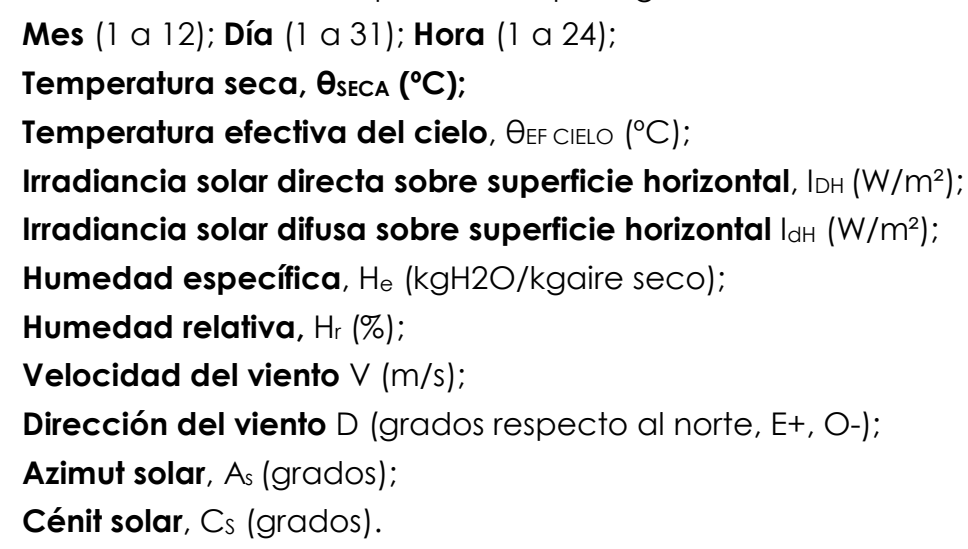

Se indican e incluyen en la información aportada por la normativa en vigor los parámetros que son determinantes del comportamiento del clima tipo reglamentario, en negrita y recuadradas en la figura, como son la temperatura seca $\left({ }^{\circ} \mathrm{C}\right)$, la humedad relativa (\%) y la irradiancia solar global sobre plano horizontal, o suma de la Irradiancia solar directa y difusa sobre plano horizontal. 


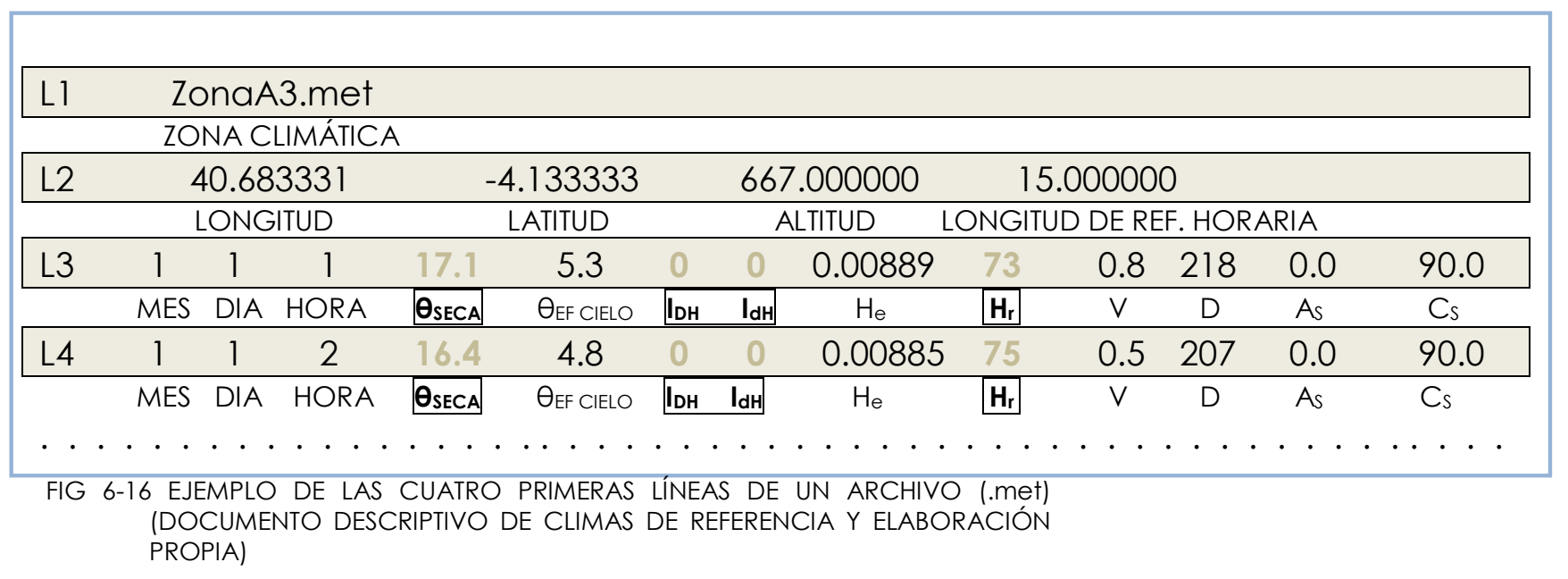

Además se indican lo valores que pueden darse a otros parámetros climáticos, como son la temperatura no perturbada del suelo profundo, muy similar a la temperatura media anual del aire, la presión atmosférica, que puede ser considerada de 1 atm $(101,325 \mathrm{kPa})$ y la velocidad media del viento, que puede tomarse igual a $2,8 \mathrm{~m} / \mathrm{s}$.

Por otra parte existen diversos climas de referencia que describen un año climatológico tipo de referencia y que son de aplicación a una misma zona climática, por lo que será oportuno compararlos entre sí como primer paso para comprobar su aplicabilidad.

El proyectista dispone de dos fuentes de información para obtener estos datos climáticos de segregación horaria:

1. De una parte la aportada por el Ministerio de Fomento a través de la aplicación de seguimiento del Código Técnico de la Edificación (CTE) y sus Documentos Reconocidos, en la que podemos encontrar los archivos climáticos de los climas de referencia (.met) para cada una de las zonas climáticas establecidas en razón a sus severidades climáticas de verano y de invierno.

2. De otra parte la aportada por el Ministerio de Industria, Energía y Turismo, en su aplicación para el seguimiento del DB HE 2, también denominado Reglamento de las Instalaciones Térmicas del Edificio (RITE) y sus Documentos Reconocidos. Además de archivos climáticos (.met) para los climas de referencia específicos, se recogen los climas sintéticos prestacionales de las capitales de provincia españolas. 


\section{ARCHIVOS DIGITALES DE OTROS CLIMAS DE APLICACIÓN SUSCEPTIBLES DE SER APLICADOS A LA NORMATIVA ESPAÑOLA}

Por otra parte el uso de herramientas informáticas hace que se empleen frecuentemente archivos de distintas procedencias para la simulación del comportamiento del edificio frente al clima.

La más común de estas fuentes es la World Meteorological Organization (WMO) en http://public.wmo.int/en_2016_04_18, en España conocida como la Organización Meteorológica Mundial (OMM) lque puede consultarse en español en https://www.wmo.int/pages/index_es.html_2016_04_18).

La elección de esta base de datos se realiza por su carácter accesible y libre desde cualquier plataforma y por ser la empleada por el programa de simulación EnergyPlus $\left(e^{+}\right)$, programa de uso libre, con frecuentes actualizaciones y que sirve de motor de cálculo a una gran diversidad de aplicaciones comerciales. Está creado por el U.S. Department of Energy's (DOE) Building Technologies Office (BTO), y gestionado por el National Renewable Energy Laboratory (NREL) de los Estados Unidos y en él colaboran numerosas instituciones académicas y profesionales de todo el mundo (https://energyplus.net/_2016_04_18).

Esta base de datos aporta climas sintéticos de cálculo para todas las capitales de provincia Españolas (Spanish Weather for Energy Calculations) (SWEC)) elaboradas en España por el profesor PérezLombard de la Escuela Técnica Superior de Ingenieros de Sevilla, y generada sintéticamente usando Clomid, con velocidades del viento constante de $6,7 \mathrm{~m} / \mathrm{s}$ y convertido de DOE-2 binario a formato EnergyPlus en su versión horaria (epw) (https://energyplus.net/weather). 


\subsubsection{ESTUDIOS DE CASO}

La distribución geográfica de las zonas climáticas se realiza atendiendo a la provincia y a la altitud sobre el nivel del mar. Esta distribución "por tramos" provoca diferencias significativas entre dos ubicaciones geográficamente próximas pero ubicadas en zonas climáticas diferentes, ya sea por la disposición de las divisiones administrativas o por la diferencia de altitud.

Como ejemplo puede considerarse el caso de Madrid, donde el CTE distingue varias zonas climáticas en función de la altitud y, al existir una gran continuidad de la edificación, las diferencias entre zonas climáticas se producen en el seno de zonas edificadas y son de aplicación a edificios contiguos.

Así, mientras para la capital se establece una clasificación climática D3, para una altitud de $200 \mathrm{~m}$ mayor, se establece una clasificación de Dl y El cuando ésta la supera en $400 \mathrm{~m}$.

En la práctica esto supone que a las localizaciones situadas a una altitud mayor de $998 \mathrm{~m}$ se les aplicará una clasificación El, a las que estén por encima de $798 \mathrm{~m}$. la D1 y al resto la D3. La mayor parte de la población está situada por debajo de los $700 \mathrm{~m}$ de altitud, siendo por tanto la clasificación mayoritaria D3.

Para establecer las diferencias más significativas entre las tres zonas climáticas pueden realizarse algunas sencillas comparaciones. En una primera aproximación se comparan las horas en que la temperatura supera los $18^{\circ}$ (FIG. 6.17).

\begin{tabular}{|cc|c|cc|}
\hline \multicolumn{3}{|c|}{ HORAS CON TEMPERATURAS MAYORES DE $18^{\circ} \mathrm{C}$ SEGÚN CLIMAS DE REFERENCIA D3, D1 Y E1 } \\
\hline$(-60,00 \%)$ & 1605 & 2675 & 1830 & $(-68,41 \%)$ \\
\hline \multicolumn{2}{|c|}{ E1 } & D3 & \multicolumn{3}{|c|}{ D1 } \\
\hline
\end{tabular}

FIG 6-17 Cuadro comparado del tiempo en horas en que las temperaturas de los climas de referencia superan el umbral de $18^{\circ} \mathrm{C}$ en Madrid. (elaboración propia a partir de CTE)

Puede observarse una reducción del tiempo en horas con temperaturas mayores de $18^{\circ} \mathrm{C}$ muy significativa al superar una altitud de $798 \mathrm{~m}$. (Zona climática D1), con respecto a las superaciones que se producen en la zona climática D3.

Si se comparan las zonas climáticas Dl y El, la diferencia es de poco más de un $8 \%$.

Si se computan los grados en que se superan los $18^{\circ} \mathrm{C}$ en las tres zonas climáticas (FIG. 6.18).

\begin{tabular}{|cc|c|cc|}
\hline \multicolumn{4}{|c|}{${ }^{\circ} \mathrm{C}$ EN QUE SE SUPERAN LOS $18^{\circ} \mathrm{C}$ SEGÚN CLIMAS DE REFERENCIA D3, D1 Y E1 } \\
\hline$(54,77 \%)$ & 35.778 & 65.324 & 40.742 & $(62,37 \%)$ \\
\hline \multicolumn{2}{|c|}{ E1 } & D3 & \multicolumn{2}{c|}{ D1 } \\
\hline
\end{tabular}

FIG 6-18 Cuadro comparado de $\operatorname{los}^{\circ} \mathrm{C}$ que superan un umbral de $18^{\circ} \mathrm{C}$ en Madrid. (elaboración propia a partir de CTE)

Las diferencias porcentuales en los ${ }^{\circ} \mathrm{C}$ en que se superan los $18^{\circ} \mathrm{C}$ son ligeramente inferiores a las periodos en los que se producen estas superaciones. 
Si se consideran los valores inferiores a $0^{\circ} \mathrm{C}$ pueden observarse diferencias aún mayores (FIG. 6.19 y 6.20).

HORAS CON TEMPERATURAS MENORES DE 0C SEGÚN CLIMAS DE REFERENCIA D3, D1 Y E1

\begin{tabular}{|c|c|c|c|c|}
\hline $252,75 \%$ & 551 & 218 & 217 & $99,54 \%$ \\
\hline & & D3 & & \\
\hline
\end{tabular}

FIG 6-19 Cuadro comparado del tiempo en horas en que las temperaturas de los climas de referencia no superan el umbral de $0^{\circ} \mathrm{C}$ en Madrid. (elaboración propia a partir de CTE)

\begin{tabular}{|cc|c|cc|}
\hline \multicolumn{3}{|c|}{${ }^{\circ} \mathrm{C}$ EN QUE NO SE SUPERAN LOS } & $0^{\circ} \mathrm{C}$ SEGÚN CLIMAS DE REFERENCIA D3, D1 Y E1 \\
\hline $270,13 \%$ & 941 & 348 & 367 & $105,37 \%$ \\
\hline E1 & D3 & \multicolumn{3}{|c|}{ D1 } \\
\hline
\end{tabular}

FIG 6-20 Cuadro comparado de $\operatorname{los}^{\circ} \mathrm{C}$ que no superan un umbral de $0^{\circ} \mathrm{C}$ en Madrid. (elaboración propia a partir de CTE)

Sirvan estas observaciones como indicador de la imprecisión en que necesariamente se incurre cuando a partir de un solo parámetro, en este caso la altitud, se pasa de una a otra zona climática, y han de considerarse diferencias sustanciales en el clima de referencia al que se enfrentarán dos edificios separados apenas unos metros e independientemente, por ejemplo, de su exposición al sol 0 al viento 0 de estar afectado por algún microclima específico.

Se ha optado por considerar solamente los valores climáticos dentro de la zona climática D3, para observar en ella las diferencias entre los valores realmente medidos en diferentes localizaciones y explorar una forma más precisa para determinar este clima de aplicación a las estimaciones en edificación.

Para la aplicación de los diversos climas asignados a una localización, como son los climas de referencia o normativos o los climas promedio o medios, se ha elegido la ciudad de Zaragoza, situada en la zona climática D3.

Los valores registrados en las estaciones meteorológicas situadas en esta localización que han sido consultados son:

AEMET_TIPO_ZG_CNL

AEMET_TIPO_ZG_AER

AEMET_TIPO_ZG_VLD

Para observar la evolución de la temperatura en las zonas edificadas se han considerado los valores obtenidos, tanto en estaciones meteorológicas situadas sobre los edificios como junto a paramentos exteriores e interiores, entre los años 2012 y 2015 en edificios ubicados Zaragoza. 


\subsection{CLIMA REGISTRADO EN LA ESTACIONES METEOROLÓGICAS SITUADAS EN LA ZONA CLIMÁTICA D3}

La comprobación en localizaciones concretas de la evolución anual de las temperaturas ofrece una imagen de las condiciones climáticas previsibles a las que se someterá el edificio durante su vida útil en dicha localización.

Se han elegido grandes núcleos de población situados en una misma zona climática para establecer similitudes y diferencias probables en zonas urbanas, en atención a la ubicación preferente de la población en estos núcleos y a la mayor influencia de la edificación en el clima, limitando la influencia de factores naturales.

El estudio de las condiciones climáticas a las que se someten los edificios se realiza considerado secuencias térmicas largas. En nuestro caso se ha considerado una de 30 años, un periodo de medidas climáticas suficientemente largo, al mantener unas similares especificaciones de validación de los equipos y una calidad similar de los datos.

Para comparar los climas de referencia con el clima local registrado en las estaciones meteorológicas locales se ha considerado que serán suficientes series térmicas de 10 años en distintas localizaciones de la zona geográfica de aplicación de los climas sintéticos. Se consideran para este estudio series térmicas horarias, agrupadas en secuencias anuales. También se considera que este periodo es más afín a las condiciones ambientales en las que se desenvolverá la edificación en un futuro próximo.

Los climas locales, frente a los climas de referencia, son climas observados en lugares concretos y no están formados a partir de datos climáticos. Esto hace que, en función de la amplitud geográfica para la que se proponen los climas de referencia, pueda haber muchas diferencias entre ellos. Para comprobar esta relación se realizarán las comparaciones considerando dos localidades con registros meteorológicos suficientes.

Frente a la opción de realizar un análisis extensivo aplicado a una o varias localidades de cada zona climática se ha optado por aplicar el análisis a una sola zona climática, tanto por la facilidad para la obtención de datos como por el conocimiento de las exigencias a la edificación para conseguir espacios aclimatados, tanto en tiempo como en severidad, y para concretar la observación en poblaciones concretas con patrones de uso y costumbres conocidas, más allá de la mera representación del clima que nos ofrece la secuencia de valores climáticos.

Los climas de referencia considerados serán los ya descritos y que se denominan por las regulaciones o procedimientos de aplicación, como CTE, RITE y $e^{+}$.

Se usa la información de libre acceso ofrecida por la Agencia Española de Meteorología (AEMET), en su página web pública, tratada por otros agentes y que también se ofrece gratuitamente 
en sus páginas web, y algunas series de 10 años para distintas localizaciones en Madrid y Zaragoza, que han sido facilitadas por la Agencia para la elaboración de éste y otros estudios aplicados a la edificación realizados en la Universidad Politécnica de Madrid.

\subsubsection{FUENTES DE INFORMACIÓN CLIMÁTICA LOCAL}

En un primer nivel, la información considerada se refiere a los parámetros de temperatura, precipitaciones, radiación y viento, recogidos por AEMET, en sus informes y en los realizados por otros agentes, como son:

1. Resúmenes anuales climatológicos:

Redactados por AEMET recogen un análisis de las singularidades y valores comparados que se consideran significativos en relación a la temperatura del aire, precipitaciones, insolación y viento durante un año.

Normalmente este análisis se ilustra con mapas y sólo muy ocasionalmente aporta gráficos. No se acompaña de series de datos.

2. Resúmenes estacionales climatológicos:

Redactados por la agencia recogen un análisis de las singularidades y valores comparados que se consideran significativos en relación a temperatura del aire, precipitaciones, insolación y viento, en cada estación.

Normalmente este análisis de ilustra con mapas y solo muy ocasionalmente aportan gráficos. No se acompañan de series de datos.

3. Resúmenes mensuales climatológicas

Redactados por AEMET recogen un análisis mensual de las singularidades y valores comparados que se consideran significativos en relación a la temperatura del aire, precipitaciones, insolación y viento en cada estación.

Normalmente este análisis se ilustra con mapas y sólo muy ocasionalmente aporta gráficos. No se acompaña de series de datos.

4. Avances climatológicos mensuales por comunidades:

Redactados por AEMET recogen un avance de los datos mensuales por localidades en un análisis de las singularidades y valores comparados que se consideran significativos en relación a la temperatura del aire, precipitaciones, insolación y viento.

Normalmente este avance se ilustra con mapas y sólo muy ocasionalmente aporta gráficos. Se acompañan de medias mensuales por localidades de temperatura y precipitación y de los valores que se consideran reseñables. 
5. Datos medios anuales:

En distintas aplicaciones se recogen valores medios anuales elaborados a partir de los datos recogidos por estaciones meteorológicas nacionales o privadas. Se han utilizado los datos recogidos en la página web:

http://www.tutiempo.net/clima/Espana/ES_2.html consultado 23_04_2016 14:49

Del mismo modo las agencias locales o regionales ofrecen datos de libre acceso que pueden ser consultados en sus páginas web.

En un segundo nivel se consideran las series de temperaturas horarias registradas durante una década en varias estaciones meteorológicas de cada zona de estudio, aportados por AEMET. 


\subsubsection{VALORES REPRESENTATIVOS DEL ESTADO TÉRMICO LOCAL}

Los valores representativos de las temperatura local durante un periodo determinado, son muy diversos en función de su aplicación. Para la identificación de las condiciones medias y las singularidades se emplean medias, máximas, mínimas, oscilaciones térmicas, percentiles y grados-hora, normalmente en periodos horarios, diarios $y$, eventualmente, periodos más cortos en secuencias térmicas significativas.

Puesto que la Red Española de Meteorología permite disponer de datos locales próximos a las zonas más pobladas, se han podido elegir para hacer una estimación comparada con otras fuentes de datos climáticos las localidades de Zaragoza y de Madrid.

\section{A. SERIES LARGAS}

La elección se realiza, entre otras razones, por la existencia de archivos climáticos homogéneos y de calidad con una antigüedad suficiente.

En la ciudad de Zaragoza existen varios observatorios meteorológicos de la red nacional con datos disponibles de distinta antigüedad, para ser empleados en el estudio.

La relación entre los diferentes parámetros climáticos puede verse en lo gráficos adjuntos donde se reflejan en medias anuales los valores de temperatura, viento, precipitaciones, y meteoros registrados durante el periodo entre 1973 y 2012.

Los valores climáticos medios tienen la ventaja de describir el clima local en un periodo suficientemente largo, reduciendo la influencia de las anomalías y permitiendo ver tendencias y diferencias locales de carácter general.

Su gran inconveniente para la aplicación en edificación radica en el incremento de la desviación típica y, con ella, de las condiciones climáticas más exigentes para conseguir el bienestar higrotérmico interior.

\section{B. SERIES MEDIAS}

Las series térmicas mínimas adecuadas para describir un clima local, según se recoge en las recomendaciones meteorológicas, tienen una duración mínima de 10 años, considerado este un periodo de tiempo suficiente para describir las condiciones climáticas exteriores, sirviendo así para el diseño de instalaciones que permitan atender la demanda de bienestar y salud de los residentes en los edificios (IDAE, 2010, pág. 1).

La evolución térmica en la década 2005 a 2014, se emplea para establecer la variación anual de los valores medios y mejorar el conocimiento del entorno térmico en que se va a desenvolver el edificio en la zona de estudio. 


\subsubsection{OBSERVACIONES GENERALES SOBRE EL ESTADO TÉRMICO LOCAL}

La observación local del clima permite identificar la evolución de la temperatura que indican los modelos de cambio climático, circunstancia que habrá de ser tenida en cuenta en las recomendaciones de diseño para el clima probable durante toda la vida útil y no sólo para el clima pasado.

Esta valoración merece probablemente un análisis específico que repercutirá de forma diferente según sea la zona de la península ibérica considerada y que quizás requiera escalas temporales más amplias y proyecciones más complejas que aquéllas a las que se tiene acceso.

Las medianas de los valores climáticos máximos, mínimos y medios medias en la zona de estudio, haciendo caso omiso del proceso de evolución citado, permiten observar que:

La oscilación térmica se confirma mayor en los periodos cálidos que en los fríos.

La temperatura media es confortable en los meses cálidos con temperaturas extremas muy elevadas y temperaturas nocturnas frías.

Los periodos de evolución desde periodos cálidos a periodos fríos se producen en periodos que no suelen superar los dos meses.

La temperatura máxima durante los meses de evolución entre periodos cálidos y fríos alcanza temperaturas confortables en sus valores máximos.

Los valores medios de máximas mínimas y medias de los meses

FRÍOS más fríos, casi el $50 \%$ del tiempo, se mantiene siempre por debajo de las temperaturas de confort.

Los periodos más fríos y más cálidos se alejan de los solsticios en un mes y siendo el enfriamiento más rápido que el calentamiento.

OBSERVACIONES GENERALES EN PERIODOS:

CÁLIDOS

EVOLUCION DE CÁLIDOS A FRÍOS 


\subsection{MICROCLIMA URBANO: VALORES TÉRMICOS EN ZONAS URBANAS.}

Está muy documentada la influencia urbana en el clima*, de modo que en el entorno de los edificios situados en núcleos urbanos se reconoce un microclima* específico en las clasificaciones climáticas.

La ciudad es un ecosistema humano* que modifica los factores que influyen en la formación del clima en su seno y, ya sea por la existencia de singularidades debidas a su posición relativa en la zona, por la geomorfología urbana, por sus efluentes o por la existencia de una alta proporción de masas construidas, se observan alteraciones en las condiciones climáticas con respecto a las que corresponderían a la zona o región donde se ubica.

La intensidad con que se manifiestan estos mismos factores y la desigual presencia de componentes de alta repercusión climática como son, por ejemplo, grandes masas de agua, valles, ríos, la clinometría o las zonas con una presencia significativa de vegetación hacen que allí las condiciones no sean tan homogéneas como las de otras zonas microclimáticas, manifestando diferencias bruscas en distancias cortas.

Se han observado las series climáticas en diversas zonas de la ciudad poniendo en evidencia las diferencias y similitudes con los climas registrados en las estaciones meteorológicas próximas.

Para estas observaciones se han considerado las estaciones de referencia de AEMET que ya han servido de apoyo a este estudio, por los que sus datos se corresponden con los indicados en capítulos anteriores.

También se han dispuesto estaciones meteorológicas en edificios integrados en la trama urbana.

\subsection{MICROCLIMA DE PROXIMIDAD: VALORES TÉRMICOS EN EL ENTORNO PRÓXIMO DE UN EDIFICIO.}

Los valores meteorológicos en cada zona o localidad no pueden considerarse uniformes, sino que se subdividen, a su vez, en nuevos microclimas. En una primera instancia en entornos urbanos se pueden distinguir también microclimas que manifiestan la oposición de, por ejemplo, los cauces o valles, frente a las elevaciones, las zonas perimetrales y las situadas en el interior de las zonas más densamente edificadas, entre las zonas más alejadas o las más próximas a las zonas verdes. Esta complejidad, ya comentada, hace que el microclima urbano ya se considere un microclima muy heterogéneo, que tiene cualidades diferentes según las distintas zonas urbanas.

Estos microclimas a su vez se ven afectados en las proximidades de cada edificio según las características de este y las de su entorno, dando lugar a zonas de su influencia directa regidas por loq ve aquí se denomina como microclima de proximidad*. 
Si se considera el edificio en su intercambio con el exterior y que éste se producen a través de las envolventes se pone de manifiesto la importancia de establecer las similitudes y diferencias entre las condiciones meteorológicas a las que está sometida cada una de ellas. Estas diferencias son más evidentes entre aquellas superficies más expuestas, como puede ser la cubierta o la última planta, y las menos expuestas, como pueden ser las plantas inferiores o los espacios interiores.

Los valores analizados comparten con los microclimas descritos su sesgo climático, normalmente asociado a la exposición al viento y al sol o a la orientación y que se manifiesta, en los casos observados como:

Las temperaturas en la zona norte son menores que las de la zona sur.

Las zonas más batidas por el viento, como lo son las zonas más altas o las más expuestas en función del viento dominante y las obstrucciones, se enfrían más rápidamente, tanto en el ciclo diario como en el ciclo estacional.

Las zonas más soleadas incrementan su temperatura durante el día más rápidamente.

Las características de los espacios adyacentes determinan algunas cualidades de las condiciones térmicas en el perímetro del edificio:

Las vías perimetrales estrechas provocan una mayor diferencia entre las temperaturas de las plantas inferiores y las superiores.

Los espacios amplios incrementan las tendencias por orientación o exposición.

Los patios interiores mantienen una menor oscilación térmica y amortiguan los efectos de los valores meteorológicos exteriores, constituyendo una aclimatación natural.

Las terrazas semi-cerradas o retallos en las envolventes reducen la oscilación térmica. Su temperatura se mantiene más alta que en el entorno de las orientadas al sur y menor en las orientadas al norte, siempre y cuando los espacios contiguos no estén calefactados.

Las observaciones realizadas confirman estos comportamientos térmicos aunque con diferencias significativas entre las localizaciones, por lo que no parece posible establecer correlaciones cuantitativas y si que, para que un diseño sea adecuado a un lugar, es preciso cuantificar localmente estas circunstancias.

En conclusión, las características del clima contiguo al edificio se encuentran mediatizados por su inserción en el microclima urbano, difiriendo de las condiciones regionales, y por la posición relativa de la observación con respecto al edificio. 
El primer aspecto se denomina, a efectos divulgativos, como isla de calor. La posición relativa dentro del núcleo urbano, la presencia de zonas verdes, corredores ventilados o protegidos, orientaciones soleadas o umbrías y la actividad local están documentadas como factores que se superponen a las condiciones climáticas regionales manifestándose, en resumen, en unas condiciones higrotérmicas con una sensación térmica más cálida.

También hay que tener en cuenta que esta sensación queda fuertemente condicionada por la localización relativa de la zona en la que se sitúa el observador dentro de la zona urbanizada.

Por último se debe concluir que la dificultad de segregar la influencia urbana y la del propio edificio invita a la consideración conjunta de ambos procesos.

\subsubsection{MICROCLIMA DE PROXIMIDAD EN ZARAGOZA CENTRO: SAN PABLO-} B. BOGGIERO

Los datos obtenidos "in situ", permiten observar las diferencias entre las temperaturas tomadas en los patios interiores, en el patio de la manzana y en la estación meteorológica instalada en un edificio de la zona centro de Zaragoza.

\subsection{PROCEDIMIENTOS DIGITALES DE ESTIMACIÓN DE LA DEMANDA}

Los procedimientos digitales de estimación de la demanda permiten acreditar el cumplimiento de las exigencias normativas.

Actualmente existen documentos reconocidos que permite la clasificación de los edificios en función de la energía que precisan para mantener unas determinadas condiciones de bienestar interior. Todos ellos utilizan como motor de cálculo procedimientos derivados del antiguo DOE2. Este procedimiento desarrollado en USA, por diversas universidades tiene como patrocinador principal al U.S. Department of Energy's (DOE) y está en el germen del programa denominado como Energy Plus que sirve de base a otros programas como DesignBuilder.

Mediante ellos se puede estimar la respuesta de un edificio determinado y comprobar la influencia del empleo de uno $u$ otro clima de referencia, tanto en términos de demanda como de temperatura. 


\section{RESULTADOS}

Para realizar un análisis de los datos registrados, ya sea en estaciones meteorológicas oficiales a las que se ha tenido acceso o en estaciones propias, se ha ordenado la información en tablas, cuadros y gráficos que permitan su posterior análisis, comenzando por ordenar y relacionar entre sí los valores de climas de referencia tanto para su aplicación en el RITE como en el CTE, para la zona climática D3, así como otros aplicados específicamente a Zaragoza (ZG).

Posteriormente se abordan los registros desde 1973 a 2012, aportados en sus valores medios por AEMET, que permiten realizar una primera aproximación a la secuencia térmica y a sus valores representativos y los registros en las estaciones de referencia desde el año 2004 al 2014 s0n tratados para obtener valores medios y establecer la relación entre ellos.

Se establece con ello la variabilidad local del clima en los valores que se consideran significativos.

También se ha aplicado el mismo procedimiento a localizaciones concretas de las que se disponen datos meteorológicos, tanto de AEMET como de estaciones meteorológicas propias.

Estos valores se han organizado por anualidades y por series de varios días. 


\subsection{CLIMAS DE REFERENCIA PARA ZONA CLIMÁTICA D3}

La existencia de diversos climas de referencia para la misma zona climática pone de manifiesto la dificultad de establecer sus valores y plantea la cuestión de hallar sus similitudes y diferencias al ser aplicados en la prescripción arquitectónica.

La observación de los valores climáticos asignados a cada zona climática por los climas de referencia permite hacer una primera visualización de la que se deduce que no todas utilizan los mismos parámetros ni los mismos valores.

Es en una segunda visualización donde se observan sus similitudes y diferencias, para lo que se han considerado la temperatura media anual y mensual, los valores medios de los percentiles centrales, entre el $25 \%$ y el $75 \%$, los valores de humedad por encima del $80 \%$ y por debajo del $30 \%$ y la media de radiación diaria anual y mensual.

Para contrastar la información climática asignada a la zona climática D3 con otras de aplicación local se utiliza la específica de la localidad de Zaragoza.

En definitiva, la comparación de las distintas secuencias climáticas que son de aplicación a la zona climática D3 se concreta en establecer la relación que hay entre las temperaturas de bulbo seco, la humedad relativa, la radiación incidente sobre un plano horizontal y la velocidad y la dirección del viento asignada al clima sintético prestacional por diferentes fuentes:

FUENTE DEL MINISTERIO DE FOMENTO

CTE_CLIMA_D3 D3_CTE Clima para la zona climática definida como D3 descrito en el Código Técnico de la Edificación (CTE).

FUENTE DEL MINISTERIO DE INDUSTRIA

$\begin{array}{ll}\text { RITE_CLIMA_D3 } & \text { D3_RITE Clima para la zona climática definida } \\ \text { como D3 descrito para la aplicación del } \\ \text { Reglamento de Instalaciones térmicas de edificios } \\ \text { (RITE) }\end{array}$

RITE_CLIMA_ZG ZG_RITE Clima para Zaragoza descrito para la aplicación del Reglamento de Instalaciones térmicas de edificios (RITE)

FUENTE OMM

SWEC_ZG_AER ZG_e+Clima para Zaragoza descrito por AEMET y la OMM para Zaragoza, de aplicación en las herramientas de simulación promovidas por la EPA (USA), por ejemplo Energy Plus. Recogida en el DOE

Se han contemplado para distintos escenarios o rangos para las temperaturas que se han considerado adecuadas para el confort interior, variables en función de la tolerancia, el confort 
adaptativo y la influencia del edificio y sus envolventes en la amortiguación térmica. Las variaciones térmicas consideradas son las siguientes:

Temperatura constante de

Temperatura variable entre

Temperatura variable entre

Temperatura variable entre $22^{\circ} \mathrm{C}$

$20^{\circ} \mathrm{C}$ y $24^{\circ} \mathrm{C}$

$18^{\circ} \mathrm{C}$ y $26^{\circ} \mathrm{C}$

$16^{\circ} \mathrm{C}$ y $28^{\circ} \mathrm{C}$

Las diversas series climáticas que representan las condiciones en el mismo lugar, han sido integradas en un formato que permita compararlas entre sí y con otras series empleadas en la simulación del comportamiento térmico de los edificios.

Los resultados que se han considerado relevantes son los datos térmicos, de humedad, de velocidad y dirección del viento y de radiación. Por lo que se ha realizado la comparación entre estos valores, siempre que se ha dispuesto de ellos en las series consideradas.

Los datos climáticos se han obtenido descargado de la web oficial del CTE en el formato ".met" original, pasándose a un formato ".xls" en el que se han operado las variables para obtener los valores significativos.

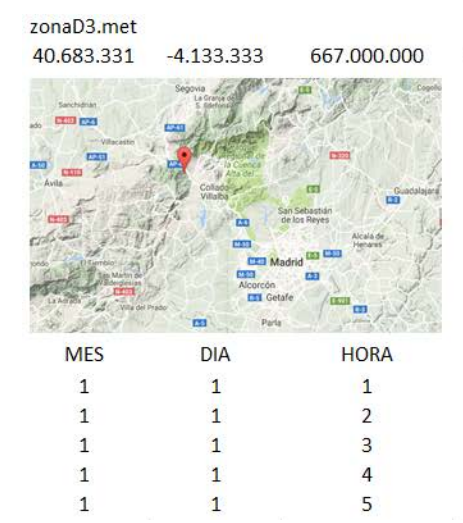

\begin{tabular}{|c|c|c|c|c|c|c|c|c|c|}
\hline \multirow{2}{*}{\multicolumn{2}{|c|}{ TEMPERATURA $(\theta)$}} & \multirow{2}{*}{\multicolumn{2}{|c|}{$\begin{array}{l}\text { RADIACIÓN } \\
\mathrm{W} / \mathrm{m}^{2}\end{array}$}} & \multicolumn{2}{|c|}{ HUMEDAD } & \multicolumn{2}{|c|}{ VIENTO } & \multirow{3}{*}{$\begin{array}{c}\text { AZIMUT } \\
\varrho\end{array}$} & \multirow{3}{*}{$\begin{array}{c}\text { CENIT } \\
\varrho\end{array}$} \\
\hline & & & & ESPECÍFICA & RELATIVA & VELOCIDAD & DIRECCIÓN & & \\
\hline$\stackrel{\circ}{\mathrm{C}}$ & EFECTIVA & RAD DIRECTA & RAD DIFUSA & $\mathrm{kgH}_{2} \mathrm{O} / \mathrm{kg}_{\text {ore seco }}$ & $\%$ & $\mathrm{~m} / \mathrm{s}$ & $E=+90$ & & \\
\hline 10.0 & -2.9 & 0 & 0 & 0.00572 & 75 & 1.1 & 218 & 0.0 & 90.0 \\
\hline 9.5 & -3.4 & 0 & 0 & 0.00568 & 77 & 0.7 & 207 & 0.0 & 90.0 \\
\hline 9.0 & -3.9 & 0 & 0 & 0.00564 & 79 & 0.5 & 249 & 0.0 & 90.0 \\
\hline 8.4 & -4.6 & 0 & 0 & 0.00555 & 81 & 0.8 & 265 & 0.0 & 90.0 \\
\hline 7.9 & -5.0 & 0 & 0 & 0.00556 & 84 & 0.8 & 263 & 0.0 & 90.0 \\
\hline
\end{tabular}

7-1 EJEMPLO DE LAS PRIMERAS LÍNEAS DE LA TABLA DE CÁLCULO (.xls)) DEL CLIMA DE REFERENCIA PARA LA ZONA CLIMÁTICA D3 (elaboración propia)

Para realizar la comparación y el análisis de las diferentes climas de aplicación a una misma zona climática se han representado y descrito algunos parámetros significativos de sus temperaturas, humedades, radiaciones y velocidad y dirección del viento.

El conjunto de las descripciones mediante gráficos y cuadros de los distintos climas sintéticos considerados se recopilan como ANEXO.

VER ANEXO 05 DESCRIPCIÓN CLIMAS DE REFERENCIA PARA LA ZONA CLIMÁTICA D3. 


\subsubsection{TEMPERATURA}

La temperatura en los distintos climas de referencia se ha procesado para obtener valores comparables entre las distintas series térmicas consultadas.

Se reproduce, con ejemplos explicativos, el conjunto de parámetros que se han considerado significativos y el proceso seguido para la obtención de estos valores.

La operativa ha requerido independizar los archivos con datos relativos a un periodo completo, en este caso anual, y los correspondientes a periodos más breves que pueden considerarse significativos.

Las tablas y gráficos relativas a las distintas series térmicas que describen el clima en la zona climática D3 se incluyen como anexo.

\section{A. EN PERIODOS ANUALES}

Para las temperaturas se han elaborado tablas anuales a partir de datos horarios, como son los valores máximos y mínimos absolutos y medios y la media anual de las temperaturas y los valores de oscilación térmica anual media, máxima y mínima.

\begin{tabular}{|c|c|c|c|c|c|c|c|c|}
\hline \multirow{3}{*}{\multicolumn{2}{|c|}{$\begin{array}{cc}\text { CTE } & \text { D3 } \\
8760 \text { líneas }\end{array}$}} & \multicolumn{4}{|c|}{ TEMPERATURAS ANUALES } & \multirow{2}{*}{\multicolumn{3}{|c|}{$\begin{array}{c}\text { OSCILACION TERMICA } \\
\text { ANUAL }\end{array}$}} \\
\hline & & \multicolumn{2}{|c|}{ ABSOLUTA } & \multirow{2}{*}{$\begin{array}{l}37,0 \\
18,8 \\
\end{array}$} & \multirow{2}{*}{$\begin{array}{l}-5,1 \\
8,0\end{array}$} & & & \\
\hline & & MED & 13,6 & & & 10,8 & 17,9 & 1,5 \\
\hline FECHA & HORA & $\stackrel{\circ}{C}$ & MED & MAX & MIN & MEDIA & MAX & MIN \\
\hline 1-ene. & 1:00 & 10,0 & 9,3 & 12,1 & 6,8 & 5,3 & & \\
\hline 1-ene. & 2:00 & 9,5 & 9,3 & 12,1 & 6,8 & 5,3 & & \\
\hline 1-ene. & $3: 00$ & 9,0 & 9,3 & 12,1 & 6,8 & 5,3 & & \\
\hline 1-ene. & $4: 00$ & 8,4 & 9,3 & 12,1 & 6,8 & 5,3 & & \\
\hline
\end{tabular}

7-2 EJEMPLO DE LAS PRIMERAS LíNEAS DE LA TABLA DE CÁLCULO (.xIs) DE LAS TEMPERATURAS PARA EL CLIMA DE REFERENCIA (Elaboración propia)

Del mismo modo se calcula la proporción de temperaturas en cada rango desde las más frías, por debajo de $0^{\circ} \mathrm{C}$, hasta las más cálidas, superiores a $28^{\circ} \mathrm{C}$. Para los valores medios se toman otros valores significativos como son las temperaturas horarias totales $y$ las medias, máximas absolutas y mínimas absolutas diarias. 


\begin{tabular}{|c|c|c|c|c|}
\hline \multicolumn{5}{|c|}{ TEMPERATURAS HORARIAS } \\
\hline FRIA $<0 \circ \mathrm{C}$ & MUY BAJA 0-10ㄷ & BAJA 10-18ㄷ & TEMPLADA 18-28C & CALIDA >=28C \\
\hline $3 \%$ & $37 \%$ & $29 \%$ & $24 \%$ & $7 \%$ \\
\hline 228 & 3260 & 2570 & 2088 & 614 \\
\hline
\end{tabular}

\begin{tabular}{|c|c|c|c|c|}
\hline \multicolumn{5}{|c|}{ TEMPERATURAS MEDIAS DIARIAS } \\
\hline FRIA $\angle 0 \circ \mathrm{C}$ & MUY BAJA 0-10ㄷ & BAJA 10-18ㄷ & TEMPLADA 18-28ㄷ & CALIDA >28ㄷ C \\
\hline $1 \%$ & $40 \%$ & $27 \%$ & $30 \%$ & $2 \%$ \\
\hline 3 & 147 & 98 & 109 & 8 \\
\hline
\end{tabular}

\begin{tabular}{|c|c|c|c|c|}
\hline \multicolumn{5}{|c|}{ TEMPERATURAS MÁXIMAS DIARIAS ABSOLUTAS } \\
\hline FRIA <0C & MUY BAJA 0-10C & BAJA 10-18ㄷ & TEMPLADA 18-28ㄷ & CALIDA >28C \\
\hline $0 \%$ & $15 \%$ & $37 \%$ & $27 \%$ & $21 \%$ \\
\hline 0 & 56 & 136 & 97 & 76 \\
\hline
\end{tabular}

\begin{tabular}{|c|c|c|c|c|}
\hline \multicolumn{5}{|c|}{ TEMPERATURAS MINIMAS DIARIAS ABSOLUTAS } \\
\hline FRIA $<0 \circ \mathrm{C}$ & MUY BAJA 0-10ㄷ & BAJA 10-18ㄷ & TEMPLADA 18-28ㄷ & CALIDA >28C \\
\hline $12 \%$ & $50 \%$ & $28 \%$ & $10 \%$ & $0 \%$ \\
\hline 45 & 181 & 103 & 36 & 0 \\
\hline
\end{tabular}

7-3 TABLAS RESUMEN DE LA FRACCIÓN DE TEMPERATURAS: HORARIAS, MEDIAS, MÁXIMAS Y MÍNIMAS POR RANGO EN \% Y HORAS (Elaboración propia)

También se han calculado varios percentiles (quintiles y cuartiles), para obtener sus medias anuales y su oscilación media anual.

\begin{tabular}{|c|c|c|c|c|c|c|c|c|c|}
\hline \multirow{3}{*}{$\begin{array}{c}\text { CTE } \\
8760\end{array}$} & \multicolumn{4}{|l|}{ D3 } & \multicolumn{5}{|c|}{ QUINTILES } \\
\hline & líneas & INT & RVALOS & 2,09 & 2,55 & 2,18 & $-6,82$ & 3,96 & 10,79 \\
\hline & MEDIA & 13,6 & 8,0 & 10,1 & 12,6 & 14,8 & 8,0 & 18,8 & OSCIL \\
\hline & & $\stackrel{\circ}{C}_{C}$ & MIN & $20 \%$ & $40 \%$ & $60 \%$ & $80 \%$ & AAX & TOTAL \\
\hline
\end{tabular}

\begin{tabular}{|c|c|c|c|c|c|c|c|c|}
\hline \multirow{3}{*}{$\begin{array}{c}\text { CTE } \\
8760\end{array}$} & \multirow{3}{*}{$\begin{array}{l}\text { D3 } \\
\text { líneas } \\
\end{array}$} & \multicolumn{7}{|c|}{ CUARTILES } \\
\hline & & \multicolumn{2}{|c|}{ INTERVALOS } & \multirow{2}{*}{$\begin{array}{l}2,09 \\
10,1\end{array}$} & \multirow{2}{*}{$\begin{array}{l}2,55 \\
12,6\end{array}$} & \multirow{2}{*}{$\frac{2,19}{14,8}$} & \multirow{2}{*}{$\begin{array}{l}3,96 \\
18,8\end{array}$} & \multirow{2}{*}{$\begin{array}{c}10,789 \\
\text { OSCIL }\end{array}$} \\
\hline & & 13,6 & 8,0 & & & & & \\
\hline & & $\stackrel{\circ}{C}^{-}$ & MIN & $25 \%$ & $50 \%$ & $75 \%$ & MAX & TOTAL \\
\hline
\end{tabular}

7-4 TABLAS RESUMEN DE PERCENTILES (Elaboración propia) 
Para facilitar la visualización de las series térmicas se han elaborado varias gráficas anuales describiendo su evolución. Aunque no se pretende ningún valor estadístico se han incorporado líneas de tendencia que pueden informar de la evolución media de las temperaturas y la oscilación térmica.

CLIMA TIPO D3.

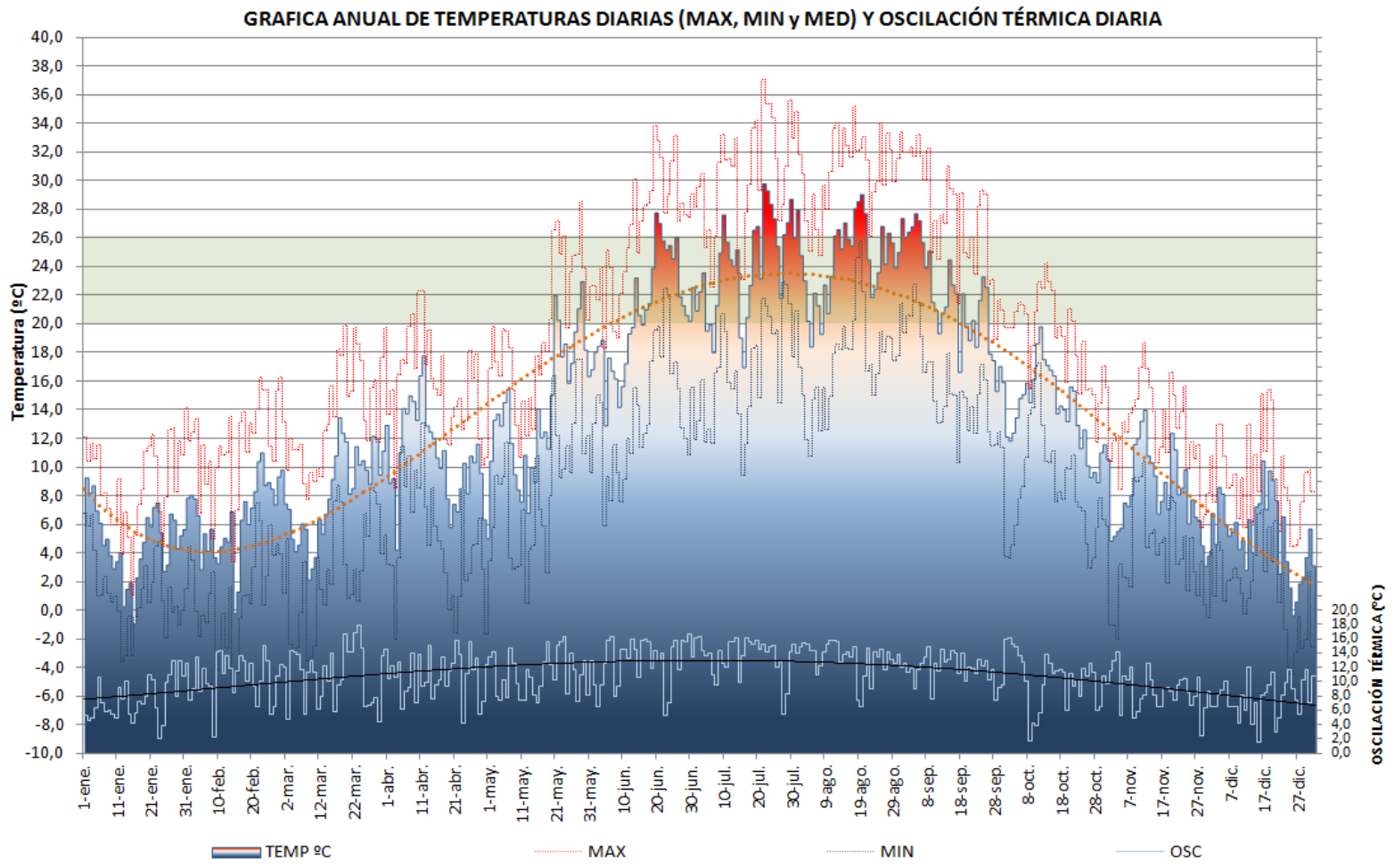

7-5 GRÁFICA ANUAL DE TEMPERATURAS HORARIAS Y OSCILACIONES TÉRMICAS PARA CLIMA DE REFERENCIA DE LA ZONA CLIMÁTICA D3 (ELABORACIÓN PROPIA) 
También se han elaborado gráficas con los valores medios, máximos y mínimos cada 3 días y sus correspondientes líneas de tendencia para ilustrar la evolución comparada de los valores medios considerados cada día o cada varios días.

CLIMA TIPO D3.

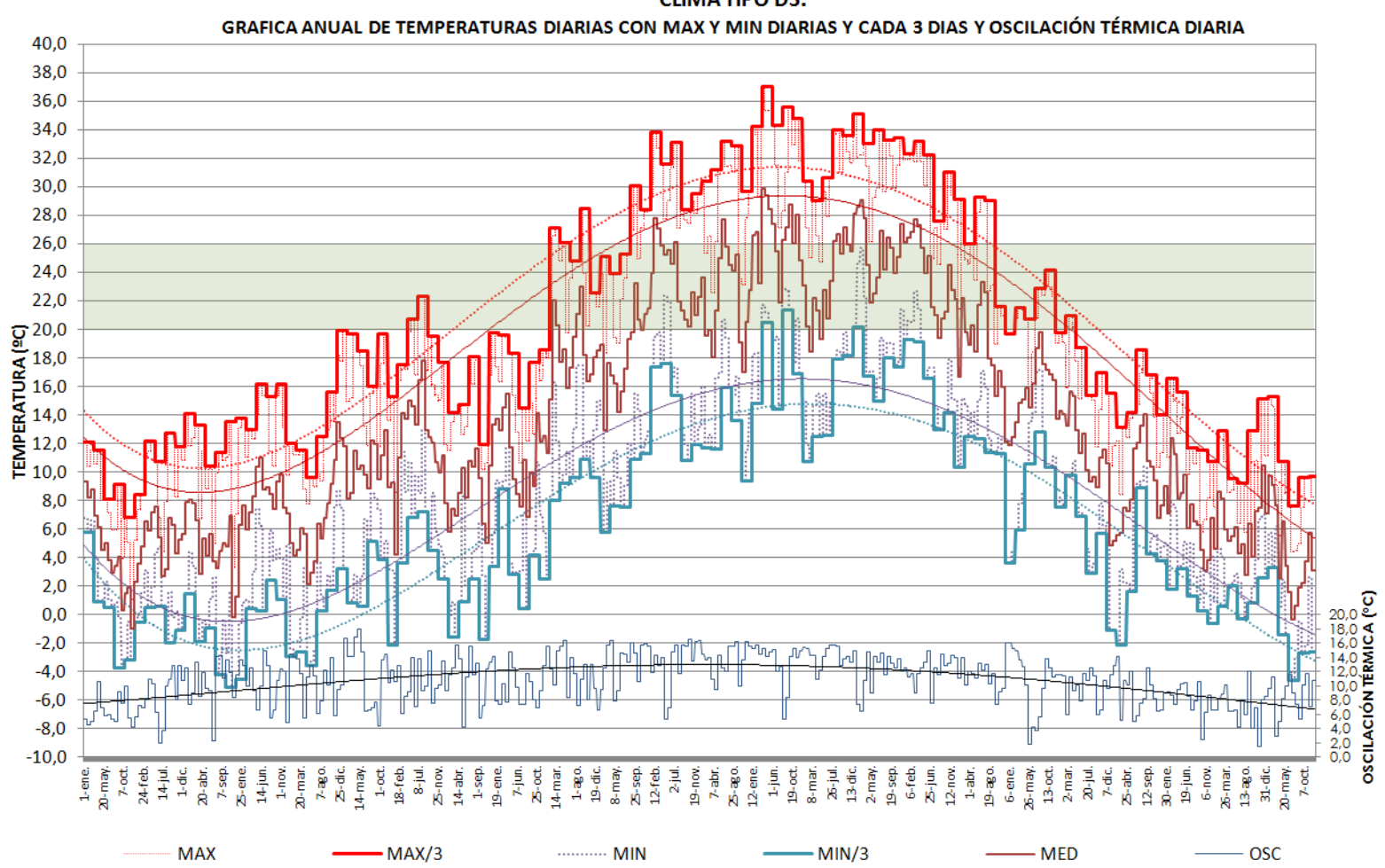

7-6 GRÁFICA ANUAL DE TEMPERATURAS HORARIAS Y DE LAS MEDIAS CADA 3 DÍAS Y OSCILACIONES TÉRMICAS PARA CLIMA DE REFERENCIA DE LA ZONA CLIMÁTICA D3 (Elaboración propia) 
CUMATIPO D3.

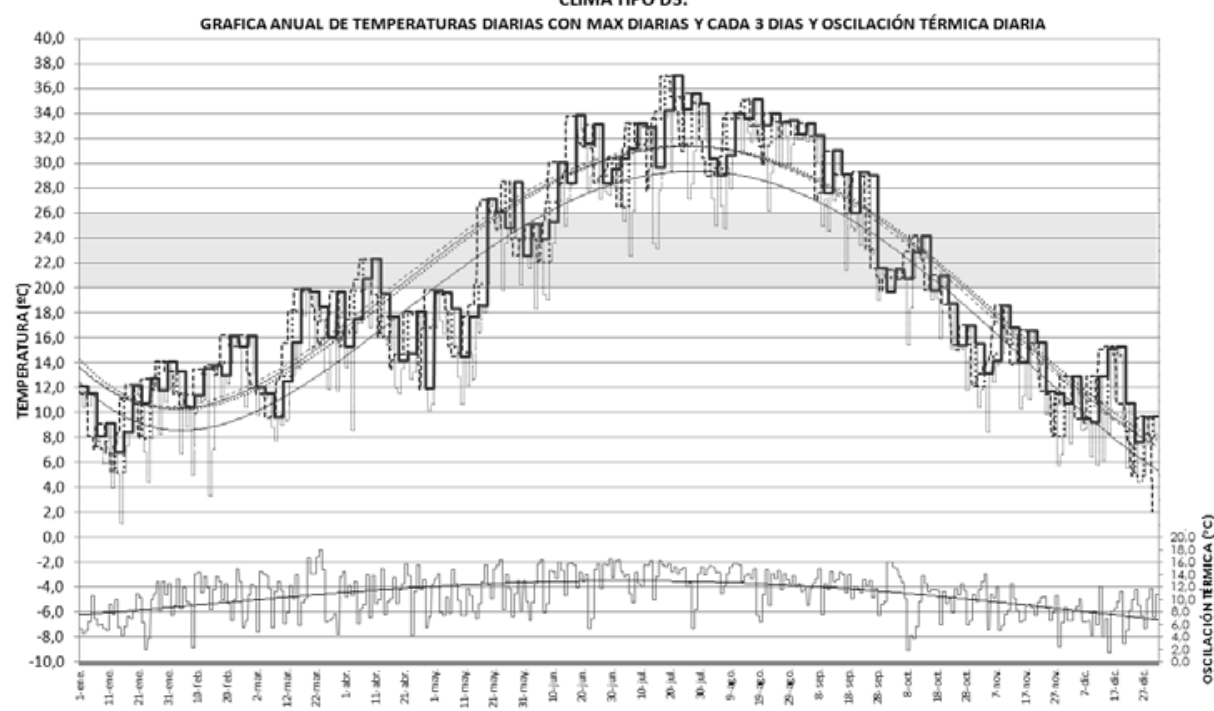

DESCRIPCIÓN CLIMAS DE REFERENCIA PARA LA ZONA CLIMÁTICA D3

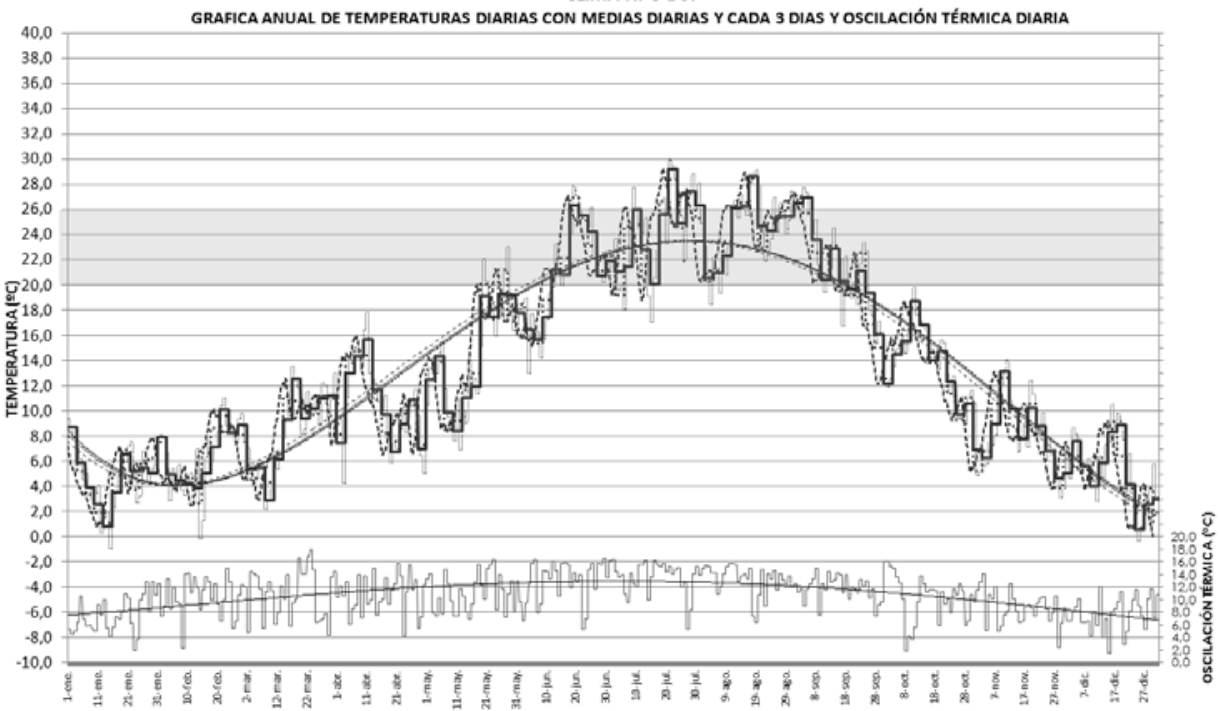

MED

-MED/3

....... MED2/3

.......MED2/3

- osc

CUMATIPO D3.

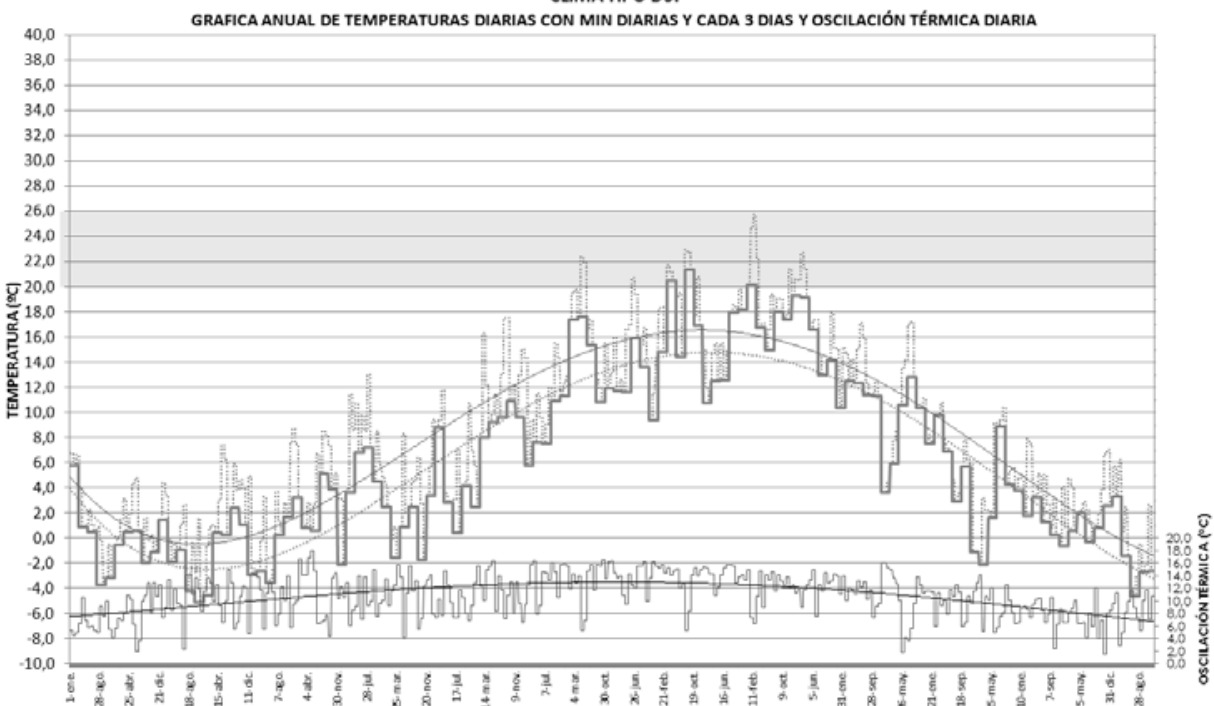

MIN - MIN/3 $\longrightarrow$ OSC

7-7 GRÁFICA ANUAL DE TEMPERATURAS MEDIAS HORARIAS CADA 3 DÍAS Y OSCILACIONES TÉRMICAS PARA CLIMA DE REFERENCIA DE LA ZONA CLIMÁTICA D3 (Elaboración propia) 
B. EVOLUCIÓN MENSUAL DE LA TEMPERATURA EXTERIOR PARA CLIMAS DE REFERENCIA EN LA ZONA CLIMÁTICA D3-CTE

La importancia de las secuencias diarias y de la evolución de la temperatura a lo largo de varios días para la respuesta del edificio, habida cuenta del retardo y la amortiguación de su respuesta, invita a elaborar secuencias más breves que permitan observar aquellos periodos que pueden considerarse como singulares o extraordinarios y los que se repiten con más frecuencia en la vida útil del edificio.

Para observar la capacidad de los climas de referencia de representar estas circunstancias se realizan segregaciones de los datos anuales en secuencias más cortas, como son las mensuales, de las que se deducirán los periodos que manifiestan características comunes.

Se han elaborado gráficas mensuales incluyendo, junto a la temperatura, los valores de humedad relativa, radiación total y velocidad del viento, y observar así mejor las correlaciones.

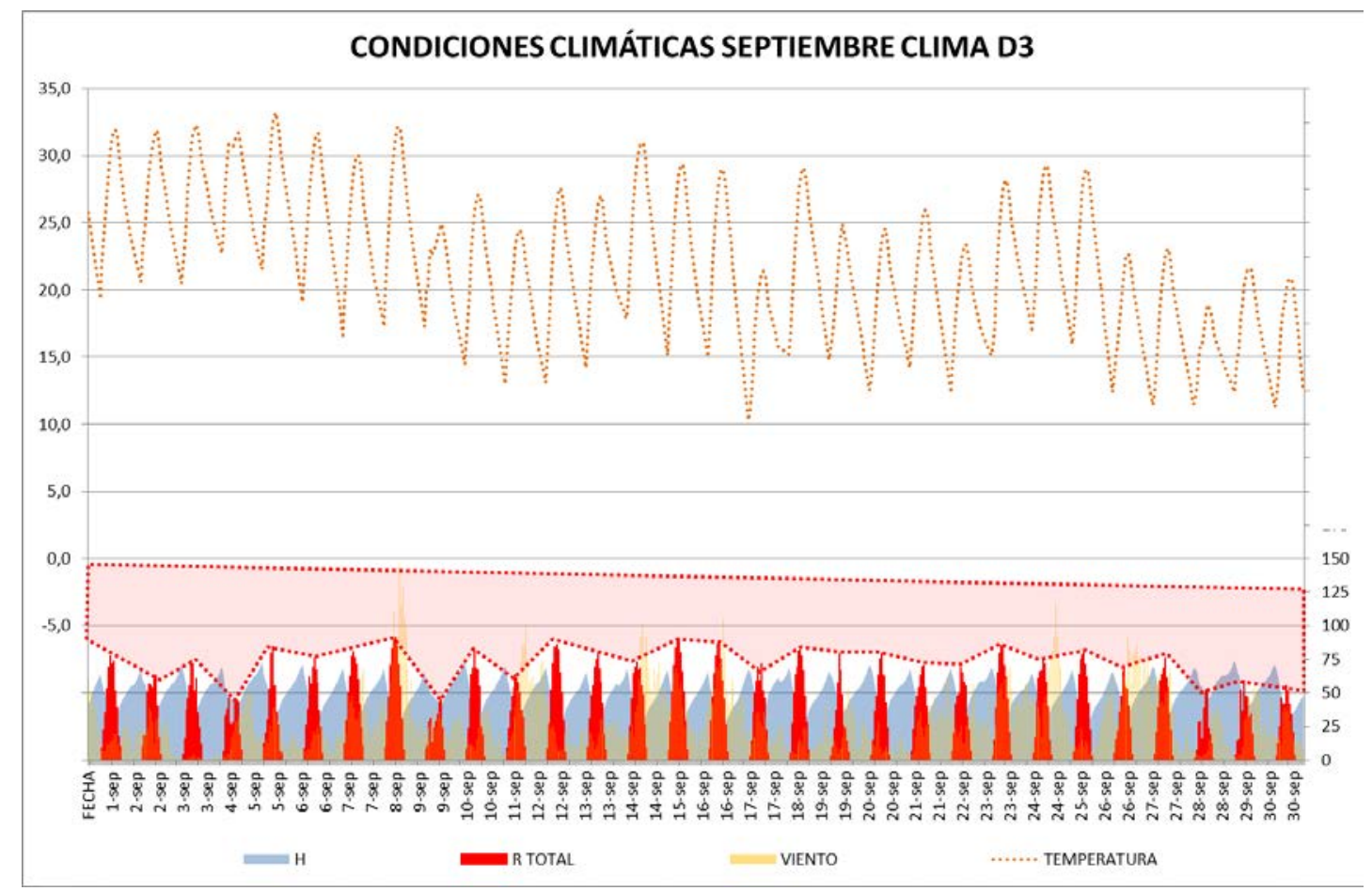

7-8 GRAFICA MENSUAL DE VALORES HORARIOS TIPO (MES DE SEPTIEMBRE) PARA LA ZONA CLIMÁTICA D3, SEGÚN CTE, INDICANDO LA RADIACIÓN TOTAL, VELOCIDAD DEL VIENTO Y LA HUMEDAD RELATIVA (ELABORACIÓN PROPIA) 
Para facilitar la observación de la evolución de la temperatura durante este periodo se complementa el gráfico con la curva de regresión.
VER ANEXO 05

DESCRIPCIÓN CLIMAS DE REFERENCIA PARA LA ZONA CLIMÁTICA D3.

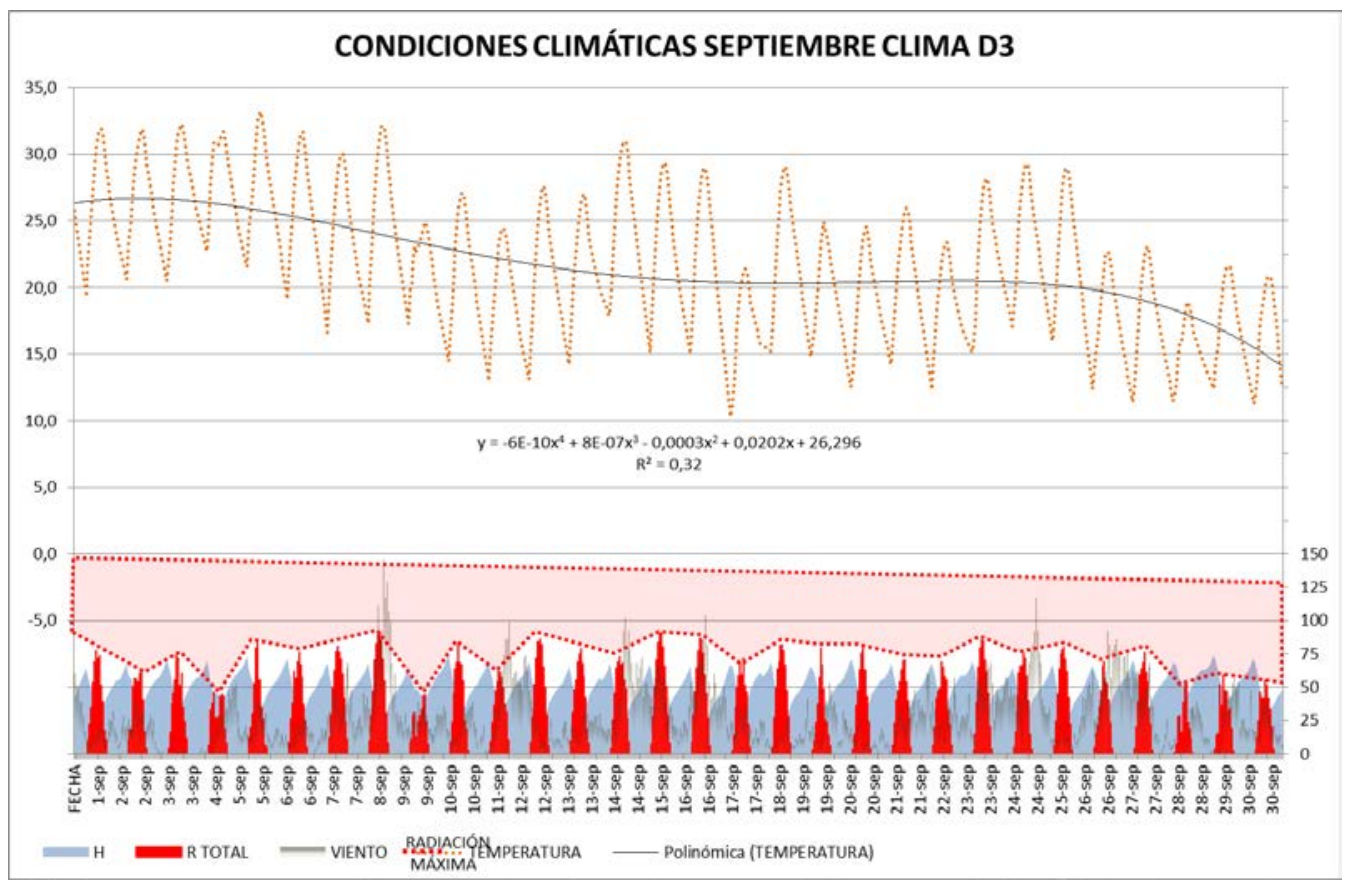

7-9 GRAFICA MENSUAL DE VALORES HORARIOS TIPO (MES DE SEPTIEMBRE) PARA LA ZONA CLIMÁTICA D3, SEGÚN CTE, INDICANDO LA RADIACIÓN TOTAL, VELOCIDAD DEL VIENTO Y LA HUMEDAD RELATIVA Y LA CURVA DE REGRESIÓN DE LA SECUENCIA TÉRMICA (ELABORACIÓN PROPIA) 
La representación de las temperaturas medias sobre este gráfico permite observar su evolución y la relación con la oscilación térmica diaria.

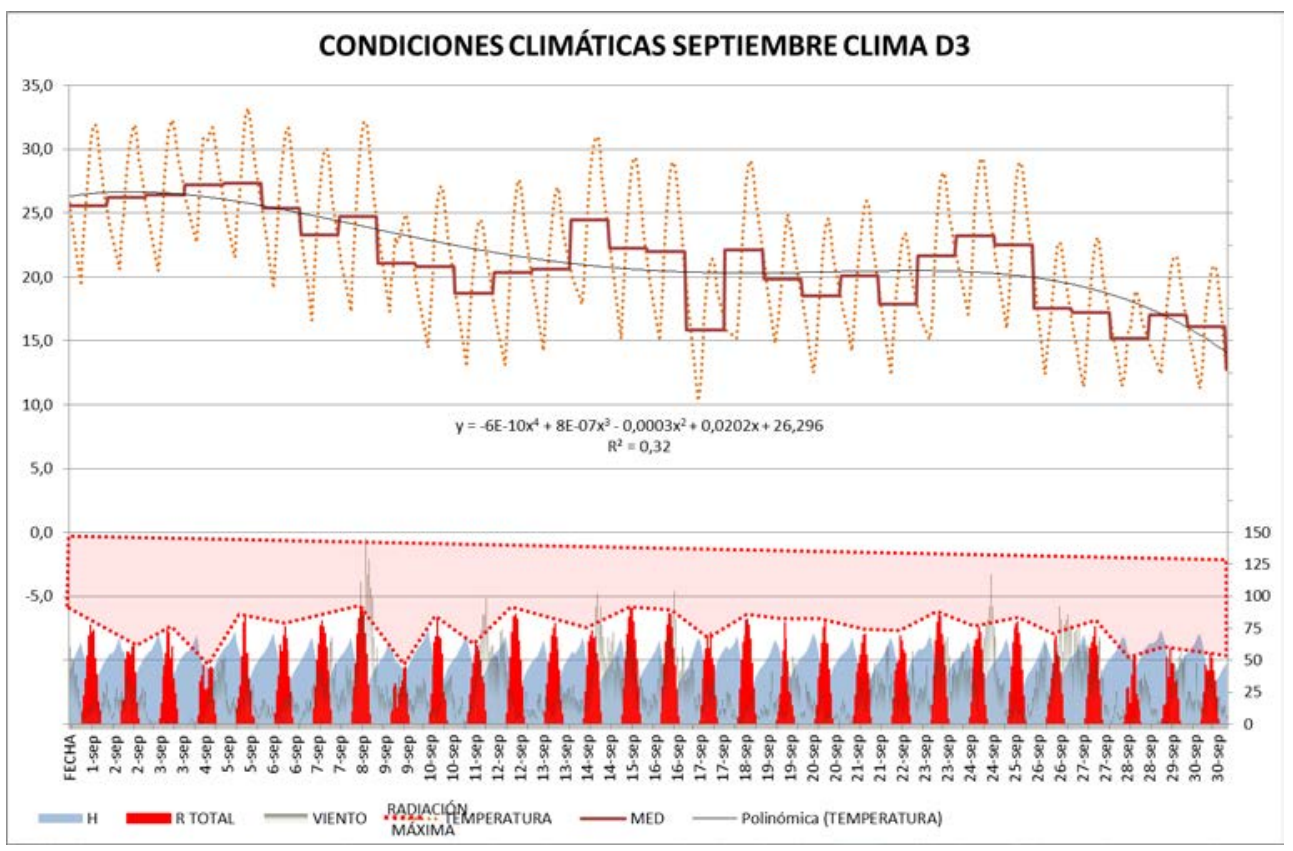

VER ANEXO 05

DESCRIPCIÓN CLIMAS DE REFERENCIA PARA LA ZONA CLIMÁTICA D3.

7-10 GRAFICA MENSUAL DE VALORES HORARIOS TIPO (MES DE SEPTIEMBRE) PARA LA ZONA CLIMÁTICA D3, SEGÚN CTE, INDICANDO LA RADIACIÓN TOTAL, VELOCIDAD DEL VIENTO Y LA HUMEDAD RELATIVA, Y LAS TEMPERATURAS MEDIAS DIÁRIAS (ELABORACIÓN PROPIA) 
Otra representación gráfica para facilitar el análisis hace una segregación de los periodos más representativos, ya sea por su tendencia ascendente o descendente, por reducir la oscilación térmica o ampliarla, o por mantener los valores máximos y mínimos varios días consecutivos.

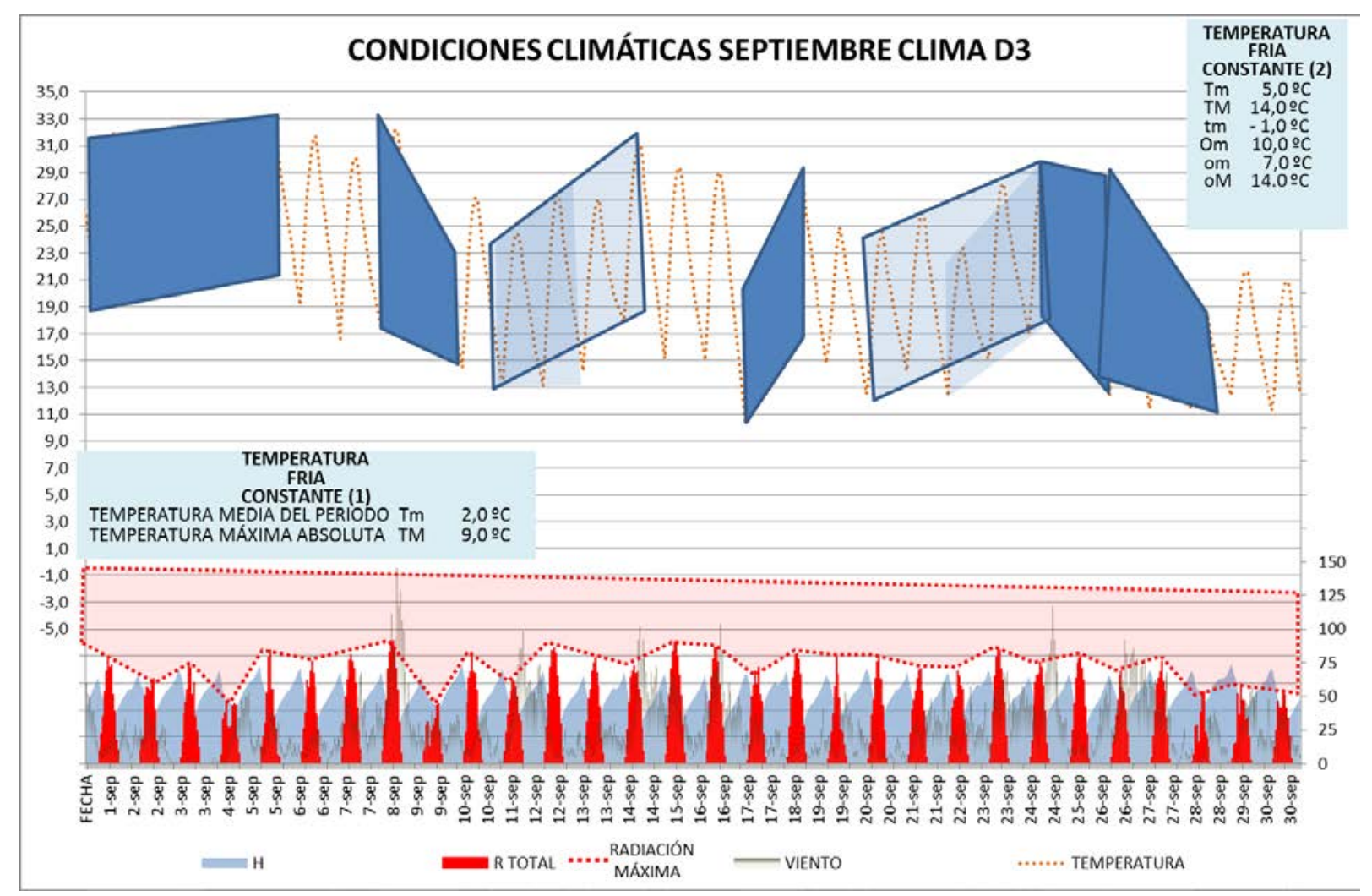

7-11 GRAFICA MENSUAL DE VALORES HORARIOS TIPO (MES DE SEPTIEMBRE) PARA LA ZONA CLIMÁTICA D3, SEGÚN CTE, INDICANDO LA RADIACIÓN TOTAL, VELOCIDAD DEL VIENTO Y LA HUMEDAD RELATIVA Y ALGUNAS SECUENCIAS ASCENDENTES Y RESCENDENTES REPRESENTATIVAS (ELABORACIÓN PROPIA) 


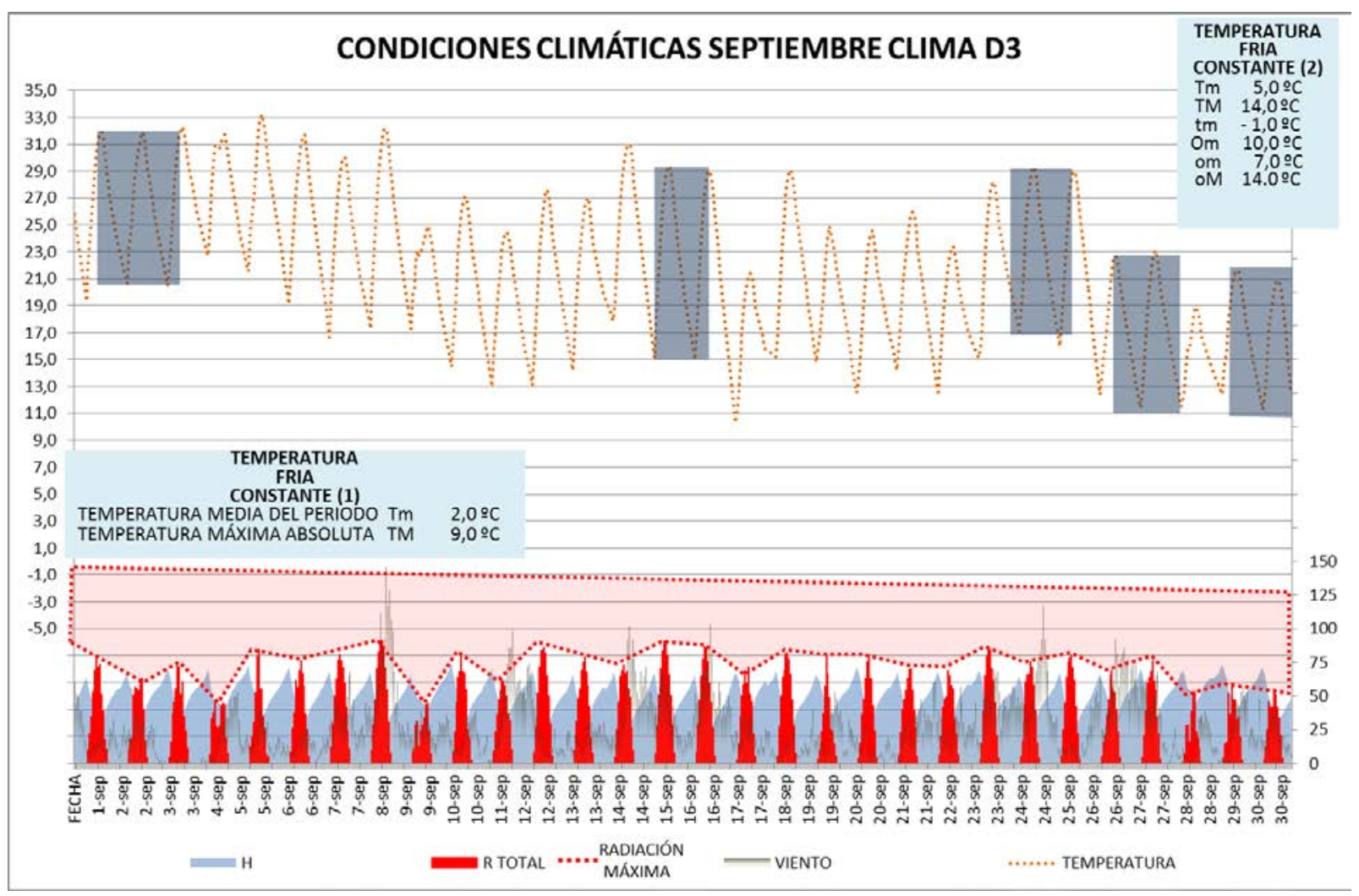

7-12 GRAFICA MENSUAL DE VALORES HORARIOS TIPO (MES DE SEPTIEMBRE) PARA LA ZONA CLIMÁTICA D3, SEGÚN CTE, INDICANDO LA RADIACIÓN TOTAL, VELOCIDAD DEL VIENTO Y LA HUMEDAD RELATIVA Y ALGUNAS SECUENCIAS REPRESENTATIVAS DONDE LAS TEMPERATURAS SE MANTIENEN (ELABORACIÓN PROPIA) 
La representación en periodos más cortos (7 días) permite matizar las observaciones realizadas en secuencias mensuales.

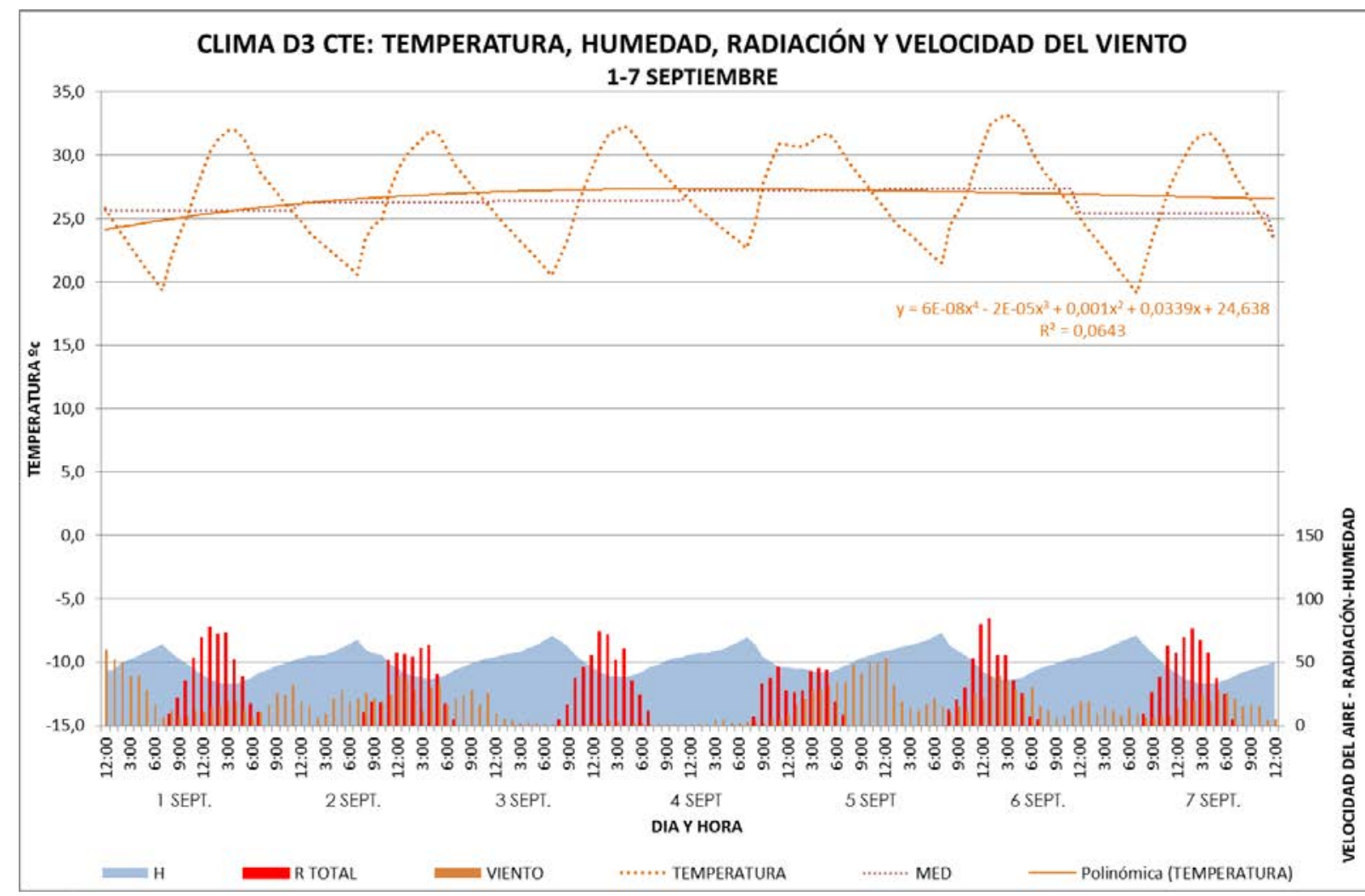

7-13 GRAFICA SEMANAL DE VALORES HORARIOS TIPO (1-7 DE SEPTIEMBRE) PARA LA ZONA CLIMÁTICA D3, SEGÚN CTE, INDICANDO LA RADIACIÓN TOTAL, VELOCIDAD DEL VIENTO Y LA HUMEDAD RELATIVA (ELABORACIÓN PROPIA) 


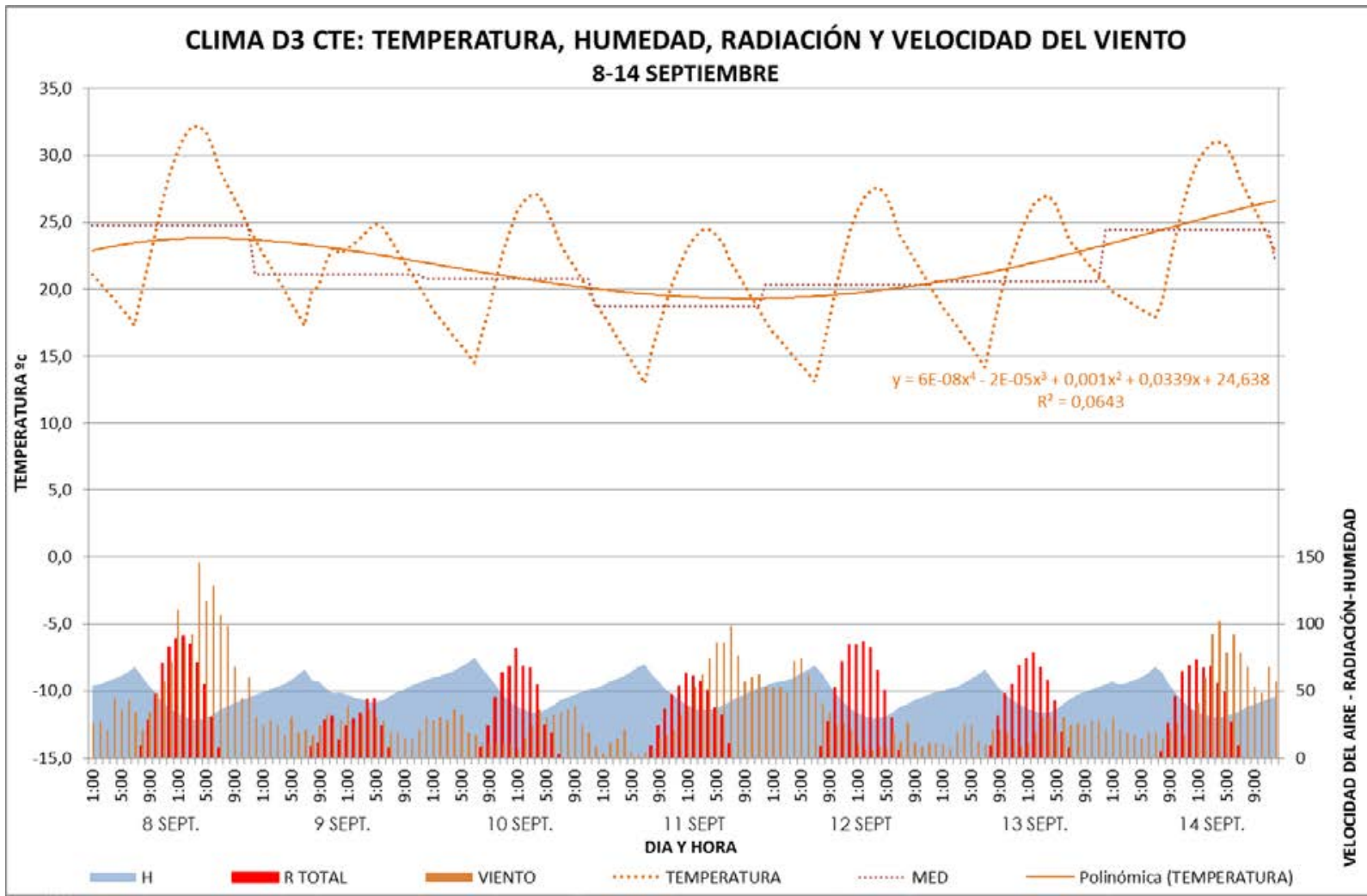

7-14 GRAFICA SEMANAL DE VALORES HORARIOS TIPO (8-14 DE SEPTIEMBRE) PARA LA ZONA CLIMÁTICA D3, SEGÚN CTE, INDICANDO LA RADIACIÓN TOTAL, VELOCIDAD DEL VIENTO Y LA HUMEDAD RELATIVA (ELABORACIÓN PROPIA) 


\subsubsection{HUMEDAD RELATIVA}

Para analizar las humedades relativas se han elaborado cuadros y tablas con valores anuales a partir de estos datos horarios extrayendo y extraído sus valores máximos y mínimos absolutos y medios y la temperatura media anual y los valores de oscilación térmica anual media, máxima y mínima. En este caso se ha considerado significativa la oscilación térmica y la proporción de horas en que se producen superaciones de humedades extremas, que se han considerado del $20 \%$ y del $80 \%$.

\begin{tabular}{|c|c|c|c|c|c|c|c|c|}
\hline CTE & D3 & HUMEDAD & MAX & MIN & MED & Omin & Omax & Omed \\
\hline \multirow[t]{3}{*}{8760} & líneas & $\mathrm{H}_{\max }$ & 98 & 80 & \multirow{2}{*}{58} & 10 & 59 & 34 \\
\hline & & $\mathrm{H}_{\min }$ & 53 & 20 & & \multicolumn{3}{|c|}{ OSCILACIÓN DIARIA } \\
\hline & & & $>80 \%$ & $<20 \%$ & \multirow{2}{*}{\multicolumn{4}{|c|}{$90,3 \%$ horas entre $20 \%$ y $80 \%$}} \\
\hline FECHA & HORA & & $9,7 \%$ & $0,0 \%$ & & & & \\
\hline 1-ene. & $1: 00$ & 75 & 89 & 68 & 78,5 & 2 & & \\
\hline 1-ene. & $2: 00$ & 77 & 89 & 68 & 78,5 & 2. & & \\
\hline 1-ene. & $3: 00$ & 79 & 89 & 68 & 78,5 & 2 & & \\
\hline 1-ene. & $4: 00$ & 81 & 89 & 68 & 78,5 & 2 & & \\
\hline
\end{tabular}

7-15 TABLAS RESUMEN DE HUMEDADES RELATIVAS MEDIAS, MÁXIMAS, MíNIMAS, OSCILACIONES TÉRMICAS Y SUPERACIÓN DE UMBRALES (Elaboración propia)

La evolución anual de la humedad relativa horaria y su oscilación diaria, se representa en un gráfico con los días en las abscisas y los valores de humedad relativa y la oscilación en las ordenadas.

\section{CLIMA TIPO D3. HUMEDAD RELATIVA DISTRIBUCIÓN ANUAL}

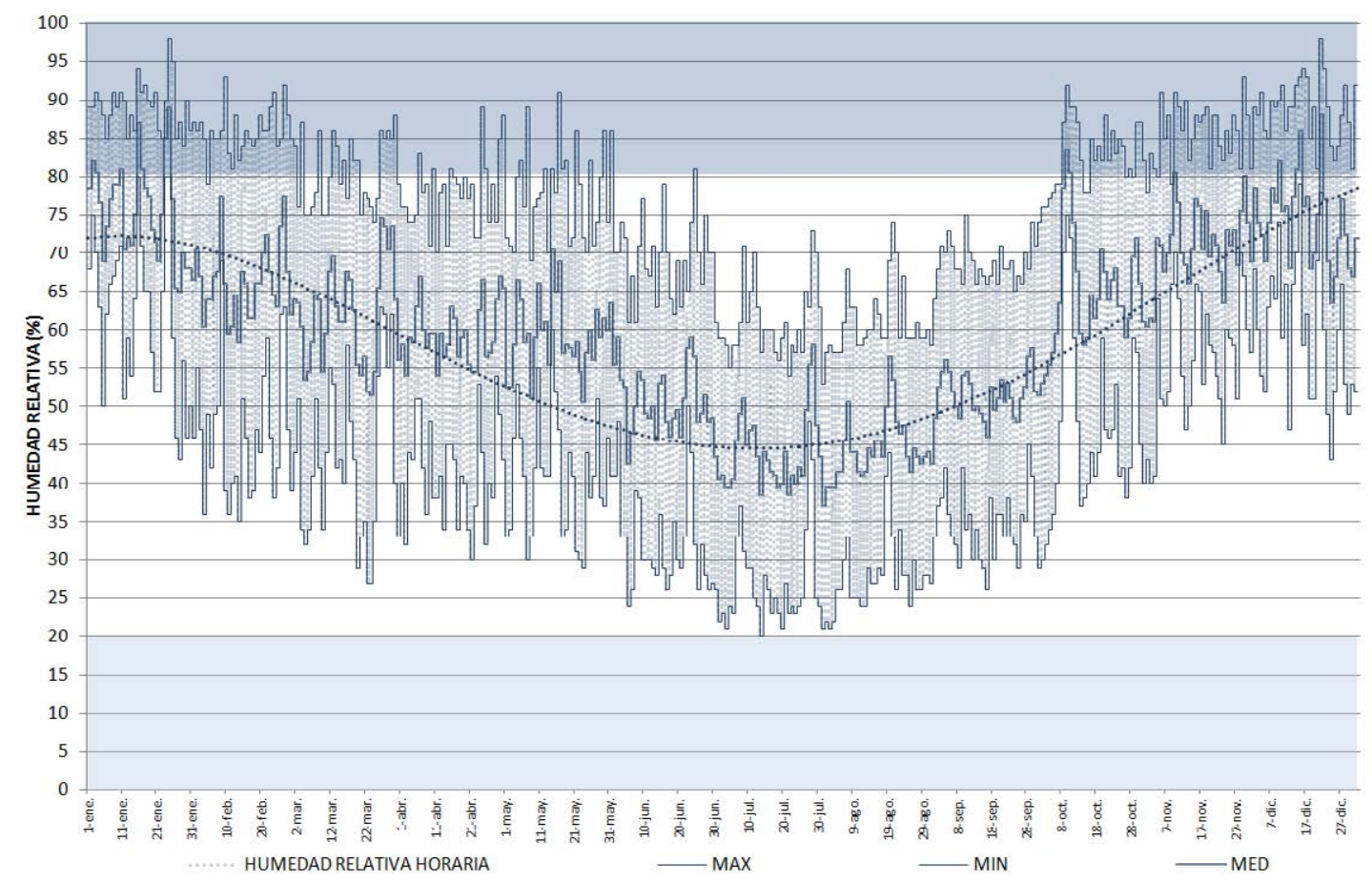

7-16 GRÁFICO DE LA EVOLUCIÓN ANUAL DE LAS HUMEDADES RELATIVAS HORARIAS Y LAS OSCILACIONES DIARIAS (Elaboración propia) 


\subsubsection{RADIACIÓN}

Para representar la radiación se ha dispuesto de gráficos anuales con las radiaciones totales diarias, expresada en $\mathrm{kW} / \mathrm{m}^{2}$, y su curva de tendencia y los valores no acumulados de radiación directa y difusa, expresados en $\mathrm{W} / \mathrm{m}^{2}$.

La radiación segregada en directa, difusa y total y sus correspondientes curvas de regresión a lo largo del año aportan información muy valiosa para establecer el potencial de captación por periodos.

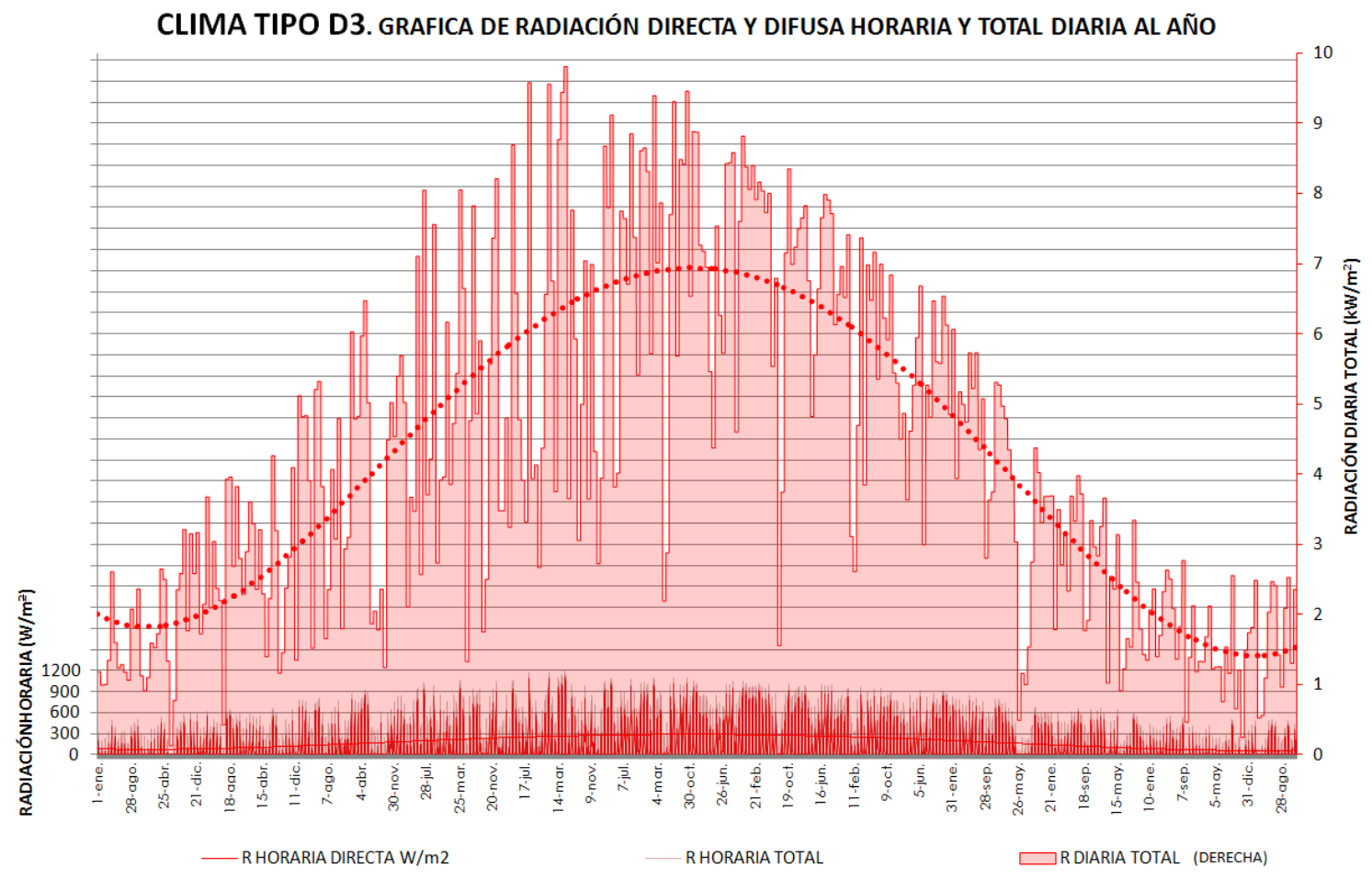

\section{7-17 GRAFICA ANUAL DE RADIACIÓN DIARIA CON CURVA DE REGRESIÓN Y} RADIACIÓN HORARIA DIFUSA Y DIRECTA (Elaboración propia)

Ha resultado de interés mostrar la radiación total diaria a lo largo del año segregada por rangos, desde aquellas menores de 2,0 $\mathrm{kW} / \mathrm{m}^{2}$ hasta las mayores de $8,0 \mathrm{~kW} / \mathrm{m}^{2}$. Del mismo modo se segrega la radiación horaria máxima diaria desde valores menores de $250 \mathrm{~W} / \mathrm{m}^{2}$ hasta valores mayores de $1000 \mathrm{~W} / \mathrm{m}^{2}$, expresados ambos valores en horas y porcentajes. 
DISTRIBUCIÓN DE LA RADIACIÓN SOLAR DIARIA TOTAL $\left(\mathrm{kW} / \mathrm{m}^{2}\right)$ DURANTE EL AÑO MUY BAJA $<2,0 \quad$ BAJA 2,0-4,0 MEDIA 4,0-6,0 ALTA 6,0-8,0 MUY ALTA $>8,0$

\begin{tabular}{|c|c|c|c|c|}
\hline $21 \%$ & $33 \%$ & $20 \%$ & $17 \%$ & $9 \%$ \\
\hline 78 & 119 & 74 & 61 & 33 \\
\hline \multicolumn{5}{|c|}{ NÚMERO DE DÍAS EN EL AÑO } \\
\hline
\end{tabular}

DISTRIBUCIÓN DE LA RADIACIÓN MÁXIMA SOLAR DIARIA (W/m²) DURANTE EL AÑO

\begin{tabular}{|c|c|c|c|c|}
\hline MUY BAJA $<250$ & BAJA $250-500$ & MEDIA 500 - 750 & ALTA 750-1000 & MUY ALTA >1000 \\
\hline $9 \%$ & $27 \%$ & $19 \%$ & $36 \%$ & $8 \%$ \\
\hline 32 & 99 & 71 & 133 & 30 \\
\hline \multicolumn{5}{r|r}{ NÚMERO DE DÍAS EN EL AÑO } \\
\hline
\end{tabular}

7-18 TABLAS DE RADIACIÓN MÁXIMA DIARIA Y RADIACIÓN TOTAL DIARIA SEGREGADA POR RANGOS EXPRESADA EN PORCENTAJE Y N ${ }^{\circ}$ DE DÍAS (Elaboración propia) 


\subsubsection{DIRECCIÓN Y VELOCIDAD DEL VIENTO}

La velocidad del viento se representa gráficamente en sus valores absolutos horarios. También se representan los valores medios, medios y mínimos diarios, expresados en $\mathrm{m} / \mathrm{s}$.

VER ANEXO 05

DESCRIPCIÓN CLIMAS DE REFERENCIA PARA ZONA

CLIMÁTICA D3

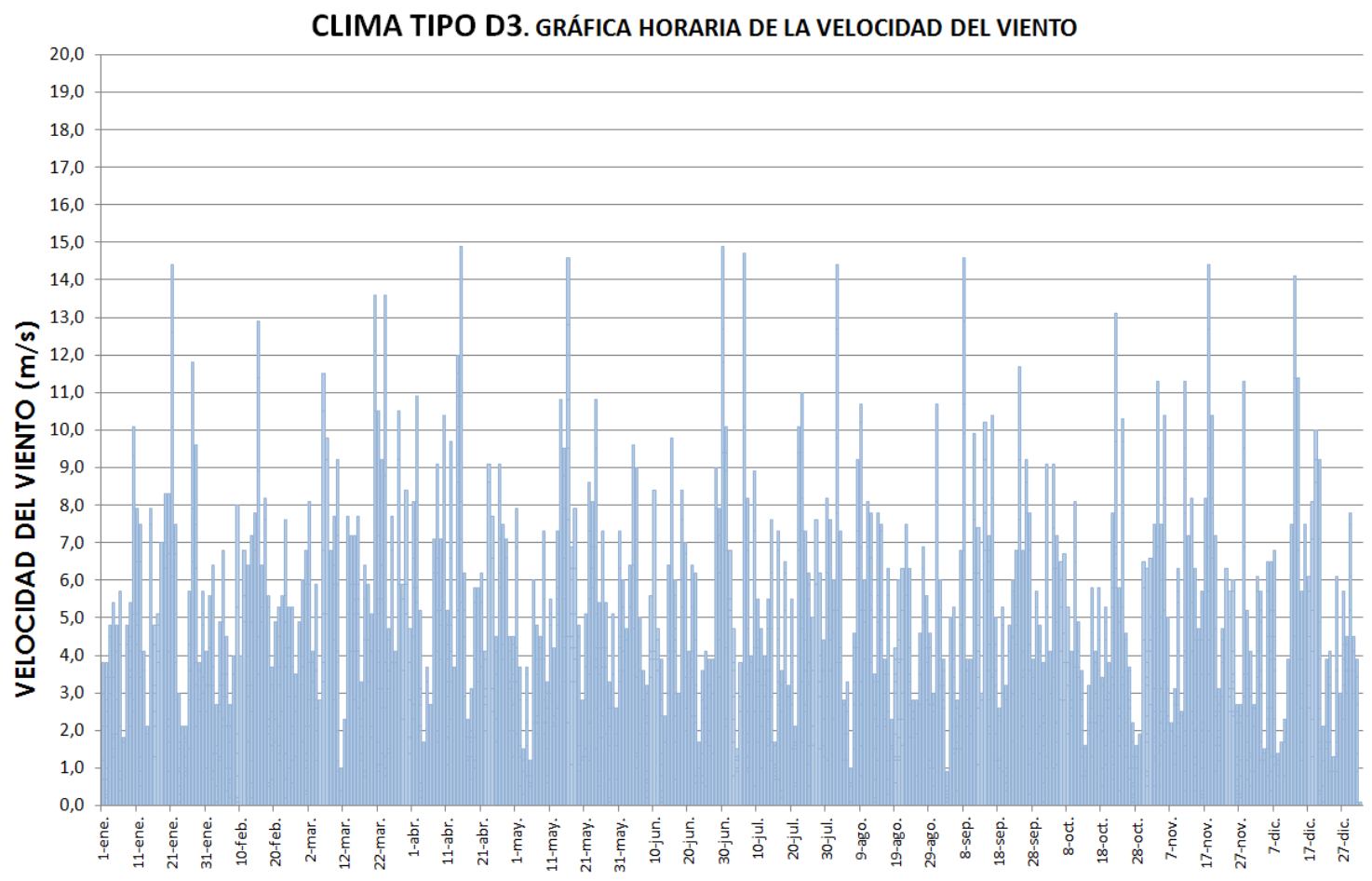

7-19 GRAFICA ANUAL DE VELOCIDADES DEL VIENTO HORARIA EN m/s (Elaboración propia)

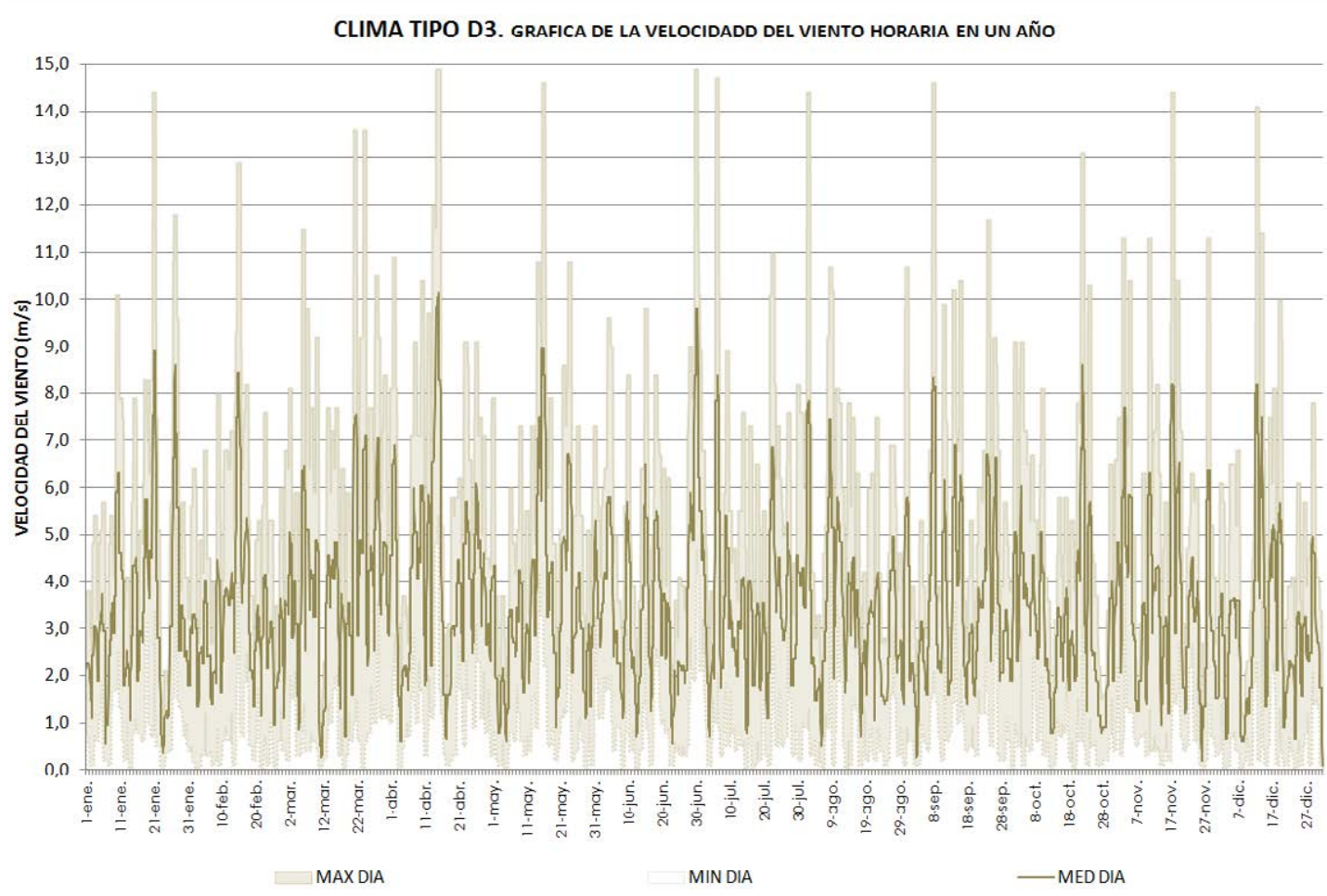

7-20 GRÁFICA ANUAL DE VELOCIDADES MÁXIMAS, MEDIAS Y MÍNIMAS DIARIAS EXPRESADAS EN m/s (Elaboración propia)

La gran dispersión de los valores de velocidad del viento se expresa en valores de calma, oscilación diaria y velocidades máximas y mínimas del viento expresadas en $\mathrm{m} / \mathrm{s}$. 


\begin{tabular}{|c|c|c|c|c|c|c|c|c|c|}
\hline \multicolumn{10}{|c|}{ VELOCIDAD DEL VIENTO (m/s) } \\
\hline MAX & MED & $\mathrm{n} \div$ cal & mas & $\mathrm{MAX}_{\text {DIA }}$ & MIN DIA & $M_{\text {DIA }}$ & Omin & Omed & Omax \\
\hline 14,9 & 2,8 & 193,0 & $2,2 \%$ & 1,49 & 0,01 & 0,62 & 0,0 & 5,4 & 14,2 \\
\hline \multicolumn{2}{|c|}{$\mathrm{m} / \mathrm{s}$} & \multicolumn{2}{|c|}{ HORAS } & \multicolumn{3}{|c|}{$\mathrm{m} / \mathrm{s}$} & \multicolumn{3}{|c|}{$\mathrm{m} / \mathrm{s}$} \\
\hline
\end{tabular}

7-21 TABLA DE LA PROPORCIÓN EN POCENTAJE Y HORAS DE LAS CALMAS PRODUCIDAS, VELOCIDAD DEL VIENTO MÁXIMA, MÍNIMA Y MEDIA Y OSCILACIÓN DIARIA EN LA VELOCIDAD DEL VIENTO(Elaboración propia)

Se ha considerado de interés la segregación por rangos de la velocidad del viento, expresando como calmas los periodos en que es menor de $1 \mathrm{~m} / \mathrm{s}$ y como muy altos los valores superiores a 10 $\mathrm{m} / \mathrm{s}$.

\begin{tabular}{|c|c|c|c|c|}
\hline \multicolumn{5}{|c|}{ VELOCIDAD DEL VIENTO (m/s) POR PERIODOS HORARIOS } \\
\hline calma $\leq 1$ & baja 2-4 & moderada 4-6 & alta 6-10 & extrema >10 \\
\hline $23 \%$ & $52 \%$ & $15 \%$ & $8 \%$ & $1 \%$ \\
\hline 2018 & 4574 & 1356 & 710 & 102 \\
\hline \multicolumn{5}{|c|}{ HORAS } \\
\hline
\end{tabular}

7-22 TABLA DE LA PROPORCIÓN EN POCENTAJES Y HORAS DE LAS VELOCIDADES DEL VIENTO SEGREGADOS POR RANGOS (Elaboración propia)

La velocidad del viento se expresa en un gráfico de dirección e intensidad y en la forma convencional de rosa de los vientos, en la que se han marcado las direcciones en que llega el viento, agrupándolas en las 8 direcciones principales. También se ha considerado de interés, para expresar la proporción de direcciones del viento durante el año, segregar horas frías, considerando éstas las que tienen temperaturas menores de $16^{\mathrm{a}} \mathrm{C}$, y las cálidas, con temperaturas mayores de $26^{\circ} \mathrm{C}$. También se han descrito estos valores en tablas resumen.

\begin{tabular}{|c|c|c|c|c|c|c|c|c|c|c|}
\hline CTE & D3 & \multicolumn{9}{|c|}{ DIRECCIÓN DEL VIENTO } \\
\hline \multicolumn{2}{|l|}{ VIENTO } & DIR & $s$ & SW & W & NW & $\mathrm{N}$ & NE & $E$ & SE \\
\hline \multicolumn{2}{|l|}{ TOTAL } & $\%$ & $18 \%$ & $12 \%$ & $16 \%$ & $18 \%$ & $11 \%$ & $6 \%$ & $8 \%$ & $12 \%$ \\
\hline \multicolumn{2}{|c|}{ PERIODO FRIO } & $\%$ & $8 \%$ & $14 \%$ & $17 \%$ & $20 \%$ & $13 \%$ & $6 \%$ & $8 \%$ & $13 \%$ \\
\hline \multicolumn{2}{|c|}{ PERIODO CALOR } & $\%$ & $10 \%$ & $11 \%$ & $18 \%$ & $18 \%$ & $10 \%$ & $5 \%$ & $13 \%$ & $16 \%$ \\
\hline
\end{tabular}

7-23 CUADRO CON LA PROPORCIÓN DE DIRECCIONES DEL VIENTO TOTALES ANUALES EN NEGRO, EN ROJO LA PROPORCIÓN DE HORAS FRÍAS $\left(<16^{\circ} \mathrm{C}\right)$, Y EN AZUL EN HORAS CÁLIDAS ( $>26^{\circ} \mathrm{C}$ ). RECUADADA LA DIRECCIÓN DE MENOR VIENTO EN HORAS FRÍAS Y MAYOR EN HORAS CALIENTES (Elaboración propia) 


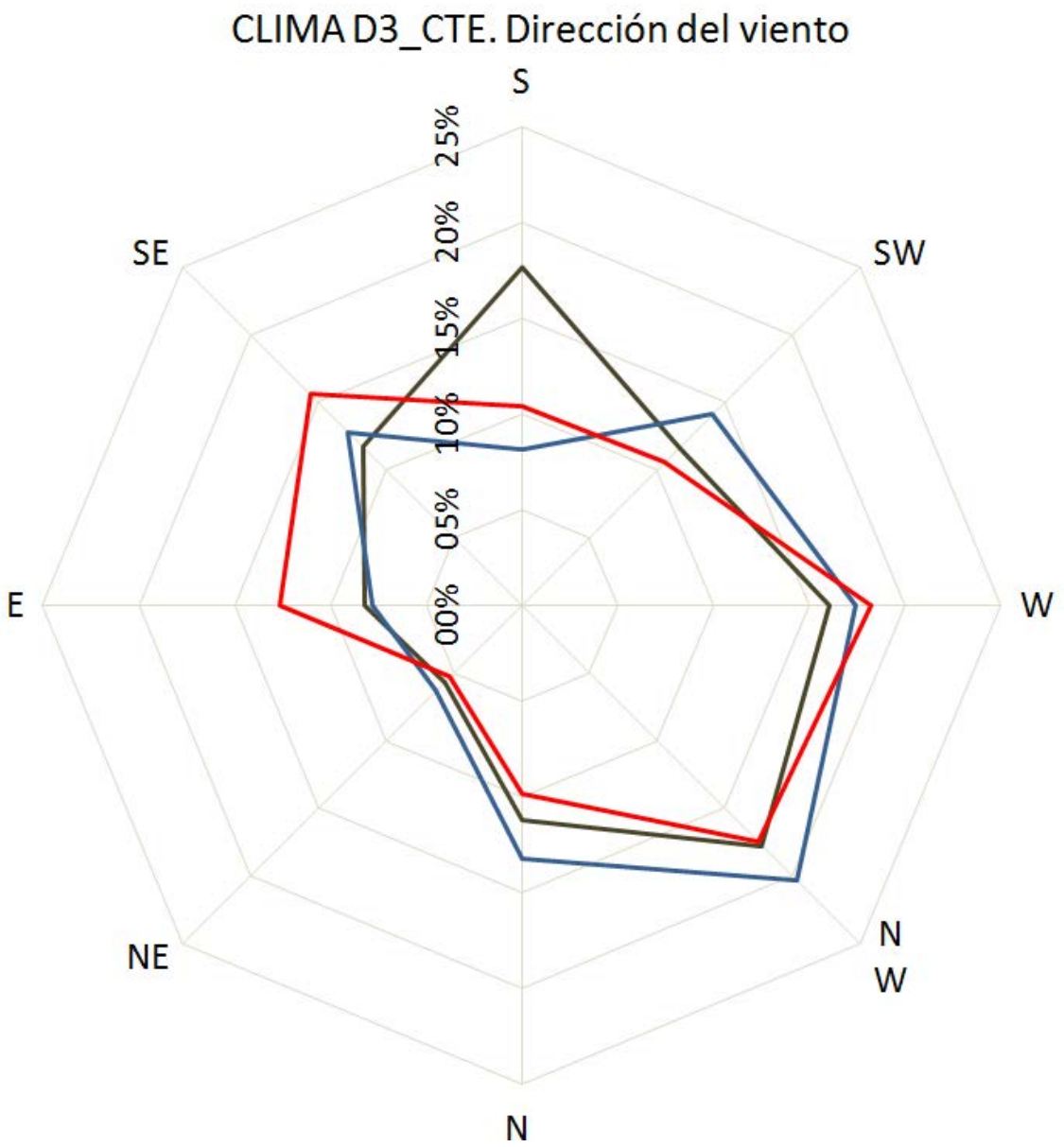

7-24 ROSA DE LOS VIENTOS ANUAL EN NEGRO LOS VALORES TOTALES, EN ROJO EN HORAS FRIAS $\left(<16^{\circ} \mathrm{C}\right)$ Y EN HORAS CÁLIDAS $\left(>26^{\circ} \mathrm{C}\right)$ DISTRIBUIDAS EN LAS 8 DIRECCIONES PRINCIPALES (Elaboración propia)

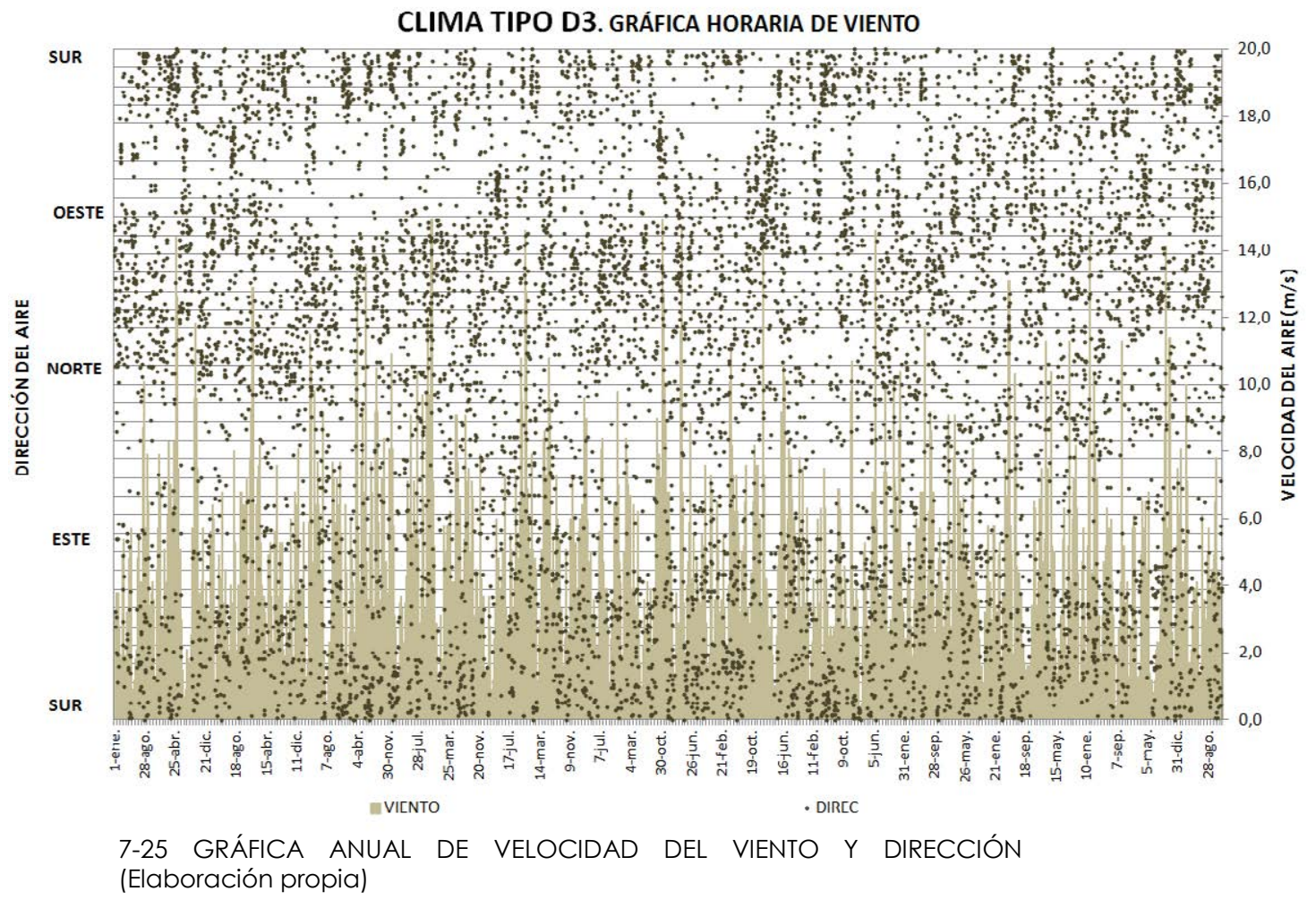




\subsection{CLIMA REGISTRADO EN ZARAGOZA}

Los datos disponibles del clima en Zaragoza se ordenan en dos tipos de secuencias. unas más largas de 40 años de duración, desde 1973 a 2012, y otras decenales, desde 2004 a 2014, con el objetivo de establecer la variabilidad local del clima en los valores que se consideran significativos para su aplicación a la edificación.

\subsubsection{SECUENCIAS DE 40 AÑOS (1973-2012) PARA ZARAGOZA}

Tomando los datos disponibles en la información divulgada por AEMET, se han elaborado gráficos a partir de la evolución de la velocidad diversos parámetros que indican tanto la proporción de meteoros, como pueden ser el granizo, la nieve, o la pluviometría, como la ocultación solar y de la velocidad del viento y de la temperatura.

Las dos localizaciones manifiestan diferencias en los valores observados $y$, aunque no son de gran magnitud las series de medias anuales agrupadas en series moderadamente largas establecen unos invariantes que se mantienen a lo largo del periodo, como es, por ejemplo, el incremento de la temperatura durante la década 2005-2014, según los indicadores seleccionados y los promedios de las temperaturas mínimas, medias, máximas, que ya se han comentado anteriormente.

Los parámetros recogidos en estas tablas son:

\begin{tabular}{|c|l|}
\hline T & Temperatura media anual \\
\hline TM & Temperatura máxima media anual \\
\hline Tm & Temperatura mínima media anual \\
\hline PP & Precipitación total anual de lluvia y/o nieve derretida $(\mathrm{mm})$ \\
\hline V & Velocidad media anual del viento $(\mathrm{Km} / \mathrm{h})$ \\
\hline RA & Total días con lluvia durante el año \\
\hline SN & Total días que nevó durante el año \\
\hline TS & Total días con tormenta durante el año \\
\hline FG & Total días con niebla durante el año \\
\hline TN & Total días con tornados o nubes de embudo durante el año \\
\hline GR & Total días con granizo durante el año \\
\hline
\end{tabular}

7-26 TABLA DESCRIPTIVA DE LOS PARÁMETROS RECOGIDOS EN LA GRÁFICA CONDICIONES CLIMÁTICAS ANUALES PARA EL PERIODO 1973-2012 (AEMET y elaboración propia)

Los valores climáticos medios permiten la comparación entre unidades temporales dadas, en este caso una secuencia de 30 años, minimizando la influencia de las discontinuidades en las series y aportando una imagen comparada muy fiable.

El empleo de un mismo esquema gráfico para mostrar las condiciones registradas en una secuencia de 30 años correspondiente al periodo entre 1973 al 2012 con datos medios anuales, ofrece una imagen clara de la evolución comparada del clima en las dos localizaciones elegidas, lo que ya permite extraer algunas conclusiones. 


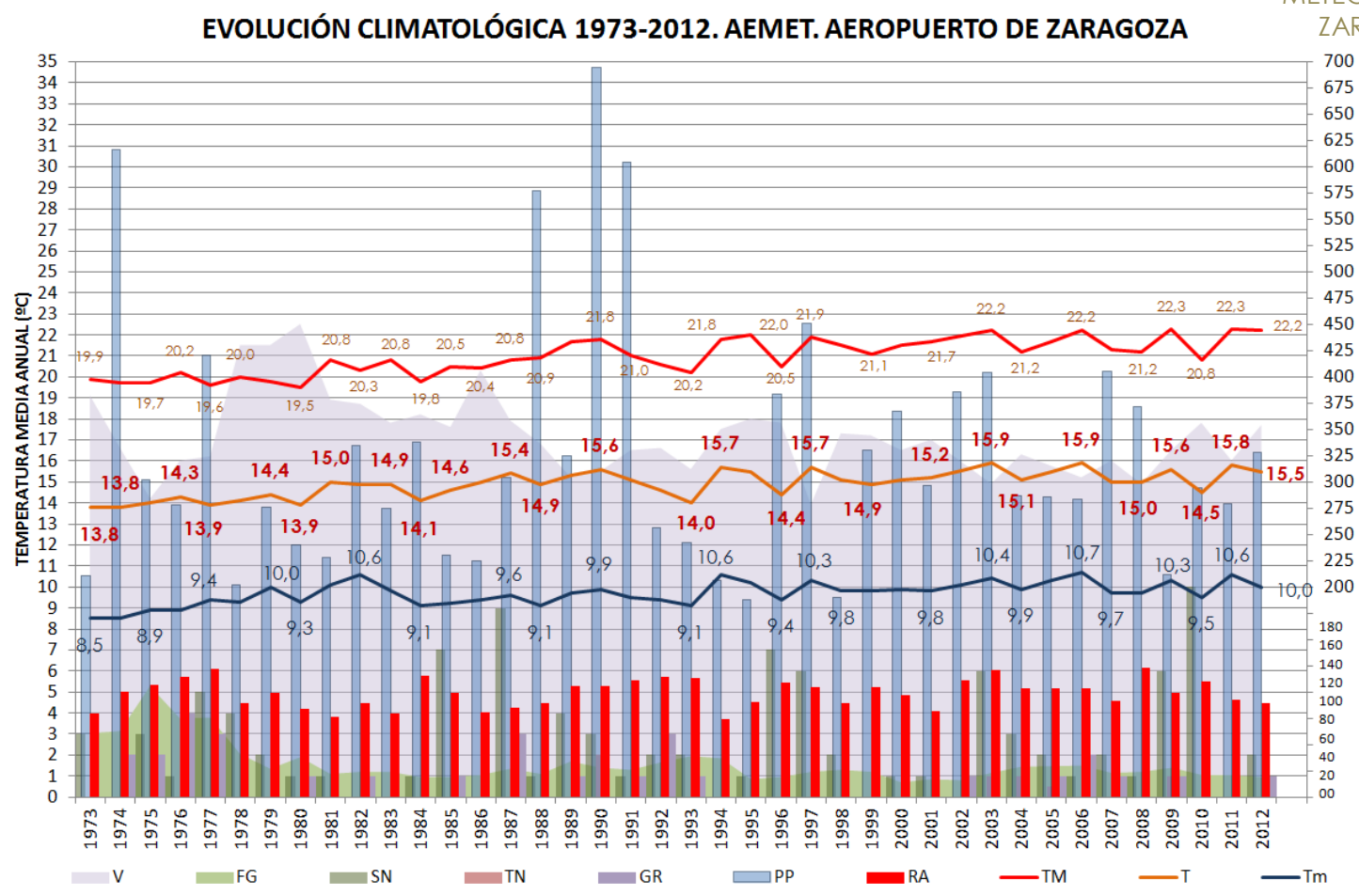

7-27 GRÁFICA DE CONDICIONES CLIMÁTICAS ANUALES PARA EL PERIODO 1973-2012

EN EL AEROPUERTO DE ZARAGOZA (AEMET y elaboración propia) 
7.2.2 SECUENCIAS COMPARADAS DE SECUENCIAS TÉRMICAS DECENALES EN ZARAGOZA

La descripción de la secuencia térmica decenal se realiza a través distintos valores representativos.

Por una parte los valores medios anuales permiten conocer las cualidades climáticas medias del conjunto del periodo, y su relación con cada una de las anualidades, así como la variación producida durante este periodo.

VALORES MÁXIMOS, MÍNIMOS Y MEDIOS DIARIOS. AEROPUERTO DE ZARAGOZA PERIODO 2005 A 2014

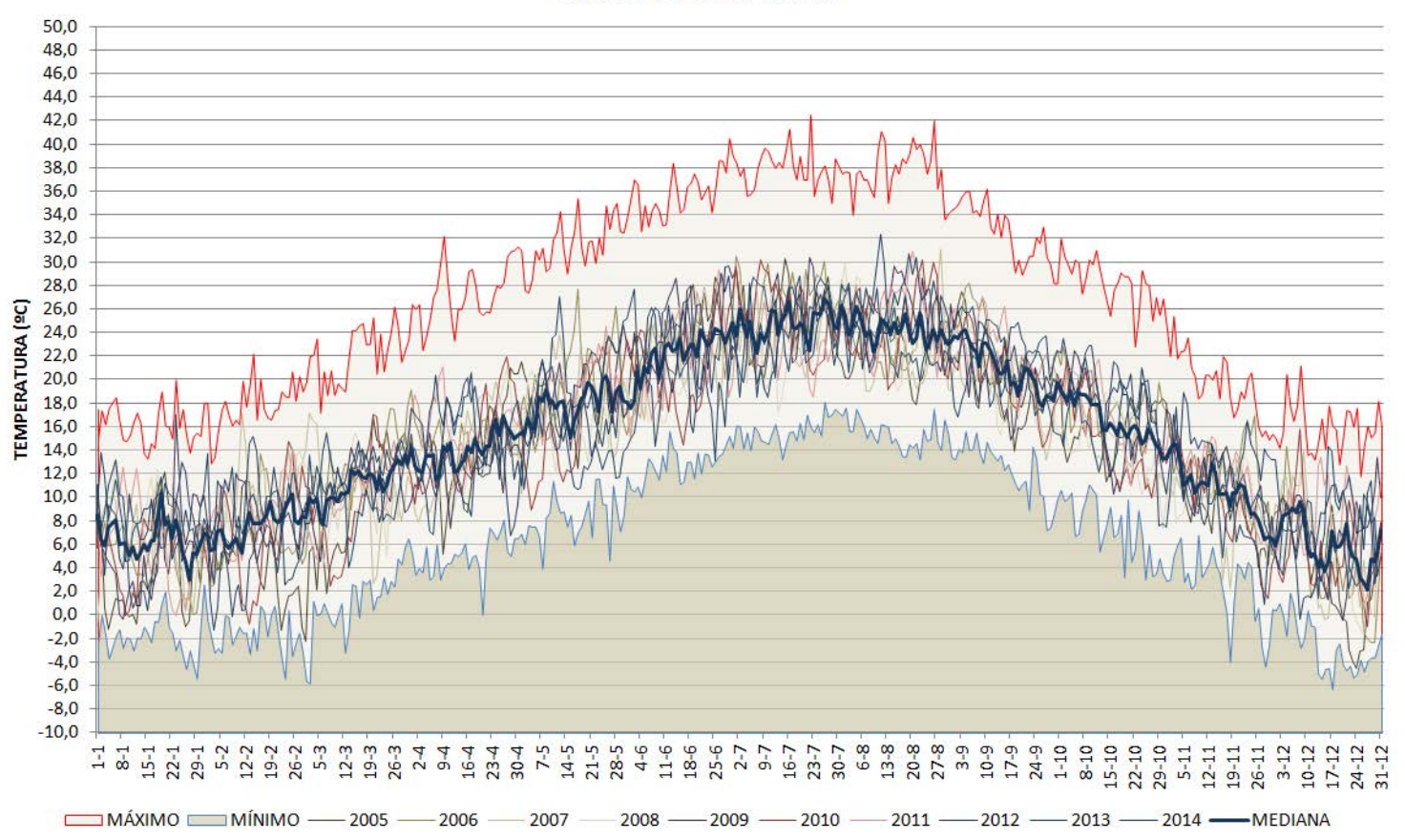

7-28 GRÁFICA DE VALORES MEDIOS DIARIOS Y VALORES MÁXIMOS, MÍNIMOS Y AEROPUERTO (AEMET y elaboración propia)

\section{PROMEDIO REGISTRADOS DURANTE LA DÉCADA 2005-2014 EN ZARAGOZA}


Los valores promedio de las máximas, mínimas medianas y promedios diarios permiten establecer una imagen del perfil térmico.
VER ANEXO 06 y 07 REGISTROS ESTACIONES METEOROLÓGICAS DE ZARAGOZA 1 y 2

VALORES PROMEDIO. AEROPUERTO DE ZARAGOZA PERIODO 2005-2014

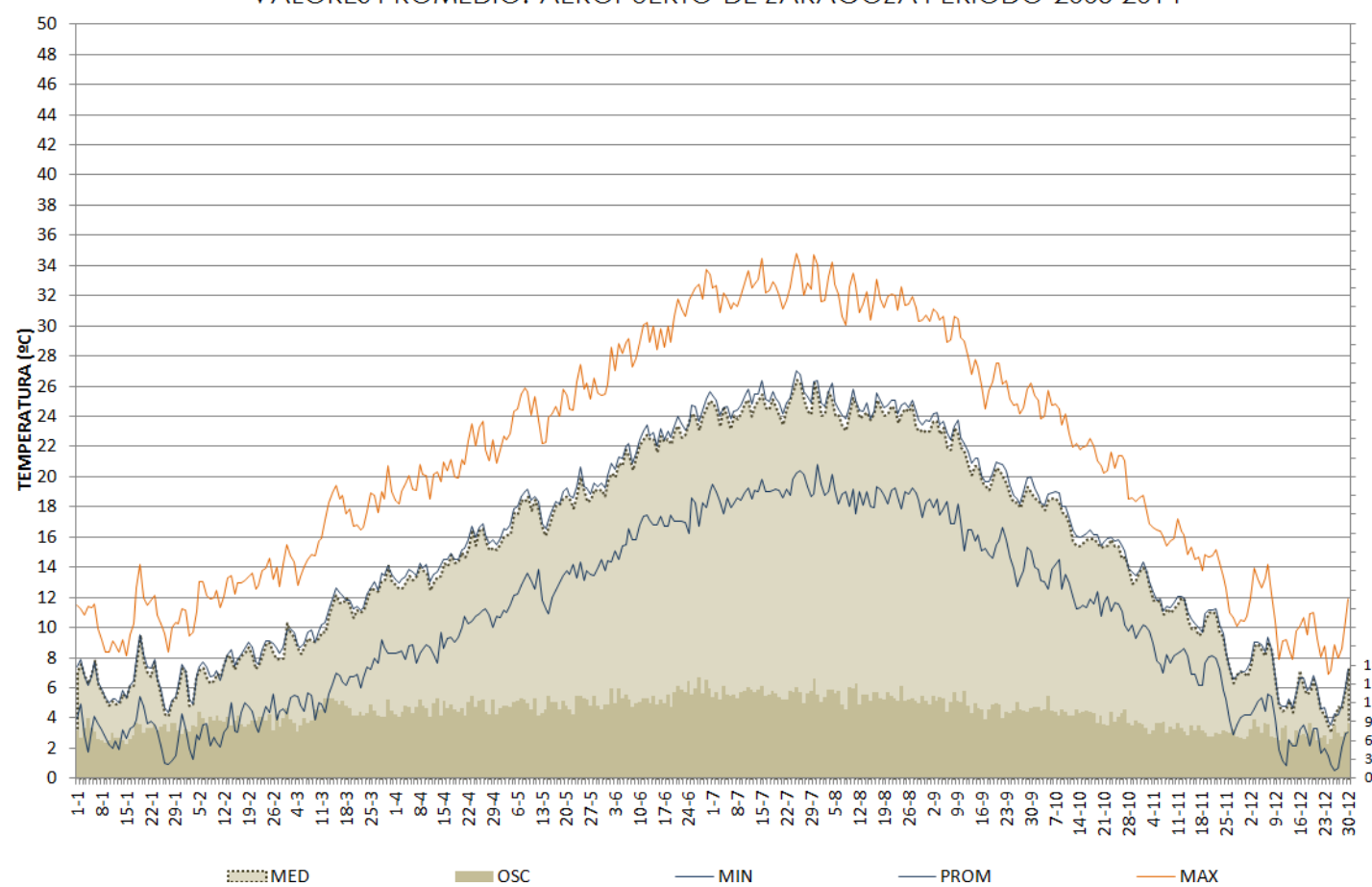

VALORES PROMEDIO. AEROPUERTO DE ZARAGOZA PERIODO 2005-2014

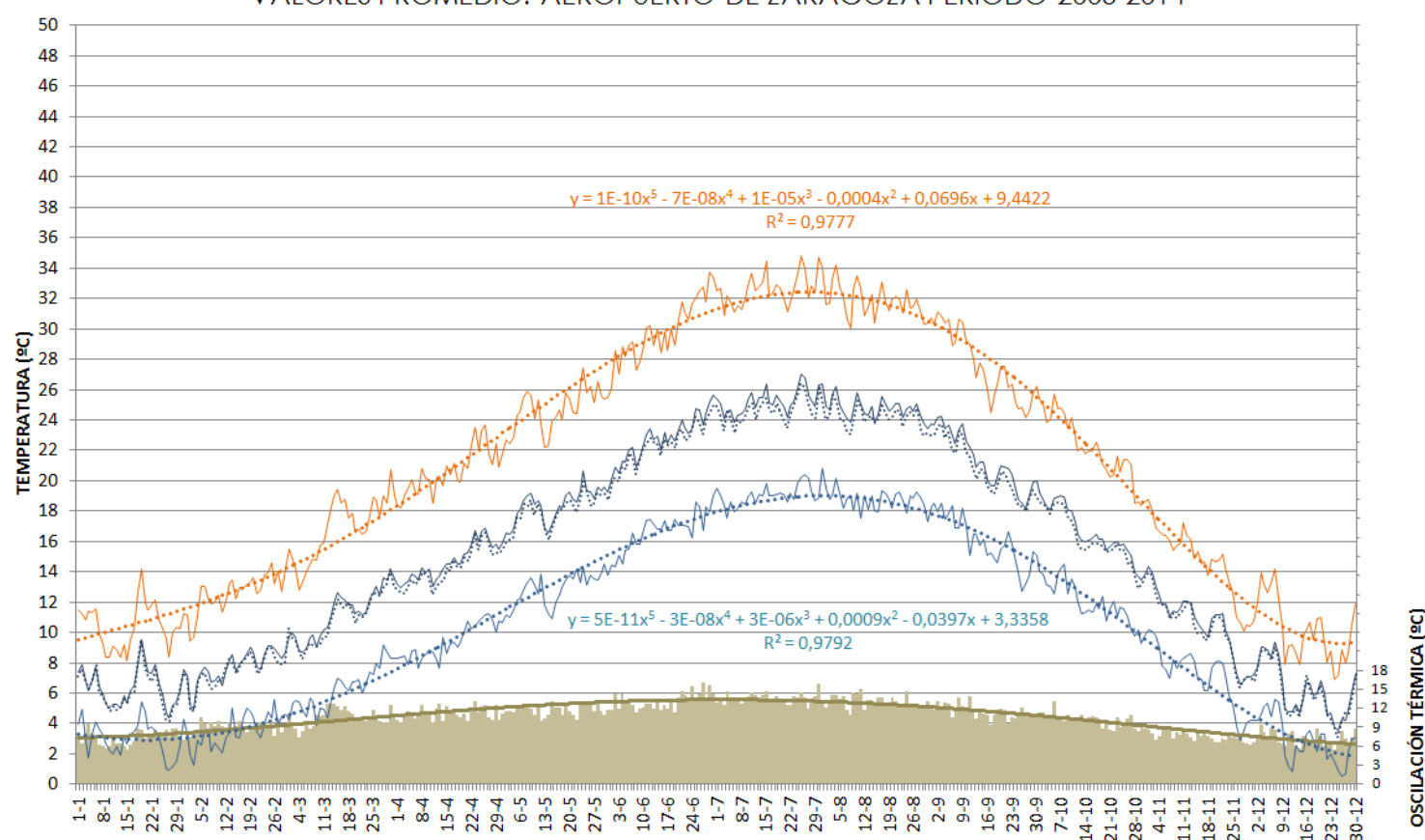

7-29 GRÁFICA DE VALORES PROMEDIO DIARIOS DE LA DÉCADA 2015-2014 EN ZARAGOZA AEROPUERTO (AEMET y elaboración propia) 
La comparativa se establece también en los valores medios, máximos, mínimos y en las oscilaciones térmicas diarias, en los valores promedio de la década.
VER ANEXO 06 y 07 REGISTROS ESTACIONES METEOROLÓGICAS DE ZARAGOZA 1 y 2

VALORES MÁXIMOS DIARIOS. AEROPUERTO DE ZARAGOZA. PERIODO 2005-2014

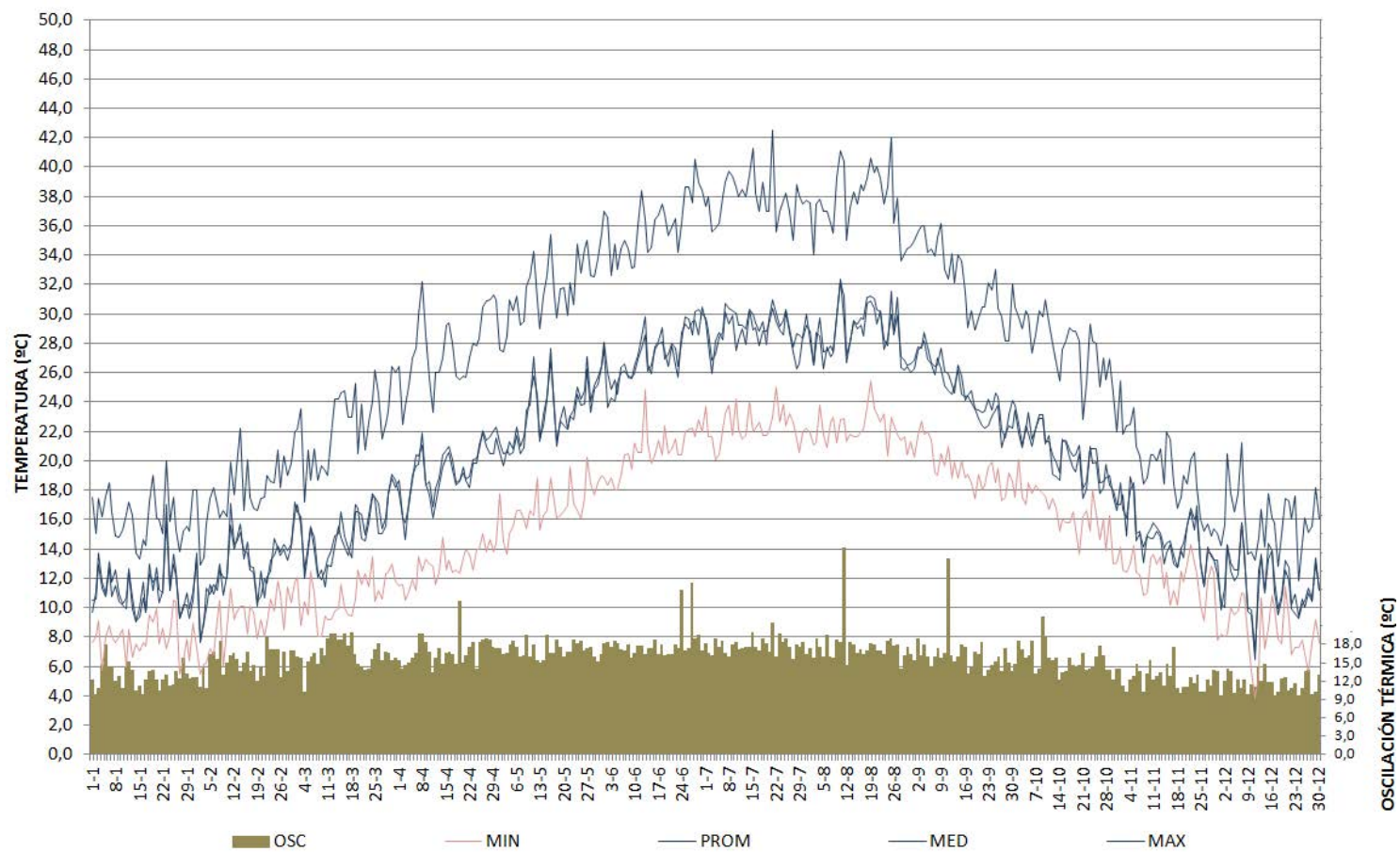

VALORES MÍNIMOS DIARIOS.AEROPUERTO DE ZARAGOZA. PERIODO 2005-2014

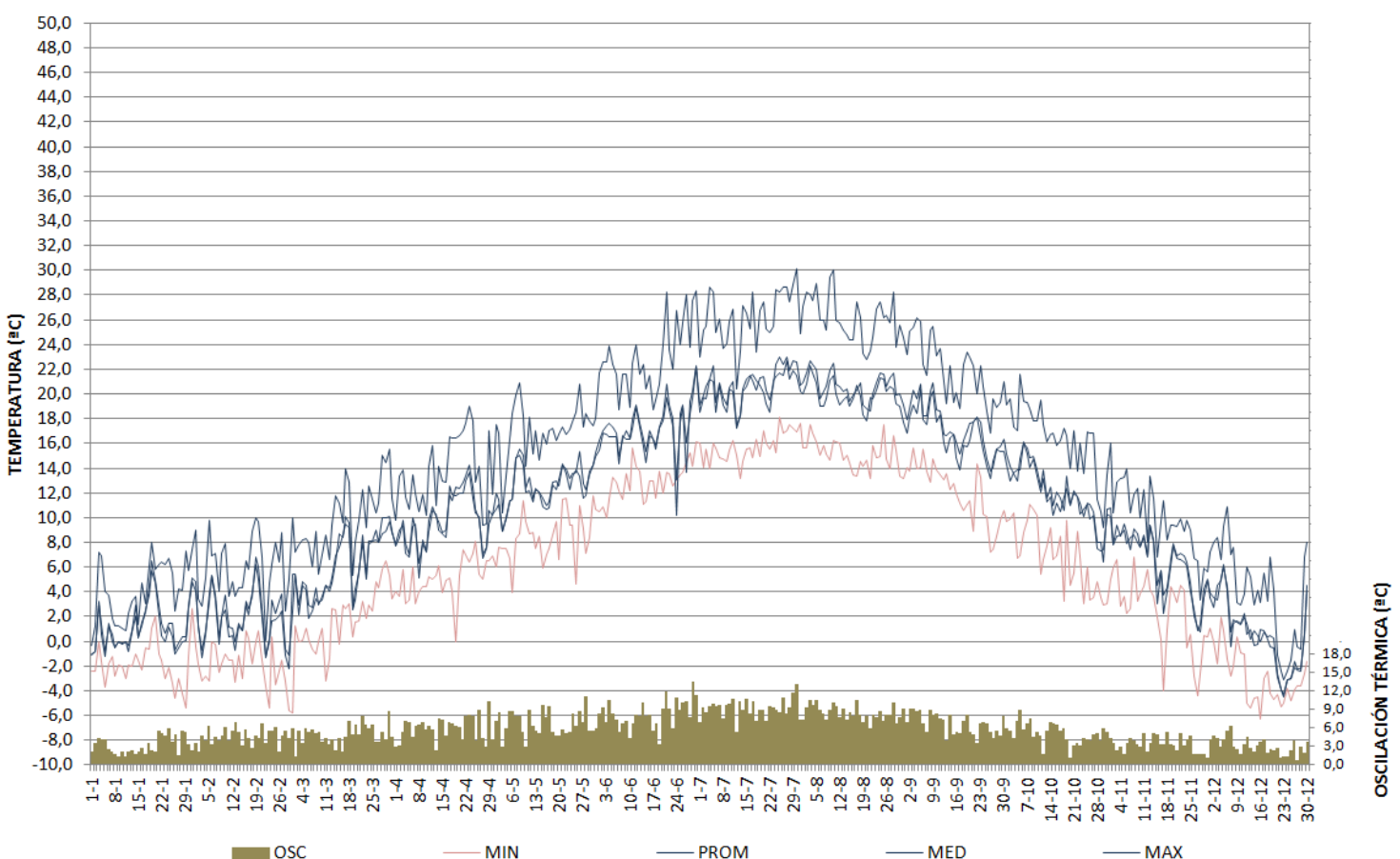

7-30 GRÁFICOS DE VALORES MÁXIMOS Y MÍNIMAS DIARIAS PROMEDIO EN EL PERIODO 2005 A 2014 EN EL AEROPUERTO DE ZARAGOZA (AEMET Y elaboración propia) 
La comparativa se establece también en los valores medios, máximos, mínimos y en las oscilaciones térmicas diarias, para cada uno de los años de la década. Así como compararlos con los valores promedio de la década.
VER ANEXO 06 y 07 REGISTROS ESTACIONES METEOROLÓGICAS DE ZARAGOZA 1 y 2

VALORES DIARIOS MÁXIMOS Y MÍNIMOS. AEROPUERTO DE ZARAGOZA. AÑO 2014

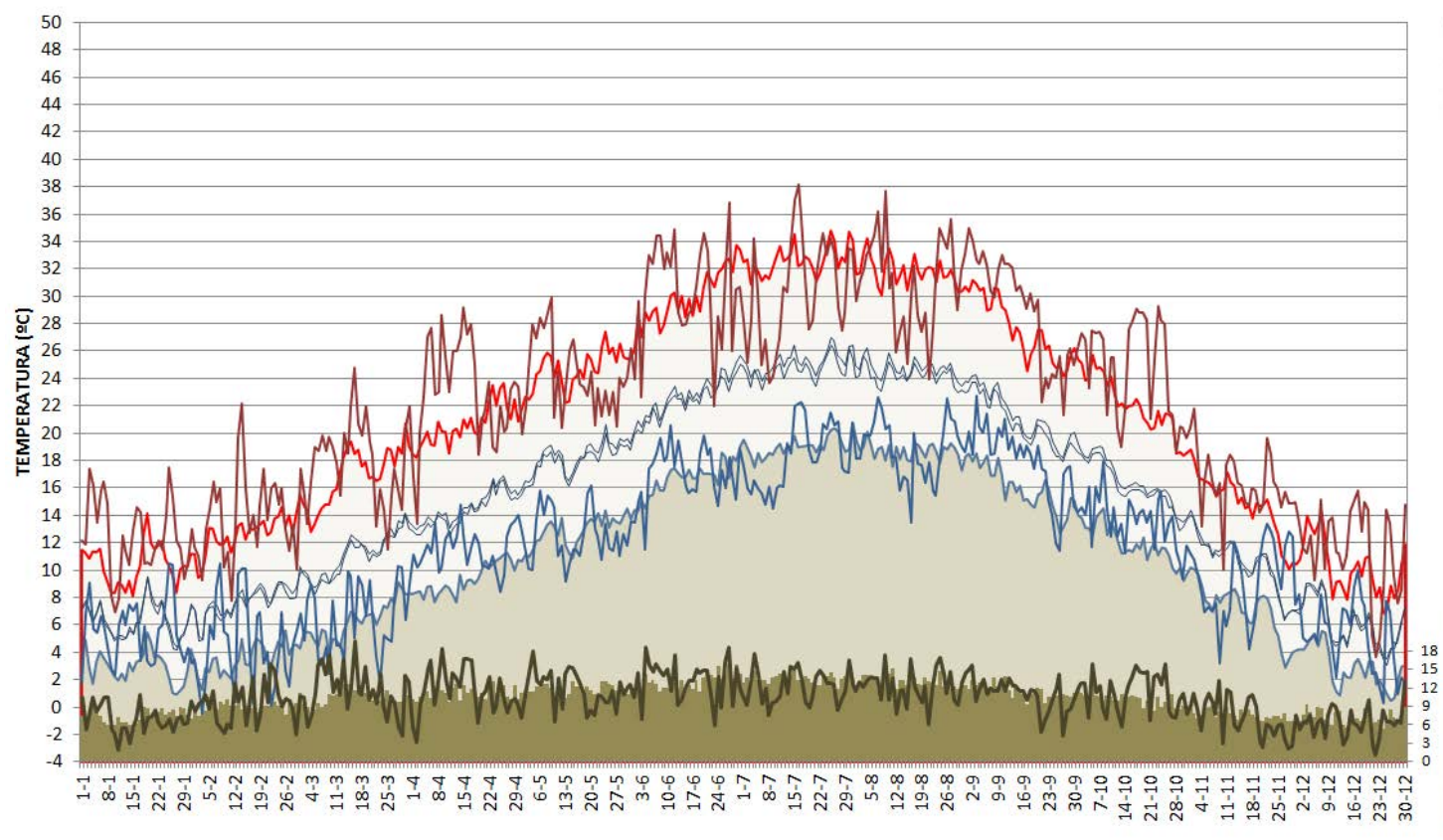

$\square$ MIN $\square$ MAX $\square$ OSC —PROM —MED —MIN —MAX —OSC

VALORES DIARIOS MÁXIMOS Y MÍNIMOS. AEROPUERTO DE ZARAGOZA. AÑO 2014

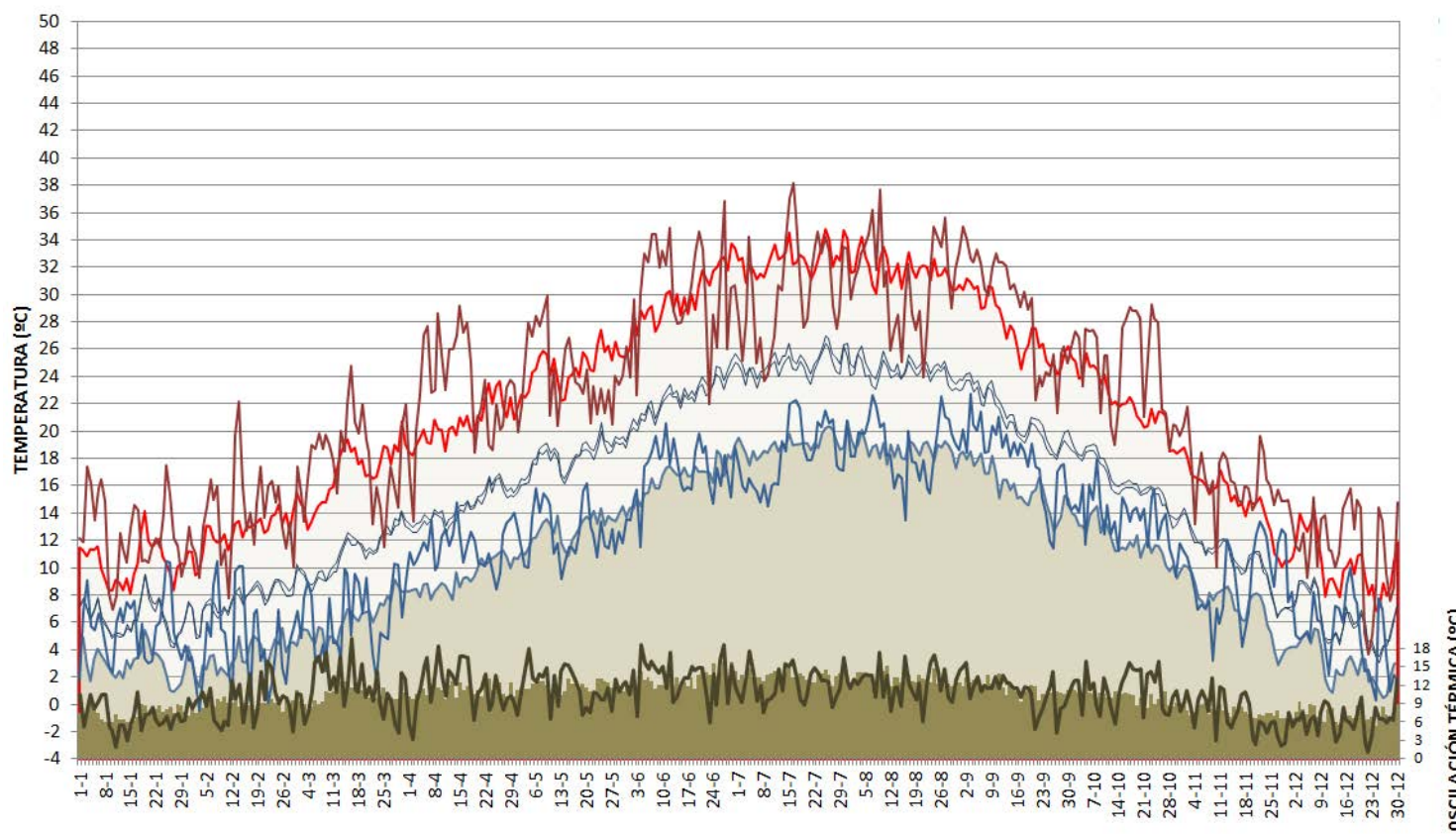

$\square$ MIN $\square$ MAX

7-31 GRÁFICA DE VALORES PROMEDIOS DIARIOS DURANTE EL AÑO 2014, COMPARADO CON LOS VALORES PROMEDIO DE LA DÉCADA 2005-2014 EN ZARAGOZA AEROPUERTO (AEMET y elaboración propia)

Estas secuencias anuales de valores térmicos diarios permiten comparar los valores medios con los valores registrados en cada uno de los años de la década. 
También se realiza un análisis por periodos cálidos y fríos que independiza las condiciones térmicas en función de las previsibles necesidades de disipación o aportación de energía al edificio, tanto en sus valores promedio como anuales.
VER ANEXO 06 y 07 REGISTROS ESTACIONES METEOROLOGICAS DE ZARAGOZA 1 y 2

VALORES PROMEDIO DIARIOS. AEROPUERTO DE ZARAGOZA EN PERIODO FRÍO PERIODO 2005-2014

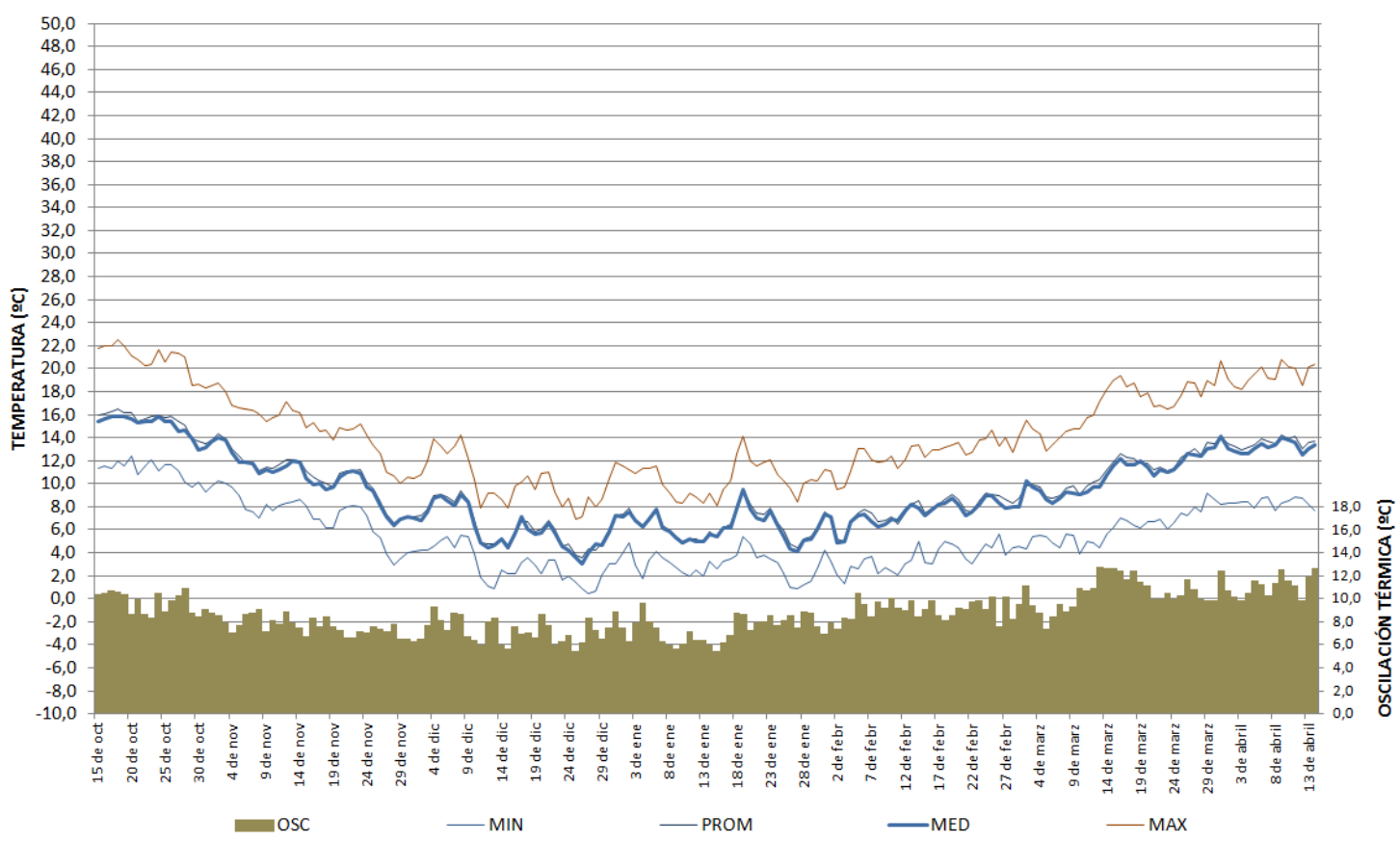

7-32 GRÁFICA DE VALORES MÁXIMOS, MEDIANAS, PROMEDIO Y MÍNIMAS DIARIAS DESDE 15/10 AL 31/5 EN LA DÉCADA 2005-2014 EN ZARAGOZA AEROPUERTO (AEMET y elaboración propia)

VALORES PROMEDIO DIARIOS. AEROPUERTO DE ZARAGOZA EN PERIODO CÁLIDO PERIODO 2005-2014

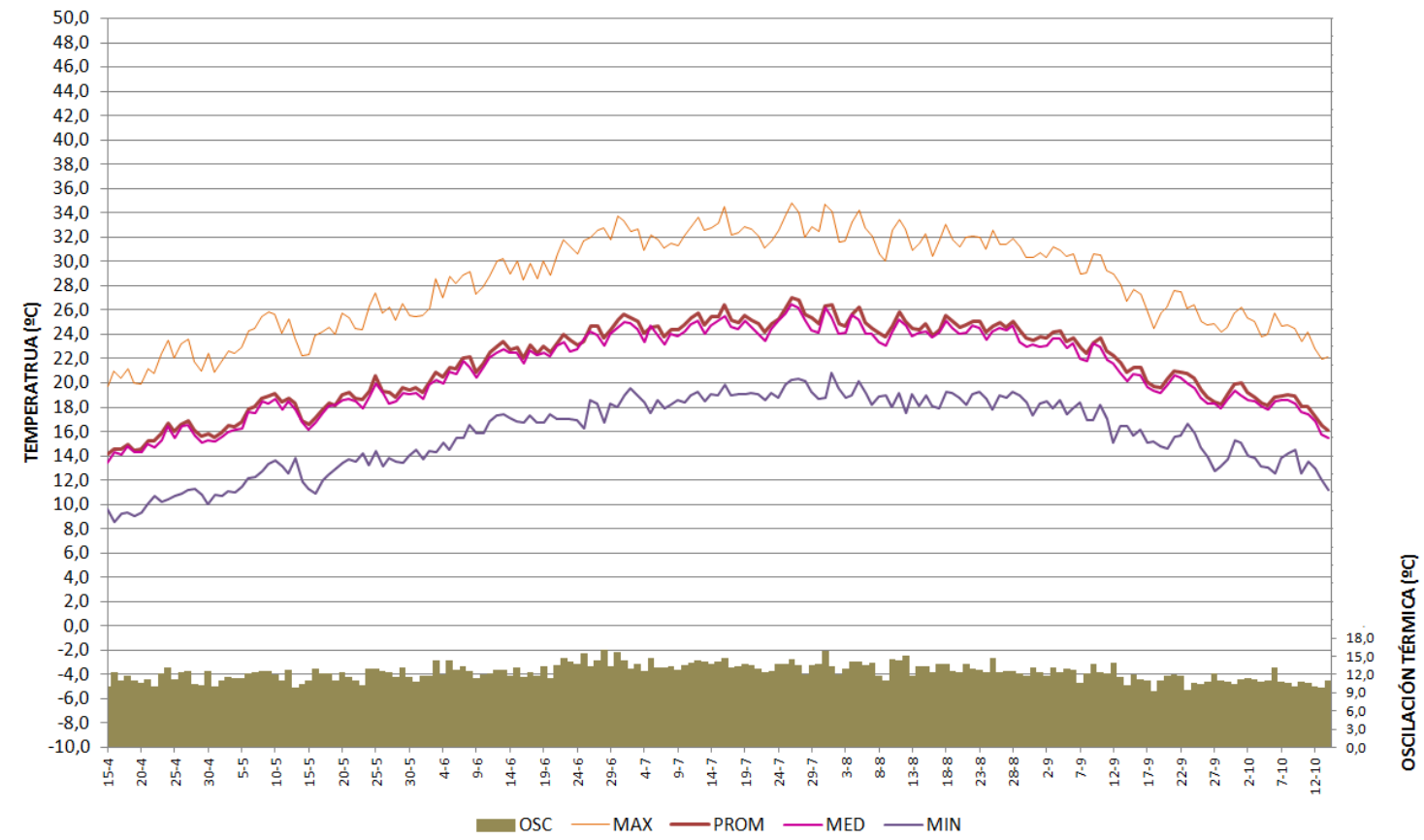

7-33 GRÁFICA DE VALORES MÁXIMOS, MEDIANAS, PROMEDIO Y MÍNIMAS DIARIAS DESDE 15/04 AL 14/10 EN LA DÉCADA 2005-2014 EN ZARAGOZA AEROPUERTO (AEMET y elaboración propia) 
Por último se recogen los valores en periodos mensuales que reflejan el perfil térmico en periodos de duración media.

VALORES PROMEDIO DIARIOS. AEROPUERTO DE ZARAGOZA. ENERO PERIODO 2005-2014

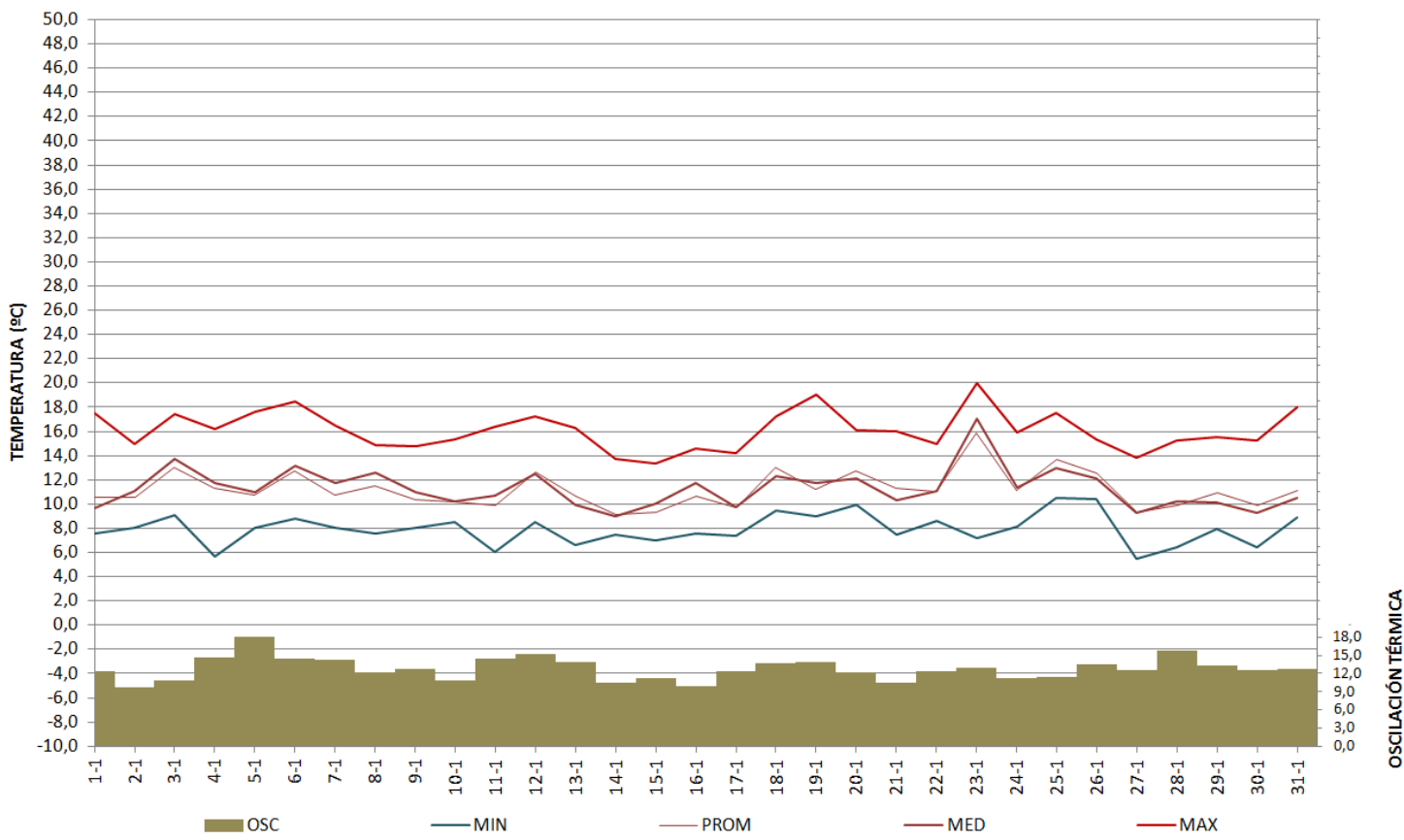

7-34 GRÁFICA DE VALORES MÁXIMOS, MEDIANAS, PROMEDIO Y MÍNIMAS DIARIAS EN ENERO EN LA DÉCADA 2005-2014 EN ZARAGOZA AEROPUERTO (AEMET Y elaboración propia)

VALORES PROMEDIO DIARIOS. AEROPUERTO DE ZARAGOZA. JULIO PERIODO 2005-2014

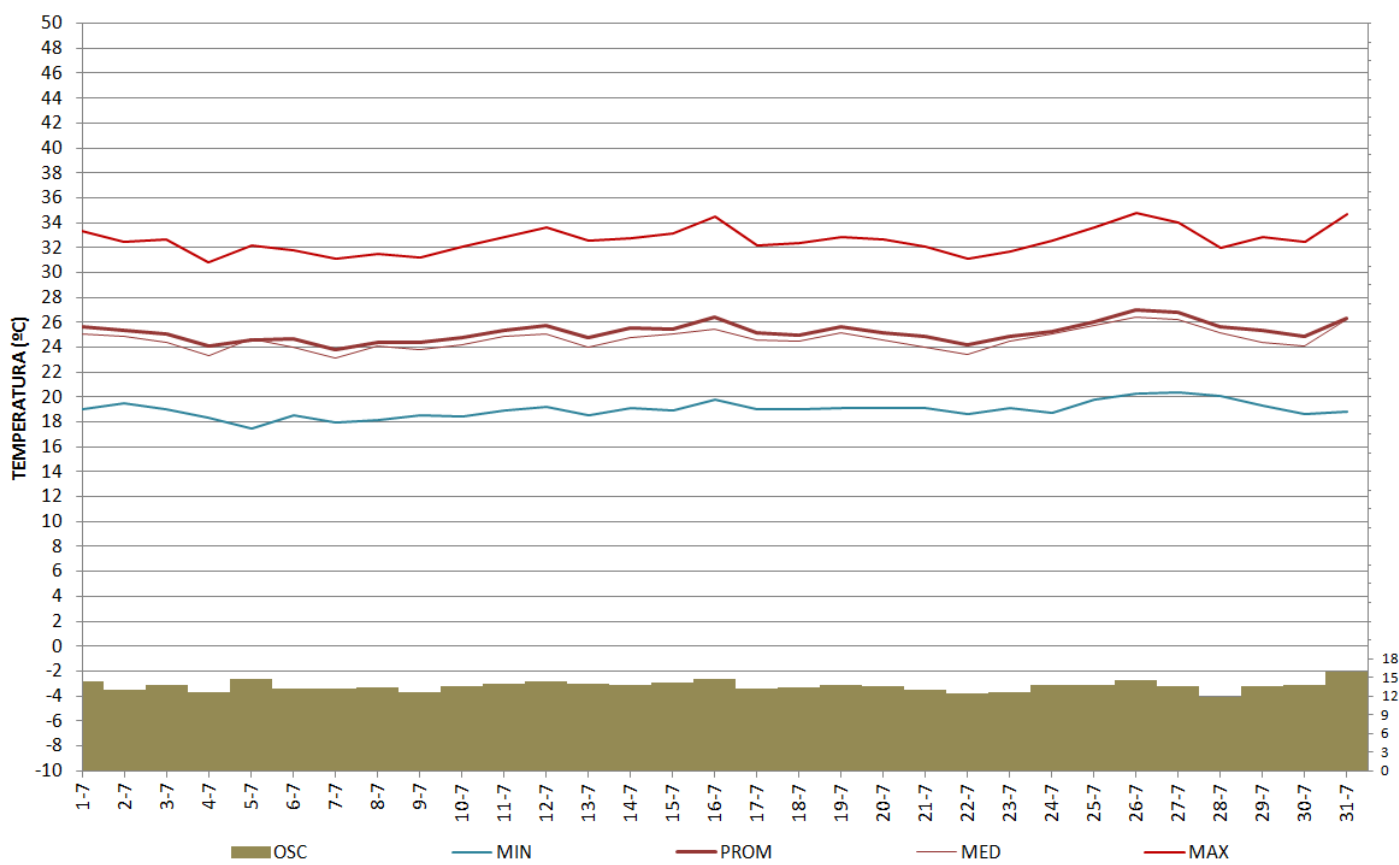

7-35 GRÁFICA DE VALORES MÁXIMOS, MEDIANAS, PROMEDIO Y MÍNIMAS DIARIAS EN ENERO EN LA DÉCADA 2005-2014 EN ZARAGOZA AEROPUERTO (AEMET Y elaboración propia) 
La comparación de los registros térmicos ordenados según máximos, medios y mínimos mensuales permite la comparación con los valores registrados en cada anualidad.
VER ANEXO 06 y 07 REGISTROS ESTACIONES METEOROLÓGICAS DE ZARAGOZA 1 y 2

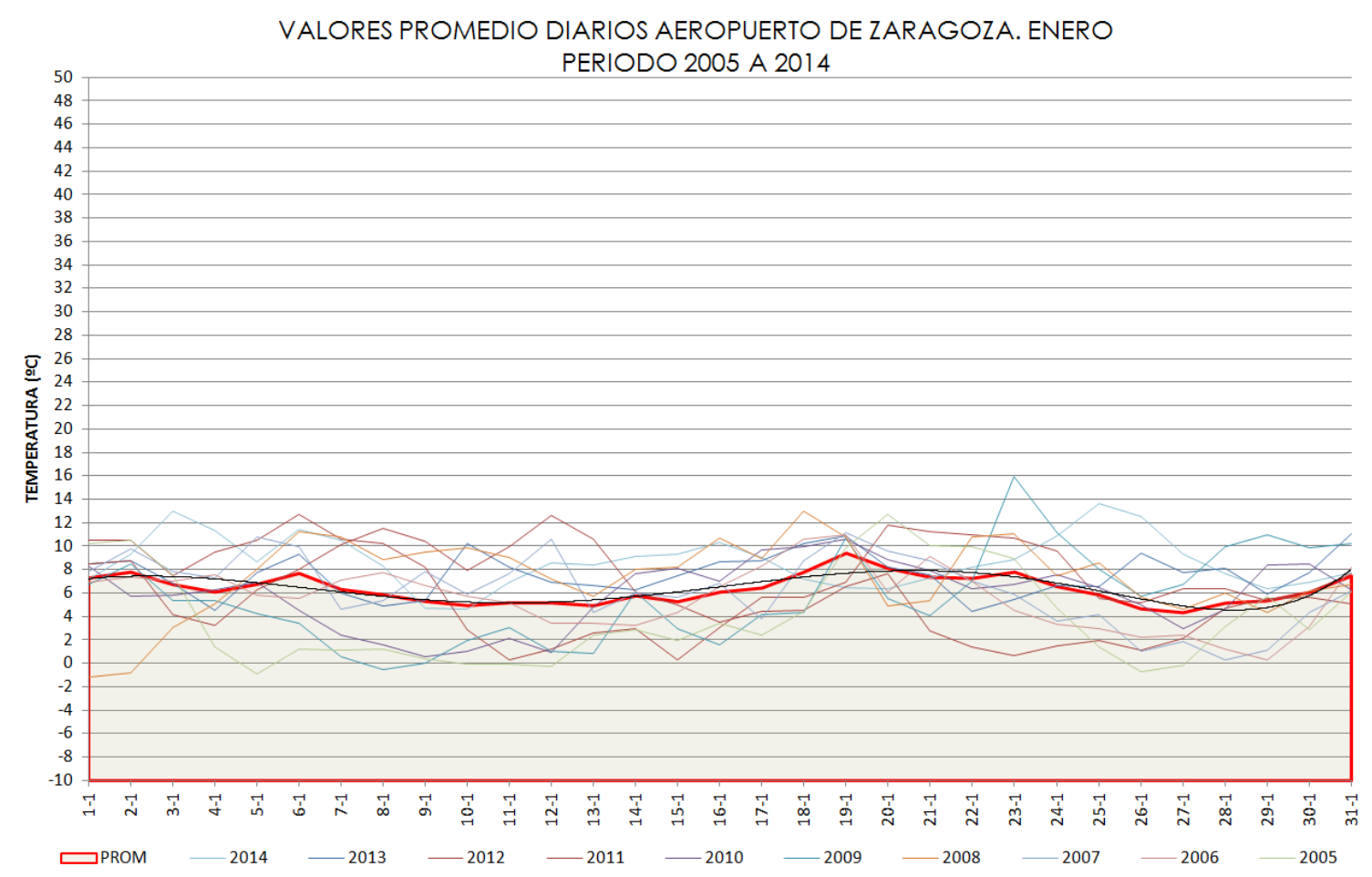

7-36 GRÁFICA DE VALORES PROMEDIO DIARIAS EN ENERO EN LA DÉCADA 2005-2014 EN ZARAGOZA AEROPUERTO (AEMET y elaboración propia)

VALORES PROMEDIO DIARIOS. AEROPUERTO DE ZARAGOZA. JULIO PERIODO 2005 A 2014

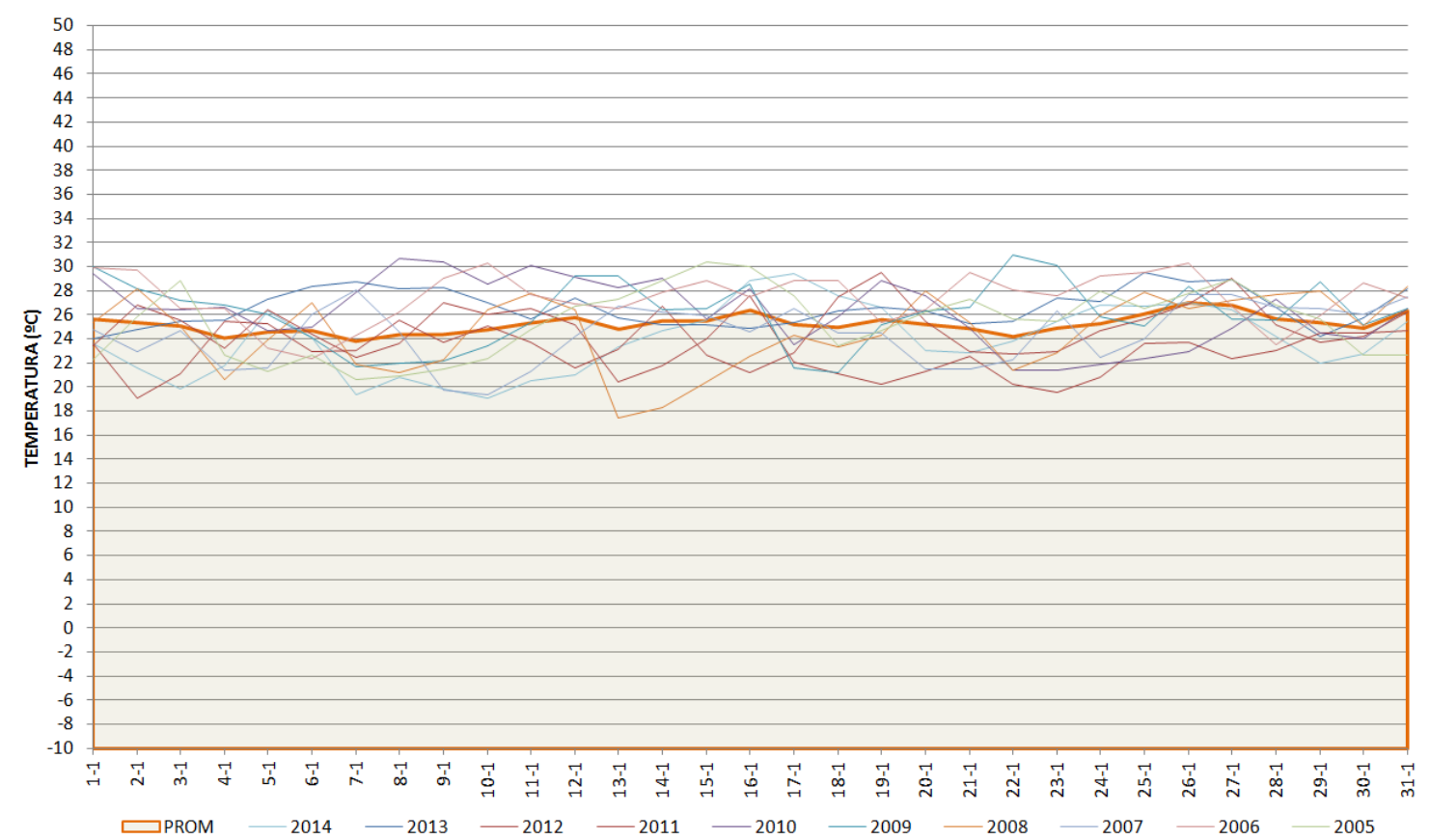

7-37 GRÁFICA DE VALORES PROMEDIO DIARIAS EN ENERO EN LA DÉCADA 2005-2014 EN ZARAGOZA AEROPUERTO (AEMET y elaboración propia) 
La representación gráfica se complementa con cuadros donde se cuantifican estos valores para hacer posible su comparación. Se han elegido los grados-hora con diferentes temperaturas de referencia como indicador, al ofrecer una imagen que facilita la comparación entre las diversas anualidades, los promedios y los climas de referencia.

\begin{tabular}{|c|c|c|c|c|c|c|c|c|c|}
\hline$?$ & \multicolumn{3}{|c|}{$\begin{array}{l}\text { Horas en que la temperaatura es } \\
\text { superior a } \ldots\end{array}$} & \multirow{2}{*}{\begin{tabular}{c|} 
TOTAL $9 \mathrm{C}$ \\
sobre 0
\end{tabular}} & \multicolumn{5}{|c|}{$\begin{array}{c}\text { Horas en las que la temperatura debe subir para llegar } \\
\text { a... }\end{array}$} \\
\hline oC exteriores de referencia & $>26 \circ \mathrm{C}$ & $>22 \circ \mathrm{C}$ & $>20 \div \mathrm{C}$ & & $<209 \mathrm{C}$ & $<18 \circ \mathrm{C}$ & $<14{ }^{\circ} \mathrm{C}$ & $<10 \div \mathrm{C}$ & $\angle 09 \mathrm{C}$ \\
\hline HORAS & 1.036 & 2.084 & 2.832 & 144.692 & 5.869 & 5.066 & 3.497 & 1.892 & 3 \\
\hline وc & 3.591 & 6.125 & 4.957 & bajo 0 & -72.417 & -34.199 & -16.840 & -13.619 & -1 \\
\hline \multirow[t]{2}{*}{ oC exteriores de referencia } & $>269 \mathrm{C}$ & $>22 \circ \mathrm{C}$ & $>20 \div \mathrm{C}$ & -1 & $<20 \circ \mathrm{C}$ & $<189 \mathrm{C}$ & $<14$ 으 & $<10$ ㅇ C & $<0 \circ \mathrm{C}$ \\
\hline & \multicolumn{3}{|c|}{ grados a enfriar para bajar a ... } & TOTAL $9 \mathrm{C}$ & \multicolumn{5}{|c|}{ grados a calentar para subir a ... } \\
\hline
\end{tabular}

7-38 HORAS Y GRADOS-HORA EN QUE ES PRECISO DISIPAR O APORTAR ENERGÍA PARA ALCANZAR DIVERSAS TEMPERATURAS DE REFERENCIA DURANTE EL AÑO 2014 EN ZARAGOZA AEROPUERTO (AEMET y elaboración propia)

Las tablas resumen elaboradas muestran, por ejemplo, las secuencias de grados-hora registrados anvalmente en la década 2005-2014 y el promedio en que se producen superaciones de los $0^{\circ} \mathrm{C}$, así como cuántos grados-hora son necesarios para alcanzar $\operatorname{los} 0^{\circ} \mathrm{C}$.

\begin{tabular}{|c|c|c|c|c|c|}
\hline \multirow{2}{*}{\multicolumn{2}{|c|}{ 2005- 14}} & \multicolumn{4}{|c|}{ TOTAL ${ }^{\circ} \mathrm{C}+$} \\
\hline & & \multicolumn{2}{|c|}{ sobre 0} & \multicolumn{2}{|c|}{ bajo 0} \\
\hline 2005 & $\begin{array}{r}\text { HORAS } \\
{ }^{\circ} \mathrm{C}\end{array}$ & 129.191 & $-5,05 \%$ & -920 & $288,06 \%$ \\
\hline 2006 & HORAS & 139.754 & $2,72 \%$ & -305 & $28,62 \%$ \\
\hline 2007 & $\begin{array}{r}\text { HORAS } \\
{ }^{\circ} \mathrm{C}\end{array}$ & 132.163 & $-2,86 \%$ & -291 & $22,55 \%$ \\
\hline 2008 & $\begin{array}{r}\text { HORAS } \\
{ }^{\circ} \mathrm{C}\end{array}$ & 132.067 & $-2,93 \%$ & -152 & $-35,92 \%$ \\
\hline 2009 & $\begin{array}{r}\text { HORAS } \\
{ }^{\circ} \mathrm{C}\end{array}$ & 140.009 & $2,90 \%$ & -128 & $-46,00 \%$ \\
\hline 2010 & $\begin{array}{r}\text { HORAS } \\
{ }^{\circ} \mathrm{C}\end{array}$ & 130.226 & $-4,29 \%$ & -212 & $-10,78 \%$ \\
\hline 2011 & $\begin{array}{r}\text { HORAS } \\
{ }^{\circ} \mathrm{C}\end{array}$ & 141.578 & $4,06 \%$ & -132 & $-44,40 \%$ \\
\hline 2012 & $\begin{array}{r}\text { HORAS } \\
{ }^{\circ} \mathrm{C}\end{array}$ & 138.946 & $2,12 \%$ & -150 & $-36,55 \%$ \\
\hline 2013 & \begin{tabular}{r|} 
HORAS \\
${ }^{\circ} \mathrm{C}$
\end{tabular} & 131.944 & $-3,02 \%$ & -81 & $-66,00 \%$ \\
\hline 2014 & $\begin{array}{r}\text { HORAS } \\
{ }^{\circ} \mathrm{C}\end{array}$ & 144.692 & $6,35 \%$ & -1 & $-99,58 \%$ \\
\hline PRON & :DIO & 136.057 & ${ }^{\circ} \mathrm{C}$ - HORA & $-23 \pi$ & ${ }^{\circ} \mathrm{C}-$ HORA \\
\hline
\end{tabular}

7-39 HORAS Y GRADOS-HORA SOBRE Y BAJO 0C EN LA DÉCADA 2005 A 2014 EN ZARAGOZA AEROPUERTO (AEMET y elaboración propia) 
También se elaboran secuencias de superaciones de umbrales, que en este caso se han considerado $26^{\circ} \mathrm{C}, 22^{\circ} \mathrm{C}$ y $20^{\circ} \mathrm{C}$, expresando en grados-hora y en horas estas superaciones

\begin{tabular}{|c|c|c|c|c|}
\hline \multirow{2}{*}{\multicolumn{2}{|c|}{ 2005- 14}} & \multicolumn{3}{|c|}{$\begin{array}{c}\text { HORAS y }{ }^{\circ} \mathrm{C} \text {-HORA en las que debe bajar la temperatura } \\
\text { para legar a... }\end{array}$} \\
\hline & & $>26^{\circ} \mathrm{C}$ & $>22^{\circ} \mathrm{C}$ & $>20^{\circ} \mathrm{C}$ \\
\hline \multirow{2}{*}{2005} & HORAS & $984-3,82 \%$ & $\begin{array}{ll}1.948 & -1,01 \% \\
\end{array}$ & $\begin{array}{ll}1.948 & -1,01 \% \\
\end{array}$ \\
\hline & & $4090^{\prime}-2,08 \%$ & $9830^{\prime \prime}-2,33 \%$ & $19664^{\prime}-1,46 \%$ \\
\hline \multirow{2}{*}{2006} & HORAS & $1.099 \quad 7,42 \%$ & $2.156 \quad 9,56 \%$ & $2.156 \quad 9,56 \%$ \\
\hline & & $4434^{\prime} \quad 6,15 \%$ & $10833^{\prime} \quad 7,63 \%$ & $21683^{\prime}$ \\
\hline \multirow{2}{*}{2007} & HORAS & $828-19,07 \%$ & $1.697-13,76 \%$ & $\begin{array}{ll}1.697 & -13,76 \%\end{array}$ \\
\hline & ${ }^{\circ} \mathrm{C}$ & $3086^{\prime}-26,13 \%$ & $8078^{\prime}-19,74 \%$ & $16810^{\prime}-15,77 \%$ \\
\hline \multirow{2}{*}{2008} & HORAS & $850-16,92 \%$ & $1.665-15,39 \%$ & $\begin{array}{ll}1.665 & -15,39 \%\end{array}$ \\
\hline & ${ }^{\circ} \mathrm{C}$ & $3506^{\prime}-16,08 \%$ & $8389^{\prime}-16,65 \%$ & $16937^{\prime}-15,13 \%$ \\
\hline \multirow{2}{*}{2009} & HORAS & $1.198 \quad 17,10 \%$ & $2.199 \quad 11,75 \%$ & 2.199 \\
\hline & ${ }^{\circ} \mathrm{C}$ & $5404^{\prime} 29,37 \%$ & $12120^{\prime} 20,42 \%$ & $22969^{\prime} \quad 15,09 \%$ \\
\hline \multirow{2}{*}{2010} & HORAS & $990 \quad-3,24 \%$ & $\begin{array}{ll}1.864 & -5,27 \% \\
\end{array}$ & 1.864 \\
\hline & ${ }^{\circ} \mathrm{C}$ & $4131^{\prime}-1,12 \%$ & $9823^{\prime}-2,41 \%$ & $19102^{\prime} \quad-4,28 \%$ \\
\hline \multirow{2}{*}{2011} & HORAS & $1.102 \quad 7,71 \%$ & $2.108 \quad 7,12 \%$ & 2.108 \\
\hline & ${ }^{\circ} \mathrm{C}$ & $\begin{array}{llll}4358^{\prime} & 4,33 \% \\
\end{array}$ & $10696^{\prime \prime} \quad 6,27 \%$ & $21227^{\prime}$ \\
\hline \multirow{2}{*}{2012} & HORAS & $1.195 \quad 16,80 \%$ & $2.108 \quad 7,12 \%$ & 2.108 \\
\hline & ${ }^{\circ} \mathrm{C}$ & $5512^{\prime} 31,95 \%$ & $12039^{\prime} 19,61 \%$ & $22450^{\prime} \quad 12,49 \%$ \\
\hline \multirow{2}{*}{2013} & HORAS & $949 \quad-7,24 \%$ & $1.849 \quad-6,04 \%$ & 1.849 \\
\hline & ${ }^{\circ} \mathrm{C}$ & $3661-12,36 \%$ & $9126^{\prime}-9,32 \%$ & $18383 \quad-7,88 \%$ \\
\hline \multirow{2}{*}{2014} & HORAS & $1.036 \quad 1,26 \%$ & $2.084 \quad 5,91 \%$ & 2.084 \\
\hline & ${ }^{\circ} \mathrm{C}$ & $3591-14,03 \%$ & $9717-3,46 \%$ & 20338 \\
\hline \multirow{2}{*}{\multicolumn{2}{|c|}{ PROMEDIO }} & 1.023 HORAS & 1.968 HORAS & 1.968 HORAS \\
\hline & & $4177{ }^{\circ} \mathrm{C}$ & $10065^{\circ} \mathrm{C}$ & $19956^{\circ} \mathrm{C}$ \\
\hline
\end{tabular}

7-40 HORAS Y GRADOS-HORA EN QUE ES PRECISO DISIPAR ENERGÍA PARA ALCANZAR DIVERSAS TEMPERATURAS DE REFERENCIA DURANTE LA DÉCADA 2005-2014 EN ZARAGOZA AEROPUERTO (AEMET y elaboración propia) 
Del mismo modo se ha elaborado secuencias en las que se indican los periodos expresados en horas y en grados-hora que son necesarios para alcanzar varias temperaturas de referencia, en este $20^{\circ} \mathrm{C}, 18^{\circ} \mathrm{C}, 16^{\circ} \mathrm{C}, 10^{\circ} \mathrm{C}$ y $0^{\circ} \mathrm{C}$.

\begin{tabular}{|c|c|c|c|c|c|c|c|c|c|c|c|}
\hline \multirow{2}{*}{\multicolumn{2}{|c|}{ 2005- 14}} & \multicolumn{10}{|c|}{ HORAS y ${ }^{\circ} \mathrm{C}-$ HORA en las que debe subir la temperatura para llegar a ... } \\
\hline & & $<20^{\circ} \mathrm{C}$ & $<18^{\circ} \mathrm{C}$ & \multicolumn{2}{|c|}{$<16^{\circ} \mathrm{C}$} & \multicolumn{2}{|c|}{$<14^{\circ} \mathrm{C}$} & \multicolumn{2}{|c|}{$<10^{\circ} \mathrm{C}$} & \multicolumn{2}{|c|}{$<0^{\circ} \mathrm{C}$} \\
\hline \multirow{2}{*}{2005} & HORAS & $\begin{array}{ll}6.069 & -0,07 \%\end{array}$ & $\begin{array}{ll}5.347 & -0,27 \% \\
\end{array}$ & 4.645 & $0,23 \%$ & 4.035 & $2,50 \%$ & 2.789 & $13,56 \%$ & 428 & $193,75 \%$ \\
\hline & & $-50817^{\prime \prime} 18,59 \%$ & $-50817^{\prime \prime} \quad 18,59 \%$ & $-68601^{\prime}$ & $16,89 \%$ & -31984 & $13,95 \%$ & $-29261^{\prime}$ & $36,60 \%$ & $-919,9$ & $288,06 \%$ \\
\hline \multirow{2}{*}{2006} & HORAS & $\begin{array}{|ll|}5.793 & -4,62 \% \\
\end{array}$ & $5.034 \quad-6,10 \%$ & 4.260 & $-8,08 \%$ & 3.601 & $-8,52 \%$ & 2.254 & $-8,22 \%$ & 181 & $24,23 \%$ \\
\hline & & $-41079^{\prime}-4,14 \%$ & $-41079^{\prime}-4,14 \%$ & $-57274^{\prime}$ & $-2,41 \%$ & -23770 & $-15,31 \%$ & $-21071^{\prime}$ & $-1,63 \%$ & $-304,9$ & $28,62 \%$ \\
\hline \multirow{2}{*}{2007} & HORAS & $6.359 \quad 4,70 \%$ & 5.591 & 4.777 & $3,07 \%$ & 4.072 & $3,44 \%$ & 2.488 & $1,31 \%$ & 141 & $-3,23 \%$ \\
\hline & ${ }^{\circ} \mathrm{C}$ & $-43712^{\prime} \quad 2,01 \%$ & $-43712^{\prime}$ & -61943 & $5,55 \%$ & -24389 & $-13,11 \%$ & $-21063^{\prime}$ & $-1,67 \%$ & $-290,5$ & $22,55 \%$ \\
\hline \multirow{2}{*}{2008} & HORAS & \begin{tabular}{|ll}
6.424 & $5,77 \%$ \\
\end{tabular} & \begin{tabular}{|l}
5.721 \\
\end{tabular} & 4.986 & $7,58 \%$ & 4.209 & $6,93 \%$ & 2.516 & $2,45 \%$ & 136 & $-6,66 \%$ \\
\hline & ${ }^{\circ} \mathrm{C}$ & $-43808^{\prime} \quad 2,23 \%$ & $-43808^{\prime}$ & $-43808^{\prime}$ & $-25,35 \%$ & -62918 & $124,17 \%$ & $-23710^{\prime}$ & $10,69 \%$ & $-151,9$ & $-35,92 \%$ \\
\hline \multirow{2}{*}{2009} & HORAS & $\begin{array}{|ll|}5.850 & -3,68 \% \\
\end{array}$ & 5.138 & 4.490 & $-3,12 \%$ & 3.896 & $-1,03 \%$ & 2.495 & $1,59 \%$ & 112 & $-23,13 \%$ \\
\hline & ${ }^{\circ} \mathrm{C}$ & $-41628^{\prime} \quad-2,85 \%$ & \begin{tabular}{|ll}
$-41628^{\prime}$ & $-2,85 \%$ \\
\end{tabular} & $-58890^{\prime}$ & $0,35 \%$ & -23497 & $-16,28 \%$ & $-20503^{\prime}$ & $-4,29 \%$ & -128 & $-46,00 \%$ \\
\hline \multirow{2}{*}{2010} & HORAS & $6.251 \quad 2,92 \%$ & $\begin{array}{ll}5.570 & 3,89 \% \\
\end{array}$ & 4.898 & $5,69 \%$ & 4.220 & $7,20 \%$ & 2.835 & $15,44 \%$ & 168 & $15,31 \%$ \\
\hline & ${ }^{\circ} \mathrm{C}$ & $-47678^{\prime} \quad 11,26 \%$ & $-47678^{\prime} \quad 11,26 \%$ & $-66527^{\prime}$ & $13,36 \%$ & -27972 & $-0,34 \%$ & $-24971^{\prime}$ & $16,57 \%$ & $-211,5$ & $-10,78 \%$ \\
\hline \multirow{2}{*}{2011} & HORAS & $\begin{array}{|ll|}5.918 & -2,56 \% \\
\end{array}$ & \begin{tabular}{|ll}
5.269 & $-1,72 \%$ \\
\end{tabular} & 4.484 & $-3,25 \%$ & 3.677 & $-6,59 \%$ & 2.101 & $-14,45 \%$ & 100 & $-31,37 \%$ \\
\hline & ${ }^{\circ} \mathrm{C}$ & $-38304^{\prime}-10,61 \%$ & $-38304^{\prime \prime}-10,61 \%$ & $-55398^{\prime}$ & $-5,60 \%$ & -20257 & $-27,83 \%$ & $-17245^{\prime}$ & $-19,49 \%$ & $-131,8$ & $-44,40 \%$ \\
\hline \multirow{2}{*}{2012} & HORAS & $\begin{array}{|ll|}5.943 & -2,15 \% \\
\end{array}$ & $\begin{array}{ll}5.293 & -1,27 \% \\
\end{array}$ & 4.636 & $0,03 \%$ & 3.994 & $1,46 \%$ & 2.493 & $1,51 \%$ & 120 & $-17,64 \%$ \\
\hline & ${ }^{\circ} \mathrm{C}$ & $-42332^{\prime}-1,21 \%$ & $\begin{array}{|ll|}-42332^{\prime} & -1,21 \% \\
\end{array}$ & $-60181^{\prime}$ & $2,55 \%$ & -23671 & $-15,66 \%$ & -20496 & $-4,32 \%$ & $-150,4$ & $-36,55 \%$ \\
\hline \multirow{2}{*}{2013} & HORAS & $6.258 \quad 3,04 \%$ & 5.584 & 4.861 & $4,89 \%$ & 4.163 & $5,76 \%$ & 2.696 & $9,78 \%$ & 68 & $-53,33 \%$ \\
\hline & ${ }^{\circ} \mathrm{C}$ & \begin{tabular}{|l|l}
$-44957^{\prime}$ & $4,91 \%$ \\
\end{tabular} & \begin{tabular}{|l|l|}
$-44957^{\prime}$ & $4,91 \%$ \\
\end{tabular} & -63648 & $8,45 \%$ & -25375 & $-9,59 \%$ & $-22268^{\prime}$ & $3,96 \%$ & $-80,6$ & $-66,00 \%$ \\
\hline \multirow{2}{*}{2014} & HORAS & $\begin{array}{|ll|}5.869 & -3,37 \% \\
\end{array}$ & $\begin{array}{|ll|}5.066 & -5,51 \% \\
\end{array}$ & 4.308 & $-7,04 \%$ & 3.497 & $-11,16 \%$ & 1.892 & $-22,96 \%$ & 3 & $-97,94 \%$ \\
\hline & ${ }^{\circ} \mathrm{C}$ & $-34199-20,19 \%$ & \begin{tabular}{|ll}
-34199 & $-20,19 \%$ \\
\end{tabular} & -50594 & $-13,79 \%$ & -16840 & $-40,00 \%$ & -13619 & $-36,42 \%$ & -1 & $-99,58 \%$ \\
\hline \multirow{2}{*}{\multicolumn{2}{|c|}{ PROMEDIO }} & 6.073 HORAS & 5.361 HORAS & 4.635 & HORAS & 3.936 & HORAS & 2.456 & HORAS & 146 & HORAS \\
\hline & & $-428511^{\circ} \mathrm{C}$ & $-428511^{\circ} \mathrm{C}$ & $-58686^{\circ}$ & & -28067 & & $-21421^{\circ}$ & & $-237,05$ & \\
\hline
\end{tabular}

7-41 HORAS Y GRADOS-HORA EN QUE ES PRECISO APORTAR ENERGÍA PARA ALCANZAR DIVERSAS TEMPERATURAS DE REFERENCIA DURANTE LA DÉCADA 2005-2014 EN ZARAGOZA AEROPUERTO (AEMET y elaboración propia) 

PRÓXIMAS EN ZARAGOZA

Se han recogido las series térmicas correspondientes a tres estaciones meteorológicas situadas en Zaragoza.

La estación mejor documentada es la situada en el aeropuerto de Zaragoza, en la que se dispone de series térmicas al menos desde 1981, y de la que se han extraído los valores medios para 30 años (1981-2010) utilizados para formar parte de los datos estadísticos básicos elaborados por AEMET para toda España.

Se han utilizado también los datos recogidos durante un periodo más breve en las estaciones de Canal y Valdespartera, que están situadas en el interior de la trama urbana de la ciudad de Zaragoza. Las citadas estaciones se encuentran en una zona de 10 $\mathrm{Km} \times 5 \mathrm{Km}$ en el sur de la zona edificada de Zaragoza. La altitud de todas las estaciones meteorológicas es menor de $300 \mathrm{~m}$ sobre el nivel del mar.

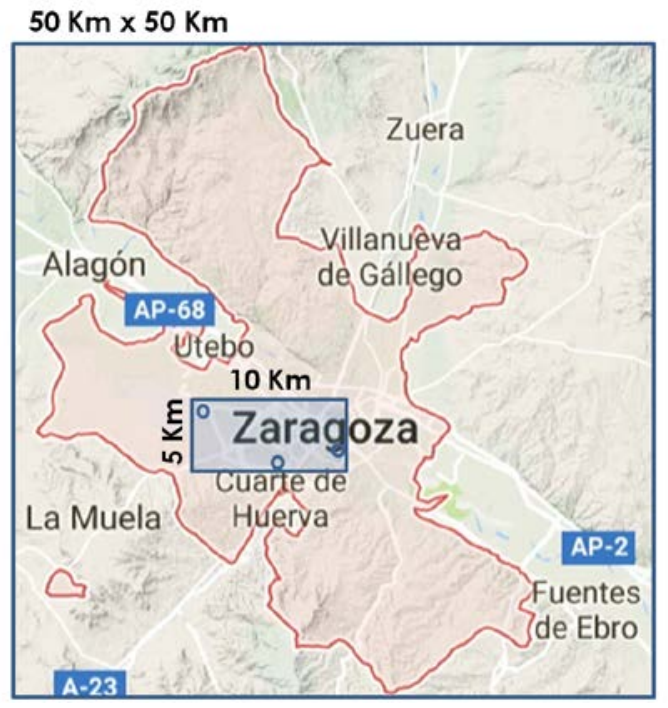

7-42 UBICACIÓN DE LAS ESTACIONES METEOROLÓGICAS DE REFERENCIA EN ZARAGOZA (google. maps y elaboración propia)

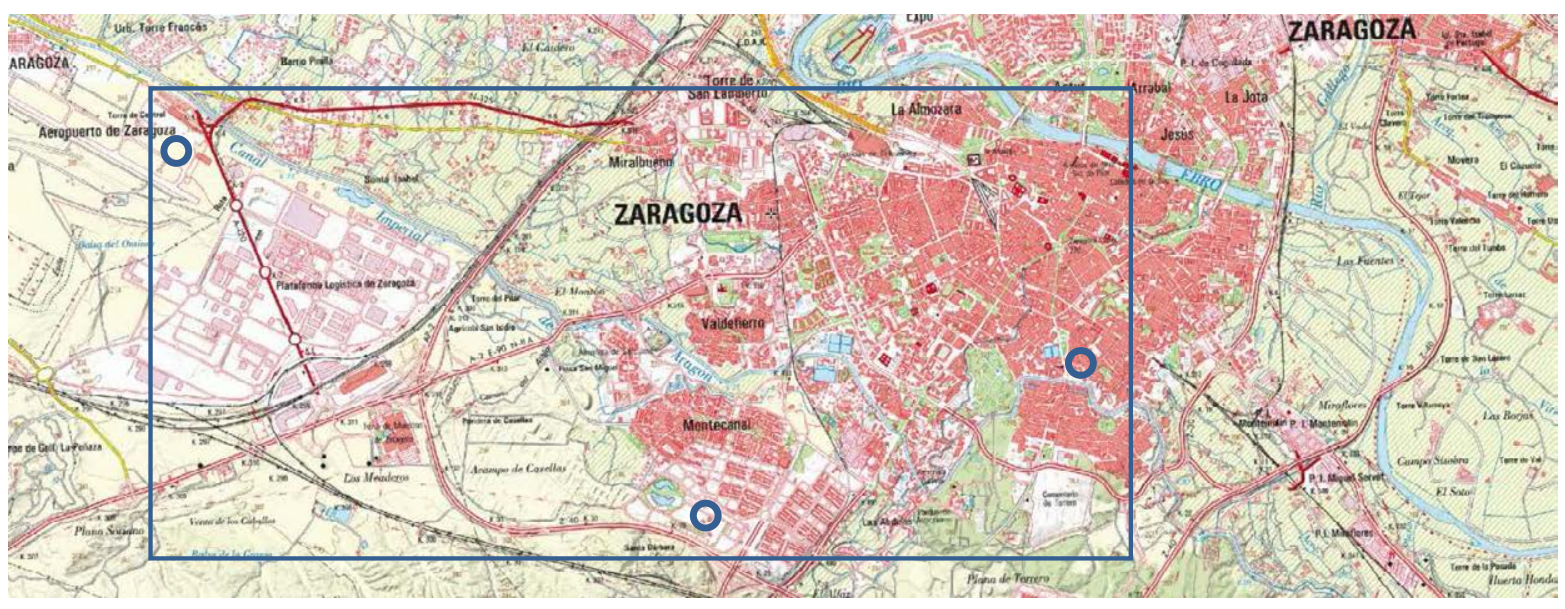

7-43 UBICACIÓN DE LAS ESTACIONES METEOROLÓGICAS DE REFERENCIA EN ZARAGOZA SOBRE CARTOGRAFÍA 1:50000 (ign.es/iberpix2/visor y elaboración propia) 
Las estaciones meteorológicas se describen por su altura sobre el nivel del mar, sus coordenadas y su localización visual.
VER ANEXO 08 DESCRIPCIÓN ESTACIONES METEOROLÓGICAS LOCALES 
La estación meteorológica del Aeropuerto de Zaragoza está en una zona periférica al suroeste del centro urbano de Zaragoza. El nivel de urbanización es alto aunque con menos edificación que las existentes en las proximidades de las otras estaciones. Se dispone de datos de los años 2005 a 2014, siendo ésta una de las estaciones meteorológicas de referencia para obtener una serie climática significativa para Zaragoza y para España desde el 1981 al 2010, formando parte de la edición realizada por AEMET.

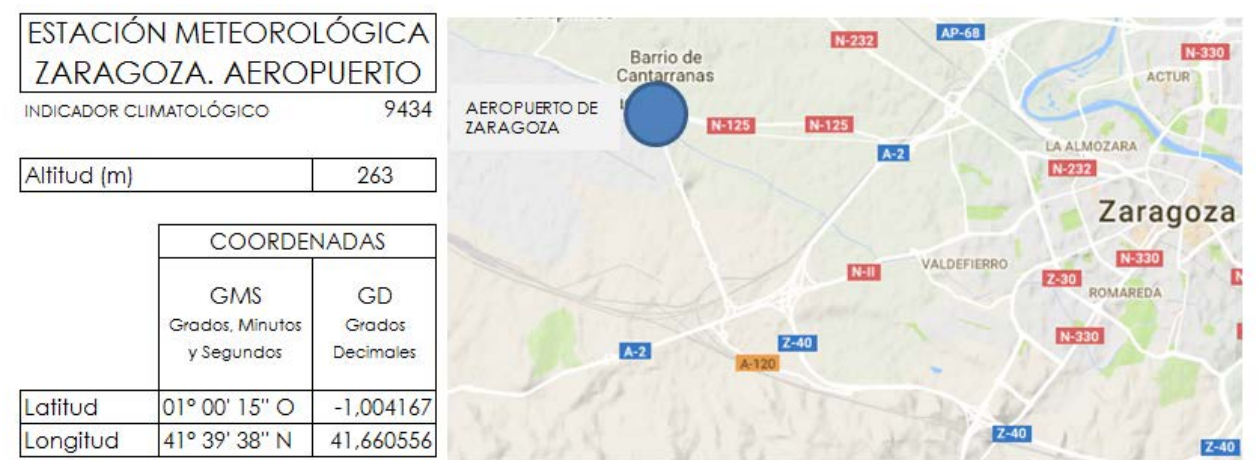

7-44 DATOS DE DESCRIPTIVOS Y UBICACIÓN DE LA ESTACIÓN METEOROLÓGICA DE AEROPUERTO EN ZARAGOZA (AEMET, google maps y elaboración propia)

A partir de los datos obtenidos en esta estación se han elaborado tablas, cuadros y gráficos con los valores térmicos registrados durante un año, desde el 10 de Junio de 2013 al 9 de junio de 2014.

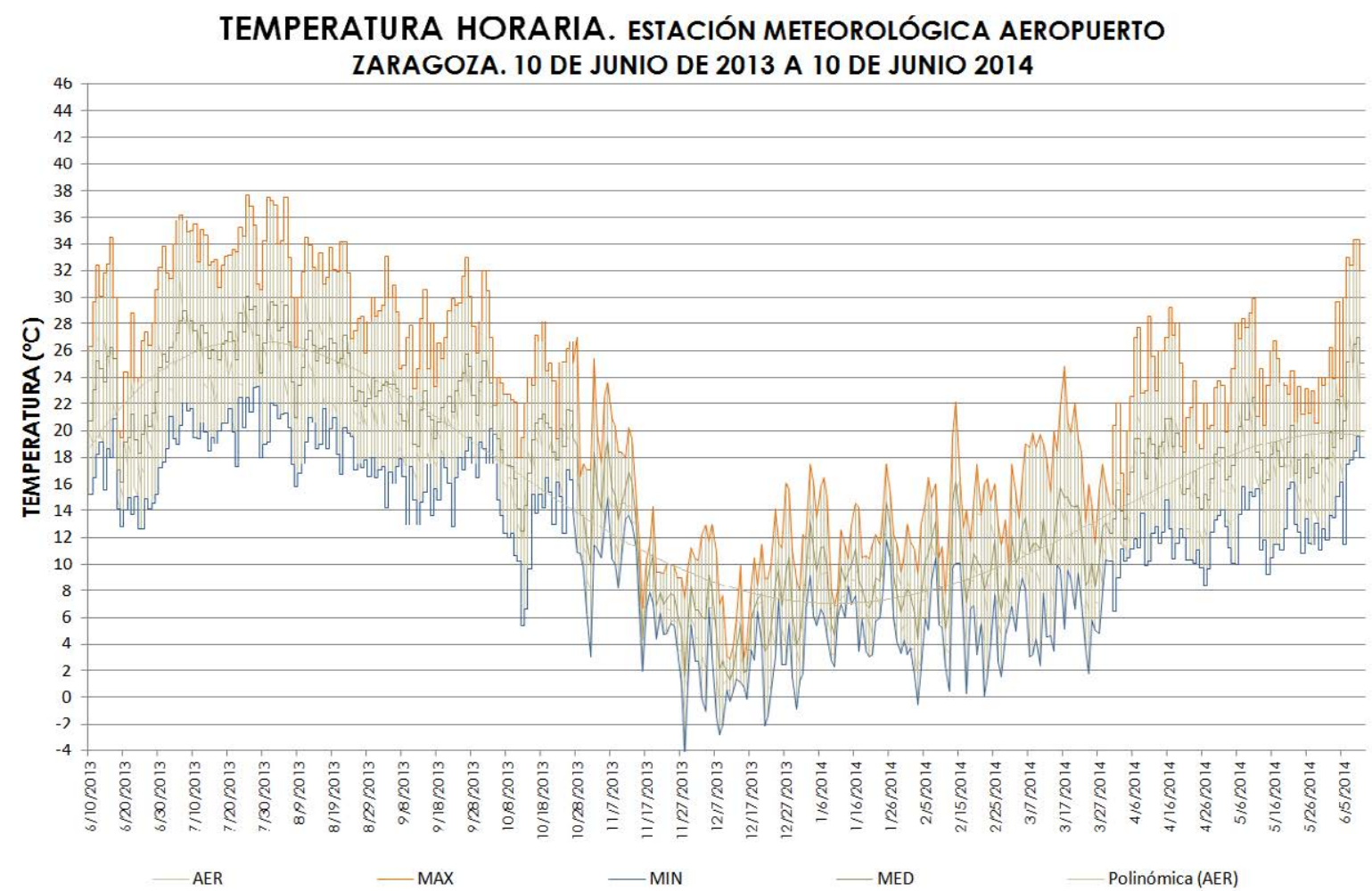

7-45 GRÁFICA DE LA EVOLUCION DE LA TEMPERATURA DURANTE UN CICLO ANUAL (DE 10 DE JUNIO DE 2013 A 10 DE JUNIO DE 2014) EN LA ESTACIÓN METEOROLÓGICA DE AEROPUERTO EN ZARAGOZA. (AEMET y elaboración propia) 


\subsubsection{ESTACIÓN METEOROLÓGICA DE CANAL}

Esta estación meteorológica de la Agencia Meteorológica Nacional está situada al sur del centro urbano y muy próxima a un gran canal del rio Ebro, estando rodeada por zonas muy urbanizadas. Se dispone de datos de los años 2007 a 2014.

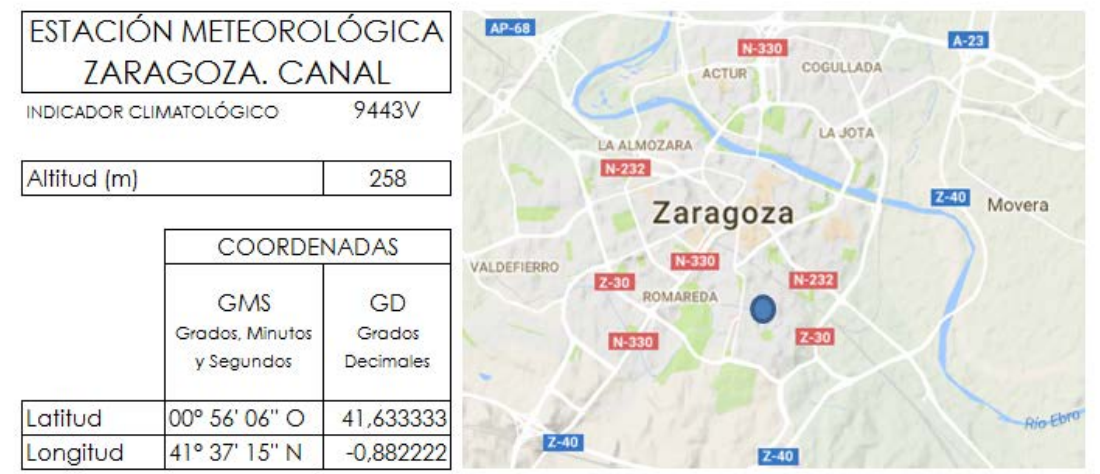

7-46 DATOS DE DESCRIPTIVOS Y UBICACIÓN DE LA ESTACIÓN METEOROLÓGICA DE CANAL EN ZARAGOZA (AEMET, google maps y elaboración propia)

TEMPERATURA HORARIA. ESTACIÓN METEOROLÓGICA CANAL. ZARAGOZA. 10 DE JUNIO DE 2013 A 10 DE JUNIO 2014

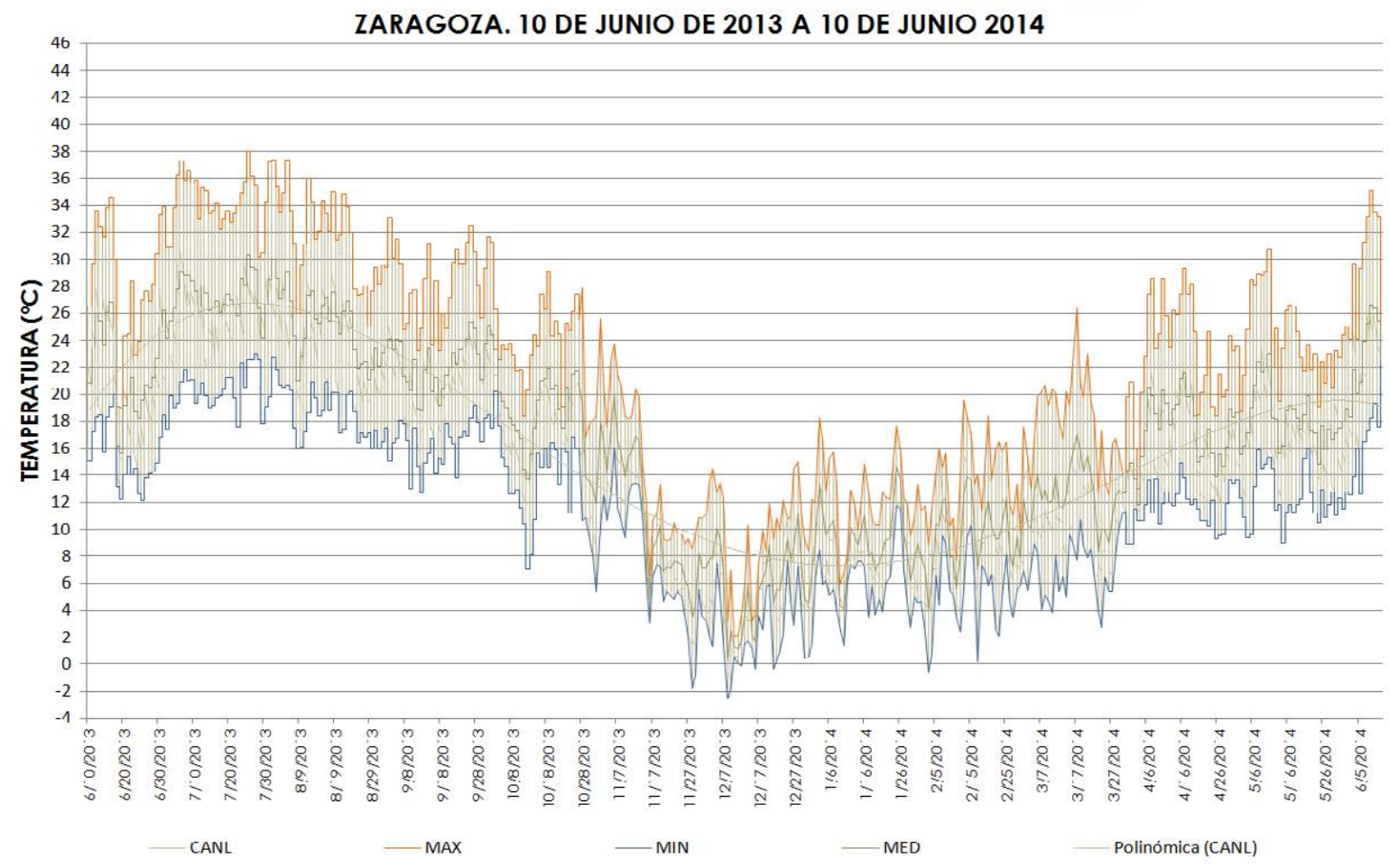

7-47 GRÁFICA DE LA EVOLUCION DE LA TEMPERATURA DURANTE UN CICLO ANUAL (DE 10 DE JUNIO DE 2013 A 10 DE JUNIO DE 2014) EN LA ESTACIÓN METEOROLÓGICA DE CANAL EN ZARAGOZA. (AEMET y elaboración propia) 


\subsubsection{ESTACIÓN METEOROLÓGICA DE VALDESPARTERA}

Esta estación meteorológica del Centro de Urbanismo Sostenible de Zaragoza y está situada al sur del centro urbano, en una zona de nueva urbanización. Se dispone de datos de los años 2013 a 2014.

\begin{tabular}{|c|c|}
\hline $\begin{array}{l}\text { ESTACIÓN METEOF } \\
\text { ZARAGOZA. VALD }\end{array}$ & $\begin{array}{l}\text { ŚGICA } \\
\text { ARTERA }\end{array}$ \\
\hline INDICADOR CLIMATOLÓGICO & $9434 \mathrm{P}$ \\
\hline Altitud (m) & 254 \\
\hline
\end{tabular}

\begin{tabular}{|l|c|c|}
\cline { 2 - 3 } \multicolumn{1}{c|}{} & \multicolumn{2}{c|}{ COORDENADAS } \\
\cline { 2 - 3 } \multicolumn{1}{c|}{$\begin{array}{c}\text { GMS } \\
\text { Grados, Minutos } \\
\text { y Segundos }\end{array}$} & $\begin{array}{c}\text { GD } \\
\text { Grados } \\
\text { Decimales }\end{array}$ \\
\hline Latitud & $00^{\circ} 56^{\prime} 06^{\prime \prime} \mathrm{O}$ & 41,620833 \\
\hline Longitud & $41^{\circ} 37^{\prime} 15^{\prime \prime} \mathrm{N}$ & $-0,935000$ \\
\hline
\end{tabular}

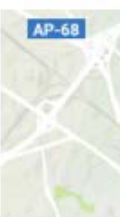

7-48 DATOS DE DESCRIPTIVOS Y UBICACIÓN DE LA ESTACIÓN METEOROLÓGICA DE VALDESPARTERA EN ZARAGOZA (AEMET, google maps y ELABORACIÓN PROPIA)

TEMPERATURA HORARIA. ESTACIÓN METEOROLÓGICA VALDESPARTERA. ZARAGOZA. 10 DE JUNIO DE 2013 A 10 DE JUNIO 2014

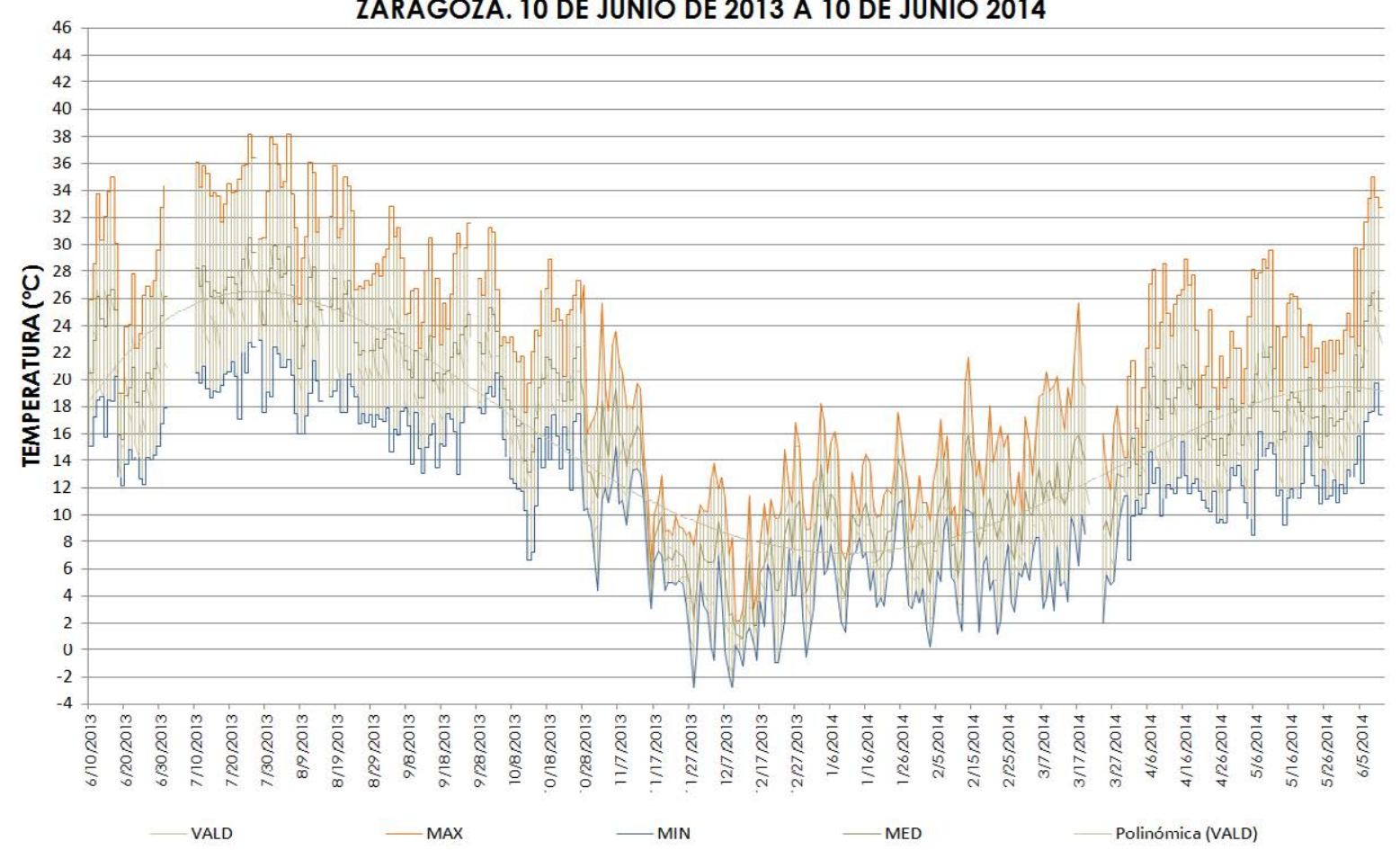

7-49 GRÁFICA DE LA EVOLUCION DE LA TEMPERATURA DURANTE UN CICLO ANUAL (DE 10 DE JUNIO DE 2013 A 10 DE JUNIO DE 2014) EN LA ESTACIÓN METEOROLÓGICA DE VALDESPARTERA EN ZARAGOZA. (AEMET Y elaboración propia)

Se elaboran los datos disponibles para establecer la evolución anual de las temperaturas horarias en las tres estaciones meteorológicas. 
Se dispone de datos comparables entre el 10 de junio del año 2013 y el 9 de junio del año 2014, por lo que se han realizado las comparaciones entre estaciones a lo largo de este periodo.

En una primera aproximación se han elaborado tablas, cuadros y gráficas para comparar los grados-hora en varias bases diferentes anuales y para los periodos fríos y cálidos indicados en la legislación para la eficiencia energética. Se consideran por tanto el periodo cálido, los meses de junio hasta septiembre incluidos, y el periodo frío que transcurre entre los meses de octubre a mayo.

En una segunda aproximación se determinan las diferencias horarias de cada estación con el valor medio formado con las tres estaciones meteorológicas de referencia durante este periodo.

En tercer lugar se elaboran tablas cuadros y gráficas para comparar los valores máximos, mínimos, medios y las oscilaciones térmicas diarias a través de sus máximos absolutos, las medias de las máximas, medias y mínimas y las oscilaciones térmicas diarias en este periodo.

Por último se representa la evolución diaria de las temperaturas en las estaciones cuando se producen situaciones singulares.

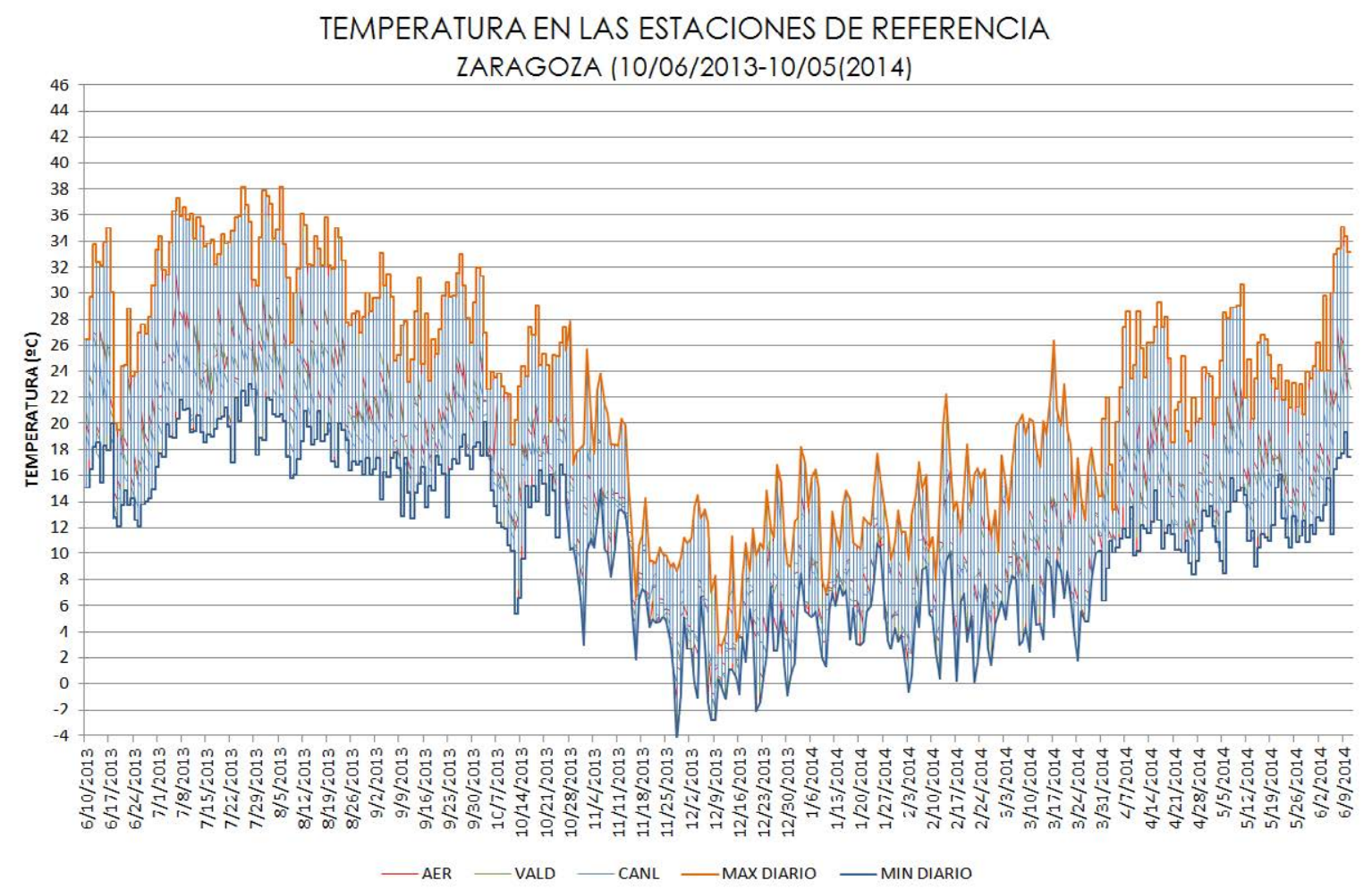

7-50 GRÁFICA ACUMULADA ANUAL DE TEMPERATURAS HORARIAS EN LAS ESTACIONES DE REFERENCIA DE ZARAGOZA (10/06/2013-10/06/2014) (AEMET y elaboración propia) 

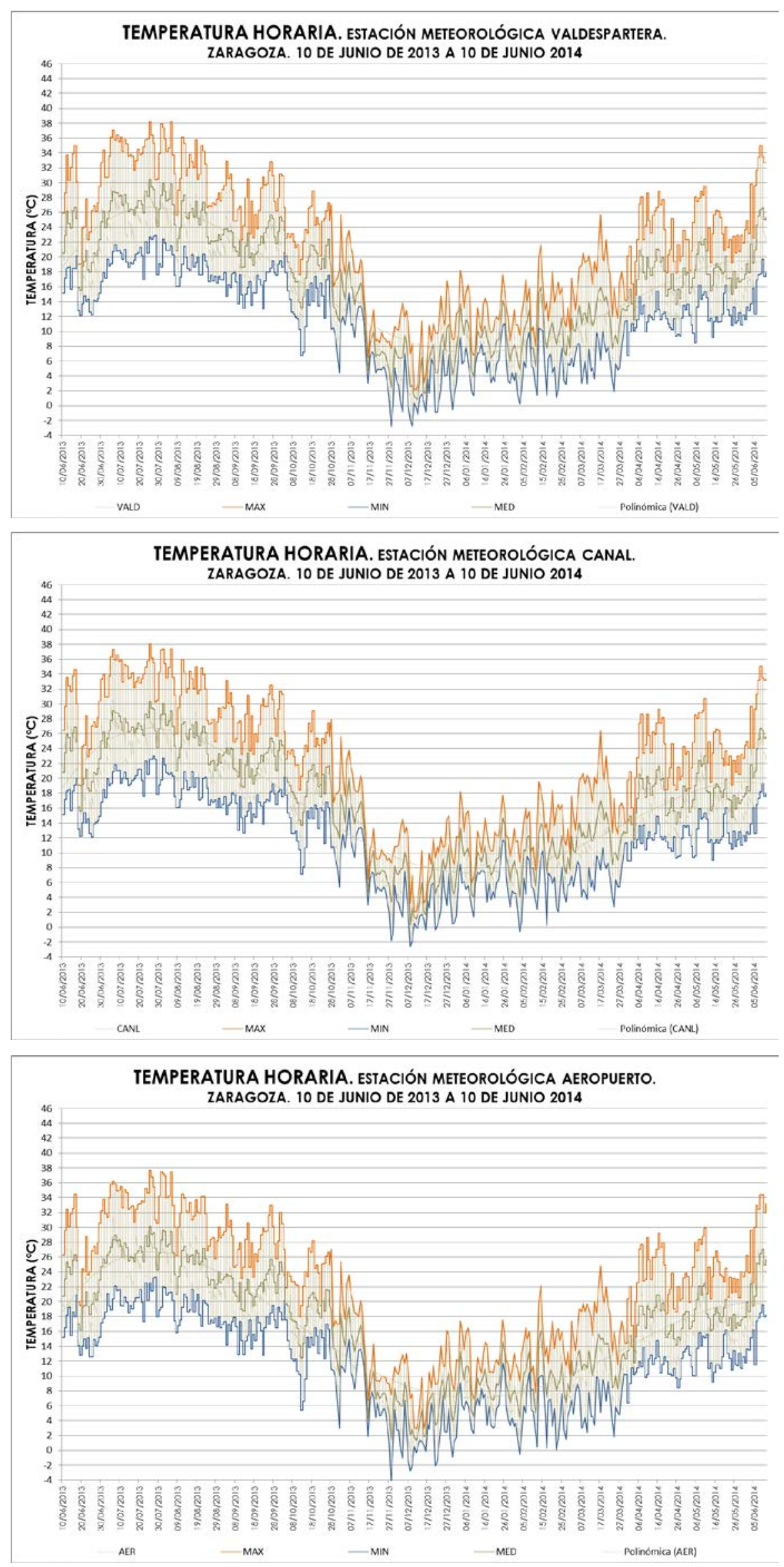

7-51 GRÁFICAS ANUALES DE TEMPERATURAS HORARIAS EN LAS ESTACIONES DE REFERENCIA DE ZARAGOZA (10/06/2013-10/06/2014) (AEMET y elaboración propia) 


\subsection{ESTUDIO COMPARADO DE LAS SECUENCIAS TÉRMICAS EN CLIMAS REGISTRADOS Y DE REFERENCIA}

Los climas elaborados para su aplicación en la normativa de obligado cumplimiento provienen de varias fuentes $y$, como se ha visto, tienen aplicación en la determinación de las cualidades exigidas a los edificios y a sus sistemas, en la justificación del cumplimiento de las condiciones establecidas en la normativa (HE 0, HE 1 y RITE) y, ocasionalmente, en la estimación del desempeño energético y ambiental de los edificios.

Se han elaborado gráficos que describan y comparan los climas de referencia para la zona climática D3 y los registrados en la década 2005-2014 en la localidad de referencia.

Para su aplicación a la zona D3 en el código técnico se ha elaborado una secuencia térmica horaria.

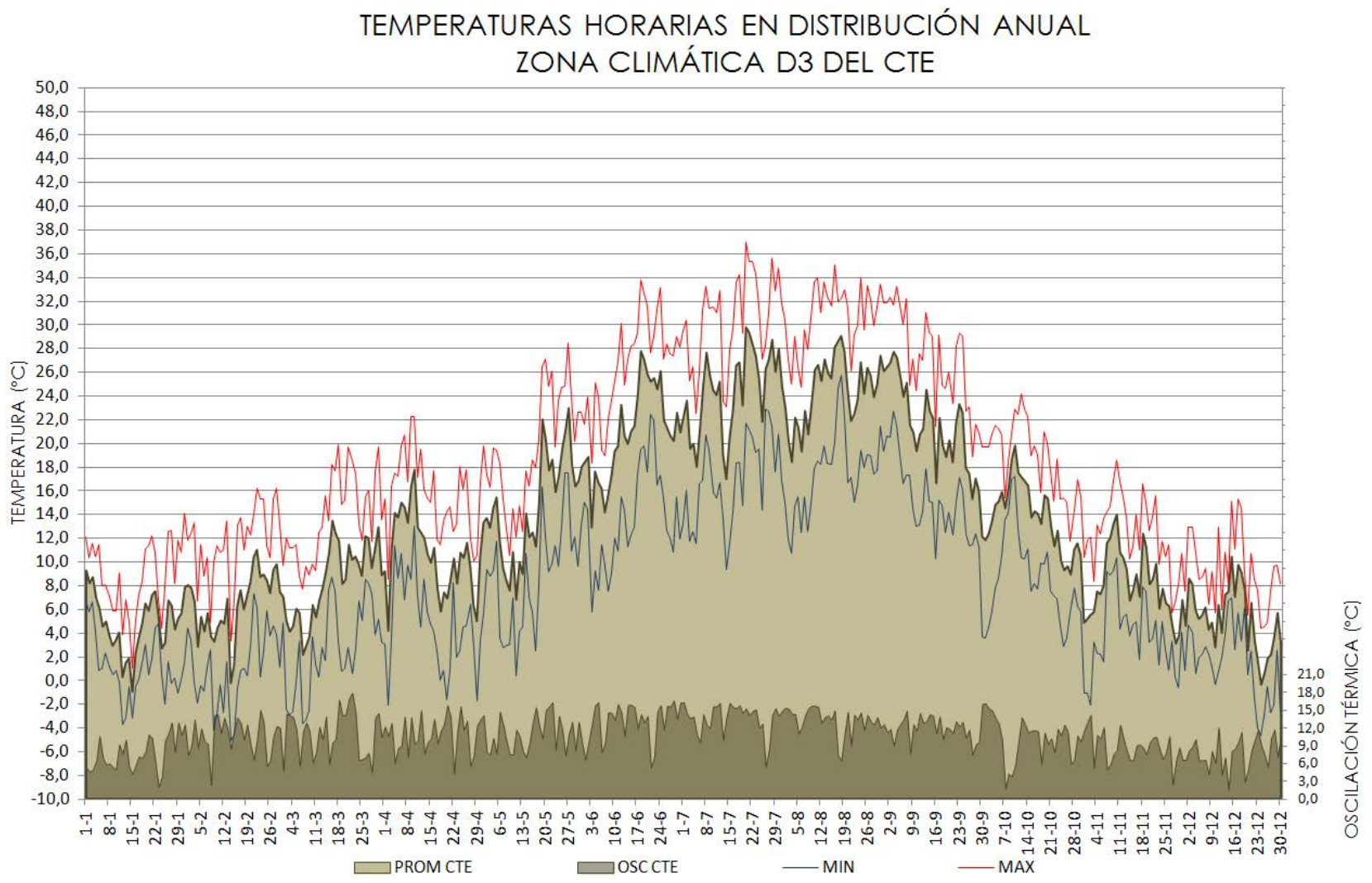

7-52 GRÁFICA DE LA DISTRIBUCIÓN ANUAL DE LAS TEMPERATURAS MÁXIMAS, MEDIAS Y MÁXIMAS DIÁRIAS Y OSCILACIONES TÉRMICAS DIARIAS PARA LA ZONA CLIMÁTICA D3 (CTE y elaboración propia) 
Se comparan los valores medios máximos y mínimos y las oscilaciones térmicas del clima diseñado para la zona climática D3, así como el promedio de las temperaturas durante la década de 2005 a 2014.

TEMPERATURAS PROMEDIO EN ZONA CLIMÁTICA D3-CTE Y VALORES PROMEDIO AEROPUERTO DE ZARAGOZA. PERIODO 2005 A 2014

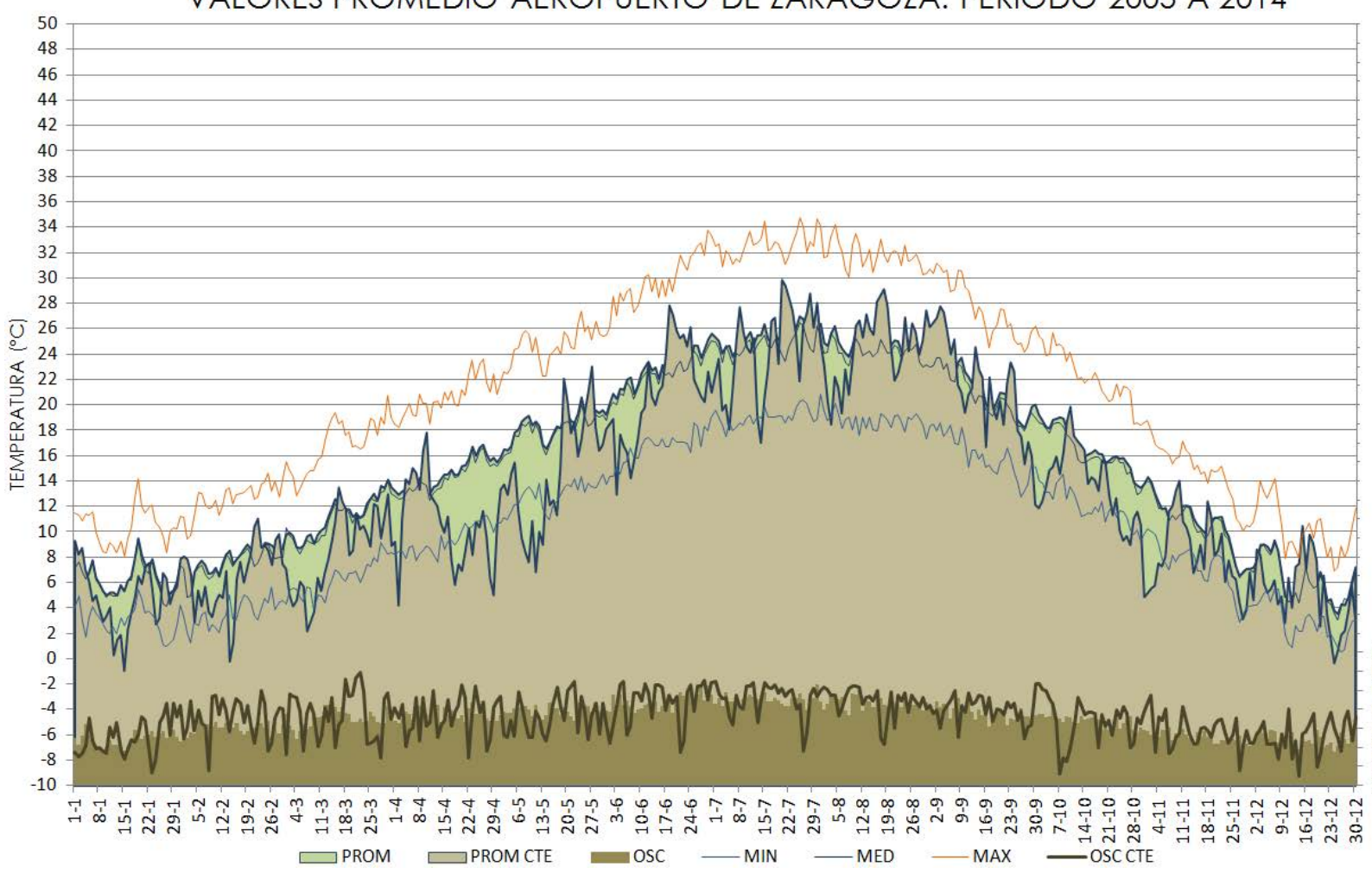

7-53 GRÁFICA DE LA DISTRIBUCIÓN ANUAL DE LAS TEMPERATURAS PROMEDIO DIÁRIAS Y OSCILACIONES TÉRMICAS DIARIAS PARA LA ZONA CLIMÁTICA D3 y EL PROMEDIO DE LA DÉCADA 2005 Y 2014 (CTE, AEMET y elaboración propia)

La exposición en términos de grados-hora permite una comparación cuantitativa en rangos de temperaturas diferentes. 
De otra parte se comparan los grados-hora necesarios para alcanzar las temperaturas de $20^{\circ} \mathrm{C}, 18^{\circ} \mathrm{C}, 16^{\circ} \mathrm{C}, 14^{\circ} \mathrm{C}, 10^{\circ} \mathrm{C}$ y $0^{\circ} \mathrm{C}$, cuando las temperaturas son menores de estos valores. También se refleja el tiempo, en horas, durante el que se producen las superaciones de las temperaturas de referencia.

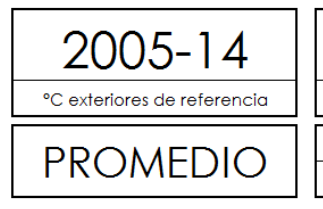

\begin{tabular}{|c|c|c|c|c|c|}
\hline \multicolumn{7}{|c|}{ HORAS $^{\circ} \mathrm{C}-$ HORA en las que debe subir la temperatura para llegar a ... } \\
\hline$<20^{\circ} \mathrm{C}$ & $<18^{\circ} \mathrm{C}$ & $<16^{\circ} \mathrm{C}$ & $<14^{\circ} \mathrm{C}$ & $<10^{\circ} \mathrm{C}$ & $<0^{\circ} \mathrm{C}$ \\
\hline \hline 6.073 HORAS & $5.361 \mathrm{HORAS}$ & 4.635 HORAS & 3.936 HORAS & 2.456 HORAS & 146 HORAS \\
\hline$-42851,266^{\circ} \mathrm{C}$ & $-42851,26{ }^{\circ} \mathrm{C}$ & $-58686{ }^{\circ} \mathrm{C}$ & $-28067{ }^{\circ} \mathrm{C}$ & $-21421{ }^{\circ} \mathrm{C}$ & $-237,05{ }^{\circ} \mathrm{C}$ \\
\hline
\end{tabular}

\begin{tabular}{|l|r|}
\hline CTE-D3 & HORAS \\
\cline { 2 - 2 } & ${ }^{\circ} \mathrm{C}$ \\
\hline
\end{tabular}

\begin{tabular}{|rr|rr|rr|rr|rr|rr|}
\hline 6.578 & $8,31 \%$ & 6.058 & $12,99 \%$ & 5.499 & $18,65 \%$ & 4.875 & $23,84 \%$ & 3.488 & $42,03 \%$ & 218 & $49,62 \%$ \\
\hline$-56152,4$ & $31,04 \%$ & -56.152 & $31,04 \%$ & -77.576 & $32,19 \%$ & -34.177 & $21,77 \%$ & -31.172 & $45,52 \%$ & -349 & $47,02 \%$ \\
\hline
\end{tabular}

\begin{tabular}{|l|r|}
\hline \multirow{2}{*}{ RITE-D3 } & HORAS \\
\cline { 2 - 2 } & ${ }^{\circ} \mathrm{C}$ \\
\hline
\end{tabular}

\begin{tabular}{|rr|rr|rr|rr|rr|rr|}
\hline 6.674 & $9,89 \%$ & 5.926 & $10,53 \%$ & 5.218 & $12,59 \%$ & 4.532 & $15,13 \%$ & 3.068 & $24,92 \%$ & 2 & $-98,63 \%$ \\
\hline-46904 & $9,46 \%$ & -46.904 & $9,46 \%$ & -67.034 & $14,22 \%$ & -25.955 & $-7,52 \%$ & -22.819 & $6,53 \%$ & -1 & $-99,62 \%$ \\
\hline
\end{tabular}

\begin{tabular}{l|r|}
\hline \multirow{2}{*}{ RITE_ZG } & HORAS \\
\cline { 2 - 2 } & ${ }^{\circ} \mathrm{C}$ \\
\hline
\end{tabular}

\begin{tabular}{|rr|rr|rr|rr|rr|rr|}
\hline 6.496 & $6,96 \%$ & 5.749 & $7,23 \%$ & 5.097 & $9,98 \%$ & 4.390 & $11,52 \%$ & 2.878 & $17,19 \%$ & 19 & $-86,96 \%$ \\
\hline$-45588,2$ & $6,39 \%$ & -45.588 & $6,39 \%$ & -65.319 & $11,30 \%$ & -25.200 & $-10,21 \%$ & -21.954 & $2,49 \%$ & -9 & $-96,37 \%$ \\
\hline
\end{tabular}

7-55 CUADRO COMPARADO EN ${ }^{\circ} \mathrm{C}-\mathrm{HORA}$ Y EN HORAS DE LAS SUPERACIONES DE LAS TEMPERATURAS DE REFERENCIA EN EL PROMEDIO DE LA DÉCADA 20052014 Y LOS CLIMAS PROPUSTOS EN EL CTE Y EL RITE PARA LA ZONA CLIMÁTICA D3 Y EL CLIMA PROPUESTO POR EL RITE PARA ZARAGOZA (AEMET, RITE, CTE y elaboración propia)

Se elaboran también tablas con los grados registrados durante la década 2005-2014 y los establecidos para los climas sintéticos sobre y bajo $0^{\circ} \mathrm{C}$.

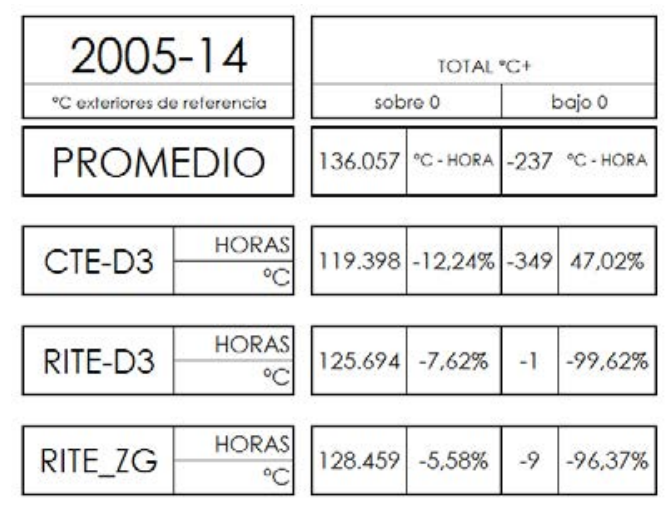

7-56 CUADRO COMPARADO LOS ${ }^{\circ} \mathrm{C}$-HORA NECSARIOS PARA ALCANZAR LOS ${ }^{\circ} \mathrm{C}$ DESDE EMPERATURAS INFERIORES O SUPERIORES EN EL PROMEDIO DE LA DÉCADA 2005-2014 Y LOS CLIMAS PROPUSTOS EN EL CTE Y EL RITE PARA LA ZONA CLIMÁTICA D3 Y EL CLIMA PROPUESTO POR EL RITE PARA ZARAGOZA (AEMET, RITE, CTE y elaboración propia) 


\subsection{MICROCLIMA URBANO EN ZARAGOZA}

Para conocer el microclima urbano se ha dispuesto una estación meteorológica en un edificio situado en el interior de la trama urbana de la que se obtienen series discontinuas durante los años 2012,2013 y 2014.

Está situada en el centro histórico de Zaragoza, en la calle S. Pablo, 85, en el centro urbano de Zaragoza, con coordenadas: (LATITUD $41^{\circ}$ 39' 20.20" LONGITUD 0 53' 17.37"W)

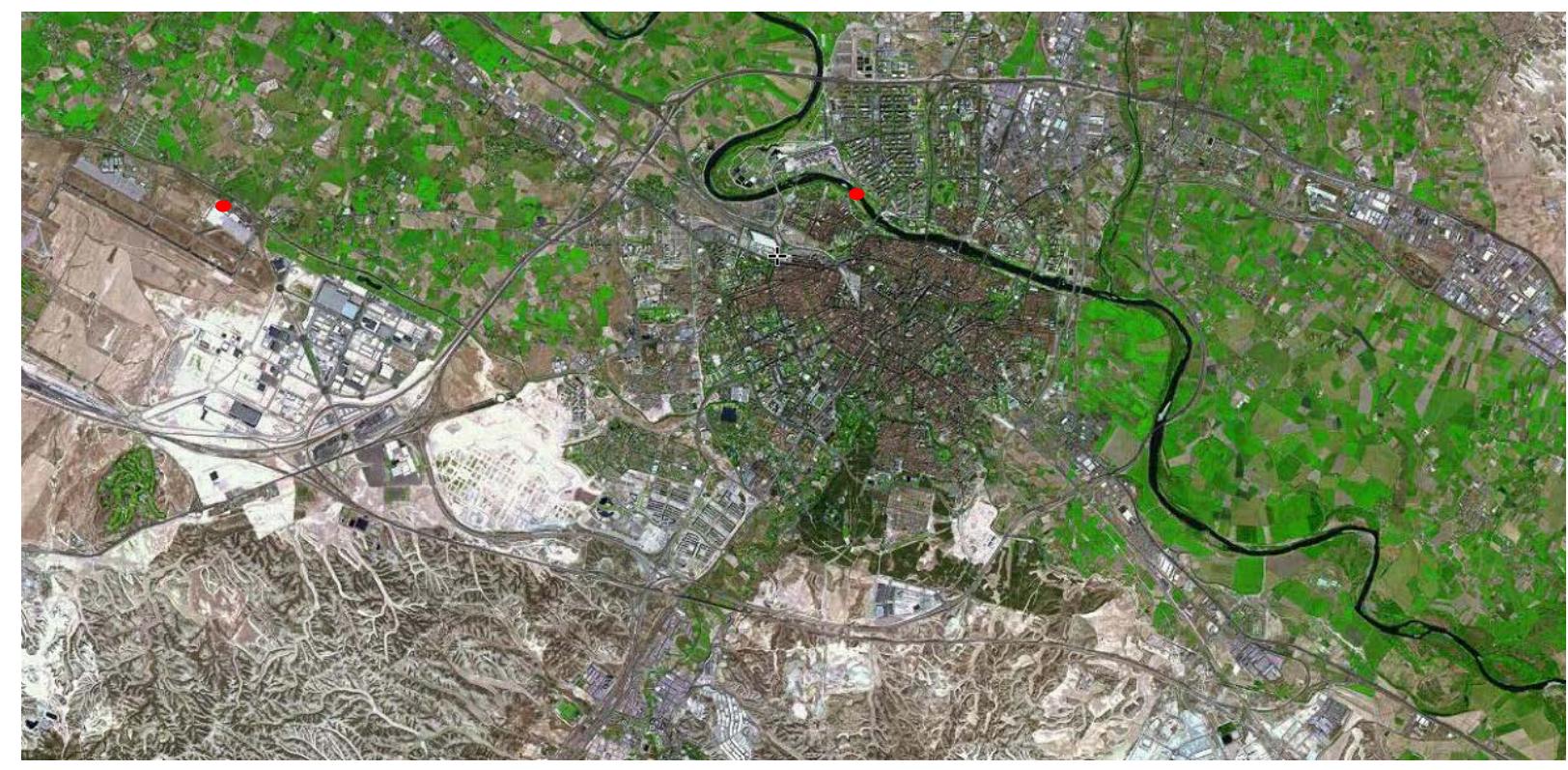

7-57 FOTO AÉREA CON LA UBICACIÓN DE LA ESTACIÓN URBANA EN ZARAGOZA Y LA ESTACIÓN DEL AEROPUERTO DE ZARAGOZA (IBERPIX2 y elaboración propia) 


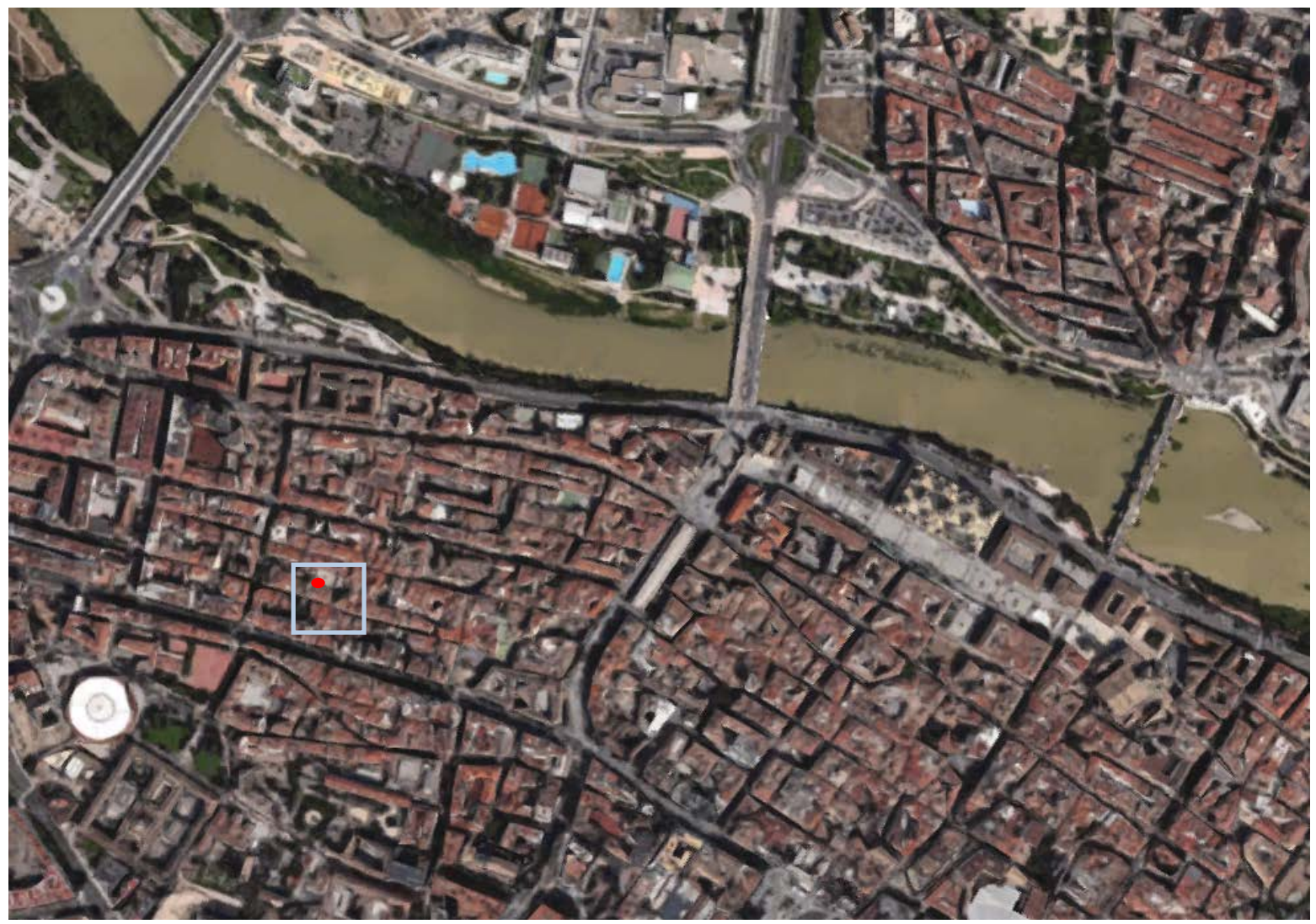

7-58 FOTO AÉREA CON LA UBICACIÓN DE LA ESTACIÓN URBANA EN ZARAGOZA

(GOOGLE y elaboración propia)

Los datos obtenidos en la estación urbana se tratan de un modo similar a los procedentes de estaciones de la red nacional.

Para establecer comparaciones se emplean series térmicas de la estación de AEMET situada en el AEROPUERTO de ZARAGOZA, y en la estación meteorológica dispuesta en la calle S. Pablo en la cubierta de un edificio interior de la trama urbana de Zaragoza, en concreto las registradas durante los años 2012, 2013 y 2014.

La observación de la serie horaria permite observar una secuencia anual que presenta una distribución de aspecto casi senoidal, aunque se ajusta mejor a una función polinómica, en este caso de sexto grado con muchos valores alejados, sin una correlación evidente, de la curva de tendencia, con valores máximos entre junio y agosto y mínimos entre diciembre y febrero y, por tanto, con una pendiente ligeramente mayor en la transición hacia periodos fríos y menor cuando se incrementan las temperaturas. 
Las diferencias entre ambas son muy a menudo de varios grados pudiendo llegar a superar los diez grados, sin una correlación muy clara.

TEMPERATURA EN ESTACIONES METEOROLÓGICAS LOCALES AEMET (A)-EDIFICIO(E)

ZARAGOZA. 2014

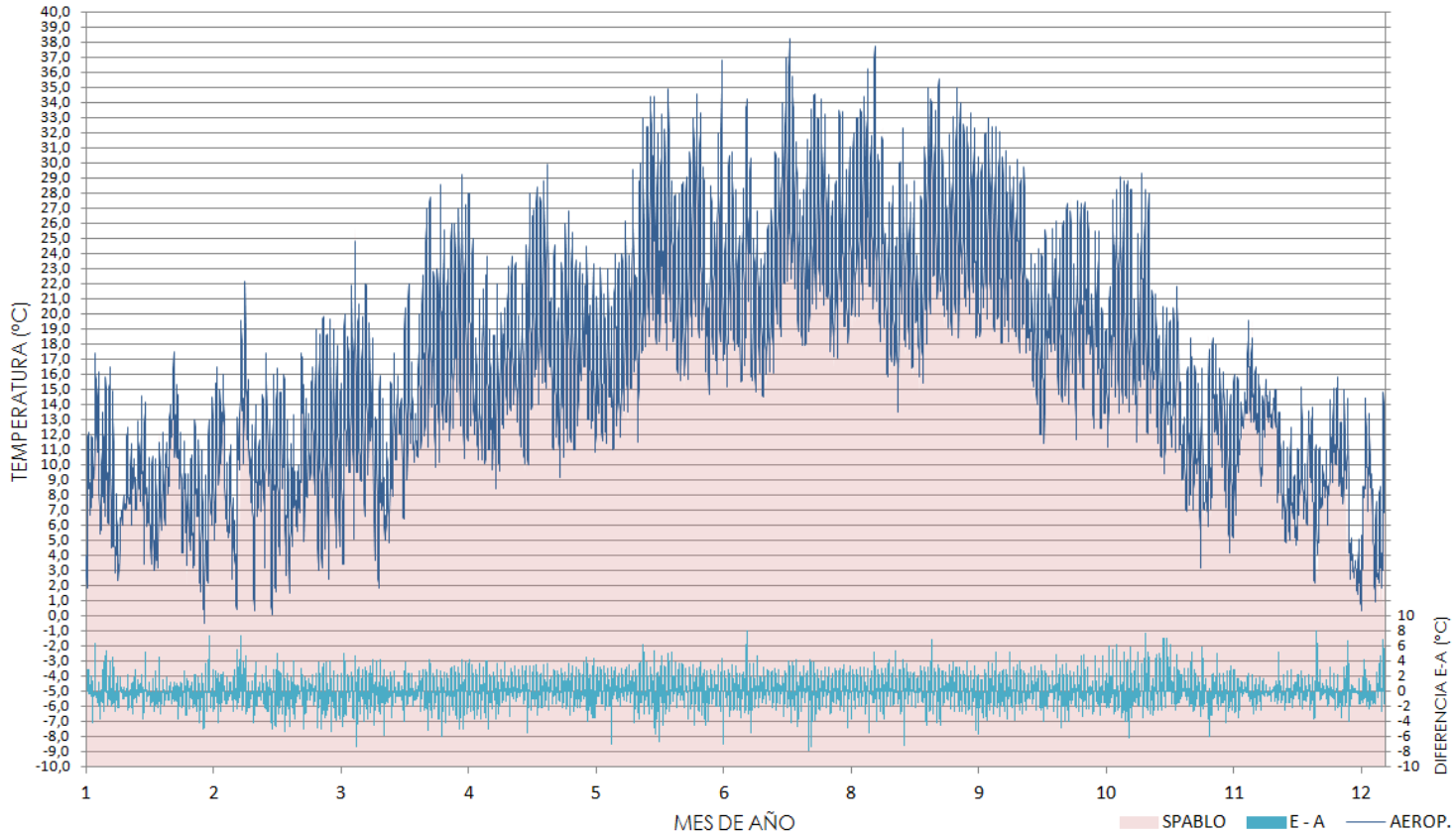

7-59 GRÁFICA COMPARADA DE TEMPERATURAS MEDIAS DARIAS Y OSCILACIONES TÉRMICAS EN LA ESTACIÓN DE ZARAGOZA-AEROPUERTO DURANTE EL AÑO 2014. (AEMET y elaboración propia) 
La observación de las temperaturas medias diarias a lo largo del año para las dos estaciones consideradas, permite definir las diferencias con más nitidez. Para ello se elaboran gráficas y cuadros donde se independizan los valores medios y máximos, mínimos y las oscilaciones térmicas.

\section{TEMPERATURA MEDIA DIARIA EN LAS ESTACIONES METEOROLÓGICAS}

DE AEMET Y SAN PABLO. ZARAGOZA. 2014

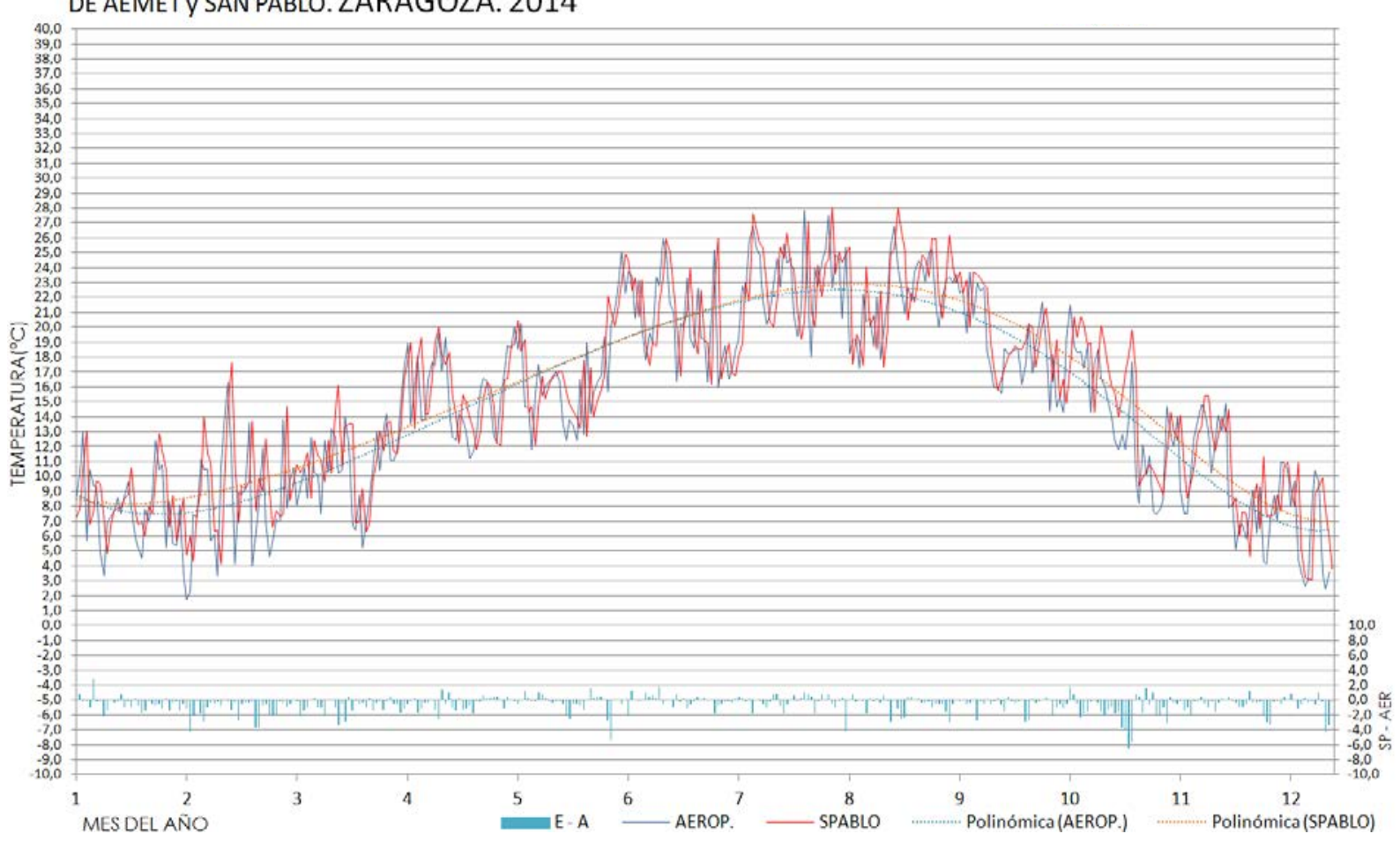

7-60 GRÁFICA COMPARADA DE TEMPERATURAS MEDIAS DARIAS Y DIFERENCIAS ENTRE ESTACIONES DE SAN PABLO Y LA ESTACIÓN DE ZARAGOZAAEROPUERTO DURANTE EL AÑO 2014. (AEMET y elaboración propia) 
B1 Series anuales

Considerando la reacción del edificio y el retardo* con que las temperaturas exteriores afectan a las series térmicas interiores, se observa la relación entre los valores medios diarios en secuencias continuas diarias y cada 3,6 y 9 días.

La evolución anual de las temperaturas se ordena en valores medios diarios, cada 3 días, 6 días y 9 días (promedio, máximas, mínimas y mediana) y la oscilación térmica diaria en estos periodos.
VER ANEXO 07

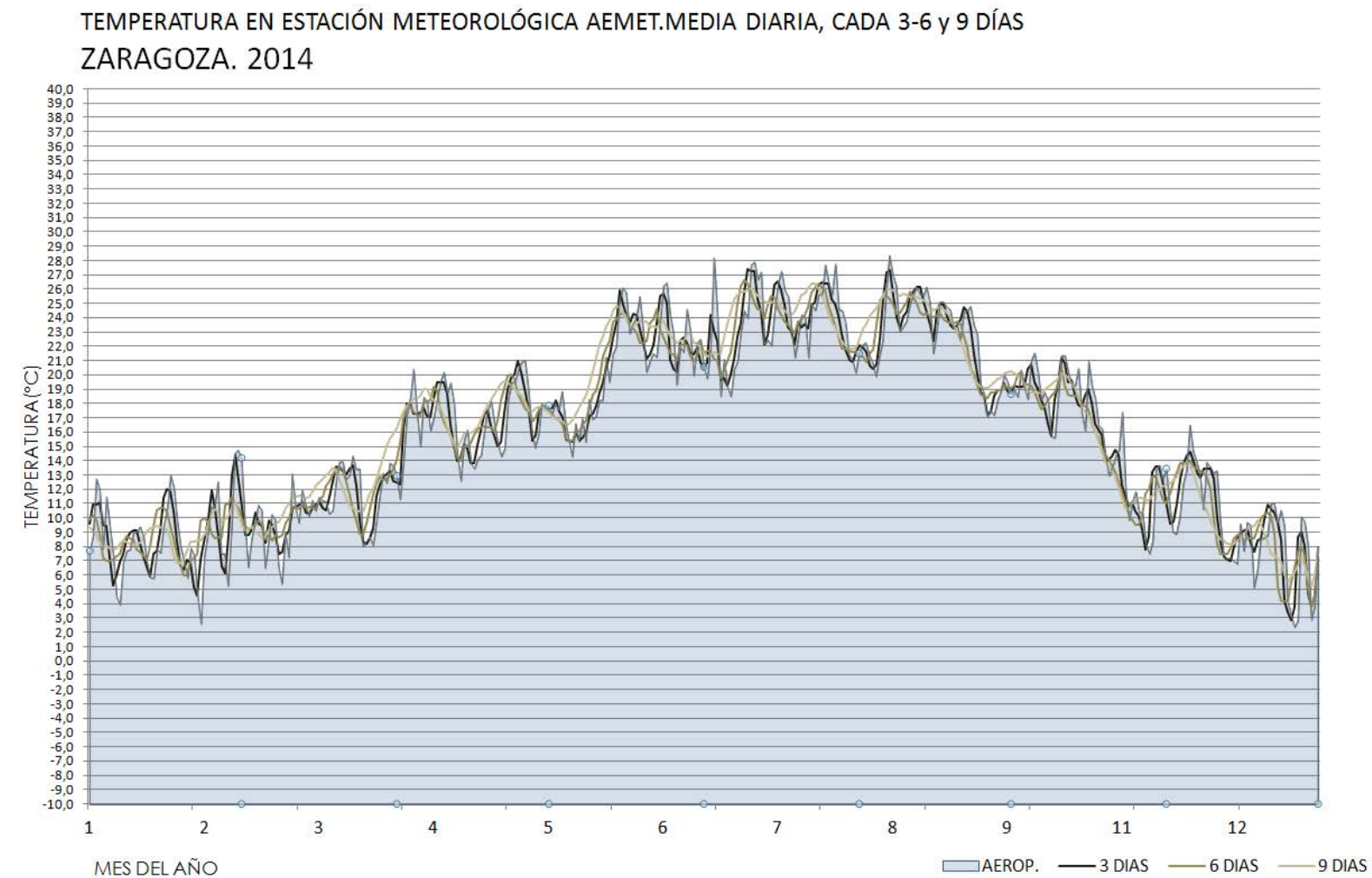

7-61 GRÁFICA DE LAS MEDIAS DIARIAS EN LA ESTACIÓN DE ZARAGOZA-AEROPUERTO DURANTE EL AÑO 2014 Y LAS MEDIANAS CADA 3-6 y 9 DÍAS (AEMET y elaboración propia)

La representación gráfica de las temperaturas en la estación de referencia permite visualizar el amortiguamiento de los valores medios cuando las medias se consideran cada más tiempo.

Cuando esta misma circunstancia se comprueba para las dos estaciones se pueden obtener gráficas que indican ligeras diferencias entre ambas localizaciones, observándose que se reduce los valores máximos y mínimos alcanzados en la estación referencia. 
Tanto en el caso de considerar las medianas cada 3 días :

TEMPERATURA EN ESTACIÓN METEOROLÓGICA AEMETY S. PABLO

MEDIANA CADA 3 DÍAS. ZARAGOZA. 2014

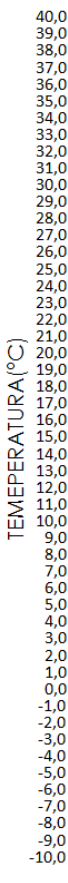

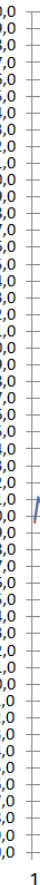

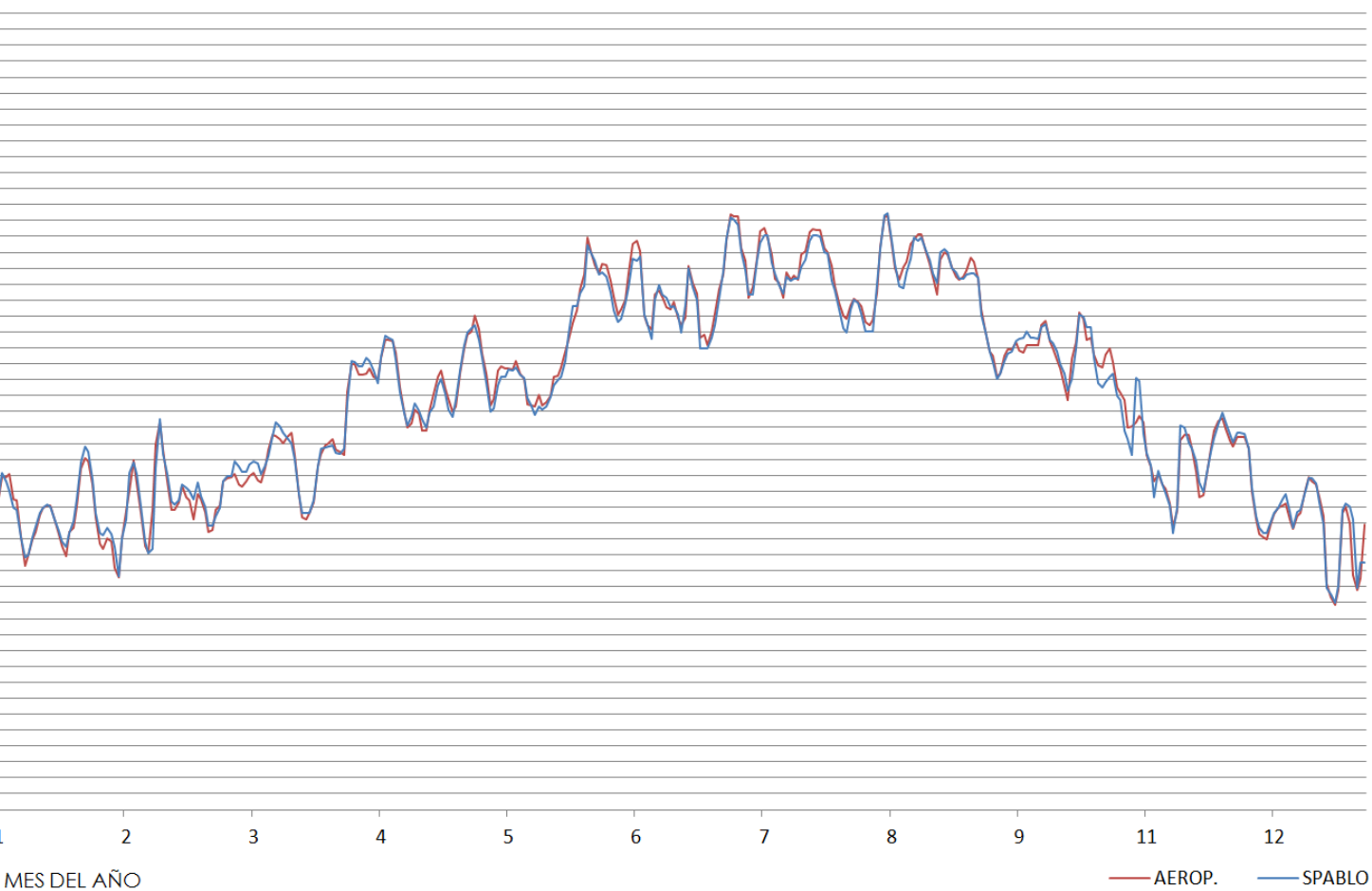

7-62 GRÁFICA DE LAS MEDIAS CADA 3 DÍAS EN LA ESTACIÓN DE ZARAGOZAAEROPUERTO Y EN S. PABLO DURANTE EL AÑO 2014 (AEMET y elaboración propia)

Como en el caso de considerar las medianas cada 9 días:

TEMPERATURA EN ESTACIÓN METEOROLÓGICA AEMET Y S. PABLO CADA 9 DÍAS

ZARAGOZA. 2014

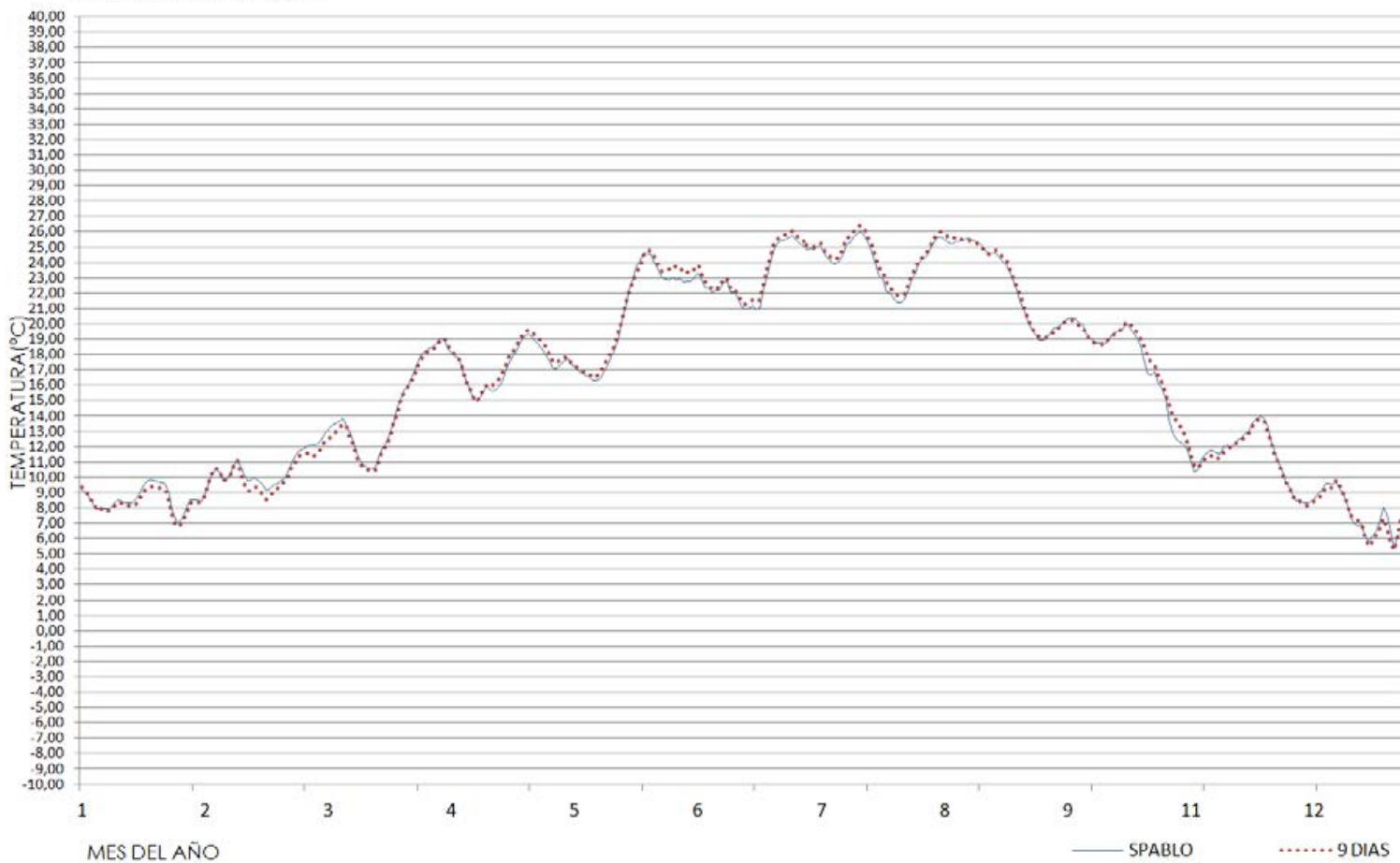

7-63 GRÁFICA DE LAS MEDIAS CADA 9 DÍAS EN LA ESTACIÓN DE ZARAGOZAAEROPUERTO Y EN S. PABLO DURANTE EL AÑO 2014 (AEMET y elaboración propia) 
B2 Series térmicas mensuales y cada tres meses.

Para un manejo eficaz de la información se elaboran series parciales que permitan un análisis gráfico individualizado, se fraccionan las series térmicas en periodos asociados a la ordenación temporal convencional en trimestres.

TEMPERATURA EN ESTACIONES METEOROLÓGICAS LOCALES AEMET-EDIFICIO ZARAGOZA. ENERO a MARZO 2014

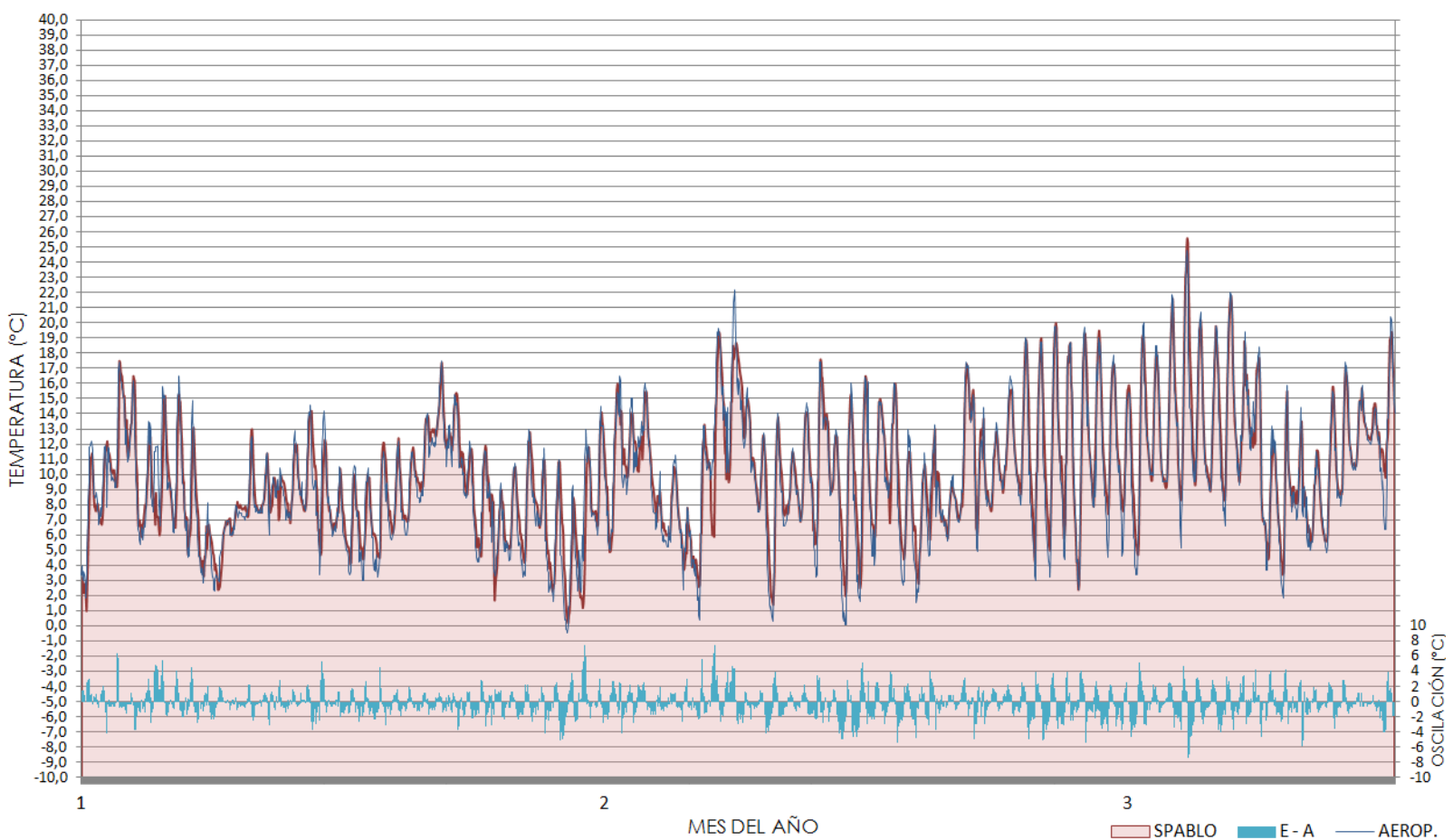

7-64 GRÁFICA COMPARADA DE LAS SERIES TÉRMICAS EN LA ESTACIÓN DE ZARAGOZA Y EN EL EDIFICIO DE LA CALLE SAN PABLO, EN ZARAGOZA DURANTE ENERO-FEBRERO Y MARZO DEL AÑO 2014. (AEMET y elaboración propia)
VER ANEXO 07 
Esta amplitud temporal puede permitir observar la tendencia y la secuencia de series térmicas pero para su análisis se ha considerado preciso reducir esta representación a periodos mensuales.
VER ANEXO 07 REGISTROS ESTACIONES METEOROLÓGICAS DE ZARAGOZA 2

TEMPERATURA EN ESTACIONES METEOROLÓGICAS LOCALES AEMET

ZARAGOZA. ENERO 2014

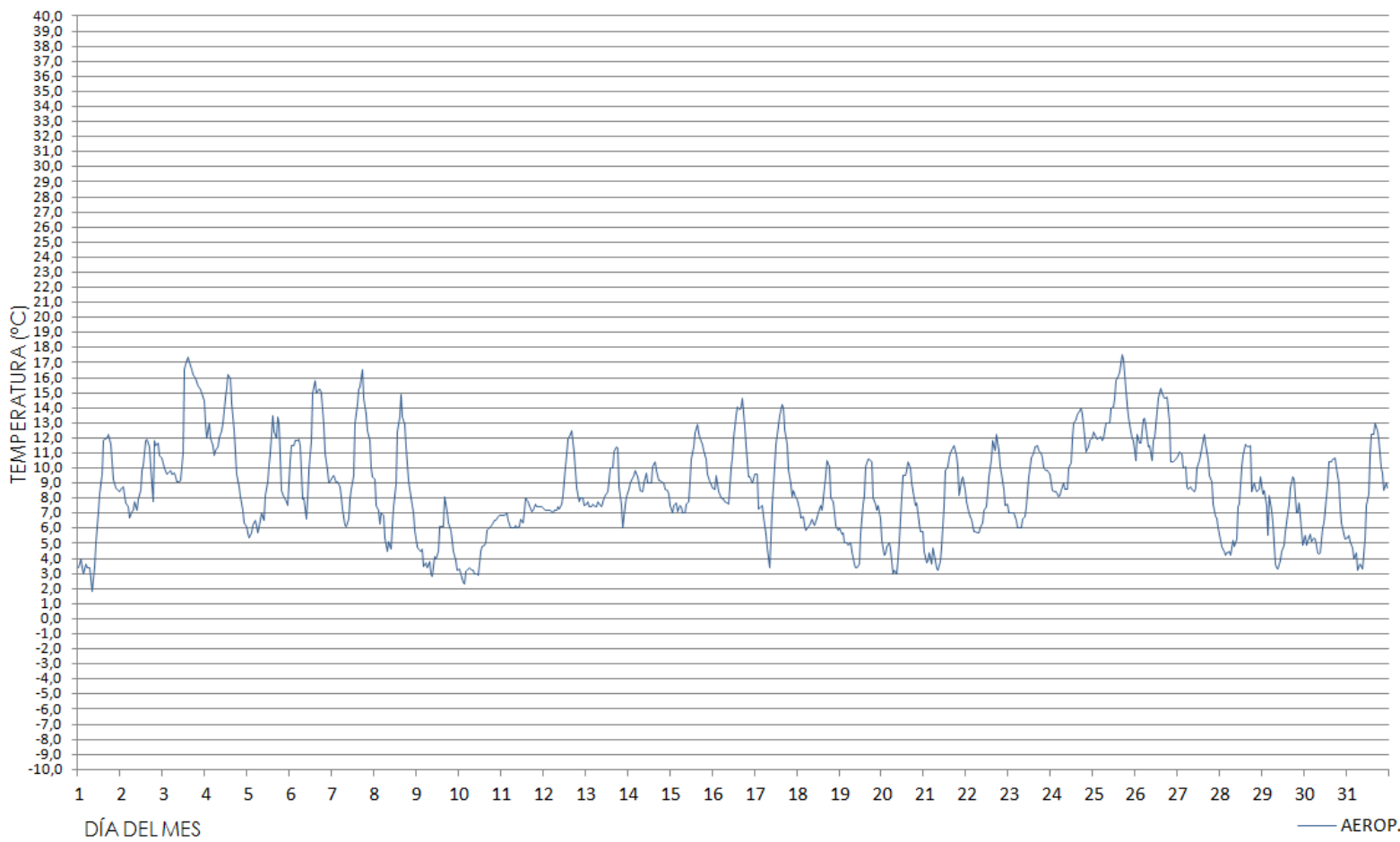

7-65 GRÁFICA DE LA SERIE TÉRMICA HORARIA EN LA ESTACIÓN DE ZARAGOZAAEROPUERTO DURANTE EL MES DE ENERO DEL AÑO 2014(AEMET Y elaboración propia) 
En estos periodos resulta probablemente más clara la observación de la relación entre las tendencias generales del periodo y la evolución de los valores diarios.
VER ANEXO 07

TEMPERATURA EN ESTACIONES METEOROLÓGICAS LOCALES AEMET-EDIFICIO ZARAGOZA. ENERO 2014

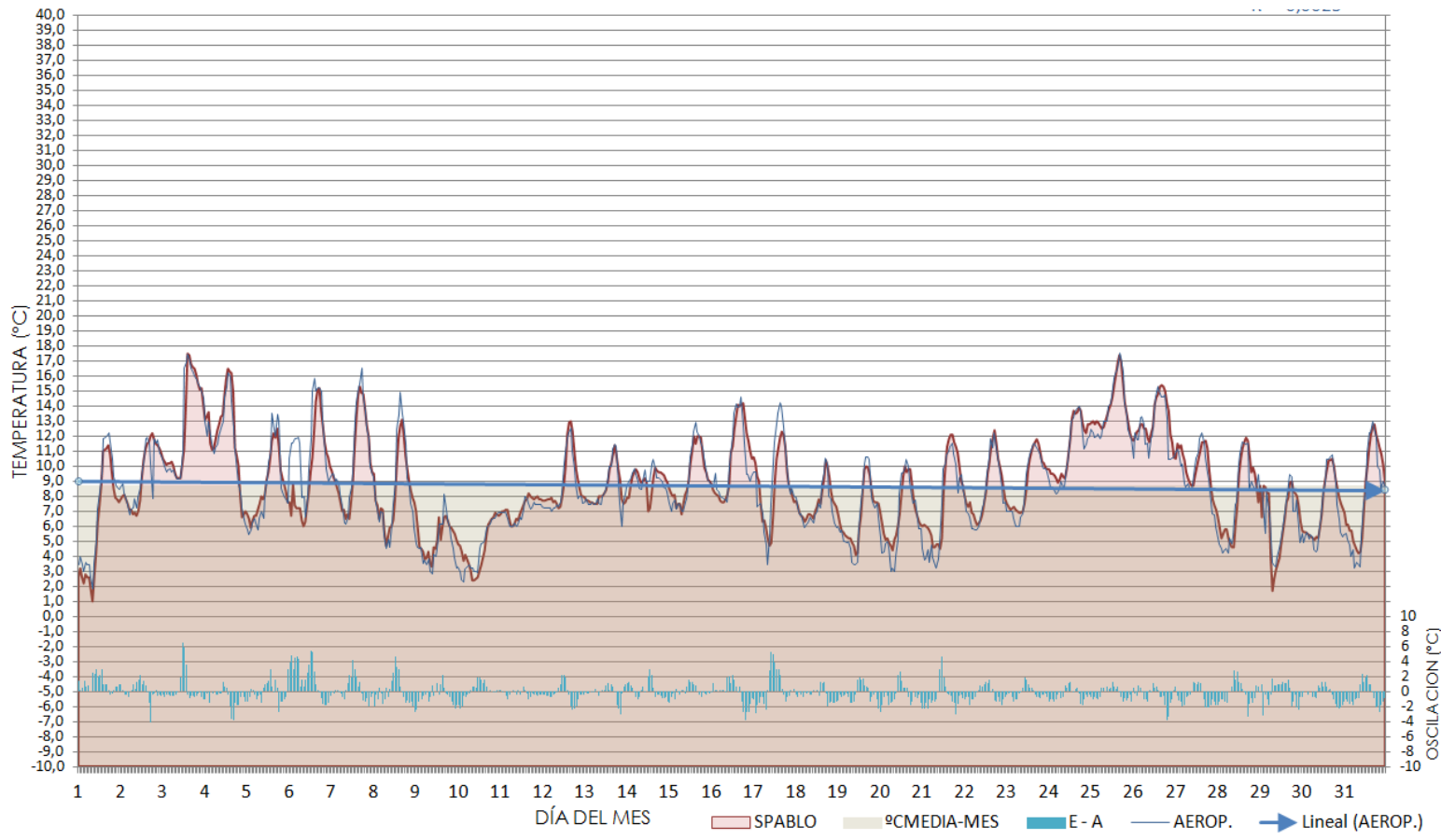

7-66 GRÁFICA COMPARADA DE LAS SERIES TÉRMICAS EN LA ESTACIÓN DE ZARAGOZA Y EN EL EDIFICIO DE LA CALLE SAN PABLO, EN ZARAGOZA DURANTE EL MES DE ENERO DEL AÑO 2014. (AEMET y elaboración propia) 
Así como la aplicación de las medias cada varios días donde puede observarse la comparación entre la amortiguación y el retardo de sus valores extremos.

TEMPERATURA EN ESTACIÓN METEOROLÓGICA AEMET. MEDIA DIARIA Y CADA 9 DÍAS

ZARAGOZA. ENERO 2014

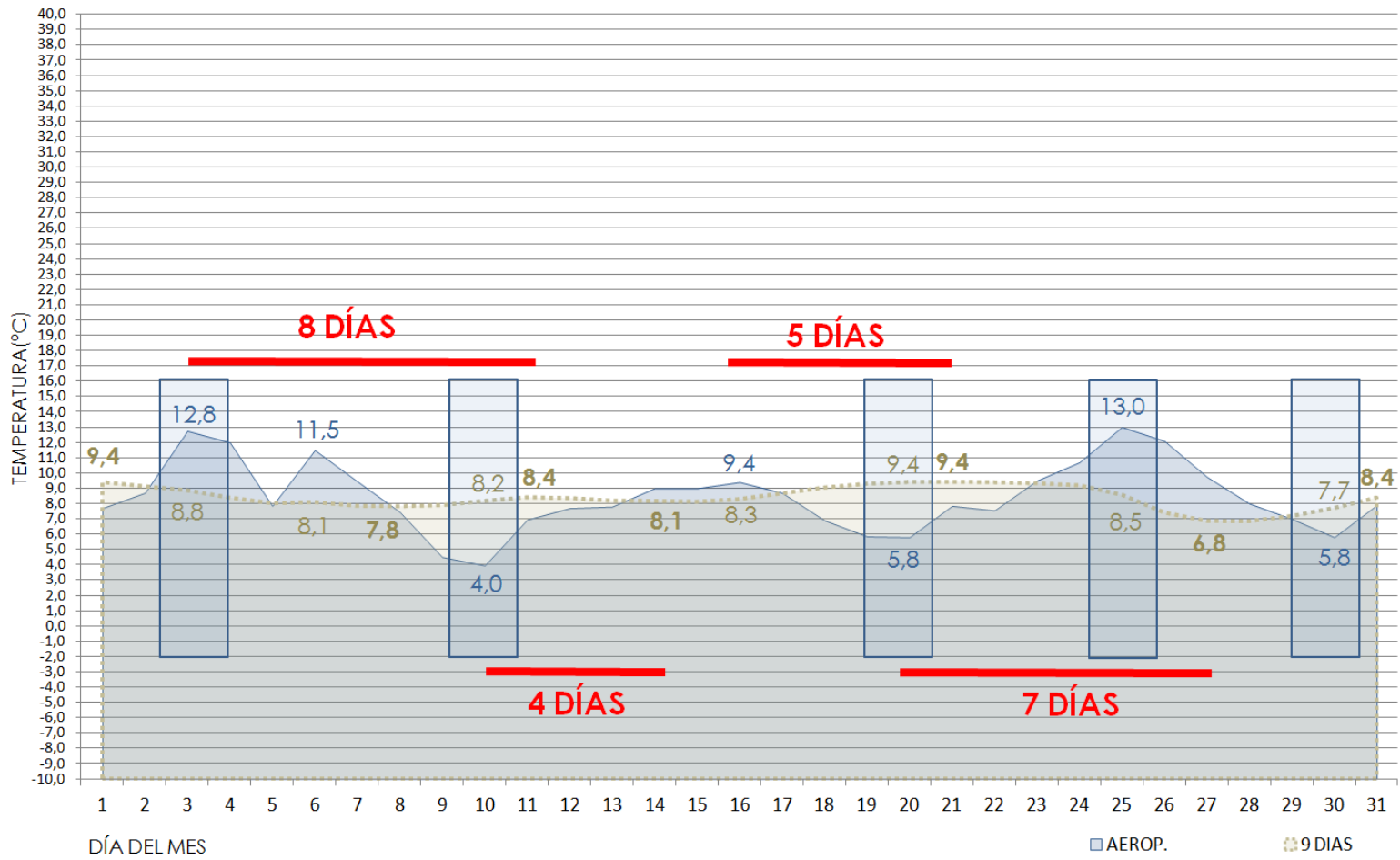

7-67 GRÁFICA COMPARADA DE LAS SERIES TÉRMICAS MEDIAS DIARIAS REGISTRADAS EN LA ESTACIÓN DE ZARAGOZA Y LAS MEDIAS CADA 9 DÍAS, DURANTE EL MES DE ENERO DEL AÑO 2014. (AEMET y elaboración propia) 
B3 Series en periodos en los que se mantiene la tendencia.

En la serie completa se identifican los periodos en los que la temperatura asciende, desciende o permanece en valores similares.

Pueden observarse los valores en un periodo homogéneo desde el punto de vista de la temperatura ambiente

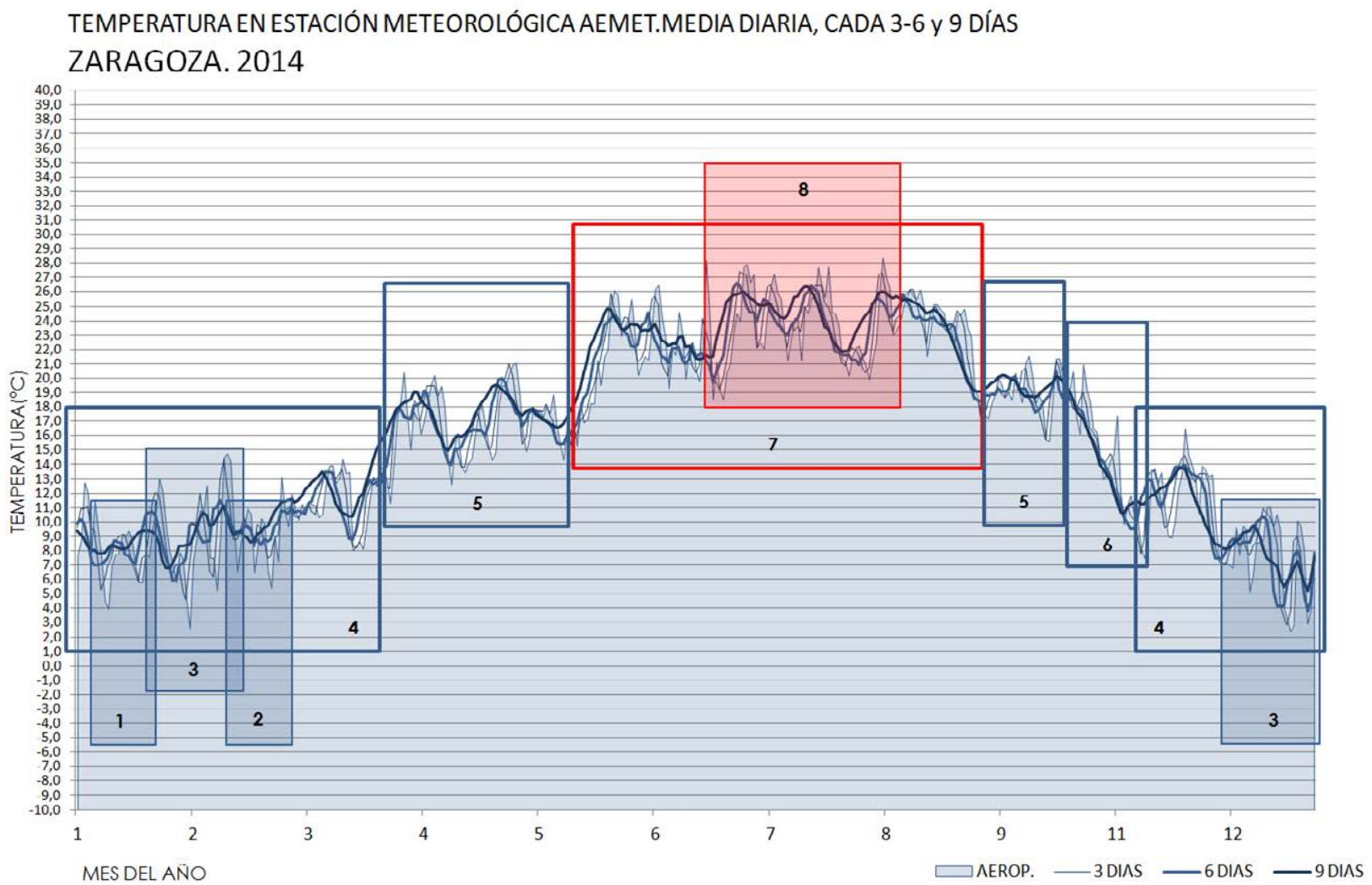

7-68 GRÁFICA ANUAL DESGLOSADA EN ZONAS HOMOGÉNEAS EN LA EVOLUCIÓN

DE LA MEDIANA DE SU TEMPERATURAS DIARIAS DURANTE EL AÑO 2014 (AEMET y elaboración propia)

\section{VER ANEXO 07}


Cada una de las zonas da lugar a dados que pueden segregarse para su estudio por separado.
VER ANEXO 07

REGISTROS ESTACIONES METEOROLÓGICAS DE ZARAGOZA 2

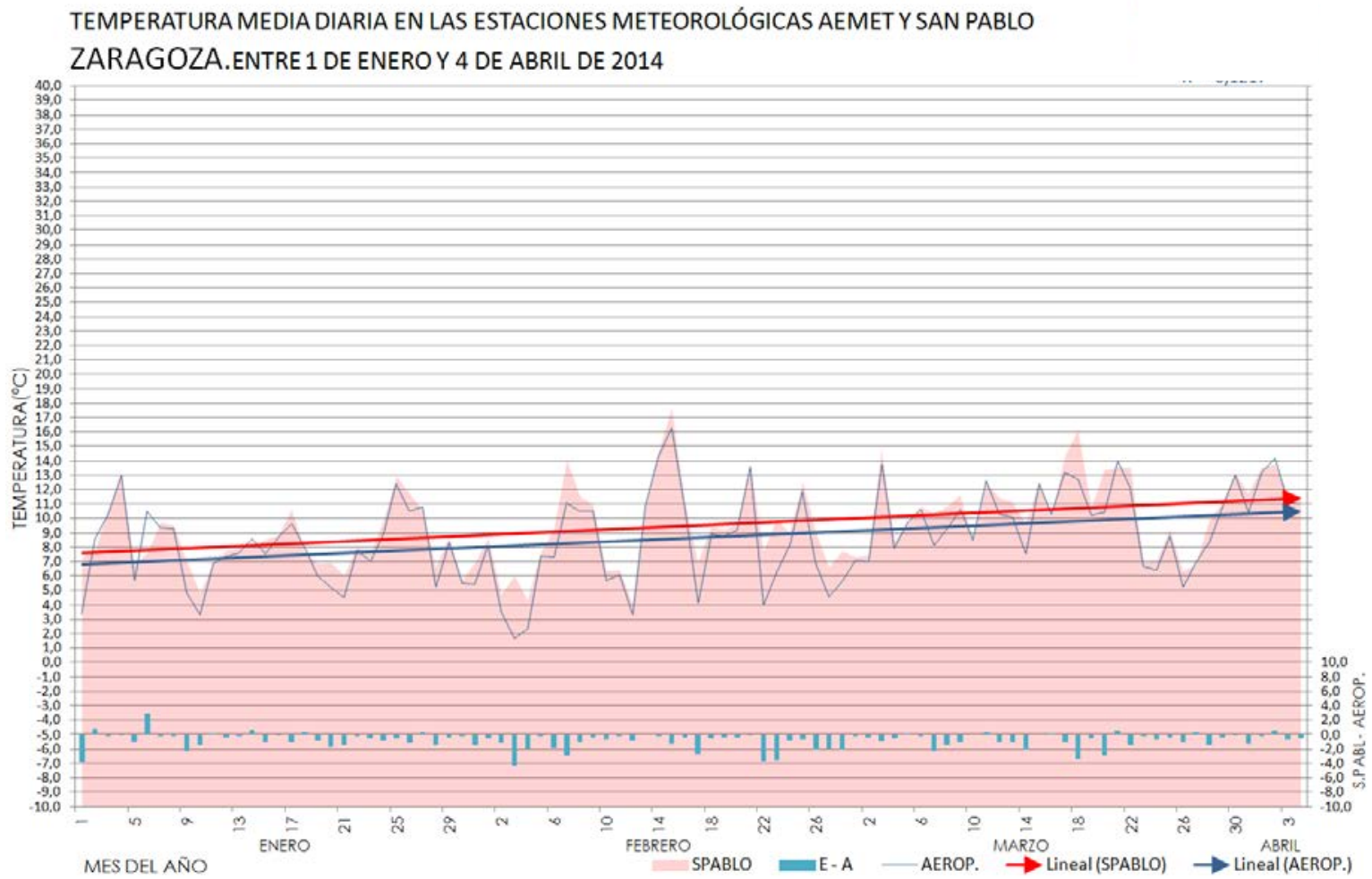

7-69 GRÁFICA DE MEDIA DIARIA EN LAS ESTACIONES DE ZARAGOZA-AEROPUERTO Y SAN PABLO DESDE EL 1 DE ENERO AL 4 DE ABRIL DEL AÑO 2014(AEMET Y elaboración propia) 
Aunque la tendencia durante un periodo pueda ser clara, cuando se fracciona esta tendencia se distorsiona, observándose cómo está formada por secuencias ascendentes, descendentes o sensiblemente constantes que, en su conjunto, forman la tendencia.
VER ANEXO 07

REGISTROS ESTACIONES METEOROLÓGICAS DE ZARAGOZA 2

\section{TEMPERATURA MEDIA DIARIA EN LAS ESTACIONES METEOROLÓGICAS AEMET Y SAN PABLO}

ZARAGOZA. ENTRE 1 DE ENEROY 3 DE FEBRERO DE 2014

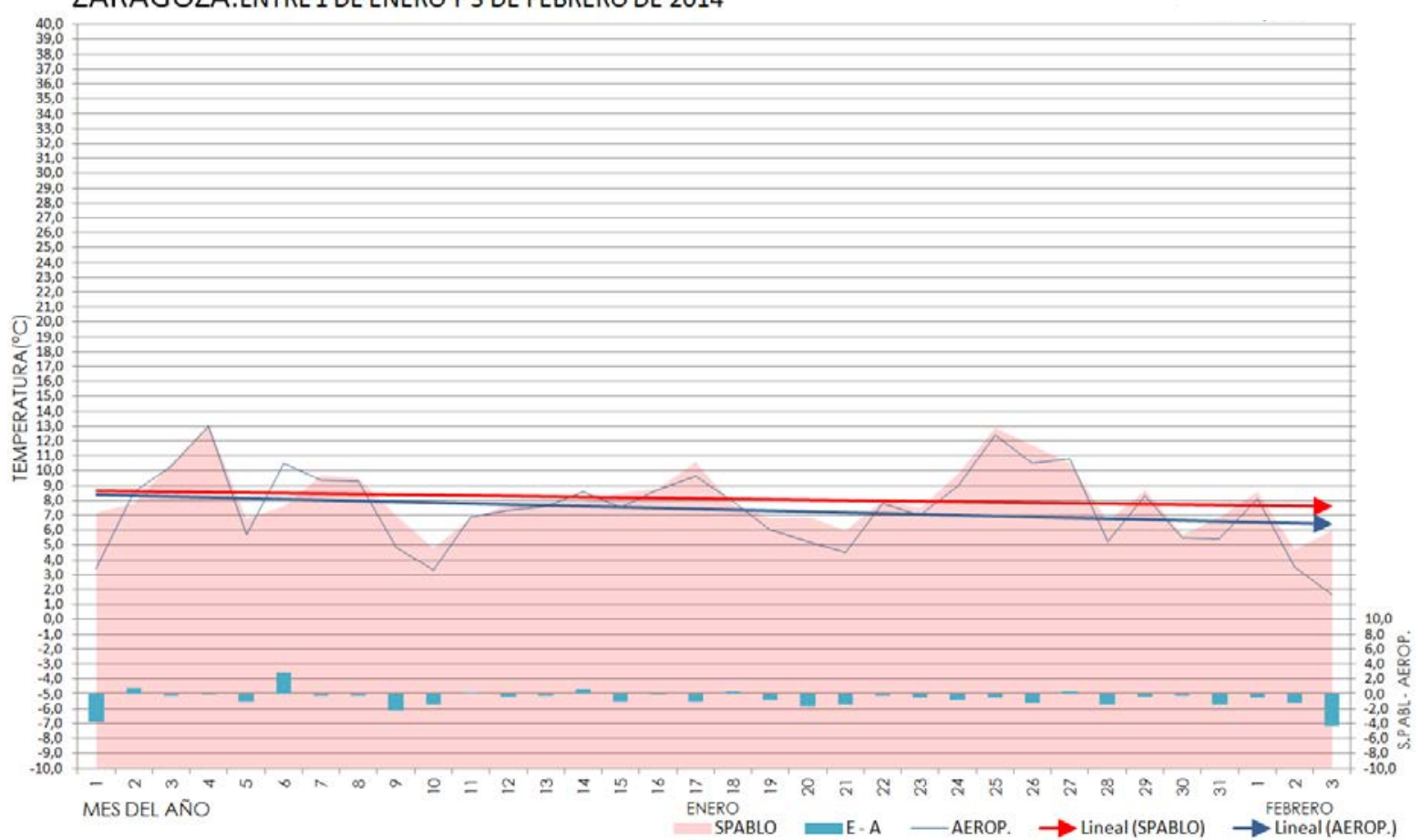

7-70 GRÁFICA DE MEDIA DIARIA EN LAS ESTACIONES DE ZARAGOZA-AEROPUERTO Y SAN PABLO DESDE EL 1 DE ENERO AL 3 DE FEBRERO DEL AÑO 2014(AEMET y elaboración propia) 
Se pueden realizar segregaciones puntuales en algunas de las zonas de tendencia para observar su evolución diaria.
VER ANEXO 07

REGISTROS ESTACIONES METEOROLÓGICAS DE ZARAGOZA 2

TEMPERATURA EN ESTACIONES METEOROLÓGICAS LOCALES AEMET-EDIFICIO

ZARAGOZA. 10 ENERO a 19 ENERO 2014

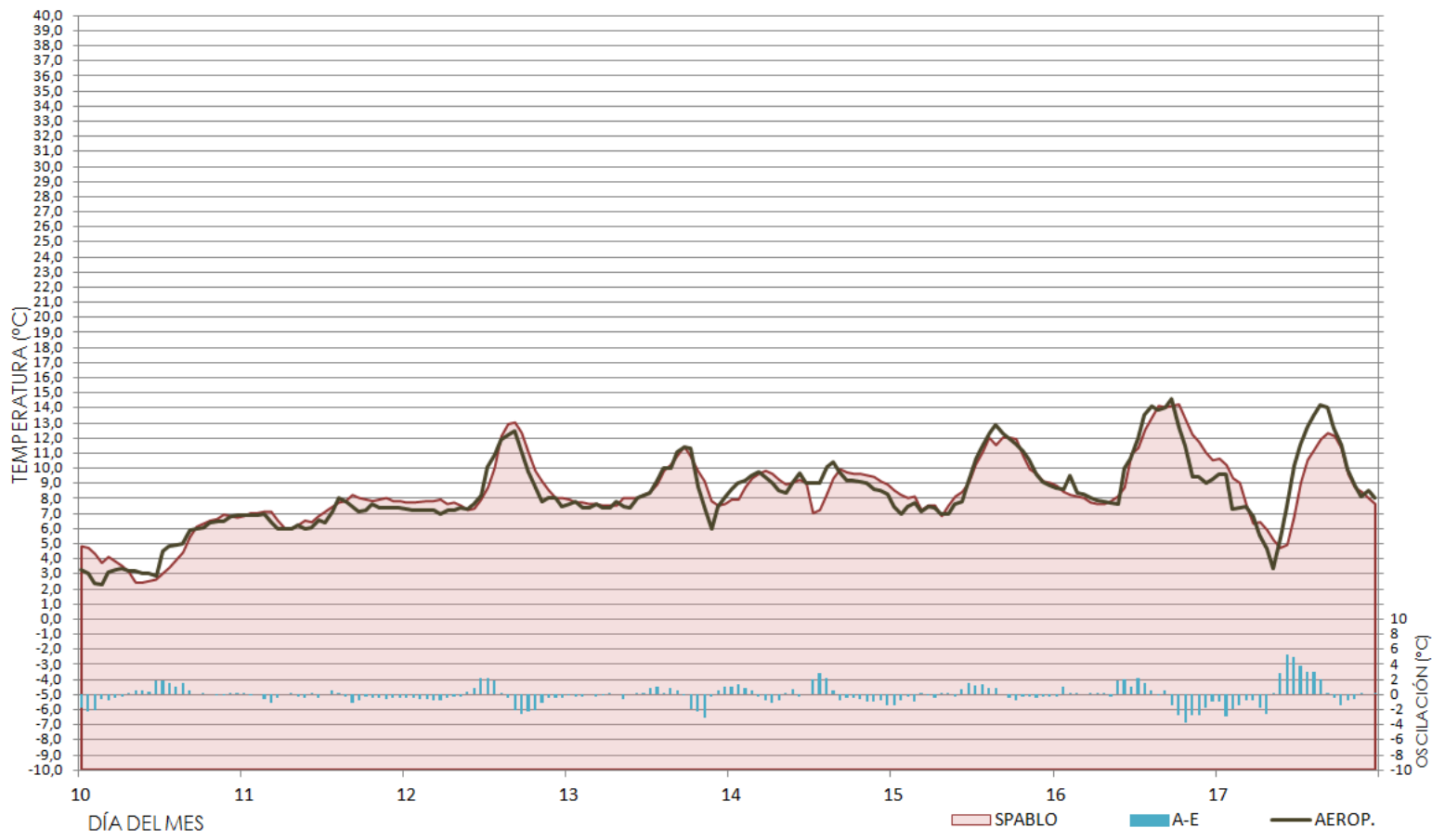

7-71 GRÁFICA DE MEDIA DIARIA EN LAS ESTACIONES DE ZARAGOZA-AEROPUERTO Y SAN PABLO DESDE EL 1 DE ENERO AL 3 DE FEBRERO DEL AÑO 2014(AEMET y elaboración propia) 
TEMPERATURA MEDIA DIARIA EN LAS ESTACIONES METEOROLÓGICAS AEMET Y SAN PABLO

ZARAGOZA.ENTRE 1 DE ENERO Y 3 DE FEBRERO DE 2014

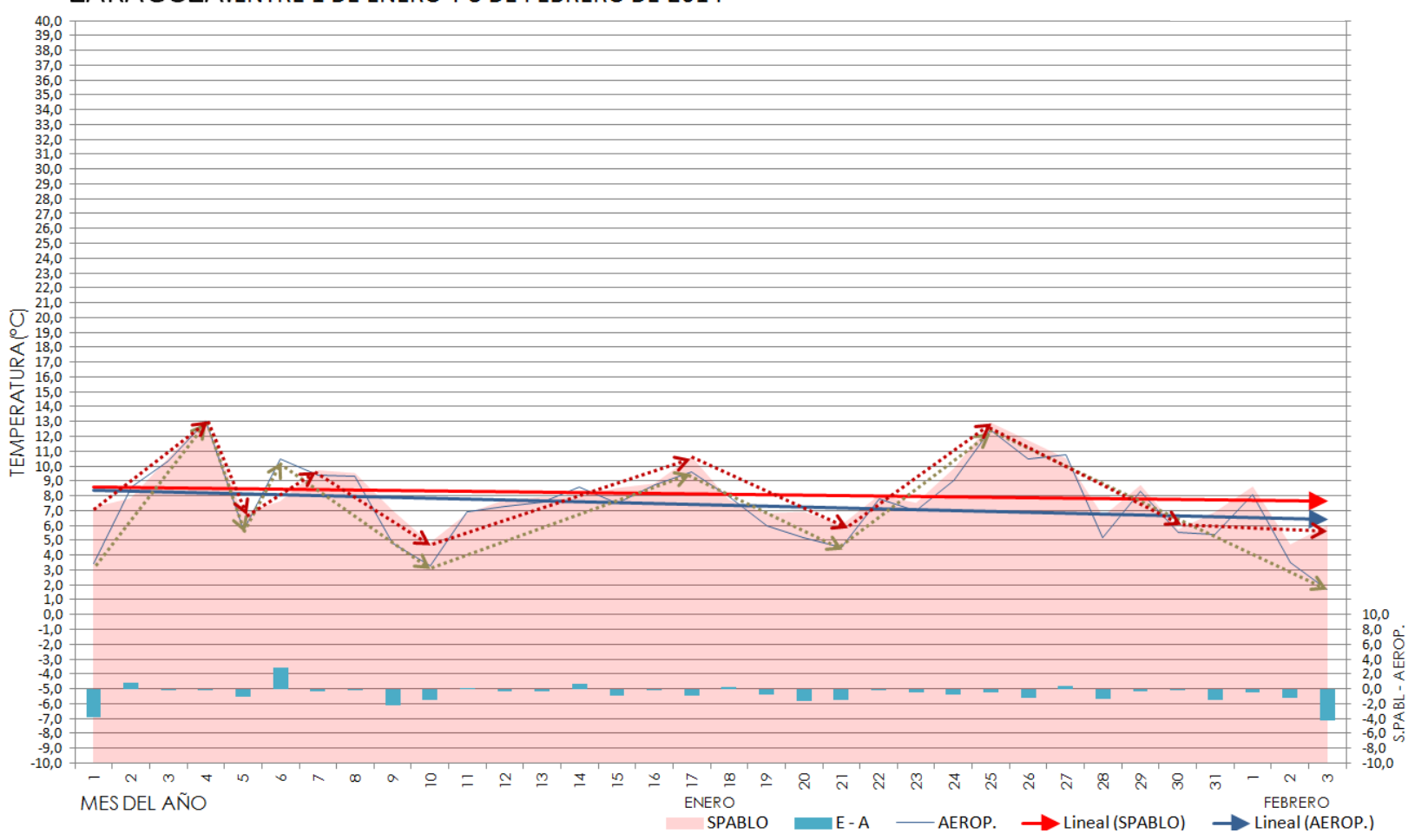

7-72 GRÁFICA COMPARADA DE LAS SERIES TÉRMICAS EN LA ESTACIÓN DE ZARAGOZA Y EN EL EDIFICIO DE LA CALLE SAN PABLO, EN ZARAGOZA ENTRE LOS DÍAS 10 Y 19 DE ENERO EL AÑO 2014. (AEMET y elaboración propia 
TEMPERATURA MEDIA DIARIA EN LAS ESTACIONES METEOROLÓGICAS AEMET Y SAN PABLO

ZARAGOZA.ENTRE 3 DE FEBREROY EL 4 DE ABRIL DE 2014

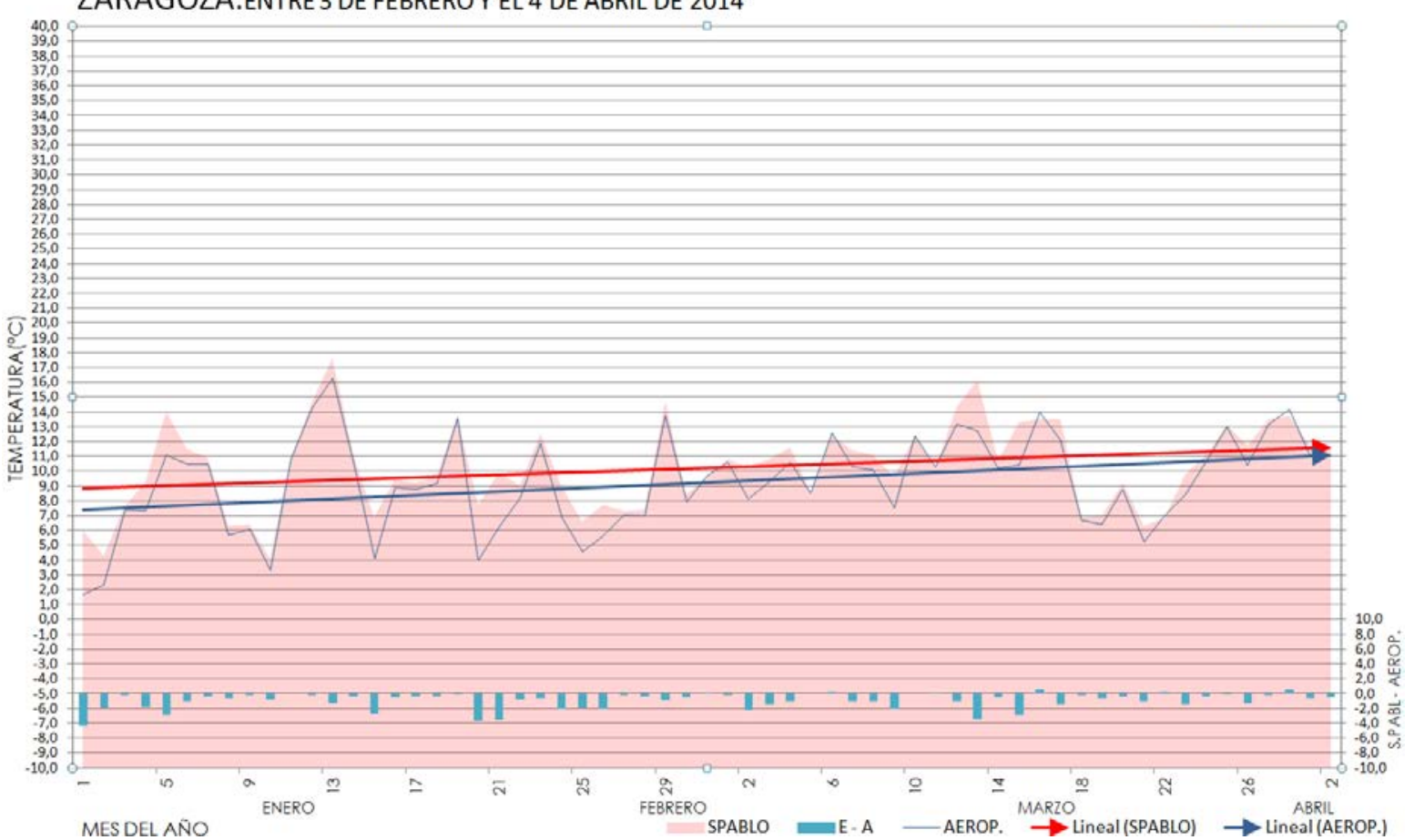

7-73 GRÁFICA DE MEDIA DIARIA EN LAS ESTACIONES DE ZARAGOZA-AEROPUERTO Y SAN PABLO DESDE EL 3 DE FEBRERO AL 4 DE ABRIL DEL AÑO 2014(AEMET Y elaboración propia) 


\subsection{MICROCLIMA DE PROXIMIDAD}

Para estimar la influencia del edificio en el clima que se conforma en su entorno se han tomado los valores de humedad y temperatura en la proximidad del edificio a lo largo de un año. Representados en gráficos y tablas, se recogen las temperaturas registradas desde el 10 de junio de 2013 al 10 de junio de 2014 .

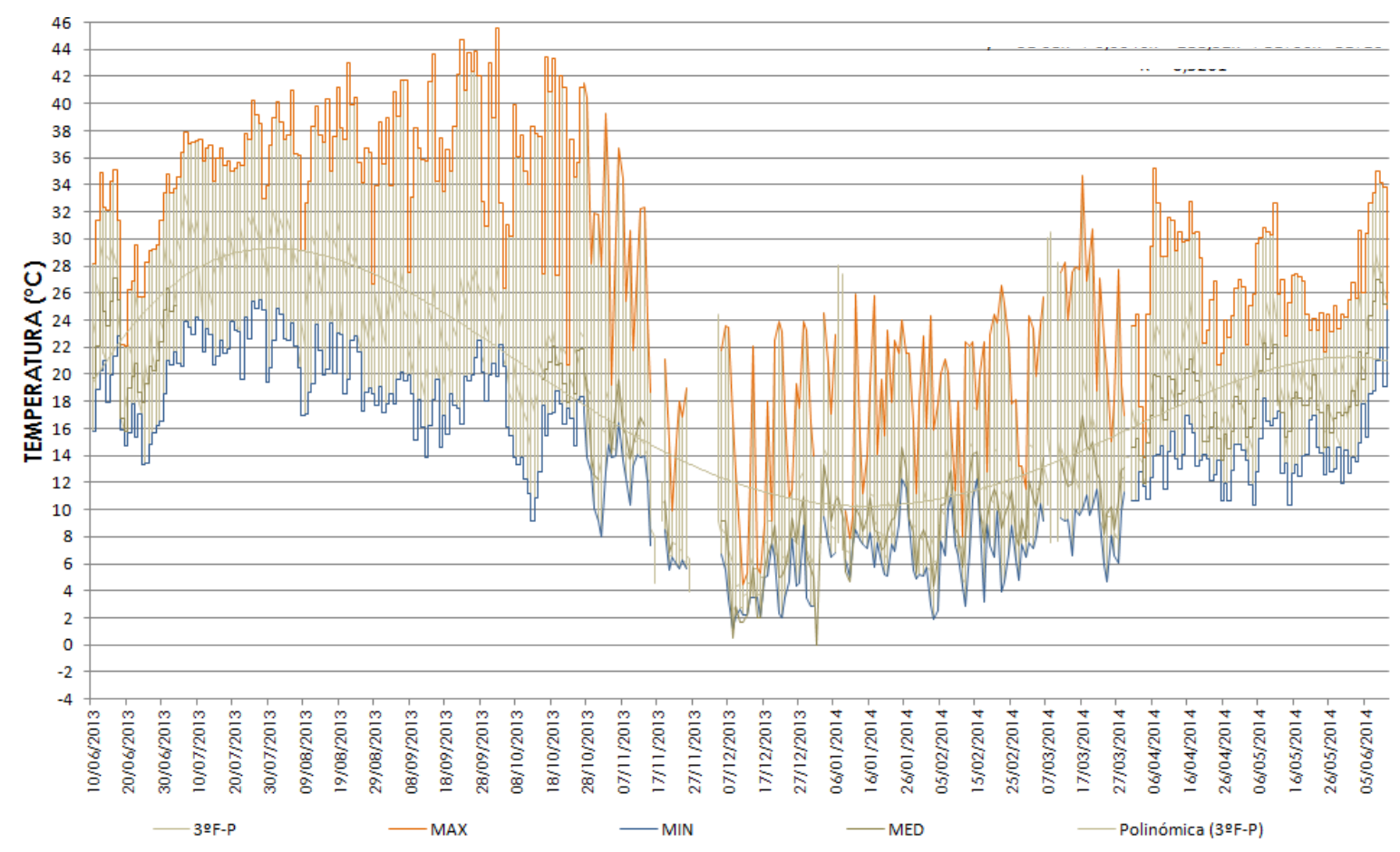

7-74 GRÁFICA DE LA EVOLUCIÓN DE LA TEMPERATURAS DIARIAS DESDE EL 10 DE JUNIO DE 2013 AL 10 DE JUNIO DE 2014 EN UN PATIO INTERIOR DEL EDIFICIO SITUADO EN CALLE S. PABLO DE ZARAGOZA (Elaboración propia) 
Para facilitar su lectura se representan sólo los valores máximos mínimos y medios diarios de temperatura y, sólo a efectos de servir de indicador de su evolución, las curvas de tendencia.

TEMPERATURA HORARIA. SAN PABLO PATIO DE MANZANA.

ZARAGOZA. 10 DE JUNIO DE 2013 A 10 DE JUNIO 2014

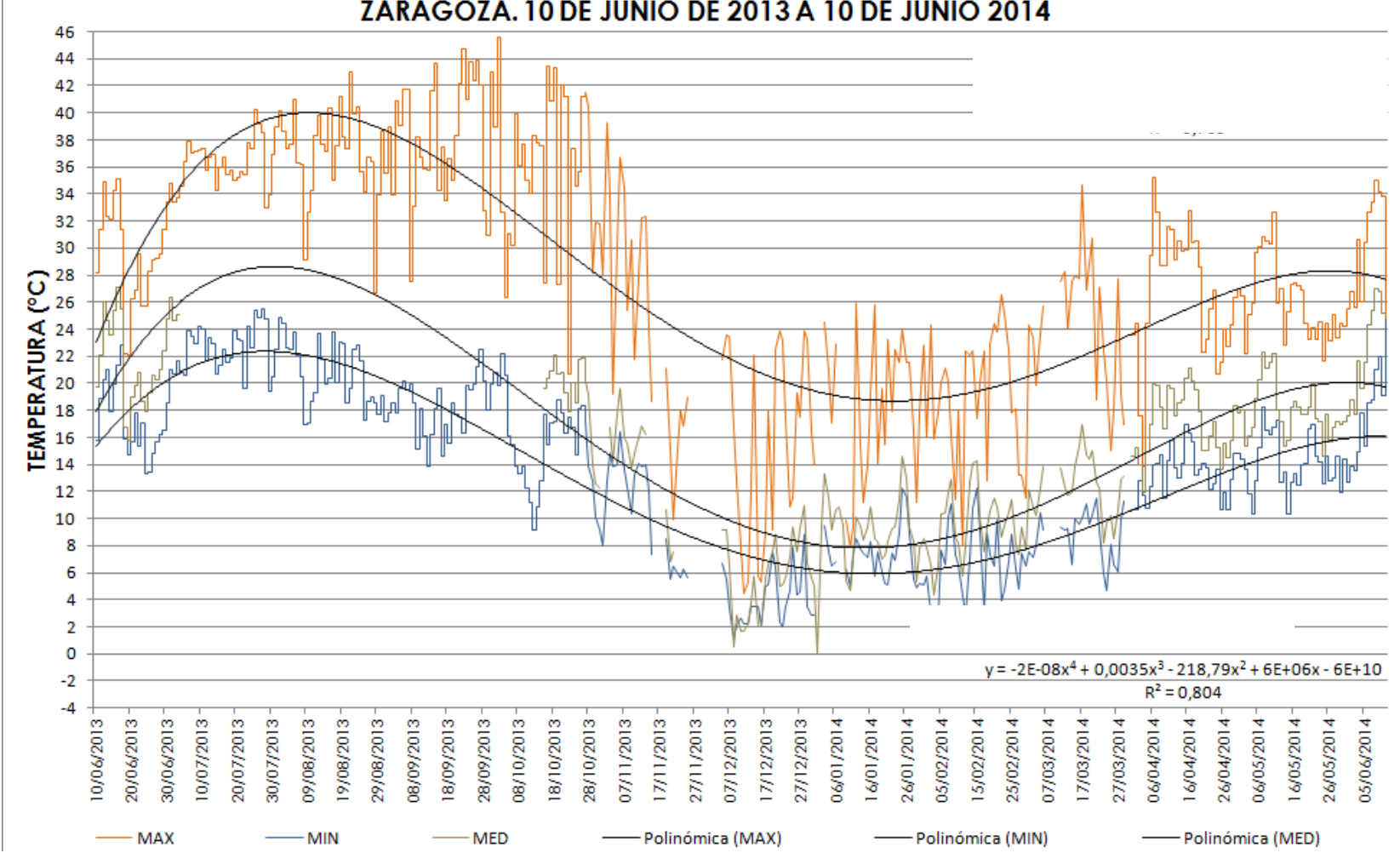

7-75 GRÁFICA DE LA EVOLUCIÓN DE LA TEMPERATURAS MEDIAS MÁXIMAS Y MÍNIMAS DIARIAS DESDE EL 10 DE JUNIO DE 2013 AL 10 DE JUNIO DE 2014 EN UN PATIO INTERIOR DEL EDIFICIO SITUADO EN CALLE S. PABLO DE ZARAGOZA (Elaboración propia) 
Las oscilaciones térmicas diarias registradas en la proximidad del edificio ofrecen un rango muy amplio de valores.

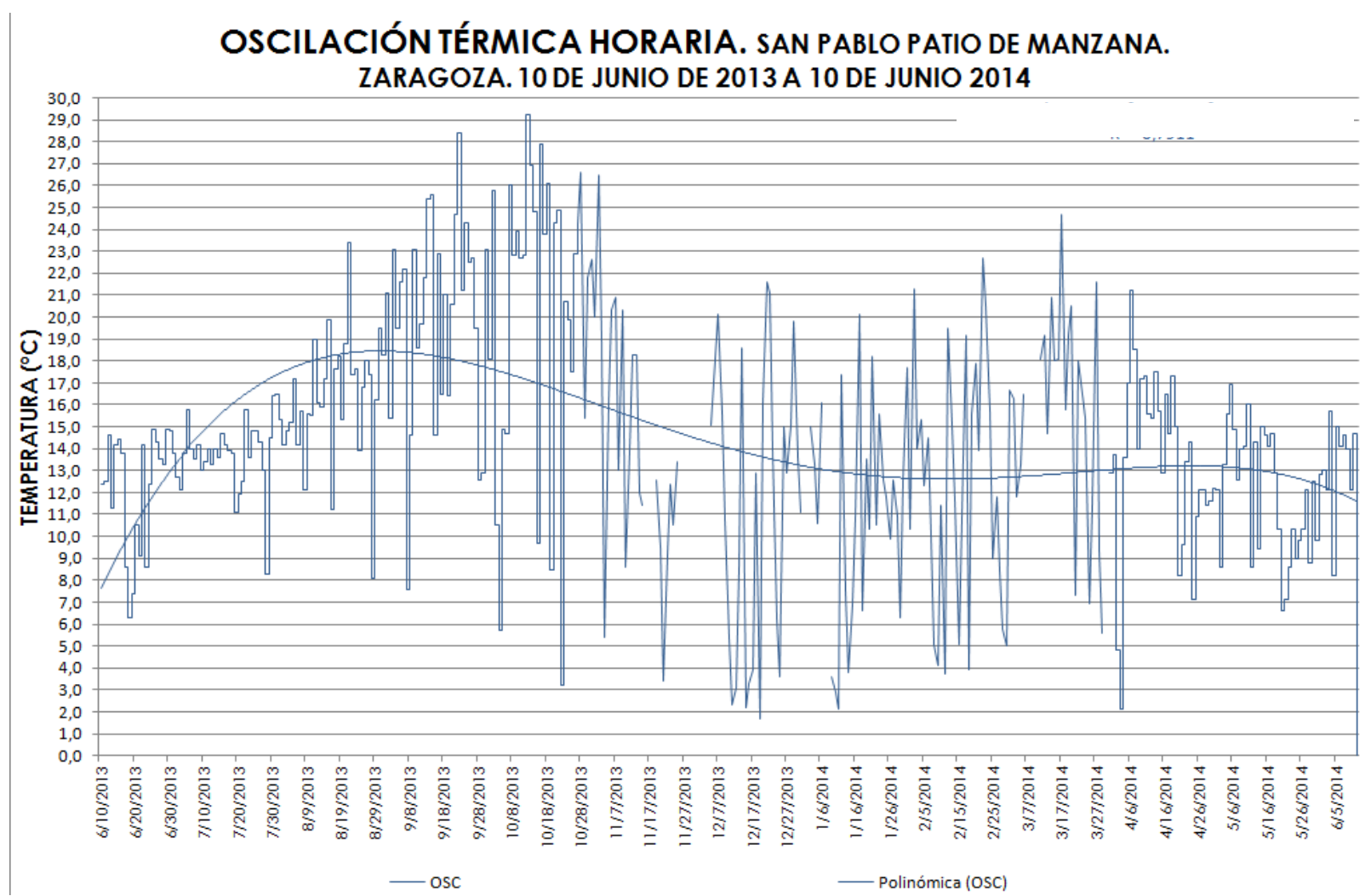

7-76 GRÁFICA DE LA OSCILACIÓN TÉRMICA DESDE EL 10 DE JUNIO DE 2013 AL 10 DE JUNIO DE 2014 EN UN PATIO INTERIOR DEL EDIFICIO SITUADO EN CALLE S. PABLO DE ZARAGOZA (Elaboración propia) 
Para facilitar las comparaciones se elaboran tablas y gráficos con las diferencias horarias de las temperaturas entre la estación meteorológica local y los equipos dispuestos en el exterior de los paramentos del edificio.

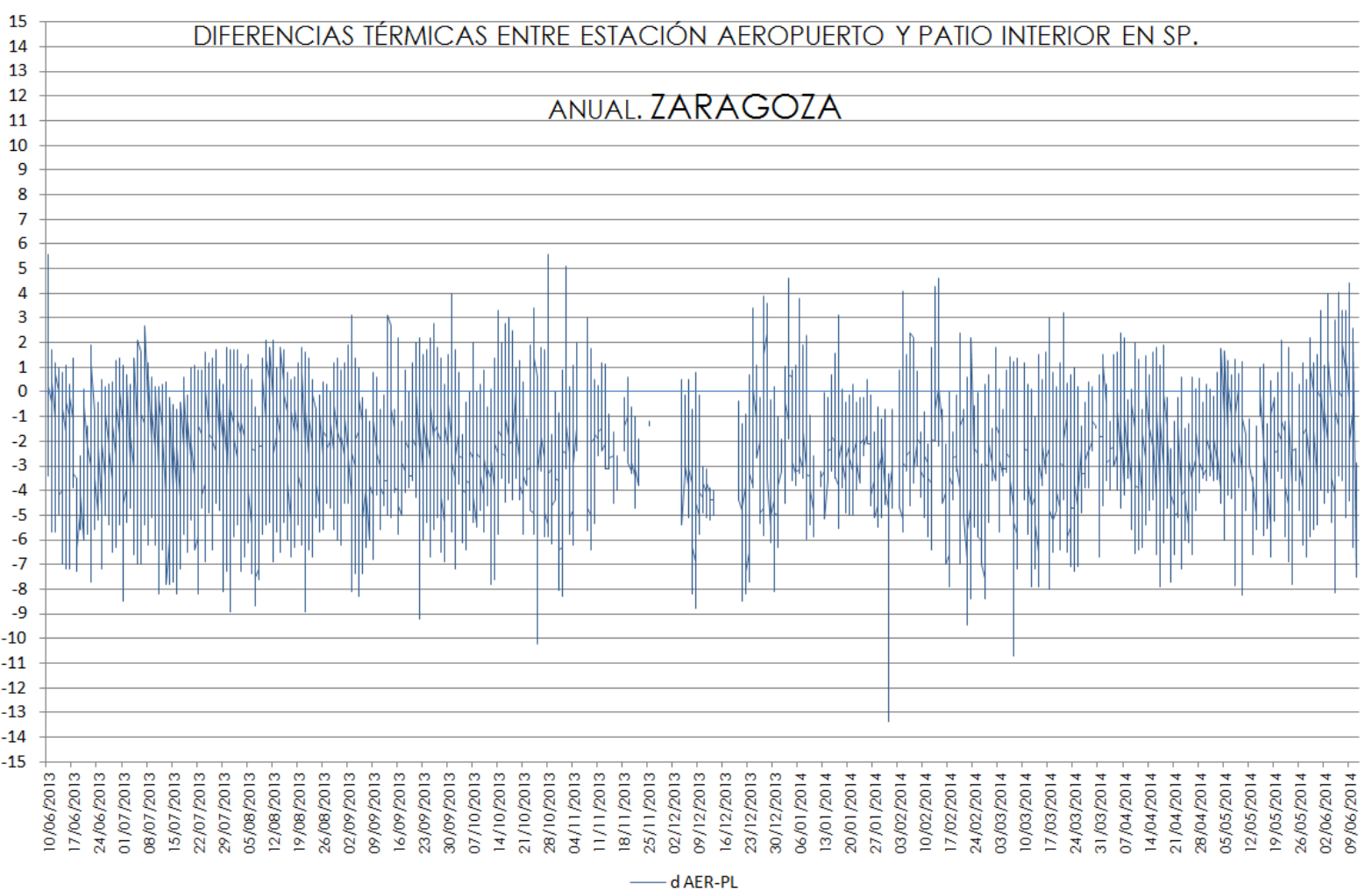

7-77 GRÁFICO ANUAL DE DIFERENCIAS ENTRE LA TEMPERATURA EN ESTACIÓN METEOROLÓGICA DEL AEROPUERTO DE ZARAGOZA Y EN EL PATIO INTERIOR DEL EDIFICIO DEMOSTRADOR (Elaboración propia) 
Se realiza la segregación de periodos en función de la tendencia y la velocidad de cambio de la temperatura (pendiente de la tendencia), así como la diferencia absoluta y por periodos de las temperaturas en las distintas ubicaciones de los equipos de medida con respecto a la estación meteorológica y la diferencia entre sus cuartiles.

Estas diferencias se hacen también patentes en las gráficas por periodos.

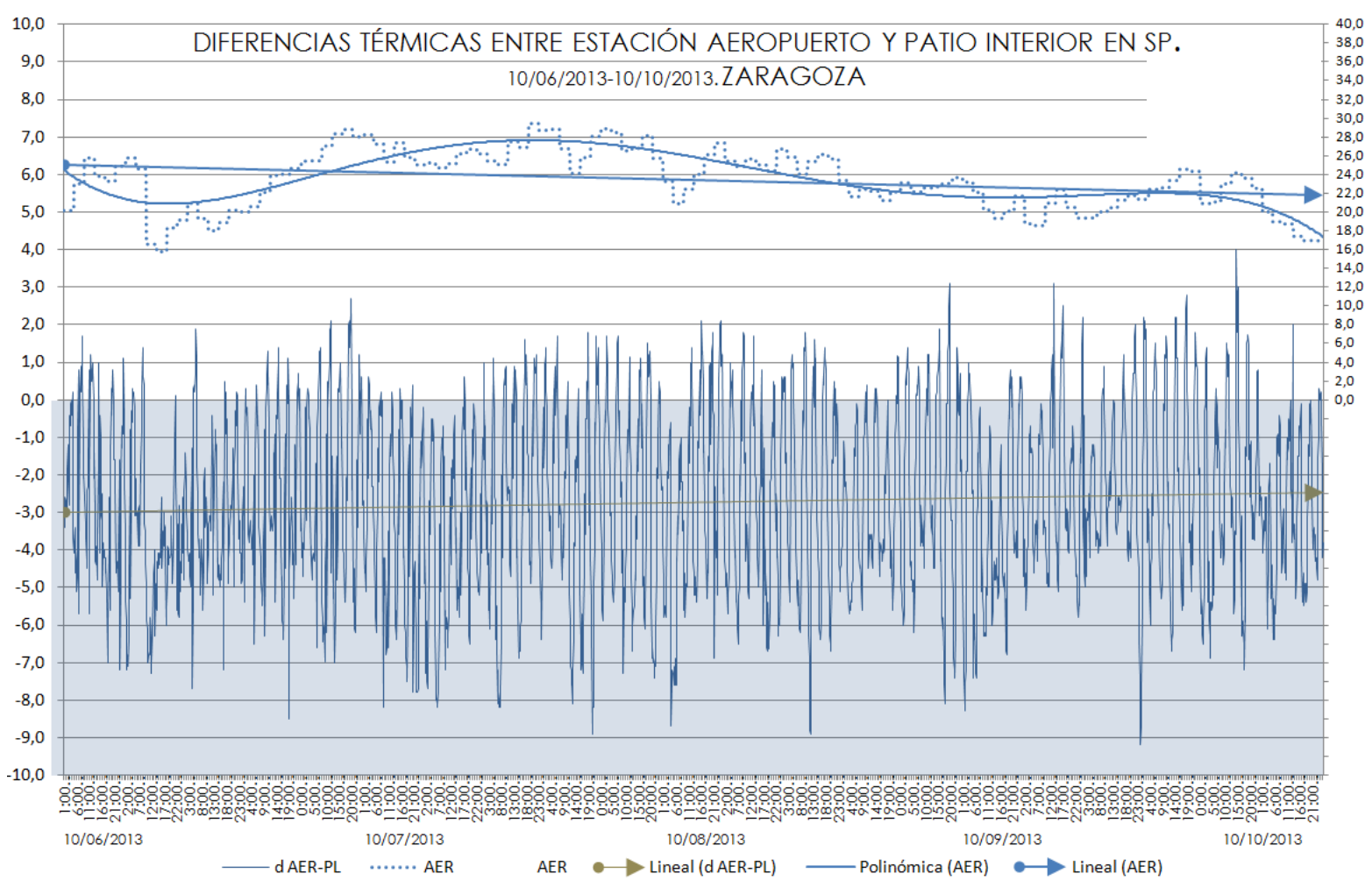

7-78 GRÁFICA DE DIFERENCIAS TÉRMICAS ENTRE LA ESTACIÓN METEOROLÓGICA DEL AEROPUERTO DE ZARAGOZA Y EL PATIO DE LUCES DEL EDIFICIO DEMOSTRADOR. (Elaboración propia)

Se procede a la comparación diaria entre las temperaturas registradas en la estación meteorológica local y en el exterior de las envolvente del edificio demostrador, en un periodo durante 24 horas.

Dentro del gráfico diario se incluye un patrón de uso, que se ha simplificado expresándolo como rectángulos en los siguientes periodos.

Entre las 0:00 y las 8:00 PERIODO NOCTURNO

Se asocia a periodos sin actividad laboral ni de ocio y en la que la principal actividad es la de dormir.

Entre las 8:00 y las 17:00 PERIODO DIURNO

Se asocia a periodos con actividad laboral y actividad doméstica destinada a trabajos domésticos y ocasionalmente de ocio.

Entre las 17:00 y las 24:00 PERIODO VESPERTINO

Se asocia a periodos sin actividad laboral y ni actividad doméstica, destinados principalmente a actividades sedentarias (ocio). 
Se eligen estos periodos como una opción de las muchas posibles y pretenden sólo ofrecer una imagen de las temperaturas diarias haciendo referencia al uso interior de los edificios.

Tanto la ocupación como la actividad y las temperaturas máximas, mínimas y de consigna, es preciso que sean ajustadas a la naturaleza del estudio. Si afecta a un caso concreto requieren la estimación mediante consulta, si se refiere a observar los valores para una localidad, una actividad o un edificio pueden ajustarse según las recomendaciones normativas o la experiencia.

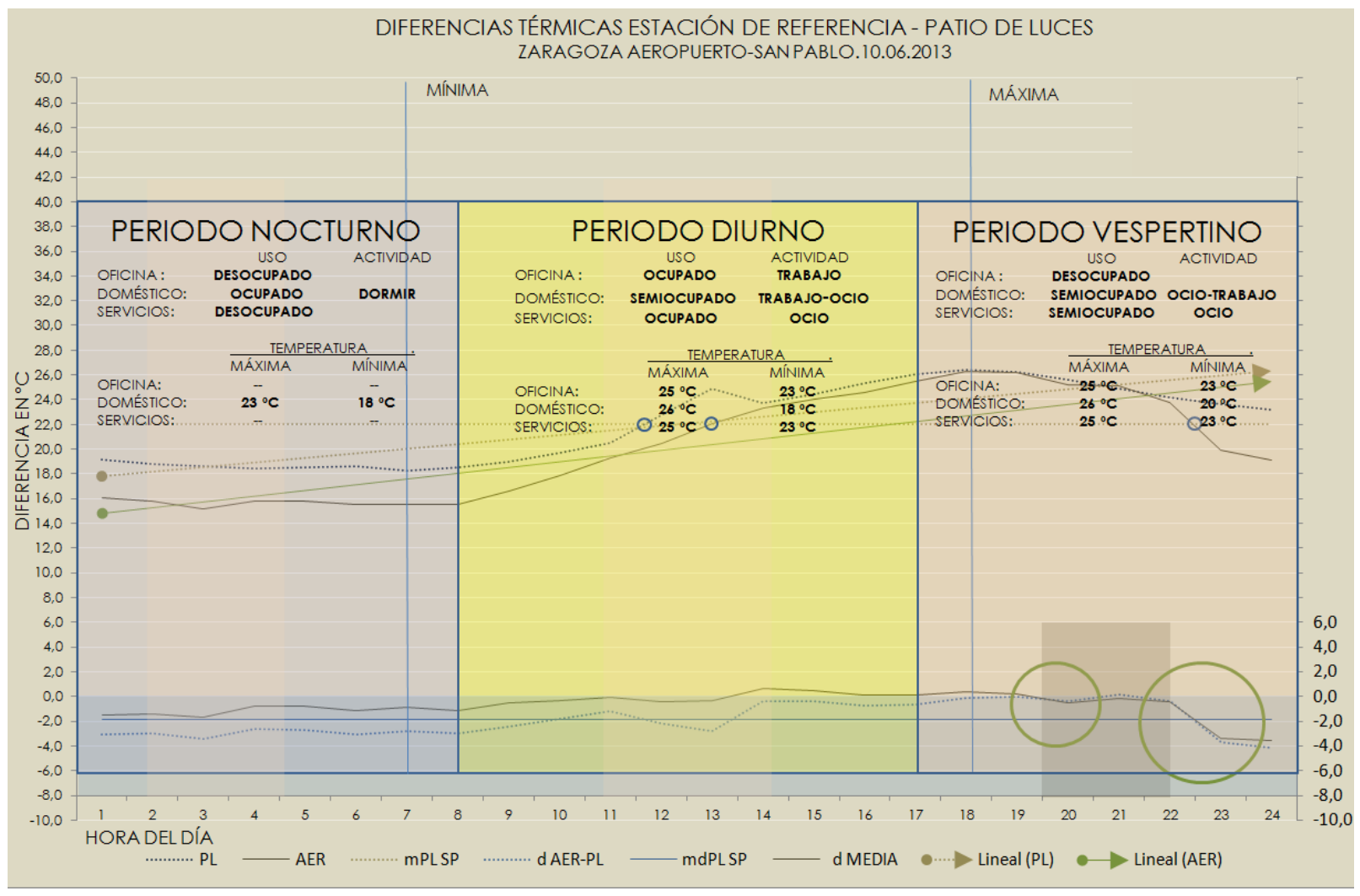

7-79 COMPARACIÓN DIARIA ENTRE LAS TEMPERATURAS EN LA ESTACIÓN DE REFERENCIA Y EL PATIO DE LUCES DE EDIFICIO EN CALLE SAN PABLO. PERIODO CÁLIDO. PATRÓN DE USO. (Elaboración propia) 
Para su interpretación se asocian al gráfico 5 leyendas. Comenzando con la descripción tanto de los ejes de abscisas y ordenadas, como de las leyendas y la descripción general del gráfico.

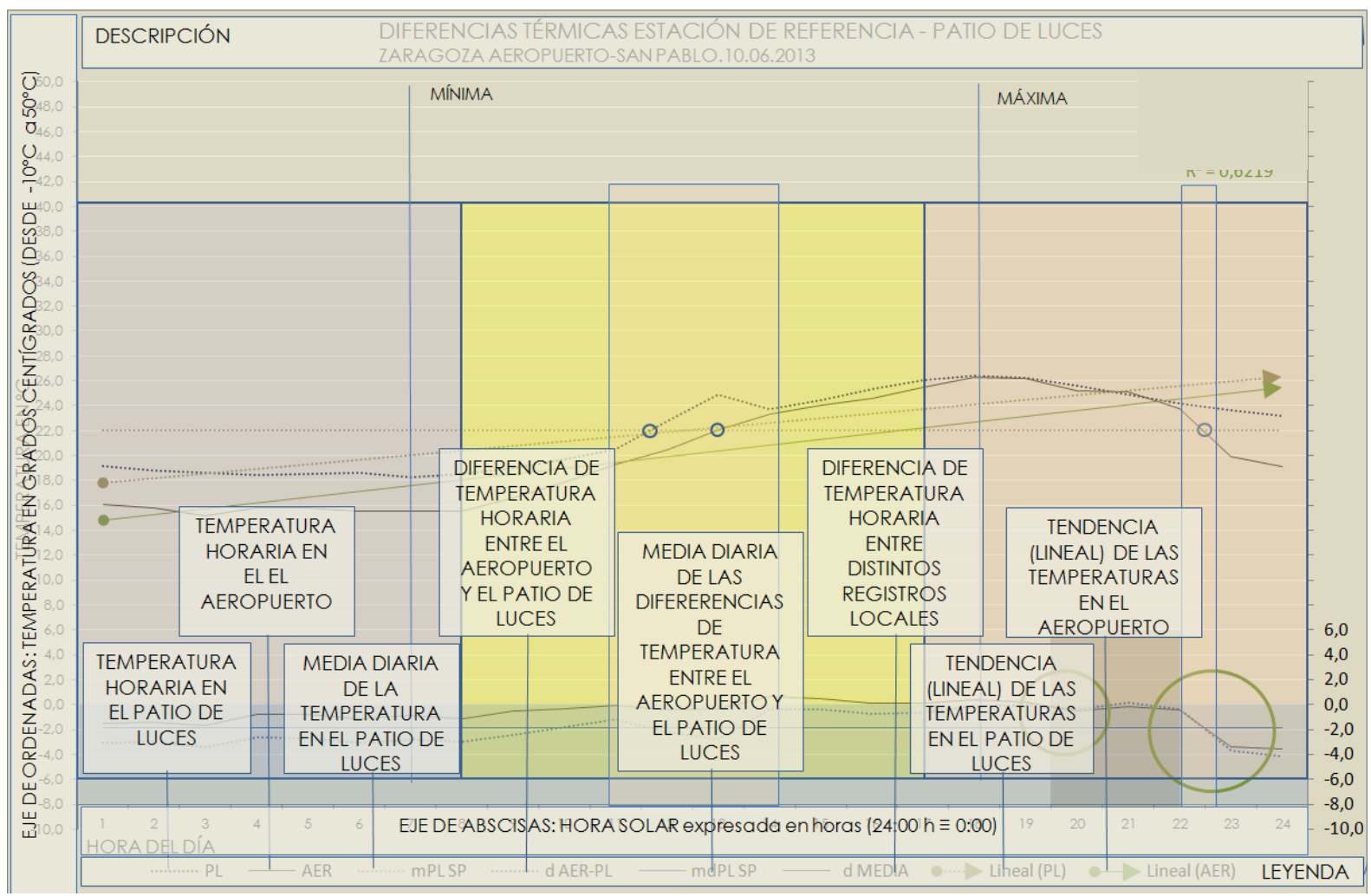

7-80 COMPARACIÓN DIARIA ENTRE LAS TEMPERATURAS EN LA ESTACIÓN DE REFERENCIA Y EL PATIO DE LUCES DE EDIFICIO EN CALLE SAN PABLO. PERIODO CÁLIDO. LEYENDAS DESCRIPTIVAS. (Elaboración propia) 
El eje de abscisas distribuye los datos en periodos horarios, sobre él se marca la posición de la máxima y la mínima de la temperatura registrada en el exterior de la envolvente de la edificación.
REGISTROS MICROCLIMA DE PROXIMIDAD

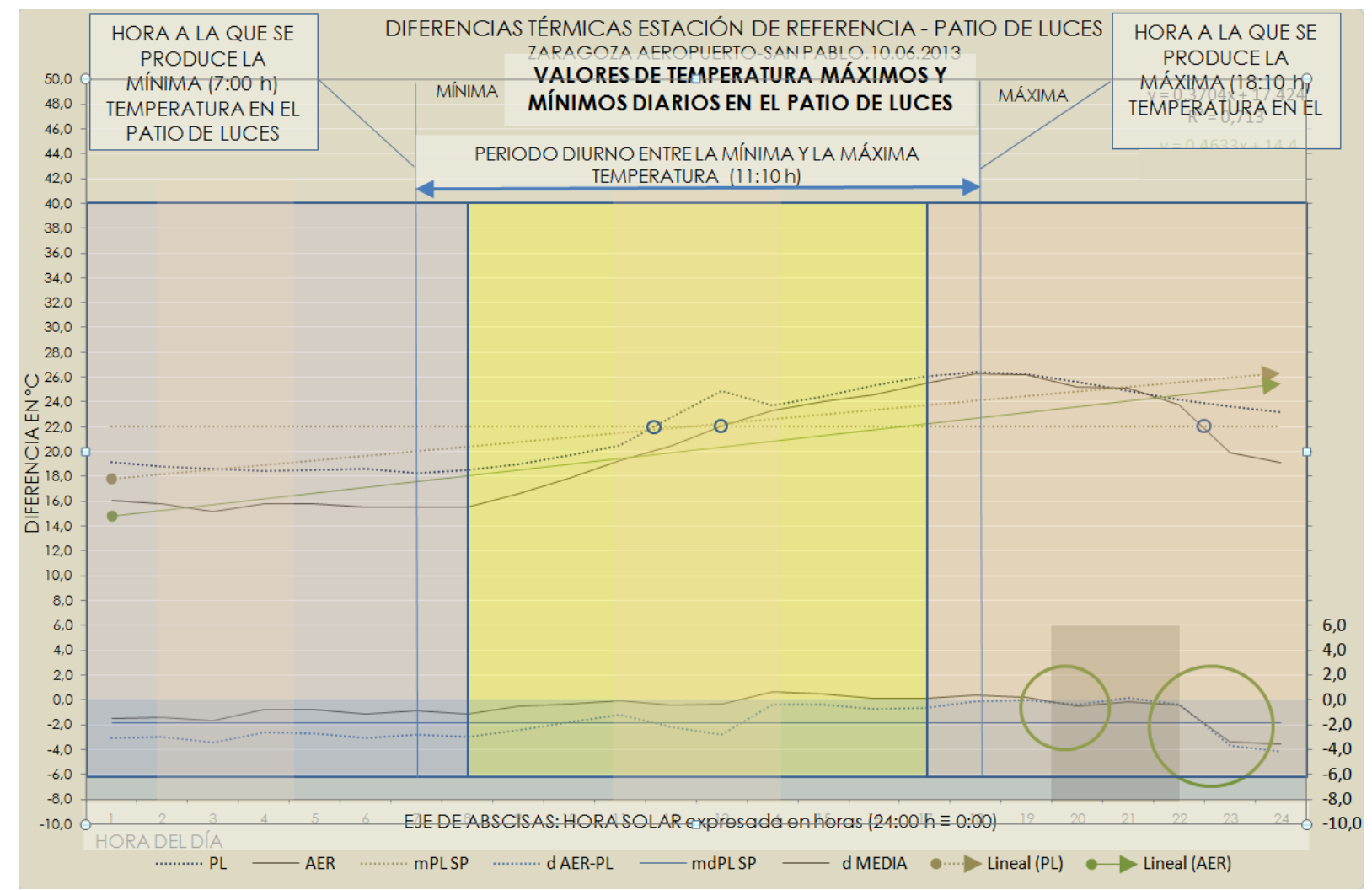

7-81 COMPARACIÓN DIARIA ENTRE LAS TEMPERATURAS EN LA ESTACIÓN DE REFERENCIA Y EL PATIO DE LUCES DE EDIFICIO EN CALLE SAN PABLO. PERIODO CÁLIDO. MÁXIMOS Y MINIMOS. (Elaboración propia) 
La zona inferior recoge, referidas a la ordenada secundaria (derecha) las diferencias entre los valores de temperatura registrados en la estación meteorológica local y los registros tomados en el exterior de la envolvente del edificio.
VER ANEXO 09

REGISTROS MICROCLIMA DE PROXIMIDAD

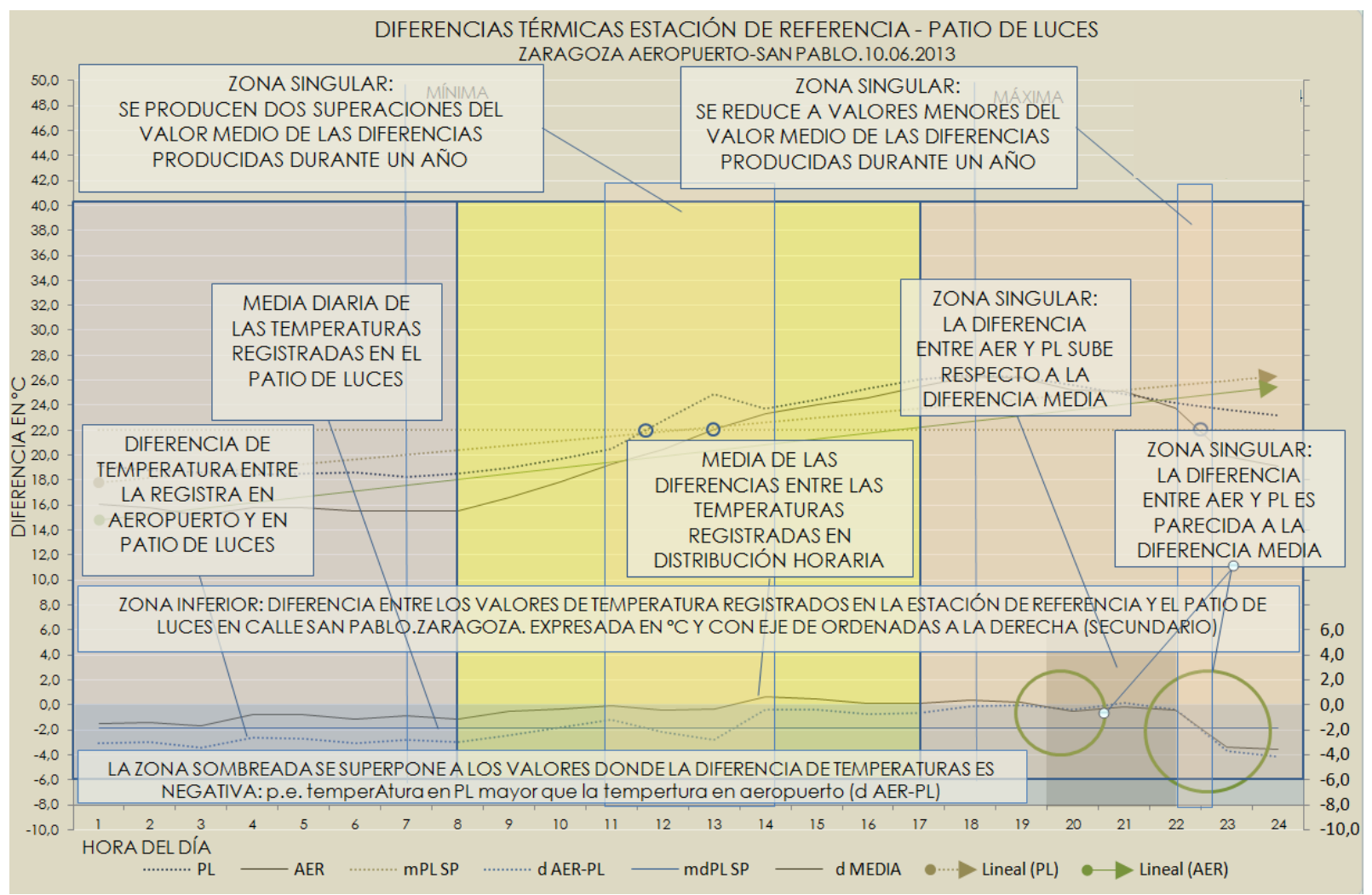

7-82 COMPARACIÓN DIARIA ENTRE LAS TEMPERATURAS EN LA ESTACIÓN DE REFERENCIA Y EL PATIO DE LUCES DE EDIFICIO EN CALLE SAN PABLO. PERIODO CÁLIDO DIFERENCIAS ENTRE TEMPERATURAS. (Elaboración propia) 
La zona superior muestra el gráfico de temperatura horaria durante un día en la estación meteorológica local de referencia, y la situada en el exterior de la envolvente del edificio demostrador.

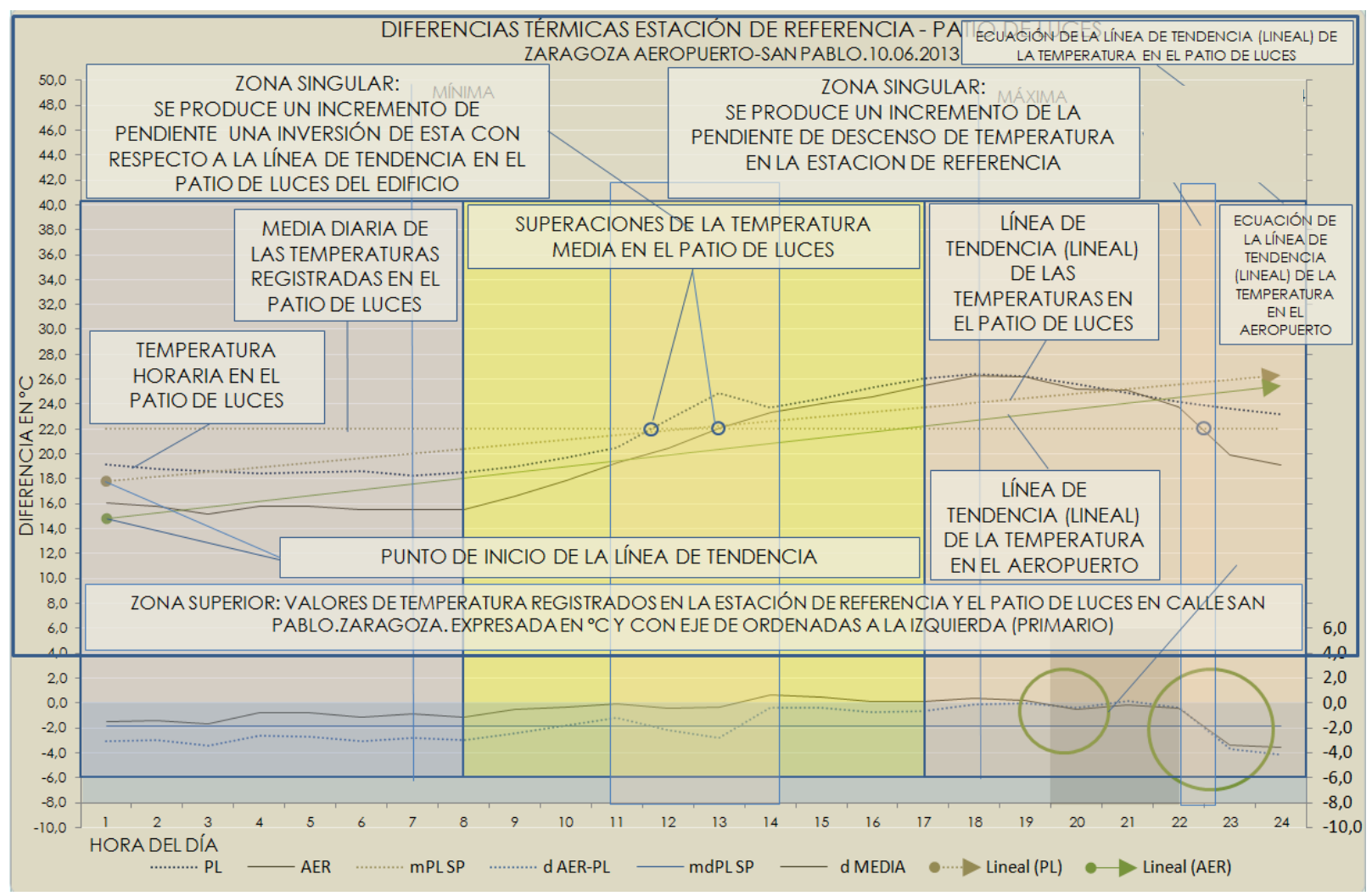

7-83 COMPARACIÓN DIARIA ENTRE LAS TEMPERATURAS EN LA ESTACIÓN DE REFERENCIA Y EL PATIO DE LUCES DE EDIFICIO EN CALLE SAN PABLO. PERIODO CÁLIDO PERIODOS Y MAGNITUDES SINGULARES. (Elaboración propia) 


\section{ANÁLISIS}

La recopilación y el tratamiento de los datos permite lecturas muy variadas.

Se ha elegido hacer patentes aquellos aspectos térmicos con incidencia en la simulación, prescripción, operación y evaluación del comportamiento termodinámico de los edificios.

Se ha considerado de especial importancia realizar un proceso de análisis que permita ser replicado para servir de soporte a una lectura correcta del ambiente térmico que rodea al edificio, valorando su capacidad para disipar la energía cuando la temperatura del edificio es mayor y de aportarla cuando su temperatura sea menor que la del ambiente.

Este análisis excluye la posibilidad de disipación o captación forzada, como puede ser la provocada por la acción del viento o por la incidencia solar directa, aunque se realiza conociendo estas capacidades del edificio y su potencial eficacia para modificar el balance térmico.

Una consideración similar se tiene con la capacidad de los edificios para amortiguar y demorar, en su seno, los efectos de su diferencial energético con el ambiente. Explícitamente está excluida de las consideraciones realizadas, aunque está implícita en la decisión de considerar, o no, los valores térmicos extremos, habida cuenta de que en el interior del edificio apenas se harán patentes sus efectos si se producen por un breve lapso de tiempo. 
Los valores climáticos que se emplean para la caracterización del clima con el que se realizarán las prescripciones técnicas y se establecerán las prestaciones a los efectos de cumplir las exigencias normativas, que denominaremos como climas de cálculo, son diferentes en función de la finalidad de las determinaciones para las que se emplean.

De una parte se han considerado los climas que se aportan para la aplicación del código técnico de la edificación y de otra los incluidos como documentos reconocidos para la aplicación del DB HE 2 (RITE).

Podemos observar que el CTE aporta unos valores climáticos diferentes de los que acompañan al RITE, y dentro de éste se singularizan los valores para cada capital de provincia.

Dentro de ellos se consideran los climas sintéticos prestacionales, establecidos para la zona climática D3 en ambas series climáticas.

Estos climas se han descrito como:

D3_CTE Clima recogido en la aplicación del CTE para la zona climática D3.

D3_RITE Clima recogido en la aplicación del RITE para la zona climática D3.

ZG_RITE Clima recogido en la aplicación del RITE para Zaragoza.

Del mismo modo se describe el clima de referencia específicos para Zaragoza, con uso en diversos procedimientos informatizados de simulación del comportamiento estimado de los edifico frente a la acción del clima, como son las aplicaciones Climate Consultant, Energy Plus o DesignBuilder, ente otras.

ZG_ePLUS Clima recogido en la aplicación del DOE para Zaragoza.

Estas tres series de comparaciones permiten observar diferencias importantes en los climas de referencia considerados. Especialmente en las temperaturas con las que fundamentalmente se obtienen los flujos energéticos que servirán para establecer las estrategias, las cualidades térmicas del edificio, los equipos y la maniobra y gestión adecuada para alcanzar las temperaturas de consigna interiores que se consideran apropiadas a cada situación.

La comparación entre las series consideradas se realiza mediante el análisis de los grados-hora, la temperatura, la humedad relativa, la radiación y la velocidad del viento en los distintos climas.

Las tablas comparativas se han confeccionado con dos columnas, una reflejando los datos brutos, muchas veces indicando el porcentaje con respecto al total anual de cada rango segregado, y otra columna comparando este valor con la serie de referencia 
propuesta por el Código Técnico de la Edificación (CTE) para la zona climática D3.
VER ANEXO 05 DESCRIPCIÓN CLIMAS DE REFERENCIA PARA LA ZONA CLIMÁTICA D3 
Se ha determinado la diferencia en grados-hora existente entre los distintos climas sintéticos prestacionales. Como puede verse en la tabla siguiente, se han reflejado según los códigos de clima descritos y en cada uno de los rangos establecido los grados hora totales para los meses fríos o de invierno y cálidos o de verano según se describen en el CTE HEl, observando las diferencias con lo considerado en el CTE y disponible en la web del Ministerio de Fomento para el CTE.

La comparativa se ha realizado tomando como base el clima anual que definen los valores climáticos establecidos para la zona climática en el CTE y sus documentos anexos.

En esta primera aproximación se analizan las temperaturas horarias, para las que se ha establecido, siguiendo un procedimiento análogo al de los grados-día, los grados en que se supera un determinado rango de temperaturas, próximas a las confortables, en cuyo caso se denomina como grados que es necesario enfriar, ${ }^{\circ}$ ENFRIAMIENTO, y aquellos que están por debajo de estos rangos de temperatura, ${ }^{\circ}$ CALEFACCIÓN.

A partir de estos valores se han establecido las diferencias entre los valores aportados por distintas fuentes y localidades situadas en la zona D3:

ZG-RITE Valores climáticos para Zaragoza del RITE

AEMET-ZG Valores climáticos para Zaragoza (DOE)

Estas comparaciones se han realizado para diferentes rangos de temperaturas. Se ha considerado un rango muy amplio, entre $16^{\circ} \mathrm{C}$ y $28^{\circ} \mathrm{C}$, para recoger todos los ambientes térmicos que son susceptibles de ser aceptados y corregidos para, en función de la sensibilidad y las condiciones específicas de cada individuo permitir un ajuste mediante medidas pasivas, como pueden ser el arropamiento, la ventilación o la exposición a la radiación, y metabólicas, como puede ser la producción de sudor.

Para observar la diferencia en grados-hora existente entre los distintos climas sintéticos prestacionales, se han contemplado distintos escenarios o rangos para las temperaturas de consigna establecidas, posibles en función de la tolerancia, el confort adaptativo y la influencia del edificio y sus envolventes en la amortiguación térmica. Desde una temperatura de $22^{\circ} \mathrm{C}$ y alejándose de ella en rangos cada vez más amplios.

Las variaciones térmicas consideradas son las siguientes:

Temperatura de consigna interior $22^{\circ} \mathrm{C}$

Temperatura de consigna interior

Temperatura de consigna interior

Temperatura de consigna interior entre $20^{\circ} \mathrm{C}$ y $24^{\circ} \mathrm{C}$

entre $18^{\circ} \mathrm{C}$ y $26^{\circ} \mathrm{C}$

entre $16^{\circ} \mathrm{C}$ y $28^{\circ} \mathrm{C}$ 


\begin{tabular}{|c|c|c|c|c|c|c|c|c|}
\hline \multirow{2}{*}{ FUENTE } & \multirow{2}{*}{ K } & \multicolumn{3}{|c|}{ CALEFACCION } & \multicolumn{3}{|c|}{ ENFRIAMIENTO } & \multirow{2}{*}{$\begin{array}{l}0 \\
0 \\
z \\
\alpha \\
\alpha\end{array}$} \\
\hline & & ${ }^{\circ} \mathrm{C}$ & $\%$ & $\begin{array}{l}\text { DIFERENCIA } \\
\text { CON D3-CTE }\end{array}$ & ${ }^{\circ} \mathrm{C}$ & $\%$ & $\begin{array}{l}\text { DIFERENCIA } \\
\text { CON D3-CTE }\end{array}$ & \\
\hline D3_CTE & 2512192,4 & 43403,3 & $100,00 \%$ & PATRÓN & 1643,1 & $100,00 \%$ & PATRÓN & \\
\hline D3-RITE & 2521253,4 & 35925,8 & $82,77 \%$ & $-17,23 \%$ & 1332,7 & $81,11 \%$ & $-18,89 \%$ & \\
\hline ZG-RITE & 2518487,6 & 36479,8 & $84,05 \%$ & $-15,95 \%$ & 1121,4 & $68,25 \%$ & $-31,75 \%$ & ن \\
\hline ZG-ePLUS & 2521243,9 & 35099,2 & $80,87 \%$ & $-19,13 \%$ & 1316,1 & $80,10 \%$ & $-19,90 \%$ & \\
\hline D3_CTE & 2512192,4 & 55455,4 & $100,00 \%$ & PATRÓN & 3175,9 & $100,00 \%$ & PATRÓN & u \\
\hline D3-RITE & 2521253,4 & 45571 & $82,18 \%$ & $-17,82 \%$ & 2640 & $83,13 \%$ & $-16,87 \%$ & \\
\hline ZG-RITE & 2518487,6 & 46902,2 & $84,58 \%$ & $-15,42 \%$ & 2274,8 & $71,63 \%$ & $-28,37 \%$ & ن \\
\hline ZG-ePLUS & 2521243,9 & 45546,7 & $82,13 \%$ & $-17,87 \%$ & 2618,5 & $82,45 \%$ & $-17,55 \%$ & \\
\hline D3_CTE & 2512192,4 & 68111,3 & $100,00 \%$ & PATRÓN & 5394,8 & $100,00 \%$ & PATRÓN & 0 \\
\hline D3-RITE & 2521253,4 & 57869,2 & $84,96 \%$ & $-15,04 \%$ & 4600,3 & $85,27 \%$ & $-14,73 \%$ & 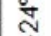 \\
\hline ZG-RITE & 2518487,6 & 59549,7 & $87,43 \%$ & $-12,57 \%$ & 4037,1 & $74,83 \%$ & $-25,17 \%$ & ú \\
\hline ZG-ePLUS & 2521243,9 & 57850,2 & $84,93 \%$ & $-15,07 \%$ & 4577,1 & $84,84 \%$ & $-15,16 \%$ & \\
\hline D3_CTE & 2512192,4 & 81729,7 & $100,00 \%$ & PATRÓN & 8408,1 & $100,00 \%$ & PATRÓN & \\
\hline D3-RITE & 2521253,4 & 71584 & $87,59 \%$ & $-12,41 \%$ & 7323,4 & $87,10 \%$ & $-12,90 \%$ & u \\
\hline ZG-RITE & 2518487,6 & 73543,3 & $89,98 \%$ & $-10,02 \%$ & 6516,9 & $77,51 \%$ & $-22,49 \%$ & \\
\hline ZG-ePLUS & 2521243,9 & 71575,2 & $87,58 \%$ & $-12,42 \%$ & 7305,1 & $86,88 \%$ & $-13,12 \%$ & \\
\hline
\end{tabular}

8-1 TABLA RESUMEN DE LAS DIFERENCIAS DE DISTINTOS CLIMAS DE REFERENCIA EN GRADOS-HORA PARA DISTINTOS RANGOS DE TEMPERATURA. (Varias fuentes y elaboración propia)

Tomando como base la serie térmica considerada por el CTE para la zona climática D3 y observando las diferencias con otras series aplicadas a la misma zona climática se nos permite observar diferencias negativas, para una temperatura de consigna $\mathrm{O}$ de referencia de $22^{\circ} \mathrm{C}$, entre un $6,48 \%$ y un $12,42 \%$ Esto quiere decir que las demandas estimadas por el CTE para la zona climática D3 son mayores en esta proporción de las estimadas por otras series térmicas sintéticas aplicadas a la misma zona. 
Los grados-hora que es necesario aportar al edificio para mantenerlo dentro de los distintos rangos de temperaturas que se pretenden, en función de las series térmicas de la zona climática D3 consideradas, pueden observarse en el siguiente gráfico:

DIFERENCIA CON LOS VALORES DE CALEFACCIÓN DEL CLIMA D3-CTE

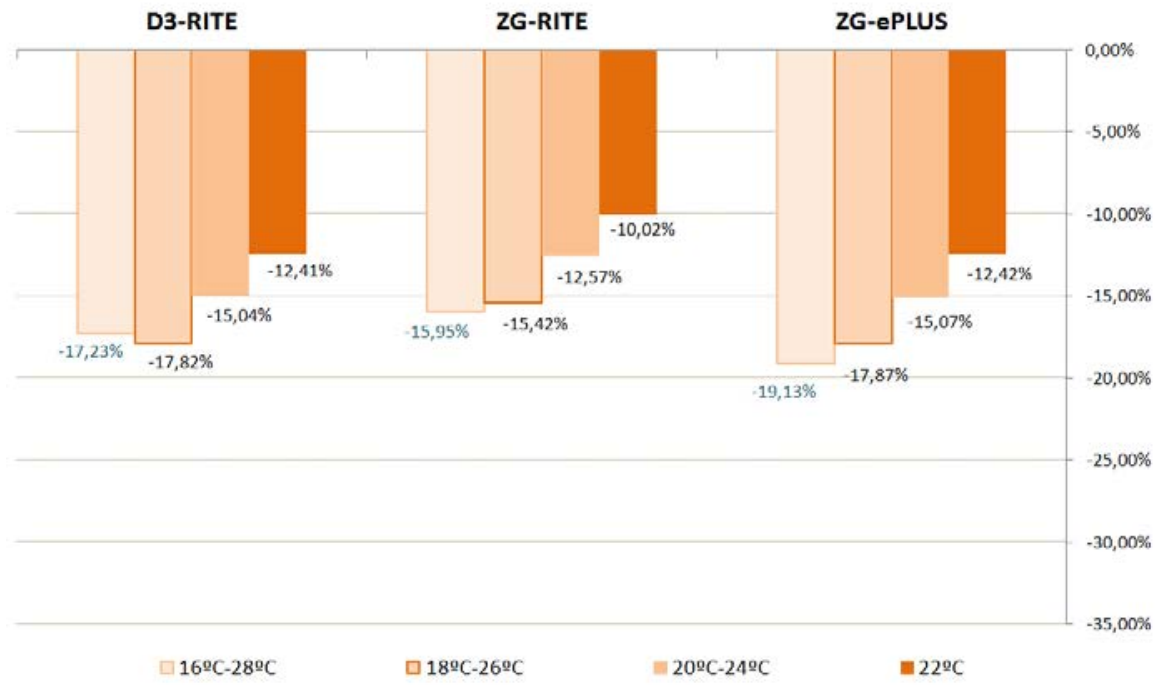

8-2 GRÁFICA COMPARADA EN GRADOS HORA PARA DIVERSOS CLIMAS SINTÉTICOS

\section{APLICABLES A LA ZONA CLIMÁTICA D3 PARA DIVERSOS RANGOS DE TEMPERATURA INTERIOR. (Elaboración propia)}


Los grados-hora que es necesario disipar en el edificio para mantenerse en los distintos rangos de temperaturas de consigna considerados, en función de las series térmicas de la zona climática D3 consideradas, pueden observarse en el siguiente gráfico:

DIFERENCIA CON LOS VALORES DE ENFRIAMIENTO DEL CLIMA D3-CTE

D3-RITE

ZG-RITE

ZG-ePLUS

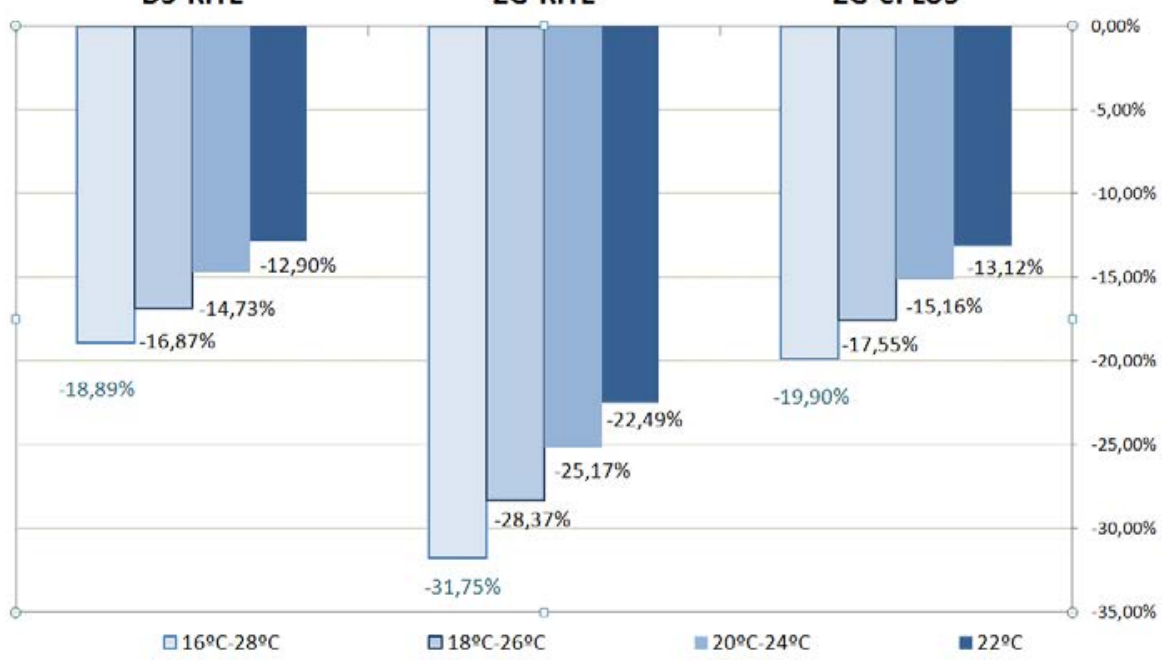

8-3 GRÁFICA COMPARADA EN GRADOS HORA PARA DIVERSOS CLIMAS SINTÉTICOS APLICABLES A LA ZONA CLIMÁTICA D3 PARA DIVERSOS RANGOS DE TEMPERATURA INTERIOR.(Elaboración propia)
VER ANEXO 05 
Puede observarse como, para mantener una temperatura interior de $22{ }^{\circ} \mathrm{C}$, sería necesario que se incremente la temperatura en el edificio, dependiendo de la serie climática considerada, en una temperatura en grados hora que se mantiene en una horquilla aproximada de $81.830^{\circ} \mathrm{C}$ para la serie térmica aportada por el CTE y de $71.580{ }^{\circ} \mathrm{C}$, para la aportada por el RITE para la misma zona climática C3.

Esto supone una diferencia del $12,4 \%$, que, aún siendo significativa, puede cumplir con la finalidad regulatoria para la que se diseña.

Algo similar ocurre con las necesidades de disipación de energía y aunque en este caso las necesidades se encuentran en el entorno del $10 \%$ de las de aportación de energía, las diferencias son también importantes oscilando en más de un $30 \%$, aunque las diferencias en valor absoluto sean un $20 \%$ de las que se observan en las necesidades de aportación de energía.

Cuando se considera un rango en las temperaturas de consigna puede observarse que las necesidades disminuyen.

Cuando el rango es de $\pm 2{ }^{\circ} \mathrm{C}$ con respecto a los $22^{\circ} \mathrm{C}$, es decir se deja fluctuar la temperatura entre $20^{\circ} \mathrm{C}$ y $24^{\circ} \mathrm{C}$, las diferencias de disipación y aportación de energía apenas se disminuyen en un $15 \%$ y las desviaciones aumentan en casi un $3 \%$ en la demanda de calefacción y en más de un 12\% en la demanda de refrigeración.

En el rango más amplio considerado la reducción de la demanda de aportación de energía en grados-hora se reduce casi a la mitad y la demanda de disipación de energía se reduce casi a un tercio, en este caso las diferencias entre las series aumentan notablemente, a casi un $20 \%$ en calefacción y más de un $50 \%$ en refrigeración.

Hay que recordar que las series térmicas de referencia sólo se diseñan para establecer valores promedio estimados para ser empleados en la regulación de exigencias constructivas, de equipos de acondicionamiento térmico o para establecer unas demandas estimadas que permitan comparar un edificio modelo con la propuesta arquitectónica más que para estimar las condiciones en las que el edificio deberá desenvolverse.

Sacar de este ámbito estas series climáticas induciría al error de emplearlas para un cometido para el que no fueron diseñadas.

La estimación de consumos o emisiones o las condiciones de operación durante su vida útil requieren series térmicas que puedan reproducir con más precisión el entorno térmico en que se desenvolverá el edificio. 


\subsubsection{TEMPERATURA}

En un primer análisis puede observarse que las temperaturas absolutas recogidas en los distintas series muestran diferencias muy significativas.

La comparación de las divergencias entre las temperaturas más altas y las más bajas evidencia unas diferencias mayores en los valores bajos que en los medios o máximos, tanto en el caso de las medias como en el de los valores absolutos.

Con respecto a estos últimos se observa una gran diferencia entre los estimados en las series propuestas para la zona climática D3 para el RITE por el Ministerio de Industria, Energía y Turismo (D3_RITE en el cuadro), siendo menos extremas que las propuestas por el Ministerio de Fomento (D3_CTE en el cuadro), siempre en cuantías mayores en los valores mayores y en los valores mínimos que en los máximos.

En la aplicación a la localidad de referencia se observa que la propuesta del Ministerio de Energía, Industria y Turismo (ZG_RITE en el cuadro) es diferente a la propuesta para la zona climática D3 por esta entidad (D3_RITE en el cuadro), con valores más extremos en sus temperaturas mínimas y, aún más manifiestamente distintos en sus temperaturas máximas, tanto si se consideran las temperaturas extremas como las medias de las máximas.

El clima elaborado para hacer las simulaciones en el motor de cálculo de Energy Plus para la zona climática D3 (D3_ePLUS en el cuadro), es diferente del propuesto para la localidad donde se ubican los estudios (ZG_ePLUS en el cuadro) y distinto a su vez a los propuestos por el Ministerio de Industria, Energía y Turismo para Zaragoza (D3_ZG en el cuadro) y el propuesto para la zona climática D3 por el Ministerio de Fomento (D3_CTE en el cuadro).

En definitiva el análisis de las temperaturas máximas y mínimas indica que una estimación de demandas extremas de la edificación daría resultados diferentes dependiendo del clima de referencia que se considerase y confirmaría que no está indicado para prescribir las soluciones arquitectónicas y de operación durante el uso del edificio.

Las mayores discrepancias se observan en los valores máximos y mínimos, manteniendo los valores medios unas diferencias mucho menores, pudiendo ser esto un indicador de su utilidad real. 
A estos efectos se resumen en cuadro siguiente los valores tomados de las series térmicas descritas:

\begin{tabular}{|l|r|r|r|r|r|r|r|r|r|r|}
\cline { 2 - 11 } \multicolumn{1}{c|}{} & \multicolumn{8}{c|}{ TEMPERATURAS ANUALES } \\
\cline { 2 - 11 } \multicolumn{1}{c|}{} & \multicolumn{4}{c|}{ ABSOLUTA } & \multicolumn{6}{c|}{ MEDIA } \\
\cline { 2 - 11 } \multicolumn{1}{c|}{ MAX } & \multicolumn{2}{c|}{ MIN } & \multicolumn{2}{c|}{ MED } & \multicolumn{2}{c|}{ MAX } & \multicolumn{1}{c|}{ MIN } \\
\hline D3-CTE & 37,0 & & $-5,1$ & & 13,6 & & 18,8 & & 8,0 & \\
\hline D3-RITE & 36,0 & $-3 \%$ & $-0,6$ & $88 \%$ & 14,3 & $5 \%$ & 19,8 & $6 \%$ & 10,2 & $28 \%$ \\
\hline ZG-RITE & 37,4 & $1 \%$ & $-1,7$ & $67 \%$ & 14,7 & $8 \%$ & 20,9 & $11 \%$ & 10,0 & $25 \%$ \\
\hline ZG-ePLUS & 37,2 & $1 \%$ & $-1,1$ & $78 \%$ & 14,7 & $8 \%$ & 20,9 & $11 \%$ & 10,0 & $25 \%$ \\
\hline
\end{tabular}

8-4 CUADRO COMPARATIVO DE TEMPERATURAS MÁXIMAS Y MÍNIMAS ABSOLUTAS Y DE VALORES MEDIOS DE MÁXIMAS, MEDIAS Y MÍNIMAS (Varias fuentes Y elaboración propia)

El análisis de las oscilaciones térmicas muestra diferencias menores de $2^{\circ} \mathrm{C}$, que solo se ven incrementadas en las oscilaciones mínimas, especialmente en sus valores absolutos. En general el clima de referencia empleado por el CTE tiene valores situados entre los más extremos, mientras que sus valores medios son menores a los de cualquier otro clima de referencia.

En general, las oscilaciones térmicas en los periodos fríos son bajas, mientras que aumentan, alcanzando los valores máximos con las temperaturas máximas.

\begin{tabular}{|l|c|c|c|c|c|c|}
\hline & \multicolumn{5}{|c|}{ OSCILACION TERMICA } \\
\hline & \multicolumn{2}{|c|}{ MEDIA } & \multicolumn{2}{c|}{ MÁXiMA } & \multicolumn{2}{c|}{ MÍNIMA } \\
\hline D3-CTE & 10,8 & & 17,9 & & 1,5 & \\
\hline D3-RITE & 9,6 & $11 \%$ & 19,8 & $-11 \%$ & 1,2 & $20 \%$ \\
\hline ZG-RITE & 11,0 & $-2 \%$ & 19,7 & $-10 \%$ & 2,3 & $-53 \%$ \\
\hline ZG-ePLUS & 10,9 & $-1 \%$ & 19,5 & $-9 \%$ & 2,3 & $-53 \%$ \\
\hline
\end{tabular}

8-5 CUADRO COMPARATIVO DE OSCILACIONES TÉRMICAS MEDIAS, MÁXIMAS Y MÍNIMAS (Varias fuentes y elaboración propia)

Una comparativa más precisa aplicada a rangos de temperaturas menores de $0^{\circ} \mathrm{C}$, muy importante al afectar a procesos de cambio de fase del agua de gran importancia constructiva y climática muestra valores mucho mayores, entre el $2 \%$ y el $3 \%$ en el clima diseñado para la zona climática D3 del CTE (D3-CTE). El resto de los climas recogen valores muy pequeños o nulos, con diferencias en el entorno de 200 horas, tanto en los propuestos para Zaragoza como en el clima D3 propuesto por el Ministerio de Industria y Energía (D3-RITE).

Las horas con temperaturas mayores de $30^{\circ} \mathrm{C}$ propuestas para la zona climática D3 por el CTE, son más de 300, con diferencias del entorno de 100 horas con el resto de los climas de referencia, lo que implica diferencia de un $1 \%$, con el resto de los climas de referencia, que son muy similares entre sí.

Todos los climas de referencia proponen para Zaragoza una proporción de días templados, con temperaturas comprendas entre $20^{\circ} \mathrm{C}$ y $30^{\circ} \mathrm{C}$, próxima al $22 \%$ del total de las horas del año.

Con pequeñas diferencias todos los climas adjudican a temperaturas entre $0^{\circ} \mathrm{C}$ y $20^{\circ} \mathrm{C}$ un $74 \% \pm 2 \%$ de las horas del año con una distribución que está muy próxima al $41 \%$ de las horas del año para las temperaturas comprendidas entre $10^{\circ} \mathrm{C}$ y $20^{\circ} \mathrm{C}$, salvo 
para el clima propuesto por el CTE para la zona climática D3 que propone una proporción ligeramente menor.

En definitiva todos los climas analizados son relativamente homogéneos para las zona climática D3 y para la ciudad de Zaragoza al estimar el número de horas con temperaturas mayores de $20^{\circ} \mathrm{C}$, aproximadamente el $25 \%$ del año, y las que tienen temperaturas menores, aproximadamente el $75 \%$ del año. Manifestando ligeras diferencias en los valores más extremos especialmente en valores bajo $0^{\circ} \mathrm{C}$ y en los valores que superan los $30^{\circ} \mathrm{C}$.

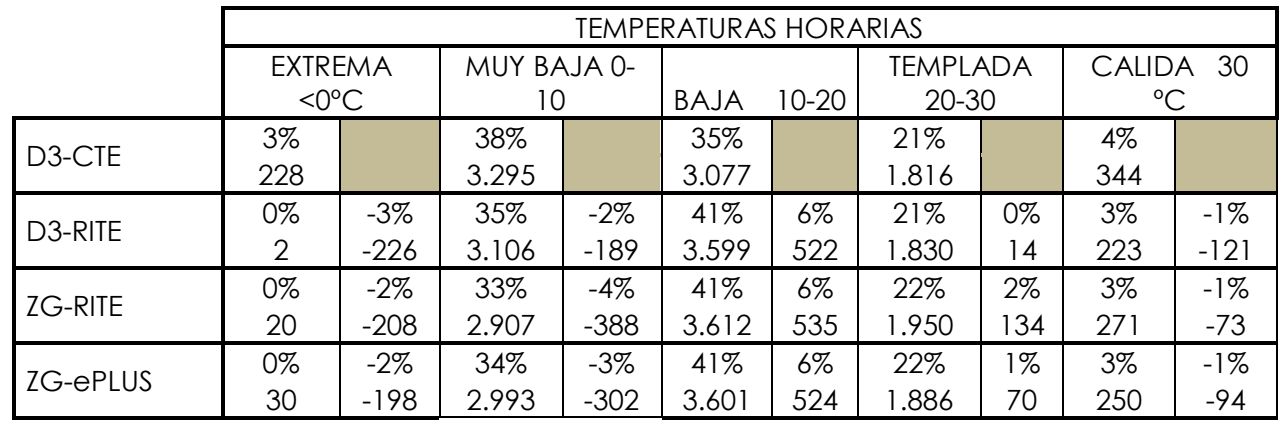

8-6 CUADRO COMPARATIVO DEL TIEMPO EN HORAS EN QUE LAS TEMPERATURAS OCUPAN RANGOS DE MENORES DE $0^{\circ} \mathrm{C}$, ENTRE $0^{\circ} \mathrm{C} Y 10^{\circ} \mathrm{C}$, ENTRE $10^{\circ} \mathrm{C} Y$ $20 \%$ Y MAYORES DE $30^{\circ} \mathrm{C}$. (Varias fuentes y elaboración propia)

Cuando el análisis afecta a las temperaturas medias diarias los valores menores de $0^{\circ} \mathrm{C}$ son irrelevantes y sólo en la propuesta del CTE para el clima D3 se recoge algún día esta circunstancia.

También son irrelevantes o nulas las temperaturas medias diarias por encima de $30^{\circ} \mathrm{C}$.

Como era predecible, los valores medios diarios concentran las temperaturas en los tres rangos centrales.

El único de los climas analizados donde es mayor el número de días con medias entre $0^{\circ} \mathrm{C}$ y $10^{\circ} \mathrm{C}$ es el propuesto para la zona climática D3 por el CTE (D3-CTE) con el $40 \%$ de los días (147), mientras que el resto de los climas proponen para Zaragoza y la zona climática D3 una cifra similar para los días con temperaturas medias diarias entre $10^{\circ} \mathrm{C}$ y $20^{\circ} \mathrm{C}$. 
La propuesta más común es adjudicar casi un tercio de las horas a cada uno de los tramos descritos, con unos valores ligeramente menores para las temperaturas comprendidas entre $20^{\circ} \mathrm{C}$ y $30^{\circ} \mathrm{C}$, sin apenas periodos asignados a temperaturas menores de $0^{\circ} \mathrm{C}$ y mayores de $30^{\circ} \mathrm{C}$.

\begin{tabular}{|l|c|c|c|c|c|c|c|c|c|c|}
\cline { 2 - 11 } \multicolumn{1}{c|}{} & \multicolumn{9}{c|}{ TEMPERATURAS MEDIAS DIARIAS } \\
\cline { 2 - 12 } \multicolumn{1}{c|}{} & \multicolumn{2}{c|}{$\begin{array}{c}\text { EXTREMA } \\
<0^{\circ} \mathrm{C}\end{array}$} & \multicolumn{2}{c|}{$\begin{array}{c}\text { MUY BAJA 0- } \\
10\end{array}$} & \multicolumn{2}{c|}{ BAJA $10-20$} & \multicolumn{2}{c|}{$\begin{array}{c}\text { TEMPLADA 20- } \\
30\end{array}$} & \multicolumn{2}{c|}{$\begin{array}{c}\text { CALIDA 30 } \\
{ }^{\circ} \mathrm{C}\end{array}$} \\
\hline \multirow{2}{*}{ D3-CTE } & $1 \%$ & & $40 \%$ & & $32 \%$ & & $27 \%$ & & $0 \%$ & \\
& 3 & & 147 & & 118 & & 97 & & 0 & \\
\hline \multirow{2}{*}{ D3-RITE } & $0 \%$ & $-1 \%$ & $33 \%$ & $-7 \%$ & $39 \%$ & $7 \%$ & $28 \%$ & $1 \%$ & $0 \%$ & $0 \%$ \\
& 0 & -3 & 122 & -25 & 142 & 24 & 101 & 4 & 0 & 0 \\
\hline \multirow{2}{*}{ D3-ZG } & $0 \%$ & $-1 \%$ & $32 \%$ & $-8 \%$ & $40 \%$ & $8 \%$ & $28 \%$ & $1 \%$ & $0 \%$ & $0 \%$ \\
& 0 & -3 & 117 & -30 & 147 & 29 & 101 & 4 & 0 & 0 \\
\hline \multirow{2}{*}{ e+_ZG } & $0 \%$ & $-1 \%$ & $33 \%$ & $-8 \%$ & $40 \%$ & $8 \%$ & $27 \%$ & $1 \%$ & $0 \%$ & $0 \%$ \\
& 0 & -3 & 119 & -28 & 146 & 28 & 100 & 3 & 0 & 0 \\
\hline
\end{tabular}

8-7 CUADRO COMPARADO DE LAS TEMPERATURAS MEDIAS DIARIAS POR RANGOS DE MENORES DE $0^{\circ} \mathrm{C}$, ENTRE $0^{\circ} \mathrm{C} Y 10^{\circ} \mathrm{C}$, ENTRE $10^{\circ} \mathrm{C}$ Y $20 \%$ Y MAYORES DE $30^{\circ} \mathrm{C}$. (Varias fuentes y elaboración propia)

El análisis correspondiente a las temperaturas máximas diarias y mínimas diarias sí muestra unas grandes diferencias en las propuestas para Zaragoza y para el resto.

Zaragoza con el $50 \%$ de las máximas diarias superiores a $20^{\circ} \mathrm{C}$ y sólo el $7 \%$ inferiores a $10^{\circ} \mathrm{C}$, es la propuesta con temperaturas máximas mayores, mientras el resto, salvo lo indicado para la zona climática D3 por el CTE, no superan el $42 \% \pm 2 \%$ las temperaturas máximas diarias superiores a $20^{\circ} \mathrm{C}$ e inferiores a $10^{\circ} \mathrm{C}$ más del $10 \%$.

El clima propuesto para la zona climática D3 por el CTE es el que asigna menos horas de temperaturas máximas diarias por encima de los $20^{\circ} \mathrm{C}$ y más con temperaturas por debajo de los $10^{\circ} \mathrm{C}$.

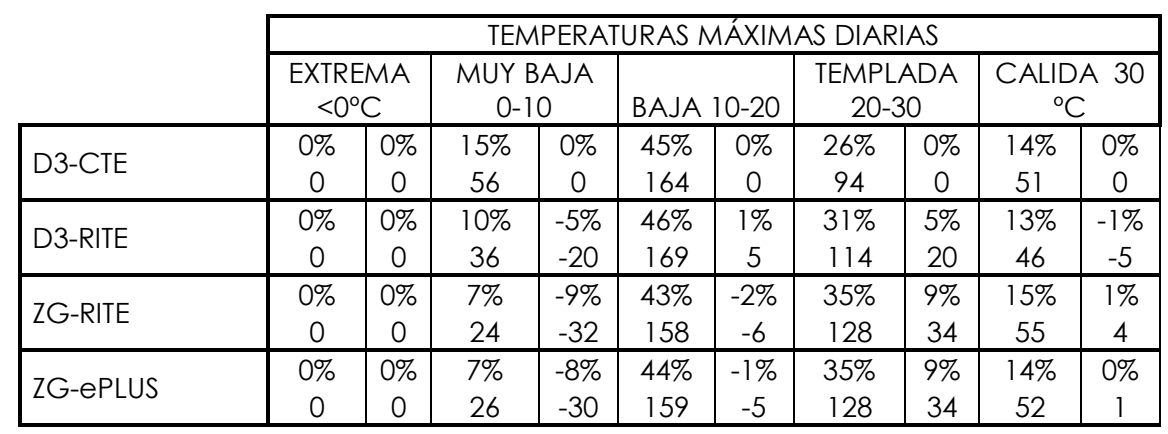

8-8 CUADRO COMPARATIVO DE LAS TEMPERATURAS MÁXIMAS DIARIAS POR RANGOS DE MENORES DE $0^{\circ} \mathrm{C}$, ENTRE $0^{\circ} \mathrm{C} Y 10^{\circ} \mathrm{C}$, ENTRE $10^{\circ} \mathrm{C}$ Y $20 \%$ Y MAYORES DE $30^{\circ} \mathrm{C}$. (Varias fuentes y elaboración propia) 
Las temperaturas mínimas diarias sólo superan los $20^{\circ} \mathrm{C}$ muy ocasionalmente, $4 \pm 1$ día en Zaragoza, aunque tampoco el resto de climas lo hace en más de 19 días.

Las propuestas para la zona climática D3 del CTE son las que sitúan un mayor número de días con temperaturas mínimas diarias por debajo de $0^{\circ} \mathrm{C}(45)$, en el entorno del $12 \%$ de los días, frente al resto de los climas que estiman proporciones nulas o, a lo sumo, del $3 \%$.

Cuando se consideran las temperaturas menores de $10^{a} \mathrm{C}$, la propuesta para la zona climática D3 mantiene esta directriz, con un $62 \%$ de los días, mientras que el resto de los climas de referencia, lo fija en un $55 \%$ de los días.

Así, para todos los climas de referencia es del $43 \% \pm 1 \%$, mientras que para el clima de referencia para la zona D3 del CTE es del $33 \%$.

La existencia de periodos en los que las temperaturas mínimas superen los $20^{\circ} \mathrm{C}$ es muy importante para el desempeño energético del edificio, por lo que estas diferencias en los climas de referencia pueden ser determinantes en su fase de diseño.

\begin{tabular}{|c|c|c|c|c|c|c|c|c|c|c|}
\hline \multirow[b]{3}{*}{ D3-CTE } & \multicolumn{10}{|c|}{ TEMPERATURAS MÍNIMAS DIARIAS } \\
\hline & \multicolumn{2}{|c|}{ EXTREMA $<0^{\circ} \mathrm{C}$} & \multicolumn{2}{|c|}{$\begin{array}{c}\text { MUY BAJA 0- } \\
10\end{array}$} & \multicolumn{2}{|c|}{ BAJA 10-20 } & \multicolumn{2}{|c|}{$\begin{array}{c}\text { TEMPLADA 20- } \\
30 \\
\end{array}$} & \multicolumn{2}{|c|}{$\begin{array}{l}\text { CALIDA } \\
30^{\circ} \mathrm{C} \\
\end{array}$} \\
\hline & $\begin{array}{c}12 \% \\
45\end{array}$ & & $\begin{array}{c}50 \% \\
181\end{array}$ & & $\begin{array}{l}33 \% \\
120\end{array}$ & & $\begin{array}{c}5 \% \\
19\end{array}$ & & $\begin{array}{c}0 \% \\
0\end{array}$ & \\
\hline D3-RITE & $\begin{array}{c}0 \% \\
1\end{array}$ & $\begin{array}{c}-12 \% \\
-44 \\
\end{array}$ & $\begin{array}{l}54 \% \\
198 \\
\end{array}$ & $\begin{array}{l}5 \% \\
17 \\
\end{array}$ & $\begin{array}{l}42 \% \\
155 \\
\end{array}$ & $\begin{array}{c}10 \% \\
35 \\
\end{array}$ & $\begin{array}{l}3 \% \\
11 \\
\end{array}$ & $\begin{array}{c}-2 \% \\
-8 \\
\end{array}$ & $\begin{array}{c}0 \% \\
0 \\
\end{array}$ & $\begin{array}{c}0 \% \\
0 \\
\end{array}$ \\
\hline ZG-RITE & $\begin{array}{l}3 \% \\
10 \\
\end{array}$ & $\begin{array}{c}-10 \% \\
-35 \\
\end{array}$ & $\begin{array}{l}52 \% \\
188 \\
\end{array}$ & $\begin{array}{c}2 \% \\
7 \\
\end{array}$ & $\begin{array}{l}4 \% \\
162 \\
\end{array}$ & $\begin{array}{c}12 \% \\
42 \\
\end{array}$ & $\begin{array}{c}1 \% \\
5 \\
\end{array}$ & $\begin{array}{l}-4 \% \\
-14 \\
\end{array}$ & $\begin{array}{c}0 \% \\
0\end{array}$ & $\begin{array}{c}0 \% \\
0 \\
\end{array}$ \\
\hline ZG-ePLUS & $\begin{array}{c}3 \% \\
11\end{array}$ & $\begin{array}{l}-9 \% \\
-34 \\
\end{array}$ & $\begin{array}{r}53 \% \\
192 \\
\end{array}$ & $\begin{array}{l}3 \% \\
11\end{array}$ & $\begin{array}{l}44 \% \\
159 \\
\end{array}$ & $\begin{array}{l}11 \% \\
39\end{array}$ & $\begin{array}{c}1 \% \\
3\end{array}$ & $\begin{array}{l}-4 \% \\
-16 \\
\end{array}$ & $\begin{array}{c}0 \% \\
0\end{array}$ & $\begin{array}{c}0 \% \\
0\end{array}$ \\
\hline
\end{tabular}

8-9 CUADRO COMPARATIVO DE LAS TEMPERATURAS MÍNIMAS DIARIAS POR RANGOS DE MENORES DE $0^{\circ} \mathrm{C}$, ENTRE $0^{\circ} \mathrm{C} \mathrm{Y} 10^{\circ} \mathrm{C}$, ENTRE $10^{\circ} \mathrm{C}$ Y $20 \%$ Y MAYORES DE $30^{\circ} \mathrm{C}$. (Varias fuentes y elaboración propia)

En general puede observarse cómo las temperaturas se mantienen por debajo de las de confort salvo entre los meses de junio y septiembre, con periodos por debajo de $10^{\circ} \mathrm{C}$ desde mediados de noviembre hasta mediados de marzo. La corrección al alza de la temperatura será, por tanto, el objetivo de la climatización.

Las temperaturas medias sólo ocasionalmente superan las temperaturas confortables y siempre en las horas centrales del día manteniendo, dentro de la alta oscilación térmica, valores mayores que la media en estos periodos.

Las temperaturas extremas pueden mantenerse más altas que las confortables desde mediados de mayo hasta finales de septiembre con ligeros periodos más frescos y, por lo tanto, confortables. Por su parte, las temperaturas extremas mínimas no son confortables más que en breves periodos de no más de dos días entre junio y agosto, estando el resto del año por debajo de las adecuadas para un ambiente confortable. 
Puede concluirse que sólo la ganancia térmica (flujo energético positivo) permitirá alcanzar temperaturas de confort en los espacios interiores durante casi todo el año, desde mediados de septiembre a finales de mayo, mientras que es necesario reducir esta ganancia (flujo energético negativo) sólo en varios periodos de varios días, entre 3 y 7 , entre los meses de julio y agosto. 


\subsubsection{HUMEDAD RELATIVA}

La humedad media sólo muy ocasionalmente se extiende más allá de la zona de bienestar, estimada entre $80 \%$ y $20 \%$, por lo que podemos considerar que no llega a valores críticos que exijan unas grandes correcciones. En general podemos observar que aunque son más frecuentes los periodos de una ligera falta de humedad, una oscilación diaria alta hace que sólo ocurra en las franjas horarias centrales del día durante cuatro meses entre junio y septiembre y muy ocasionalmente desde finales de marzo, en abril y en mayo.

La corrección más usual es la de refrescar la piel o mantenerse en lugares donde una temperatura dos o tres grados menor haría que la humedad se mantuviese en valores confortables.

Puede observarse exceso de humedad en algún momento del día durante seis meses de octubre a marzo. En ellos la humedad circunstancialmente puede resultar incómoda, aunque las altas oscilaciones hacen que la mayor parte del día se mantenga en valores confortables.

En este caso la humedad se corresponde con temperaturas frías por lo que la corrección siempre pasa por aumentarla, lo cual es muchas veces posible mediante soleamiento directo, aunque lo más frecuente es que la calefacción convencional mantenga la humedad baja en los interiores.

La curva de regresión nos sirve para observar que sigue una secuencia que alcanza su mínimo en verano, con las temperaturas más altas, y un máximo en invierno, cuando la temperatura es más baja, también muestra una alta varianza en los valores horarios por lo que no es significativa en su función de estimar valores por este medio, siendo necesario el empleo de series de Fourier o estrategias operativas similares para buscar esta capacidad de previsión :

$$
\begin{gathered}
y=2 E-0,8 x^{4}+0,0039 x^{3}-240,24 x^{2}+7 E+0,6 x-7 E+10 \\
\left(R^{2}=0,3991\right)
\end{gathered}
$$

El análisis por rangos de humedad relativa horaria muestra una gran mayoría de valores entre el $20 \%$ y el $80 \%$, mientras que los valores inferiores al $20 \%$ son muy escasos, por debajo del $2 \%$ de las horas del año, según la estimación realizada para confeccionar el clima propuesto para la zona climática D3 para su aplicación en el RITE (D3-RITE).

Las mayores diferencias entre los distintos climas se manifiesta en la proporción de horas en que la humedad relativa rebasa el $80 \%$ de humedad, que es, en el caso de Zaragoza, del entorno del $20 \%$, un $10 \%$ más de las superaciones estimadas para el clima de referencia en la zona climática D3 elaborada por el CTE. 


\begin{tabular}{|c|c|c|c|c|c|c|c|c|c|c|}
\hline \multirow[b]{3}{*}{ D3-CTE } & \multicolumn{10}{|c|}{ HUMEDAD RELATIVA } \\
\hline & \multicolumn{2}{|c|}{$\begin{array}{c}\text { muy baja } \\
\leq 20\end{array}$} & \multicolumn{2}{|c|}{$\begin{array}{l}\text { baja } \\
20-40\end{array}$} & \multicolumn{2}{|c|}{ media $\quad 40-60$} & \multicolumn{2}{|c|}{ alta $80^{60-}$} & \multicolumn{2}{|c|}{ extrema $>80$} \\
\hline & $\begin{array}{c}0 \% \\
3\end{array}$ & & $\begin{array}{l}15 \% \\
1345 \\
\end{array}$ & & \begin{tabular}{|l|}
$36 \%$ \\
3148 \\
\end{tabular} & & $\begin{array}{l}38 \% \\
3296 \\
\end{array}$ & & $\begin{array}{l}11 \% \\
968 \\
\end{array}$ & \\
\hline D3-RITE & $\begin{array}{l}2 \% \\
192\end{array}$ & $\begin{array}{l}2 \% \\
189\end{array}$ & $\begin{array}{l}20 \% \\
1771\end{array}$ & $\begin{array}{l}5 \% \\
426\end{array}$ & $\begin{array}{l}34 \% \\
2947\end{array}$ & $\begin{array}{l}-2 \% \\
-201\end{array}$ & $\begin{array}{l}34 \% \\
2946\end{array}$ & $\begin{array}{l}-4 \% \\
-350\end{array}$ & $\begin{array}{l}10 \% \\
904\end{array}$ & $\begin{array}{l}-1 \% \\
-64\end{array}$ \\
\hline ZG-RITE & $\begin{array}{c}0 \% \\
8 \\
\end{array}$ & $\begin{array}{c}0 \% \\
5 \\
\end{array}$ & $\begin{array}{l}14 \% \\
1244 \\
\end{array}$ & $\begin{array}{l}-1 \% \\
-101 \\
\end{array}$ & $\begin{array}{l}31 \% \\
2754 \\
\end{array}$ & $\begin{array}{l}-4 \% \\
-394 \\
\end{array}$ & $\begin{array}{r}34 \% \\
2964 \\
\end{array}$ & $\begin{array}{r}-4 \% \\
-332 \\
\end{array}$ & $\begin{array}{l}20 \% \\
1790 \\
\end{array}$ & $\begin{array}{l}9 \% \\
822 \\
\end{array}$ \\
\hline ZG-ePLUS & $\begin{array}{c}0 \% \\
7\end{array}$ & $\begin{array}{c}0 \% \\
4\end{array}$ & $\begin{array}{l}14 \% \\
1187\end{array}$ & $\begin{array}{l}-2 \% \\
-158\end{array}$ & $\begin{array}{l}31 \% \\
2732\end{array}$ & $\begin{array}{l}-5 \% \\
-416\end{array}$ & $\begin{array}{l}34 \% \\
2984\end{array}$ & $\begin{array}{l}-4 \% \\
-312\end{array}$ & $\begin{array}{l}21 \% \\
1850\end{array}$ & $\begin{array}{l}10 \% \\
882\end{array}$ \\
\hline
\end{tabular}

8-10 CUADRO COMPADO DE PERIODOS EN HORAS EN QUE LAS HUMEDADES RELATIVAS HORARIAS ESTÁN DISTRIBUIDAS EN RANGOS DE MENORES DE 20\%, ENTRE 20 Y 40\%, ENTRE 40\% Y 60\% Y MAYORES DEL 80\% (Varias fuentes y elaboración propia) 


\subsubsection{RADIACIÓN}

La radiación se representa sobre el eje secundario en centésimas de $\mathrm{W} / \mathrm{m}^{2}$ tiene un valor horario máximo de aproximadamente 1200 $\mathrm{W} / \mathrm{m}^{2}$ y una media anual de $624 \mathrm{~W} / \mathrm{m}^{2}$. La radiación difusa influye en un máximo de $390 \mathrm{~W} / \mathrm{m}^{2}$ y mientras que la radiación total influye en un máximo de $1.115 \mathrm{~W} / \mathrm{m}^{2}$ (93\%).

La media de radiación total que proviene de la radiación directa es de aproximadamente un $70 \%$ mientras que la proveniente de la radiación difusa es de un $30 \%$.

Cuando en lugar de los valores horarios consideramos la aportación media diaria de la radiación directa ésta es de 2720 $\mathrm{W} / \mathrm{m}^{2}$ y la de la radiación difusa es de $1520 \mathrm{~W} / \mathrm{m}^{2}$. Podemos observar que la diferencia entre ambas es apenas menor del 55\%.

Entre los valores máximos se ha considerado una radiación directa de $8800 \mathrm{~W} / \mathrm{m}^{2}$ y una radiación difusa de $3100 \mathrm{~W} / \mathrm{m}^{2}$, observándose que la diferencia entre ellas es del $35 \%$.

La radiación total media se ha estimado en $4243 \mathrm{~W} / \mathrm{m}^{2}$ y la máxima en $9800 \mathrm{~W} / \mathrm{m}^{2}$, es decir, que la media diaria a lo largo del año es casi el $40 \%$ menor que la máxima, con pocos días con valores máximos y muchos próximos a los valores medios.

Esto puede verse cuando se representan las aportaciones por radiación difusa y por la directa y se comparan con la total acumulada por días a lo largo del año.

Se observa cómo la radiación difusa tiene una mayor continuidad a lo largo del año siendo mayor que la directa ocasionalmente en invierno y siempre mucho menor en verano. También puede observarse que la radiación difusa y la directa tienen valores medios similares en los meses más fríos mientras que en primavera y otoño la radiación directa es bastante mayor. En verano, cuando la radiación es mayor de la necesaria, es la directa la que sobrepasa en mucho a la difusa. Por otra parte, con respecto a valores medios, la oscilación de la radiación es muy alta por lo que para el acondicionamiento éste debe ser complementado con sistemas de inercia que permitan corregirla en las temperaturas interiores.

La radiación total en todos los climas de referencia consultados está en valores absolutos muy similares, del entorno de 37,2 $\mathrm{MW} / \mathrm{m}^{2}, \pm 0,3$, aunque hay grandes diferencias con los datos preparados para ser aplicados en la herramienta Energy Plus, entre otras, con valores que pueden duplicar los previstos en los climas de referencia. 


\begin{tabular}{|c|c|c|}
\cline { 2 - 3 } \multicolumn{1}{c|}{} & \multicolumn{2}{c|}{ RADIACIÓN SOLAR ANUAL } \\
\cline { 2 - 3 } \multicolumn{1}{c|}{} & $\mathrm{kW} / \mathrm{m}^{2}$ & $\Delta$ (S/D3-CTE) \\
\hline D3-CTE & 37170,528 & $0,75 \%$ \\
\hline D3-RITE & 37451,136 & $-0,63 \%$ \\
\hline ZG-RITE & 36936,528 & $104,96 \%$ \\
\hline ZG-ePLUS & 76184,952 & \\
\hline
\end{tabular}

8-11 CUADRO DE RADIACIÓN TOTAL INCIDENTE SOBRE PLANO HORIZONTAL EN VALOR ABSOLUTO Y EN PORCENTAJE CON RESPECTO A LA RECOGIDA EN EL CTE PARA LA ZONA CLIMÁTICA D3 (Varias fuentes y elaboración propia)

La radiación incidente sobre un plano horizontal recogida en las series climáticas ofrece, al ser comparada, diferencias significativas entre las diseñadas para ser utilizadas en las aplicaciones de Energy Plus, entre otras, y las que han sido diseñadas para la aplicación al CTE y al RITE por el Ministerio de Fomento y el Ministerio de Industria, Energía y Turismo. Con diferencias tan grandes que aún manteniendo proporciones similares en valores bajos, menores de $250 \mathrm{~W} / \mathrm{m}^{2}$, llegan a considerarse para Zaragoza valores del $65 \%$ y para Madrid del $23 \%$ por encima de $1000 \mathrm{~W} / \mathrm{m}^{2}$, cuando para el resto de los climas este valor es bajo o nulo.

\begin{tabular}{|l|c|c|c|c|c|}
\cline { 2 - 6 } \multicolumn{1}{c|}{} & \multicolumn{5}{c|}{ RADIACIÓN MÁXIMA SOLAR DIARIA (W/m²) } \\
\cline { 2 - 6 } \multicolumn{1}{c|}{} & MUY BAJA $\leq$ & BAJA & MEDIA & ALTA & EXTREMA > \\
& 250 & $250-500$ & $500-750$ & $750-1000$ & 1000 \\
\hline \multirow{2}{*}{ D3-CTE } & $9 \%$ & $27 \%$ & $28 \%$ & $28 \%$ & $8 \%$ \\
& 32 & 99 & 101 & 103 & 30 \\
\hline \multirow{2}{*}{ D3-RITE } & $7 \%$ & $33 \%$ & $28 \%$ & $33 \%$ & $0 \%$ \\
& 24 & 119 & 101 & 121 & 0 \\
\hline \multirow{2}{*}{ ZG-RITE } & $9 \%$ & $30 \%$ & $29 \%$ & $32 \%$ & $0 \%$ \\
& 32 & 111 & 106 & 116 & 0 \\
\hline \multirow{2}{*}{ ZG-EPLUS } & $7 \%$ & $8 \%$ & $9 \%$ & $11 \%$ & $65 \%$ \\
& 24 & 29 & 32 & 41 & 237 \\
\hline
\end{tabular}

8-12 CUADRO RESUMEN DE RADIACIÓN MÁXIMA DIARIA SOBRE PLANO HORIZONTAL DISTRIBUIDA LOS RANGOS <250 W/m², ENTRE 250 y $500 \mathrm{~W} / \mathrm{m}^{2}$, ENTRE 500 y $750 \mathrm{~W} / \mathrm{m}^{2}$, ENTRE 750 y $1000 \mathrm{~W} / \mathrm{m}^{2} \mathrm{Y}>1000 \mathrm{~W} / \mathrm{m}^{2}$. (Varias fuentes y elaboración pública)

Las observación de la radiación total solar diaria indica que sus valores son muy similares a los máximos de radiación diaria.

\begin{tabular}{|l|c|c|c|c|c|}
\cline { 2 - 6 } \multicolumn{1}{c|}{} & \multicolumn{5}{c|}{ RADIACIÓN MÁXIMA SOLAR DIARIA (W/m²) } \\
\cline { 2 - 6 } \multicolumn{1}{c|}{} & MUY BAJA $\leq$ & BAJA & MEDIA & ALTA & EXTREMA \\
& 2,00 & $2,00-4,00$ & $4,00-6,00$ & $6,00-8,00$ & $>8,00$ \\
\hline \multirow{2}{*}{ D3-CTE } & $21 \%$ & $33 \%$ & $20 \%$ & $17 \%$ & $9 \%$ \\
& 78 & 119 & 74 & 61 & 33 \\
\hline \multirow{2}{*}{ D3-RITE } & $21 \%$ & $32 \%$ & $18 \%$ & $22 \%$ & $7 \%$ \\
& 77 & 117 & 65 & 80 & 25 \\
\hline \multirow{2}{*}{ ZG-RITE } & $19 \%$ & $33 \%$ & $21 \%$ & $19 \%$ & $7 \%$ \\
& 70 & 120 & 78 & 70 & 27 \\
\hline \multirow{2}{*}{ ZG-ePLUS } & $10 \%$ & $13 \%$ & $15 \%$ & $13 \%$ & $49 \%$ \\
& 38 & 47 & 53 & 47 & 180 \\
\hline
\end{tabular}

8-13 CUADRO RESUMEN DE RADIACIÓN TOTAL SOLAR DIARIA SOBRE PLANO HORIZONTAL DISTRIBUIDA LOS RANGOS $<2,00 \mathrm{KW} / \mathrm{m}^{2}$, ENTRE 2,00 y 4,00 $\mathrm{KW} / \mathrm{m}^{2}$, ENTRE 4,00 y $6,00 \mathrm{KW} / \mathrm{m}^{2}$, ENTRE 6,00 y $8,00 \mathrm{KW} / \mathrm{m}^{2} \mathrm{Y}>8,00 \mathrm{KW} / \mathrm{m}^{2}$. (Varias fuentes y elaboración propia) 


\subsubsection{DIRECCIÓN Y VELOCIDAD DEL VIENTO}

La velocidad del viento se mantiene en valores moderados con una media de $2,8 \mathrm{~m} / \mathrm{s}$ y un máximo de $14,9 \mathrm{~m} / \mathrm{s}$, sin una clara distribución en función del periodo del año ya que se observan periodos con menores intensidades de varios días de baja velocidad repartidos a lo largo del año con algunos días aislados, también repartidos a lo largo del año, con las velocidades más altas. Parece, sin embargo que las velocidades son ligeramente mayores en marzo y ligeramente menores en agosto.

La dirección del viento se ha marcado por horas en los correspondientes puntos cardenales observándose mayor frecuencia en las direcciones $S$ y NW y una menor frecuencia en las direcciones N, NE y E.

La velocidad media de las máximas diarias es de $6,1 \mathrm{~m} / \mathrm{s}$ y la velocidad mínima diaria es de 0,4 m/s.

Muchas de las series climáticas carecen de información sobre la velocidad del viento y su dirección, por lo que en su defecto se adjudican valores convenidos.

Por ejemplo la base de datos para todas las capitales de provincia Españolas (Spanish Weather for Energy Calculations (SWEC), generada sintéticamente usando Clomid, adjudica velocidades del viento constantes de $6,7 \mathrm{~m} / \mathrm{s}$. procedente del norte (0).

Por su parte, los climas de referencia generados con CLIMED 1.3 a partir de los datos climáticos del Instituto Nacional de Meteorología para cada una de las capitales de provincia, Ceuta y Melilla, no disponen de datos fiables de la dirección del viento por lo que se deja como procedente del norte (0) (IDAE, 2015, pág. 7), pudiéndose considerar un valor de velocidad media constante de 2,8 m/s (FOMENTO,2013. pág. 2).

En las distintas secuencias de datos se pueden observar velocidades entre 2,00 y $2,6 \mathrm{~m} / \mathrm{s}$, para el denominado como D3RITE y entre $4,21 \mathrm{~m} / \mathrm{s}$ y $5,8 \mathrm{~m} / \mathrm{s}$ en el denominado ZG-RITE.

Sólo es posible, por tanto, hacer una comparación de los diferentes climas de referencia, en términos muy limitados.

\begin{tabular}{|c|c|c|c|c|c|}
\hline & \multicolumn{5}{|c|}{ VELOCIDAD DEL VIENTO POR RANGOS $(\mathrm{m} / \mathrm{s})$} \\
\hline & $\begin{array}{c}\text { CALMAS } \leq \\
1,00\end{array}$ & $\begin{array}{c}\text { BAJA } \\
2,00-4,00\end{array}$ & $\begin{array}{c}\text { MODERADA } \\
4,00-6,00\end{array}$ & $\begin{array}{c}\text { ALTA } 6,00 \\
-10,00\end{array}$ & $\begin{array}{c}\text { EXTREMA } \\
>10,00\end{array}$ \\
\hline \multirow{2}{*}{ D3-CTE } & $23 \%$ & $52 \%$ & $15 \%$ & $8 \%$ & $1 \%$ \\
\hline & 2018 & 4574 & 1356 & 710 & 102 \\
\hline \multirow{2}{*}{ D3-RITE } & $0 \%$ & $100 \%$ & $0 \%$ & $0 \%$ & $0 \%$ \\
\hline & 0 & 8760 & 0 & 0 & 0 \\
\hline \multirow{2}{*}{ ZG-RITE } & $0 \%$ & $0 \%$ & $100 \%$ & $0 \%$ & $0 \%$ \\
\hline & 0 & 0 & 8760 & 0 & 0 \\
\hline \multirow{2}{*}{ ZG-ePLUS } & $0 \%$ & $0 \%$ & $0 \%$ & $100 \%$ & $0 \%$ \\
\hline & 0 & 0 & 0 & 8760 & 0 \\
\hline
\end{tabular}

8-14 CUADRO RESUMEN DE LA VELOCIDAD DEL VIENTO DISTRIBUIDA POR RANGOS (Varias fuentes y elaboración propia) 


\begin{tabular}{|c|c|c|cr|}
\cline { 2 - 5 } \multicolumn{1}{c|}{} & \multicolumn{3}{c|}{ VELOCIDAD DEL VIENTO } \\
\cline { 2 - 5 } \multicolumn{1}{c|}{} & MAX & MED & \multicolumn{2}{c|}{ № CALMAS } \\
\hline D3-CTE & 14,90 & 2,80 & 193 & 0,02 \\
\hline D3-RITE & 2,60 & 2,30 & 0,00 & 0,00 \\
\hline ZG-RITE & 5,80 & 5,00 & 0,00 & 0,00 \\
\hline ZG-ePLUS & 6,70 & 6,70 & 0,00 & 0,00 \\
\hline
\end{tabular}

8-15 CUADRO CON ALGUNOS PARÁMETROS DE VELOCIDAD DEL VIENTO COMPARADOS (Varias fuentes y elaboración propia) 


\subsection{CLIMA LOCAL REGISTRADO}

La zona de estudio se localiza en Zaragoza, por lo que se hace un tratamiento de los datos más significativos pos su repercusión en la edificación.

\subsubsection{SECUENCIAS CLIMÁTICAS ZARAGOZA (1973-2012)}

La influencia conjunta de estos parámetros del clima será la que interactúe con el edificio, aunque cada uno de los factores lo hace con distinta intensidad y en distintos aspectos, por ejemplo la presencia de altas velocidades del viento maximiza los intercambios por convección y las infiltraciones en el edificio que, en el caso de Zaragoza, es notablemente activa.

Las nieblas, días de lluvia y los meteoros en general afectan, en función de la organización geométrica, a la capacidad de las envolventes para modular el balance térmico del edificio.

Los factores que se incluyen en la comparativa son los recogidos en el cuadro siguiente:

\begin{tabular}{|l|}
\hline Temperatura media anual \\
\hline Temperatura máxima media anual \\
\hline Temperatura mínima media anual \\
\hline Precipitación total anual de lluvia y/o nieve derretida $(\mathrm{mm})$ \\
\hline Velocidad media anual del viento ( $\mathrm{Km} / \mathrm{h})$ \\
\hline Total días con lluvia durante el año \\
\hline Total días que nevó durante el año \\
\hline Total días con tormenta durante el año \\
\hline Total días con niebla durante el año \\
\hline Total días con tornados o nubes de embudo durante el año \\
\hline Total días con granizo durante el año \\
\hline
\end{tabular}

De la determinación de las temperaturas medias correspondientes a cada década del periodo y de la comparación de sus valores se observa cómo cuanto más se aleja la década del momento presente más diferentes son sus valores.

\subsubsection{SECUENCIAS DECENALES (2005-2014)}

El análisis independiente de los valores promedio, máximos y mínimos, permite percibir las diferencias entre cada año y las condiciones medias y con ello las desviaciones y la variabilidad anual con respecto a los valores medios.

Por ejemplo, en el gráfico que aparece a continuación se indica la magnitud y la distribución temporal de las desviaciones con respecto a los valores medios y se puede observar la diferencia entre las temperaturas promedio del año 2014 y las temperaturas promedio de la década 2005-2014. Así, quedan reflejadas en color morado el mayor número de superaciones y en verde las 
deflaciones, lo que corresponde, como ya se ha visto, con un año, el 2014, comparativamente más cálido en su conjunto.

También se observa cómo estas superaciones tienen frecuentes aproximaciones a los valores medios, de forma que las secuencias más cálidas sólo son de varios días, superando las dos semanas en algún periodo de abril, septiembre, octubre y noviembre. Por otra parte sólo se registran temperaturas inferiores al promedio puntualmente, salvo un periodo algo mayor en mayo.

Las oscilaciones térmicas diarias son, como cabía esperar, mucho más irregulares que los valores promedio.

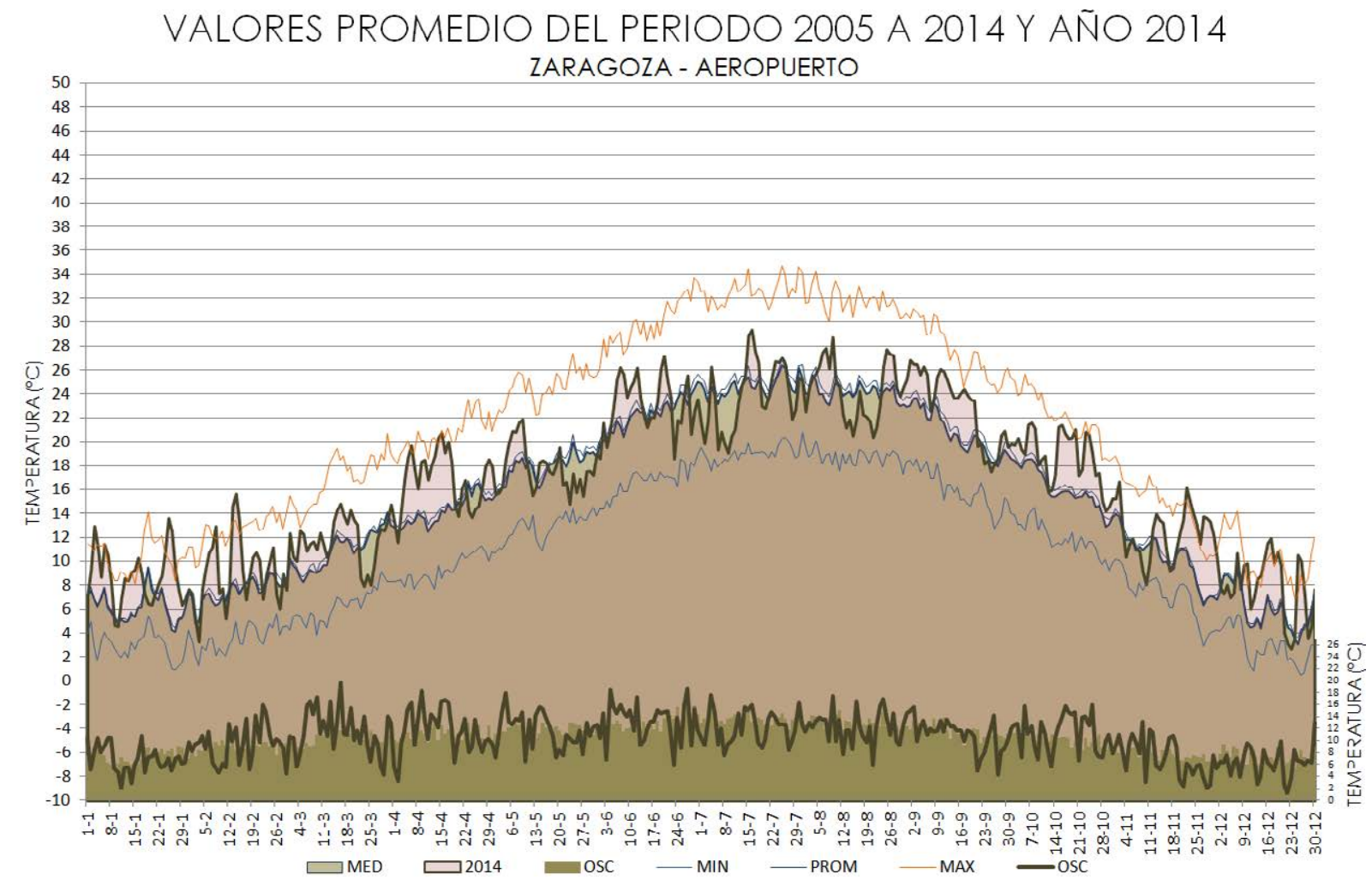

8-16 VALORES PROMEDIOS DIARIOS DURANTE EL AÑO 2014, COMPARADO CON LOS

\footnotetext{
VALORES PROMEDIO DE LA DÉCADA 2015-2014 EN ZARAGOZA AEROPUERTO (AEMET y elaboración propia)
} 
El análisis detallado de los periodos en que la temperatura es superior a $26^{\circ} \mathrm{C}$ es, como promedio, un $11,7 \%$ del año y oscila entre el $9,5 \%$ y el $13,7 \%$, es decir que oscila un $4,22 \%$ (370 horas) del año o lo que sería igual a un $36,2 \%$ del valor promedio del periodo en que la temperatura es mayor de $26^{\circ} \mathrm{C}$ en la década 2005-2014. También puede concluirse que el periodo en que la temperatura es mayor de $26^{\circ} \mathrm{C}$ durante la década $2005-2014$ es de un $11,56 \%$ del año, $\pm 2,11 \%$.

\begin{tabular}{|c|c|c|c|c|c|c|c|}
\hline \multicolumn{6}{|c|}{8760 HORAS AÑO } & DÉCADA 2005-2014 & \multirow[b]{2}{*}{$13,68 \% \operatorname{MAX}$} \\
\hline \multirow{4}{*}{\multicolumn{2}{|c|}{$\begin{array}{l}u \\
\frac{1}{0} \\
\frac{1}{0}\end{array}$}} & 1198 & MAX & $13,68 \%$ & OSCILACIÓN & HORAS $9 \mathrm{C}>26 \circ \mathrm{C}$ & \\
\hline & & 1023 & MEDIA & $11,68 \%$ & $4,22 \%$ & $1013 \pm 2,11 \%$ & $11,56 \%$ MEDIA \\
\hline & & 828 & MIN & $9,45 \%$ & \multicolumn{2}{|c|}{370 HORAS } & $9,45 \% \mathrm{MIN}$ \\
\hline & & & & & $36,16 \%$ & \multicolumn{2}{|c|}{ PORCENTAJE SOBRE EL PROMEDIO } \\
\hline \multirow{4}{*}{$\begin{array}{l}\underset{0}{0} \\
\underset{\wedge}{N}\end{array}$} & \multirow{4}{*}{ 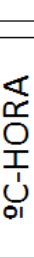 } & & & & $38,88 \%$ & \multicolumn{2}{|c|}{ PORCENTAJE SOBRE EL PROMEDIO } \\
\hline & & 36582 & MAX & $118,86 \%$ & \multicolumn{2}{|c|}{11968 ㅇ-C-HORA } & \multirow{4}{*}{$\begin{array}{l}\text { 118,86\% MAX } \\
\text { 99,42\% MEDIA } \\
\text { 79,97\% MIN }\end{array}$} \\
\hline & & 30778 & MEDIA & $100,00 \%$ & $38,88 \%$ & $30598 \pm 5984(19,44 \%)$ & \\
\hline & & 24614 & MIN & $79,97 \%$ & OSCILACIÓN & 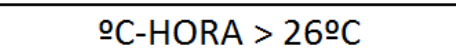 & \\
\hline & & & & & & DÉCADA 2005-2014 & \\
\hline
\end{tabular}

8-17 CUADRO ANALÍTICO DE ${ }^{\circ} \mathrm{C}-$ HORA Y PERIODO EN HORAS EN QUE LA TEMPERATURA ES MAYOR DE $26^{\circ} \mathrm{C}$ EN LA DÉCADA 2004-2014 EN ZARAGOZA-AEROPUERTO (AEMET y elaboración propia)

Un análisis similar de los grados-hora que superan una temperatura de $26^{\circ} \mathrm{C}$, indica una oscilación similar pudiéndose afirmar que se produce una superación del umbral en 30.598 horas, $\pm 19,44 \%$, o, lo que es lo mismo, casi 6.000 grados-hora.

\section{${ }^{\circ} \mathrm{C}-\mathrm{HORA}>26^{\circ} \mathrm{C}$ DESDE 2004-2014 EN ZARAGOZA}

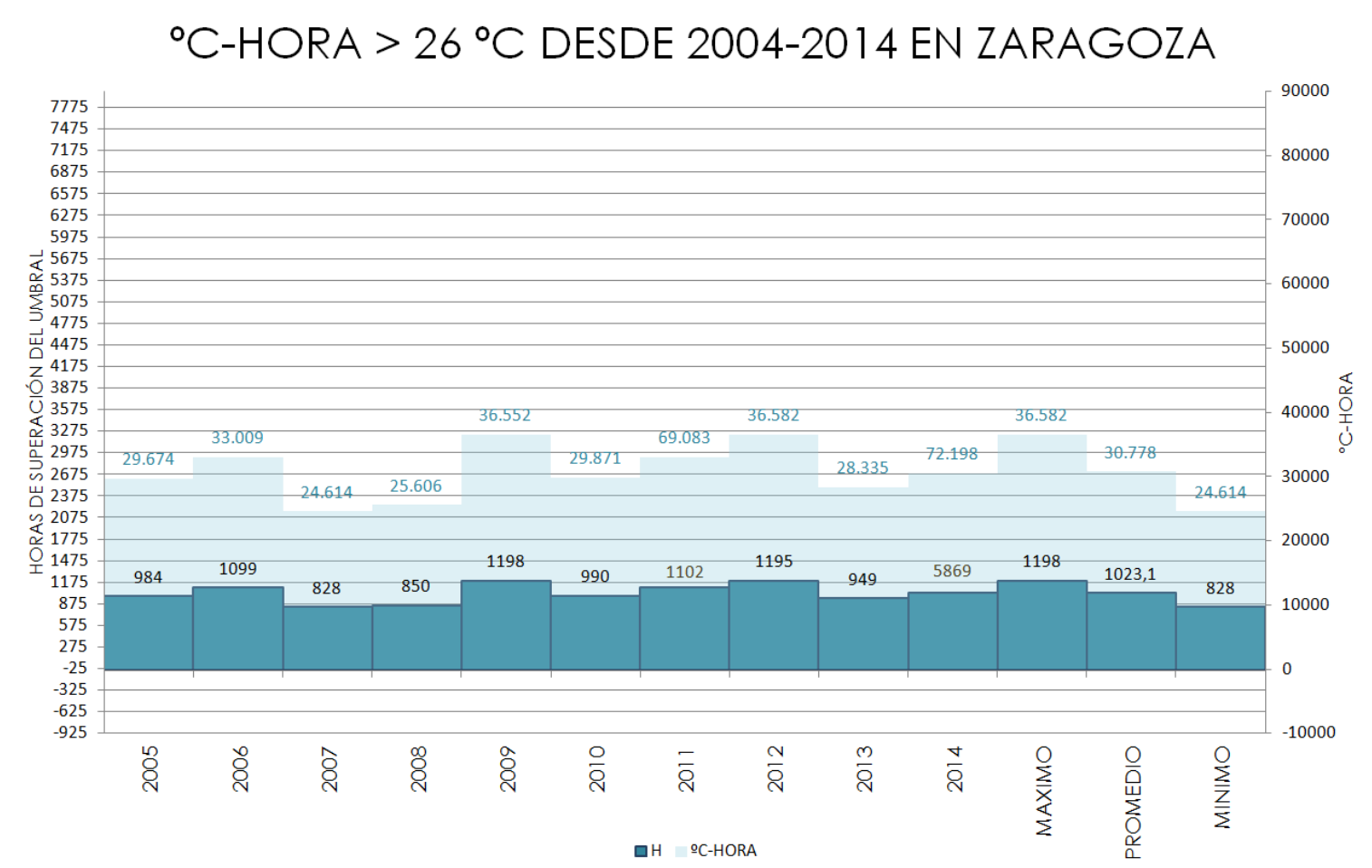

\footnotetext{
8-18 GRADOS-HORA MAYORES DE 26 C EN LA DÉCADA 2004-2014 EN ZARAGOZA AEROPUERTO (AEMET Y ELABORACIÓN PROPIA)
} 
Si el análisis se realiza en los distintos rangos de temperatura considerados permitirá completar una imagen cuantitativa de las necesidades térmicas del edificio, tanto de disipación como de aportación de energía.

\section{${ }^{\circ} \mathrm{C}-\mathrm{HORA}>22^{\circ} \mathrm{C}$ DESDE 2004-2014 EN ZARAGOZA}

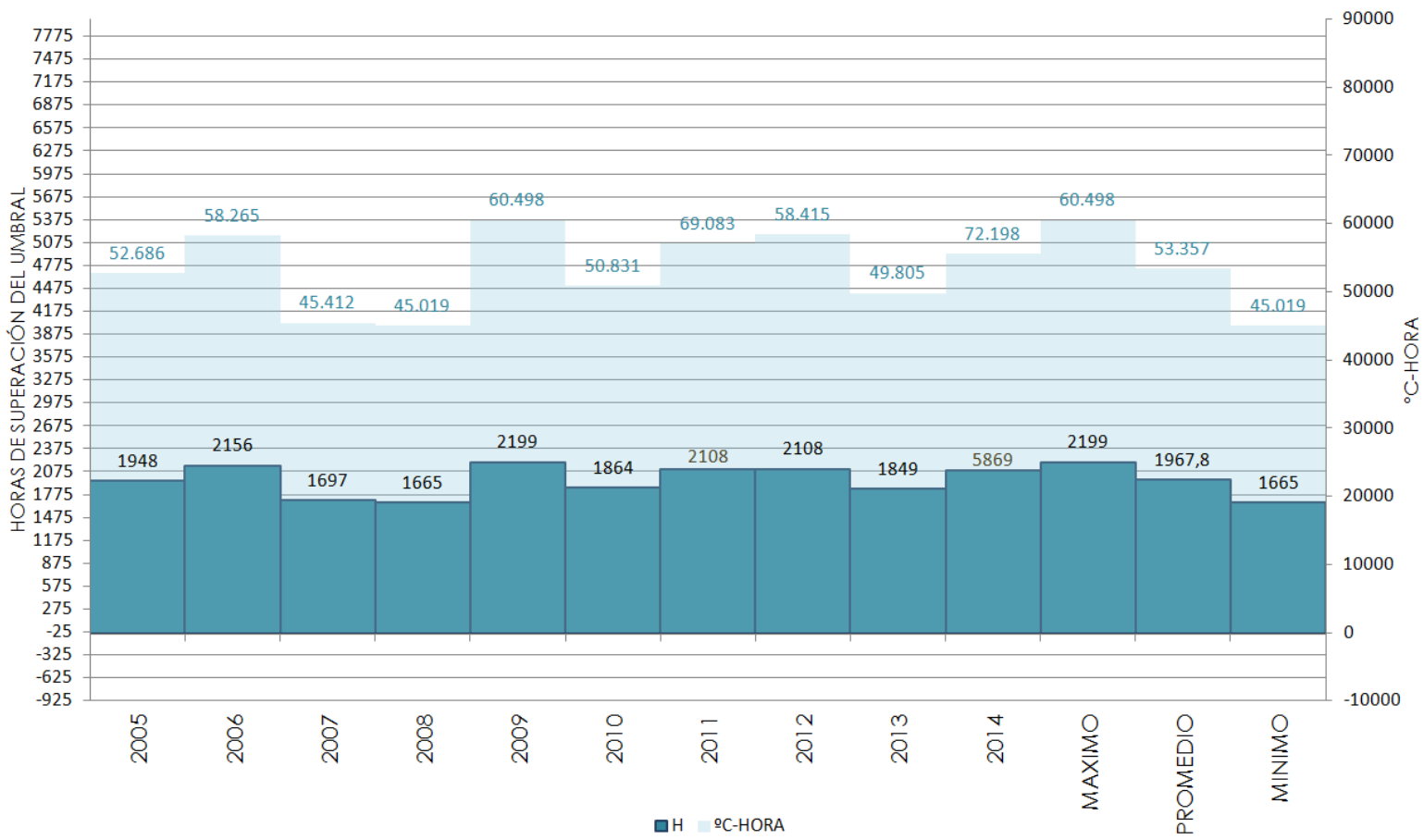

8-19 GRADOS-HORA MAYORES DE $22^{\circ} \mathrm{C}$ EN LA DÉCADA 2004-2014 EN ZARAGOZA AEROPUERTO (AEMET y elaboración propia)

\section{${ }^{\circ} \mathrm{C}-\mathrm{HORA}>20^{\circ} \mathrm{C}$ DESDE 2004-2014 EN ZARAGOZA}

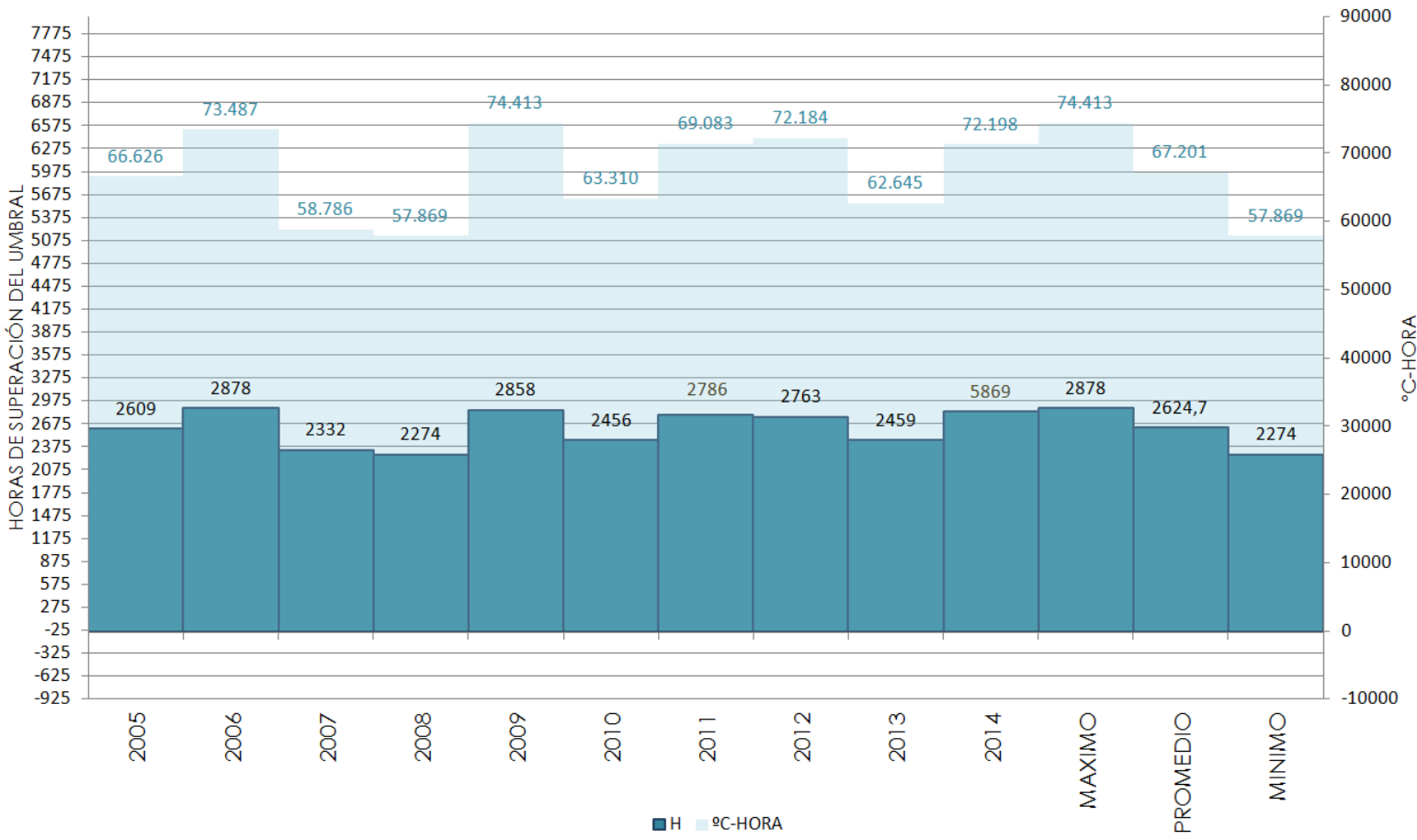

8-20 GRADOS-HORA MAYORES DE 20C EN LA DÉCADA 2004-2014 EN ZARAGOZA AEROPUERTO (AEMET y elaboración propia) 


\section{${ }^{\circ} \mathrm{C}-\mathrm{HORA}<20^{\circ} \mathrm{C}$ DESDE 2004-2014 EN ZARAGOZA}

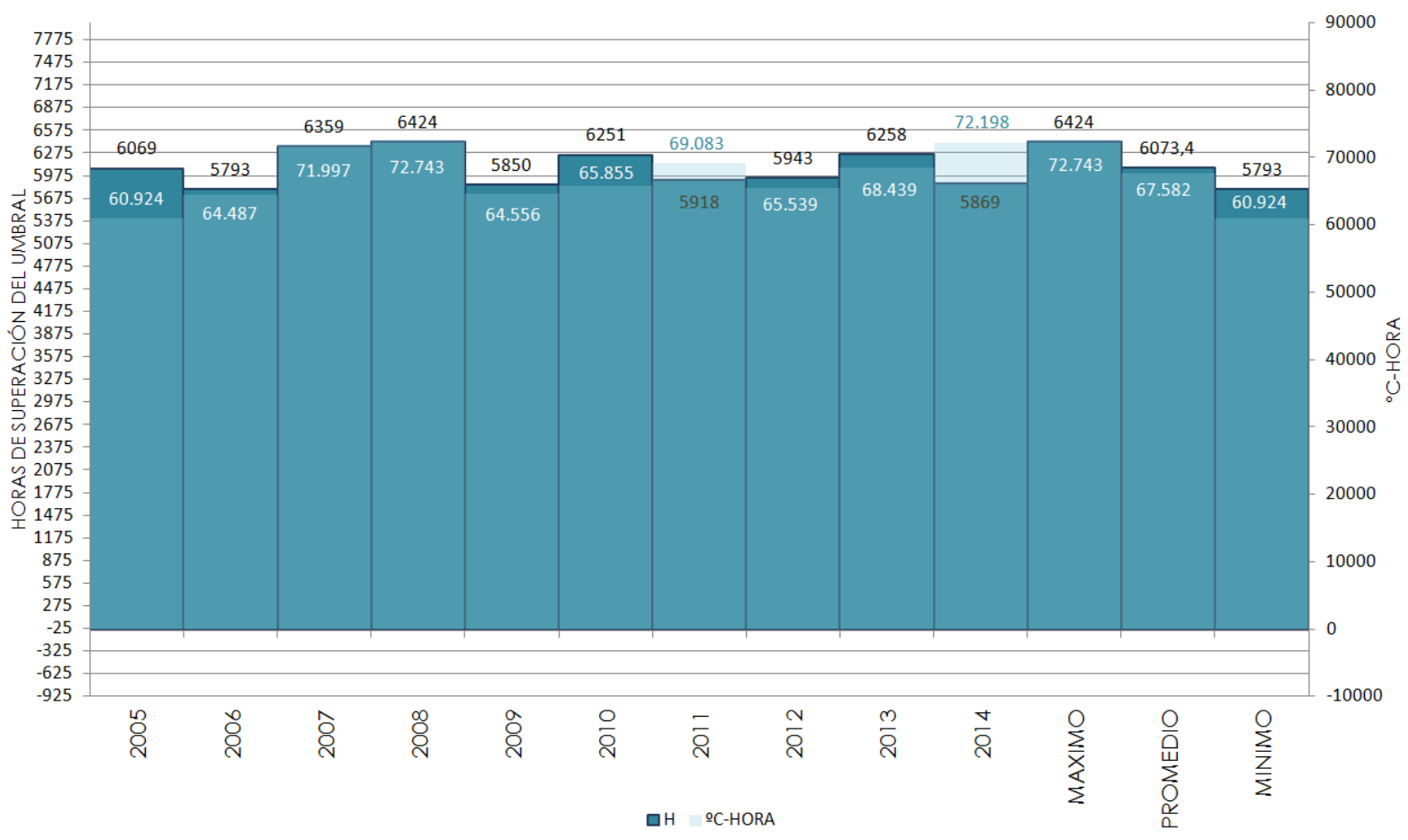

8-21 GRADOS-HORA MENORES DE 20C EN LA DÉCADA 2004-2014 EN ZARAGOZA AEROPUERTO (AEMET y elaboración propia) 
${ }^{\circ} \mathrm{C}-H O R A<18{ }^{\circ} \mathrm{C}$ DESDE 2004-2014 EN ZARAGOZA

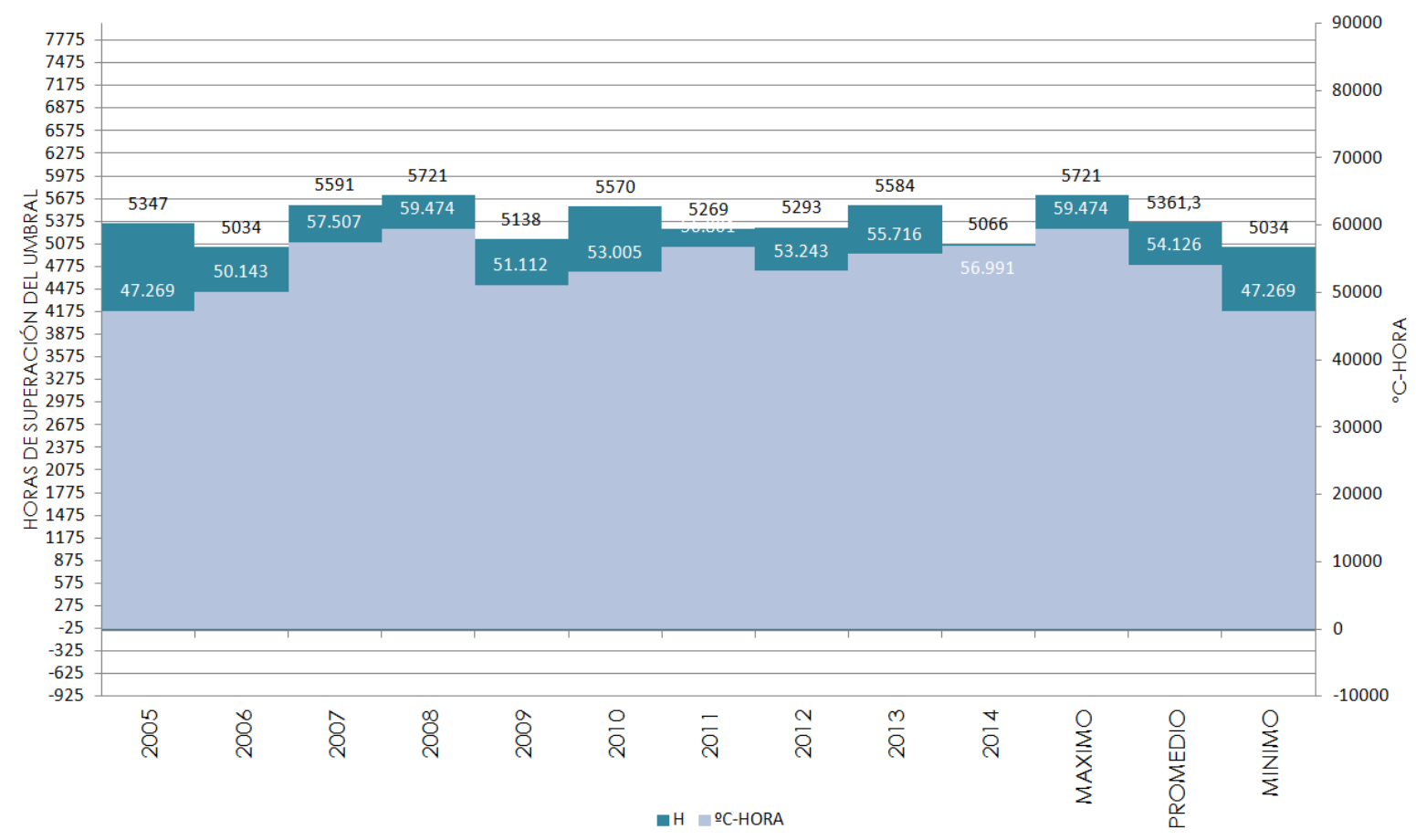

8-22 GRADOS-HORA MENORES DE $18^{\circ} \mathrm{C}$ EN LA DÉCADA 2004-2014 EN ZARAGOZA

AEROPUERTO (AEMET y elaboración propia) 
${ }^{\circ} \mathrm{C}-\mathrm{HORA}<16^{\circ} \mathrm{C}$ DESDE 2004-2014 EN ZARAGOZA

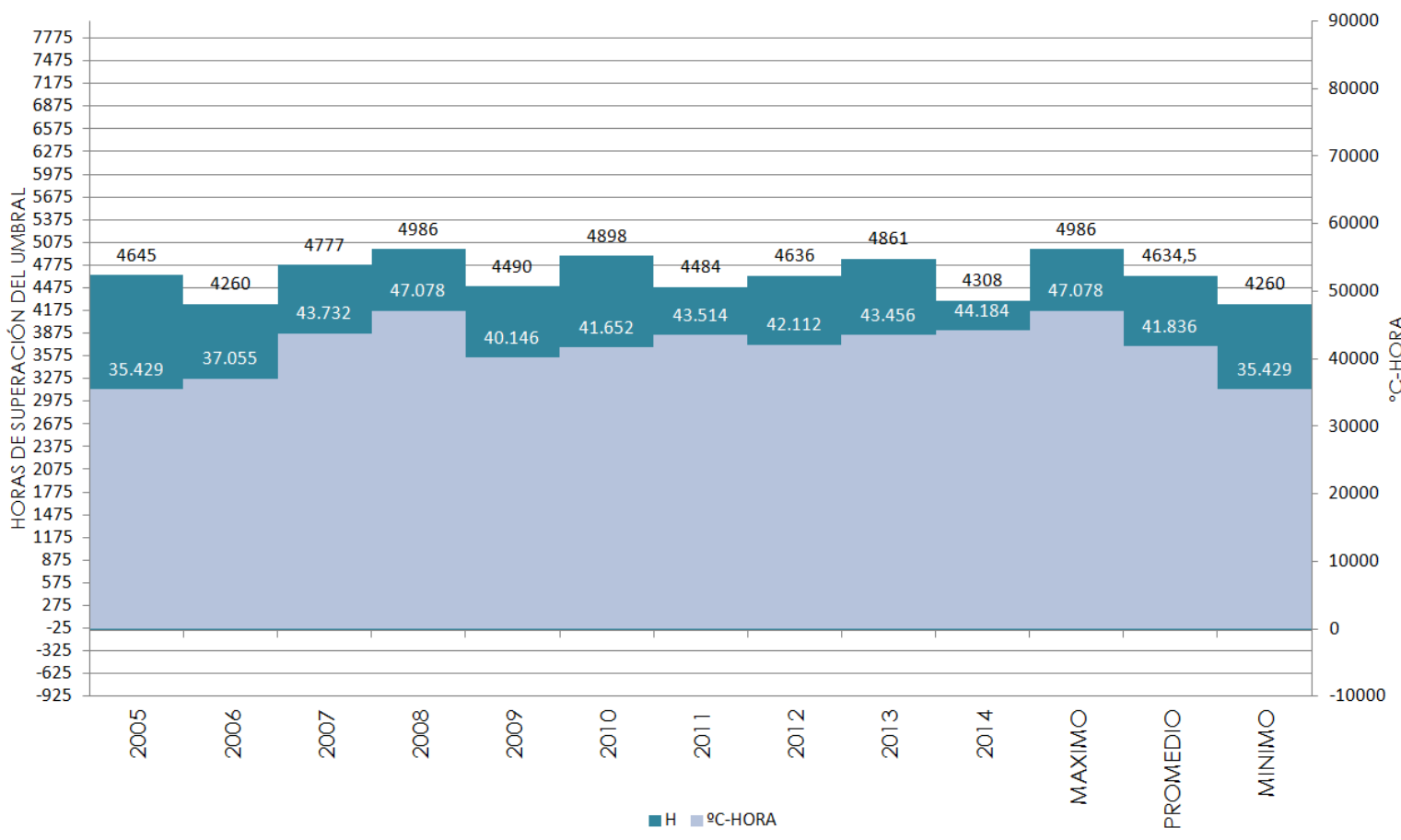

8-23 GRADOS-HORA MENORES DE $16^{\circ} \mathrm{C}$ EN LA DÉCADA 2004-2014 EN ZARAGOZA AEROPUERTO (AEMET y elaboración propia) 


\section{${ }^{\circ} \mathrm{C}-\mathrm{HORA}<14{ }^{\circ} \mathrm{C}$ DESDE 2004-2014 EN ZARAGOZA}

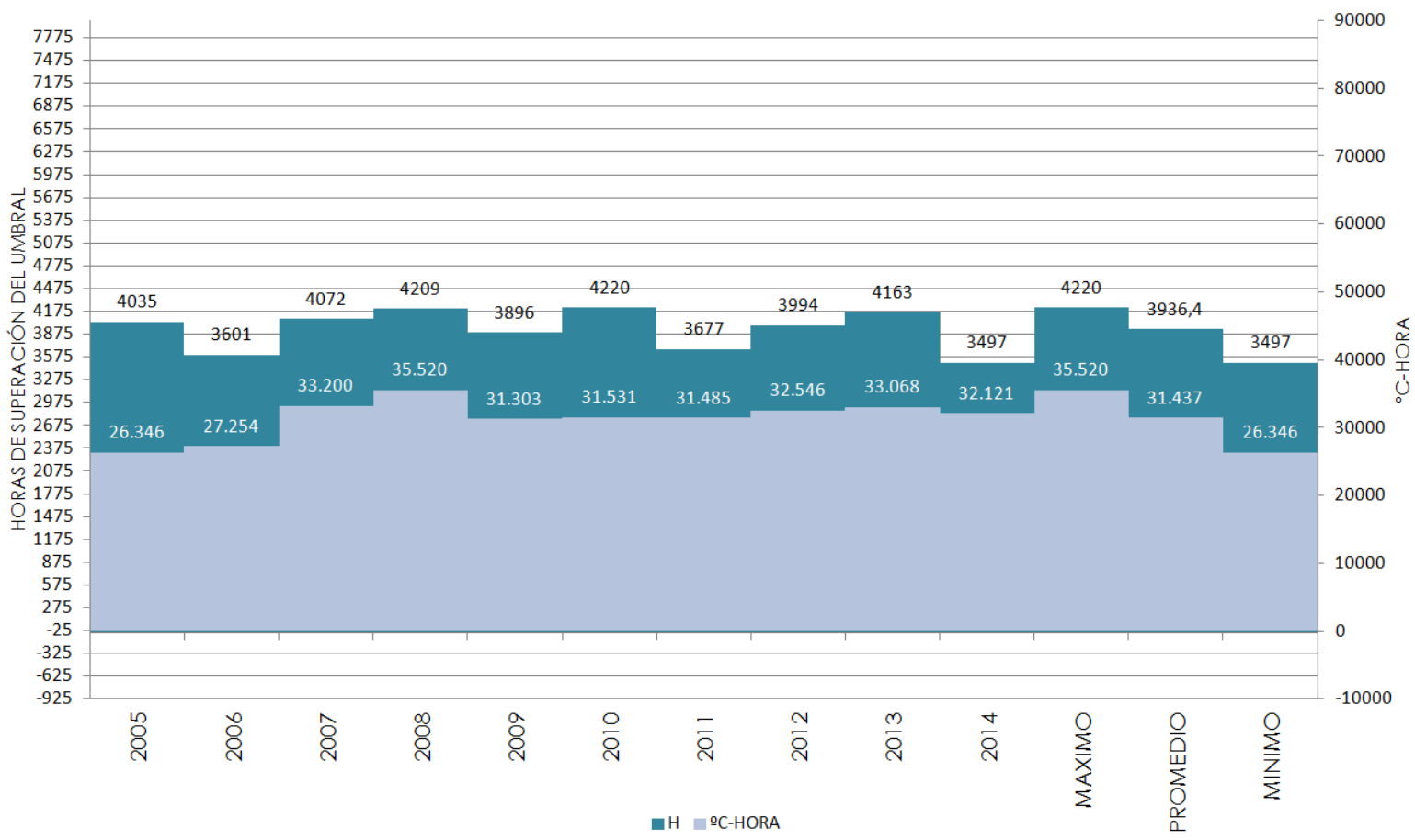

8-24 GRADOS-HORA MENORES DE 14 C EN LA DÉCADA 2004-2014 EN ZARAGOZA AEROPUERTO (AEMET y elaboración propia) 


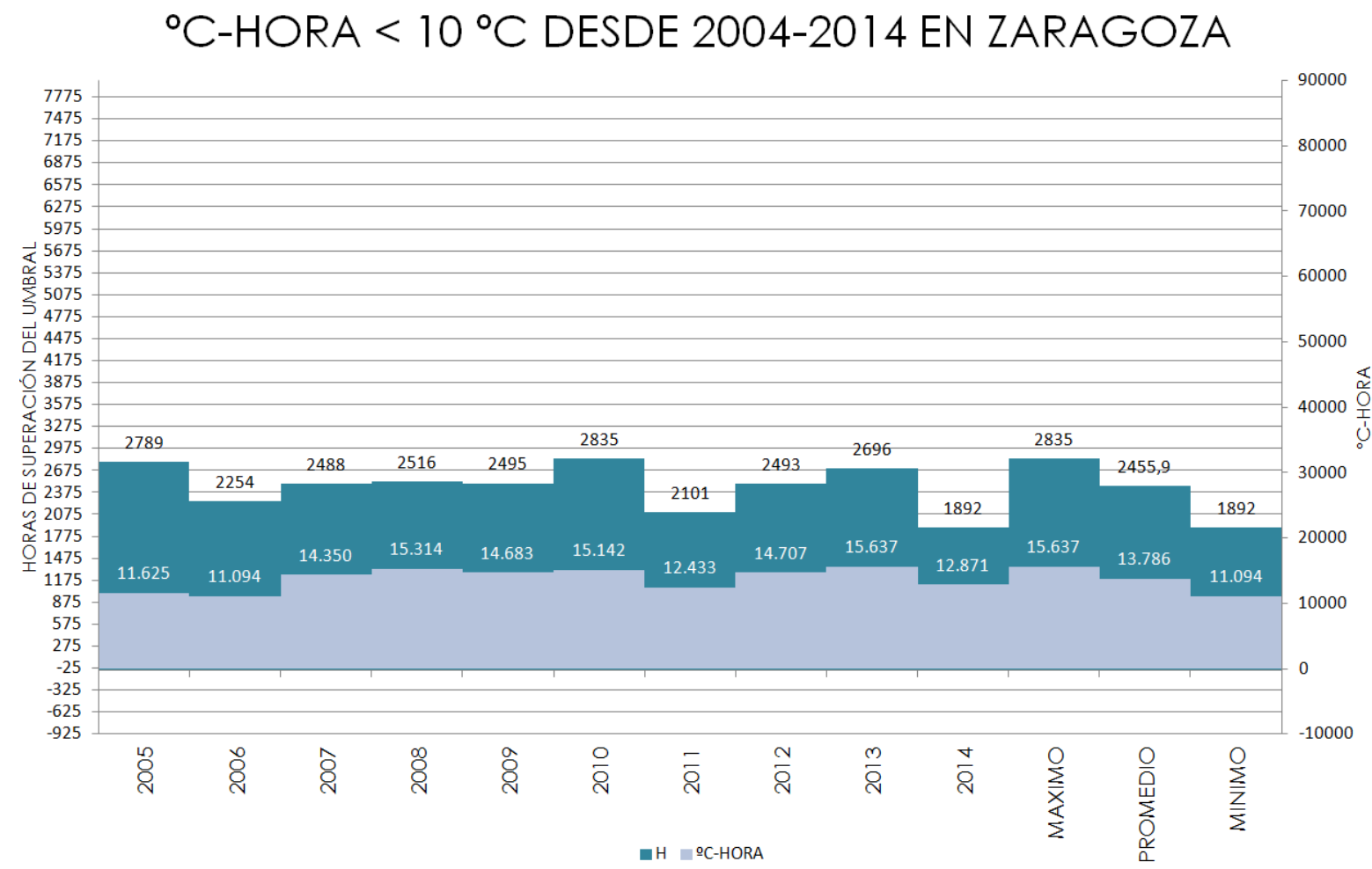

8-25 GRADOS-HORA MENORES DE $10^{\circ} \mathrm{C}$ EN LA DÉCADA 2004-2014 EN ZARAGOZA AEROPUERTO (AEMET y elaboración propia) 
${ }^{\circ} \mathrm{C}-\mathrm{HORA}<0,0^{\circ} \mathrm{C}$ DESDE 2004-2014 EN ZARAGOZA

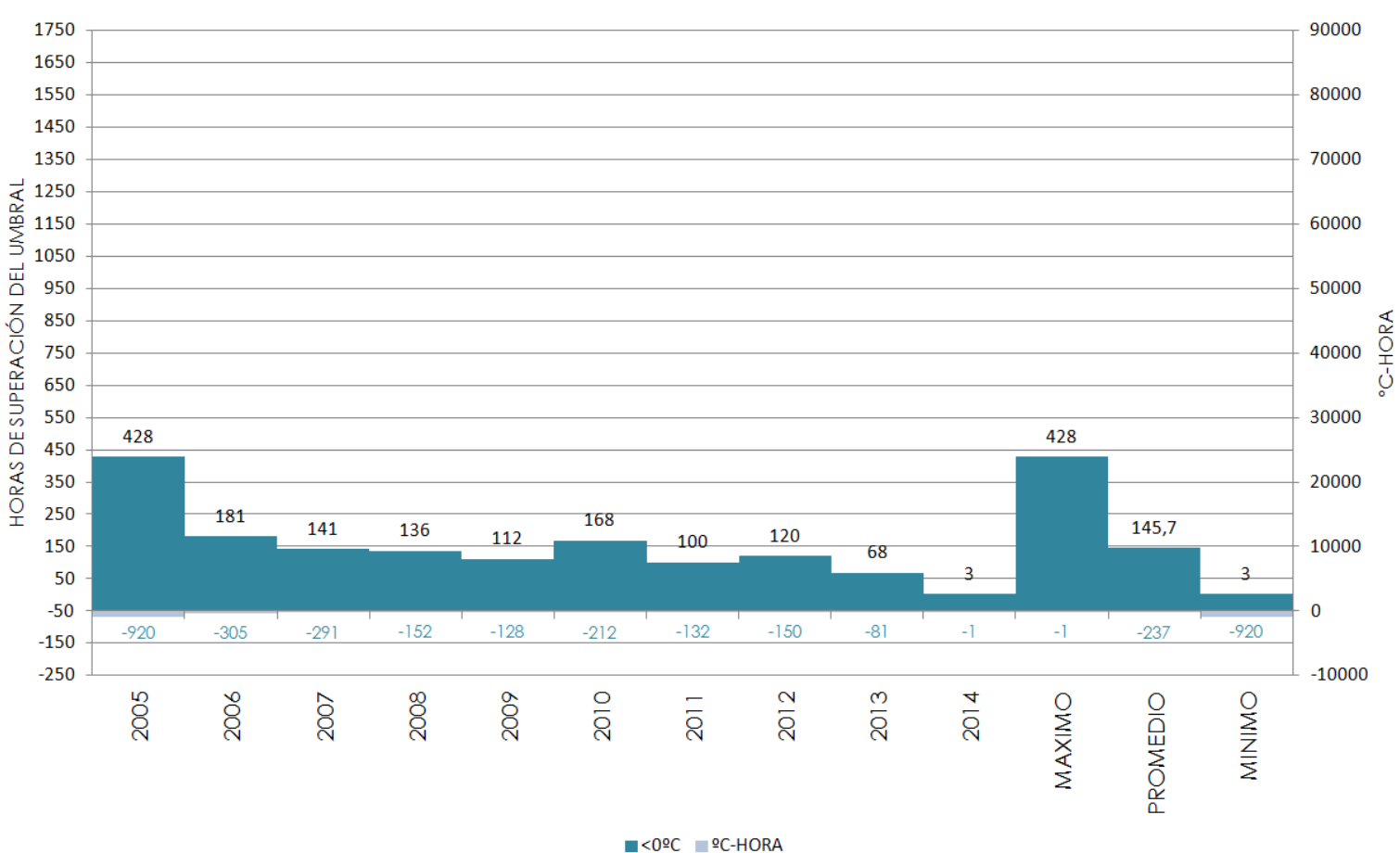

8-26 GRADOS-HORA MENORES DE $10^{\circ} \mathrm{C}$ EN LA DÉCADA 2004-2014 EN ZARAGOZA AEROPUERTO (AEMET y elaboración propia)

Una comparación similar se realiza para un rango comprendido entre $16^{\circ} \mathrm{C}$ y $26^{\circ} \mathrm{C}$, reflejando los periodos en horas y los gradoshora en que se supera el umbral máximo o no se alcanza el valor mínimo. 
Se puede observar que se trata de secuencias asimétricas, siendo mucho mayores los periodos y los grados-hora en los que no se alcanza la temperatura de $16^{\circ} \mathrm{C}$ que aquéllos en los que se superan los $26^{\circ} \mathrm{C}$, confirmando que hay más periodos fríos que cálidos y que previsiblemente es más necesaria la aportación de energía que su disipación y permitiendo observar la variación de estos valores en el tiempo, en nuestro caso en una década, y su desviación con respecto a los valores promedio, tanto en tiempo como en grados-hora.

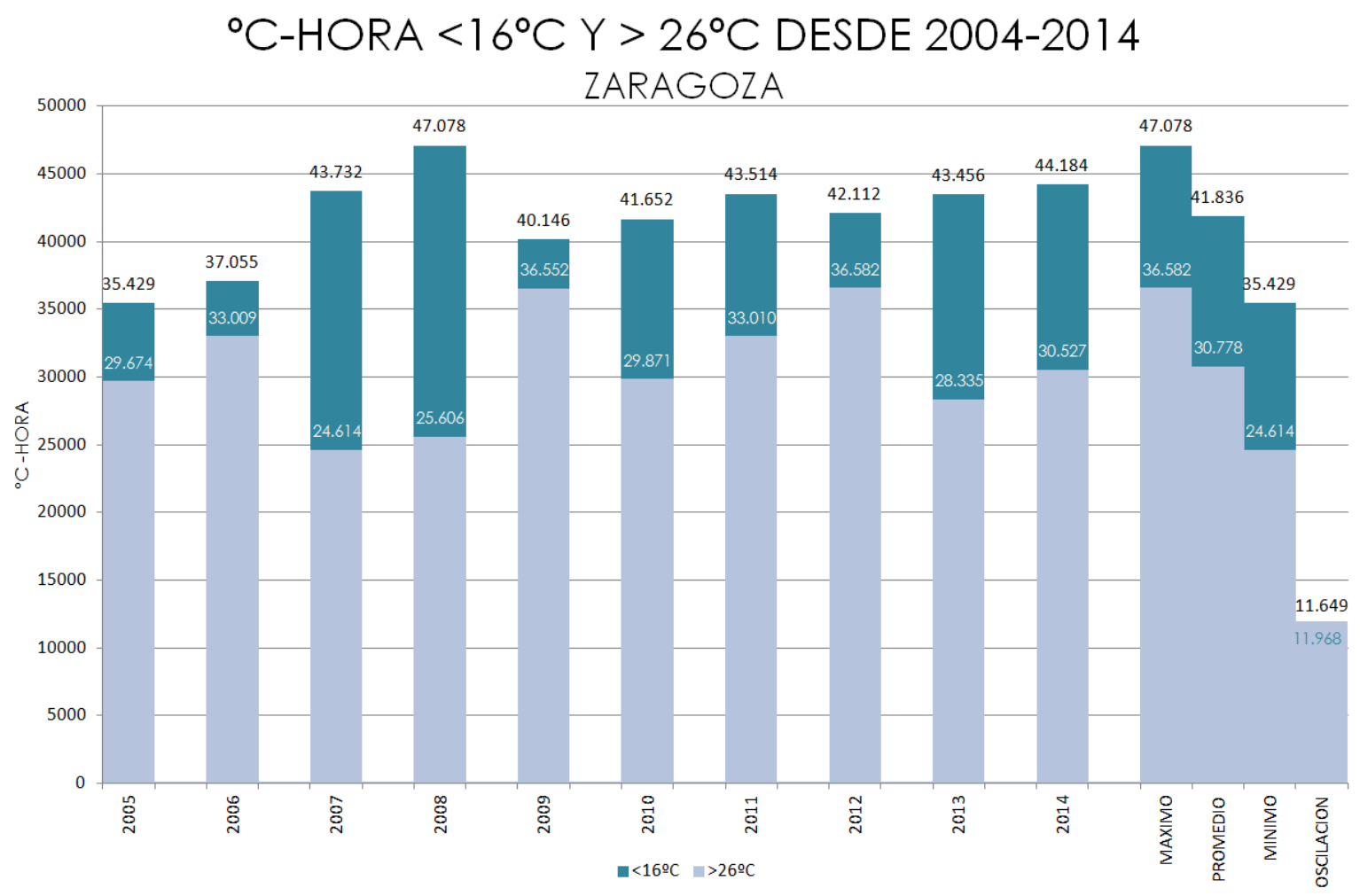

8-27 GRADOS-HORA MENORES DE $16^{\circ} \mathrm{C}$ Y MAYORES DE $26^{\circ} \mathrm{C}$ EN LA DÉCADA 2004-

2014 EN ZARAGOZA AEROPUERTO (AEMET y elaboración propia) 
HORAS $<16^{\circ} \mathrm{C} Y>26^{\circ} \mathrm{C}$ DESDE 2004-2014 ZARAGOZA

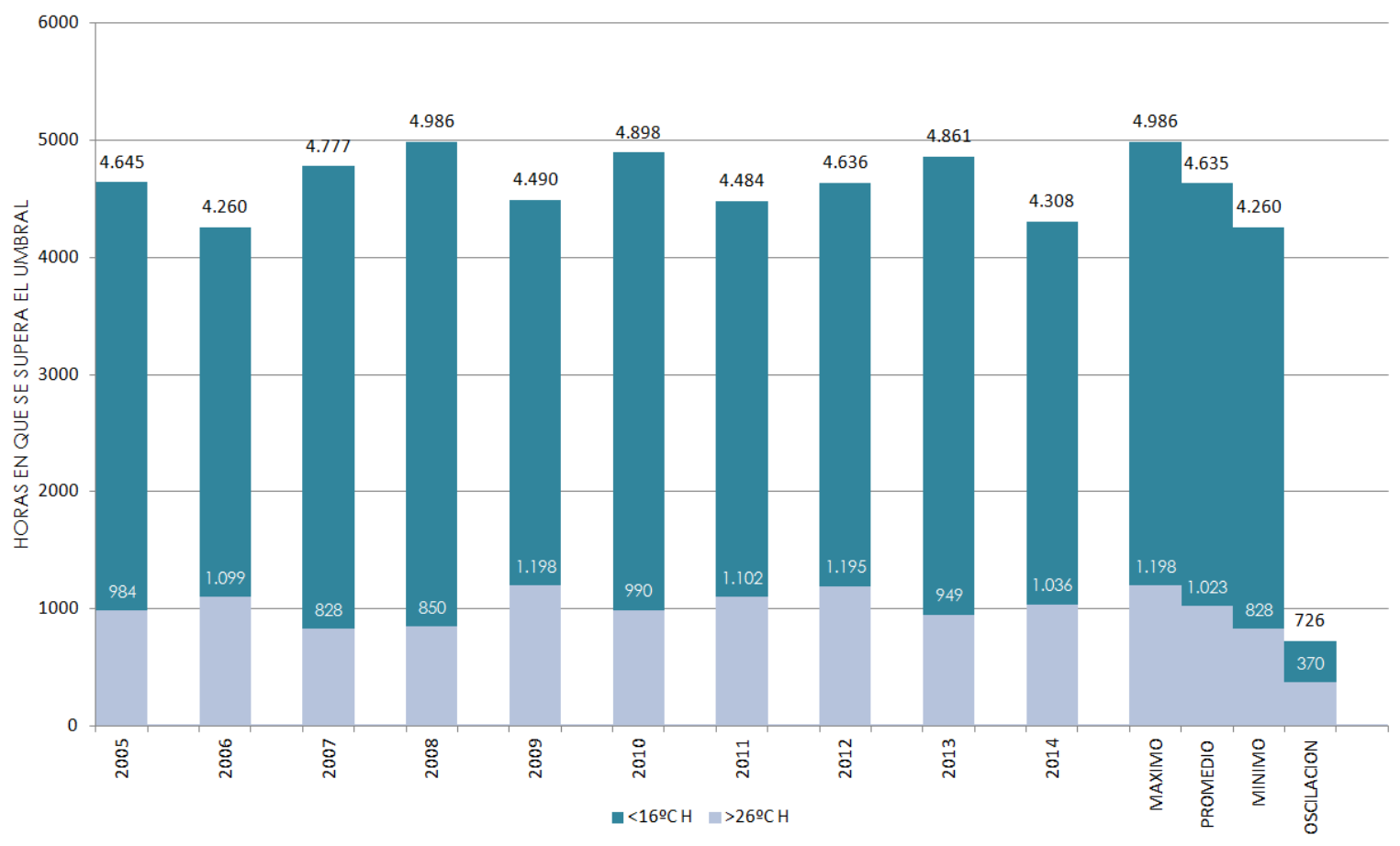

8-28 HORAS CON TEMPERATURAS MENORES DE $16^{\circ} \mathrm{C}$ Y MAYORES DE $26^{\circ} \mathrm{C}$ EN LA DÉCADA 2004-2014 EN ZARAGOZA AEROPUERTO (AEMET y elaboración propia) 
Un análisis de la variabilidad de estas acumulaciones de gradoshora y del periodo temporal en que se producen ofrece una imagen del clima aplicada a su repercusión en el edificio y en sus cualidades termodinámicas. Para definirla se confeccionan tablas que permitan la visión unitaria de todos los parámetros en sus valores absolutos y porcentuales con respecto al promedio durante la década, tal como reflejan los cuadros numéricos que se reproducen a continuación.
VER ANEXOS O6 Y 07 REGISTROS EN ESTACIONES METEOROLÓGICAS DE ZARAGOZA 1 y 2

\begin{tabular}{|l|l|l|l|l|l|l|l|l|l|l|l|}
\hline 24 HORAS & 2005 & 2006 & 2007 & 2008 & 2009 & 2010 & 2011 & 2012 & 2013 & 2014 & PROMEDIO \\
\hline
\end{tabular}

\begin{tabular}{|c|c|c|c|c|c|c|c|c|c|c|c|c|}
\hline \multirow{4}{*}{$\angle 0^{\circ} \mathrm{C}$} & \multirow{2}{*}{ H } & 428 & 181 & 141 & 136 & 112 & 168 & 100 & 120 & 68 & 3 & \multirow{2}{*}{146} \\
\hline & & $193.75 \%$ & $24,23 \%$ & $-3.23 \%$ & $-6.66 \%$ & $-23.13 \%$ & $15.31 \%$ & \begin{tabular}{|l|} 
\\
$-31,37 \%$
\end{tabular} & $-17.64 \%$ & $-53,33 \%$ & $-97,94 \%$ & \\
\hline & \multirow{2}{*}{${ }^{\circ} \mathrm{C}-\mathrm{HORA}$} & -920 & -305 & 291 & -152 & \begin{tabular}{|l|}
-128 \\
\end{tabular} & \begin{tabular}{|l|}
-212 \\
\end{tabular} & \begin{tabular}{|l|}
-132 \\
\end{tabular} & -150 & -81 & $\begin{array}{l}-1 \\
\end{array}$ & \multirow{2}{*}{-237} \\
\hline & & $288,06 \%$ & 28,6256 & $22,55 \%$ & $-35,92 \%$ & $-46,00 \%$ & $-10,78 \%$ & $-44,40 \%$ & $-36,55 \%$ & $-66,00 \%$ & $-99,58 \%$ & \\
\hline \multirow{4}{*}{$<10^{\circ} \mathrm{C}$} & \multirow{2}{*}{$\mathrm{H}$} & 2.789 & 2.254 & 2.488 & 2.516 & 2.495 & 2.835 & 2.101 & 2.493 & 2.696 & 1.892 & \multirow{2}{*}{2.456} \\
\hline & & $13,56 \%$ & $-8.22 \%$ & $1.31 \%$ & $2.45 \%$ & $1.59 \%$ & $15,44 \%$ & $-14,45 \%$ & $1,51 \%$ & $9.78 \%$ & $-22,96 \%$ & \\
\hline & \multirow{2}{*}{${ }^{\circ} \mathrm{C}-\mathrm{HORA}$} & 11.625 & 11.094 & 14.350 & 15.314 & 14.683 & 15.142 & 12.433 & 14.707 & 15.637 & 12.871 & \multirow{2}{*}{13.786} \\
\hline & & $-15,67 \%$ & -19.5226 & $4,09 \%$ & $11,09 \%$ & $6.51 \%$ & $9,84 \%$ & $-9.82 \%$ & $6.68 \%$ & $13,43 \%$ & $-6,64 \%$ & \\
\hline \multirow{4}{*}{$<14^{\circ} \mathrm{C}$} & \multirow{2}{*}{ H } & 4.035 & 3.601 & 4.072 & 4.209 & 3.896 & 4.220 & 3.677 & 3.994 & 4.163 & 3.497 & \multirow{2}{*}{3.936} \\
\hline & & $2,50 \%$ & $-8,52 \pi \%$ & $3,44 \%$ & $6,93 \%$ & $-1,03 \%$ & $7,20 \%$ & $-6,59 \%$ & $1,46 \%$ & $5,76 \%$ & $-11,16 \%$ & \\
\hline & \multirow{2}{*}{${ }^{\circ} \mathrm{C}-\mathrm{HORA}$} & 26.346 & 27.254 & 33.200 & 35.520 & 31.303 & 31.531 & 31.485 & 32.546 & 33.068 & 32.121 & \multirow{2}{*}{31.437} \\
\hline & & $-16,19 \%$ & $-13,31 \%$ & $5,61 \%$ & $12,99 \%$ & $-0,43 \%$ & $0,30 \%$ & $0,15 \%$ & $3,53 \%$ & $5,19 \%$ & $2,17 \%$ & \\
\hline \multirow{4}{*}{$<16^{\circ} \mathrm{C}$} & \multirow{2}{*}{$\mathrm{H}$} & 4.645 & 4.260 & 4.777 & 4.986 & 4.490 & 4.898 & 4.484 & 4.636 & 4.861 & 4.308 & \multirow{2}{*}{4.635} \\
\hline & & $0,23 \%$ & $-8,08 \%$ & $3,07 \%$ & $7,58 \%$ & $-3,12 \%$ & $5,69 \%$ & $-3,25 \%$ & $0,03 \%$ & $4,89 \%$ & $-7,04 \%$ & \\
\hline & \multirow{2}{*}{${ }^{\circ} \mathrm{C}-\mathrm{HORA}$} & 35.429 & 37.055 & 43.732 & 47.078 & 40.146 & 41.652 & 43.514 & 42.112 & 43.456 & 44.184 & \multirow{2}{*}{41.836} \\
\hline & & $\mid-15,31 \%$ & $-11,43 \%$ & $4,53 \%$ & $12,53 \%$ & $-4,04 \%$ & $-0,44 \%$ & $4,01 \%$ & $0,665 \%$ & $3,87 \%$ & $5,61 \%$ & \\
\hline \multirow{4}{*}{$<18^{\circ} \mathrm{C}$} & \multirow{2}{*}{$\mathrm{H}$} & 5.347 & 5.034 & 5.591 & 5.721 & 5.138 & 5.570 & 5.269 & $\begin{array}{l}5.293 \\
\end{array}$ & 5.584 & 5.066 & \multirow{2}{*}{5.361} \\
\hline & & $-0,27 \%$ & $-6,10 \%$ & $4,28 \%$ & $6,71 \%$ & $-4,17 \%$ & $3,89 \%$ & $-1,72 \%$ & $-1,27 \%$ & $4,15 \%$ & $-5,51 \%$ & \\
\hline & \multirow{2}{*}{${ }^{\circ} \mathrm{C}-\mathrm{HORA}$} & 47.269 & 50.143 & 57.507 & 59.474 & 51.112 & 53.005 & 56.801 & 53.243 & 55.716 & 56.991 & \multirow{2}{*}{54.126} \\
\hline & & $-12,67 \%$ & $\begin{array}{r}-7,36 \% \\
\end{array}$ & $6,25 \%$ & $9,88 \%$ & $-5,57 \%$ & $-2,07 \%$ & $4,94 \%$ & $-1,63 \%$ & $2,94 \%$ & $5,29 \%$ & \\
\hline \multirow{4}{*}{$<20^{\circ} \mathrm{C}$} & \multirow{2}{*}{$\mathrm{H}$} & 6.069 & $\begin{array}{l}5.793 \\
\end{array}$ & 6.359 & 6.424 & 5.850 & 6.251 & 5.918 & 5.943 & 6.258 & 5.869 & \multirow{2}{*}{6.073} \\
\hline & & $-0,07 \%$ & $-4,622 \%$ & $4,70 \%$ & $5,77 \%$ & $-3,68 \%$ & 2.9250 & $-2,56 \%$ & $-2,15 \%$ & $3,04 \%$ & $-3,37 \%$ & \\
\hline & \multirow{2}{*}{${ }^{\circ} \mathrm{C}-\mathrm{HORA}$} & 60.924 & 64.487 & 71.997 & 72.743 & 64.556 & 65.855 & 69.083 & 65.539 & 68.439 & 72.198 & \multirow{2}{*}{67.582} \\
\hline & & $-9,85 \%$ & $-4,58 \% 5$ & $6,53 \%$ & $7,64 \%$ & $-4,48 \%$ & $-2,56 \%$ & $2,222 \%$ & \begin{tabular}{|c|}
$-3,02 \%$ \\
\end{tabular} & $1,27 \%$ & $6,83 \%$ & \\
\hline
\end{tabular}

8-29 HORAS Y GRADOS-HORA EN QUE ES PRECISO APORTAR ENERGÍA PARA ALCANZAR DIVERSAS TEMPERATURAS DE REFERENCIA DURANTE LA DÉCADA 2005-2014 EN ZARAGOZA AEROPUERTO (AEMET y elaboración propia)

\begin{tabular}{|c|c|c|c|c|c|c|c|c|c|c|c|c|}
\hline \multirow{2}{*}{\multicolumn{2}{|c|}{24 HORAS }} & \multicolumn{10}{|c|}{ AÑ̃O } & \multirow[b]{2}{*}{ PROMEDIO } \\
\hline & & 2005 & 2006 & 2007 & 2008 & 2009 & 2010 & 2011 & 2012 & 2013 & 2014 & \\
\hline \multirow{4}{*}{$>20^{\circ} \mathrm{C}$} & \multirow{2}{*}{ H } & 2.609 & 2.878 & 2.332 & 2.274 & 2.858 & 2.456 & 2.786 & 2.763 & 2.459 & 2.832 & \multirow{2}{*}{2.625} \\
\hline & & $-0.60 \%$ & $9.65 \%$ & $-11,15 \%$ & $-13,36 \%$ & $8.89 \%$ & $-6.43 \%$ & $6.15 \%$ & $5.27 \%$ & $-6,31 \%$ & $7,90 \%$ & \\
\hline & \multirow{2}{*}{${ }^{\circ} \mathrm{C}$-HORA } & 66.626 & 73.487 & 58.786 & 57.869 & 74.413 & 63.310 & 71.375 & 72.184 & 62.645 & 71.314 & \multirow{2}{*}{67.201} \\
\hline & & $-0,85 \%$ & $9,35 \%$ & $-12,52 \% 6$ & $-13,89 \%$ & $10,73 \%$ & $-5,79 \%$ & $6,21 \%$ & $7,41 \%$ & $-6,78 \%$ & $6,12 \%$ & \\
\hline \multirow{4}{*}{$>22^{\circ} \mathrm{C}$} & \multirow{2}{*}{ H } & 1.948 & 2.156 & 1.697 & 1.665 & 2.199 & 1.864 & 2.108 & 2.108 & 1.849 & 2.084 & \multirow{2}{*}{1.968} \\
\hline & & $-1,01 \%$ & $9,56 \%$ & $-13,76 \%$ & $-15,39 \%$ & $11,75 \%$ & $-5,27 \%$ & 7,125 & $7,12 \%$ & $-6,04 \%$ & $5,91 \%$ & \\
\hline & \multirow{2}{*}{${ }^{\circ} \mathrm{C}-\mathrm{HORA}$} & 52.686 & 58.265 & 45.412 & 45.019 & 60.498 & 50.831 & 57.072 & 58.415 & 49.805 & 55.565 & \multirow{2}{*}{53.357} \\
\hline & & $-1.26 \%$ & $9.20 \%$ & $-14,89 \%$ & $-15,63 \%$ & $13.38 \%$ & $-4,73 \%$ & $6.96 \%$ & $9.48 \%$ & $-6,665 \%$ & $4,14 \%$ & \\
\hline \multirow{4}{*}{$>26^{\circ} \mathrm{C}$} & & 984 & 1.099 & 828 & 850 & 1.198 & 990 & 1.102 & 1.195 & 949 & 1.036 & \multirow{2}{*}{1.023} \\
\hline & & $-3,8256$ & $7.42 \%$ & $-19,07 \%$ & $-16,92 \%$ & $17,10 \%$ & $-3,24 \%$ & $7,71 \%$ & $16,80 \%$ & $-7,24 \%$ & $1,26 \%$ & \\
\hline & \multirow{2}{*}{${ }^{\circ} \mathrm{C}-$ HORA } & 29.674 & 33.009 & 24.614 & 25.606 & 36.552 & 29.871 & 33.010 & 36.582 & 28.335 & 30.527 & \multirow{2}{*}{30.778} \\
\hline & & $-3,59 \%$ & $7,25 \%$ & $-20,03 \%$ & $-16,81 \%$ & $18,76 \%$ & $-2,95 \%$ & $7,25 \%$ & $18,86 \%$ & $-7,94 \%$ & $-0,81 \%$ & \\
\hline
\end{tabular}

\begin{tabular}{|l|l|l|l|l|l|l|l|l|l|l|l|}
\hline 24 HORAS & 2005 & 2006 & 2007 & 2008 & 2009 & 2010 & 2011 & 2012 & 2013 & 2014 & PROMEDIO \\
\hline
\end{tabular}

8-30 HORAS Y GRADOS-HORA EN QUE ES PRECISO DISIPAR ENERGÍA PARA ALCANZAR DIVERSAS TEMPERATURAS DE REFERENCIA DURANTE LA DÉCADA 2005-2014 EN ZARAGOZA AEROPUERTO (AEMET y elaboración propia) 


\begin{tabular}{|c|c|c|c|c|c|c|c|c|c|c|c|c|}
\hline \multirow{2}{*}{\multicolumn{2}{|c|}{$\begin{array}{c}1 \mathrm{~h}-19 \mathrm{~h} \\
\end{array}$}} & \multicolumn{10}{|c|}{ AÑO } & \multirow[b]{2}{*}{ PROMEDIO } \\
\hline & & 2005 & 2006 & 2007 & 2008 & 2009 & 2010 & 2011 & 2012 & 2013 & 2014 & \\
\hline \multirow{4}{*}{$<0^{\circ} \mathrm{C}$} & \multirow{2}{*}{ H } & 161 & 69 & 63 & 43 & \begin{tabular}{r|}
52 \\
\end{tabular} & 82 & $\begin{array}{r}50 \\
\end{array}$ & 56 & 31 & 2 & \multirow{2}{*}{61} \\
\hline & & $164,37 \%$ & $13,30 \%$ & $3,45 \%$ & $-29,39 \%$ & $-14,61 \%$ & $34.65 \%$ & $-17,90 \%$ & $-8.05 \%$ & $-48,10 \%$ & $-96,72 \%$ & \\
\hline & \multirow{2}{*}{${ }^{\circ} \mathrm{C}-\mathrm{HORA}$} & -349 & $\begin{array}{r}.120 \\
\end{array}$ & -124 & -52 & -53 & -100 & -61 & -63 & -37 & -1 & \multirow{2}{*}{-96} \\
\hline & & $263,43 \%$ & $25.31 \%$ & $29,488 \mathrm{~B}$ & $-46,005 \%$ & $-44,85 \%$ & $3.84 \%$ & $-36,20 \%$ & $-34,11 \%$ & $-61,43 \%$ & $-99,48 \%$ & \\
\hline \multirow{4}{*}{$<10^{\circ} \mathrm{C}$} & \multirow{2}{*}{$\mathrm{H}$} & 465 & 375 & 312 & 300 & 313 & 447 & 279 & 270 & 394 & 177 & \multirow{2}{*}{333} \\
\hline & & $39,56 \%$ & $12.55 \%$ & $-6,36 \%$ & $-9.96 \%$ & $-6.06 \%$ & $34,15 \%$ & $-16.27 \%$ & $-18,97 \%$ & $18.25 \%$ & $-46,88 \%$ & \\
\hline & \multirow{2}{*}{${ }^{\circ} \mathrm{C}-$ HORA } & 2.599 & 2.301 & 2.078 & 2.052 & 1.988 & 2.933 & 1.927 & 1.807 & 2.865 & 1.334 & \multirow{2}{*}{2.188} \\
\hline & & $18,77 \%$ & $5,13 \%$ & $-5,03 \%$ & $-6,22 \%$ & $-9,14 \%$ & $34,01 \%$ & $-11,93 \mathrm{~m}$ & $-17,44 \%$ & $30,90 \%$ & $-39,04 \%$ & \\
\hline \multirow{4}{*}{$<14^{\circ} \mathrm{C}$} & \multirow{2}{*}{ H } & 753 & 604 & 643 & 700 & $\begin{array}{l}637 \\
\end{array}$ & 722 & 588 & 663 & 722 & 523 & \multirow{2}{*}{656} \\
\hline & & $14,87 \%$ & $-7,86 \%$ & $-1,91 \%$ & $6,79 \%$ & $-2,82 \%$ & $10,14 \%$ & $-10,30 \mathrm{~m}$ & $1,14 \%$ & $10,14 \%$ & $-20,21 \%$ & \\
\hline & \multirow{2}{*}{${ }^{\circ} \mathrm{C}-\mathrm{HORA}$} & 6.010 & 5.010 & 6.088 & 6.864 & 5.893 & 6.205 & 5.683 & 6.558 & 6.723 & 5.478 & \multirow{2}{*}{6.051} \\
\hline & & $-0.68 \%$ & $-17.21 \%$ & $0.60 \%$ & $13,43 \%$ & $-2.61 \%$ & $2.53 \%$ & $-6,08 \%$ & $8.37 \%$ & $11,11 \%$ & $-9,47 \%$ & \\
\hline \multirow{4}{*}{$<16^{\circ} \mathrm{C}$} & \multirow{2}{*}{ H } & 846 & 719 & 831 & 869 & 808 & 902 & 774 & 862 & 893 & 737 & \multirow{2}{*}{824} \\
\hline & & $2.66 \%$ & $-12.75 \%$ & $0.84 \%$ & $5,45 \%$ & $-1.95 \%$ & $9,45 \%$ & $-6.08 \%$ & $4.60 \%$ & $8.36 \%$ & $-10,57 \%$ & \\
\hline & \multirow{2}{*}{${ }^{\circ} \mathrm{C}-\mathrm{HORA}$} & 7.389 & 6.721 & 8.893 & 9.381 & 8.442 & 8.889 & 8.464 & 9.520 & 9.267 & 8.654 & \multirow{2}{*}{8.562} \\
\hline & & $-13,70 \%$ & $-21.50 \%$ & $3.86 \%$ & $9.56 \%$ & $-1,4086$ & $3.82 \%$ & $-1,14 \%$ & $11,19 \%$ & $8.23 \%$ & $1.08 \%$ & \\
\hline \multirow{4}{*}{$<18^{\circ} \mathrm{C}$} & \multirow{2}{*}{$\mathrm{H}$} & 965 & 892 & 1.013 & 1.034 & 972 & 1.096 & 944 & 1.033 & 1.091 & 877 & \multirow{2}{*}{992} \\
\hline & & $-2,69 \%$ & $-10,05 \%$ & $2,15 \%$ & $4,27 \%$ & $-1,99 \%$ & $10,52 \%$ & $-4,81 \%$ & $4.16 \%$ & $10.01 \%$ & $-11.57 \%$ & \\
\hline & \multirow{2}{*}{${ }^{\circ} \mathrm{C}-\mathrm{HORA}$} & 9.396 & 9.645 & 11.971 & 12.157 & 11.224 & 12.162 & 11.330 & 12.408 & 12.625 & 11.008 & \multirow{2}{*}{11.393} \\
\hline & & $-17,53 \%$ & $-15,34 \%$ & $5,08 \%$ & $6,71 \%$ & $-1,48 \%$ & $6,75 \%$ & $-0,55 \%$ & $8,91 \%$ & $10,82 \%$ & $-3,38 \%$ & \\
\hline \multirow{4}{*}{$<20^{\circ} \mathrm{C}$} & \multirow{2}{*}{ H } & 1.115 & 1.038 & 1.166 & 1.224 & 1.122 & 1.231 & \begin{tabular}{|l|l|}
1.070 \\
\end{tabular} & 1.157 & 1.221 & 1.039 & 1138 \\
\hline & & $-2,05 \%$ & $-8,81 \%$ & $2,43 \%$ & $7,53 \%$ & $-1,43 \%$ & $8,14 \%$ & $-6,00 \%$ & $1,64 \%$ & $7,27 \%$ & $8,72 \%$ & 1.138 \\
\hline & SHORA & 12.245 & 12.405 & 14.856 & 15.755 & 14.048 & 14.702 & 13.715 & 14.751 & 15.075 & 14.084 & $141<3$ \\
\hline & & $-13.55 \%$ & $-12,42 \%$ & $4.88 \%$ & 11.248 & $-0.81 \%$ & $3,80 \%$ & $-3,17 \%$ & $4,15 \%$ & $6.43 \%$ & $-0.56 \%$ & 14.163 \\
\hline
\end{tabular}

8-31 HORAS Y GRADOS-HORA EN QUE ES PRECISO APORTAR ENERGÍA PARA ALCANZAR DIVERSAS TEMPERATURAS DE REFERENCIA DURANTE LA DÉCADA 2005-2014 EN LOS PERIODOS EN QUE ES POSIBLE UNA EVENTUAL CAPTACIÓN SOLAR EN ZARAGOZA AEROPUERTO (AEMET y elaboración propia)

\begin{tabular}{|c|c|c|c|c|c|c|c|c|c|c|c|c|}
\hline \multirow{2}{*}{\multicolumn{2}{|c|}{$\begin{array}{c}\text { Horas con Soleamiento sut } \\
11 \mathrm{~h}-19 \mathrm{~h}\end{array}$}} & \multicolumn{10}{|c|}{ AÑO } & \multirow[b]{2}{*}{ PROMEDIO } \\
\hline & & 2005 & 2006 & 2007 & 2008 & 2009 & 2010 & 2011 & 2012 & 2013 & 2014 & \\
\hline \multirow{4}{*}{$>20^{\circ} \mathrm{C}$} & \multirow{2}{*}{ H } & 1.059 & 1.130 & 1.009 & 951 & 1.058 & 948 & 1.108 & 1.024 & 958 & 1.141 & \multirow{2}{*}{1.039} \\
\hline & & $1.96 \%$ & $8,80 \%$ & $-2.85 \%$ & $-8,43 \%$ & $1.87 \%$ & $-8.72 \%$ & $6.68 \%$ & $-1,41 \%$ & $-7,76 \%$ & $9.86 \%$ & \\
\hline & \multirow{2}{*}{${ }^{\circ} \mathrm{C}-\mathrm{HORA}$} & 28.466 & 30.508 & 26.647 & 25.229 & 29.504 & 25.759 & 29.839 & 28.696 & 25.900 & 30.297 & \multirow{2}{*}{28.084} \\
\hline & & $1,36 \%$ & $8,63 \%$ & $-5,1286$ & $-10,17 \%$ & $5,05 \%$ & $-8,28 \%$ & $6,25 \%$ & $2,18 \%$ & $-7,78 \%$ & $7,89 \%$ & \\
\hline \multirow{4}{*}{$>22^{\circ} \mathrm{C}$} & \multirow{2}{*}{ H } & 1.295 & 1.389 & 1.236 & 1.114 & 1.366 & 1.200 & 1.398 & 1.342 & 1.224 & 1.428 & \multirow{2}{*}{1.299} \\
\hline & & $-0,32 \%$ & $6.91 \%$ & $-4,86 \%$ & $-14,25 \%$ & $5.14 \%$ & $-7,64 \%$ & $7.60 \%$ & $3.29 \%$ & $-5.79 \%$ & $9,91 \%$ & \\
\hline & \multirow{2}{*}{${ }^{\circ} \mathrm{C}-\mathrm{HORA}$} & 36.488 & 39.122 & 34.026 & 31.239 & 39.558 & 34.069 & 39.310 & 39.004 & 34.264 & 39.406 & \multirow{2}{*}{36.649} \\
\hline & & $-0,44 \%$ & $6.75 \%$ & $-7,16 \%$ & $-14,76 \%$ & $7,94 \%$ & $-7,04 \%$ & $7.26 \%$ & $6.43 \%$ & $-6.51 \%$ & $7,52 \%$ & \\
\hline \multirow{4}{*}{$>26^{\circ} \mathrm{C}$} & \multirow{2}{*}{ H } & 826 & 890 & 722 & 692 & 945 & 791 & 905 & 949 & 783 & 885 & \multirow{2}{*}{839} \\
\hline & & $-1,53 \%$ & 6.105 & $-13,92 \%$ & $-17.50 \%$ & $12,66 \%$ & $-5.70 \%$ & $7.89 \%$ & $13.14 \%$ & $-6,65 \%$ & $5.51 \%$ & \\
\hline & \multirow{2}{*}{${ }^{\circ} \mathrm{C}-\mathrm{HORA}$} & 25.219 & 27.114 & 21.628 & 21.187 & 29.377 & 24.180 & 27.449 & 29.561 & 23.698 & 26.327 & \multirow{2}{*}{25.574} \\
\hline & & $-1,39 \%$ & $\begin{array}{l}6.02 \% \\
\end{array}$ & $-15,4336$ & $-17,15 \%$ & $14,87 \%$ & $-5,45 \%$ & $7,33 \%$ & $15,59 \%$ & $-7,34 \%$ & $2,94 \%$ & \\
\hline
\end{tabular}

\begin{tabular}{|l|l|l|l|l|l|l|l|l|l|l|l|}
\hline 11h-19h & 2005 & 2006 & 2007 & 2008 & 2009 & 2010 & 2011 & 2012 & 2013 & 2014 & PROMEDIO \\
\hline
\end{tabular}
HORAS CON SOLEAMENTO SUR

8-32 HORAS Y GRADOS-HORA EN QUE ES PRECISO DISIPAR ENERGÍA PARA ALCANZAR DIVERSAS TEMPERATURAS DE REFERENCIA DURANTE LA DÉCADA 2005-2014 EN LOS PERIODOS EN QUE ES POSIBLE UNA EVENTUAL CAPTACIÓN SOLAR EN ZARAGOZA AEROPUERTO (AEMET y elaboración propia) 


\begin{tabular}{|c|c|c|c|c|c|c|c|c|c|c|c|c|}
\hline \multirow{2}{*}{\multicolumn{2}{|c|}{$\begin{array}{l}\text { HORAS SIN SOLEAMENTO SUR } \\
17 \mathrm{~h}-10 \mathrm{~h}\end{array}$}} & \multicolumn{10}{|c|}{ AÑO } & \multirow[b]{2}{*}{ PROMEDIC } \\
\hline & & 2005 & 2006 & 2007 & 2008 & 2009 & 2010 & 2011 & 2012 & 2013 & 2014 & \\
\hline \multirow{4}{*}{$<0^{\circ} \mathrm{C}$} & \multirow{2}{*}{$\mathrm{H}$} & 383 & 163 & 138 & 111 & 112 & 168 & 100 & 119 & 68 & 3 & \multirow{2}{*}{137} \\
\hline & & $180,59 \%$ & $19,41 \%$ & $1,10 \%$ & $-18,68 \%$ & $-17,95 \%$ & $23,08 \%$ & $-26,74 \%$ & $-12,82 \%$ & $-50,18 \%$ & $-97,80 \%$ & \\
\hline & \multirow{2}{*}{${ }^{\circ} \mathrm{C}-\mathrm{HORA}$} & \begin{tabular}{|l|}
-821 \\
\end{tabular} & -283 & -290 & \begin{tabular}{|l|}
-131 \\
\end{tabular} & -128 & -212 & \begin{tabular}{|l|}
-132 \\
\end{tabular} & \begin{tabular}{|l|}
-150 \\
\end{tabular} & -81 & -1 & \multirow{2}{*}{-223} \\
\hline & & $268,55 \%$ & $27,05 \%$ & $30,02 \%$ & $-41,14 \%$ & $-42,53 \%$ & $-5,05 \%$ & $-40,83 \%$ & $-32,70 \%$ & $-63,81 \%$ & $-99,55 \%$ & \\
\hline \multirow{4}{*}{$<10^{\circ} \mathrm{C}$} & \multirow{2}{*}{ H } & 2.324 & 1.879 & 2.176 & 2.216 & 2.182 & 2.388 & 1.822 & 2.223 & 2.302 & 1.715 & \multirow{2}{*}{2.123} \\
\hline & & $9,48 \%$ & $-11,48 \%$ & $2,51 \%$ & $4,40 \%$ & $2,79 \%$ & $12,50 \%$ & $-14,17 \%$ & $4,73 \%$ & $8,45 \%$ & $-19,21 \%$ & \\
\hline & \multirow{2}{*}{${ }^{\circ} \mathrm{C}-\mathrm{HORA}$} & 9.946 & 9.099 & 12.562 & 13.414 & 12.823 & 12.421 & 10.637 & 13.050 & 12.853 & 11.537 & \multirow{2}{*}{11.834} \\
\hline & & $-15,96 \%$ & $-23,12 \%$ & $6,15 \%$ & $13,35 \%$ & $8,36 \%$ & $4,96 \%$ & $-10,12 \%$ & $10,28 \%$ & $8,61 \%$ & $-2,51 \%$ & \\
\hline \multirow{4}{*}{$<14^{\circ} \mathrm{C}$} & \multirow{2}{*}{$\mathrm{H}$} & 3.282 & 2.997 & 3.429 & 3.509 & 3.259 & 3.498 & 3.089 & 3.331 & 3.441 & 2.974 & \multirow{2}{*}{3.281} \\
\hline & & $0,03 \%$ & $-8,65 \%$ & $4,51 \%$ & $6,95 \%$ & $-0,67 \%$ & $6,62 \%$ & \begin{tabular}{|l|}
$-5,855 \%$ \\
\end{tabular} & $1,53 \%$ & $4,88 \%$ & $-9,35 \%$ & \\
\hline & \multirow{2}{*}{${ }^{\circ} \mathrm{C}-\mathrm{HORA}$} & 21.256 & 22.549 & 27.403 & 28.807 & 25.538 & 25.538 & 25.933 & 26.138 & 26.425 & 26.643 & \multirow{2}{*}{25.623} \\
\hline & & $-17,04 \%$ & $-12,00 \%$ & $6,95 \%$ & $12,43 \%$ & $-0,33 \%$ & $-0,33 \%$ & $1,21 \%$ & $2,01 \%$ & $3,13 \%$ & $3,98 \%$ & \\
\hline \multirow{4}{*}{$<16^{\circ} \mathrm{C}$} & \multirow{2}{*}{$\mathrm{H}$} & 3.799 & 3.541 & 3.946 & 4.117 & 3.682 & 3.996 & 3.710 & 3.774 & 3.968 & 3.571 & \multirow{2}{*}{3.810} \\
\hline & & $-0,30 \%$ & $\begin{array}{r}-7,07 \% \\
\end{array}$ & $3,56 \%$ & $8,05 \%$ & $-3,37 \%$ & $4,87 \%$ & $-2,63 \%$ & $-0,96 \%$ & $4,14 \%$ & $-6,287 \%$ & \\
\hline & \multirow{2}{*}{${ }^{\circ} \mathrm{C}-\mathrm{HORA}$} & 28.959 & 30.639 & 35.130 & 37.849 & 31.832 & 32.974 & 35.182 & 32.742 & 34.270 & 35.530 & \multirow{2}{*}{33.511} \\
\hline & & $-13,58 \%$ & $-8,57 \%$ & $4,83 \%$ & $12,95 \%$ & $-5,01 \%$ & $-1,60 \%$ & $4,99 \%$ & $-2,29 \%$ & 2,265 & $6,03 \%$ & \\
\hline \multirow{4}{*}{$<18^{\circ} \mathrm{C}$} & & \begin{tabular}{|l|}
4.382 \\
\end{tabular} & 4.142 & 4.578 & 4.687 & 4.166 & 4.474 & 4.325 & 4.260 & 4.493 & 4.189 & \multirow{2}{*}{4.370} \\
\hline & & $\begin{array}{l}0.28 \% \\
\end{array}$ & $-5,21 \%$ & $4,77 \%$ & $7,26 \%$ & $-4,66 \%$ & $2,399 \%$ & $-1,02 \%$ & $-2,51 \%$ & $2,82 \%$ & $-4,13 \%$ & \\
\hline & \multirow{2}{*}{${ }^{\circ} \mathrm{C}-\mathrm{HORA}$} & 38.793 & 40.803 & 45.827 & \begin{tabular}{ll|}
47.468 \\
\end{tabular} & 40.016 & 41.055 & 45.603 & 40.986 & 43.172 & 45.984 & \multirow{2}{*}{42.971} \\
\hline & & $-9,725$ & $-5,04 \%$ & $6,65 \%$ & $10,47 \%$ & $-6,88 \%$ & $-4,46 \%$ & $6,13 \%$ & $-4,62 \%$ & $0,47 \%$ & $7.01 \%$ & \\
\hline \multirow{4}{*}{$<20^{\circ} \mathrm{C}$} & \multirow{2}{*}{$\mathrm{H}$} & 4.954 & 4.755 & 5.193 & \begin{tabular}{|l|l|}
4.895 \\
\end{tabular} & 4.728 & 5.020 & \begin{tabular}{|l|}
4.848 \\
\end{tabular} & 4.786 & 5.037 & 4.830 & 4805 \\
\hline & & $1,01 \%$ & $-3,05 \%$ & $5,88 \%$ & $-0,20 \%$ & $-3,60 \%$ & $2,35 \%$ & $-1,15 \%$ & $\begin{array}{l}-4,42 \% \mathrm{~F} \\
\end{array}$ & $2,70 \%$ & $-1,52 \%$ & 4.905 \\
\hline & ${ }^{\circ} \mathrm{C}-\mathrm{HOPA}$ & 49.600 & 52.387 & 57.432 & 51.257 & 50.636 & 51.365 & 55.501 & 50.939 & 53.445 & 58.115 & \\
\hline & ${ }^{\circ} \mathrm{C}-\mathrm{HORA}$ & $-6,54 \%$ & $-1,28 \%$ & 8.225 & $-3.41 \%$ & $-4,58 \%$ & $-3,21 \%$ & $4,58 \%$ & $-4,01 \%$ & $0,71 \%$ & $9,51 \%$ & \\
\hline
\end{tabular}

8-33 HORAS Y GRADOS-HORA EN QUE ES PRECISO APORTAR ENERGÍA PARA ALCANZAR DIVERSAS TEMPERATURAS DE REFERENCIA DURANTE LA DÉCADA 2005-2014 EN LOS PERIODOS EN QUE NO ES POSIBLE UNA EVENTUAL CAPTACIÓN SOLAR EN ZARAGOZA AEROPUERTO (AEMET y elaboración propia)

\begin{tabular}{|c|c|c|c|c|c|c|c|c|c|c|c|c|}
\hline \multirow{2}{*}{\multicolumn{2}{|c|}{\begin{tabular}{|c} 
HORAS SIN SOLEAMIENTO SUR \\
$17 \mathrm{~h}-10 \mathrm{~h}$ \\
\end{tabular}}} & \multicolumn{10}{|c|}{ AÑO } & \multirow[b]{2}{*}{ PROMEDIO } \\
\hline & & 2005 & 2006 & 2007 & 2008 & 2009 & 2010 & 2011 & 2012 & 2013 & 2014 & \\
\hline \multirow{4}{*}{$>20^{\circ} \mathrm{C}$} & \multirow{2}{*}{$\mathrm{H}$} & 4.199 & 4.171 & 4.280 & 1.323 & 1.800 & 1.508 & 1.678 & 1.739 & 1.501 & 1.691 & \multirow{2}{*}{2.389} \\
\hline & & $75,76 \%$ & $74,59 \%$ & $79,15 \%$ & $-44,62 \pi$ & $-24,65 \%$ & $-36,88 \%$ & $-29,76 \%$ & $-27,21 \%$ & $-37,17 \%$ & $-29,22 \%$ & \\
\hline & \multirow{2}{*}{${ }^{\circ} \mathrm{C}-\mathrm{HORA}$} & 55.315 & 59.675 & 58.049 & 32.640 & 44.909 & 37.551 & 41.536 & 43.487 & 36.746 & 41.017 & \multirow{2}{*}{45.092} \\
\hline & & $22.67 \%$ & $32,34 \%$ & $28.73 \%$ & $-27,628$ & $-0,41 \%$ & $-16,72 \%$ & $.7 .89 \%$ & $-3.56 \%$ & $-18.51 \%$ & $-9,04 \%$ & \\
\hline \multirow{4}{*}{$>22^{\circ} \mathrm{C}$} & \multirow{2}{*}{ H } & 653 & 767 & 461 & 551 & 833 & 664 & 710 & 766 & 625 & 656 & \multirow{2}{*}{669} \\
\hline & & $-2,33 \%$ & $14,72 \%$ & $-31,05 \%$ & $-17,59 \%$ & $24,59 \%$ & $-0,69 \%$ & $6,19 \pi \pi$ & $14,57 \%$ & $-6,52 \pi$ & $-1,88 \pi$ & \\
\hline & \multirow{2}{*}{${ }^{\circ} \mathrm{C}-\mathrm{HORA}$} & 16.198 & 19.143 & 11.386 & 13.780 & 20.941 & 16.762 & 17.762 & 19.411 & 15.541 & 16.159 & \multirow{2}{*}{16.708} \\
\hline & & $-3,05 \%$ & $14,57 \%$ & $-31,85 \%$ & $-17,539$ & $25,33 \%$ & $0,32 \%$ & $6,31 \%$ & $16,18 \%$ & $-6,990$ & $-3,29 \%$ & \\
\hline \multirow{4}{*}{$>26^{\circ} \mathrm{C}$} & \multirow{2}{*}{ H } & 158 & 209 & 106 & 158 & 253 & 199 & 197 & 246 & 166 & 151 & \multirow{2}{*}{184} \\
\hline & & $-14,27 \%$ & $13,40 \%$ & $-42,49 \%$ & $-14,27 \%$ & $37,28 \%$ & $7,98 \%$ & $6,89 \%$ & $33,48 \%$ & $-9,93 \mathrm{~s}$ & $-18,07 \%$ & \\
\hline & \multirow{2}{*}{${ }^{\circ} \mathrm{C}-\mathrm{HORA}$} & 4.456 & 5.894 & 2.986 & 4.419 & 7.176 & 5.691 & 5.561 & 7.021 & 4.637 & 4.200 & \multirow{2}{*}{5.204} \\
\hline & & $-14,38 \%$ & $13,26 \%$ & $-42,63 \%$ & $-15.09 \%$ & $37,88 \%$ & $9,35 \%$ & $6.87 \%$ & $34,92 \%$ & $-10,89 \%$ & $-19,29 \%$ & \\
\hline \multicolumn{2}{|c|}{ 17h-10h } & 2005 & 2006 & 2007 & 2008 & 2009 & 2010 & 2011 & 2012 & 2013 & 2014 & \multirow[t]{2}{*}{ PROMEDIO } \\
\hline \multicolumn{2}{|c|}{ HORAS SIN SOLEAMIENTO SUR } & \multicolumn{10}{|c|}{ AÑO } & \\
\hline
\end{tabular}

8-34 HORAS Y GRADOS-HORA EN QUE ES PRECISO DISIPAR ENERGÍA PARA ALCANZAR DIVERSAS TEMPERATURAS DE REFERENCIA DURANTE LA DÉCADA 2005-2014 EN LOS PERIODOS EN QUE NO ES POSIBLE UNA EVENTUAL CAPTACIÓN SOLAR EN ZARAGOZA AEROPUERTO (AEMET y elaboración propia) 


\subsection{ESTACIONES METEOROLÓGICAS DE REFERENCIA}

En todo el territorio nacional hay estaciones meteorológicas de la red de la Agencia Estatal de Meteorología (AEMET) que pueden emplearse para obtener información climática local.

La primera aproximación será considerar sus diferencias y su idoneidad, para lo que se han analizado los datos obtenidos en varias estaciones situadas en Zaragoza.

Observando las series, se constata que la información suministrada de más calidad es la obtenida en el aeropuerto, por la continuidad de la información y el porcentaje de datos registrados frente a los que necesitaron ser elaborados o completados.

Para compararlas se ha utilizado la cuantificación de los gradoshora en base 20 , en base 16 y en base 26 .

También se han elaborado los datos correspondientes a valores medios, máximos y mínimos horarios en periodos anuales y estacionales.

Por último se ha realizado una comparativa diaria de los valores horarios registrados.

\subsubsection{DISTRIBUCIÓN TEMPORAL Y VALORES ANUALES ACUMULADOS DE GRADOS-HORA}

Se ha establecido la diferencia entre los grados-hora y los periodos en que se contabilizan entre cada estación y sus valores promedio obtenidos durante las estaciones de referencia.

Para ello se han considerado los periodos cálidos y fríos considerados en la legislación vigente, es decir, como periodo cálido el que va de junio a septiembre, ambos inclusive, y como periodo frío el resto del año, de octubre a mayo, realizando la contabilidad de grados-hora en base 20/20 y en base 16/16 para periodos fríos y en base $26 / 26$ en periodos cálidos.

Para calcular los valores medios anuales de las estaciones de referencia y con ellos los grados-hora con una temperatura base de $20^{\circ} \mathrm{C}$, se contabilizan los grados que la temperatura registrada cada hora está por debajo de $20^{\circ} \mathrm{C}$ en los meses incluidos entre octubre y mayo, que se consideran como grados-hora en periodo frío, y los grados en que la temperatura registrada cada hora está por encima de $20^{\circ} \mathrm{C}$ en los meses de junio a septiembre, que se consideran como grados-hora en periodo cálido.

También se han calculado los valores medios anuales de las estaciones de referencia y los grados hora con una temperatura base de $16^{\circ} \mathrm{C}$, contabilizando los grados que cada hora está por debajo de $16^{\circ} \mathrm{C}$ entre los meses de octubre y mayo, que se consideran como grados-hora en periodo frío, y los grados que cada hora está por encima de $26^{\circ} \mathrm{C}$, en los meses de junio a septiembre, y que se consideran como grados-hora en periodo cálido.
PERIODOS TÉRMICOS

SEGÚN LA

NORMATIVA:

CÁLIDO (VERANO): DE JUNIO A SEPTIEMBRE FRÍO (INVIERNO): DE OCTUBRE A MAYO 


\begin{tabular}{|l|r|r|}
\hline \multicolumn{3}{|c|}{ GH 2O/2O } \\
\hline \multirow{2}{*}{2014} & \multicolumn{1}{|c|}{ FRIO } & CALIDO \\
\cline { 2 - 3 } & \multicolumn{2}{|c|}{ MEDIA } \\
\hline HORAS & 5108 & 2083 \\
\hline${ }^{\circ}$ C.HORA & 45378 & 12161 \\
\hline
\end{tabular}

\begin{tabular}{|c|r|c|}
\hline \multicolumn{3}{|c|}{ GH 16/16 (FRIO) Y } \\
GH 26/26 (CALIDO) \\
\hline \multirow{2}{*}{2014} & \multicolumn{1}{|c|}{ FRIO } & CALIDO \\
\cline { 2 - 3 } & \multicolumn{2}{|c|}{ MEDIA } \\
\hline HORAS & 4344 & 1033 \\
\hline${ }^{\circ}$ C.HORA & 24749 & 3660 \\
\hline
\end{tabular}

8-35 CUADROS CON LA MEDIA DE LAS ESTACIONES METEOROLÓGICAS DE CANAL, VALDESPARTERA Y AEROPUERTO DE GRADOS-HORA EN BASE 20/20 Y EN GRADOS-HORA EN BASE16/16 EN PERIODOS FRÍOS Y EN BASE 26/26 EN PERIODOS CÁLIDOS Y DE LOS PERIODOS EN HORAS EN QUE SE PRODUCEN LA SUPERACIÓN DE ESTOS UMBRALES. ZARAGOZA. 2014 (AEMET Y elaboración propia)

Para facilitar las comparaciones entre estos valores se han establecido las diferencias en grados-hora y los periodos en que se superan los umbrales y el porcentaje con relación a los valores medios.

A continuación se expresa discursivamente, aplicados fundamentalmente al año 2014, los valores recogidos en las tablas resumidas elaboradas.

A. Comparación entre los valores medios y los registrados en la estación meteorológica de Canal.

En la estación meteorológica del canal se han registrado temperaturas menores de $20^{\circ} \mathrm{C}$ un total de 11 horas menos que en la media de las tres estaciones meteorológicas consideradas los periodos fríos del año 2014 (de enero a mayo y de octubre a diciembre), lo que supone un $0,22 \%$ del total de las horas en que se han producido estas superaciones como media.

Esta circunstancia se contabiliza como 262 grados-hora, lo que representa el $0,58 \%$ de la media de los grados-hora de los acumulados durante todo el año.

Durante el periodo cálido (de junio a septiembre) del año 2014 se han registrado en la estación meteorológica de Canal temperaturas mayores de $20^{\circ} \mathrm{C}$ un total de 17 horas menos que la media de la obtenida en las tres estaciones meteorológicas consideradas, lo que supone un $0,80 \%$ del total de las horas en que se han producido estas superaciones como media.

Esto se contabiliza, sin embargo, como 64 grados-hora más, lo que representa un incremento del 0,53\% por encima de la media de los acumulados durante el periodo cálido del año en las tres estaciones de referencia.

\begin{tabular}{|c|c|r|c|r|}
\hline \multicolumn{3}{|c|}{$\begin{array}{c}\text { GRADOS-HORA Y PERIODOS MEDIOS MENOS } \\
\text { GRADOS-HORA Y PERIODOS CANAL }\end{array}$} \\
\hline \multicolumn{5}{|c|}{ GH $20 / 20$} \\
\hline \multirow{2}{*}{2014} & \multicolumn{2}{|c|}{ FRIO } & \multicolumn{1}{c|}{ CALIDO } \\
\cline { 2 - 5 } & M-C & $\%$ S/MEDIA & M-C & $\%$ S/MEDIA \\
\hline HORAS & 11 & $0,22 \%$ & 17 & $0,80 \%$ \\
\hline${ }^{\circ}$ C.HORA & 262 & $0,58 \%$ & -64 & $-0,53 \%$ \\
\hline
\end{tabular}

8-36 CUADRO DE DIFERENCIA ANUAL CUANDO LA TEMPERATURA ES MENOR DE $20^{\circ} \mathrm{C}$ DURANTE LOS PERIODOS FRÍOS (DE OCTUBRE A MAYO) Y MAYOR DE $20^{\circ} \mathrm{C}$ DURANTE LOS PERIODOS CÁLIDOS (DE JUNIO A SEPTIEMBRE) EN GRADOS-HORA ENTRE LOS VALORES MEDIOS Y LOS REGISTRADOS EN LA ESTACIÓN METEOROLÓGICA DE CANAL (AEMET y elaboración propia) 
Se comprueban también los valores obtenidos cuando se baja la temperatura, de $16^{\circ} \mathrm{C}$, para contabilizar los grados-hora en el periodo frío y los incrementos de la temperatura desde $26^{\circ} \mathrm{C}$ para contabilizar los grados-hora en el periodo cálido, observándose que en la estación meteorológica de Canal se han registrado temperaturas menores de $16^{\circ} \mathrm{C}$ un total de 4 horas menos que la media de las tres estaciones consideradas durante los periodos fríos (de enero a mayo y de octubre a diciembre) del año 2014, lo que supone un $0,10 \%$ del total de las horas en que se han producido estas superaciones.

Esto se contabiliza como $233^{\circ} \mathrm{C}-\mathrm{HORA}$ que representa el $0,89 \%$ de los ${ }^{\circ} \mathrm{C}$-HORA de la media de los acumulados durante los periodos fríos del año.

También en la estación meteorológica de Canal se han se han registrado temperaturas mayores de $26^{\circ} \mathrm{C}$ un total de 3 horas menos que en la media de las estaciones meteorológicas de Canal, Valdespartera y Aeropuerto de Zaragoza durante los periodos cálidos (de junio a septiembre) del año 2014, lo que supone un $0,15 \%$ del total de las horas en que se han producido estas superaciones como media.

Esto se contabiliza, sin embargo, como $125^{\circ} \mathrm{C}$-HORA más que los valores medios, que representa un incremento del 1,20\% de la media de los acumulados durante los periodos cálidos del año en las estaciones de referencia.

\begin{tabular}{|c|c|r|r|r|}
\hline \multicolumn{3}{|c|}{$\begin{array}{c}\text { GRADOS-HORA Y PERIODOS MEDIOS MENOS } \\
\text { GRADOS-HORA Y PERIODOS CANAL }\end{array}$} \\
\hline \multicolumn{4}{|c|}{ GH 16/16 (FRIO) Y GH 26/26 (CALIDO) } \\
\hline \multirow{2}{*}{2014} & \multicolumn{2}{|c|}{ FRIO } & \multicolumn{2}{c|}{ CALIDO } \\
\cline { 2 - 5 } & M-C & $\%$ S/MEDIA & M-C & $\%$ S/MEDIA \\
\hline HORAS & 4 & $0,10 \%$ & 3 & $0,15 \%$ \\
\hline${ }^{\circ}$ C.HORA & 233 & $0,89 \%$ & -125 & $-1,02 \%$ \\
\hline
\end{tabular}

8-37 CUADRO DE DIFERENCIA ANUAL CUANDO LA TEMPERATURA ES MENOR DE $16^{\circ} \mathrm{C}$ DURANTE LOS PERIODOS FRÍOS (DE OCTUBRE A MAYO) Y MAYOR DE $26^{\circ} \mathrm{C}$ DURANTE LOS PERIODOS CÁLIDOS (DE JUNIO A SEPTIEMBRE) EN GRADOSHORA ENTRE LOS VALORES MEDIOS Y LOS REGISTRADOS EN LA ESTACIÓN METEOROLÓGICA DE CANAL (AEMET y elaboración propia)

Cuando la contabilidad se realiza a lo largo de todo el año, atendiendo sólo a la superación de los umbrales, observamos que en la estación meteorológica de Canal se han registrado temperaturas menores de $16^{\circ} \mathrm{C}$ un total de 10 horas más que la media de las tres estaciones meteorológicas consideradas en Zaragoza durante el año 2014 , lo que supone un $0,23 \%$ del total de las horas en que se han producido estas superaciones como media.

Esta información se contabiliza como 213 grados-hora lo que representa el $0,86 \%$ de la media de los grados-hora acumulados durante todo el año.

También en la estación meteorológica de Canal se han registrado temperaturas mayores de $26^{\circ} \mathrm{C}$ un total de 15 horas más que la media obtenida en las tres estaciones meteorológicas de 
referencia durante el año 2014, lo que supone un 1,48\% del total de horas en que se han producido como media estas superaciones.

Esto se contabiliza como 132 grados-hora lo que representa el $3,60 \%$ de la media de los acumulados durante todo el año en las estaciones de referencia de Zaragoza.

\begin{tabular}{|c|c|r|c|r|}
\hline \multicolumn{5}{|c|}{$\begin{array}{c}\text { GRADOS-HORA Y PERIODOS MEDIOS MENOS } \\
\text { GRADOS-HORA Y PERIODOS CANAL }\end{array}$} \\
\hline \multicolumn{4}{|c|}{ GH 16/16 (FRIO) Y GH $26 / 26$ (CALIDO) } \\
\hline \multirow{2}{*}{2014} & \multicolumn{3}{|c|}{ FRIO } & \multicolumn{2}{c|}{ CALIDO } \\
\cline { 2 - 5 } & M-A & $\%$ S/MEDIA & M-A & $\%$ s/MEDIA \\
\hline HORAS & -10 & $-0,23 \%$ & -15 & $-1,48 \%$ \\
\hline${ }^{\circ}$ C.HORA & 213 & $0,86 \%$ & -132 & $-3,60 \%$ \\
\hline
\end{tabular}

8-38 CUADRO DE DIFERENCIA ANUAL CUANDO LA TEMPERATURA ES MENOR DE $16^{\circ} \mathrm{C}$ (HORAS FRIAS) Y MAYOR DE $26^{\circ} \mathrm{C}$ (HORAS CÁLIDAS) EN GRADOS-HORA ENTRE LOS VALORES MEDIOS Y LOS REGISTRADOS EN LA ESTACIÓN METEOROLÓGICA DE CANAL (ELABORACIÓN PROPIA)

B. Comparación entre los valores medios y los registrados en la estación meteorológica de Valdespartera.

En la estación meteorológica de Valdespartera se han registrado temperaturas menores de $20^{\circ} \mathrm{C}$ un total de 14 horas más que la media de las de las tres estaciones meteorológicas consideradas en Zaragoza durante los periodos fríos del año 2014 (de enero a mayo y de octubre a diciembre), lo que supone un $0,27 \%$ del total de horas en que, de media, se han producido estas superaciones.

Se contabilizan 226 grados-hora y representan un 0,50\% más que la media de los grados-hora acumulados durante todo el año.

Durante el periodo cálido (de junio a septiembre) del año 2014 se han registrado en la estación meteorológica de Valdespartera temperaturas superiores de $20^{\circ} \mathrm{C}$ un total de 29 horas menos que la media de las tres estaciones meteorológicas consideradas en Zaragoza, lo que supone un 1,38\% del total de horas en que se han producido estas superaciones como media.

Esto se contabiliza como 187 grados-hora menos, lo que representa una reducción del $1,53 \%$ de la media de los acumulados durante todo el periodo cálido del año en las estaciones de referencia. 


\begin{tabular}{|c|c|r|c|r|}
\hline \multicolumn{4}{|c|}{ GRADOS-HORA Y PERIODOS MEDIOS MENOS } \\
GRADOS-HORA Y PERIODOS VALDESPARTERA \\
\hline \multicolumn{5}{|c|}{ GH 20/20 } \\
\hline \multirow{2}{*}{2014} & \multicolumn{3}{|c|}{ FRIO } & \multicolumn{1}{c|}{ CALIDO } \\
\cline { 2 - 5 } & $\mathrm{M}-\mathrm{V}$ & $\%$ S/MEDIA & M-V & $\%$ S/MEDIA \\
\hline HORAS & -14 & $-0,27 \%$ & 29 & $1,38 \%$ \\
\hline${ }^{\circ} \mathrm{C}$. HORA & -226 & $-0,50 \%$ & 187 & $1,53 \%$ \\
\hline
\end{tabular}

8-39 CUADRO DE DIFERENCIA ANUAL CUANDO LA TEMPERATURA ES MENOR DE $20^{\circ} \mathrm{C}$ DURANTE LOS PERIODOS FRÍOS (DE OCTUBRE A MAYO) Y MAYOR DE $20^{\circ} \mathrm{C}$ DURANTE LOS PERIODOS CÁLIDOS (DE JUNIO A SEPTIEMBRE) EN GRADOSHORA ENTRE LOS VALORES MEDIOS Y LOS REGISTRADOS EN LA ESTACIÓN METEOROLÓGICA DE VALDESPARTERA (AEMET y elaboración propia)

Se comprueban también los valores obtenidos cuando se baja la temperatura, de $16^{\circ} \mathrm{C}$, para contabilizar los grados-hora en el periodo frío y los incrementos de la temperatura desde $26^{\circ} \mathrm{C}$ para contabilizar los grados-hora en el periodo cálido, observándose que en la estación meteorológica de Valdespartera se han registrado temperaturas menores de $16^{\circ} \mathrm{C}$ un total de 19 horas más que la media de las obtenidas en las tres estaciones meteorológicas consideradas en Zaragoza durante los periodos fríos (de enero a mayo y de octubre a diciembre) del año 2014, lo que supone un $0,44 \%$ del total de las horas en que se han producido estas superaciones como media.

Se contabilizan también como 207 grados-hora más lo que será un $0,79 \%$ de los grados-hora del total de la media de los acumulados durante los periodos fríos del año.

También en la estación meteorológica de Valdespartera se han registrado temperaturas mayores de $26^{\circ} \mathrm{C}$ un total de 19 horas más que la media de las obtenidas en las tres estaciones meteorológicas consideradas en Zaragoza durante el periodo cálido (de junio a septiembre) del año 2014, lo que supone un $0,94 \%$ del total de horas en que se han producido estas superaciones como media.

Esto se contabiliza como 221 grados-hora lo que representa un incremento del $2,06 \%$ sobre la media de los acumulados durante el periodo cálido del año en las tres estaciones de referencia de Zaragoza.

\begin{tabular}{|c|c|r|c|r|}
\hline \multicolumn{3}{|c|}{ GRADOS-HORA Y PERIODOS MEDIOS MENOS } \\
GRADOS-HORA Y PERIODOS VALDESPARTERA \\
\hline \multicolumn{4}{|c|}{ GH 16/16 (FRIO) Y GH 26/26 (CALIDO) } \\
\hline \multirow{2}{*}{2014} & \multicolumn{2}{|c|}{ FRIO } & \multicolumn{2}{c|}{ CALIDO } \\
\cline { 2 - 5 } & $\mathrm{M}-\mathrm{V}$ & $\%$ s/MEDIA & $\mathrm{M}-\mathrm{V}$ & $\%$ s/MEDIA \\
\hline HORAS & -19 & $-0,44 \%$ & -19 & $-0,94 \%$ \\
\hline${ }^{\circ} \mathrm{C}$. HORA & -207 & $-0,79 \%$ & -221 & $-2,06 \%$ \\
\hline
\end{tabular}

8-40 CUADRO DE DIFERENCIA ANUAL CUANDO LA TEMPERATURA ES MENOR DE $16^{\circ} \mathrm{C}$ DURANTE LOS PERIODOS FRÍOS (DE OCTUBRE A MAYO) Y MAYOR DE $26^{\circ} \mathrm{C}$ DURANTE LOS PERIODOS CÁLIDOS (DE JUNIO A SEPTIEMBRE) EN GRADOSHORA ENTRE LOS VALORES MEDIOS Y LOS REGISTRADOS EN LA ESTACIÓN METEOROLÓGICA DE VALDESPARTERA (AEMET y elaboración propia)

Cuando la contabilidad se realiza atendiendo sólo a la superación de los umbrales, en la estación meteorológica de Valdespartera se han registrado temperaturas menores de $16^{\circ} \mathrm{C}$ un total de 26 horas 
más que la media de las obtenidas en las estaciones meteorológicas de Canal, de Valdespartera y del Aeropuerto de Zaragoza durante el año 2014 , lo que supone un $0,60 \%$ del total de las horas en que se han producido estas superaciones como media.

Esto, contabilizado como 217 grados-hora más, representa un $0,88 \%$ más que los grados-hora de media de los acumulados en las tres estaciones de referencia de Zarazoza durante todo el año.

También en la estación meteorológica de Valdespartera se han registrado temperaturas superiores a $26^{\circ} \mathrm{C}$ durante un total de 19 horas más que la media de las tres estaciones meteorológicas consideradas en Zaragoza durante el año 2014, lo que supone un $1,81 \%$ del total de horas en que se han producido en ellas estas superaciones como media durante todo el año.

Esto, contabilizado como 63 grados-hora representa el 1,73\% de la media de los acumulados durante todo el año en las tres estaciones de referencia de Zaragoza.

\begin{tabular}{|c|c|r|r|r|}
\hline \multicolumn{5}{|c|}{ GRADOS-HORA Y PERIODOS MEDIOS MENOS } \\
GRADOS-HORA Y PERIODOS VALDESPARTERA \\
\hline \multicolumn{4}{|c|}{ GH 16/16 (FRIO) Y GH 26/26 (CALIDO) } \\
\hline \multirow{2}{*}{2014} & \multicolumn{3}{|c|}{ FRIO } & \multicolumn{2}{c|}{ CALIDO } \\
\cline { 2 - 5 } & M-A & $\%$ S/MEDIA & M-A & $\%$ S/MEDIA \\
\hline HORAS & -26 & $-0,60 \%$ & 19 & $1,81 \%$ \\
\hline${ }^{\circ} \mathrm{C}$. HORA & -217 & $-0,88 \%$ & 63 & $1,73 \%$ \\
\hline
\end{tabular}

8-41 CUADRO DE DIFERENCIA ANUAL CUANDO LA TEMPERATURA ES MENOR DE $16^{\circ} \mathrm{C}$ (HORAS FRIAS) Y MAYOR DE $26^{\circ} \mathrm{C}$ (HORAS CÁLIDAS) EN GRADOS-HORA ENTRE LOS VALORES MEDIOS Y LOS REGISTRADOS EN LA ESTACIÓN METEOROLÓGICA DE VALDESPARTERA (AEMET y elaboración propia)

C. Comparación entre los valores medios y los registrados en la estación meteorológica del Aeropuerto.

En la estación meteorológica de Aeropuerto se han registrado temperaturas menores de $20^{\circ} \mathrm{C}$ un total de 2 horas menos que la media de las obtenidas en las tres estaciones meteorológicas de Zaragoza consideradas durante los periodos fríos del año 2014 (de enero a mayo y de octubre a diciembre), lo que supone un $0,05 \%$ del total de horas en que en ellas se han producido estas superaciones como media.

Se contabilizan, sin embargo, como 36 grados-hora más que la media de grados-hora acumulados durante todo el año en los mismos periodos en las tres estaciones de referencia de Zaragoza.

Durante el periodo cálido (de junio a septiembre) del año 2014 se han registrado en la estación meteorológica de Aeropuerto temperaturas mayores de $20^{\circ} \mathrm{C}$ un total de 45 horas más que la media de las obtenidas en las estaciones meteorológicas de Canal, de Valdespartera y del Aeropuerto de Zaragoza, lo que supone un $2,18 \%$ del total de las horas en que se han producido estas superaciones como media.

Se contabilizan como 122 grados-hora más, lo que representa una reducción del 1,00\% con respecto a la media de los acumulados 
durante el periodo cálido de dicho año en las estaciones de referencia.

\begin{tabular}{|c|c|r|r|r|}
\hline \multicolumn{5}{|c|}{$\begin{array}{c}\text { GRADOS-HORA Y PERIODOS MEDIOS MENOS } \\
\text { GRADOS-HORA Y PERIODOS AEROPUERTO }\end{array}$} \\
\hline \multicolumn{5}{|c|}{ GH 20/20 } \\
\hline \multirow{2}{*}{2014} & \multicolumn{2}{|c|}{ FRIO } & \multicolumn{1}{c|}{ CALIDO } \\
\cline { 2 - 5 } & M-A & $\%$ s/MEDIA & M-A & $\%$ s/MEDIA \\
\hline HORAS & 2 & $0,05 \%$ & -45 & $-2,18 \%$ \\
\hline${ }^{\circ}$ C.HORA & -36 & $-0,08 \%$ & -122 & $-1,00 \%$ \\
\hline
\end{tabular}

8-42 CUADRO DE DIFERENCIA ANUAL CUANDO LA TEMPERATURA ES MENOR DE $20^{\circ} \mathrm{C}$ DURANTE LOS PERIODOS FRÍOS (DE OCTUBRE A MAYO) Y MAYOR DE $20^{\circ} \mathrm{C}$ DURANTE LOS PERIODOS CÁLIDOS (DE JUNIO A SEPTIEMBRE) EN GRADOSHORA ENTRE LOS VALORES MEDIOS Y LOS REGISTRADOS EN LA ESTACIÓN METEOROLÓGICA DE AEROPUERTO (AEMET y elaboración propia)

Se comprueban también los valores obtenidos cuando se baja la temperatura, de $16^{\circ} \mathrm{C}$, para contabilizar los grados-hora en el periodo frío y los incrementos de la temperatura desde $26^{\circ} \mathrm{C}$ para contabilizar los grados-hora en el periodo cálido, observándose que, en la estación meteorológica de Aeropuerto se han registrado temperaturas menores de $16^{\circ} \mathrm{C}$ un total de 14 horas menos que en la media de las tres estaciones meteorológicas de Canal, de Valdespartera y del Aeropuerto de Zaragoza durante los periodos fríos (de enero a mayo y de octubre a diciembre) del año 2014, lo que supone un $0,34 \%$ del total de horas en que se han producido estas superaciones como media.

Esto se contabiliza, sin embargo, como 25 grados-hora más, lo que representa el $0,10 \%$ de los grados-hora de media acumulados durante los periodos fríos del año en las tres estaciones meteorológicas de referencia de Zaragoza.

También en la estación meteorológica del Aeropuerto se han registrado temperaturas superiores a $26^{\circ} \mathrm{C}$ un total de 16 horas menos que en la media de las estaciones meteorológicas de Canal, de Valdespartera y del Aeropuerto de Zaragoza durante el periodo cálido (de junio a septiembre) del año 2014, lo que supone un $0,79 \%$ del total de horas en que se han producido estas superaciones como media en las tres estaciones meteorológicas consideradas en Zaragoza.

Esto se contabiliza como 346 grados-hora menos que la media de los valores obtenidos en el periodo cálido en las tres estacioens meteorológicas de referencia, lo que representa un $2,83 \%$ de dicha media. 


\begin{tabular}{|c|c|r|c|r|}
\hline \multicolumn{3}{|c|}{$\begin{array}{c}\text { GRADOS-HORA Y PERIODOS MEDIOS MENOS } \\
\text { GRADOS-HORA Y PERIODOS AEROPUERTO }\end{array}$} \\
\hline \multicolumn{4}{|c|}{ GH 16/16 (FRIO) Y GH 26/26 (CALIDO) } \\
\hline \multirow{2}{*}{2014} & \multicolumn{2}{|c|}{ FRIO } & \multicolumn{2}{c|}{ CALIDO } \\
\cline { 2 - 5 } & M-A & $\%$ S/MEDIA & M-A & $\%$ S/MEDIA \\
\hline HORAS & 14 & $0,34 \%$ & 16 & $0,79 \%$ \\
\hline${ }^{\circ} \mathrm{C}$. HORA & -25 & $-0,10 \%$ & 346 & $2,83 \%$ \\
\hline
\end{tabular}

8-43 CUADRO DE DIFERENCIA ANUAL CUANDO LA TEMPERATURA ES MENOR DE $16^{\circ} \mathrm{C}$ DURANTE LOS PERIODOS FRÍOS (DE OCTUBRE A MAYO) Y MAYOR DE $26^{\circ} \mathrm{C}$ DURANTE LOS PERIODOS CÁLIDOS (DE JUNIO A SEPTIEMBRE) EN GRADOSHORA ENTRE LOS VALORES MEDIOS Y LOS REGISTRADOS EN LA ESTACIÓN METEOROLÓGICA DE AEROPUERTO (AEMET y elaboración propia)

Cuando la contabilidad se realiza a lo largo de todo el año atendiendo sólo a la superación de los umbrales, en la estación meteorológica del Aeropuerto se han registrado temperaturas menores de $16^{\circ} \mathrm{C}$ un total de 36 horas menos que la media obtenida en las estaciones meteorológicas de Canal, de Valdespartera y del Aeropuerto de Zaragoza durante el año 2014, lo que supone un $0,83 \%$ del total de las horas en que se han producido estas superaciones como media.

Se contabilizan sin embargo sólo 4 grados-hora de incremento, lo que representa el $0,02 \%$ de la media de los grados-hora obtenida en las tres estaciones de referencia.

También en la estación meteorológica del Aeropuerto se han se han registrado temperaturas mayores de $26^{\circ} \mathrm{C}$ un total de 3 horas más que la media de las estaciones meteorológicas de Canal, de Valdespartera y del Aeropuerto de Zaragoza durante el año 2014, lo que supone un $0,32 \%$ del total de horas en que se han producido estas superaciones como media durante todo el año en las tres estaciones de referencia.

Esto se contabiliza, sin embargo, como 68 grados-hora menos, lo que representa un $1,87 \%$ de la media de los acumulados durante todo el año en las tres estaciones de referencia.

\begin{tabular}{|c|c|r|c|r|}
\hline \multicolumn{5}{|c|}{$\begin{array}{c}\text { GRADOS-HORA Y PERIODOS MEDIOS MENOS } \\
\text { GRADOS-HORA Y PERIODOS AEROPUERTO }\end{array}$} \\
\hline \multicolumn{4}{|c|}{ GH 16/16 (FRIO) Y GH 26/26 (CALIDO) } \\
\hline \multirow{2}{*}{2014} & \multicolumn{3}{|c|}{ FRIO } & \multicolumn{2}{c|}{ CALIDO } \\
\cline { 2 - 5 } & M-A & $\%$ S/MEDIA & M-A & $\%$ S/MEDIA \\
\hline HORAS & 36 & $0,83 \%$ & -3 & $-0,32 \%$ \\
\hline${ }^{\circ} \mathrm{C}$.HORA & 4 & $0,02 \%$ & 68 & $1,87 \%$ \\
\hline
\end{tabular}

8-44 CUADRO DE DIFERENCIA ANUAL CUANDO LA TEMPERATURA ES MENOR DE $16^{\circ} \mathrm{C}$ (HORAS FRIAS) Y MAYOR DE $26^{\circ} \mathrm{C}$ (HORAS CÁLIDAS) EN GRADOS-HORA ENTRE LOS VALORES MEDIOS Y LOS REGISTRADOS EN LA ESTACIÓN METEOROLÓGICA DE AEROPUERTO (AEMET y elaboración propia) 
D. Comparación en grados-hora aplicada a varios años.

Aunque las comparativas se realizan para el año 2014, se comprueba que otros años presentan cifras similares en esta comparativa para establecer la homogeneidad de los resultados.

Para ello se dispone de datos de las estaciones meteorológicas de Canal y del Aeropuerto desde el año 2007. La estación meteorológica de Valdespartera, sin embargo, no dispone de datos para todo este periodo por lo que se ha concentrado la exploración de resultados en las dos estaciones con más información.

Se comparan por un lado los mínimos y máximos absolutos y medios diarios y por otra parte se comprueban los valores medios diarios del $2^{\circ}$ y $3 e r$. cuartil, las medias de las medianas y los promedios diarios. También se comprueban los grados-hora superiores a $26^{\circ} \mathrm{C}$ y el número de horas en que se producen estas superaciones, los grados hora menores de $16^{\circ} \mathrm{C}$ y la cantidad de horas en que esto se produce y las horas en que se mantiene la temperatura horaria entre $16^{\circ} \mathrm{C}$ y $26^{\circ} \mathrm{C}$.

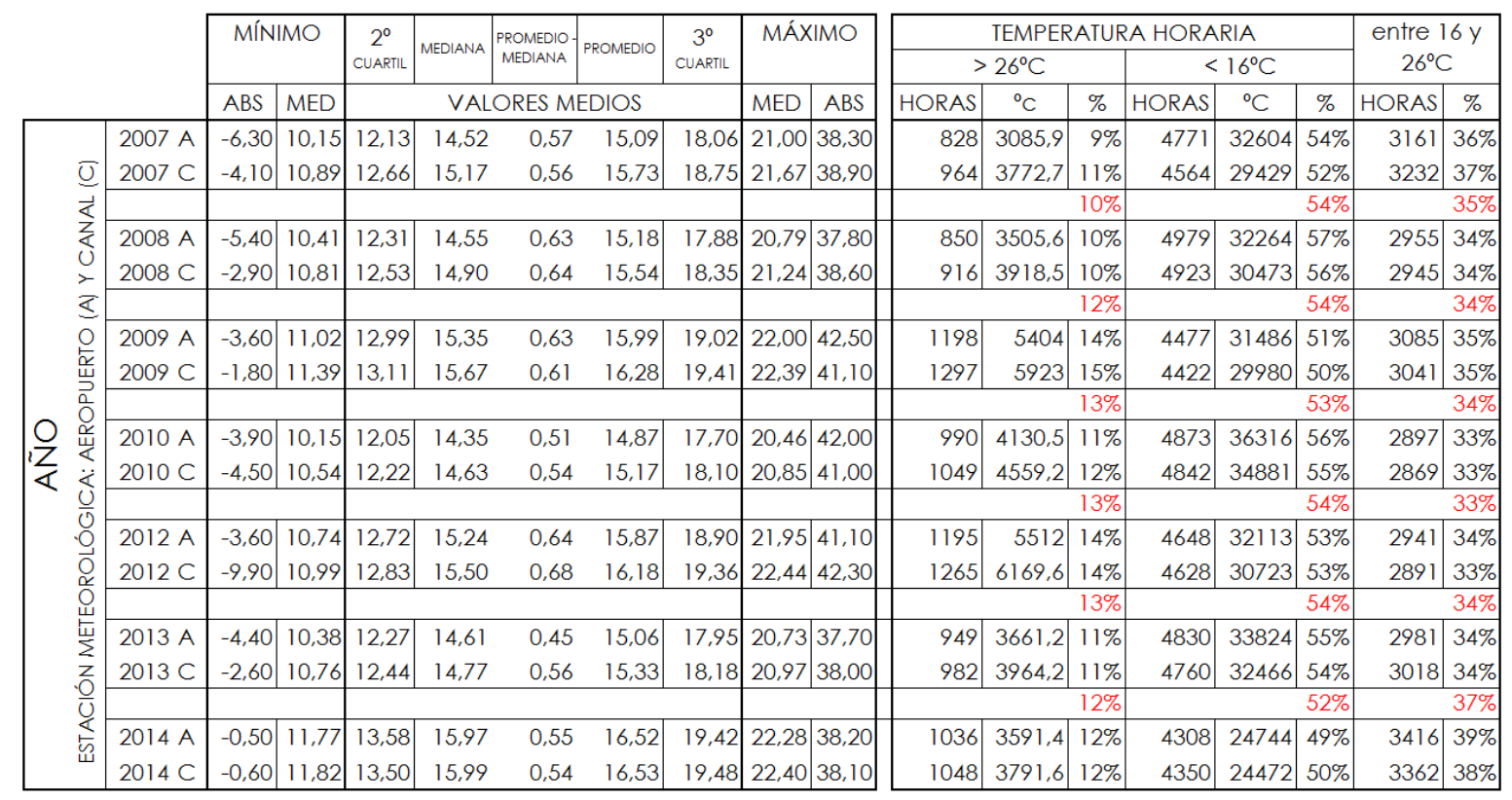

8-45 CUADRO COMPARATIVO ENTRE LAS ESTACIONES METEOROLÓGICAS DE CANAL

(C) Y DEL AEROPUERTO (A) DE ZARAGOZA DESDE EL AÑO 2007 AL 2014

(AEMET y elaboración propia) 


\begin{tabular}{|c|c|c|c|c|c|c|}
\hline \multicolumn{7}{|c|}{$\begin{array}{l}\text { @C MEDIOS ANUALES (EN NEGRO) Y } \\
\% \text { CON RESPECTO AL VALOR PROMEDIO (EN BLANCO) }\end{array}$} \\
\hline & $\begin{array}{l}\text { MIN2 } \\
\text { MET }\end{array}$ & $\begin{array}{c}\text { MED2 } 2 \\
\text { MET }\end{array}$ & $\mid \begin{array}{c}\operatorname{MAX2} 2 \\
\text { MET }\end{array}$ & $\begin{array}{l}\text { OSC } \\
\text { MET }\end{array}$ & MEDIA & \\
\hline \multirow{2}{*}{2005} & 9,98 & 20,56 & \begin{tabular}{|l|l|l|}
56,20 \\
\end{tabular} & 11,58 & 14,75 & \multirow{2}{*}{2005} \\
\hline & 0,93 & 1,32 & $\begin{array}{lll}2 & 0,97 \\
\end{array}$ & 1,01 & 0,95 & \\
\hline \multirow{2}{*}{2006} & 11,22 & 21,62 & 21,62 & 11,40 & 15,95 & \multirow{2}{*}{2006} \\
\hline & 1,04 & 1,39 & $\begin{array}{l}3,02 \\
1,02\end{array}$ & 0,99 & $\begin{array}{r}1,03 \\
150\end{array}$ & \\
\hline 2007 & $\begin{array}{r}10,24 \\
0,95 \\
\end{array}$ & $\begin{array}{r}20,85 \\
1,34\end{array}$ & $\begin{array}{r}20,85 \\
4 \quad 0,98 \\
\end{array}$ & \begin{tabular}{|r|}
$1,, 61$ \\
1,01 \\
\end{tabular} & $\begin{array}{r}15,09 \\
0,97 \\
\end{array}$ & 2007 \\
\hline 2008 & $\begin{array}{r}10,37 \\
0.9\end{array}$ & 20,72 & 20,72 & 11,35 & 15,08 & 2008 \\
\hline \multirow{2}{*}{2009} & 11,11 & 21,87 & 21,87 & 11,76 & 15,98 & \multirow{2}{*}{2009} \\
\hline & 1,03 & 1,41 & $1 \quad 1,03$ & 1,02 & 1,03 & \\
\hline \multirow{2}{*}{2010} & 10,25 & 20,33 & $\begin{array}{l}320,33 \\
\end{array}$ & 11,08 & 14,87 & \multirow{2}{*}{2010} \\
\hline & 0,95 & 1,31 & $\begin{array}{l}10,96 \\
\end{array}$ & 0,96 & 0,96 & \\
\hline \multirow{2}{*}{2011} & 11,36 & 21,93 & 321,93 & 11,57 & 16,16 & \multirow{2}{*}{2011} \\
\hline & 1,06 & 1,41 & $\begin{array}{l}1,03 \\
\end{array}$ & 1,01 & 1,04 & \\
\hline 2012 & $\begin{array}{r}10,85 \\
1,01 \\
\end{array}$ & $\begin{array}{r}21,86 \\
1,41\end{array}$ & $\begin{array}{r}21,86 \\
1,03\end{array}$ & $\begin{array}{r}12,01 \\
1,04\end{array}$ & $\begin{array}{r}15,86 \\
1,02\end{array}$ & 2012 \\
\hline \multirow{2}{*}{2013} & 10,26 & 20,66 & 20,66 & 11,39 & 15,06 & \multirow{2}{*}{2013} \\
\hline & 0,95 & 1,33 & $\begin{array}{ll}3 & 0,97 \\
\end{array}$ & 0,99 & 0,97 & \\
\hline 2014 & $\begin{array}{r}11,86 \\
1,10\end{array}$ & $\begin{array}{r}22,16 \\
1,43\end{array}$ & \begin{tabular}{|r|}
22,16 \\
3
\end{tabular} & $\begin{array}{r}11,30 \\
0,98\end{array}$ & $\begin{array}{r}16,52 \\
1,06\end{array}$ & 2014 \\
\hline \multirow[t]{2}{*}{$\begin{array}{l}\text { OC PROMEDIO } \\
\text { DE LA DÉCADA }\end{array}$} & 10,75 & 21,26 & 21,26 & 11,51 & 15,53 & \multirow[t]{2}{*}{$\begin{array}{l}\text { OC PROMEDIO } \\
\text { DE LA DÉCADA } \\
\end{array}$} \\
\hline & MIN & PROM & MAX & OSC & MEDIA & \\
\hline & & & & & & \\
\hline
\end{tabular}

8-46 CUADRO COMPARATIVO DE TEMPERATURAS MEDIAS ANUALES REPRESENTIVAS EN LA DECADA 2005-2014 ZARAGOZA. AEROPUERTO. (AEMET y elaboración propia)

E. Diferencia entre las temperaturas horarias registradas en las estaciones de referencias de Zaragoza.

Se ha considerado de interés la comparación de los datos obtenidos en cada una de las tres estaciones meteorológicas de referencia con la media de todas ellas, reflejando las diferencias en ${ }^{\circ} \mathrm{C}$ de sus valores máximos y mínimos absolutos y los percentiles que marcarán que dichos valores estén comprendidos entre el $98 \%$, el $90 \%$, el $50 \%$ y el $20 \%$, así como de el valor medio de las diferencias horarias a lo largo de todo el año.

Las diferencias de temperatura entre la media de las registradas en los observatorios meteorológicos de Canal, de Valdespartera y del Aeropuerto de Zaragoza y las registradas en cada uno de ellos tiene en común la existencia de valores absolutos muy distantes de la media, pero de muy escasa entidad en la serie. Por otra parte, el $90 \%$ de los registros están en un rango relativamente estrecho, del entorno de $1,5^{\circ} \mathrm{C}$, y el $98 \%$ en un rango del entorno de $3^{\circ} \mathrm{C}$.

E4 Comparación de los valores registrados en la estación meteorológica de Canal con los valores medios.

La diferencia media horaria a lo largo del año es superior en un $0,07^{\circ} \mathrm{C}$ al valor promedio de las tres estaciones.

La diferencia máxima registrada es de $3,77^{\circ} \mathrm{C}$ y la mínima de $4,67^{\circ} \mathrm{C}$ y tienen un carácter esporádico.

Sólo el $0,5 \%$ de los registros superan los valores medios en más de $1,77^{\circ} \mathrm{C}$ y sólo el $1 \%$ de los registros es inferior a la media en más de 
$2,03^{\circ} \mathrm{C}$, por lo que se mantienen un $99 \%$ de las diferencias en un rango de $3,80^{\circ} \mathrm{C}$.

El $90 \%$ de los valores registrados está comprendido entre $+0,77^{\circ} \mathrm{C}$ y $-0,63^{\circ} \mathrm{CC}$ con respecto a los valores medios, por lo que están en un rango de $1,40^{\circ} \mathrm{C}$.

El $50 \%$ de las diferencias está en un rango de $0,53^{\circ} \mathrm{C}$.

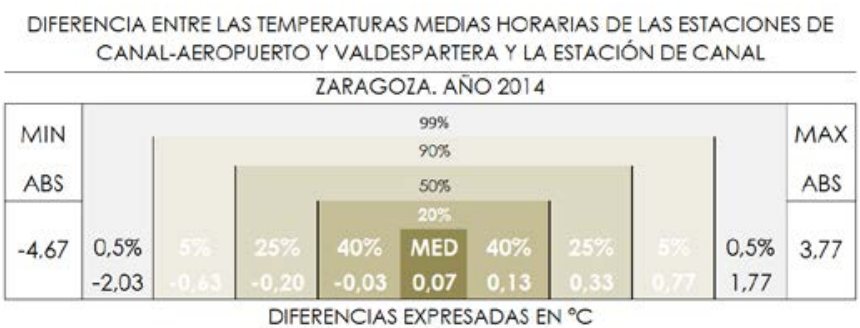

8-47 CUADRO DE PERCENTILES Y MÁXIMOS Y MÍNIMOS ABSOLUTOS DE LAS DIFERENCIAS DE LAS TEMPERATURAS HORARIAS ENTRE LOS VALORES MEDIOS DE LAS ESTACIONES METEOROLÓGICAS DE CANAL, VALDESPARTERA Y AEROPUERTO DE ZARAGOZA Y LA ESTACIÓN METEOROLÓGICA DE CANAL, DURANTE EL AÑO 2014 (AEMET Y elaboración propia)

La gráfica anual de las diferencias horarias muestra como los máximos absolutos sólo se alcanzan muy ocasionalmente y las diferencias se encuentran en su mayoría en un rango muy estrecho.

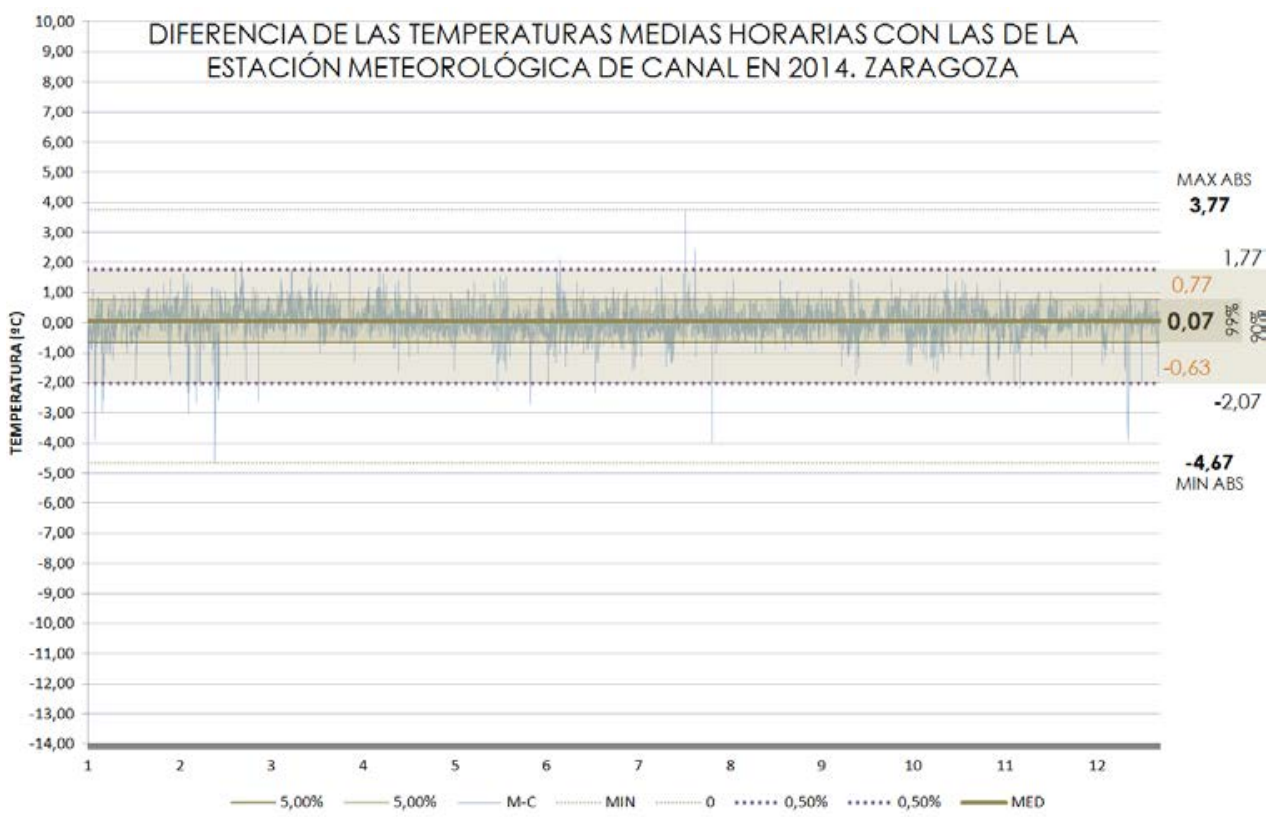

8-48 GRAFICA ANUAL DE LAS DIFERENCIAS DE LAS TEMPERATURAS HORARIAS ENTRE LOS VALORES MEDIOS DE LAS ESTACIONES METEOROLÓGICAS DE CANAL, VALDESPARTERA Y AEROPUERTO DE ZARAGOZA Y LA ESTACIÓN METEOROLÓGICA DE CANAL, DURANTE EL AÑO 2014 (AEMET Y elaboración propia) 
E5 Comparación de los valores registrados en la estación meteorológica de Valdespartera y los valores medios.

La diferencia media horaria a lo largo del año es inferior en $0,1^{\circ} \mathrm{C}$ al valor promedio de las tres estaciones.

La diferencia máxima registrada es de $6,40^{\circ} \mathrm{C}$ y la mínima de $2,97^{\circ} \mathrm{C}$ y tienen un carácter esporádico.

Sólo el $1 \%$ de los registros está fuera del rango está entre $-1,13^{\circ} \mathrm{C}$ y $+1,63^{\circ} \mathrm{C}$, o lo que es lo mismo, el $99 \%$ de las temperaturas se mantienen en un rango de $2,76^{\circ} \mathrm{C}$.

El $90 \%$ de los valores registrados está comprendido entre $+0,67^{\circ} \mathrm{C}$ y - $0,63^{\circ} \mathrm{C}$ con respecto a los valores medios, por lo que están en un rango de $1,30^{\circ} \mathrm{C}$.

El $50 \%$ de los valores registrados están entre $-0,30^{\circ} \mathrm{C}$ y $0,13^{\circ} \mathrm{C}$, por lo que se mantienen en un rango de $0,43^{\circ} \mathrm{C}$.

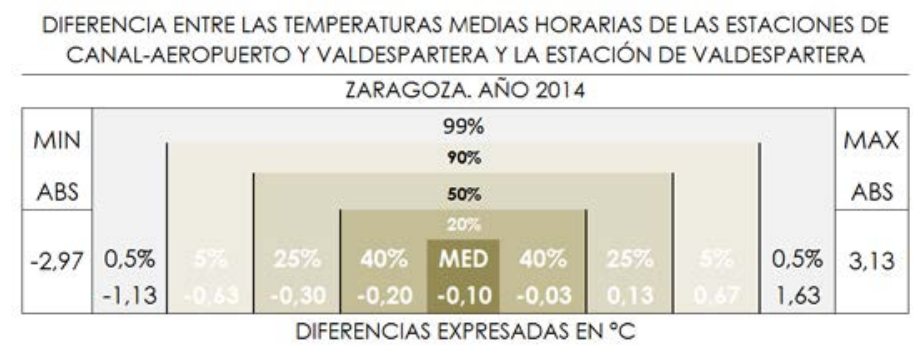

8-49 CUADRO DE PERCENTILES Y MÁXIMOS Y MÍNIMOS ABSOLUTOS DE LAS DIFERENCIAS DE LAS TEMPERATURAS HORARIAS ENTRE LOS VALORES MEDIOS DE LAS ESTACIONES METEOROLÓGICAS DE CANAL, VALDESPARTERA Y AEROPUERTO DE ZARAGOZA Y LA ESTACIÓN METEOROLÓGICA DE VALDESPARTERA, DURANTE EL AÑO 2014 (AEMET Y elaboración propia)

La gráfica anual de las diferencias horarias muestra cómo los máximos absolutos sólo se alcanzan muy ocasionalmente y las diferencias se encuentran también, en su mayoría, dentro de un rango muy estrecho. 


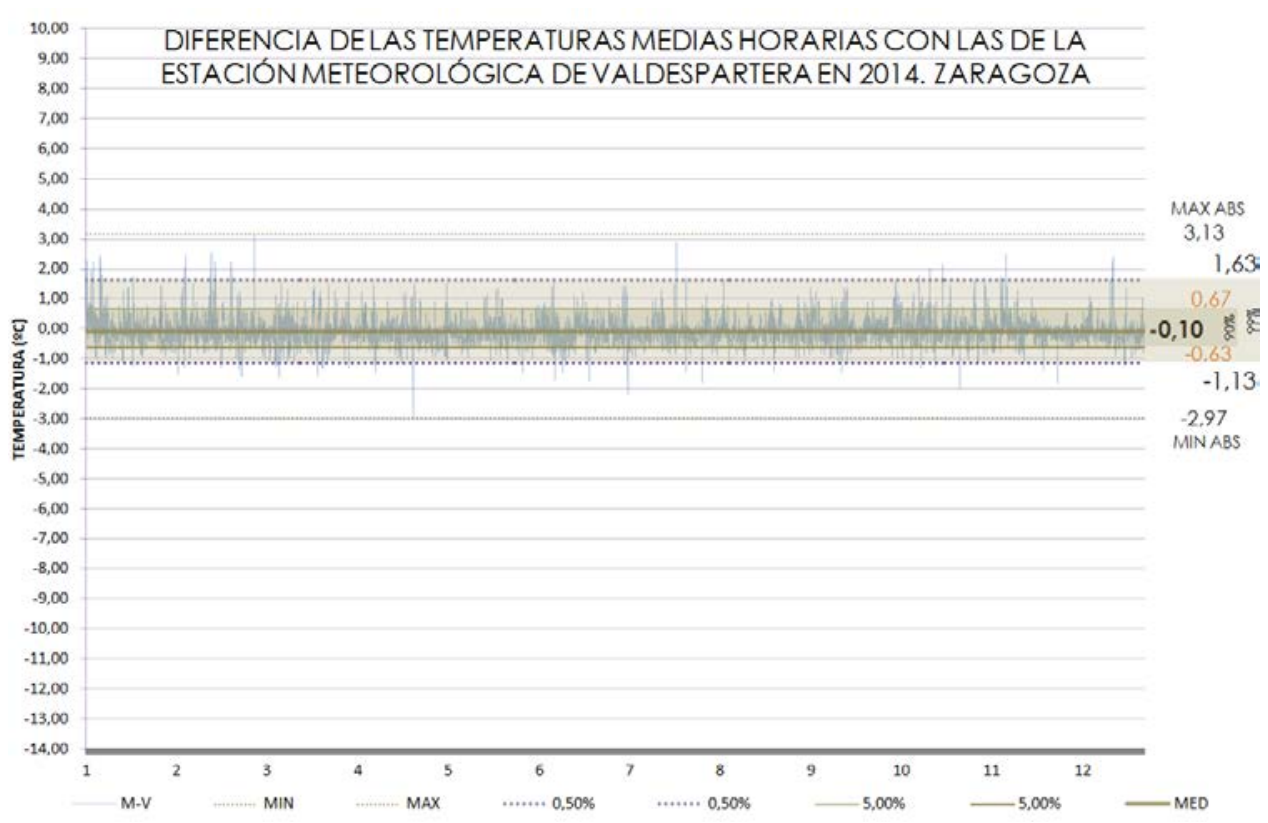

8-50 GRAFICA ANUAL DE LAS DIFERENCIAS DE LAS TEMPERATURAS HORARIAS ENTRE LOS VALORES MEDIOS DE LAS ESTACIONES METEOROLÓGICAS DE CANAL, VALDESPARTERA Y AEROPUERTO DE ZARAGOZA Y LA ESTACIÓN METEOROLÓGICA DE VALDESPARTERA, DURANTE EL AÑO 2014 (AEMET Y elaboración propia)

\section{E6 COMPARACIÓN ENTRE VALORES REGISTRADOS EN AEROPUERTO Y VALORES MEDIOS}

La diferencia media horaria a lo largo del año es superior en $0,07^{\circ} \mathrm{C}$ al valor promedio de las tres estaciones.

La diferencia máxima registrada es de $6,20^{\circ} \mathrm{C}$ y la mínima de $6,63^{\circ} \mathrm{C}$ y tienen un carácter esporádico.

Sólo el $1 \%$ de los registros es inferior $a-1,13^{\circ} \mathrm{C}$ o superior $a+1,63^{\circ} \mathrm{C}$, por lo que el $99 \%$ de las temperaturas se mantienen en un rango de $2,76^{\circ} \mathrm{C}$.

El $90 \%$ de los valores registrados está comprendido entre $+0,80^{\circ} \mathrm{C}$ y $-0,87^{\circ} \mathrm{C}$ con respecto a los valores medios, por lo que están en un rango de $1,67^{\circ} \mathrm{C}$.

El $50 \%$ de los valores registrados están entre $-0,27^{\circ} \mathrm{C}$ y $+0,33^{\circ} \mathrm{C}$, por lo que se mantienen en un rango de $0,60^{\circ} \mathrm{C}$. 
DIFERENCIA ENTRE LAS TEMPERATURAS MEDIAS HORARIAS DE LAS ESTACIONES DE CANAL-AEROPUERTO Y VALDESPARTERA Y LA ESTACIÓN DE AEROPUERTO

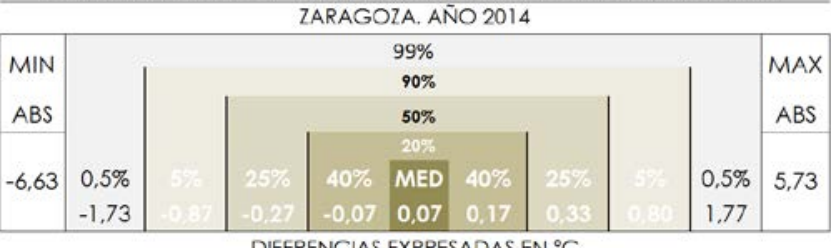

DIFERENCIAS EXPRESADAS EN ${ }^{\circ} \mathrm{C}$

8-51 CUADRO DE PERCENTILES Y MÁXIMOS Y MÍNIMOS ABSOLUTOS DE LAS DIFERENCIAS DE LAS TEMPERATURAS HORARIAS ENTRE LOS VALORES MEDIOS DE LAS ESTACIONES METEOROLÓGICAS DE CANAL, VALDESPARTERA Y AEROPUERTO DE ZARAGOZA Y LA ESTACIÓN METEOROLÓGICA DEL AEROPUERTO, DURANTE EL AÑO 2014 (AEMET Y elaboración propia)

La gráfica anual de las diferencias horarias muestra como los máximos absolutos solo se alcanzan muy ocasionalmente y las diferencias se encuentran también en su mayoría en un rango muy estrecho.

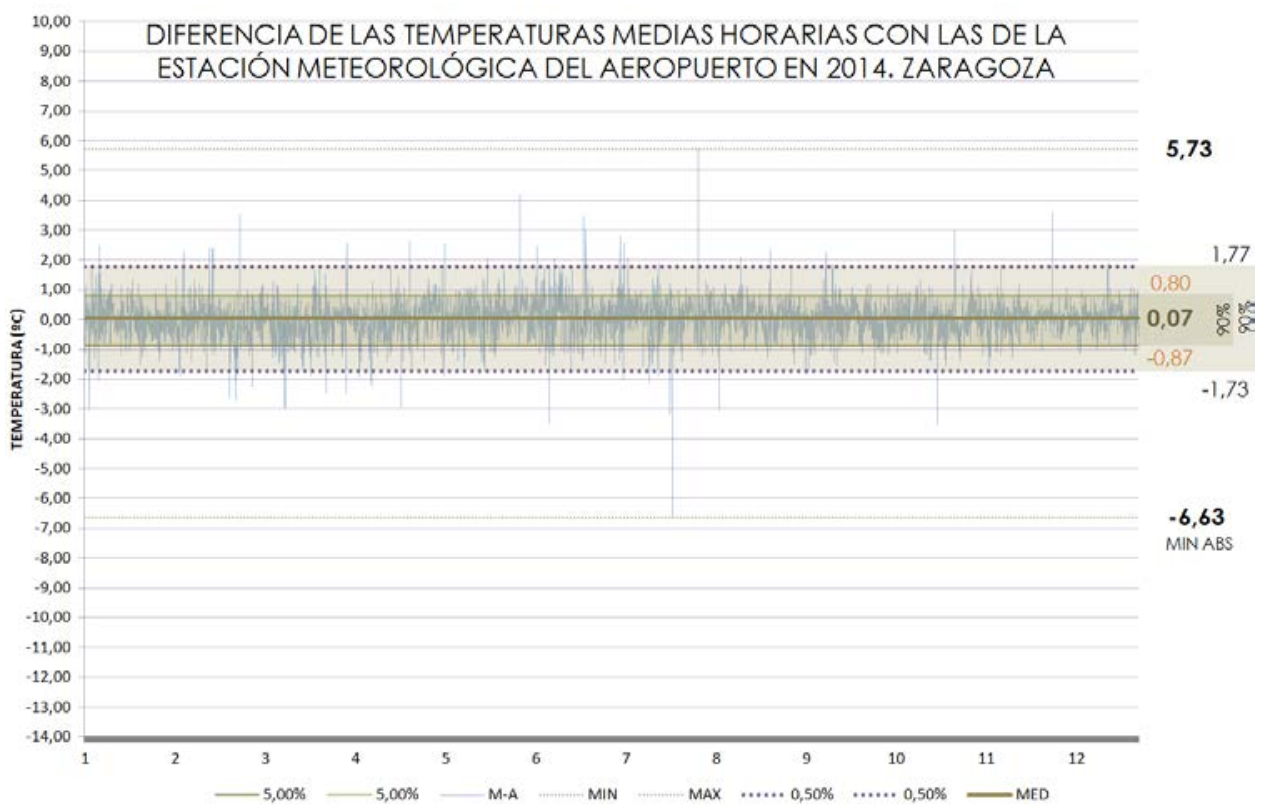

8-52 GRAFICA ANUAL DE LAS DIFERENCIAS DE LAS TEMPERATURAS HORARIAS ENTRE LOS VALORES MEDIOS DE LAS ESTACIONES METEOROLÓGICAS DE CANAL, VALDESPARTERA Y AEROPUERTO DE ZARAGOZA Y LA ESTACIÓN METEOROLÓGICA DEL AEROPUERTO, DURANTE EL AÑO 2014 (AEMET Y elaboración propia)

F. Conclusión del análisis comparativo entre estaciones.

Las cuantías absolutas y relativas de las diferencias son muy pequeñas por lo que no parece significativo considerar atendiendo a este factor, una $u$ otra estación para las precisiones requeridas en edificación para la evaluación termodínámica que requiere la adaptación a la gran variedad de estados higrotérmicos que pueden producirse durante la vida útil del edificio. La precisión de las cualidades termodinámicas de los componentes del edificio, el patrón de uso y los rangos de confort en edificación superan con mucho estas cifras en su rangos de precisión.

Aún así parece significativo que las mayores desviaciones se observen en las superaciones de $26^{\circ} \mathrm{C}$ en periodos cálidos, tanto 
en horas como en grados. Podría ser un indicador de la urbanidad (isla de calor) de las ubicaciones.

En general las gráficas anuales de desviaciones por percentiles indican que las diferencias en horas y en grados son muy pequeñas y que los máximos absolutos sólo se alcanzan muy ocasionalmente, de modo que las diferencias se encuentran también en su mayoría en un rango muy estrecho. 

MÁXIMA, MÍNIMA, MEDIA Y OSCILACIÓN TÉRMICA

Observando la evolución a lo largo del año de las temperaturas medias diarias en las distintas estaciones meteorológicas es posible realizar un gráfico con los valores superpuestos. Las curvas de regresión de estos valores ofrecen una imagen bastante clara del incremento de las diferencias en los meses más cálidos y de su reducción en los más fríos.

TEMPERATURA ANUAL MEDIA DIARIA. ZARAGOZA 10 DE JUNIO 2013- 10 DE JUNIO 2014

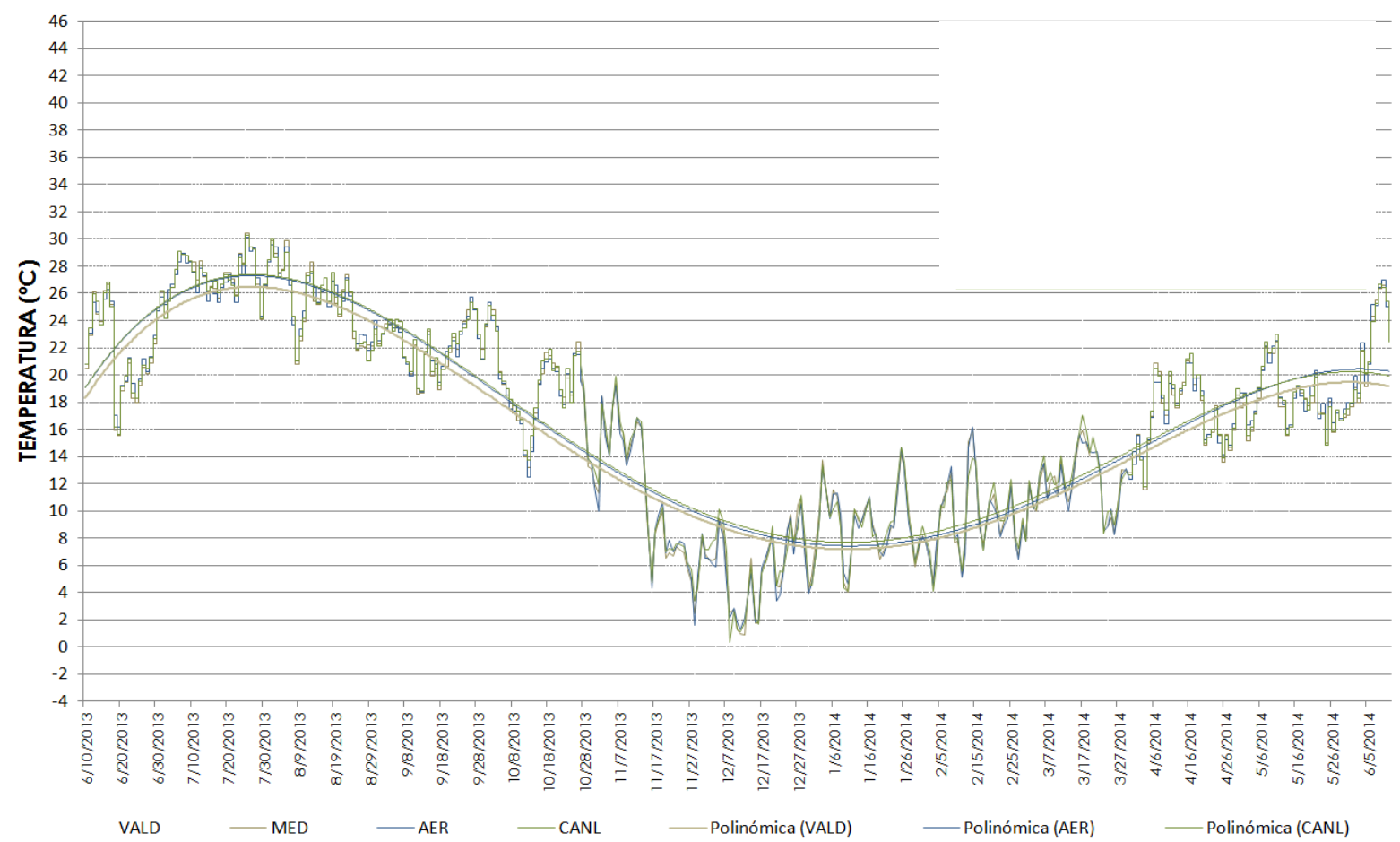

8-53 GRÁFICA ANUAL DE TEMPERATURAS MEDIAS DIARIAS EN LAS ESTACIONES DE REFERENCIA EN ZARAGOZA (10/06/2013-10/06/2014) (AEMET y elaboración propia)

Los valores medios sólo son parcialmente significativos para establecer una relación entre la temperatura ambiente y la del interior de los edificios. Lo que realmente importa es considerar las oscilaciones térmicas y los valores máximos y mínimos.

Para comprobarlo se realiza una comparativa entre las medias de los valores obtenidos en las tres estaciones consideradas en Zaragoza. 
A. Comparación conjunta de los valores registrados en las tres estaciones.

En una primera aproximación, la observación de la lectura comparada de los valores obtenidos en las estaciones meteorológicas de Zaragoza situadas en el Aeropuerto, en el Canal y en Valdespartera, muestran pequeñas diferencias no lineales, como puede observarse en la gráfica superpuesta de los valores de temperatura y especialmente en sus líneas de tendencia:

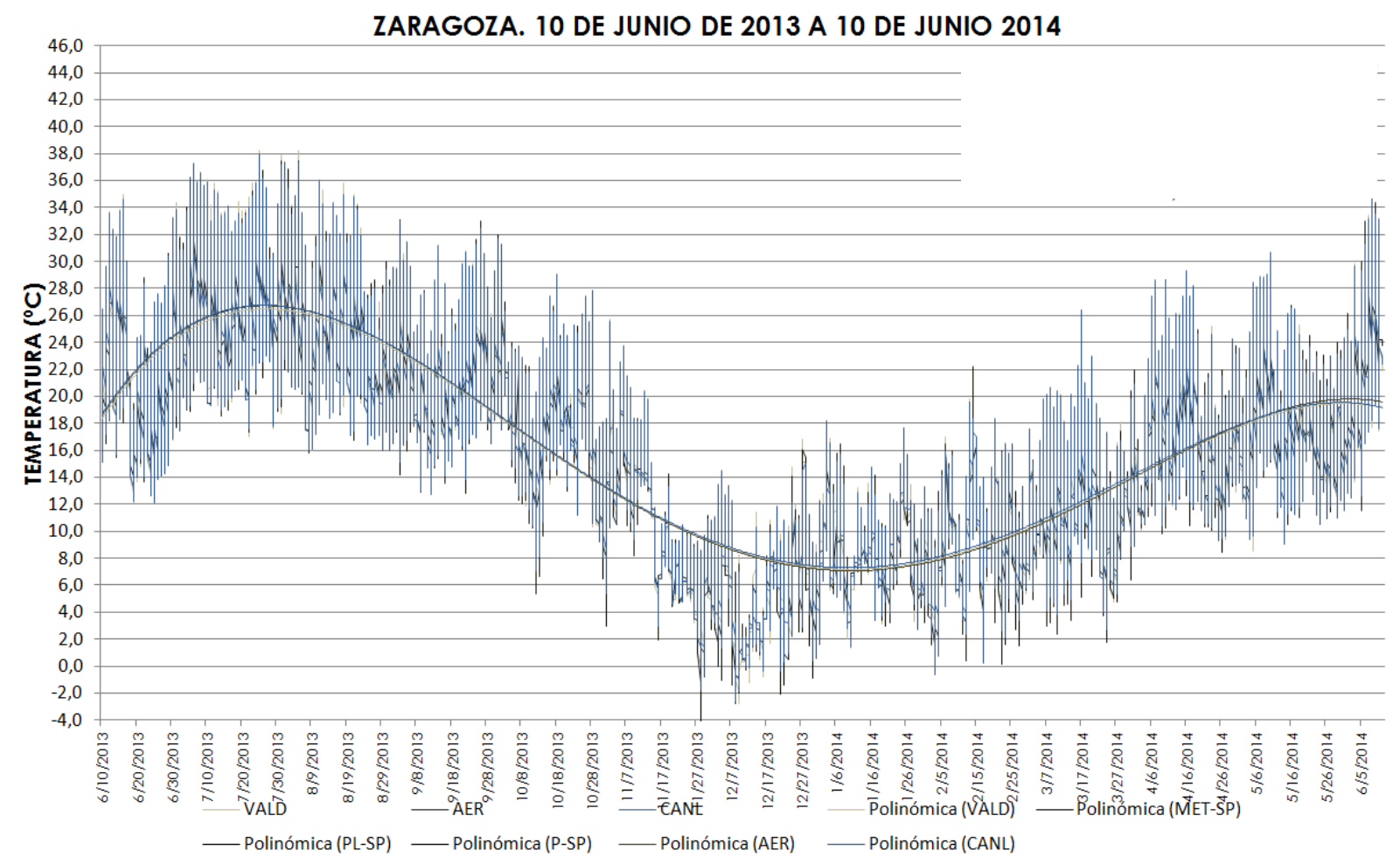

8-54 GRÁFICA ANUAL DE TEMPERATURAS HORARIAS EN LAS ESTACIONES DE REFERENCIA EN ZARAGOZA (10/06/2013-10/06/2014) (AEMET y elaboración propia)

En las tres estaciones y en un periodo anual (10/06/2013 a 10/06/2014), las desviaciones con respecto a los valores medios anuales está entre $-0,4$ y $+0,1$, lo que indica una cierta asimetría de los valores y una magnitud absoluta poco significativa en valores medios.

Tampoco la observación de los valores mínimos y máximos absolutos arroja diferencias de gran magnitud, estando comprendidas entre $+0,2^{\circ} \mathrm{C}$ y $-0,3^{\circ} \mathrm{C}$ para las máximas absolutas y de $-1,7^{\circ} \mathrm{C}$ y $+0,1^{\circ} \mathrm{C}$, para las mínimas absolutas. Tampoco la diferencia entre estos valores es significativos aunque se observa una cierta asimetría en los valores mínimos.

La media de las desviaciones sobre el valor medio de las mínimas es de casi tres grados y de casi cuatro grados y medio con respecto a las máximas, mientras que las desviaciones con respecto a la media son del orden de centésimas. Esto indica que, aunque las diferencias mencionadas pueden ser significativas puntualmente en lo referente a sus valores medios, son poco relevantes. 
Se muestra el detalle de estos valores, obtenidos de datos registrados por AEMET

\begin{tabular}{c|ccc|cccc|c|}
\cline { 2 - 8 } & \multicolumn{4}{|c|}{ TEMPERATURAS $\left.^{\circ}{ }^{\circ} \mathrm{C}\right)$} & \multicolumn{4}{c|}{ DIFERENCIAS CON LA MEDIA $\left({ }^{\circ} \mathrm{C}\right)$} \\
\cline { 2 - 8 } & AER & VALD & CANL & MEDIA & AER & VALD & CANL & MEDIA \\
\hline MIN & $-4,4$ & $-2,8$ & $-2,6$ & $-2,7$ & $-3,5$ & $-3,0$ & $-2,1$ & $-2,9$ \\
MEDIA & 16,1 & 15,7 & 16,2 & 16,1 & $-0,032$ & $-0,033$ & $-0,064$ & $-0,0431$ \\
MAX & 37,7 & 38,2 & 38,0 & 38,0 & 4,2 & 4,4 & 4,7 & 4,4 \\
\hline
\end{tabular}

8-55 CUADRO COMPARATIVO DE TEMPERATURAS MÍNIMAS, MEDIAS, MÁXIMAS EN LAS ESTACIONES METEOROLÓGICAS DE CANAL,VALDESPARTERA Y AEROPUERTO DE ZARAGOZA 10-06-2013 A 10-06-2014 (AEMET Y elaboración propia)

Estas diferencias a lo largo del año ofrecen una imagen en la que los valores térmicos observados en la estación situada en el Aeropuerto ofrece más extremos negativos, mientras que en todas las estaciones se observan puntuales máximos distribuidos a lo largo del año, con la inmensa mayoría de las diferencias comprendidas entre valores de $+1^{\circ} \mathrm{C}$ y $-1^{\circ} \mathrm{C}$, con un $50 \%$ de los valores entre $-0,3^{\circ} \mathrm{C}$ y $+0,3^{\circ} \mathrm{C}$.

\begin{tabular}{c|ccc|c|ccc|c|}
\cline { 2 - 9 } & \multicolumn{4}{|c|}{ TEMPERATURAS $\left({ }^{\circ} \mathrm{C}\right)$} & \multicolumn{4}{c|}{ DIFERENCIAS CON $2^{\circ}$ cuartil $\left({ }^{\circ} \mathrm{C}\right)$} \\
\cline { 2 - 9 } & AER & VALD & CANL & MEDIA & AER & VALD & CANL & MEDIA \\
\hline $2^{\circ}$ CUARTIL & 9,8 & 9,6 & 9,9 & 9,8 & $-0,3$ & $-0,3$ & $-0,3$ & $-0,250$ \\
3 3er CUARTIL & 21,8 & 21,2 & 21,8 & 21,7 & 0,3 & 0,2 & 0,2 & 0,156 \\
\hline
\end{tabular}

8-56 CUADRO COMPARATIVO DEL $2^{\circ}$ Y $3 E R$. EN LAS ESTACIONES METEOROLÓGICAS DE CANAL,VALDESPARTERA Y AEROPUERTO DE ZARAGOZA 10-06-2013 A 1006-2014 (AEMET y elaboración propia) 
La magnitud de las diferencias por tanto, con respecto a los valores promedio obtenidos a partir de las tres fuentes, es, como máximo, de $4,7^{\circ} \mathrm{C}$, con una diferencia media muy pequeña $\left(0,0431^{\circ} \mathrm{C}\right)$.

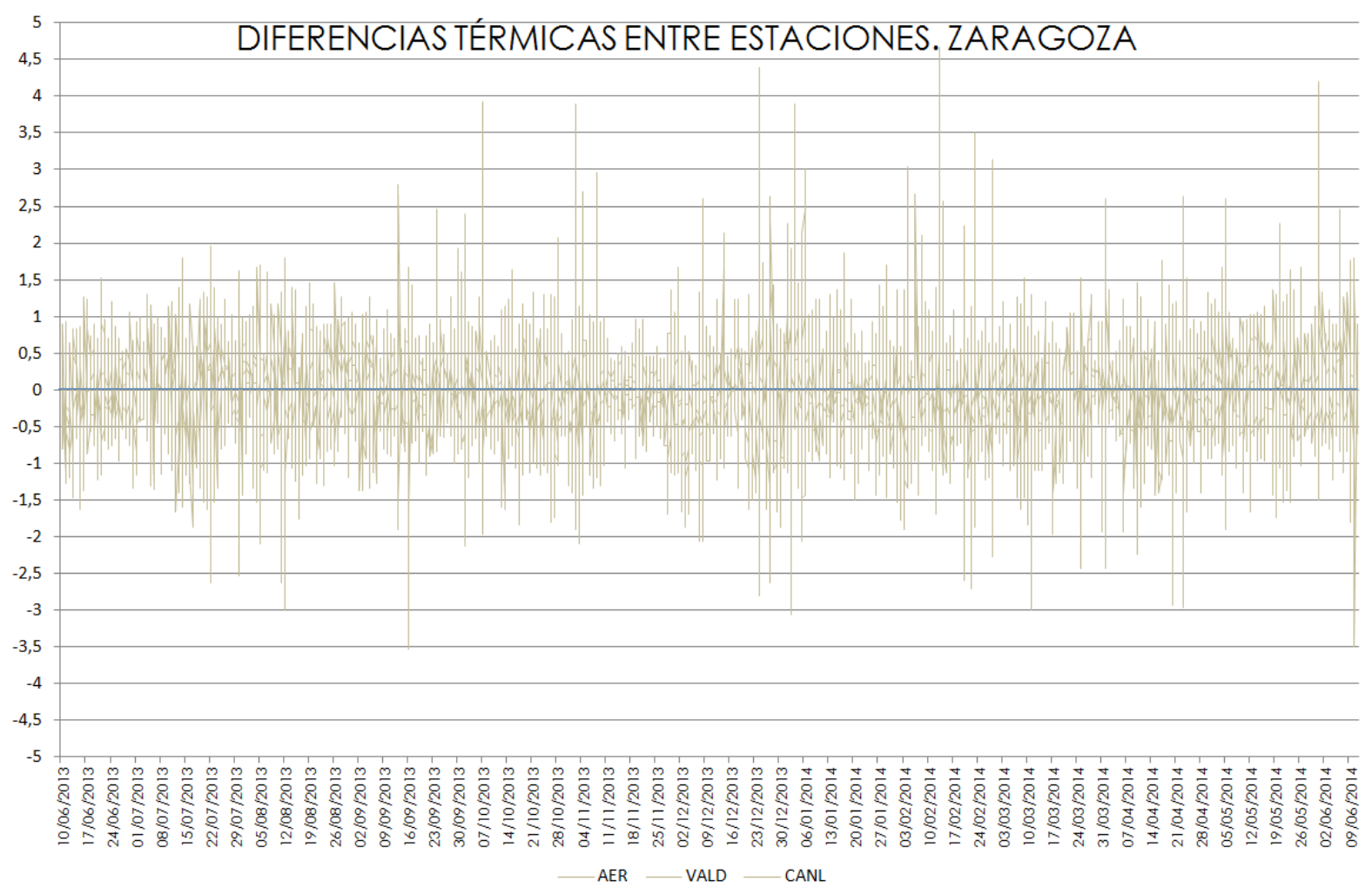

8-57 GRAFICA ANUAL DE LAS DIFERENCIAS DE LAS TEMPERATURAS HORARIAS ENTRE LOS VALORES MEDIOS DE LAS ESTACIONES METEOROLÓGICAS DE CANAL, VALDESPARTERA Y AEROPUERTO DE ZARAGOZA DE 10/06/2013 A 10/06/2014 (AEMET y elaboración propia)

Las temperaturas medias, mínimas y máximas diarias registradas en las tres estaciones a una misma hora presentan una gran similitud. Para observar la magnitud de estas diferencias se han comparado de dos en dos, lo cual ofrece una imagen porcentualmente pequeña de horas y días con diferencias significativas entre ellas.

Los días en que se producen diferencias mayores de $1^{\circ} \mathrm{C}$ entre los valores medios observados en las estaciones son muy escasos. Entre las estaciones meteorológicas del Aeropuerto y de Canal, sólo hay diferencias mayores de $1^{\circ} \mathrm{C}$ en las medias diarias durante 12 días (3,29\%), entre las estaciones del Aeropuerto y de Valdespartera se producen superaciones de esta diferencia durante 4 días $(1,1 \%)$ y entre las de Canal y la de Valdespartera durante 6 días $(1,64 \%)$.

Los valores máximos registrados en las estaciones muestran diferencias de más de un grado en más ocasiones, mostrándose muy parecidas las de Canal y las de Valdespartera, donde son mayores de $1^{\circ} \mathrm{C}$ durante 37 días $(10,14 \%)$ y las más diferentes las del Aeropuerto y las de Canal, en que se producen durante 54 días (14,79\%).

Los valores mínimos muestran diferencias de más de $1^{\circ} \mathrm{C}$ entre las estaciones del Aeropuerto y la de Canal en que se producen en 58 
días $(15,89 \%)$ y en muy pocos días, 6 días $(1,64 \%)$, entre las estaciones de Canal y de Valdespartera.

\begin{tabular}{|c|c|c|c|c|c|c|c|c|c|}
\hline \multirow{3}{*}{$\stackrel{ \pm}{\text { ঠ }}$} & \multicolumn{9}{|c|}{ DIFERENCIAS $>1{ }^{\circ} \mathrm{C}$} \\
\hline & \multicolumn{3}{|c|}{ MEDIA DIARIA } & \multicolumn{3}{|c|}{ MÁXIMA DIARIA } & \multicolumn{3}{|c|}{ MÍNIMA DIARIA } \\
\hline & AER-CNL. & AER-VALD & CNL-VALD & AER-CNL & AER-VALD & CNL-VALD & AER-CNL & AER-VALD & CNL-VALD \\
\hline DÍAS & 12 & 4 & 6 & 54 & 44 & 37 & 58 & 30 & 6 \\
\hline$\%$ & $3,29 \%$ & $1,10 \%$ & $1,64 \%$ & $14,79 \%$ & $12,05 \%$ & $10,14 \%$ & $15,89 \%$ & $8,22 \%$ & $1,64 \%$ \\
\hline
\end{tabular}

8-58 CUADRO CON LA COMPARACIÓN DE LOS VALORES MEDIOS, MÁXIMOS Y MÍNIMOS DIARIOS ENTRE LAS TRES ESTACIONES DE REFERENCIA EN ZARAGOZA. AÑO 2014 (AEMET y elaboración propia)

En la comparación de las temperaturas registradas en las estaciones a una misma hora se observan días en que estas secuencias no siguen esta correlación. La contabilidad de estas comparaciones de dos en dos estaciones ofrece una imagen porcentualmente pequeña de horas y días con saltos bruscos entre ellas.

La comparación entre los registros obtenidos en las estaciones meteorológicas de Canal y de Valdespartera en el año 2014, pone de manifiesto que sólo en 2 días $(0,55 \%)$ durante el año se han producido diferencias mayores de $3^{\circ} \mathrm{C}$ y sólo en 18 días $(4,93 \%)$ se han producido diferencias mayores de $3^{\circ} \mathrm{C}$.

Entre las estaciones del Aeropuerto y de Valdespartera las diferencias mayores de $3^{\circ} \mathrm{C}$ se producen en 17 días $(4,66 \%)$, siendo estas diferencias mayores de $3^{\circ} \mathrm{C}$ durante 26 días $(7,12 \%)$.

Aunque algo mayores estas diferencias entre las estaciones de Aeropuerto y Canal durante 33 días $(9,04)$ las diferencias superan los $2^{\circ} \mathrm{C}$, y durante 19 días $(5,21 \%)$.

También pueden documentarse frecuentes diferencias mayores de $1{ }^{\circ} \mathrm{C}$, que oscilan entre la ligera superación del $70 \%$ de los días entre las estaciones del Aeropuerto y de Canal y aproximadamente el $37,5 \%$ de los días entre las estaciones de Canal y de Valdespartera. Aún así, las horas durante las que se producen estas diferencias mayores de $1^{\circ} \mathrm{C}$ no son más del $11,40 \%$ de las posibles en el mayor de los casos ni del 4,8\% de los días, en el menor de ellos.

\begin{tabular}{|c|c|c|c|c|c|c|c|c|c|c|}
\hline & 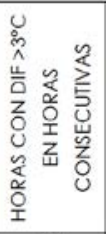 & 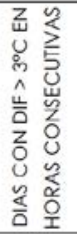 & 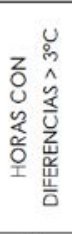 & 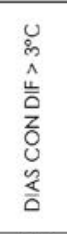 & 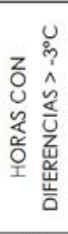 & 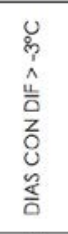 & 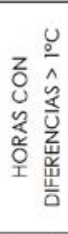 & 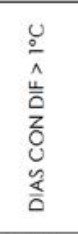 & 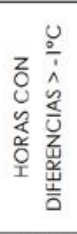 & 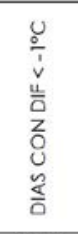 \\
\hline \multirow{2}{*}{$\mathrm{AE}-\mathrm{CN}$} & 76 & 50 & 65 & 33 & 27 & 19 & 728 & 235 & 998 & 258 \\
\hline & $20,82 \%$ & $13,70 \%$ & $0,74 \%$ & $9.04 \%$ & $0.31 \%$ & $5.21 \%$ & $8.31 \%$ & $64,38 \%$ & $11,39 \%$ & $70,68 \%$ \\
\hline \multirow{2}{*}{$A E-V$} & 59 & 35 & 19 & 17 & 33 & 26 & 701 & 249 & 648 & 218 \\
\hline & $16,16 \%$ & $9,59 \%$ & $0,22 \%$ & $4,66 \%$ & $0,38 \%$ & $7,12 \%$ & $8,00 \%$ & $68,22 \%$ & $7,40 \%$ & $59,73 \%$ \\
\hline \multirow{2}{*}{$\mathrm{CN}-\mathrm{V}$} & 24 & 15 & 2 & 2 & 56 & 18 & 497 & 208 & 418 & 137 \\
\hline & $6,58 \%$ & $4,11 \%$ & $0,02 \%$ & $0,55 \%$ & $0,64 \%$ & $4,93 \%$ & $5,67 \%$ & $56,99 \%$ & $4,77 \%$ & $37,53 \%$ \\
\hline
\end{tabular}

8-59 CUADRO CON LA COMPARACIÓN DE LAS DIFERENCIAS ENTRE LAS ESTACIONES DE REFERENCIA EN ZARAGOZA DURANTE EL AÑO 2014 (AEMET Y elaboración propia) 
B. Temperaturas máximas, mínimas y medias y oscilaciones térmicas en la estación meteorológica de Canal

Los valores medios de las máximas, mínimas y medias diarias y los valores absolutos máximos y mínimos obtenidos en la estación meteorológica de Canal siguen las pautas ya observadas, de modo que las temperaturas tienen una gran diferencia entre los periodos cálidos y fríos y las oscilaciones térmicas se reducen en invierno para aumentar durante el verano.

TEMPERATURA HORARIA. ESTACIÓN METEOROLÓGICA CANAL.

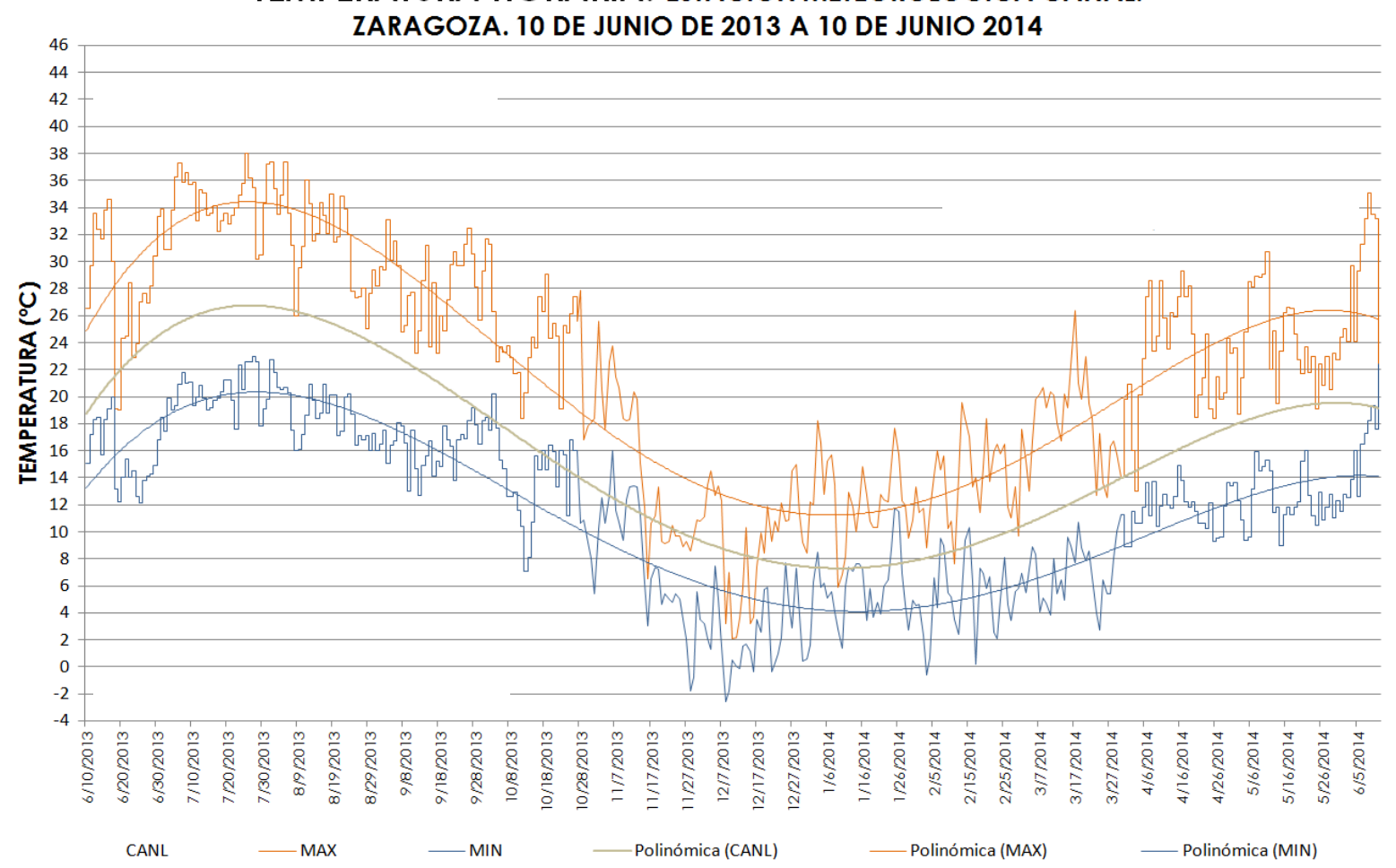

8-60 GRÁFICA DE LAS TEMPERATURAS MÁXIMAS, MÍNIMAS Y MEDIAS DIARIAS EN LA ESTACIÓN METEOROLÓGICA DE CANAL EN ZARAGOZA, DURANTE EL AÑO 2014 (AEMET y elaboración propia)

Para resumir los valores significativos en la estación de Canal se emplean los valores máximos, medios y mínimos de sus valores absolutos, máximos, promedio, mínimos y oscilaciones térmicas, donde puede observarse cómo las temperaturas absolutas a lo largo del año se mueven en un rango de casi $39^{\circ} \mathrm{C}$, las máximas de algo menos de $34^{\circ} \mathrm{C}$, las mínimas de casi $23^{\circ} \mathrm{C}$, no superando nunca parámetros convencionales de confort, las temperaturas promedio están en un rango de algo más de $26^{\circ} \mathrm{C}$ y, lo que tiene una gran importancia para el equilibrio higrotérmico del edificio, las oscilaciones térmicas están entre el $1,5^{\circ} \mathrm{C}$ y casi el $19^{\circ} \mathrm{C}$, siendo, según se observa en el gráfico, de mayor valor durante los periodos cálidos. 


\begin{tabular}{|r|r|r|r|r|}
\hline \multicolumn{5}{|c|}{ CANAL } \\
\hline ABS & MAX & PROM & MIN & OSC \\
\hline$-0,60$ & 4,50 & 2,58 & $-0,60$ & 1,50 \\
\hline 16,54 & 22,24 & 16,54 & 11,81 & 10,43 \\
\hline 38,10 & 38,10 & 28,94 & 22,30 & 18,90 \\
\hline
\end{tabular}

8-61 CUADRO DE LAS TEMPERATURAS ABSOLUTAS Y MEDIAS DIARIAS EN LA ESTACIÓN METEOROLÓGICA DE CANAL EN ZARAGOZA, DURANTE EL AÑO 2014 (AEMET y elaboración propia)

Siguiendo un mismo esquema y reflejando las diferencias entre la media de los registros obtenidos en las tres estaciones consideradas y la estación meteorológica de Canal en sus valores absolutos, máximos, promedio, mínimos y en sus oscilaciones térmicas, considerando en cada uno de ellos sus máximos, medias y mínimos, se observa como los promedios diarios indican diferencias a lo largo del año superiores a la media de $0,92^{\circ} \mathrm{C}$ y e inferiores a ella de $1,10^{\circ} \mathrm{C}$, manteniéndose en un rango del $2,02^{\circ} \mathrm{C}$, con respecto a la media.

Las diferencias entre los valores medios de las máximas y de las mínimas son de menos de $1^{\circ} \mathrm{C}$ y se amplían entre los valores más extremos de las máximas y de las mínimas, ampliando el rango a los $18^{\circ} \mathrm{C}$.

\begin{tabular}{|r|r|r|r|r|}
\hline \multicolumn{5}{|c|}{ MEDIA-CANAL } \\
\hline M-C & MAX & PROM & \multicolumn{1}{|c|}{ MIN } & OSC \\
\hline$-3,77$ & $-0,17$ & $-0,92$ & $-3,77$ & 0,40 \\
\hline$-0,04$ & 0,73 & $-0,04$ & $-0,79$ & 1,53 \\
\hline 4,67 & 4,67 & 1,10 & 0,07 & 5,80 \\
\hline
\end{tabular}

8-62 CUADRO DE LAS DIFERENCIAS EN LAS TEMPERATURAS DIARIAS ENTRE LOS VALORES MEDIOS DE LAS ESTACIONES METEOROLÓGICAS DE CANAL, VALDESPARTERA Y AEROPUERTO DE ZARAGOZA Y LA ESTACIÓN METEOROLÓGICA DE CANAL, DURANTE EL AÑO 2014. (AEMET Y elaboración propia) 
C. Temperaturas máximas, mínimas y medias y oscilaciones térmicas en la estación meteorológica de Valdespartera

Los valores medios de las máximas, mínimas y medias diarias y los valores absolutos máximos y mínimos en la estación meteorológica de Valdespartera siguen una pauta en la que las oscilaciones térmicas se reducen en invierno para aumentar durante el verano.

TEMPERATURA HORARIA. ESTACIÓN METEOROLÓGICA VALDESPARTERA ZARAGOZA. 10 DE JUNIO DE 2013 A 10 DE JUNIO 2014

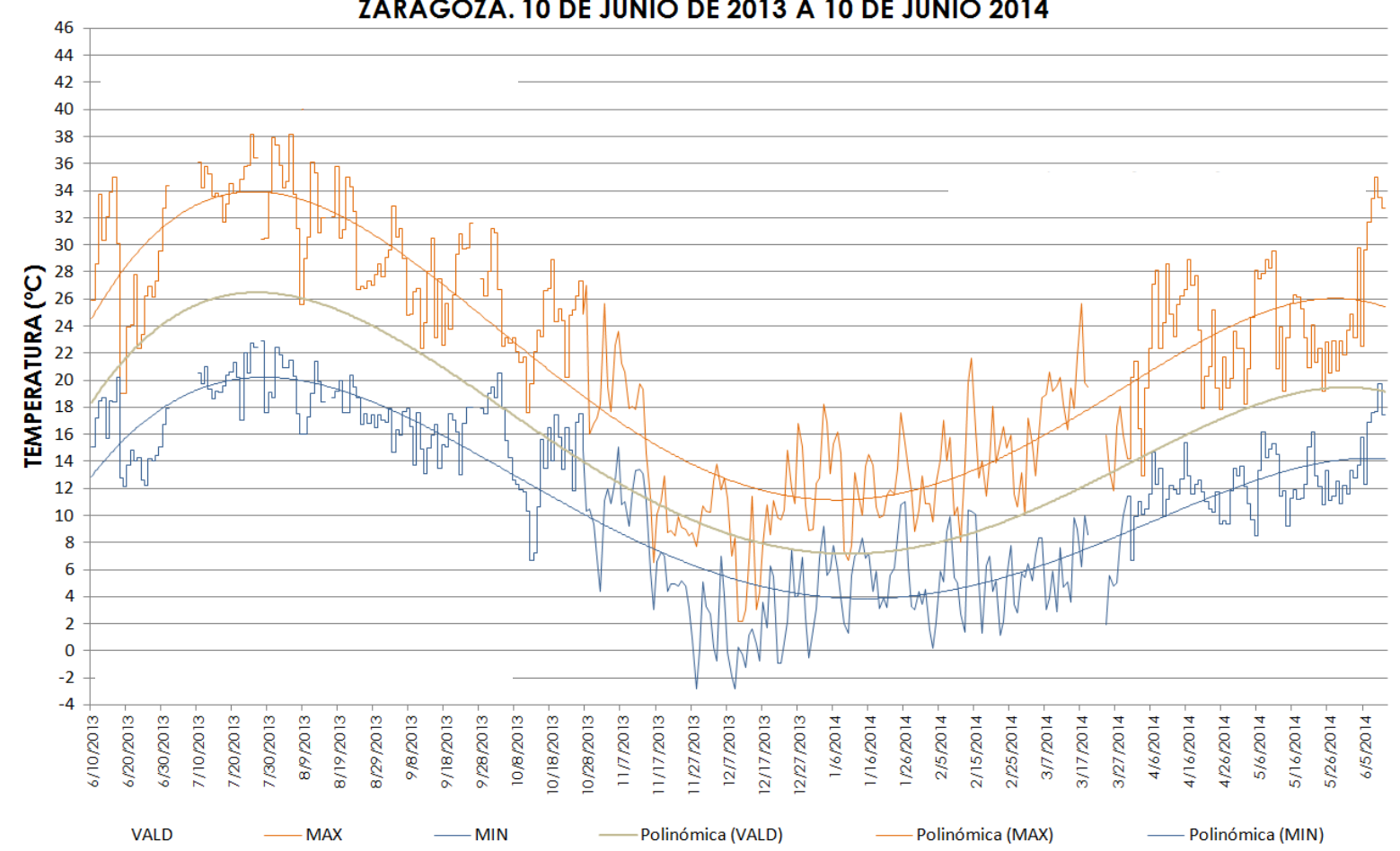

8-63 GRÁFICA DE LAS TEMPERATURAS MÁXIMAS, MÍNIMAS Y MEDIAS DIARIAS EN LA ESTACIÓN METEOROLÓGICA DE VALDESPARTERA EN ZARAGOZA, DURANTE EL AÑO 2014 (AEMET y elaboración propia)

\begin{tabular}{|r|r|r|r|r|}
\hline ABS & MAX & PROM & MIN & OSC \\
\hline$-0,60$ & 4,50 & 2,58 & $-0,60$ & 1,50 \\
\hline 16,54 & 22,24 & 16,54 & 11,81 & 10,43 \\
\hline 38,10 & 38,10 & 28,94 & 22,30 & 18,90 \\
\hline
\end{tabular}

8-64 CUADRO DE LAS TEMPERATURAS ABSOLUTAS Y MEDIAS DIARIAS EN LA ESTACIÓN METEOROLOGICA DE AEROPUERTO DE ZARAGOZA, DURANTE EL AÑO 2014 (AEMET y elaboración propia)

Se observa cómo los promedios de las diferencias diarias entre la media de las tres estaciones consideradas y la estación meteorológica de Valdespartera indican diferencias a lo largo del año de $0,75^{\circ} \mathrm{C}$ superiores a la media y de $0,62^{\circ} \mathrm{C}$ inferiores a ésta, manteniéndose en un rango de $1,37^{\circ} \mathrm{C}$.

Los valores medios de las diferencias máximas son superiores en $0,73^{\circ} \mathrm{C}$ y los valores medios de las mínimas están alejados $0,71^{\circ} \mathrm{C}$, manteniéndose en un rango de $1,44^{\circ} \mathrm{C}$.

Las diferencias en valores absolutos muestran diferencias que alcanzan un rango de algo más de $6^{\circ} \mathrm{C}$, siendo sus valores medios muy similares. 


\begin{tabular}{|r|r|r|r|r|}
\hline \multicolumn{5}{|c|}{ MEDIA - VALDESPARTERA } \\
\hline M-V & MAX & PROM & \multicolumn{1}{c|}{ MIN } & \multicolumn{1}{c|}{ OSC } \\
\hline$-3,13$ & $-0,17$ & $-0,75$ & $-3,13$ & 0,30 \\
\hline 0,07 & 0,73 & 0,07 & $-0,69$ & 1,41 \\
\hline 2,97 & 2,97 & 0,62 & 0,17 & 4,03 \\
\hline
\end{tabular}

8-65 CUADRO DE LAS DIFERENCIAS EN LAS TEMPERATURAS DIARIAS ENTRE LOS VALORES MEDIOS DE LAS ESTACIONES METEOROLÓGICAS DE CANAL, VALDESPARTERA Y AEROPUERTO DE ZARAGOZA Y LA ESTACIÓN METEOROLÓGICA DE VALDESPARTERA, DURANTE EL AÑO 2014 (AEMET Y elaboración propia)

D. Comparación entre los valores diarios de temperatura máxima, mínima, media y la oscilación térmica en la estación meteorológica del Aeropuerto.

Los valores medios de las máximas, mínimas y medias diarias y los valores absolutos máximos y mínimos en la estación meteorológica del Aeropuerto siguen una pauta en la que las oscilaciones térmicas se reducen en invierno para aumentar durante el verano.

TEMPERATURA HORARIA. ESTACIÓN METEOROLÓGICA AEROPUERTO. ZARAGOZA. 10 DE JUNIO DE 2013 A 10 DE JUNIO 2014

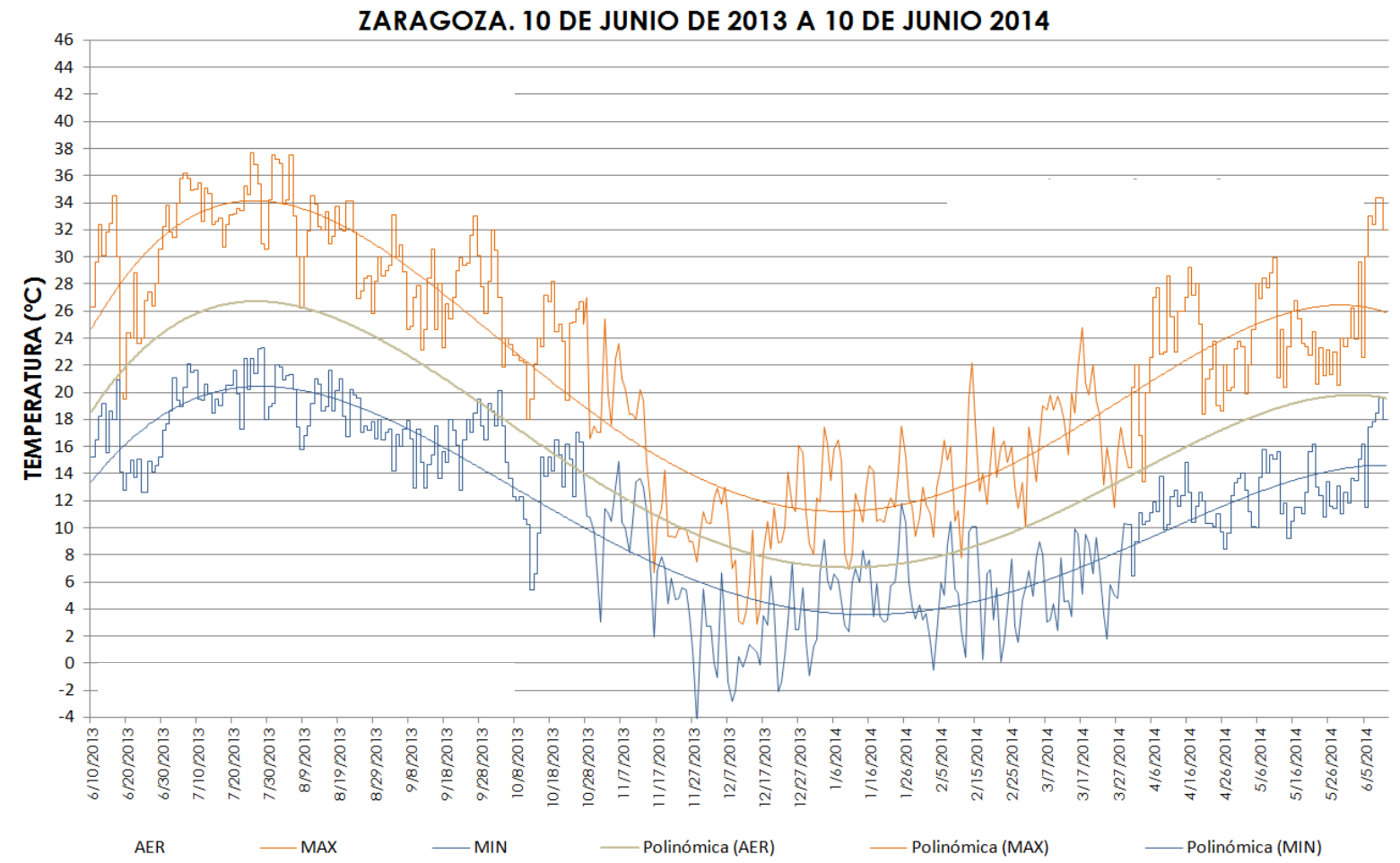

8-66 GRÁFICA DE LAS TEMPERATURAS MÁXIMAS, MÍNIMAS Y MEDIAS DIARIAS EN LA ESTACIÓN METEOROLÓGICA DE AEROPUERTO EN ZARAGOZA, DURANTE EL AÑO 2014 (AEMET y elaboración propia) 


\begin{tabular}{|l|r|r|r|r|r|}
\cline { 2 - 6 } \multicolumn{1}{c|}{} & \multicolumn{5}{c|}{ AEROPUERTO } \\
\cline { 2 - 6 } \multicolumn{1}{c|}{} & ABS & \multicolumn{1}{|c|}{ MAX } & PROM & \multicolumn{1}{c|}{ MIN } & \multicolumn{1}{c|}{ OSC } \\
\hline MIN & $-0,50$ & 3,70 & 2,70 & $-0,50$ & 1,20 \\
\hline MED & 16,52 & 22,14 & 16,52 & 11,75 & 10,39 \\
\hline MAX & 38,20 & 38,20 & 29,41 & 22,70 & 19,70 \\
\hline
\end{tabular}

8-67 CUADRO DE LAS TEMPERATURAS ABSOLUTAS Y MEDIAS DIARIAS EN LA ESTACIÓN METEOROLÓGICA DE AEROPUERTO DE ZARAGOZA, DURANTE EL AÑO 2014 (AEMET y elaboración propia)

Se observa cómo los promedios de las diferencias diarias entre la media de las tres estaciones consideradas y la estación meteorológica de Canal indican diferencias a lo largo del año de $0,99^{\circ} \mathrm{C}$ superiores a la media y de $0,71^{\circ} \mathrm{C}$ inferiores a ésta, manteniéndose en un rango de $1,70^{\circ} \mathrm{C}$.

Los valores medios de las diferencias máximas son superiores en $0,99^{\circ} \mathrm{C}$ y los valores medios de las mínimas están alejados $0,92^{\circ} \mathrm{C}$, manteniéndose en un rango de $1,91^{\circ} \mathrm{C}$.

Los valores absolutos muestran diferencias de algo más de $12^{\circ} \mathrm{C}$, siendo sus valores medios muy similares.

\begin{tabular}{|r|r|r|r|r|}
\hline \multicolumn{5}{|c|}{ MEDIA - AEROPUERTO } \\
\hline M-A & MAX & PROM & \multicolumn{1}{c|}{ MIN } & OSC \\
\hline$-5,73$ & $-0,17$ & $-0,71$ & $-5,73$ & 0,40 \\
\hline$-0,02$ & 0,92 & $-0,02$ & $-0,96$ & 1,88 \\
\hline 6,63 & 6,63 & 0,99 & $-0,07$ & 7,57 \\
\hline
\end{tabular}

8-68 CUADRO DE LAS DIFERENCIAS EN LAS TEMPERATURAS DIARIAS ENTRE LOS VALORES MEDIOS DE LAS ESTACIONES METEOROLÓGICAS DE CANAL, VALDESPARTERA Y AEROPUERTO DE ZARAGOZA Y LA ESTACIÓN METEOROLÓGICA DE AEROPUERTO, DURANTE EL AÑO 2014 (AEMET Y elaboración propia) 


\subsubsection{TEMPERATURAS HORARIAS EN PERIODOS DIARIOS}

La observación de los ciclos diarios ofrece una visión heterogénea de la distribución de temperaturas pudiéndose comprobar que la mayor parte de las secuencias diarias son muy similares con solo pequeñas diferencias de retardo horario entre las máximas y las mínimas, pero con valores muy similares tanto en máximas y mínimas como en oscilaciones y valores medios.

Es habitual la existencia de diferencias alternadas, pero con valores máximos y mínimos muy próximos. Como ilustración de este proceso pueden observarse las diferencias entre las series térmicas registradas en las estaciones meteorológicas de Canal y del Aeropuerto el día 1 de abril de 2014. Obsérvese cómo a las 13:00 horas las diferencias indican un desplazamiento de las secuencias térmicas, lo cual sin duda es debido al retardo que se produce en ellas.

Otro caso en que puede observarse la influencia de la velocidad de la evolución térmica se produce en el descenso de la temperatura vespertina, véase lo sucedido a las 19:00 horas. En otros casos se corresponde con los máximos alcanzados, tal y como se observa a las 16:00 horas.

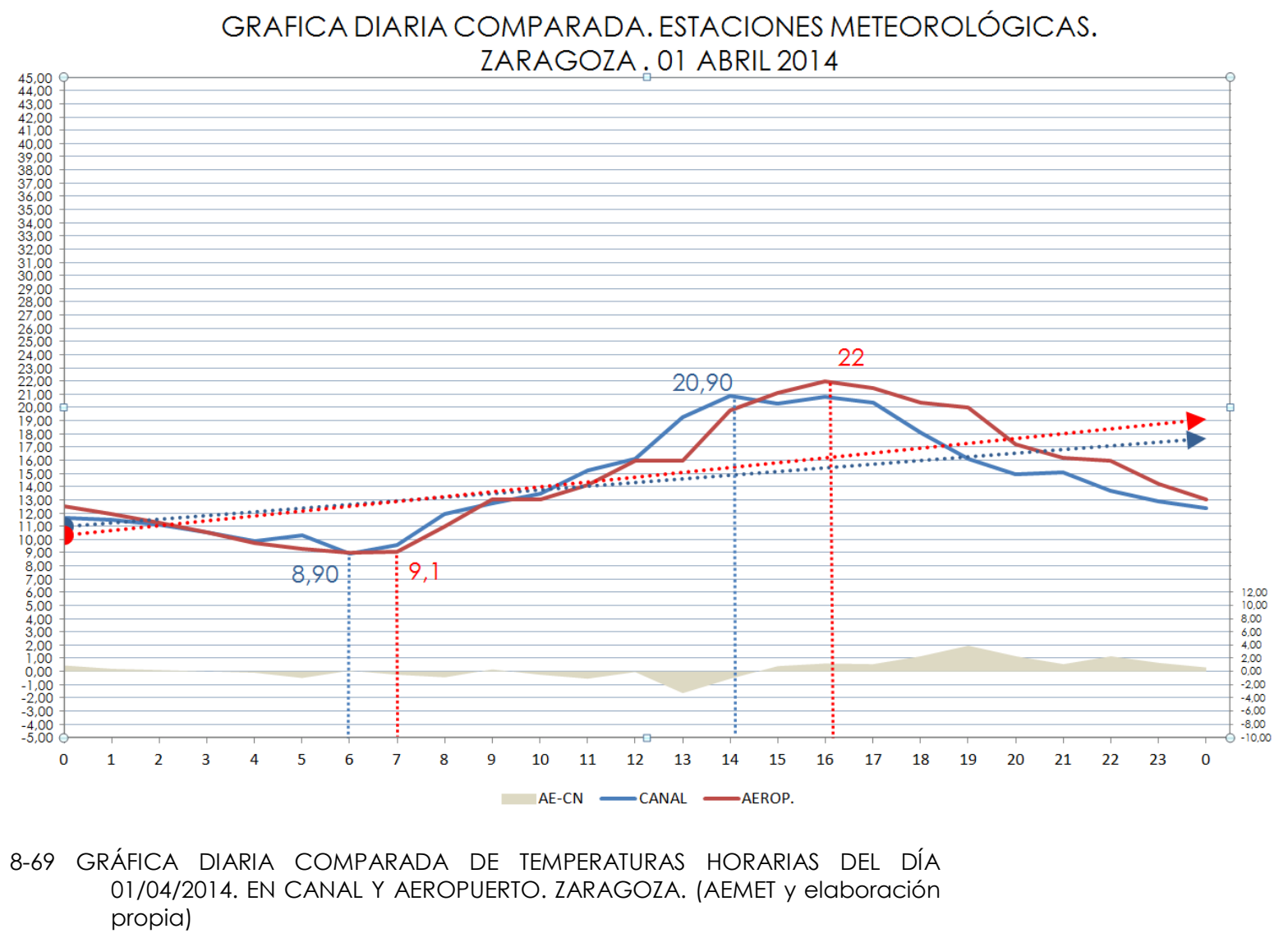


Las gráficas correspondientes a tres días del periodo frío y a uno del periodo cálido muestran la correlación más frecuente entre los valores observados en las tres estaciones meteorológicas.

GRAFICA DIARIA COMPARADA. ESTACIONES METEOROLÓGICAS.

ZARAGOZA 1 JULIO 2014

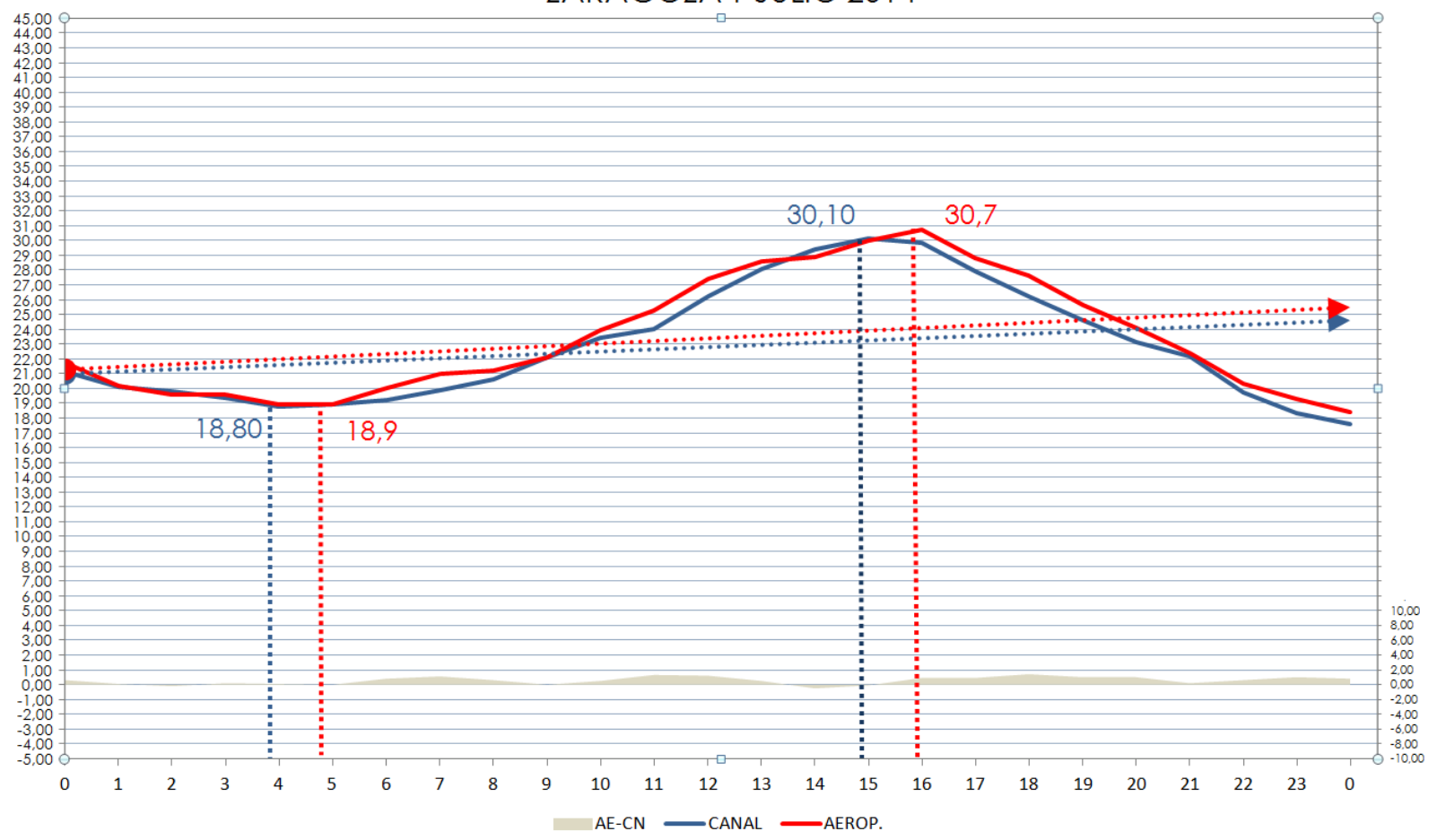

8-70 GRÁFICA DIARIA COMPARADA DE TEMPERATURAS HORARIAS DEL DÍA 01/07/2014. EN CANAL Y AEROPUERTO. ZARAGOZA. (AEMET y elaboración propia)

En los periodos cálidos las temperaturas mínimas se producen a el amanecer después de un descenso paulatino y lento desde las máximas del día anterior manteniendo una pendiente sensiblemente horizontal durante algo más de una hora en la que se ubican los valores mínimos en todas las estaciones. Las diferencias entre los mínimos absolutos nos son representativas ya que las variaciones de temperatura durante este periodo no son significativas.

Las oscilaciones térmicas diarias son muy altas $y$, aunque también la tangente de las máximas se mantiene, es más frecuente que tenga picos de mayor intensidad, por el efecto del soleamiento en las construcciones o el terreno. 
Se manifiesta un ligero retardo en las temperaturas registradas en la estación meteorológica del Aeropuerto, con respecto al resto, así como unas magnitudes ligerísimamente mayores.
VER ANEXO 10

COMPARADOR DIARIO ENTRE ESTACIONES METEOROLÓGICAS GRÁFICAS

GRAFICA DIARIA COMPARADA. ESTACIONES METEOROLÓGICAS.

ZARAGOZA 10 FEBRERO 2014

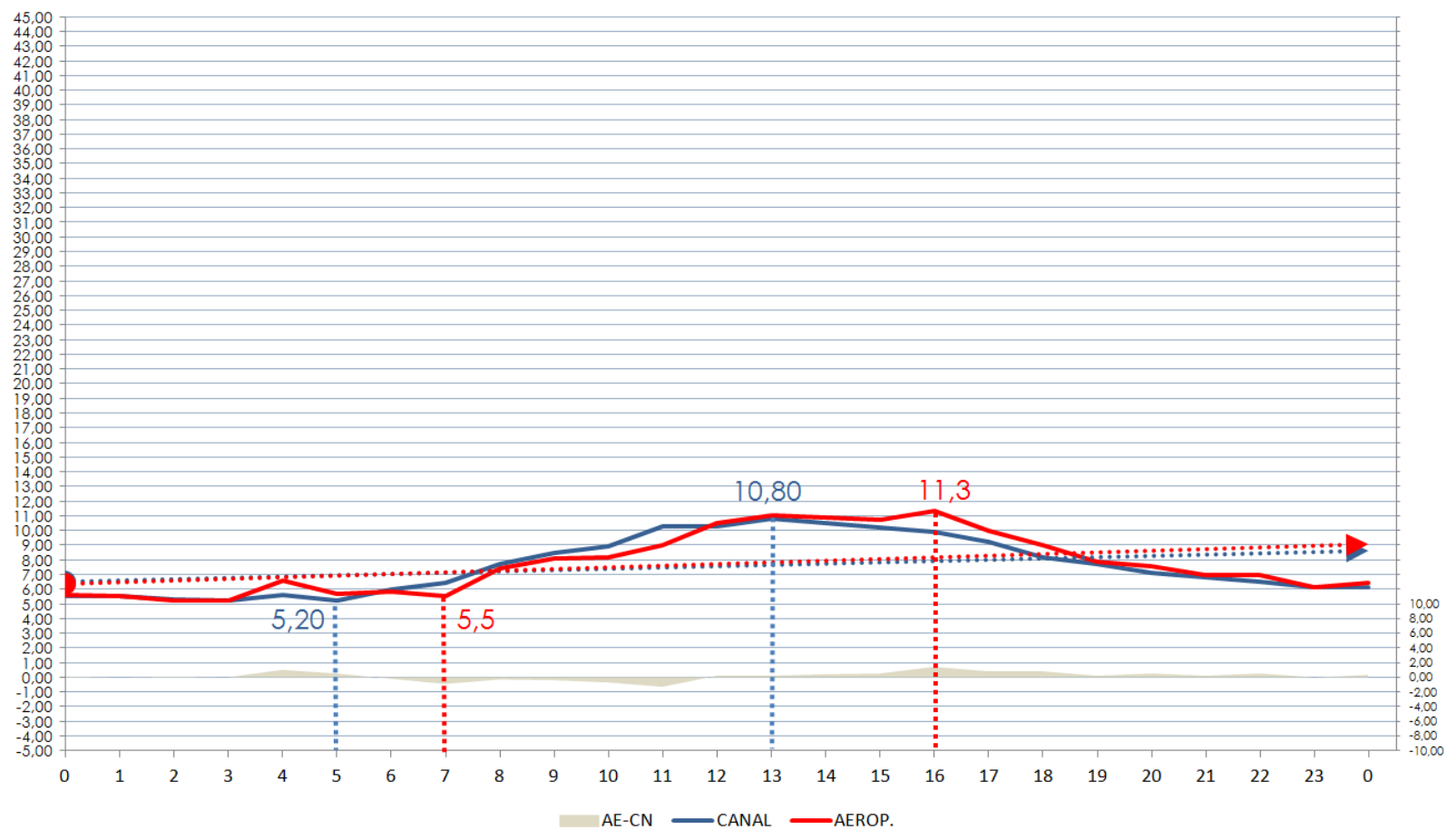

8-71 GRÁFICA DIARIA COMPARADA DE TEMPERATURAS HORARIAS DEL DÍA 10/02/2014. EN CANAL Y AEROPUERTO. ZARAGOZA. (AEMET y elaboración propia)

Durante el periodo frío la oscilación térmica es mucho menor y, dado que se mantienen las tangentes muy horizontales, los valores máximos y mínimos, aún estando muy distantes en el tiempo, se mantienen muy similares. 
También durante este periodo hay un mayor retardo en la estación meteorológica del Aeropuerto, que mantienen algo más extremos.

GRAFICA DIARIA COMPARADA. ESTACIONES METEOROLÓGICAS.

ZARAGOZA 17 MAYO 2014

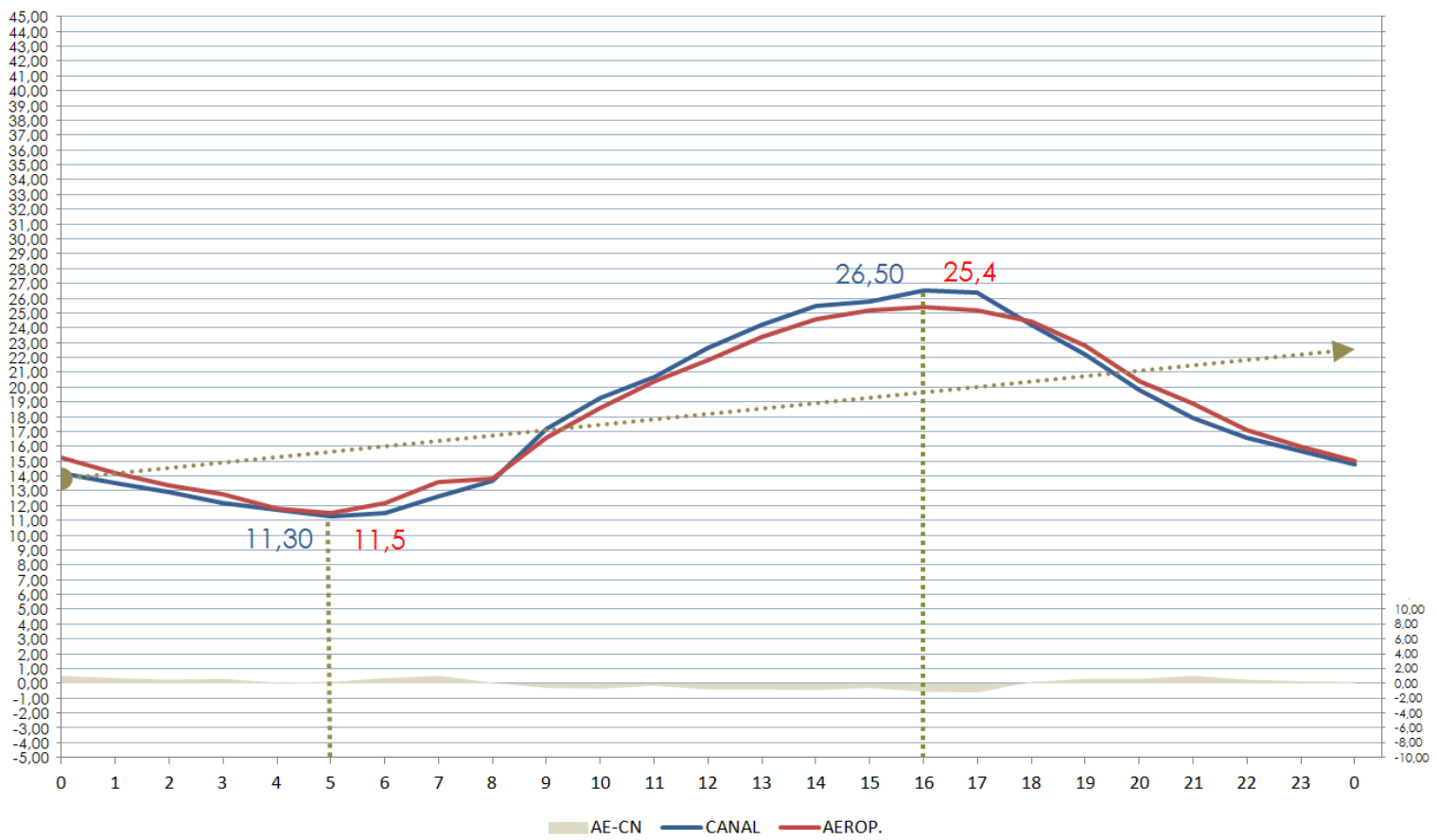

8-72 GRÁFICA DIARIA COMPARADA DE TEMPERATURAS HORARIAS DEL DÍA 17/05/2014. EN CANAL Y AEROPUERTO. ZARAGOZA. (AEMET y elaboración propia)

Los periodos de transición entre el periodo frío y el periodo cálido incrementan la oscilación térmica, con valores máximos progresivamente mayores y con unas cualidades muy similares a las observadas en el resto de los periodos aunque en pequeña medida, siempre muy ligeramente, pueden observarse temperaturas más altas en las estaciones más próximas al núcleo urbano. 
Una observación más detallada parece evidenciar un ligero incremento de la pendiente de subida y bajada de las temperaturas cuando se inicia su cambio de signo para ir suavizándose después hasta sus valores máximos o mínimos.

GRAFICA DIARIA COMPARADA. ESTACIONES METEOROLÓGICAS.

ZARAGOZA 29 AGOSTO 2014

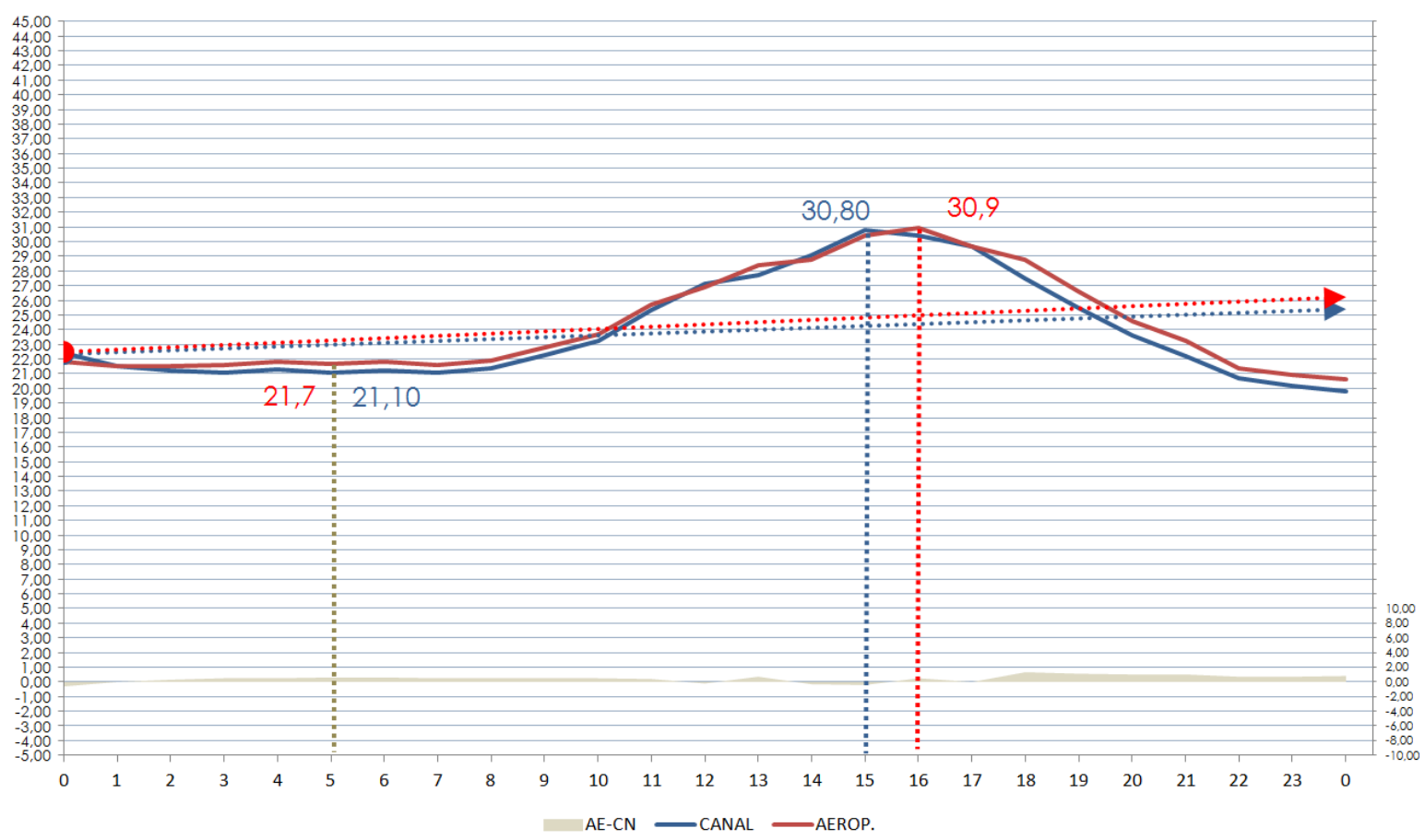

8-73 GRÁFICA DIARIA COMPARADA DE TEMPERATURAS HORARIAS DEL DÍA 29/08/2014. EN CANAL Y AEROPUERTO. ZARAGOZA. (AEMET y elaboración propia)

En el final del periodo cálido se pueden observar secuencias donde se reducen las oscilaciones por altas temperaturas mínimas, lo cual presenta un gran interés por la dificultad lógica para refrigerar las construcciones en estas circunstancias y por su incidencia por tanto en la consecución de un aceptable nivel de confort interior.

Se han estudiado también las secuencias diarias donde la correlación entre la temperatura horaria registrada en las estaciones de referencia indica diferencias mayores. 
Son estas secuencias muy similares a la del resto de los días que sufren puntuales alteraciones, bien por la influencia de la ocultación solar o por la presencia de vientos más fríos. Un ejemplo en que puede observarse una bajada brusca de la temperatura en la tarde del 9 de junio de 2014 entre las 14:00 a las 20:00 horas.

GRAFICA DIARIA COMPARADA. ESTACIONES METEOROLÓGICAS.

ZARAGOZA 09 JUNIO 2014

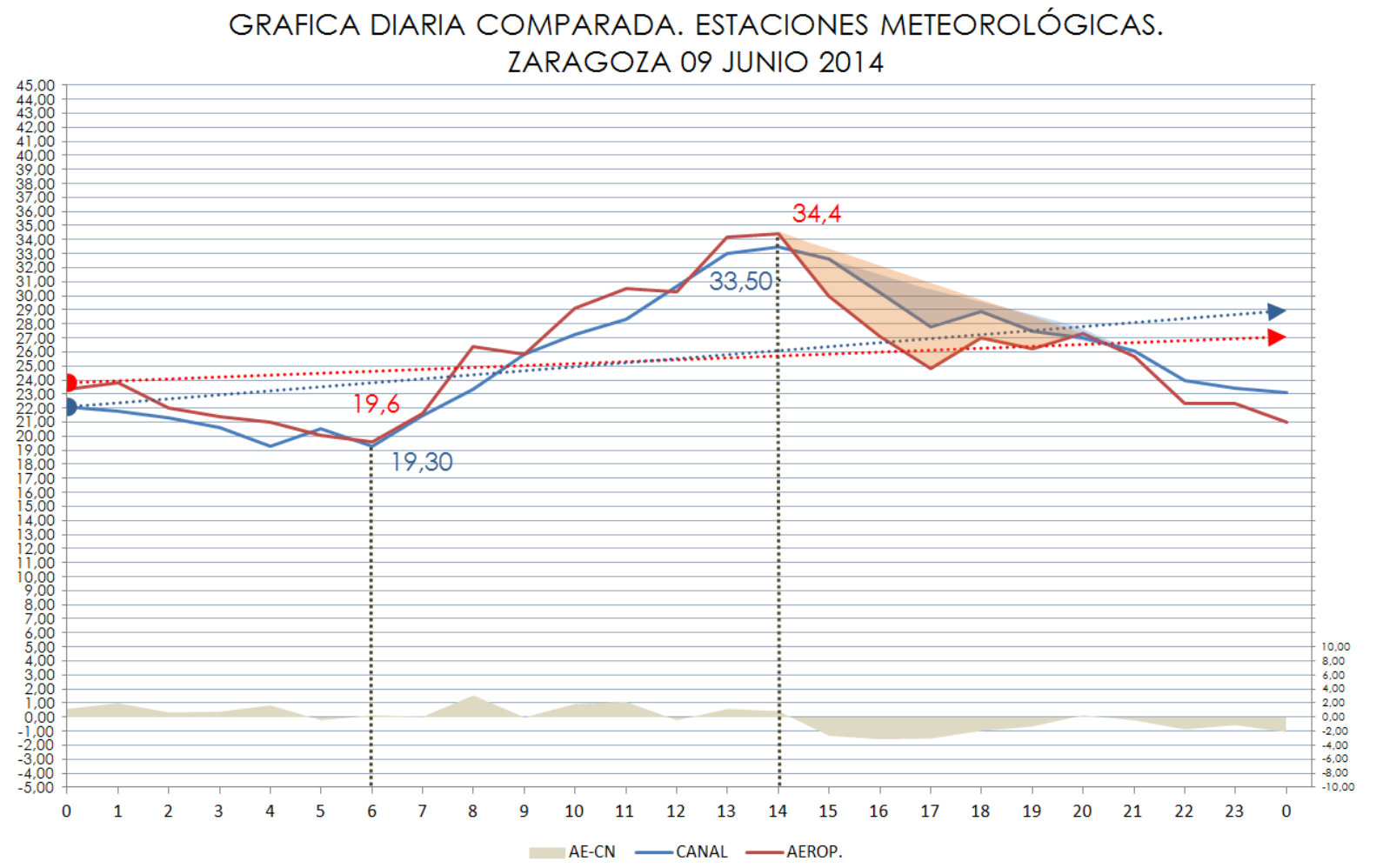

\footnotetext{
8-74 GRÁFICA DIARIA COMPARADA DE TEMPERATURAS HORARIAS DEL DÍA
09/06/2014. EN CANAL Y AEROPUERTO. ZARAGOZA. (AEMET Y elaboración

8-74 GRÁFICA DIARIA COMPARADA DE TEMPERATURAS HORARIAS DEL DÍA
09/06/2014. EN CANAL Y AEROPUERTO. ZARAGOZA. (AEMET Y elaboración propia)
} 
Del mismo modo en los periodos fríos se pueden observar procesos similares, con repentinas bajadas de temperatura coincidiendo con vientos fríos y con la posición relativa de las estaciones con respecto a ellos.
VER ANEXO 10

COMPARADOR DIARIO

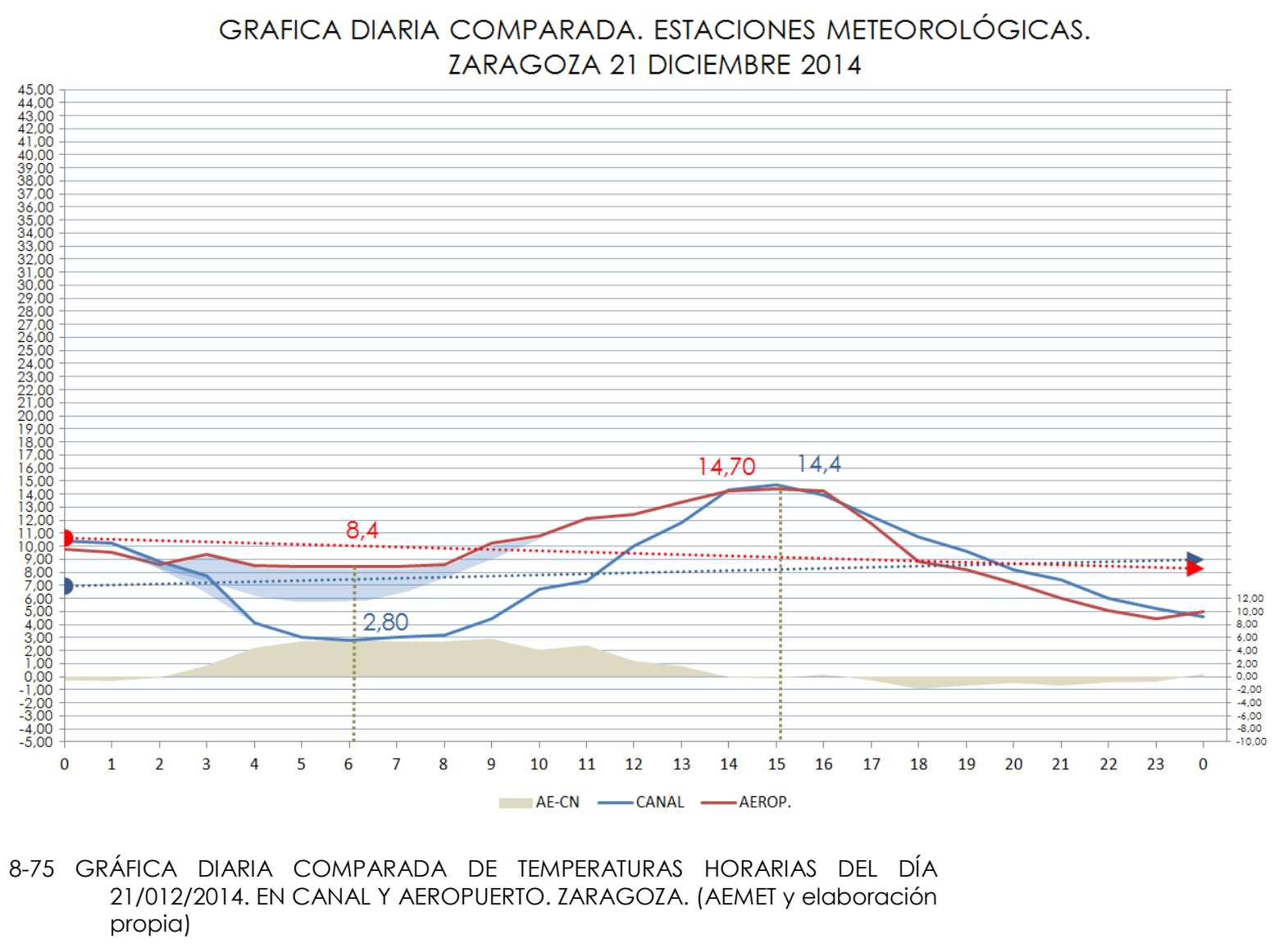

Se observa que la temperatura antes del amanecer baja repentinamente en la estación meteorológica de Canal, aunque el soleamiento hace que al ir avanzando el día las temperaturas máximas sean similares, manteniendo el patrón. 
En la estación meteorológica del Aeropuerto se puede apreciar, por ejemplo, la interrupción del descenso de la temperatura, según el patrón más común en este periodo.
VER ANEXO 10

COMPARADOR DIARIO ENTRE ESTACIONES METEOROLÓGICAS GRÁFICAS

GRAFICA DIARIA COMPARADA. ESTACIONES METEOROLÓGICAS.

ZARAGOZA 06 JULIO 2014

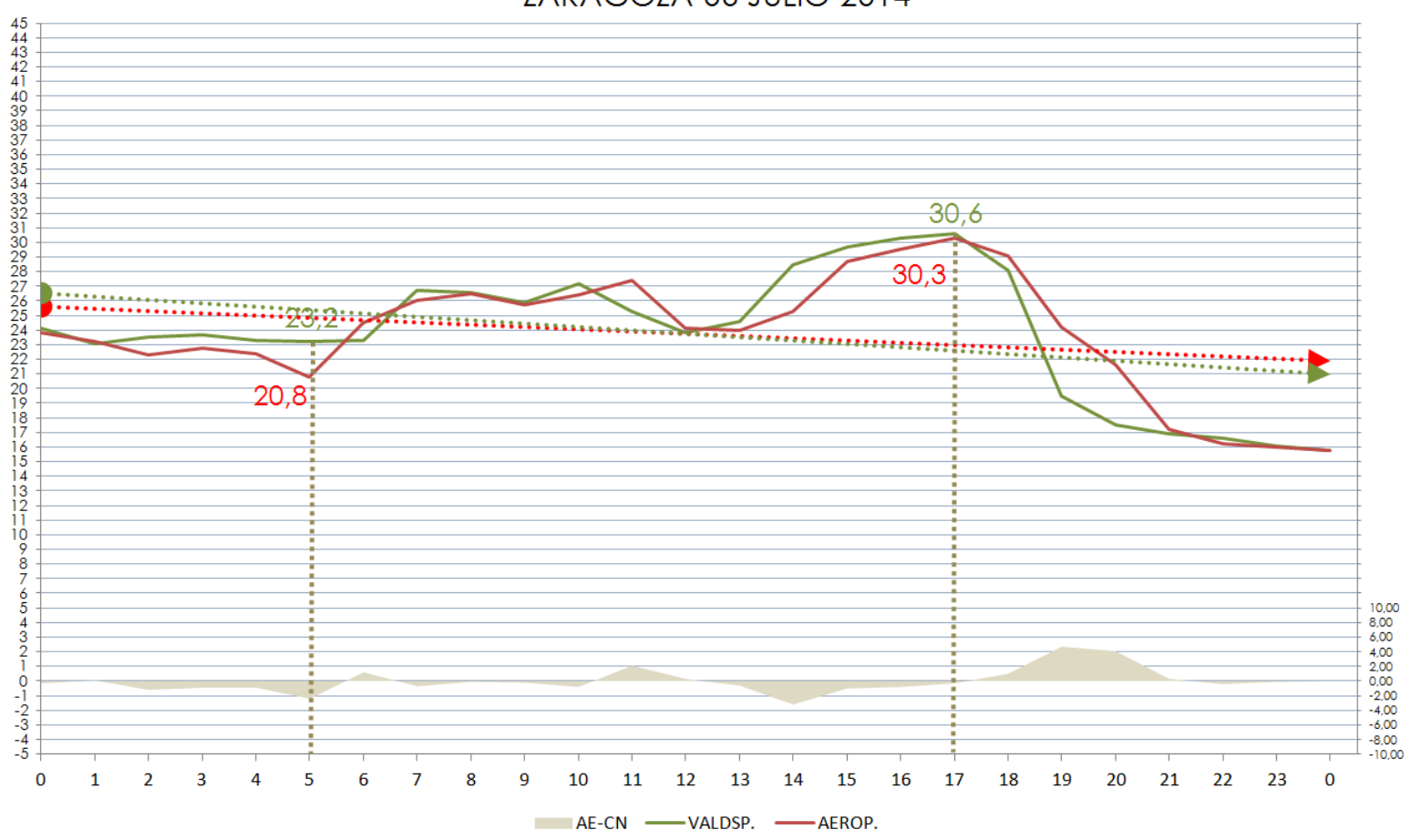

8-76 GRÁFICA DIARIA COMPARADA DE TEMPERATURAS HORARIAS DEL DÍA 21/012/2014. EN VALDESPARTERA Y AEROPUERTO. ZARAGOZA. (AEMET Y elaboración propia) 
En ocasiones la nubosidad o la niebla reducen la exposición al sol, impidiendo que se alcancen las temperaturas máximas previsibles, y la exposición a las pérdidas térmicas que se producen al estar el cielo despejado limitan también las máximas, como se ha podido apreciar.

\section{GRAFICA DIARIA COMPARADA. ESTACIONES METEOROLÓGICAS. ZARAGOZA 1 ENERO 2014}

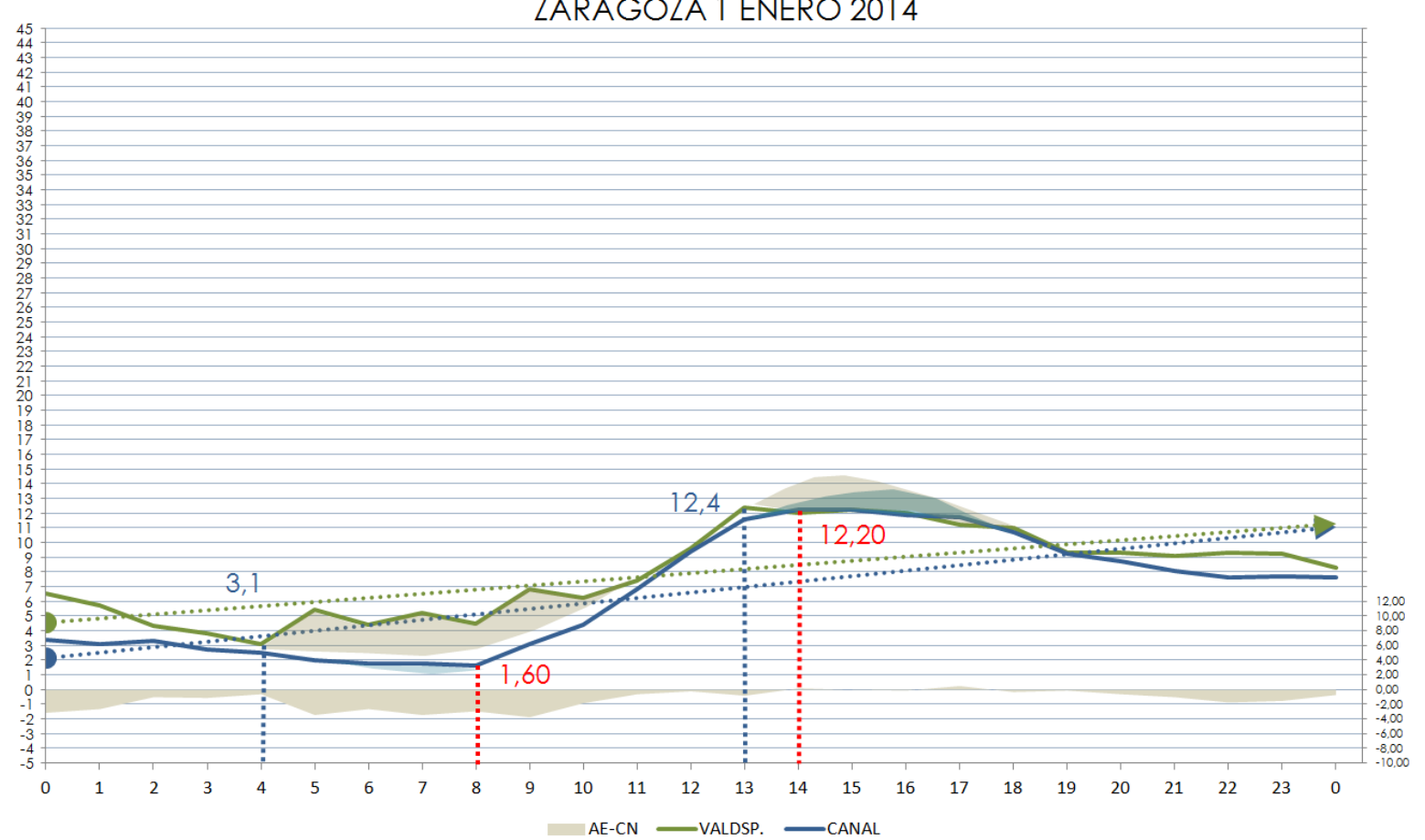

8-77 GRÁFICA DIARIA COMPARADA DE TEMPERATURAS HORARIAS DEL DÍA elaboración propia)

\section{1/01/2014. EN CANAL Y VALDESPARTERA. ZARAGOZA. (AEMET Y}


GRAFICADIARIA COMPARADA. ESTACIONES METEOROLÓGICAS.

ZARAGOZA 1 ENERO 2014

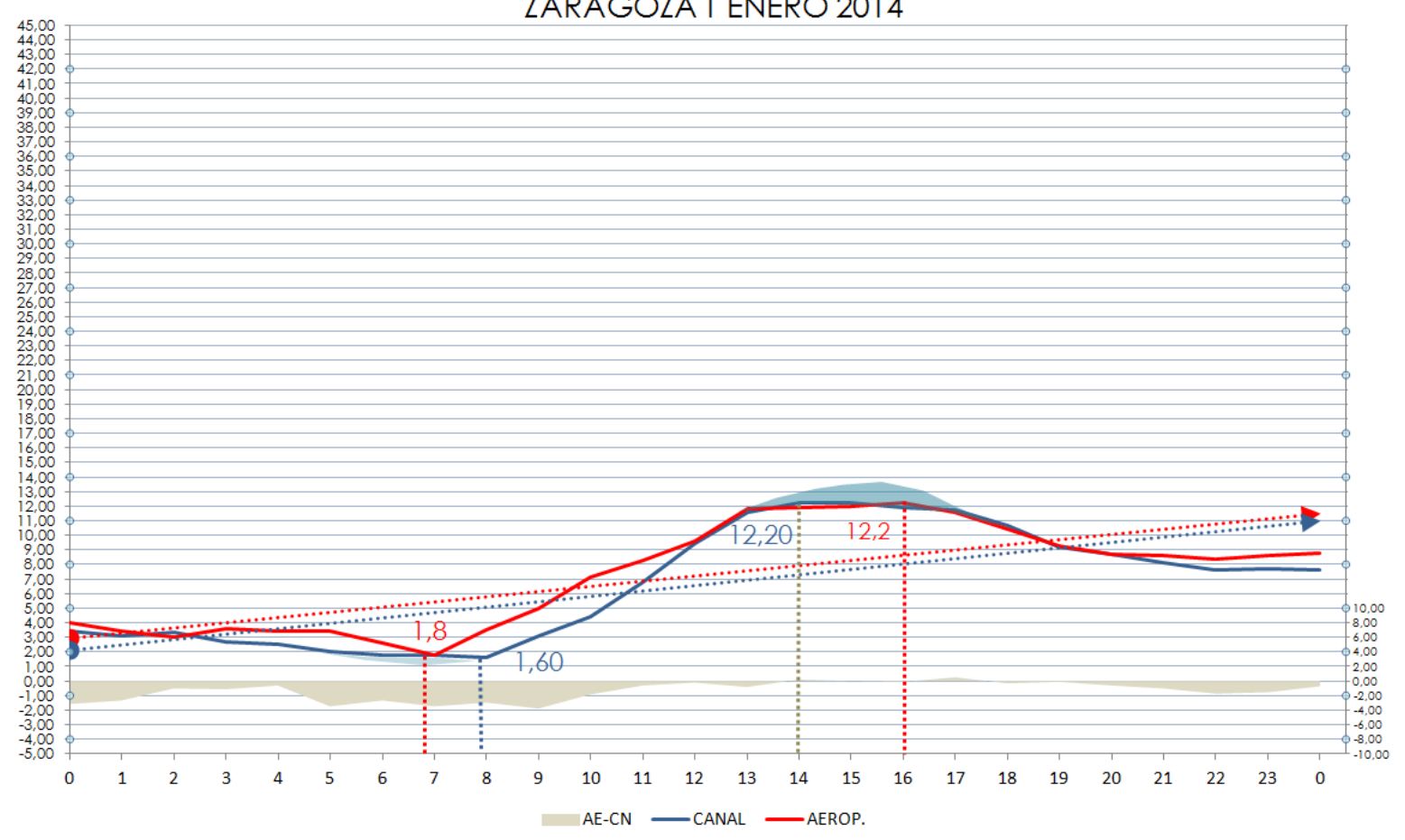

8-78 GRÁFICA DIARIA COMPARADA DE TEMPERATURAS HORARIAS DEL DÍA 01/01/2014. EN CANAL Y AEROPUERTO. ZARAGOZA. (AEMET y elaboración propia)

\section{GRAFICA DIARIA COMPARADA. ESTACIONES METEOROLÓGICAS. ZARAGOZA I ENERO 2014}

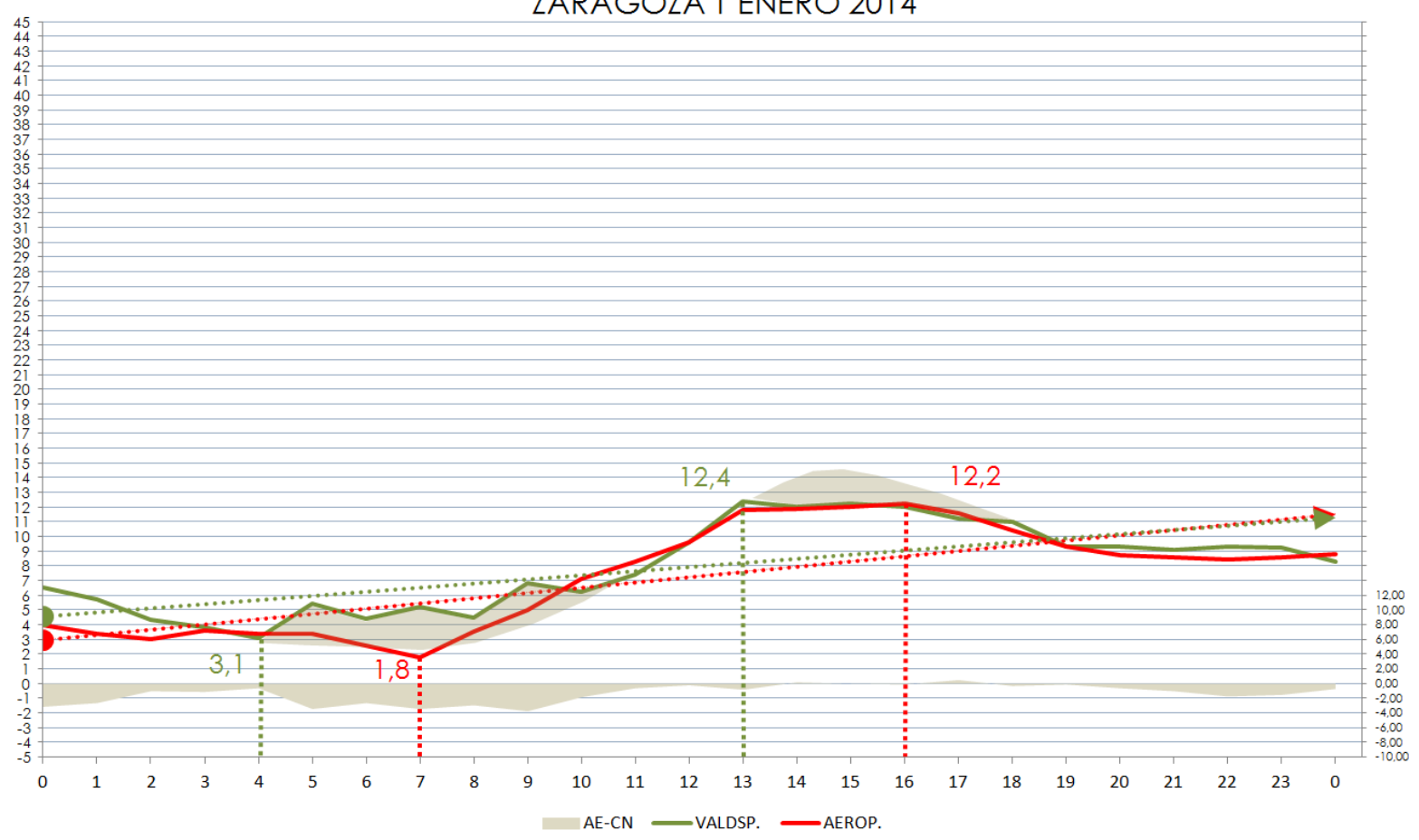

8-79 GRÁFICA DIARIA COMPARADA DE TEMPERATURAS HORARIAS DEL DÍA 01/01/2014. EN VALDESPARTERA Y AEROPUERTO. ZARAGOZA. (AEMET Y elaboración propia) 
GRAFICA DIARIA COMPARADA. ESTACIONES METEOROLÓGICAS.

ZARAGOZA 05 ABRIL 2014

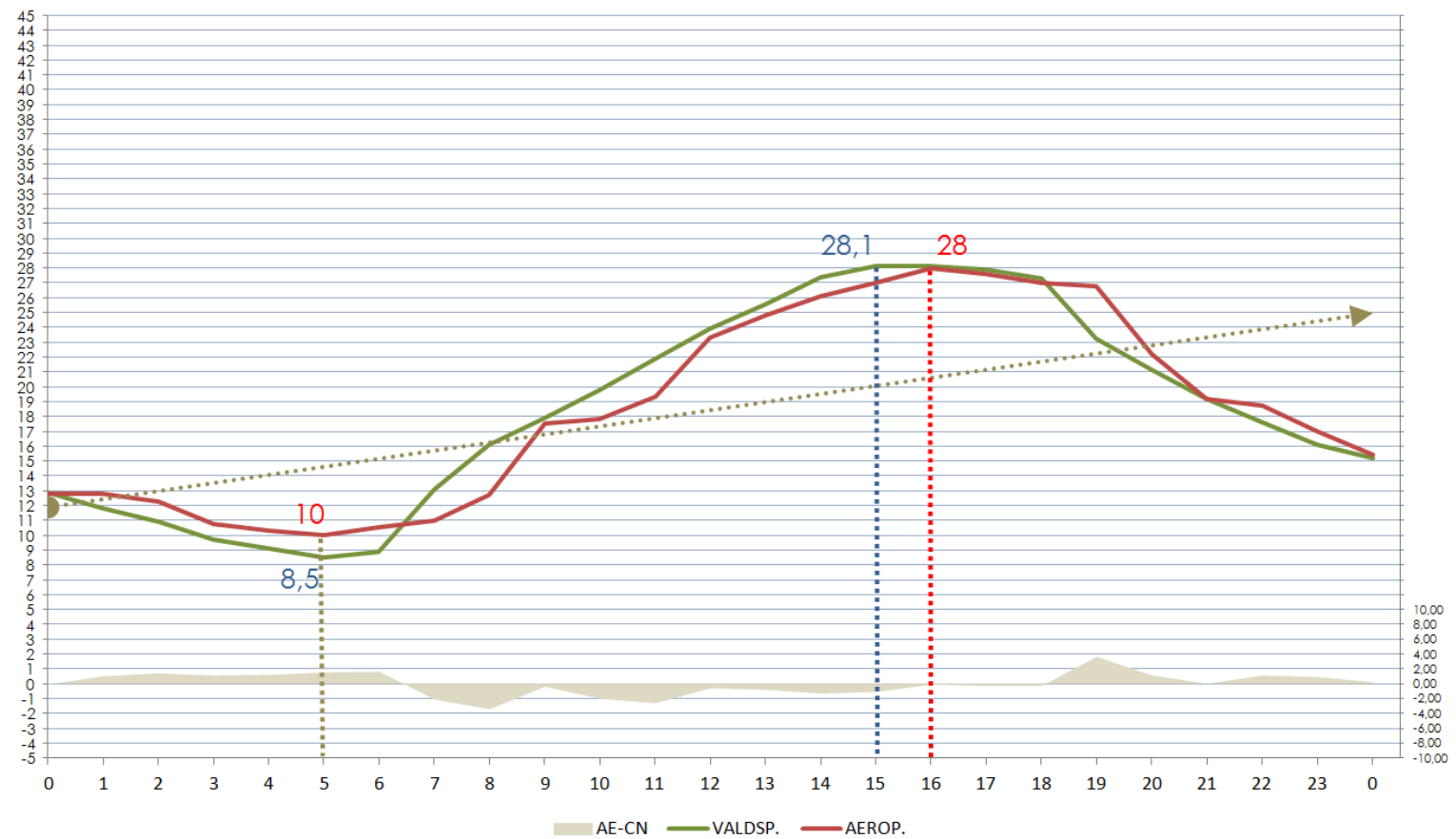

8-80 GRÁFICA DIARIA COMPARADA DE TEMPERATURAS HORARIAS DEL DÍA 01/01/2014. EN AEROPUERTO Y VALDESPARTERA. ZARAGOZA. (AEMET Y elaboración propia)

GRAFICA DIARIA COMPARADA. ESTACIONES METEOROLÓGICAS.

ZARAGOZA 1 MARZO 2014

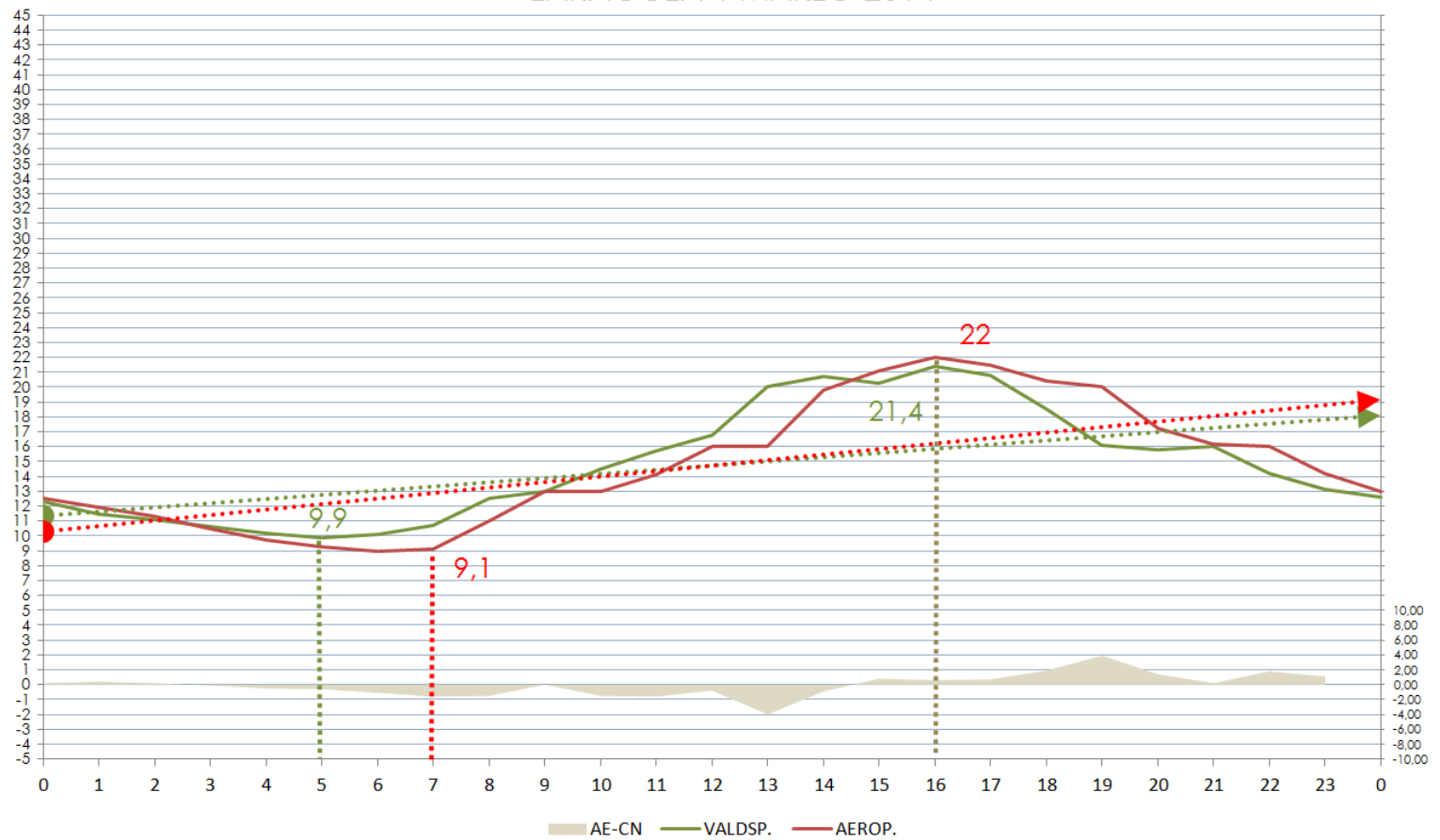

8-81 GRÁFICA DIARIA COMPARADA DE TEMPERATURAS HORARIAS DEL DÍA 01/03/2014. EN AEROPUERTO Y VALDESPARTERA. ZARAGOZA. (AEMET Y elaboración propia) 
Las singularidades, en ocasiones, no se corresponden con los patrones observados en otros casos, pudiéndose admitir eventuales errores de registro, Obsérvese el repentino incremento térmico en la estación del Aeropuerto, que no tiene reflejo en la estación de Valdespartera, a las 20:00 horas del 23 de febrero de 2014 y a las 5:00 horas del día 14 de febrero de 2014. En otros casos no se ha identificado la causa de estas diferencias, como es el caso del 4 y el 14 de febrero de 2014 o el 21 de diciembre de 2014, lo que indica la importancia de iniciar líneas de investigación causales frente al clima urbano, como primer paso hacia la cuantificación y posterior deducción de estrategias apropiadas.

GRAFICA DIARIA COMPARADA. ESTACIONES METEOROLÓGICAS.

ZARAGOZA 23 FEBRERO 2014

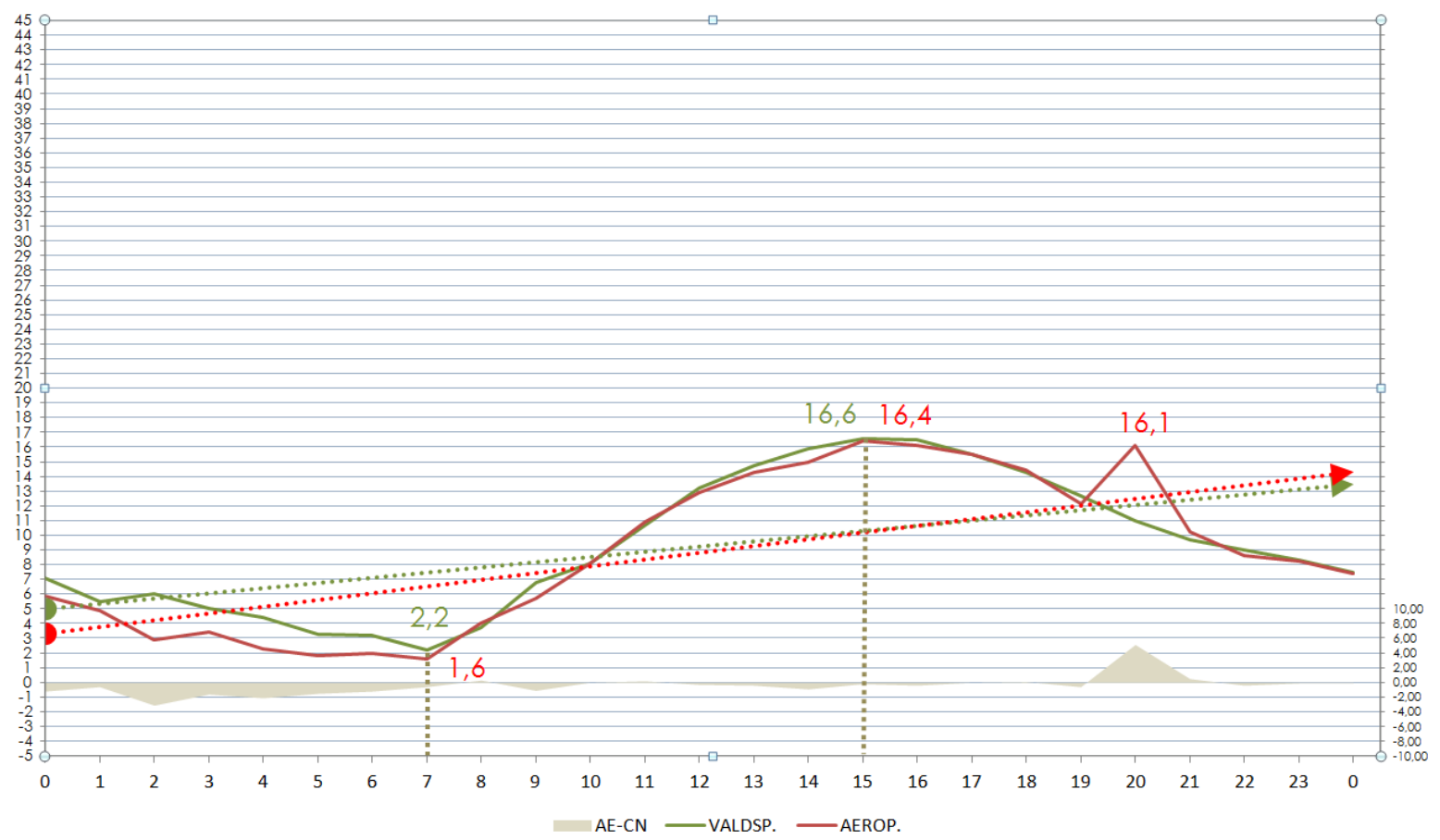

8-82 GRÁFICA DIARIA COMPARADA DE TEMPERATURAS HORARIAS DEL DÍA 23/02/2014. EN AEROPUERTO Y VALDESPARTERA. ZARAGOZA. (AEMET Y elaboración propia) 
GRAFICA DIARIA COMPARADA. ESTACIONES METEOROLÓGICAS.

ZARAGOZA 14 FEBRERO 2014

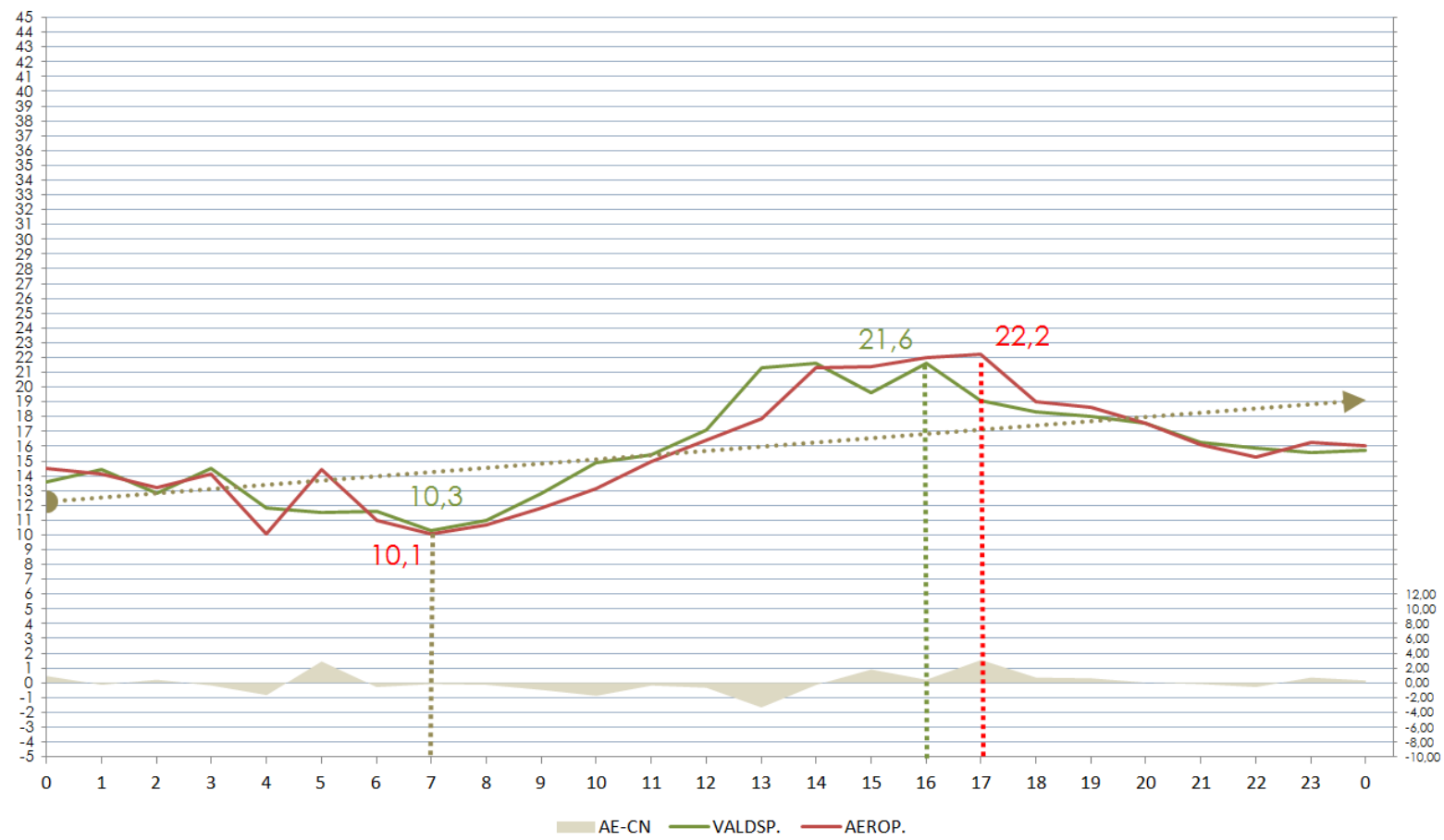

8-83 GRÁFICA DIARIA COMPARADA DE TEMPERATURAS HORARIAS DEL DÍA 14/02/2014. EN AEROPUERTO Y VALDESPARTERA. ZARAGOZA. (AEMET Y elaboración propia)

GRAFICA DIARIA COMPARADA. ESTACIONES METEOROLÓGICAS. ZARAGOZA 21 DICIEMBRE 2014

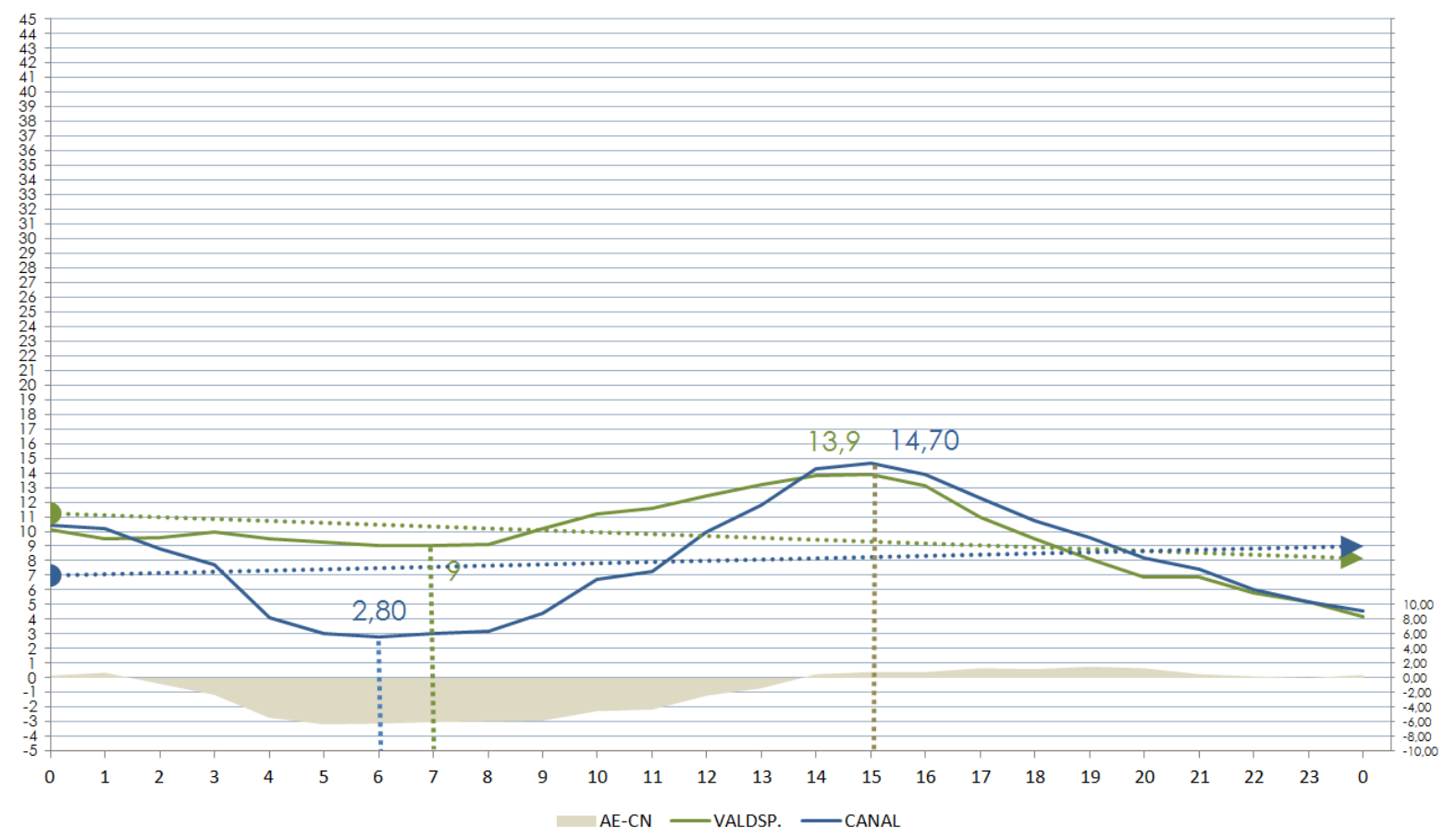

8-84 GRÁFICA DIARIA COMPARADA DE TEMPERATURAS HORARIAS DEL DÍA 21/12/2014. EN CANAL Y VALDESPARTERA. ZARAGOZA. (AEMET y elaboración propia) 
GRAFICA DIARIA COMPARADA. ESTACIONES METEOROLÓGICAS.

ZARAGOZA 4 FEBRERO 2014

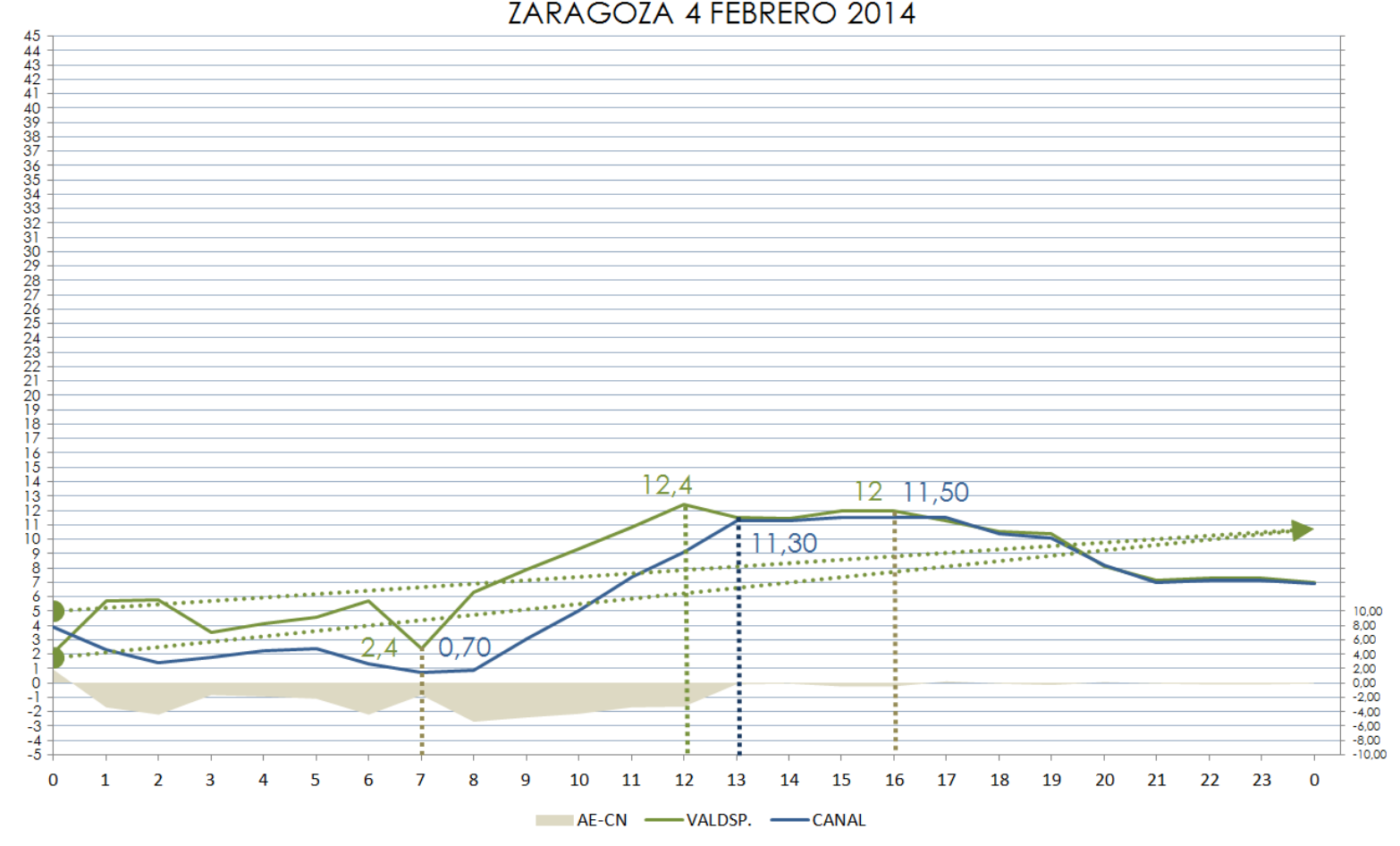

8-85 GRÁFICA DIARIA COMPARADA DE TEMPERATURAS HORARIAS DEL DÍA 04/02/2014. EN CANAL Y VALDESPARTERA. ZARAGOZA. (AEMET Y elaboración propia) 


\subsubsection{COMPENDIO DEL ANÁLISIS COMPARADO ENTRE ESTACIONES}

En el año 2014 en Zaragoza, si se consideran los grados-hora en periodos fríos en base $20 / 20$ y en base 16/16, se observa que durante poco más del $50 \%(54,5 \%)$ del año las temperaturas son inferiores a $16^{\circ} \mathrm{C}$ y durante menos de un $9 \%(8,7 \%)$ del año las temperaturas están entre $20^{\circ} \mathrm{C}$ y $16^{\circ} \mathrm{C}$.

En este periodo próximo al $9 \%(8,7 \%)$ del año los grados-hora precisos para alcanzar $20^{\circ} \mathrm{C}$ son casi el $50 \%(45,5 \%)$ del total de los grados-hora en base 20/20,

Los periodos con temperaturas inferiores a $16^{\circ} \mathrm{C}$ acumulan una media de $5,7^{\circ} \mathrm{C}$ por hora para alcanzar esta temperatura, mientras que para alcanzar una temperatura de $20^{\circ} \mathrm{C}$ en estos periodos sería necesario incrementar una media de $9,7^{\circ} \mathrm{C}$ por hora.

Un análisis similar para los periodos cálidos indica que, mientras las reducción en grados-hora al incrementar el umbral de $20^{\circ} \mathrm{C}$ a $26^{\circ} \mathrm{C}$ se reduce hasta un $30 \%$, el tiempo durante el que se producen estas superaciones se reduce a su vez un $50 \%$.

Esto supone que sería necesario bajar una media por hora de $3,5^{\circ} \mathrm{C}\left(3,54^{\circ} \mathrm{C}\right)$ durante el $12 \%(11,79 \%)$ del año, para no superar el umbral del $26^{\circ} \mathrm{C}$, mientras que para no superar el umbral de $20^{\circ} \mathrm{C}$ durante este mismo periodo serían necesario bajar $6^{\circ} \mathrm{C}\left(5,84^{\circ} \mathrm{C}\right)$ de media por hora durante el $24 \%(23,78 \%)$ del tiempo.

Las diferencias entre las estaciones de referencia en Zaragoza durante el año 2014 son muy pequeñas, tanto en los periodos en que se superan los umbrales, como en los grados-hora en que se producen estas superaciones que, con respecto a los valores medios de las diferencias, son menores del $1 \%$ en periodos fríos, independientemente de la base empleada, tanto en tiempo como en grados-hora.

Medidas con respecto a los valores medios en los periodos cálidos, las superaciones en tiempo y grados-hora, las diferencias en porcentaje entre los registros de las estaciones de referencia puede ser algo mayor, llegando ocasionalmente al 3,6\% en cuanto a los grados-hora y al 2,18\% en periodos de superación.

La comparación con otros años indica que estas cifras se mantienen muy próximas en su relación, independientemente de las diferencias de temperatura entre los distintos años.

Durante el año 2014 los valores mínimos absolutos se mantienen singularmente próximos, no siendo ésta la pauta seguida los años que van del 2007-2014 entre las estaciones de Canal y del Aeropuerto de Zaragoza, donde son frecuentes diferencias de más del $40 \%$.

Este valor resulta ser poco representativo de la evolución anual de las temperaturas. Sirva como ejemplo comprobar cómo uno de los años con menor variación, el 35\%, entre las temperaturas mínimas absolutas del año (2007) el porcentaje de diferencia de la media 
de las mínimas diarias fue el mayor de los registrados en el periodo llegando al 7,3\%, y que el año (2012) en el que se alcanzaron las mayores diferencias entre las mínimas $\left(6,3^{\circ} \mathrm{C}\right)$ con la temperatura mínima absoluta menor del periodo $\left(-9,9^{\circ} \mathrm{C}\right)$, la media de las mínimas diarias anuales mostró una diferencia del 2,24\%, una de las menores del periodo.

En definitiva, las diferencias de la media de las mínimas diarias puede aproximarse al $10 \%$ (7,3\% en este periodo), aunque normalmente permanece menor del $4 \%$.

Los valores máximos medios diarios son mucho más homogéneos, siendo siempre superiores en una de ellas, la situada en Canal. También son más homogéneas las diferencias en las temperaturas máximas absolutas que apenas superan $1^{\circ} \mathrm{C}$ ocasionalmente.

Los valores medios de las temperaturas anuales se mantienen con unas diferencias anuales siempre menores de $0,7^{\circ} \mathrm{C}\left(0,66^{\circ} \mathrm{C}\right)$, pero casi nunca superiores a $0,3^{\circ} \mathrm{C}$.

Estos valores son ligeramente menores en el $2^{\circ}$ cuartil, que marca los periodos más fríos, donde casi nunca se superan diferencias de $0,2^{\circ} \mathrm{C}$, y ligeramente mayores en el 3er. cuartil, que marca el umbral hacia el $25 \%$ de los periodos más cálidos, donde frecuentemente se superan los $0,4^{\circ} \mathrm{C}$ de diferencia.

En definitiva se confirma, en un primer análisis, que las diferencias locales de los valores térmicos medios en un radio aproximado de $5 \mathrm{Km}$ en condiciones periurbanas y urbanas son menores de un $0,7^{\circ} \mathrm{C}$.

Un análisis similar aplicado a los grados-hora sobre $26^{\circ} \mathrm{C}$ durante este periodo permite observar ocasionales diferencias de casi el $20 \%(18,20 \%$ en 2007), aunque casi siempre se encuentran en el entorno del $10 \%$.

La evolución local de las temperaturas más altas merece un estudio singular ya que muestran mayores variaciones.

Estos periodos cálidos también manifiestan una notable diferencia entre anualidades llegando a casi el 15\% (14,11 en 2007), aunque superando, ocasionalmente en poca cuantía, el $7 \%$ durante el resto de los años.

En los periodos fríos, las variaciones en grados-hora por debajo de $16^{\circ} \mathrm{C}$ son menores a las observadas en los periodos cálidos, siendo también durante el año 2007 cuando se manifiestan las mayores diferencias, de casi un $11 \%(10,79 \%)$, manteniéndose el resto de los años próxima al 5\% (entre el 5,99\% y el 4,19\%), salvo en 2014, cuando las variaciones son menores.

Los periodos en que se superan estos umbrales son también menores que en los periodos cálidos, ocasionalmente próximos al $5 \%$ (4,55\% en 2007), pero casi siempre la diferencia está próxima al $1 \%$ entre las estaciones meteorológicas de Canal y del Aeropuerto.

En todos las casos, los periodos con temperaturas comprendidas entre $16^{\circ} \mathrm{C}$ y $26^{\circ} \mathrm{C}$, se mantienen próximos en un tercio del año 
(entre el $39 \%$ en 2014 y el $33 \%$ en 2010 , pero casi siempre entre el $33 \%$ y el $35 \%$ ), con diferencias anuales en estos periodos de un $1 \%$ en función de la estación meteorológica considerada.

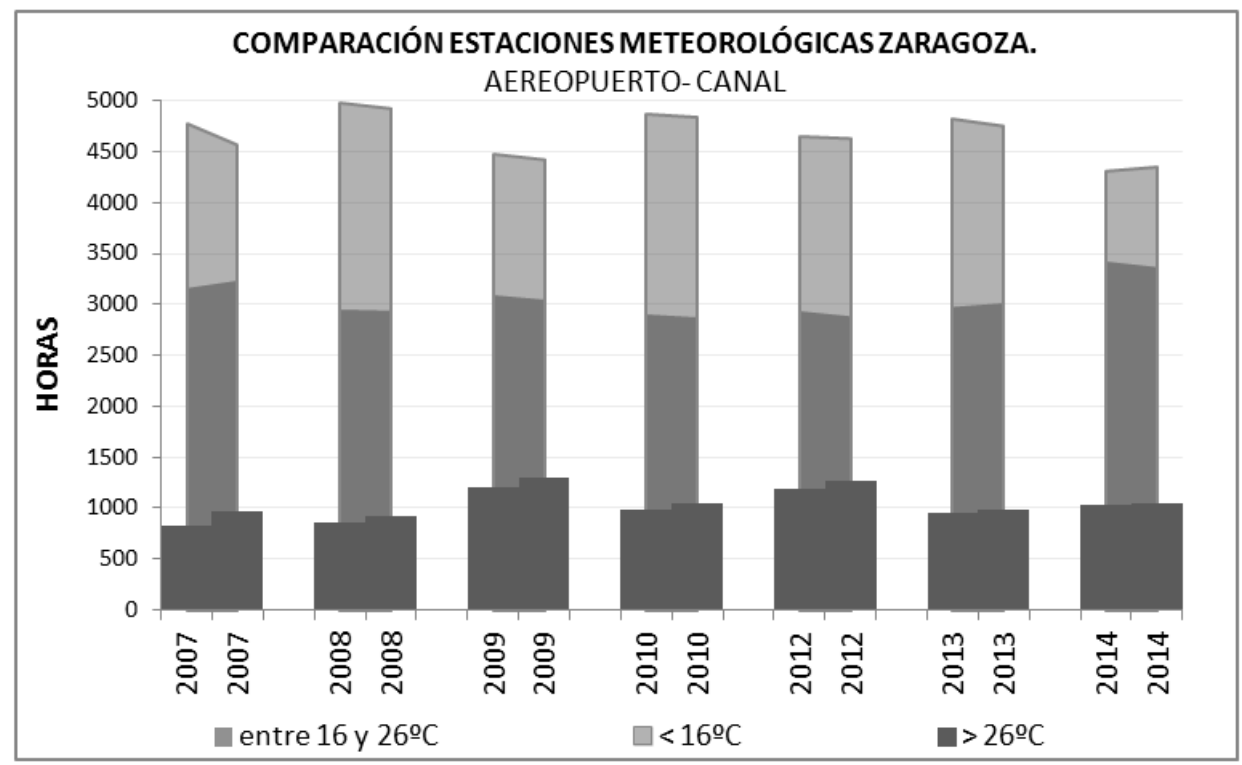

8-86 GRÁFICA COMPARATIVA DE LOS PERIODOS CON TEMPERATURAS INFERIORES A $16^{\circ} \mathrm{C}$ (NECESIDAD DE CALOR), SUPERIORES A $26^{\circ} \mathrm{C}$ (NECESIDAD DE FRÍO) Y EL PERIODO CON TEMPERATURAS ENTRE $16^{\circ} \mathrm{C}$ Y $26 \mathrm{C}$, EN LAS ESTACIONES METEOROLOGICAS DE CANAL Y AEROPUERTO EN ZARAGOZA DESDE EL AÑO 2007 AL 2014 (AEMET Y elaboración propia)

Entre las estaciones existe también una diferencia en relación a las temperaturas de confort adaptativo que se experimentarían para las temperaturas en ambas estaciones como media a lo largo del año.

Puede observarse cómo la diferencia entre ambas estaciones en lo relativo a su aplicación para la edificación es mínima a efectos prácticos

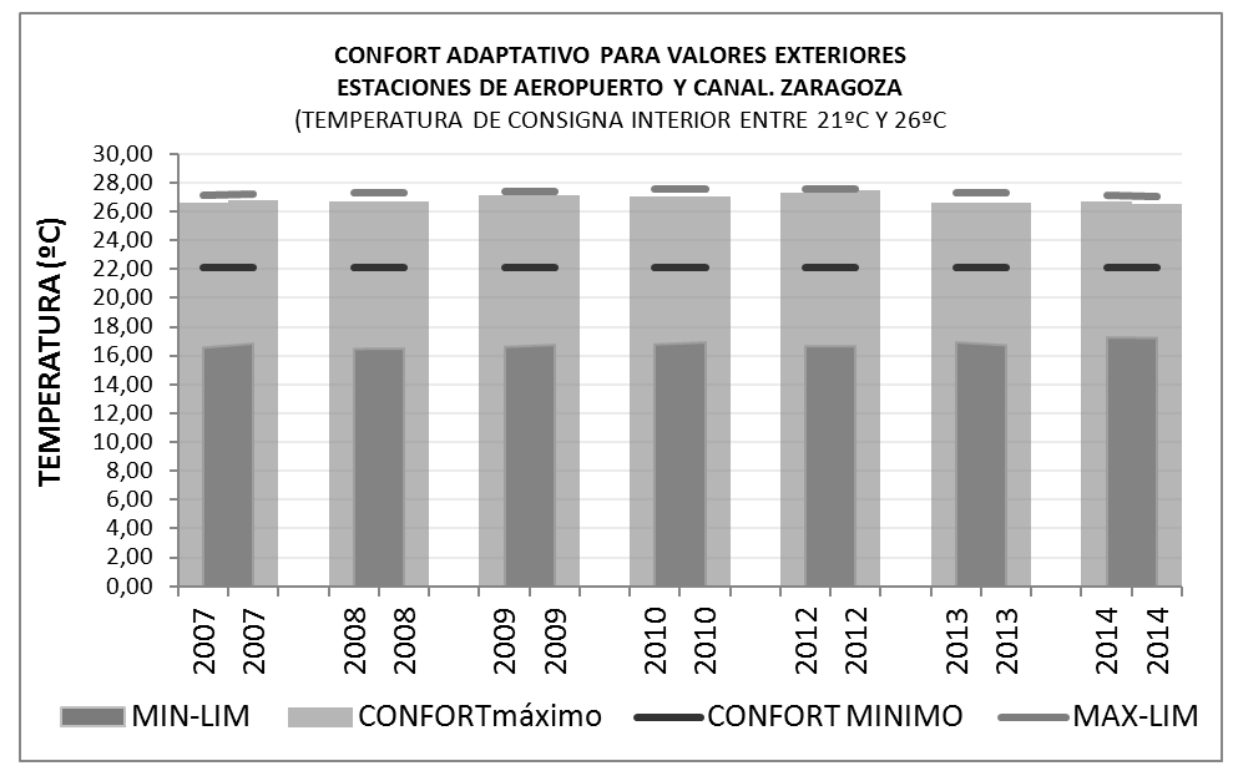

8-87 GRÁFICA COMPARATIVA DE LAS TEMPERATURAS DE CONFORT ADAPTATIVO APOYADO EN LOS VALORES DE TEMPERATURA DE LAS ESTACIONES METEOROLOGICAS DE CANAL Y AEROPUERTO EN ZARAGOZA DESDE EL AÑO 2007 AL 2014 (AEMET y elaboración propia) 
La diferencia entre los valores promedio y en los cuartíles es muy pequeña y apenas se puede observar ninguna diferencia, aunque exista una ligera tendencia a incrementarse en la estación meteorológica del Aeropuerto, con respecto a la de Canal.

Sin embargo, entre los valores máximos y mínimos existen unas mayores diferencias, no manifestándose una tendencia tan clara en los registros de las estaciones consideradas.

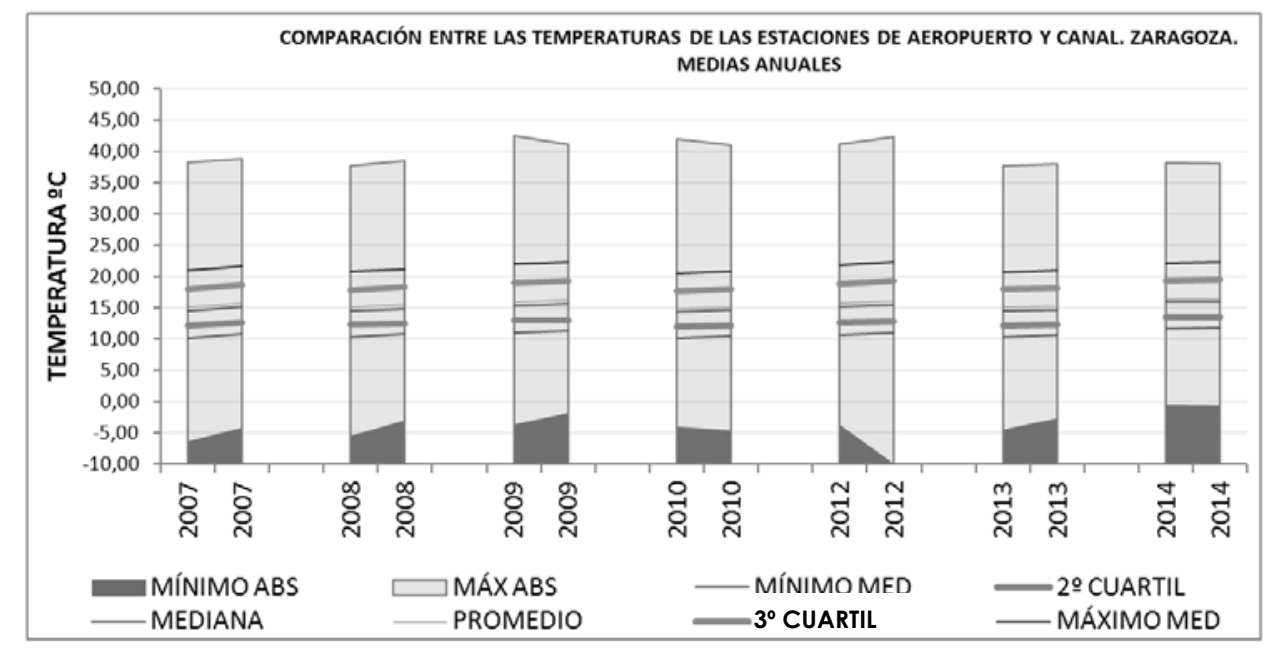

8-88 GRÁFICA COMPARATIVA DE LAS TEMPERATURAS MEDIAS ANUALES DE LAS ESTACIONES METEOROLOGICAS DE CANAL Y AEROPUERTO EN ZARAGOZA DESDE EL AÑO 2007 AL 2014 (AEMET y elaboración propia)

En las estaciones del Aeropuerto y de Canal, se observan periodos en que las temperaturas se mantienen en rangos claramente fríos, por debajo de $16^{\circ} \mathrm{C}$, en periodos ligeramente superiores al $50 \%$ del año, con muy ligeras diferencias entre los años 2007 y 2014.

Mientras los periodos con temperaturas entre $16^{\circ} \mathrm{C}$ y $26^{\circ} \mathrm{C}$ afectan a la tercera parte del año, las horas en que se superan los $26^{\circ} \mathrm{C}$ y son susceptibles de precisar el uso de sistemas de disipación de calor oscilan entre el $9 \%$ y el $14 \%$ en las anvalidades consideradas con ligeras variaciones entre estaciones. 


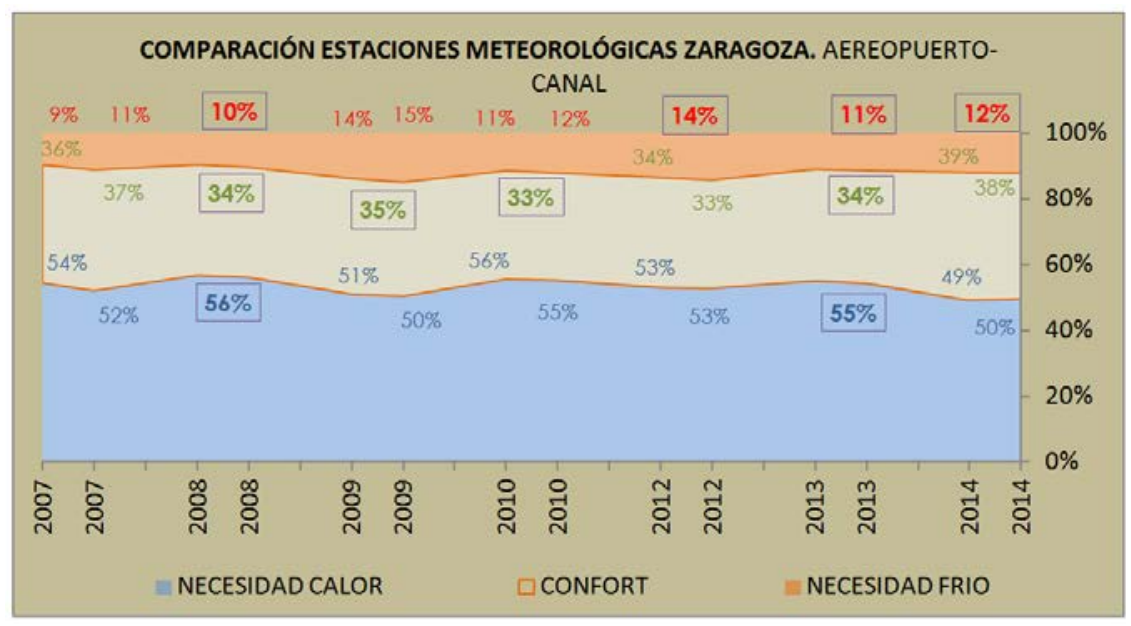

8-89 GRÁFICA COMPARATIVA DE LOS PERIODOS CON TEMPERATURAS INFERIORES A $16^{\circ} \mathrm{C}$ (NECESIDAD DE CALOR), SUPERIORES A $26^{\circ} \mathrm{C}$ (NECESIDAD DE FRÍO) Y EL PERIODO CON TEMPERATURAS ENTRE $16^{\circ} \mathrm{C}$ Y $26 \mathrm{C}$, EN LAS ESTACIONES METEOROLOGICAS DE CANAL Y AEROPUERTO EN ZARAGOZA DESDE EL AÑO 2007 AL 2014 (AEMET y elaboración propia)

La observación de los valores medios y máximos absolutos muestran una gran similitud entre las temperaturas registradas durante el año 2014 en las estaciones meteorológicas de referencia, con diferencias menores de $1^{\circ} \mathrm{C}$.

\begin{tabular}{c|c|c|c|c|c|c|c|c|}
\cline { 2 - 9 } & \multicolumn{2}{|c|}{ VALOR ABSOLUTO } & \multicolumn{3}{c|}{ PROMEDIO } & \multicolumn{3}{c|}{ OSCILACIÓN } \\
\cline { 2 - 9 } & MÍNIMA & MÁXIMA & MÍNIMA & MEDIA & MÁXIMA & MÍNIMA & MEDIA & MÁXIMA \\
\hline AEROPUERTO & $-0,50$ & 38,20 & 2,70 & 16,52 & 29,41 & 1,20 & 10,39 & 19,70 \\
\hline CANAL & $-0,60$ & 38,10 & 2,58 & 16,54 & 28,94 & 1,50 & 10,43 & 18,90 \\
\hline VALDESPARTERA & $-1,40$ & 38,70 & 2,24 & 16,43 & 29,32 & 2,00 & 10,28 & 19,60 \\
\hline
\end{tabular}

8-90 CUADRO COMPARATIVO DE LAS TEMPERATURAS MÁXIMAS Y MÍNIMAS ABSOLUTAS, VALORES PROMEDIO Y OSCILACIONES TÉRMICAS EN LAS ESTACIONES METEOROLOGICAS DE REFERENCIA DE CANAL, VALDESPARTERA Y AEROPUERTO EN ZARAGOZA DURANTE EL AÑO 2014 (AEMET y elaboración propia)

La comparación con valores medios formados entre las tres estaciones de referencia permite comprobar que hay una mayor diferencia en sus valores máximos y mínimos absolutos, especialmente en la estación meteorológica del Aeropuerto, pero en general las diferencias en los percentiles y valores medios es mucho menor de $1^{\circ} \mathrm{C}$.

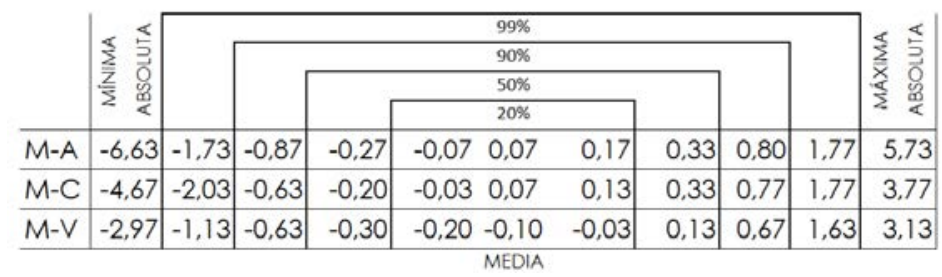

8-91 CUADRO COMPARATIVO DE LAS DIFERENCIAS CON RESPECTO A LOS VALORES MEDIOS REGISTRADOS EN LAS ESTACIONES METEOROLOGICAS DE REFERENCIA DE CANAL, VALDESPARTERA Y AEROPUERTO EN ZARAGOZA Y CADA UNA DE ELLAS DURANTE EL AÑO 2014 (AEMET y elaboración propia) 
El análisis de los gráficos diarios muestra que las diferencias entre las estaciones son pequeñas durante la mayor parte del año y cuando presentan diferencias significativas lo hacen sobre todo durante el día, manteniendo temperaturas comunes durante una parte de la noche, sin que se observen secuencias de varios días con un patrón similar, más allá de ligeros desfases térmicos.

El análisis de las estaciones próximas a Zaragoza permite observar cómo en las temperaturas máximas y mínimas las diferencias aumentan en algunos periodos dos grados más.

La observación de los valores registrados en ellas evidencia una evolución de la temperatura a lo largo del año que, en sus valores medios, evoluciona en función de la estación con altibajos, alejados en muchos periodos más de $6^{\circ} \mathrm{C}$ de los valores que podrían estimarse previsibles. mediante una curva de tendencia polinómica.

Las similitudes pueden observarse tanto en el momento en que se producen los valores máximos y mínimos como en la evolución de los valores y en sus singularidades.

Resulta significativo que en varios días del año en dos días sucesivos, ocasionalmente en periodos cálidos y más frecuentemente en periodos fríos, las temperaturas mínimas de un día superan a las máximas del día anterior.

La relación con valores confortables indica que una gran parte del año, más de 100 días, las temperaturas máximas y mínimas están muy por debajo de las que serían deseables, mientras que las temperaturas máximas se mantienen por encima de estos valores más de 100 días.

Las temperaturas medias pueden mantenerse la mitad del año por debajo de las de confort siendo ocasionalmente superiores a $28^{\circ} \mathrm{C}$.

También puede observarse una mayor oscilación térmica en periodos cálidos, con frecuencia superior a $12^{\circ} \mathrm{C}$, que en periodos fríos, entre $4^{\circ} \mathrm{C}$ y $8^{\circ} \mathrm{C}$, y ocasionalmente entre 2 y $4{ }^{\circ} \mathrm{C}$, en primavera las oscilaciones presentan fuertes alternancias para estabilizarse por en encima de los $12^{\circ} \mathrm{C}$ al llegar a los periodos más cálidos. 


\subsubsection{TENTATIVA DE SERIE ANUAL CON RETARDO}

Considerando la reacción del edificio y el retardo con que las temperaturas exteriores afectan a las series térmicas interiores se presenta la relación entre los valores medios diarios en secuencias continuas diarias y de cada 3, 6 y 9 días.

La evolución anual de las temperaturas se ordena en valores medios diarios, cada 3, 6 y 9 días (promedio, máximas, mínimas y mediana) y la oscilación térmica diaria en estos periodos.

\section{TEMPERATURA EN ESTACIÓN METEOROLÓGICA AEMET.MEDIA DIARIA, CADA 3-6 y 9 DÍAS} ZARAGOZA. 2014

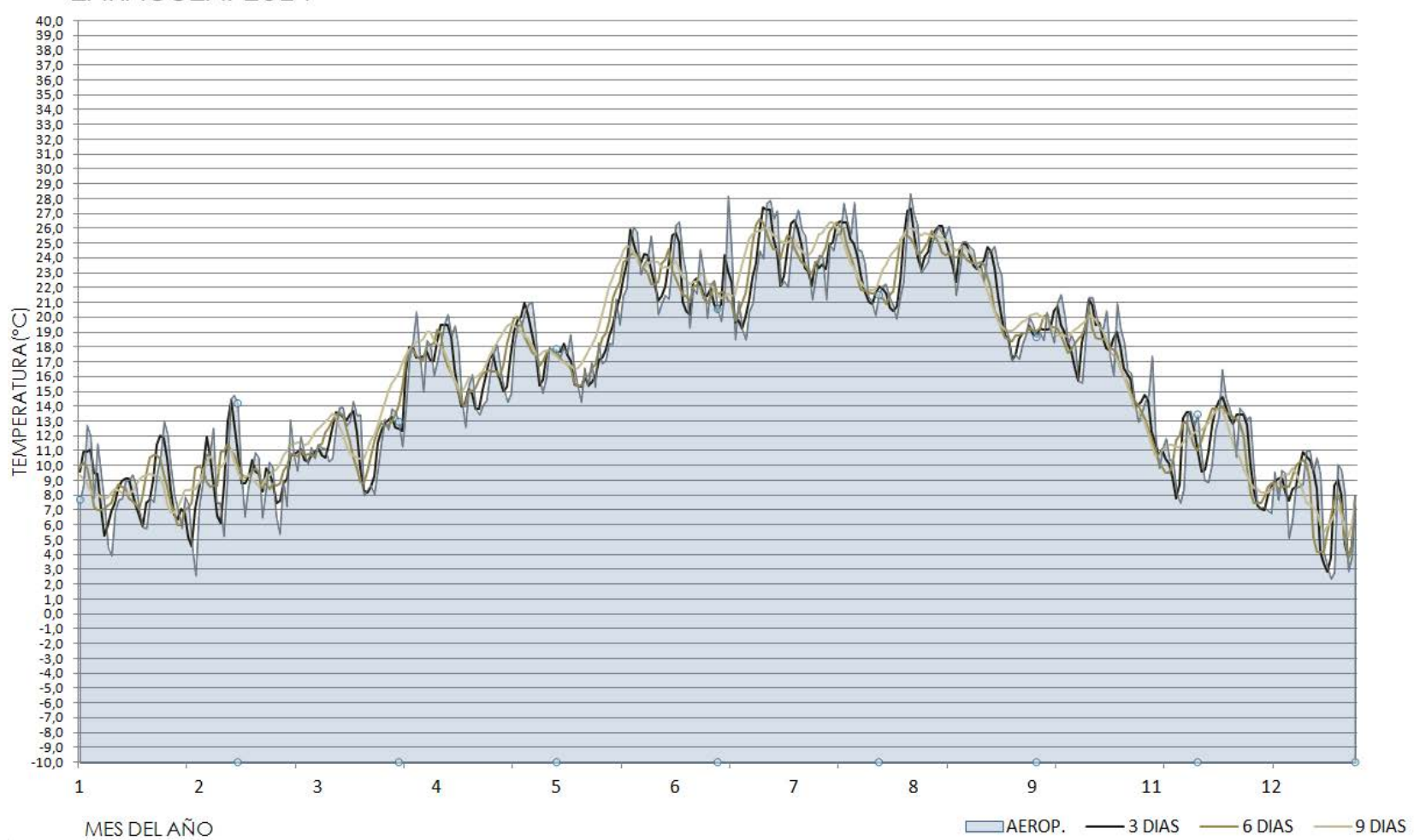

8-92 GRÁFICA DE LAS MEDIAS DIARIAS EN LA ESTACIÓN DE ZARAGOZA-AEROPUERTO DURANTE EL AÑO 2014 Y LAS MEDIANAS CADA 3-6 y 9 DÍAS (AEMET y elaboración propia)

La representación gráfica de las temperaturas en la estación de referencia permite visualizar el amortiguamiento de los valores medios cuando las medias se consideran cada más tiempo.

Cuando esta misma circunstancia se comprueba en dos estaciones y se visualizan los registros en gráficos que indiquen las ligeras diferencias entre ambas localizaciones se observa que se reduce los valores máximos y mínimos alcanzados en la estación de referencia. 
Tanto en el caso de considerar las medianas cada 3 días:

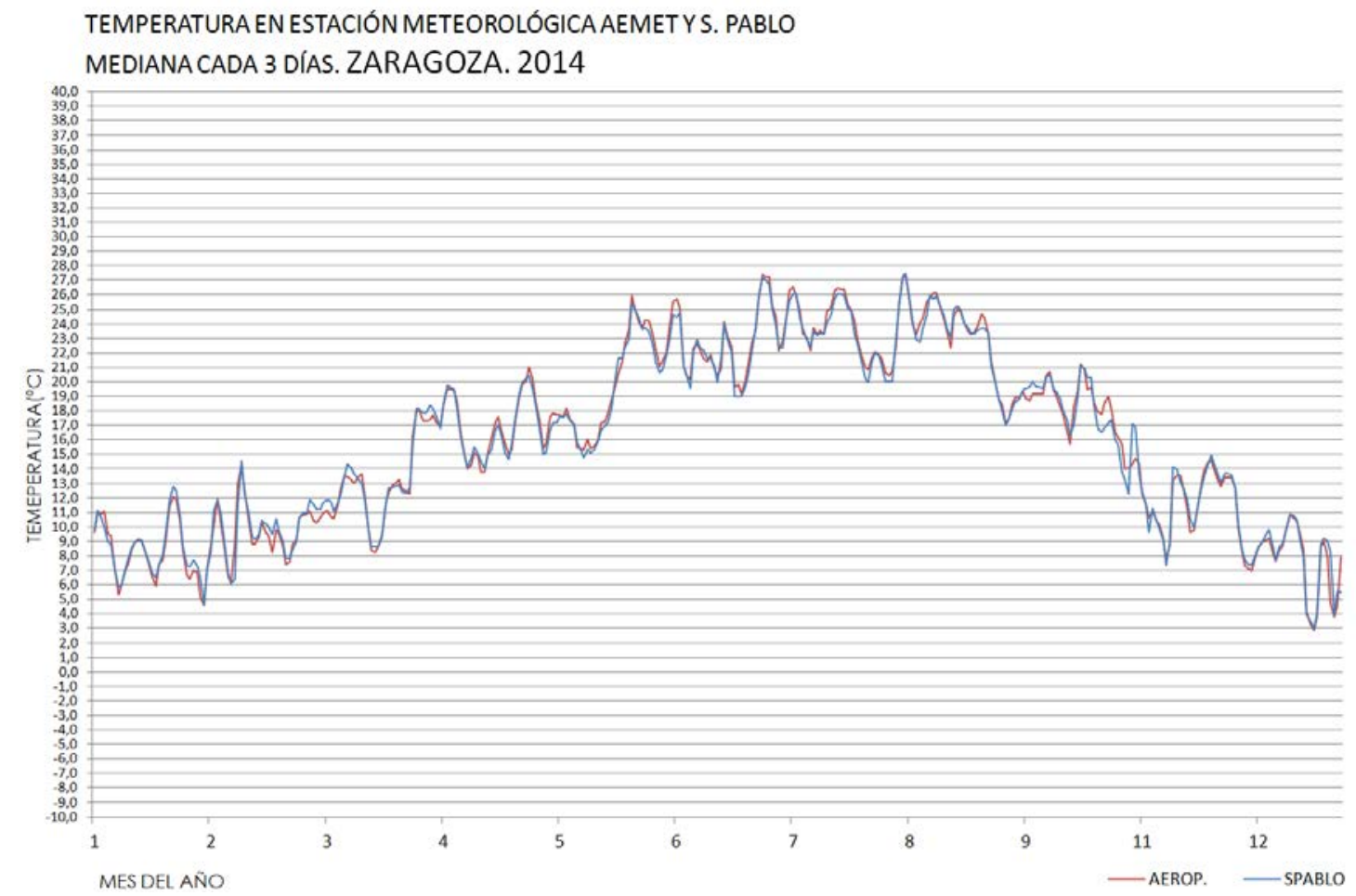

8-93 GRÁFICA DE LAS MEDIAS CADA 3 DÍAS EN LA ESTACIÓN DE ZARAGOZAAEROPUERTO Y EN S. PABLO DURANTE EL AÑO 2014 (AEMET y elaboración propia)

Como en el caso de considerar las medianas cada 9 días:

\section{TEMPERATURA EN ESTACIÓN METEOROLÓGICA AEMET Y S. PABLO CADA 9 DÍAS ZARAGOZA. 2014}

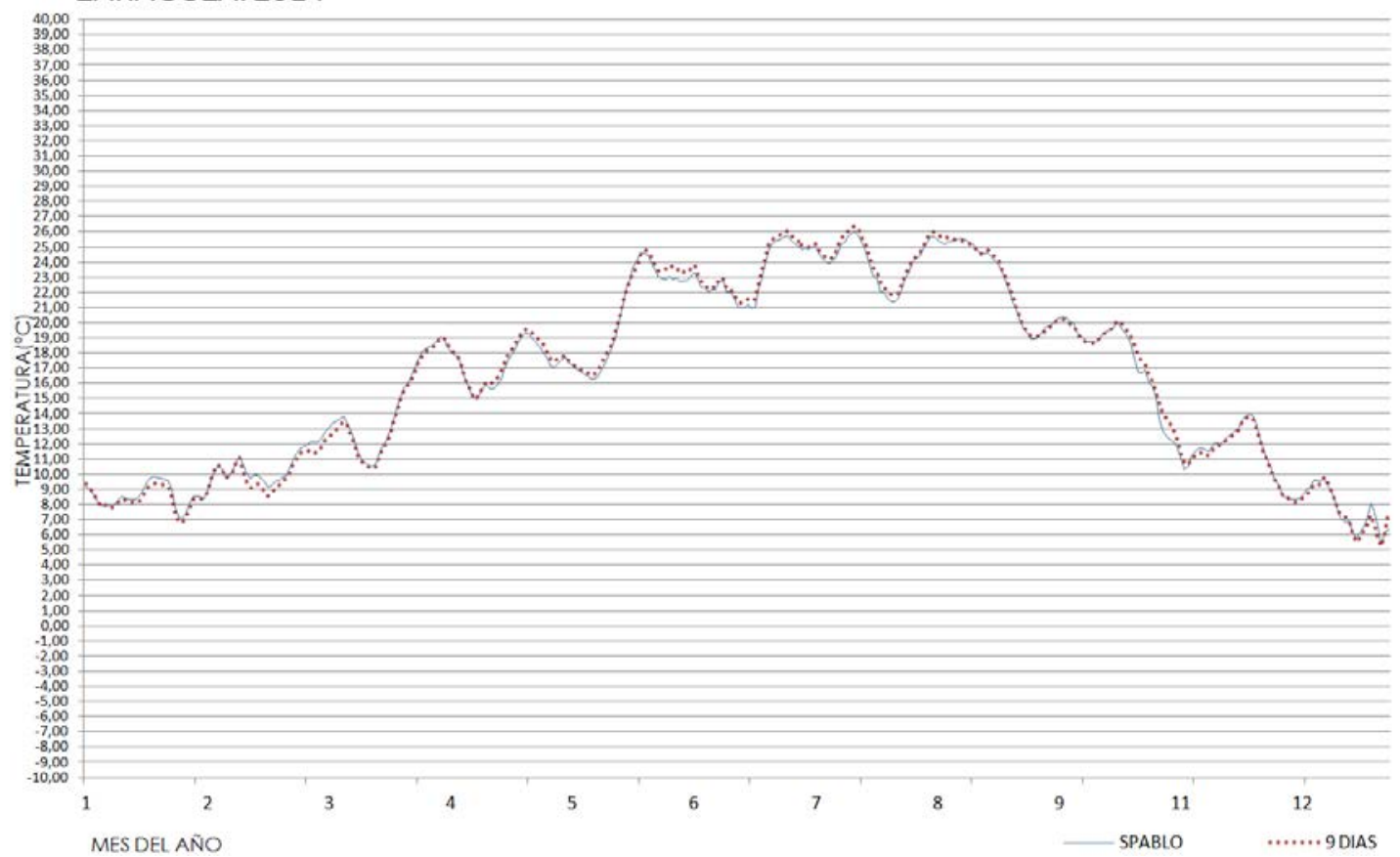

8-94 GRÁFICA DE LAS MEDIAS CADA 9 DÍAS EN LA ESTACIÓN DE ZARAGOZAAEROPUERTO Y EN S. PABLO DURANTE EL AÑO 2014 (AEMET Y elaboración propia) 


\subsubsection{SERIES TÉRMICAS MENSUALES Y CADA TRES MESES}

Para un manejo eficaz de la información se elaboran series parciales que permitan un análisis gráfico individualizado.

TEMPERATURA EN ESTACIONES METEOROLÓGICAS LOCALES AEMET

ZARAGOZA. ENERO 2014

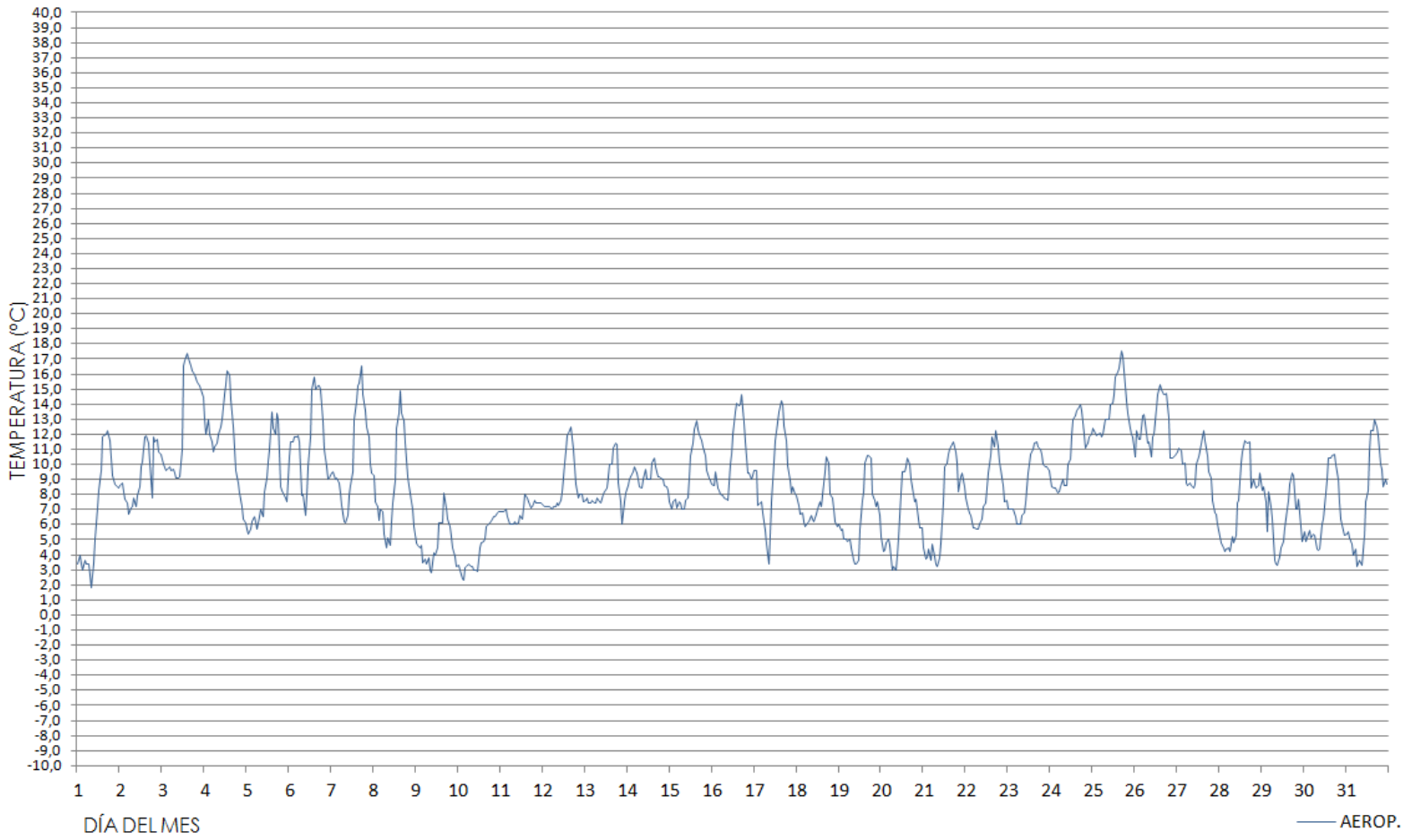

8-95 GRÁFICA DE LA SERIE TÉRMICA HORARIA EN LA ESTACIÓN DE ZARAGOZAAEROPUERTO DURANTE EL MES DE ENERO DEL AÑO 2014(AEMET Y elaboración propia) 


\subsubsection{SERIES EN PERIODOS EN LOS QUE SE MANTIENE LA TENDENCIA}

En la serie completa se identifican los periodos en los que la temperatura asciende, desciende o permanece en valores similares.

Pueden observarse los valores en un periodo homogéneo desde el punto de vista de la temperatura ambiente

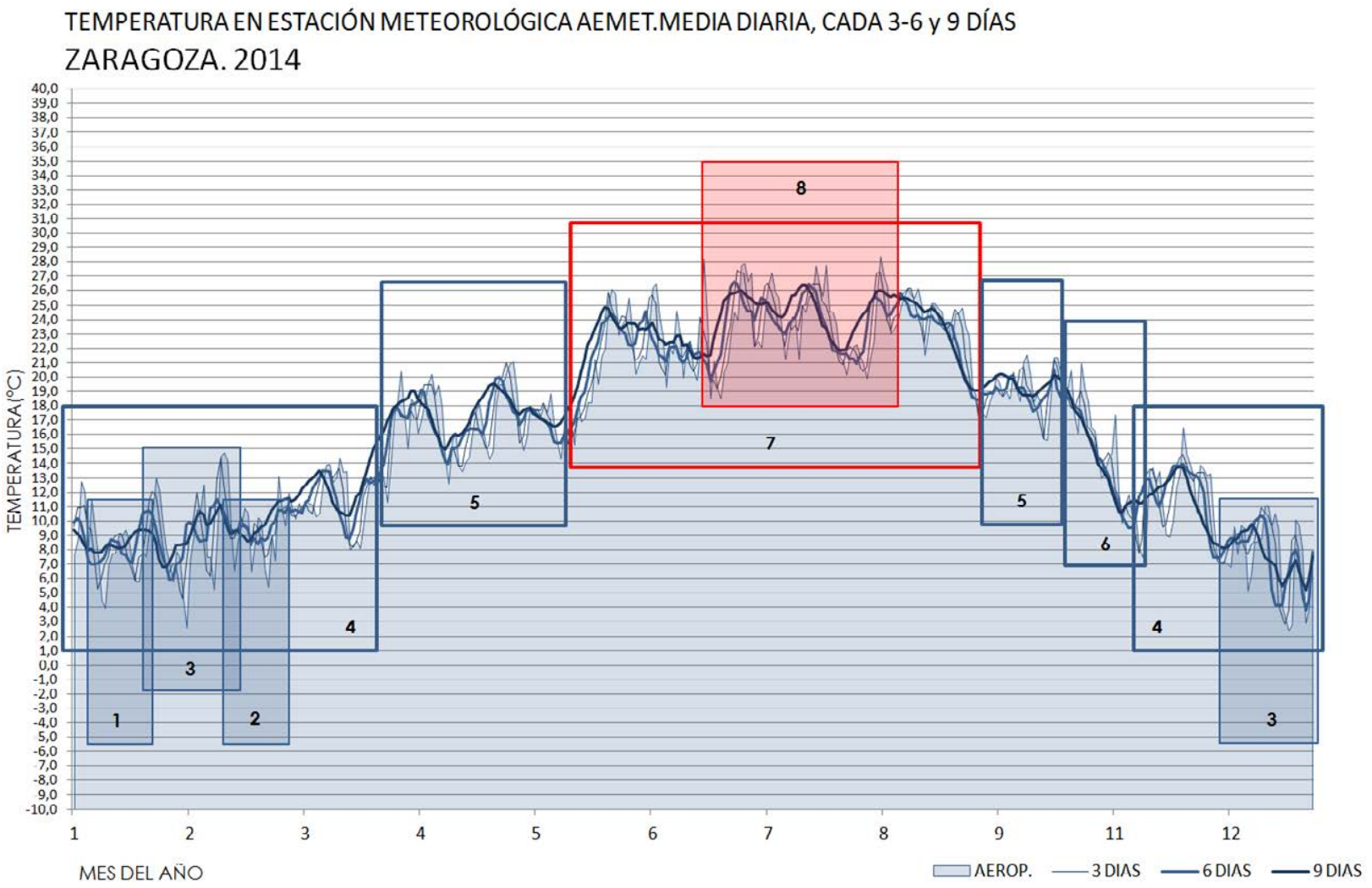

8-96 GRÁFICA ANUAL DESGLOSADA EN ZONAS HOMOGÉNEAS EN LA EVOLUCIÓN DE LA MEDIANA DE SU TEMPERATRUAS DIARIAS DURANTE EL AÑO 2014 (AEMET y elaboración propia)

Cada una de las zonas da lugar a datos que pueden segregarse para su estudio por separado. 
TEMPERATURA EN ESTACIÓN METEOROLÓGICA AEMET. MEDIA DIARIA Y CADA 9 DÍAS

ZARAGOZA. ENERO 2014

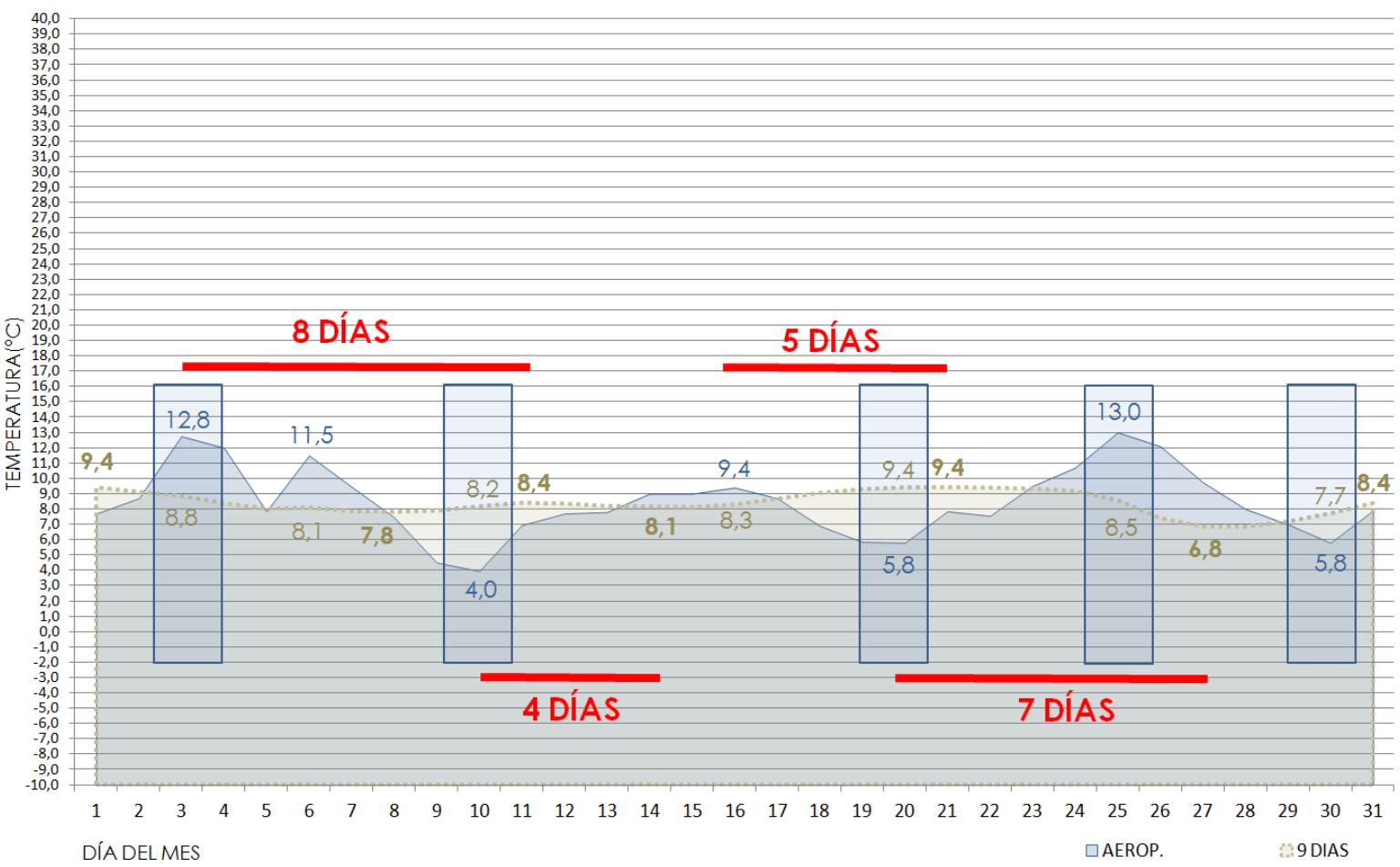

8-97 GRÁFICA DE LA SERIE TÉRMICA HORARIA EN LA ESTACIÓN DE ZARAGOZAAEROPUERTO DURANTE EL MES DE ENERO DEL AÑO 2014 CON RETARDO EN ALCANZAE LOS VALORES MÁXIMOS EN MEIDAS CADA 9 DÍAS (AEMET Y elaboración propia) 


\subsection{CLIMAS REGISTRADOS Y CLIMAS DE REFERENCIA}

La revisión conjunta de los datos aportados por las secuencias térmicas en los climas de referencia y los registrados en las estaciones meteorológicas de referencia aportará una visión de la adecuación local del uso de climas de referencia y su ámbito apropiado de utilidad.

La relación entre los climas sintéticos y el promedio de la década 2005 a 2014, expresados en un gráfico anual, permiten visualizar sus diferencias.

En el caso de la comparación entre el clima adoptado en el CTE para la zona climática D3 y el promedio de la década podemos observar cómo los valores promedios son considerablemente inferiores y con una distribución menos continua.

Especialmente significativo resulta que sean inferiores a las mínimas absolutas registradas durante la década.

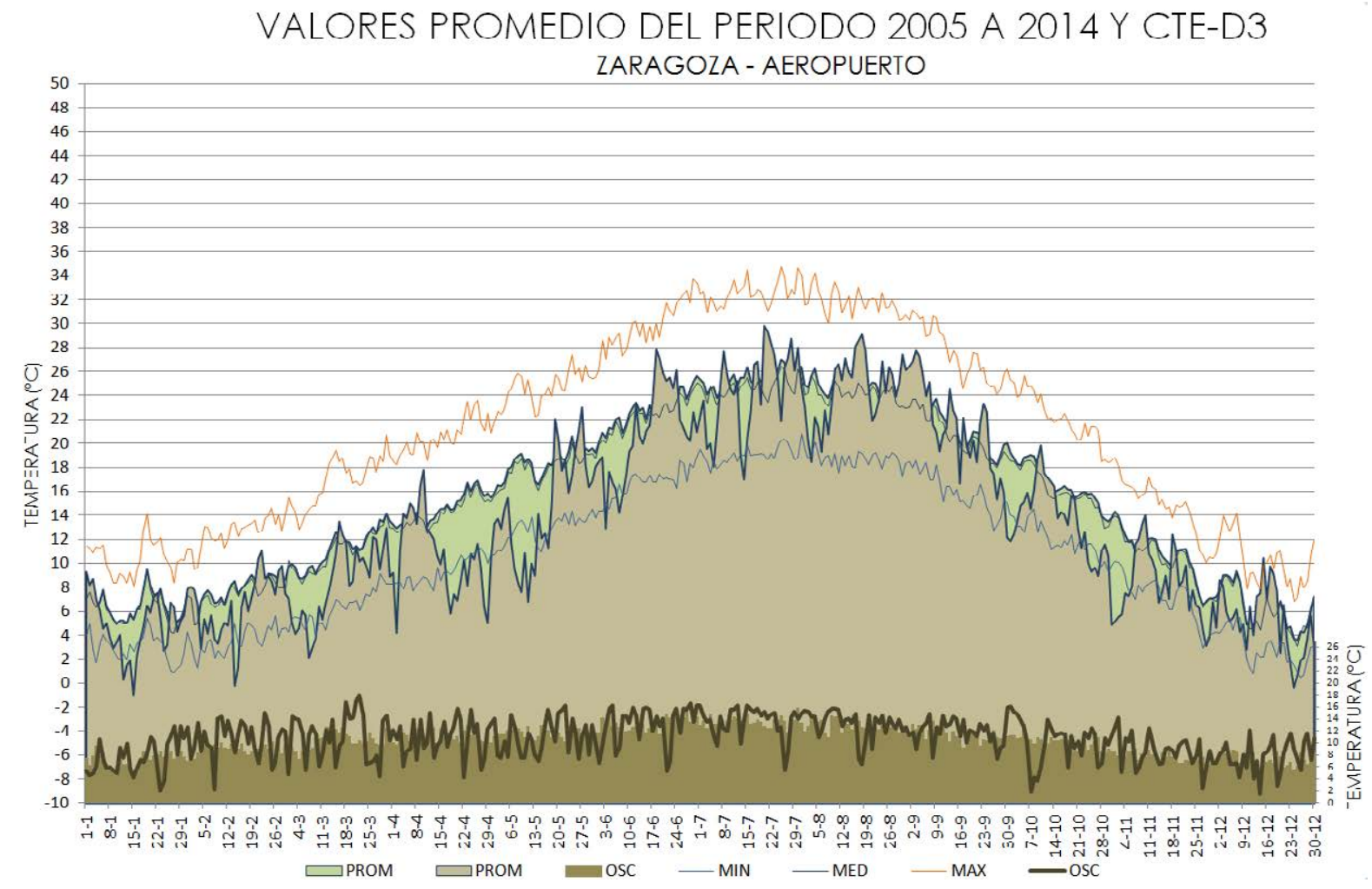

8-98 GRÁFICA DE TEMPERATURAS MÁXIMAS, MEDIAS Y MÍNIMAS DE LAS

TEMPERATURAS PROMEDIO DIARIAS DURANTE LA DÉCADA 2005-2014 EN ZARAGOZA AEROPUERTO COMPARADA CON LA TEMPERATURA PROMEDIO DIARIA DEL CLIMA ADOPTADO POR CTE PARA LA ZONA CLIMÁTICA D3 (AEMET, CTE y elaboración propia) 
El gráfico correspondiente a los valores máximos, medios y mínimos de las máximas diarias, comparado con las máximas diarias de la serie térmica adoptada por el CTE para la zona climática D3, presenta características similares a las de la comparativa de las temperaturas promedio, observándose que las temperaturas máximas están por debajo de las mínimas de las máximas absolutas de la década en los periodos más fríos y próximas a las máximas absolutas sin alcanzarlas durante el periodo más cálido.

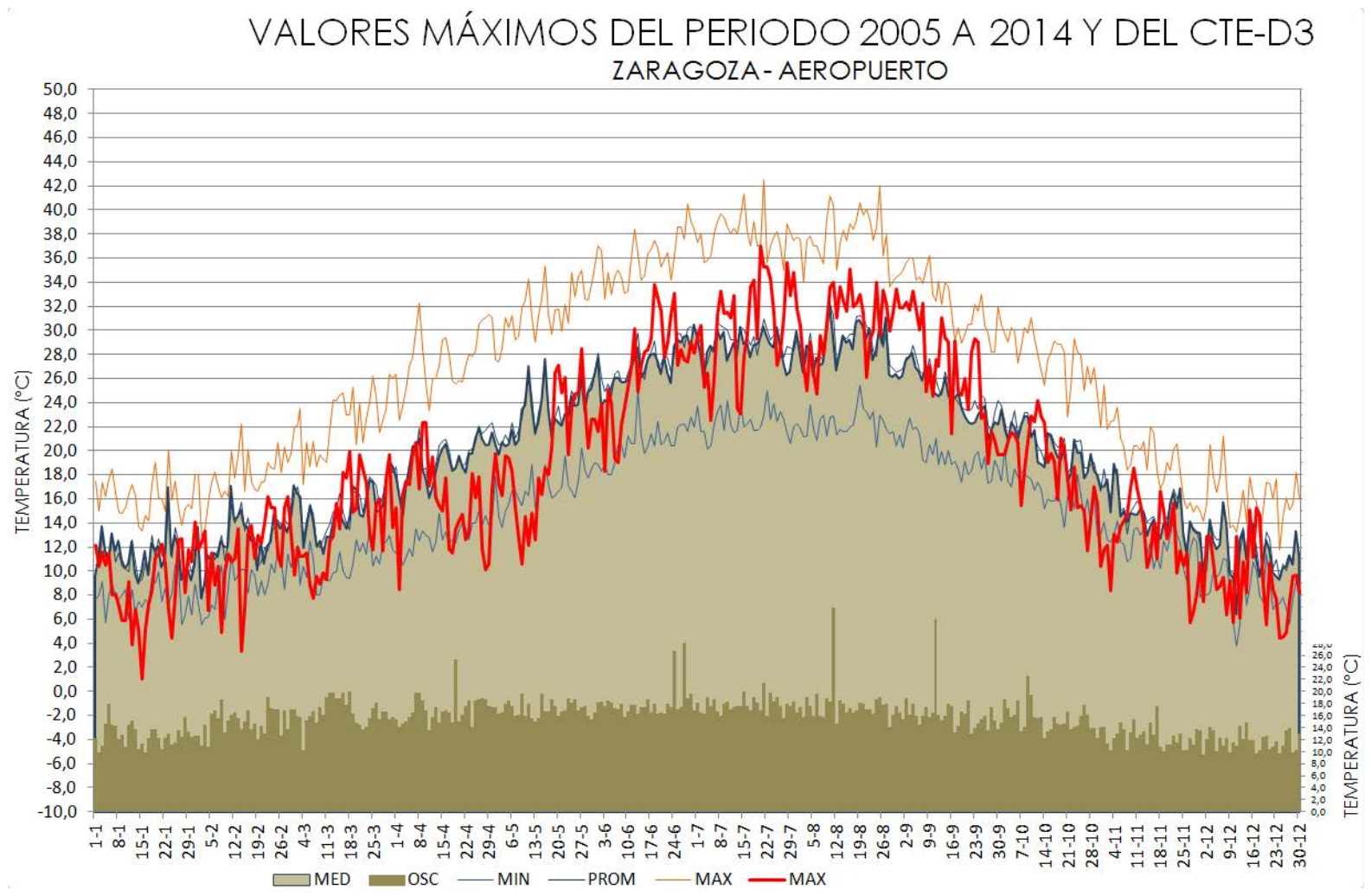

8-99 GRÁFICA DE TEMPERATURAS MÁXIMAS, MEDIAS Y MÍNIMAS DE LAS MÁXIMAS DIARIAS DURANTE LA DÉCADA 2005-2014 EN ZARAGOZA AEROPUERTO COMPARADA CON LA TEMPERATURA MÁXIMA DIARIA DEL CIMA ADOPTADO POR CTE PARA LA ZONA CLIMÁTICA D3 (AEMET, CTE Y elaboración propia) 
El gráfico correspondiente a los valores máximos, medios y mínimos de las mínimas diarias, comparado con las mínimas diarias de la serie térmica adoptada por el CTE para la zona climática D3, presenta características similares a las de la comparativa de las temperaturas promedio, observándose que las temperaturas mínimas están por debajo de las mínimas absolutas de la década en prácticamente todo el año, salvo en pequeños periodos de enero y diciembre donde se acercan e incluso sobrepasan las máximas de las mínimas.

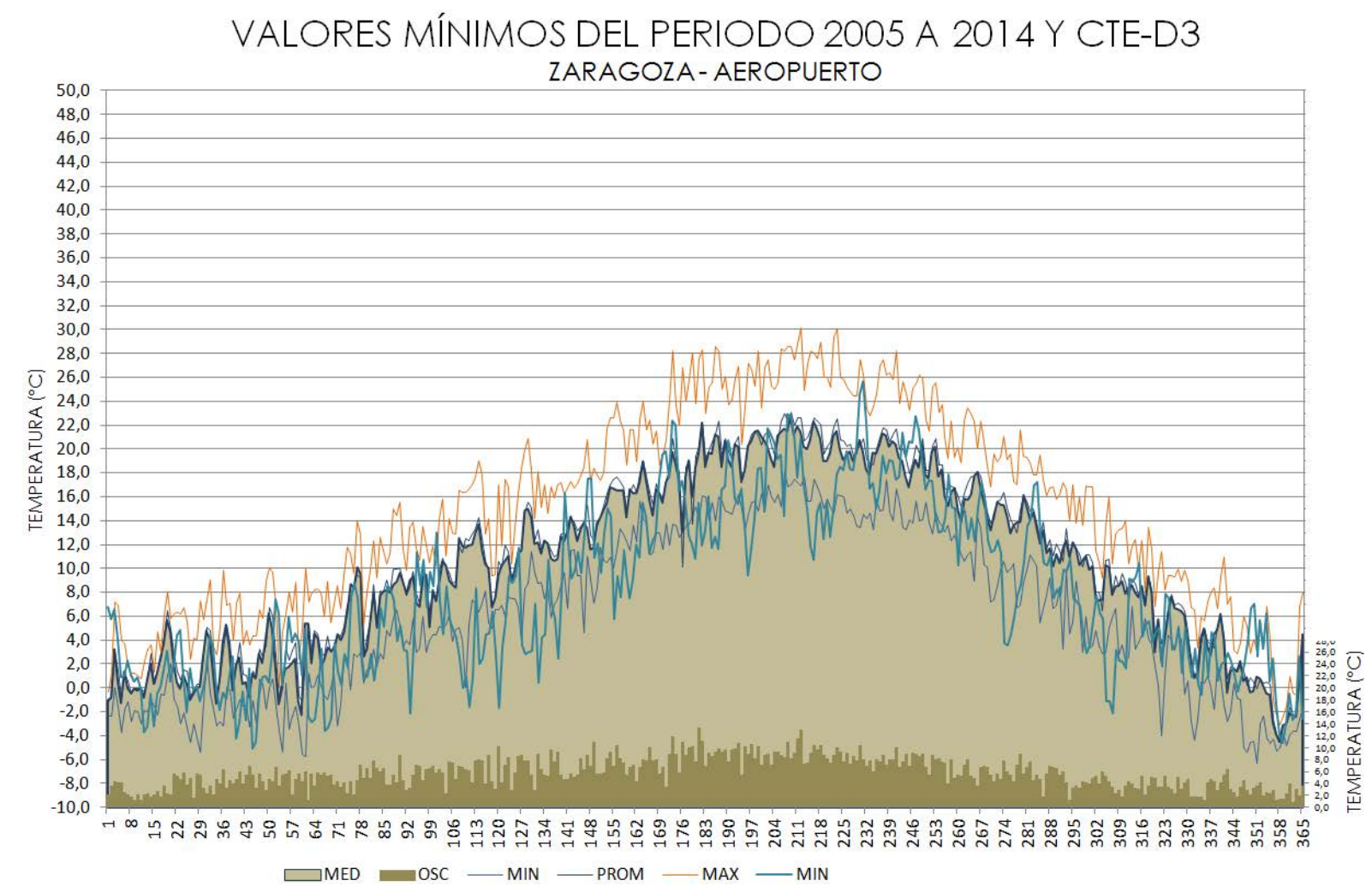

8-100 GRÁFICA DE TEMPERATURAS MÁXIMAS, MEDIAS Y MÍNIMAS DE LAS MÁXIMAS DIARIAS DURANTE LA DÉCADA 2005-2014 EN ZARAGOZA AEROPUERTO COMPARADA CON LA TEMPERATURA MÁXIMA DIARIA DEL CIMA ADOPTADO POR CTE PARA LA ZONA CLIMÁTICA D3 (AEMET, CTE Y elaboración propia)

La confrontación de los valores anuales y los establecidos para la zona climática D3 permite analizar la relación entre las temperaturas registradas y las que normativamente se aplican. 
VALORES PROMEDIO DEL CTE-D3 Y AÑO 2014 ZARAGOZA- AEROPUERTO

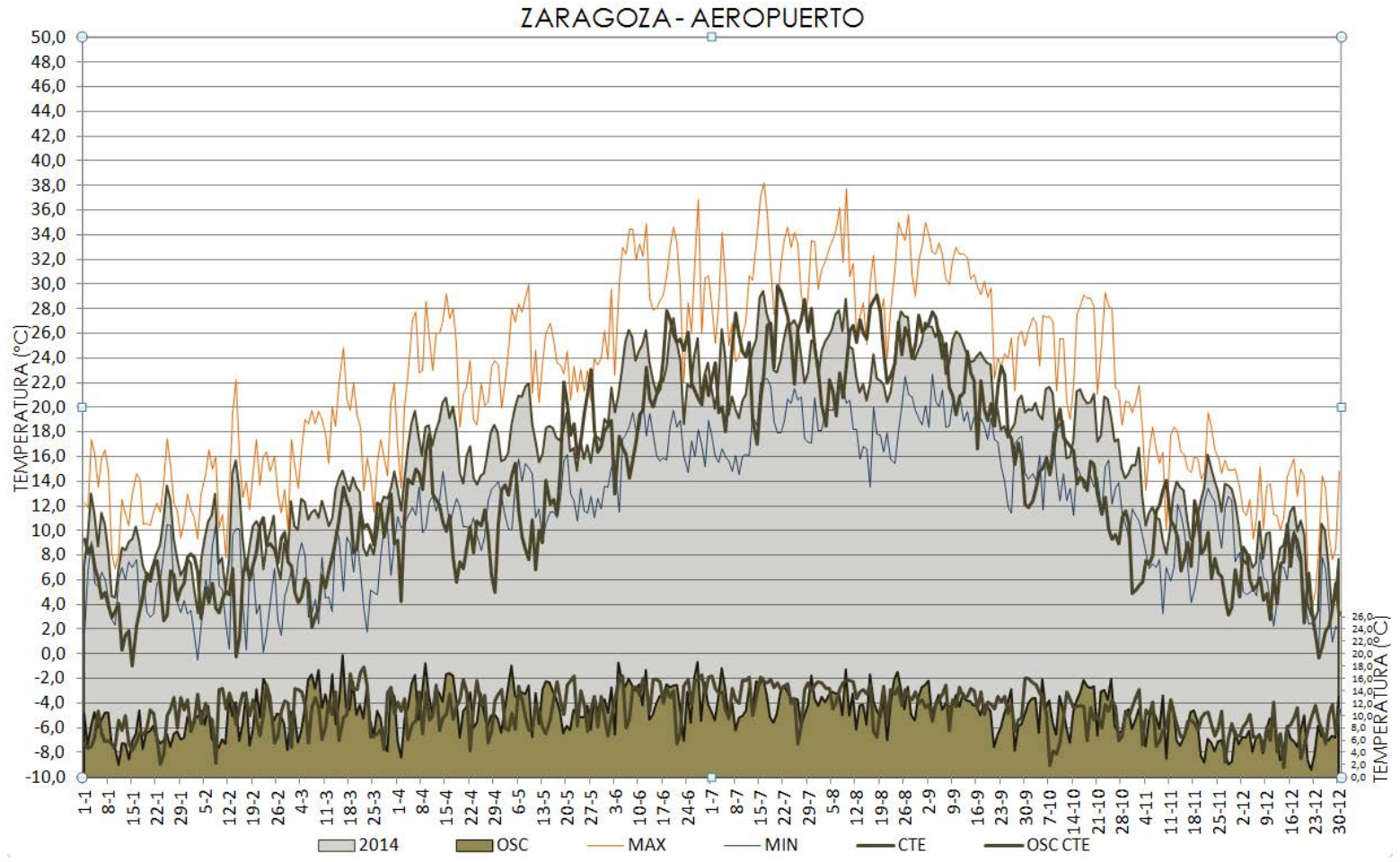

8-101 GRÁFICA DE TEMPERATURAS MÁXIMAS, MEDIAS Y MÍNIMAS DE LAS MÁXIMAS DIARIAS DURANTE LA DÉCADA 2005-2014 EN ZARAGOZA AEROPUERTO COMPARADA CON LA TEMPERATURA MÁXIMA DIARIA DEL CLIMA ADOPTADO POR CTE PARA LA ZONA CLIMÁTICA D3 (AEMET, CTE Y elaboración propia) 


\subsubsection{LÍMITE DE USO DE LOS VALORES CLIMÁTICOS MEDIOS}

Los valores climáticos medios permiten la comparación entre unidades temporales dadas, en este caso una secuencia de 30 años, minimizando la influencia de las discontinuidades en las series y aportando una imagen comparada muy fiable.

Su gran inconveniente para la aplicación en edificación radica en el incremento de la desviación típica y, con ella, de las condiciones climáticas más exigentes para conseguir el bienestar higrotérmico interior.

Una aplicación comparada de esta circunstancia a las condiciones climáticas en las dos localizaciones elegidas puede ilustrar su alcance.

El proceso elegido para su comprobación se basa en la consideración de los valores medios anuales en un periodo de 30 años. Durante este periodo se ha considerado a su vez la variación de la temperatura media, máxima y mínima.

Las temperaturas medias reflejan una constante comparable entre los distintos años, por ejemplo para observar la evolución de las temperaturas en un periodo o la diferencia de la energía recibida en dos años consecutivos. Por otra parte las medias de las temperaturas máximas o mínimas dan información sobre la diferencias térmicas a las que se ha sometido a el edificio durante cada año. Su determinación a partir de las medias anuales sin embargo no permite su aplicación al edificio ya que éste se enfrenta a las condiciones en que puntualmente se encuentra la atmósfera y habrá de responder a estas condiciones para obtener los valores higrotérmicos de consigna que se consideran apropiados en cada momento.

Sin embargo la comparación entre distintos años es un aspecto central para la observación del comportamiento energético del edificio $y$, por ende, para establecer la eficiencia energética de las medidas empleadas al hacerse necesariamente en periodos diferentes aunque se correspondan las horas del día o las estaciones.

En aras a estas comparaciones se han realizado secuencias anuales de valores medios cada 3, 5 y 10 años.

Estas secuencias se someten a su vez a la determinación de valores medios, mínimos y máximos y las oscilaciones térmicas o diferencia entre las máximas y las mínimas en cada periodo. 


\subsubsection{TEMPERATURA}

Empleando como indicador de las variaciones de los valores promedio la oscilación térmica se observa que la consideración de medias en periodos más largos aporta menores diferencias entre los valores máximos, medios y mínimos de las temperaturas mínimas, con reducciones muy importantes de las diferencias.

El climas más extremo tiene valores de oscilación absolutos mayores y también mayores diferencias que el más atemperado.

No se puede cuantificar, por tanto, una relación común para la zona climática establecida.

\begin{tabular}{|c|c|c|c|c|c|c|c|c|}
\cline { 2 - 9 } & \multicolumn{9}{c|}{ OSCILACIÓN $\left.{ }^{\circ} \mathrm{C}\right)$} & \multicolumn{2}{c|}{ MEDIA } \\
\cline { 2 - 9 } & \multicolumn{2}{c|}{ MÁXIMA } & \multicolumn{2}{c|}{ MEDIA } & \multicolumn{2}{c|}{ MÍNIMA } & & REDUCCIÓN \\
\cline { 2 - 9 } & ${ }^{\circ} \mathrm{C}$ & $\%$ & ${ }^{\circ} \mathrm{C}$ & $\%$ & ${ }^{\circ} \mathrm{C}$ & $\%$ & ${ }^{\circ} \mathrm{C}$ & $\%$ \\
\hline ANUAL & 2,20 & $93 \%$ & 2,10 & $89 \%$ & 2,80 & $118 \%$ & 2,37 & \\
\hline MEDIA - 3AÑOS & 1,67 & $90 \%$ & 1,68 & $91 \%$ & 2,18 & $118 \%$ & 1,84 & $22 \%$ \\
\hline MEDIA - 5AÑNOS & 1,15 & $76 \%$ & 1,47 & $97 \%$ & 1,93 & $128 \%$ & 1,52 & $36 \%$ \\
\hline MEDIA - 10AÑOS & 0,77 & $62 \%$ & 1,19 & $83 \%$ & 1,79 & $143 \%$ & 1,25 & $47 \%$ \\
\hline
\end{tabular}

8-102 VALORES MEDIOS DE LAS TEMPERATURAS MÁXIMAS, MEDIAS Y MÍNIMAS EN ZARAGOZA EN LA DECADA 2015-2014 (AEMET y elaboración propia)

En general se observa cómo la consideración de secuencias de medias obtenidas en periodos largos aporta valores menos extremos y que, por ello, puede aportar información sobre estimaciones globales de comportamiento, aunque no reflejan con exactitud las condiciones de trabajo en los distintos periodos de servicio del edificio. Esto, en la práctica, significa que los periodos de más exigencia para alcanzar valores de bienestar térmico no se ven reflejados. Si bien el edificio amortigua en buena medida los valores extremos de temperatura, no todas las configuraciones lo hacen por igual, pudiendo afirmarse que los edificios de mayor inercia térmica los amortiguarán más, precisando una mayor aportación de energía para incrementar o bajar su temperatura ambiente. Por otra, parte los edificios con menor inercia térmica se verán más afectados por breves periodos de temperaturas extremas, y a su facilidad para acompasar su temperatura interior con el clima deberán, en función de la capacidad aislante de sus envolventes, el uso de más o menos energía para la modificación de la temperatura interior.

La capacidad de disipación, en la mayor parte de los casos, y, ocasionalmente, de la aportación de energía por la acción directa del viento se ve incrementada por su velocidad. La consideración de valores promedios de largos periodos ofrece una imagen desvirtuada de la realidad al minorar la influencia que tienen cuando son más extremos, lo que coincide frecuentemente con los momentos de máxima dificultad en alcanzar el bienestar térmico. La influencia de la dirección del viento y la posibilidad de evitar su acción sobre el edificio, tanto con medidas externas 
como integradas en éste, permite una consideración independiente del análisis térmico.

La observación de la incidencia específica de la localización de edificio y de cada una de sus envolventes puede segregarse de otros análisis ofreciendo soluciones aplicadas a cada orientación, exposición y necesidad higrotérmica.

La capacidad de captación solar gratuita a través de las envolventes altera sustancialmente las estimaciones higrotérmicas basadas en la temperatura ambiente, tanto por la cantidad de energía recibida como por la capacidad del edificio de retener la onda térmica en su interior. También en este caso la energía recibida depende de la orientación y la exposición y puede ser modulada mediante el diseño y los elementos de protección o captación, tanto del edificio como de su entorno, por lo que también puede segregarse su aportación del problema general de la adaptación a la temperatura ambiente del edificio.

En cualquier caso, los valores climatológicos medios en periodos largos no ofrecen una imagen adecuada del clima para edificios con cualidades térmicas convencionales. 


\subsubsection{COMPARACIÓN ENTRE EL CLIMA DE REFERENCIA Y LOS VALORES MEDIOS DE LA DÉCADA 2005 A 2014.}

Las observaciones realizadas sugieren comparar la imagen climática ofrecida por los climas sintéticos aplicados a una localidad y una serie climática concreta.

La complejidad del estudio simultáneo de todos los parámetros climáticos hace que las comparaciones se planteen segregando las estimaciones. En una primera instancia se consideran los valores térmicos.

Se ha elegido la última década (2005-2014) para establecer los valores medios y extremos que se compararán con los climas sintéticos descritos.

La comparación año a año nos aportará las diferencias entre las estimaciones y los valores reales.

Tiene interés considerar la diferencia en medias anuales, mensuales, diarias y horarias, pero solo indicarán las diferencias los valores acumulados a lo largo del año o los valores acontecidos a lo largo de la década anualizados.

Como indicadores se han considerado los grados hora acumulados. La repercusión sobre la edificación de la temperatura exterior está condicionada por las características de la edificación que se manifiesta en un retardo y una amortiguación. Esta última provoca que, considerando la captación solar del edificio, especialmente a través de sus huecos vidriados, el control de la exposición al viento y al sol, las transmitancias y las capacidades térmicas convencionales, las temperaturas interiores sin aportaciones energéticas complementarias se mantengan alejadas de las exteriores, tanto en periodos cálidos como fríos. En los periodos cálidos se ha considerado que temperaturas exteriores de $26^{a} \mathrm{C}$ pueden manifestarse en el interior de los edificios como confortables. En periodos fríos se ha considerado que temperaturas superiores a $16^{\mathrm{a}} \mathrm{C}$ permiten temperaturas de confort interiores.

La decisión se ha contrastado con la medición de valores interiores y exteriores en edificios sin aportaciones complementarias de energía, observando que estas cifras son conservadoras en periodos fríos para edificios de baja capacidad térmica, bien aislados y edificios convencionales bien aislados y soleados, en ambos casos con una captación solar de moderada a elevada, mientras que en edificios sin aislamiento, con captación solar moderada y con alta capacidad térmica pueden observarse sensaciones térmicas por debajo de las de confort.

En periodos cálidos, valores de temperatura ambiente exterior por debajo de $26^{\circ} \mathrm{C}$ se perciben como confortables en los edificios de alta capacidad térmica, moderadamente soleados y sin aislamiento, mientras que edificios convencionales o de baja inercia térmica, aislados, dependen de la reducción a la 
exposición a la radiación solar y a su capacidad de ventilación nocturna.

Un estudio que asocie las cualidades de los edificios, las temperaturas de ambiente exteriores y las temperaturas observadas en el interior sin la aportación o detracción de energía complementaria permitiría ajustar mejor estos valores y mejoraría la capacidad de establecer los rangos térmicos exteriores que requieren acciones complementarias en el edificio y su entorno.

A falta de estos estudios y basándose en las experiencias puntuales realizadas se aportan unos valores para los rangos establecidos, por debajo de $16^{\circ} \mathrm{C}$, entre $16^{\circ} \mathrm{C}$ y $26^{a} \mathrm{C}$ y por encima de $26^{\circ} \mathrm{C}$, en el periodo decenal comprendido entre 2004 y 2014.

\begin{tabular}{|c|c|c|c|c|c|c|c|c|c|c|c|c|c|c|}
\hline & $\begin{array}{l}\text { MIN } \\
\text { ABS }\end{array}$ & $\begin{array}{c}\text { ler } \\
\text { cuartil } \\
\text { MÍN } \\
\text { DIARIA }\end{array}$ & $\begin{array}{c}2^{\circ} \\
\text { cuartil }\end{array}$ & mediana & $\begin{array}{l}\text { dif(MEDIA- } \\
\text { MEDIANA) }\end{array}$ & media & $\begin{array}{l}\text { 3er. } \\
\text { Cuartil }\end{array}$ & $\begin{array}{c}\text { 4er. } \\
\text { Cuartil } \\
\text { MÁX } \\
\text { DIARIA }\end{array}$ & $\begin{array}{l}\text { MAX } \\
\text { ABS }\end{array}$ & $\begin{array}{l}\text { HORAS } \\
\text { BAJO } \\
16^{\circ} \mathrm{C}\end{array}$ & $\begin{array}{c}{ }^{\circ} \mathrm{C} \mathrm{HASTA} \\
16^{\circ} \mathrm{C}\end{array}$ & $\begin{array}{c}\text { HORAS } \\
\text { SOBRE } \\
26^{\circ} \mathrm{C}\end{array}$ & $\begin{array}{c}{ }^{\circ} \mathrm{C} \text { HASTA } \\
26^{\circ} \mathrm{C}\end{array}$ & $\begin{array}{l}\text { HORAS } \\
\text { ENTRE } \\
16^{\circ} \mathrm{C} Y \\
36^{\circ} \mathrm{C} \\
\end{array}$ \\
\hline 2005 & $-5,80$ & 9,93 & 11,81 & 14,17 & 0,58 & 14,74 & 17,65 & 20,67 & 41,30 & 4642 & 38843,1 & 984 & $-4090,4$ & 3134 \\
\hline 2006 & $-5,30$ & 11,21 & 13,08 & 15,42 & 0,53 & 15,95 & 18,82 & 21,72 & 39,40 & 4260 & 31101,4 & 1099 & $-4434,5$ & 3401 \\
\hline 2007 & $-6,30$ & 10,15 & 12,12 & 14,51 & 0,57 & 15,08 & 18,05 & 20,99 & 38,30 & 4777 & 32699,6 & 828 & $-3085,9$ & 3155 \\
\hline 2008 & $-5,40$ & 10,42 & 12,32 & 14,56 & 0,62 & 15,17 & 17,88 & 20,79 & 37,80 & 4983 & 32327,9 & 850 & $-3505,6$ & 2951 \\
\hline 2009 & $-3,60$ & 11,03 & 12,99 & 15,36 & 0,62 & 15,98 & 19,02 & 21,99 & 42,50 & 4490 & 31693,8 & 1198 & $-5404,1$ & 3072 \\
\hline 2010 & $-3,90$ & 10,15 & 12,05 & 14,35 & 0,51 & 14,87 & 17,70 & 20,46 & 42,00 & 4562 & 32931,2 & 990 & $-4130,5$ & 3208 \\
\hline 2011 & $-4,60$ & 11,28 & 13,21 & 15,62 & 0,53 & 16,15 & 19,08 & 22,02 & 40,60 & 4484 & 28229,9 & 1102 & $-4358,3$ & 3174 \\
\hline 2012 & $-3,60$ & 10,68 & 12,62 & 15,10 & 0,63 & 15,73 & 18,72 & 21,71 & 41,10 & 4659 & 32528,8 & 1195 & -5512 & 2930 \\
\hline 2013 & $-4,40$ & 10,38 & 12,28 & 14,61 & 0,44 & 15,05 & 17,95 & 20,73 & 37,70 & 4861 & 34320,3 & 949 & $-3661,2$ & 2950 \\
\hline 2014 & $-0,50$ & 11,78 & 13,59 & 15,98 & 0,53 & 16,51 & 19,42 & 22,28 & 38,20 & 4308 & 24744,4 & 1036 & $-3591,4$ & 3416 \\
\hline MEDIA & $-4,34$ & 10,70 & 12,61 & 14,97 & 0,56 & 15,52 & 18,43 & 21,33 & 39,89 & 4602,60 & 31942,04 & 1023,10 & $-4177,39$ & 3139,10 \\
\hline CTE D3 & $-5,10$ & 7,86 & 10,70 & 13,63 & $-0,01$ & 13,62 & 16,58 & 18,99 & 37,00 & 5499,00 & 43885,20 & 927,00 & $-3175,90$ & 2334,00 \\
\hline RITE D3 & $-0,60$ & 10,13 & 11,55 & 13,56 & 0,77 & 14,33 & 17,20 & 19,89 & 36,00 & 5218,00 & 35724,30 & 723,00 & $-2274,80$ & 2819,00 \\
\hline RITE-ZG & $-1,70$ & 9,90 & 11,46 & 13,75 & 0,90 & 14,65 & 17,91 & 20,98 & 37,40 & 5097,00 & 34719,30 & 802,00 & $-2640,00$ & 2861,00 \\
\hline
\end{tabular}

8-103 VALORES EN GRADOS HORA DE LOS CUARTILES DE LAS TEMPERATURAS EN LA DÉCADA 2005 A 2014 Y EN LOS CLIMAS DE REFERENCIA PARA LA ZONA D3 Y PARA ZARAGOZA (CTE, RITE, AEMET y elaboración propia)

Para estas estimaciones aplicadas a una localidad se han obtenido los siguientes resultados:

Las temperaturas absolutas, máximas y mínimas, mantienen oscilaciones térmicas anuales sólo ligeramente inferiores a $40^{\circ} \mathrm{C}$ en el pasado 2014. El resto de los años superan siempre esta diferencia y llegan a los $45^{\circ} \mathrm{C}$.

Las temperaturas mínimas absolutas son siempre superiores a $0^{\circ} \mathrm{C}$, con un valor medio de $4,34^{\circ} \mathrm{C}$.

Las temperaturas máximas absolutas son frecuentemente superiores a $40^{\circ} \mathrm{C}$, con un valor medio de $39,9^{\circ} \mathrm{C}$.

Valores medios del primer cuartil de $10,7^{\circ} \mathrm{C}$ y oscilando entre los $9,9^{\circ} \mathrm{C}$ y los $11,8^{\circ} \mathrm{C}$ indican que las temperaturas sólo ocasionalmente son muy bajas, y casi siempre en horarios nocturnos.

Valores medios del $4^{\circ}$ cuartil de $21,3^{\circ} \mathrm{C}$, indican que sólo ocasionalmente las temperaturas son muy altas.

Los valores medios del $2^{\circ}$ y $3 e r$ cuartil se encuentran entre los $12,6^{\circ} \mathrm{C}$ y los $18,4^{\circ} \mathrm{C}$, lo que supone una oscilación térmica 
relativamente pequeña y unos valores templados durante muchas horas al año.

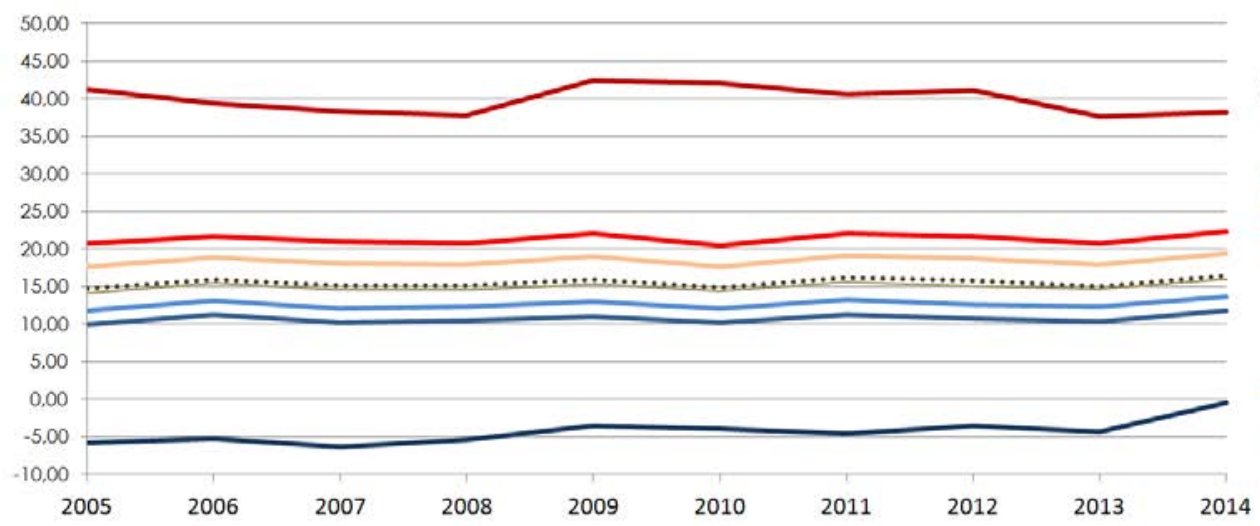

8-104 GRÁFICA DECENAL DE CUARTILES EN ZARAGOZA (AEMET y elaboración propia)

Las horas en que la temperatura ambiente exterior está por debajo de $16^{\circ} \mathrm{C}$ oscilan entre 4.200 y 5.000 , con un valor medio de 4.603 horas durante el periodo considerado.

Los grados-hora necesarios para alcanzar los $16^{\circ} \mathrm{C}$ en este periodo superan siempre los 28.300 grados-hora, no siendo superiores a 39.000 grados-hora, con un valor medio de 31.942 grados-hora.

Las horas en las que la temperatura supera los $26^{\circ} \mathrm{C}$ están entre 800 y 1200 , con un valor medio de 1.023 horas.

Los grados-hora en que se superan los $26^{\circ} \mathrm{C}$ están entre 3000 y 5500 con una media de 4.177 grados-hora.

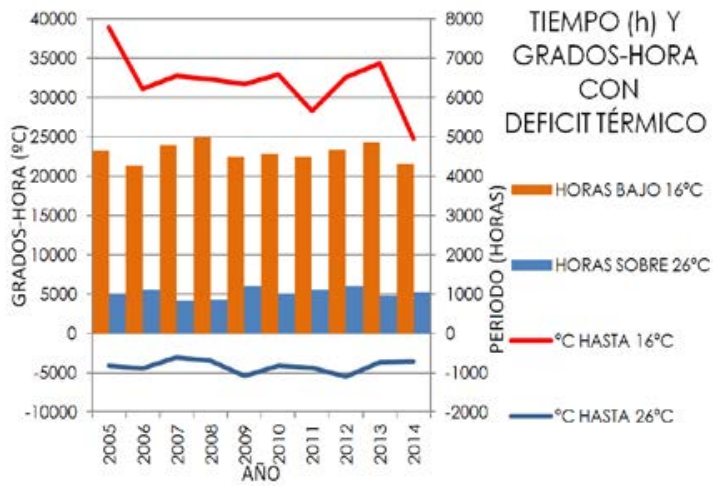

8-105 GRÁFICA DE GRADOS HORA QUE SUPERAN LOS $26^{\circ} \mathrm{C}$ (A DISIPAR, NO ALCANZAN LOS $16^{\circ} \mathrm{C}$ (A CALEFACTAR) Y QUEDAN ENTRE AMBOS (AEMET Y elaboración propia)

Cuando se comparan los valores registrados durante la década con los climas sintéticos se observa que su relación varía según se consideren promedios, medianas, máximos o mínimos. 


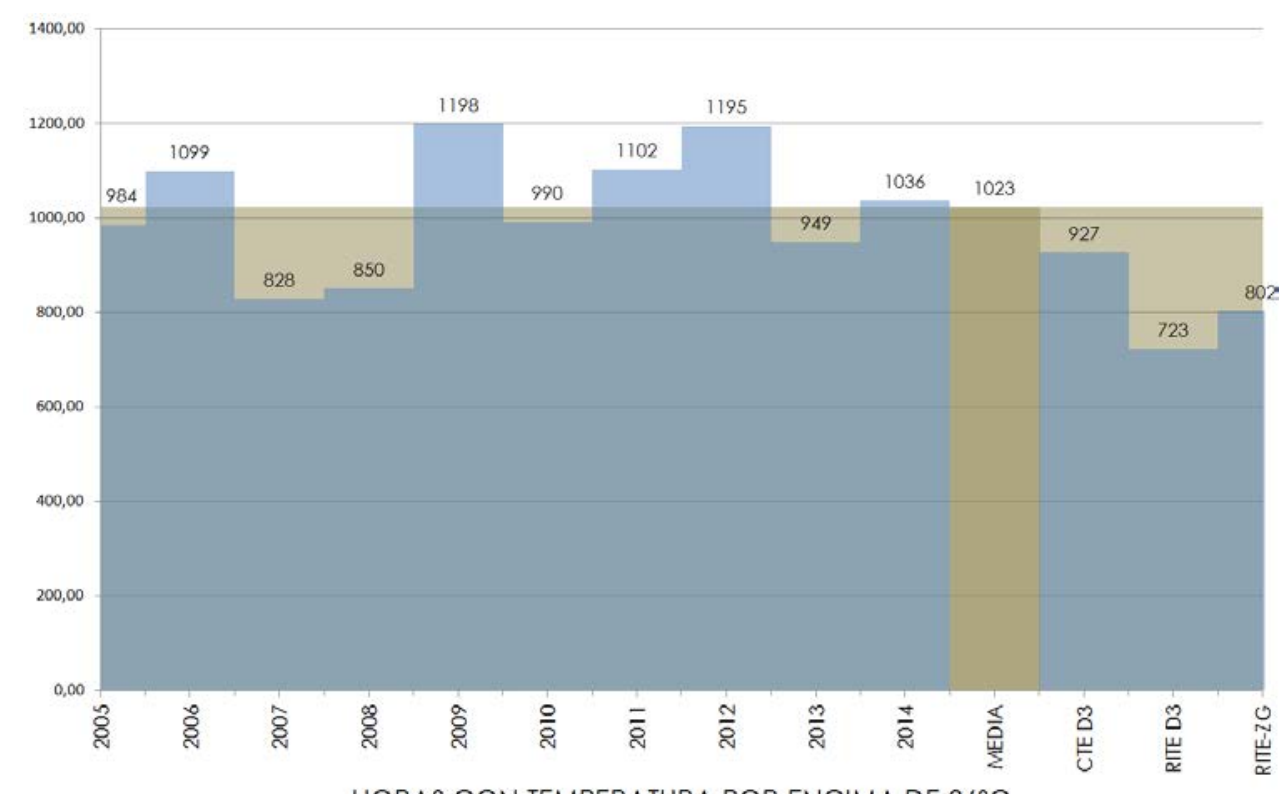

HORAS CON TEMPERATURA POR ENCIMA DE $26^{\circ} \mathrm{C}$

8-106 GRÁFICA COMPARADA CON LOS VALORES DE TIEMPO EN QUE LA TEMPERATURA ES MAYOR DE $26^{\circ} \mathrm{C}$ (PERIODO CÁLIDO) EN ZARAGOZA EN LA DECADA DE 2005 A 2014. (AEMET y elaboración propia).

Las horas en que se estiman temperaturas mayores de $26^{\circ} \mathrm{C}$ son menores que los valores medios y no se ajustan a los máximos registrados, por lo que es previsible que la prescripción siguiendo la pauta dada por los climas de referencia no esté diseñada para soportar durante tanto tiempo temperaturas por encima de $26^{\circ} \mathrm{C}$, aunque su recurrencia sea muy baja.

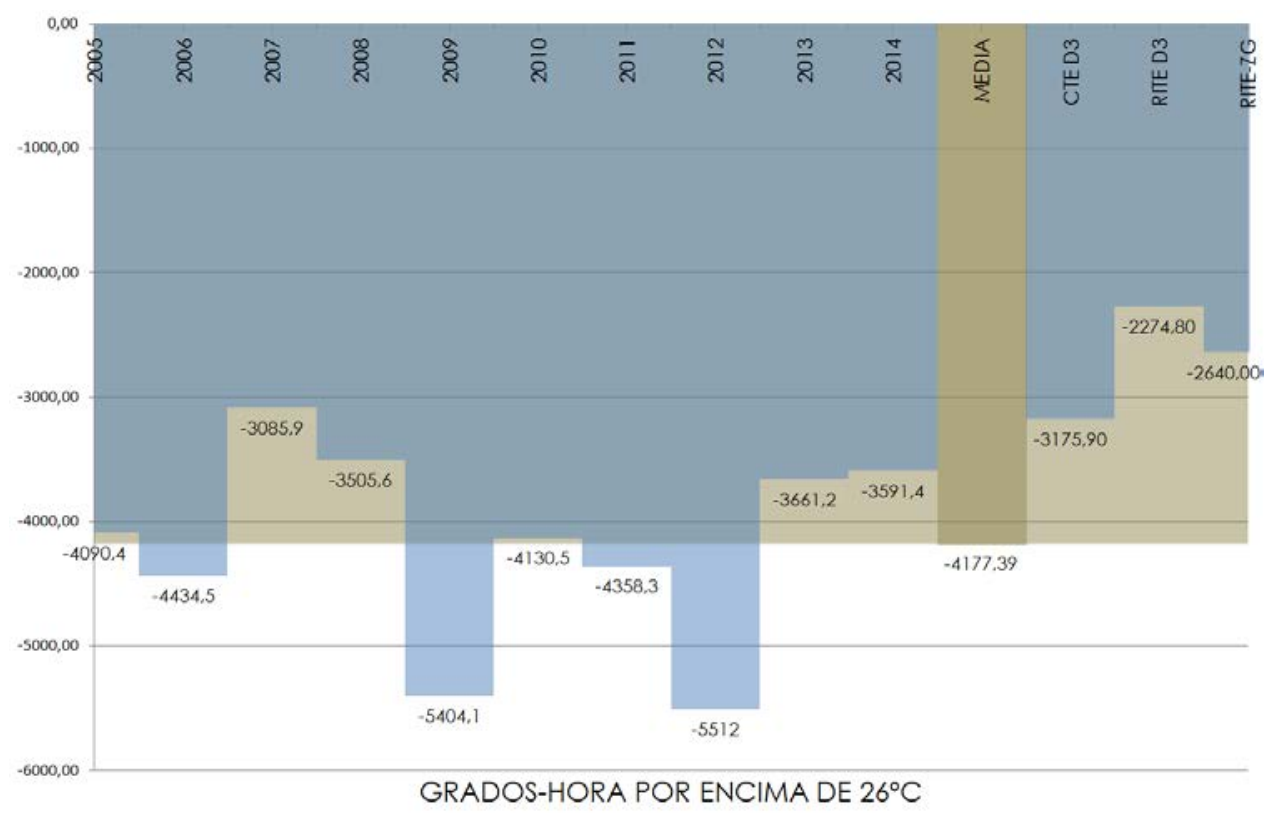

8-107 GRÁFICA COMPARADA CON LOS VALORES DE GRADOS-HORA SOBRE $26^{\circ} \mathrm{C}$ (PERIODO CÁLIDO) EN ZARAGOZA EN LA DECADA DE 2005 A 2014. (AEMET Y ELABORACIÓN PROPIA).

Los grados-hora necesarios para bajar las temperaturas hasta $26^{\circ} \mathrm{C}$ no se ven bien representados por los climas sintéticos con valores entre 3.176 y 2.275 , mientras que la media de la década está en 4.177 grados-hora, por lo que previsiblemente el edificio habrá de soportar temperaturas más altas durante más tiempo que lo previsto en los climas de referencia. 


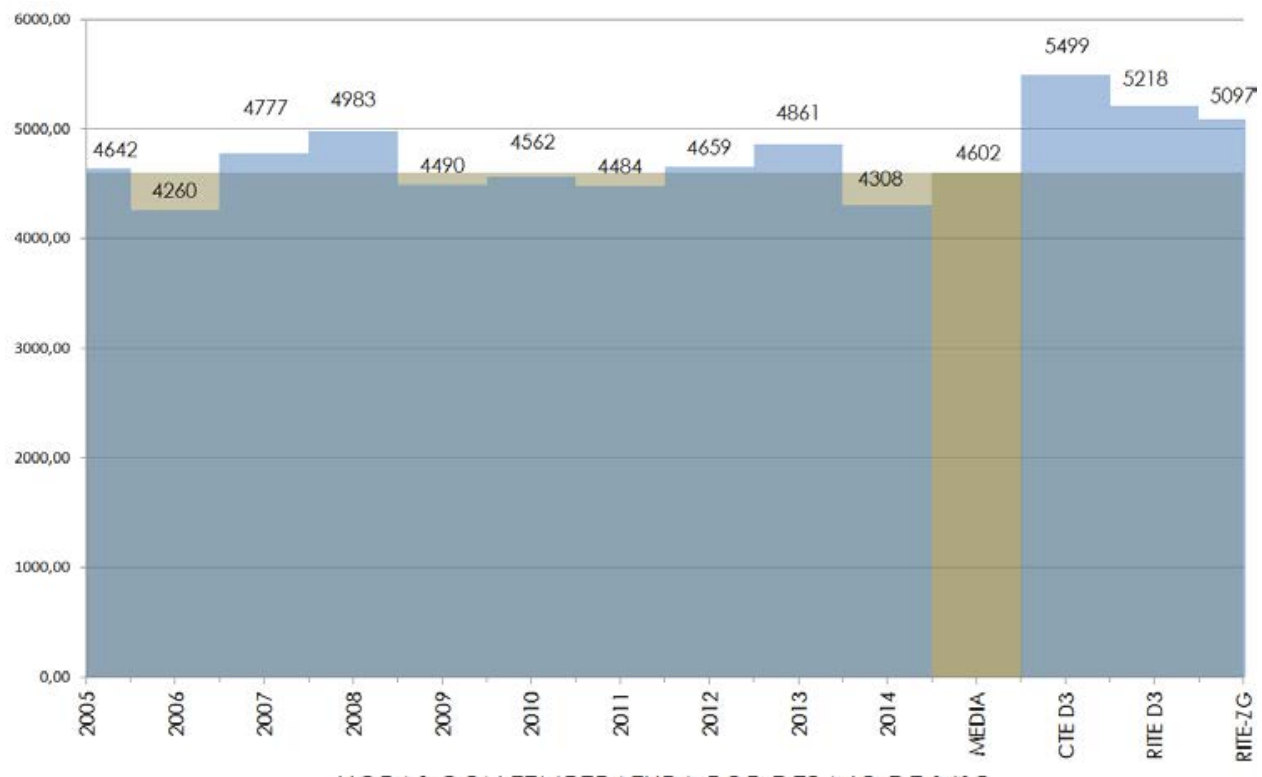
HORAS CON TEMPERATURA POR DEBAJO DE $16^{\circ} \mathrm{C}$

8-108 GRÁFICA COMPARADA CON LOS VALORES DE TIEMPO EN QUE LA TEMPERATURA ES MENOR DE $16^{\circ} \mathrm{C}$ (PERIODO CÁLIDO) EN ZARAGOZA EN LA DECADA DE 2005 A 2014. (AEMET y elaboración propia).

Las horas en que es necesario un aporte de energía para llegar a $16^{\circ} \mathrm{C}$ son, 4.602 de media, en la década estudiada, mientras que en los climas sintéticos van de 5.499 a 5.097 horas, es decir, entre un $10 \%$ y un $17 \%$ más que la media y entre valores similares a los máximos y un $10 \%$ mayores.

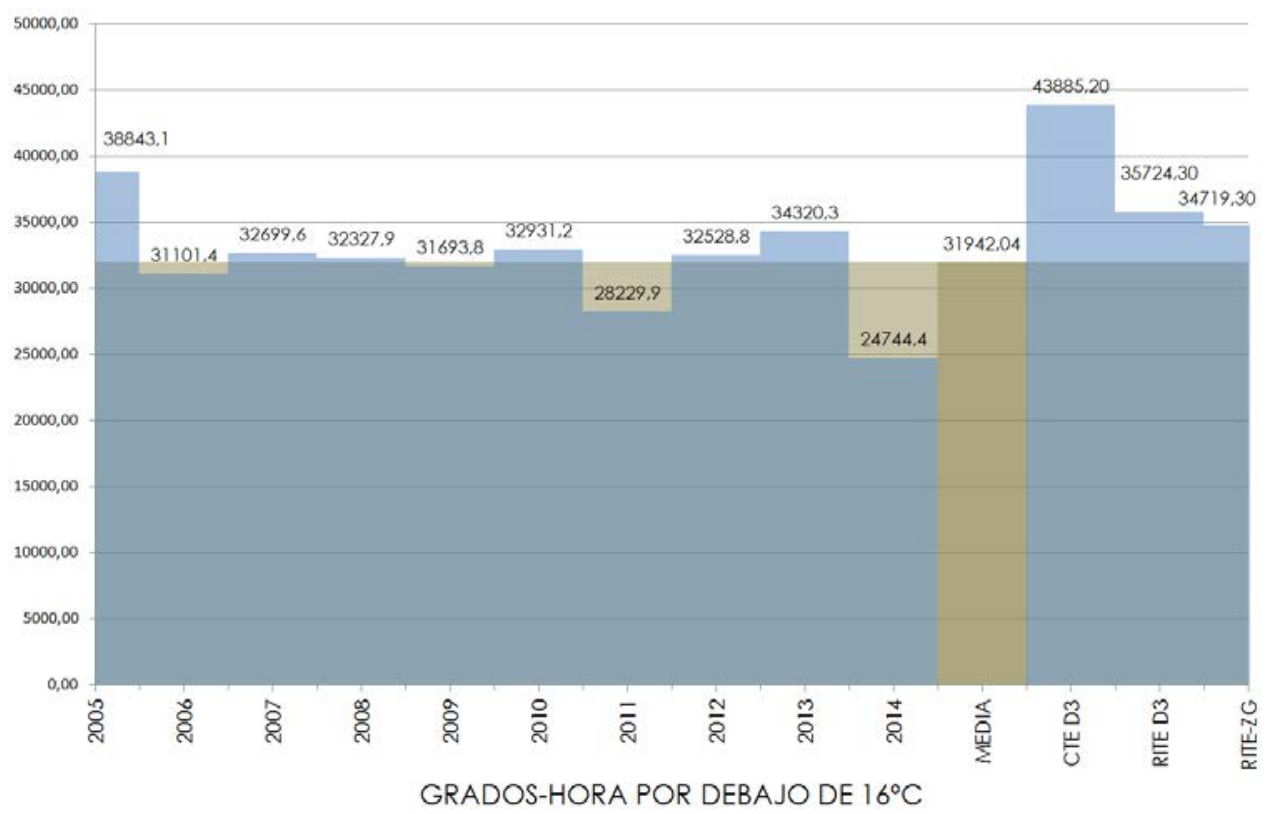

8-109 GRÁFICA COMPARADA CON LOS VALORES DE GRADOS-HORA BAJO $16^{\circ} \mathrm{C}$ (PERIODO CÁLIDO) EN ZARAGOZA EN LA DECADA DE 2005 A 2014. (AEMET y elaboración propia).

Las temperaturas estimadas en los climas sintéticos por debajo de $16^{\circ} \mathrm{C}$, son más de las que se observan en los climas consultados, 
por lo que es previsible que la previsión de equipos y consumos realizada basándose en ella sea errónea.

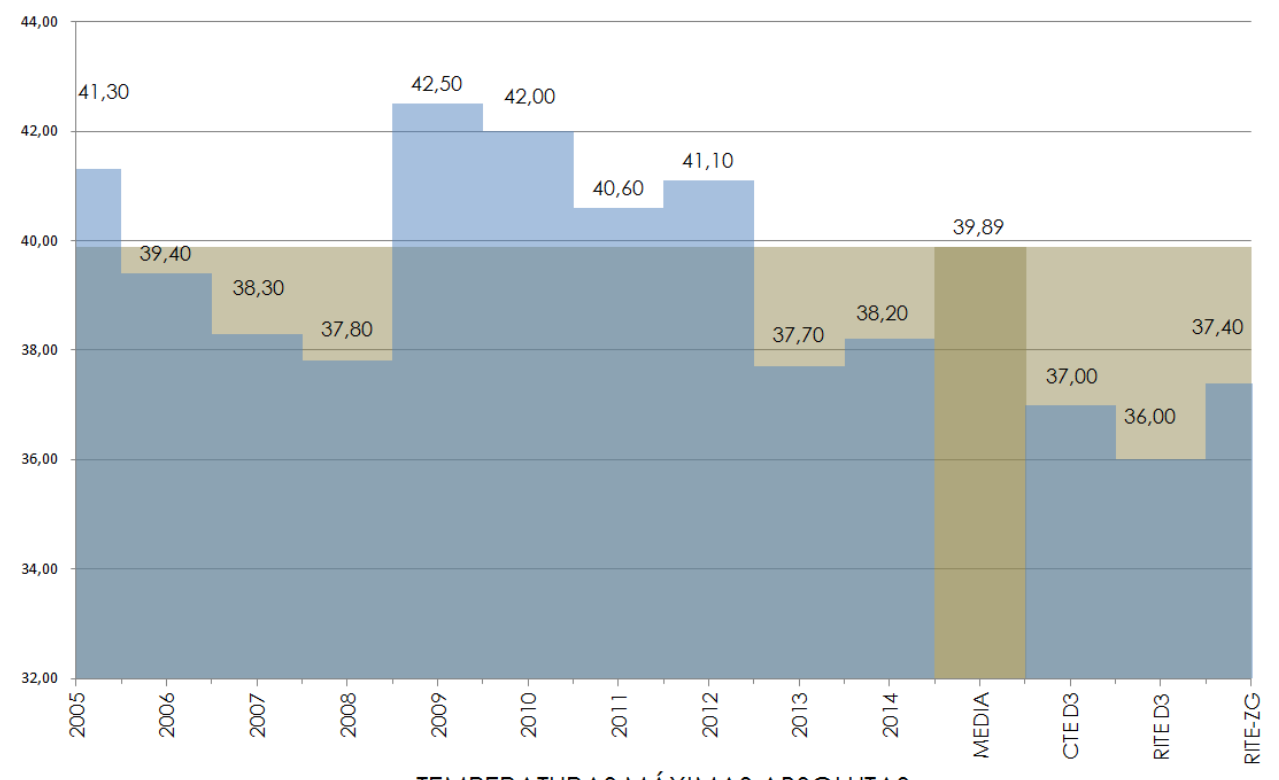

TEMPERATURAS MÁXIMAS ABSOLUTAS

8-110 GRÁFICA COMPARADA CON LAS TEMPERATURAS MÁXIMAS ABSOLUTAS ANUALES EN ZARAGOZA EN LA DECADA DE 2005 A 2014 (AEMET Y elaboración propia).

Las temperaturas máximas absolutas reales durante la década se corresponden con las recogidas en los climas sintéticos, aunque entre ellos manifiestan alguna diferencia, el diseñado para Zaragoza se ajusta mejor y los diseñados para regiones climáticas más amplias tiene un valor menor, por lo que su estimación sería menos exigente que la real.

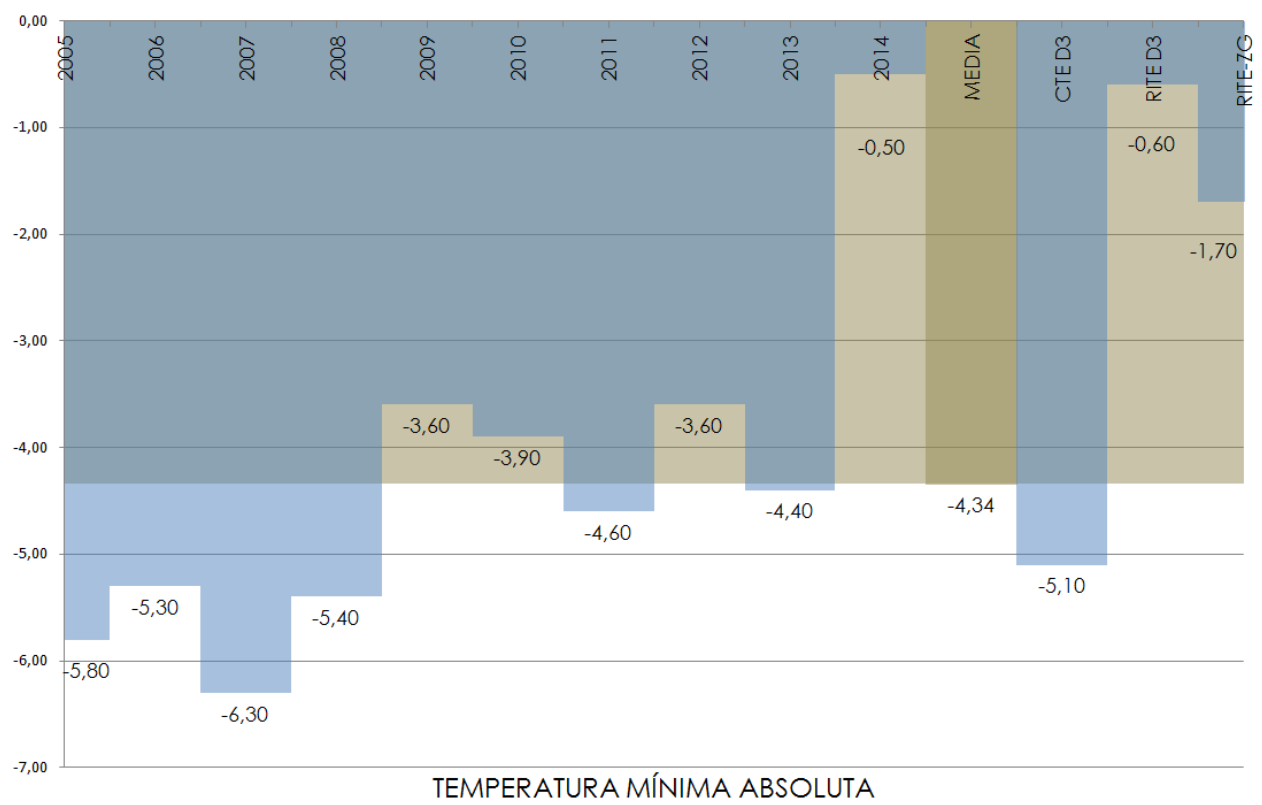

8-111 GRÁFICA COMPARADA CON LAS TEMPERATURAS MÍNIMAS ABSOLUTAS ANUALES EN ZARAGOZA EN LA DECADA DE 2005 A 2014. (AEMET y elaboración propia).

Las temperaturas mínimas absolutas en los climas sintéticos son muy dispares por lo que puede observarse como mientras el CTE es algo más de un grado menos exigente que los valores mínimos 
registrados, los climas diseñados por RITE son casi 5 grados menos exigentes.

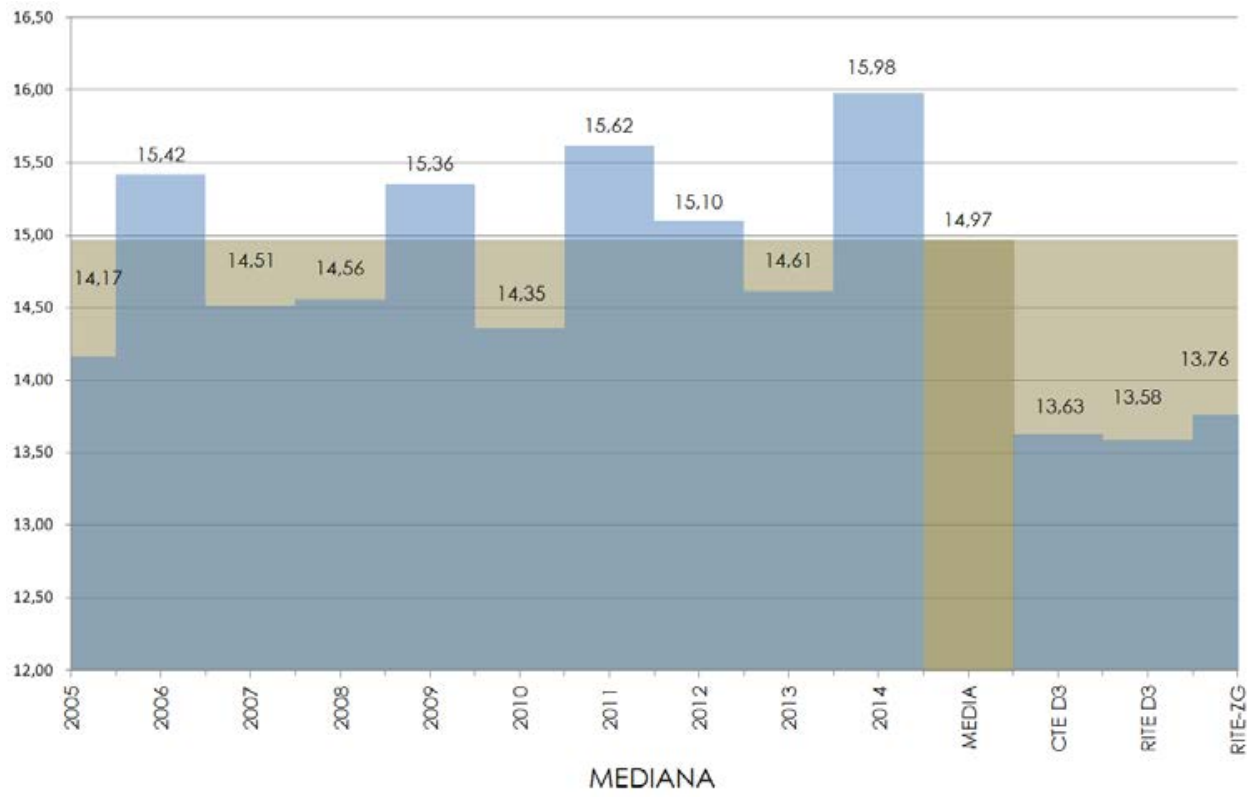

8-112 GRÁFICA COMPARADA CON LAS TEMPERATURA MEDIANA ANUAL EN ZARAGOZA EN LA DECADA DE 2005 A 2014. (AEMET y elaboración propia).

La mediana de los climas sintéticos es similar con diferencias máximas de 0,22 grados más bajas que la menor de las percibidas en la década en más de $0,5^{\circ} \mathrm{C}$ y más de $1,2^{\circ} \mathrm{C}$ de la media durante el periodo considerado.

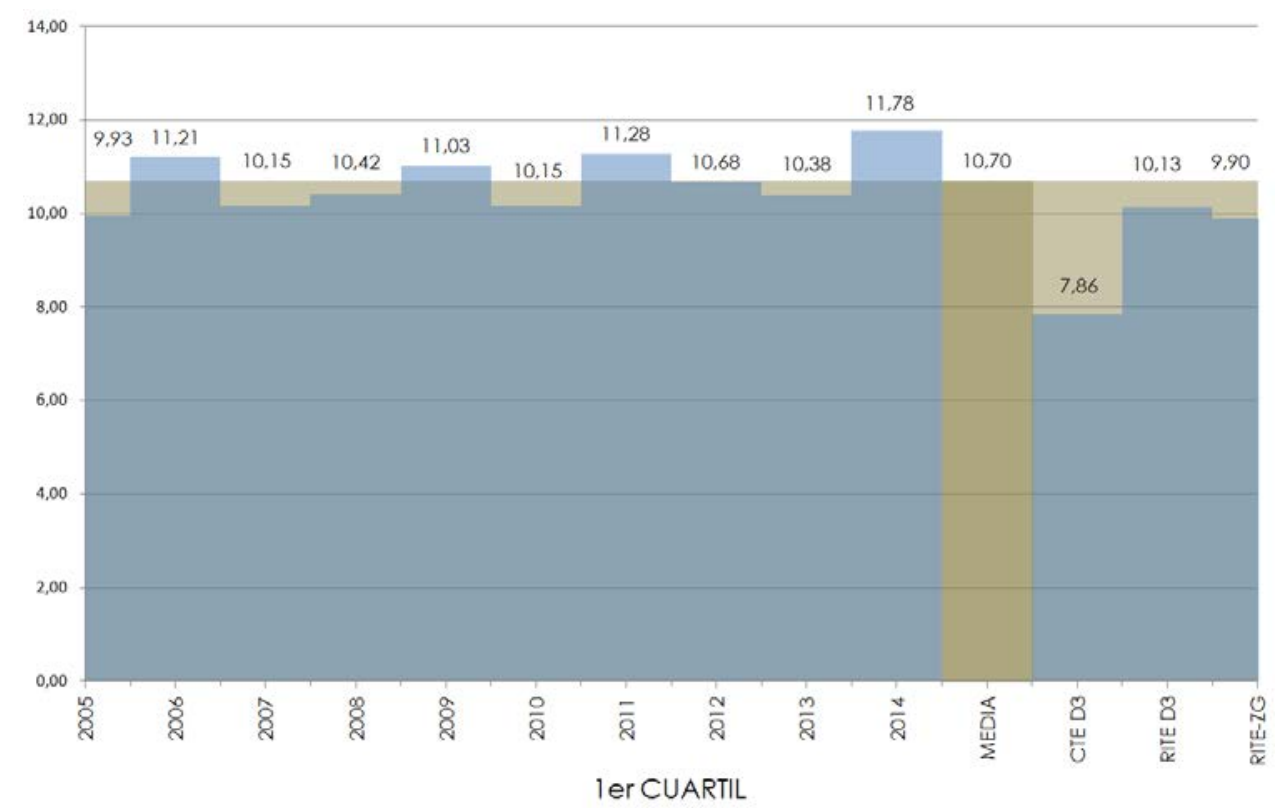

8-113 GRÁFICA COMPARADA CON LAS TEMPERATURA DEL PRIMER CUARTIL ANUAL EN ZARAGOZA EN LA DECADA DE 2005 A 2014. (AEMET y elaboración propia). 


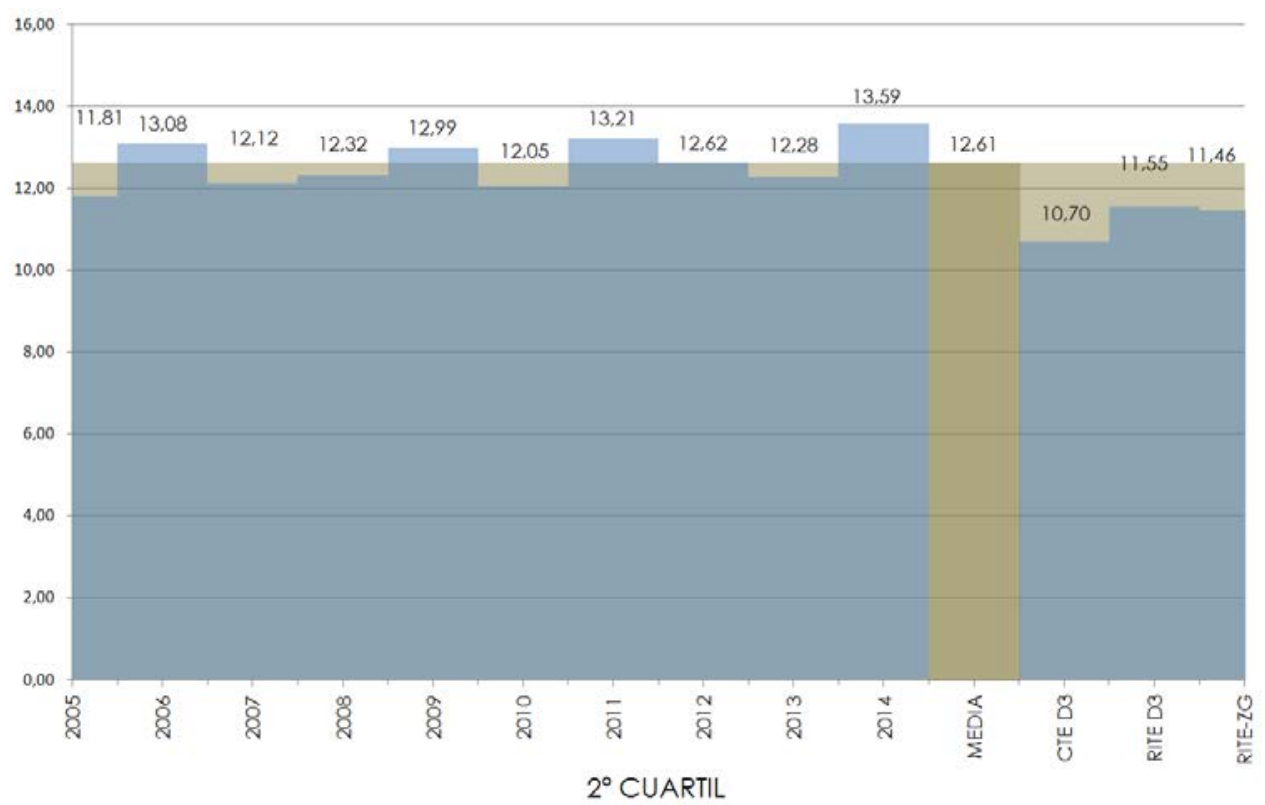

8-114 GRÁFICA COMPARADA CON LAS TEMPERATURA DEL SEGUNDO CUARTIL ANUAL EN ZARAGOZA EN LA DECADA DE 2005 A 2014. (AEMET y elaboración propia).

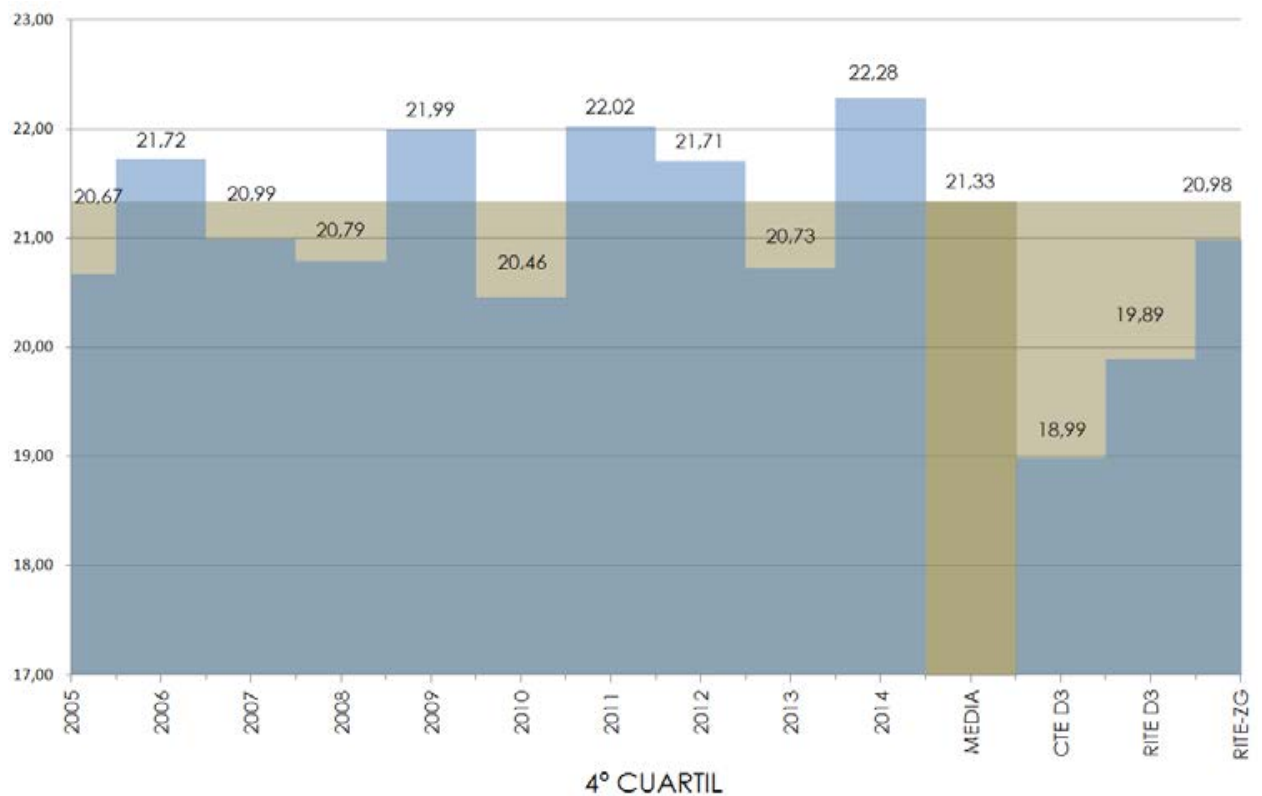

8-115 GRÁFICA COMPARADA CON LAS TEMPERATURA DEL CUARTO CUARTIL ANUAL EN ZARAGOZA EN LA DECADA DE 2005 A 2014. (AEMET y elaboración propia). 


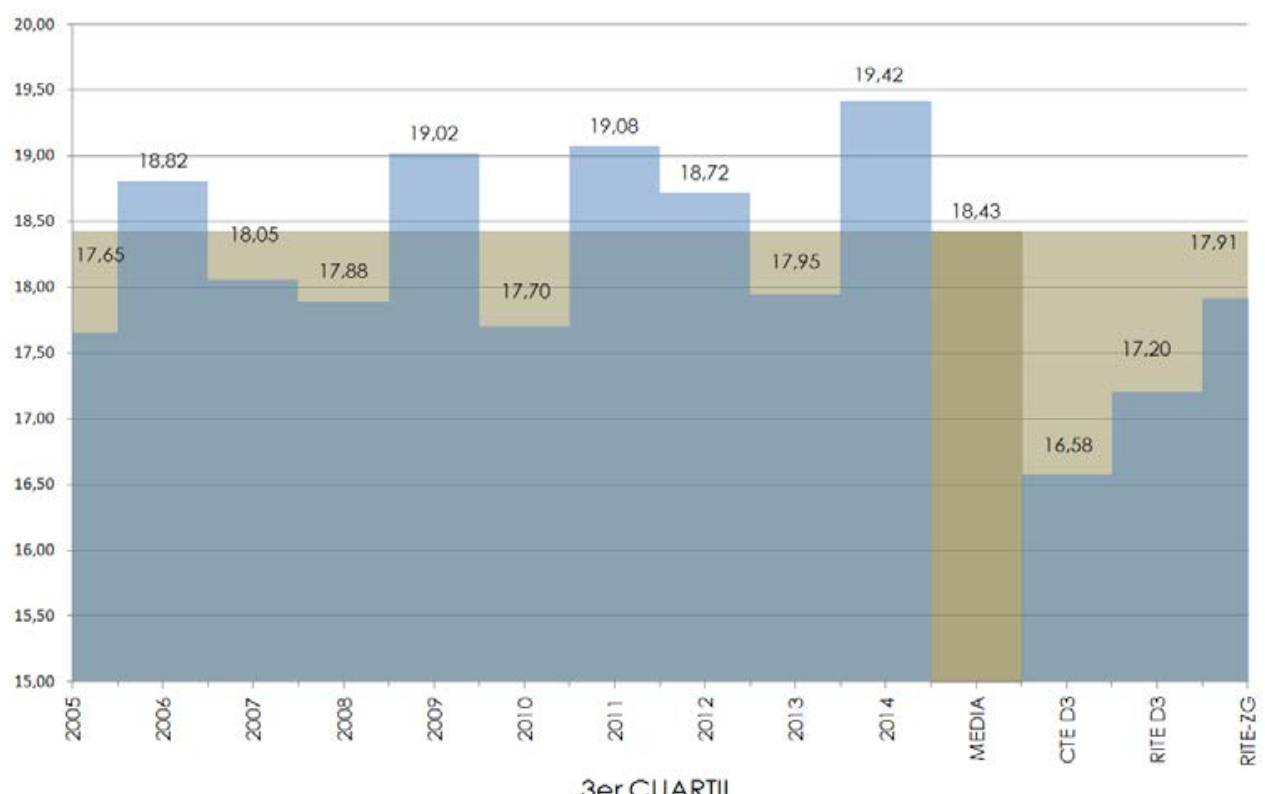

8-116 GRÁFICA COMPARADA CON LAS TEMPERATURA DEL CUARTO CUARTIL ANUAL EN ZARAGOZA EN LA DECADA DE 2005 A 2014. (AEMET y elaboración propia).

El análisis por cuartiles arroja resultados similares, siendo siempre más exigentes los valores en los climas sintéticos que los observados durante la década. En general se aproximan más cuando los cuartiles considerados son más altos. El diseñado específicamente para Zaragoza es el que mejor se ajusta a los valores registrados, siendo el establecido por el CTE el de menor valor tanto en periodos cálidos como fríos. 


\subsubsection{ANÁLISIS DE LAS SECUENCIAS TÉRMICAS REGISTRADAS Y DE REFERENCIA}

Aún tratándose de medias horarias la superación puntual de un valor no es significativa para el edificio, por lo que resulta importante conocer la evolución de las temperaturas en periodos algo más largos.

Se ha estudiado la serie de temperaturas horarias valorando los siguientes supuestos:

1. Periodos cálidos, fríos y templados en que se alcanzan temperaturas superiores a $26^{\circ} \mathrm{C}$ y temperaturas inferiores a $16^{\circ} \mathrm{C}$, aunque sea puntualmente.

2. Periodos cálidos, fríos y templados en que se alcanzan temperaturas superiores a $26^{\circ} \mathrm{C}$ y temperaturas inferiores a $16^{\circ} \mathrm{C}$, aunque sea puntualmente, durante un periodo de 6 horas. Se reflejan también los periodos en los que se superan los umbrales durante más de un 30\% (2 horas en un periodo de 6 horas).

ANEXO: DESCRIPCÍÓN DEL CLIMA. INDICADOR PARA UN PERIODO DE 6 HORAS DE LA DURACIÓN Y MAGNITUD DE PERIODOS CÁLIDOS, FRÍOS Y TEMPLADOS

Los grados-hora medios que es necesario aportar para alcanzar $16^{\circ} \mathrm{C}$ en la década son cerca de 32.000 grados-hora, mientras que la región climática D3 establece una demanda próxima a 43.900 grados-hora.

Con diferencias próximas al $40 \%$ en los grados-hora en cuanto a necesidades de calor, la simulación del comportamiento para establecer la capacidad de las medidas activas, pasivas y de gestión para aclimatar el edificio y la demanda estimada de éste en su vida útil no pueden ser sólo el resultado de la consideración de los valores máximos o medios.

Las temperaturas superan los $26^{\circ} \mathrm{C}$ durante más de 1.000 horas al año de media, mientras que los climas sintéticos consideran que este valor oscila entre 723 y 927 horas, no describiendo bien los valores más exigentes para la climatización y sólo reflejando los valores con menor demanda del periodo.

Las temperaturas inferiores $16^{\circ} \mathrm{C}$ consideradas en los climas sintéticos permiten establecer las condiciones más desfavorables pero no la estimación de los valores de demanda que se producirán durante la vida útil del edificio.En resumen puede observarse cómo los climas sintéticos no reflejan la situación real producida cada año y cómo son, por lo general, conservadores en los periodos fríos, no alcanzando las temperaturas registradas en los periodos cálidos. 


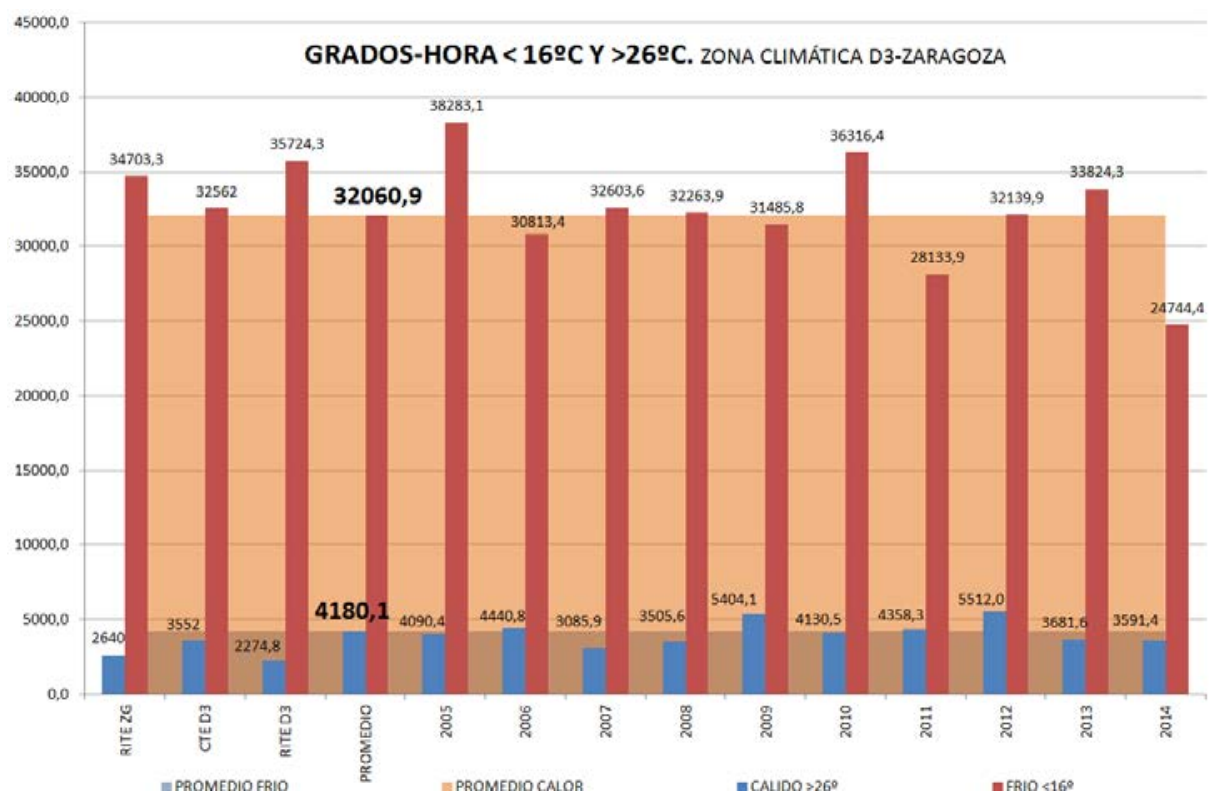

VER ANEXO 11

DESCRIPCÍÓN DEL CLIMA INDICADOR ELEMENTAL DE LA DURACIÓN Y MAGNITUD DE PERIODOS CÁLIDOS, FRÍOS TEMPLADOS

8-117 GRÁFICA ANUAL CONJUNTA DE GRADOS-HORA POR ENCIMA DE $26^{\circ} \mathrm{C} Y$ MENORES DE $16^{\circ} \mathrm{C}$ EN LA DÉCADA DE 2005 A 2014 EN ZARAGOZA (AEMET Y elaboración propia).

Las horas en que la temperatura es mayor de $26^{\circ} \mathrm{C}$ y las que están por debajo de $16^{\circ} \mathrm{C}$ también son reflejados con poca exactitud por los climas sintéticos, observándose que, en algunos casos, como es el clima sintético CTE D3, las horas en las que no se alcanzan los $16^{\circ} \mathrm{C}$ son menos que las reales, mientras que los grados-hora establecidos son mayores, por lo que se constata que existirán menos días con temperaturas más bajas de los reales.

En los periodos cálidos se constata la circunstancia inversa: los grados-hora son menos que los reales contabilizados en la década mientras que las horas en las que se producen son más, lo que indica que las superaciones serán, previsiblemente, mayores de lo estimado.

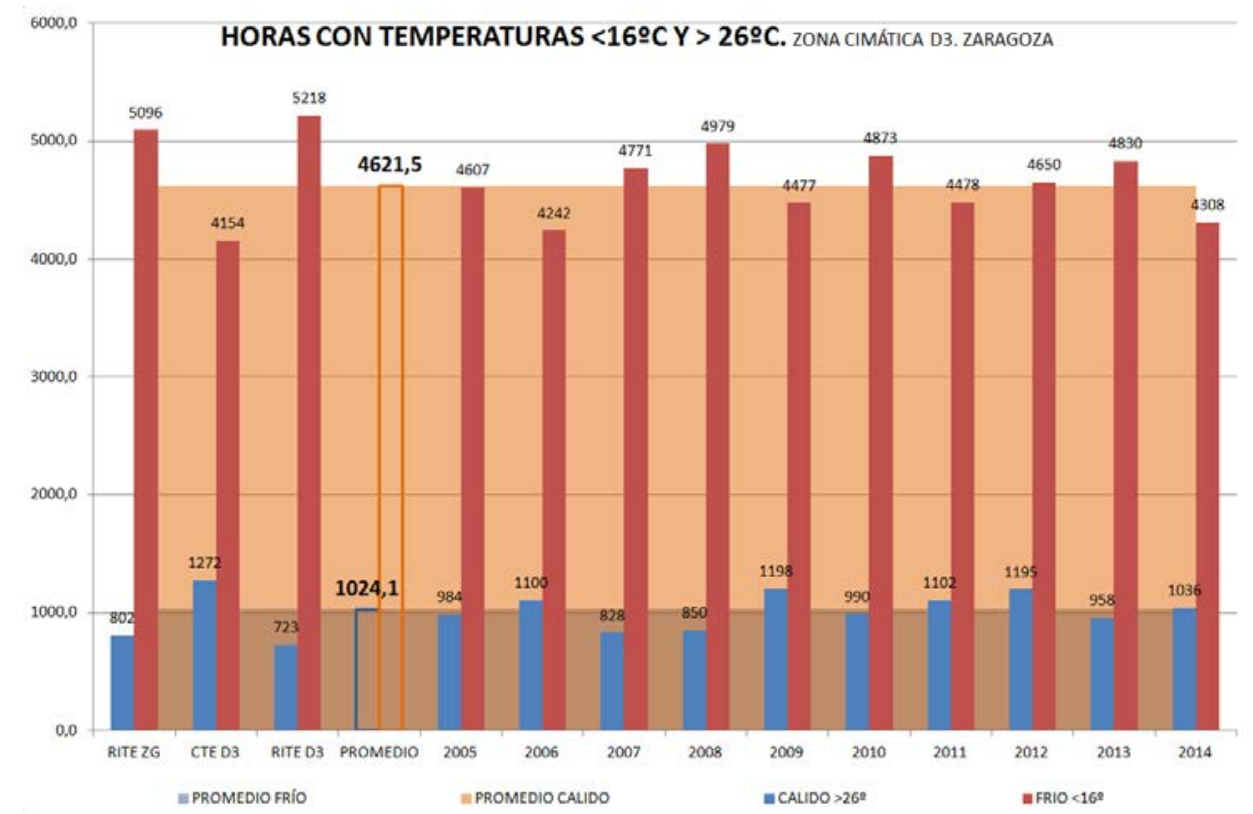

8-118 GRÁFICA ANUAL CONJUNTA DE PERIODOS CON TEMPERATURA POR ENCIMA DE $26^{\circ} \mathrm{C}$ Y MENOR DE $16^{\circ} \mathrm{C}$ EN LA DÉCADA DE 2005 A 2014 EN ZARAGOZA (AEMET y elaboración propia). 


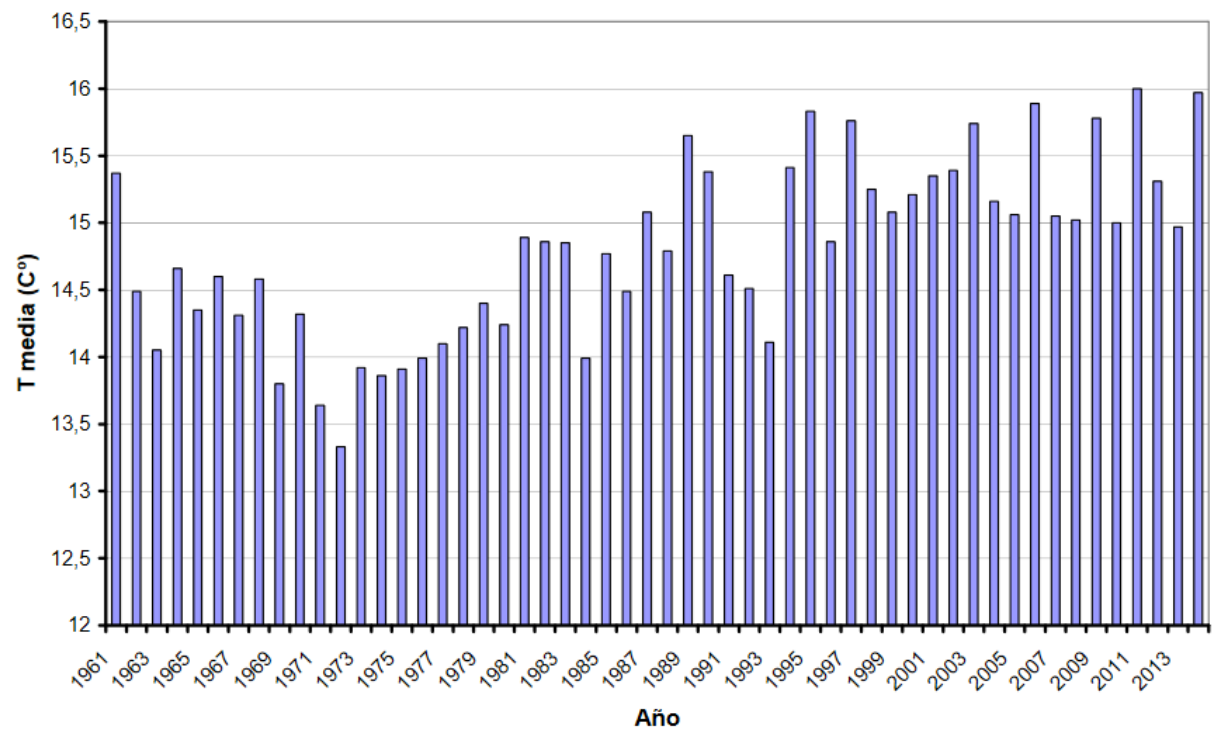

8-119 SERIE DE TEMPERATURAS MEDIAS ANUALES (1961-2014) INFORME CLIMÁTICO DEL AÑO 2014. (AEMET)

(http://www.aemet.es/documentos/es/serviciosclimaticos/vigilancia_cli ma/resumenes_climat/anuales/res_anual_clim_2014.pdf, consultado 23_04_2016 14:08h)

Las temperaturas medias anuales indican, más allá de la posible evolución del clima, que pueden oscilar entre casi $13^{\circ} \mathrm{C}(1973)$ y $16^{\circ} \mathrm{C}(2011$ y 2014$)$.

La observación local del clima permite identificar la evolución de la temperatura que indican los modelos de cambio climático.

En los periodos estimados del ciclo de vida de los edificios se observaría esta evolución, de ahí la recomendación de diseñar para el clima probable durante toda la vida útil de éstos y no sólo para el clima pasado conocido. Esta valoración merece un análisis específico que probablemente repercutirá de forma diferente según sea la zona de la península ibérica considerada y requerirá escalas temporales más amplias y proyecciones más complejas que aquéllas a las que se tiene acceso.

El análisis de los periodos con superaciones de $26^{\circ} \mathrm{C}$, periodos cálidos, en los que no se alcanzan los $16^{\circ}$, periodos fríos, y los periodos templados en los que las temperaturas están entre $16^{\circ} \mathrm{C}$ y $26^{\circ} \mathrm{C}$, observados durante la década 2005-2014 en Zaragoza indica que más de la mitad del año existe demanda de energía, siendo preciso disiparla en un $12 \%$ del año.

PERIODOS PROMEDIO(h) DÉCADA 2005-2014

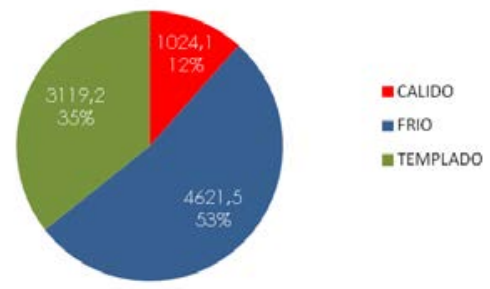

8-120 PROMEDIO DE LOS PERIODOS EN QUE LA TEMPERATURA ES INFERIOR A $16^{\circ} \mathrm{C}$, (PERIODO FRÍO), Y SUPERIOR A $26^{\circ} \mathrm{C}$ (PERIODO CÁLIDO) Y ESTÁ ENTRE AMBAS (PERIODO TEMPLADO) (AEMET y elaboración propia) 


\subsection{ESTACIONES METEOROLÓGICAS DE REFERENCIA Y ESTACIONES INTERIORES A LA TRAMA URBANA}

En el estudio de caso de Zaragoza se emplean las series térmicas obtenidas de los registros efectuados durante los años 2012, 2013 y 2014 en la estación meteorológica del Aeropuerto de Zaragoza, que forma parte de la red nacional de AEMET, y en una estación meteorológica dispuesta a este efecto en la cubierta de un edificio situado en la calle S. Pablo en el interior a la trama urbana de Zaragoza

La observación de la serie horaria permite observar una secuencia anual con valores máximos entre junio y agosto y mínimos entre diciembre y febrero y una pendiente mayor en la transición hacia periodos fríos y menor cuando se incrementan las temperaturas.

Las diferencias entre ellas son a menudo de varios grados pudiendo superar los diez sin una correlación clara a esta escala.

La observación de las temperaturas medias diarias a lo largo del año para las dos estaciones consideradas, permite definir las diferencias con más nitidez.

Los datos disponibles permiten una comparación entre los valores medios diarios registrados en la estación de la red de AEMET en el Aeropuerto de Zaragoza y la estación colocada en un edificio del interior de la trama urbana.

Más allá de los valores medios diarios se ha preferido establecer periodos térmicos basados en los valores máximos y mínimos alcanzados.
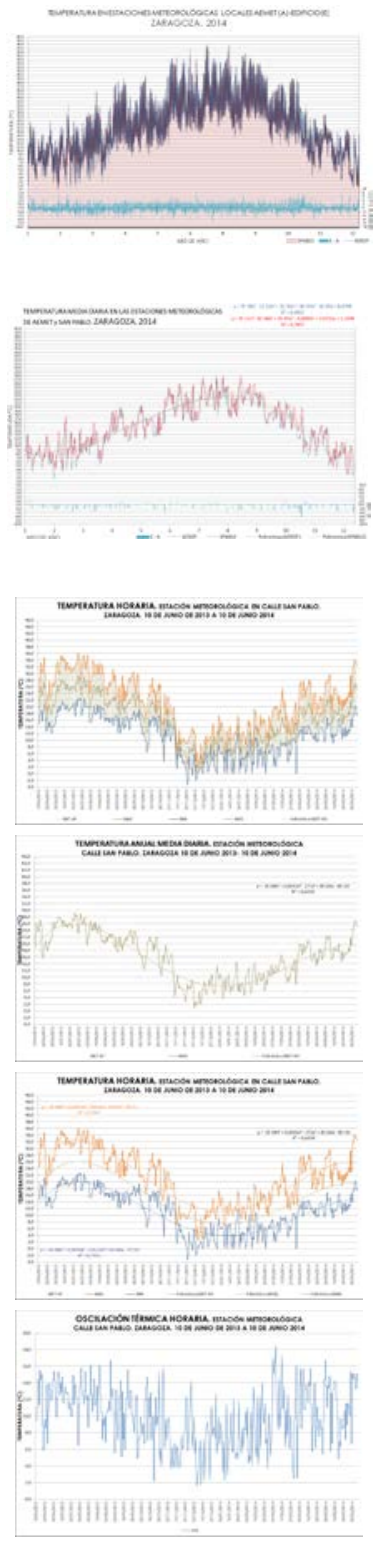


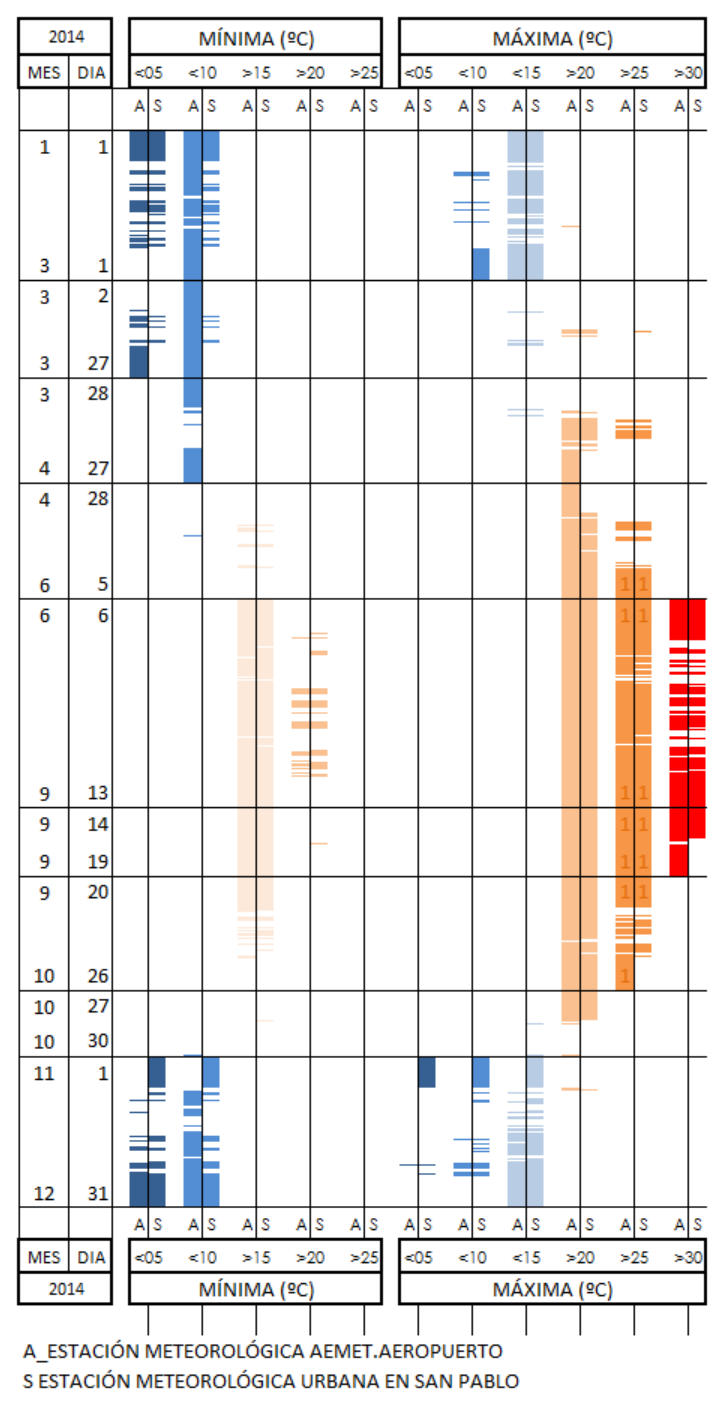

8-121 COMPARACIÓN DE UMBRALES PARA TEMPERATURAS MÍNIMAS Y MÁXIMAS REGISTRADAS EN LA ESTACIÓN DE REFERENCIA EN EL AEROPUERTO DE ZARAGOZA Y EN LA SITUADA EN LA CALLE S. PABLO DE ZARAGOZA DURANTE EL AÑO 2014 (AEMET y elaboración propia) 


\subsubsection{SECUENCIAS COMPARADAS ENTRE ESTACIÓN METEOROLÓGICA AEROPUERTO Y SAN PABLO}

Aunque la tendencia durante un periodo pueda ser clara, cuando se fracciona esta tendencia se distorsiona.

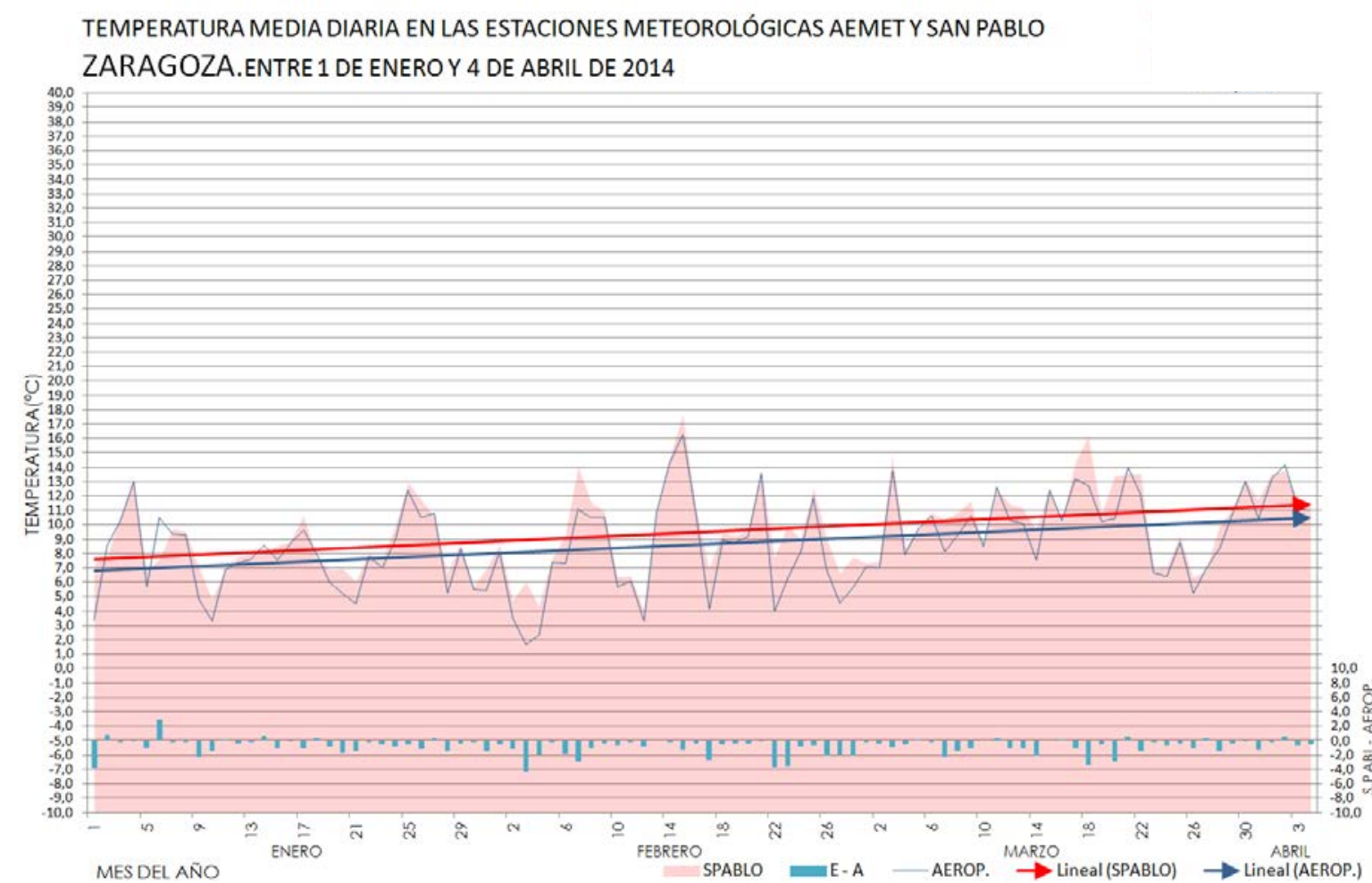

8-122 GRÁFICA DE MEDIA DIARIA EN LAS ESTACIONES DE ZARAGOZA-AEROPUERTO Y SAN PABLO DESDE EL 1 DE ENERO AL 4 DE ABRIL DEL AÑO 2014(AEMET Y elaboración propia)

TEMPERATURA MEDIA DIARIA EN LAS ESTACIONES METEOROLÓGICAS AEMET Y SAN PABLO ZARAGOZA.ENTRE 1 DE ENEROY 3 DE FEBRERO DE 2014

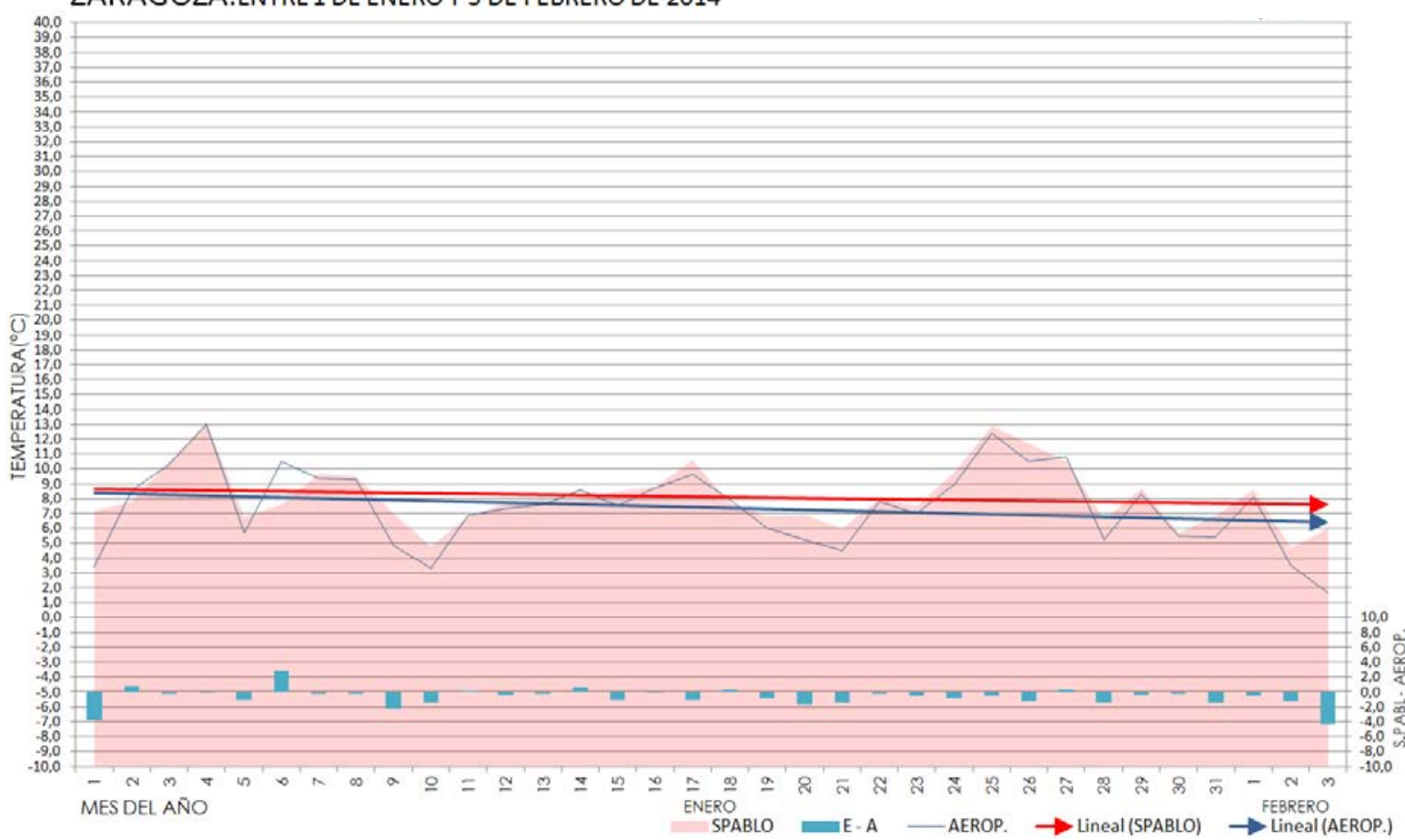

8-123 GRÁFICA DE MEDIA DIARIA EN LAS ESTACIONES DE ZARAGOZA-AEROPUERTO Y SAN PABLO DESDE EL 1 DE ENERO AL 3 DE FEBRERO DEL AÑO 2014(AEMET y elaboración propia) 
TEMPERATURA MEDIA DIARIA EN LAS ESTACIONES METEOROLÓGICAS AEMET Y SAN PABLO

ZARAGOZA.ENTRE 3 DE FEBREROY EL 4 DE ABRIL DE 2014

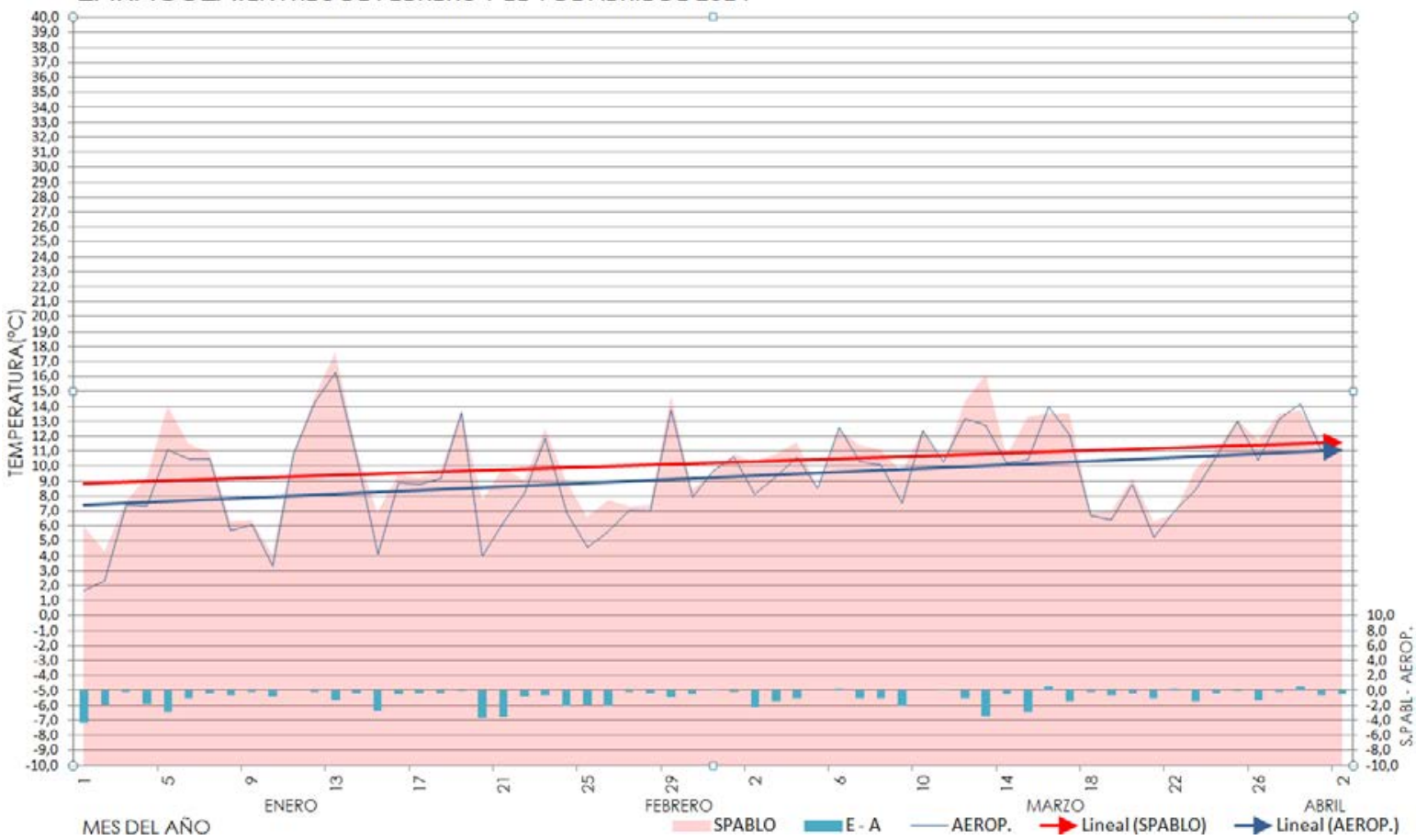

8-124 GRÁFICA DE MEDIA DIARIA EN LAS ESTACIONES DE ZARAGOZA-AEROPUERTO Y SAN PABLO DESDE EL 3 DE FEBRERO AL 4 DE ABRIL DEL AÑO 2014(AEMET Y elaboración propia)

TEMPERATURA MEDIA DIARIA EN LAS ESTACIONES METEOROLÓGICAS AEMET Y SAN PABLO ZARAGOZA.ENTRE 1 DE ENERO Y 3 DE FEBRERO DE 2014

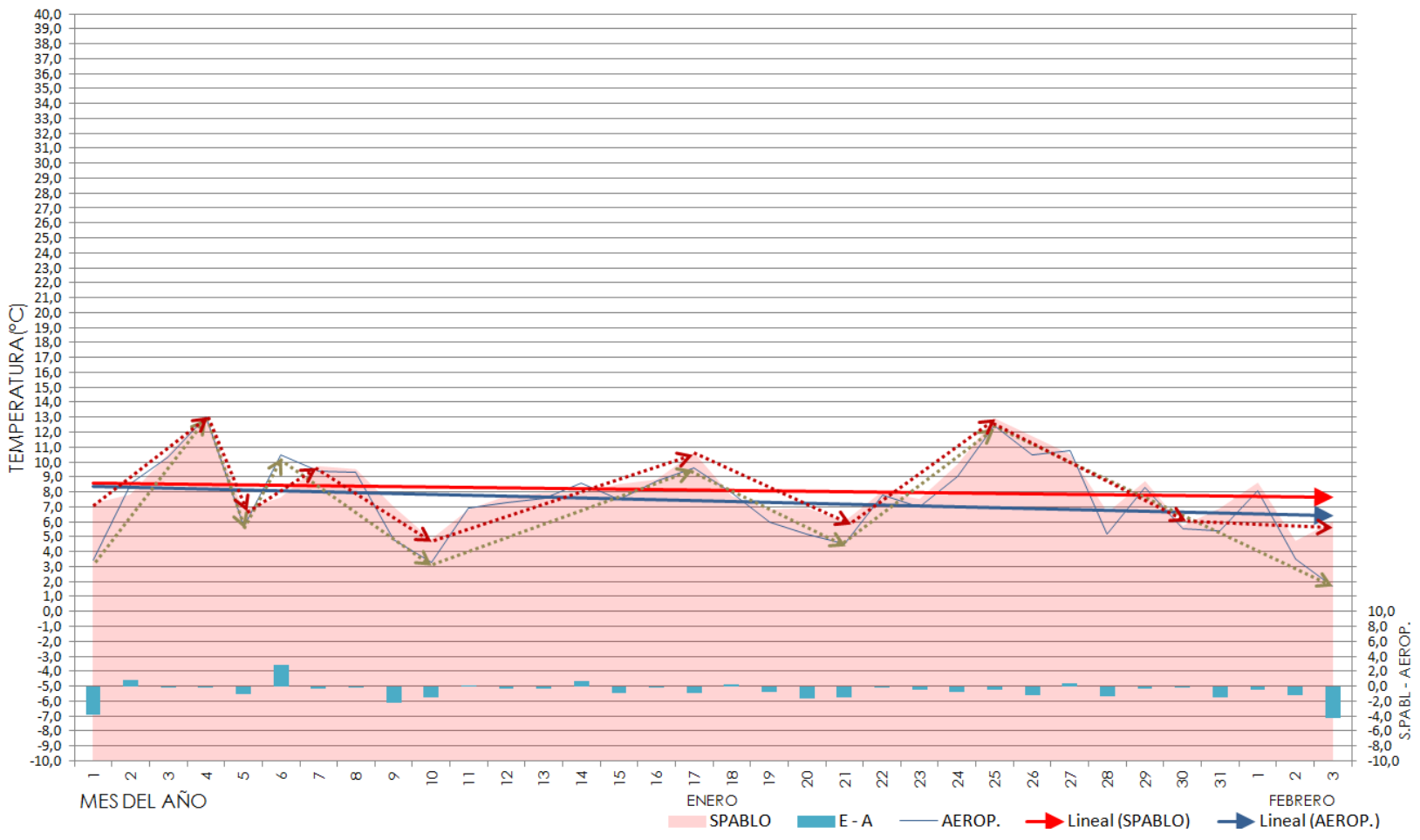

8-125 GRÁFICA DE MEDIA DIARIA EN LAS ESTACIONES DE ZARAGOZA-AEROPUERTO Y SAN PABLO DESDE EL 1 DE ENERO AL 3 DE FEBRERO DEL AÑO 2014(AEMET y elaboración propia) 


\subsection{ESTUDIO COMPARADO DE SECUENCIAS TÉRMICAS}

A. Series anuales

El análisis de la serie anual en su conjunto permite establecer que ambas secuencias siguen un patrón similar. En esta escala se observa la existencia de periodos cálidos, fríos y templados, como corresponde al clima mediterráneo continental. También se observa que se producen evoluciones dentro de estos periodos no lineales en una sucesión de valores medios, máximos y mínimos diarios que, aunque mantienen en su conjunto la tendencia del periodo en el que se encuentran, tienen frecuentes altibajos con respecto a la tendencia, siendo ésta una componente más estadística que percibida en apreciaciones instantáneas en las que una pequeña serie térmica no es con frecuencia inscribible automáticamente en el periodo en el que realmente se encuentra.

Esto se manifiesta en la escasa diferencia en los valores medios anuales y en la posibilidad de establecer periodos fríos, cálidos y templados idénticos para ambas series, y, en definitiva, para ambas ubicaciones. 
B. Series de tres meses

En las series de tres meses elegidas y sensiblemente coincidentes con las obtenidas en otras estaciones meteorológicas convencionales, puede observarse la evolución seguida en su conjunto y que, para la ubicación situada en el interior de la trama urbana, manifiesta una mayor pendiente lo que nos indica que la temperatura crece, en su conjunto algo más en las zonas urbanas.

TEMPERATURA EN ESTACIONES METEOROLÓGICAS LOCALES AEMET-EDIFICIO ZARAGOZA. ENERO a MARZO 2014

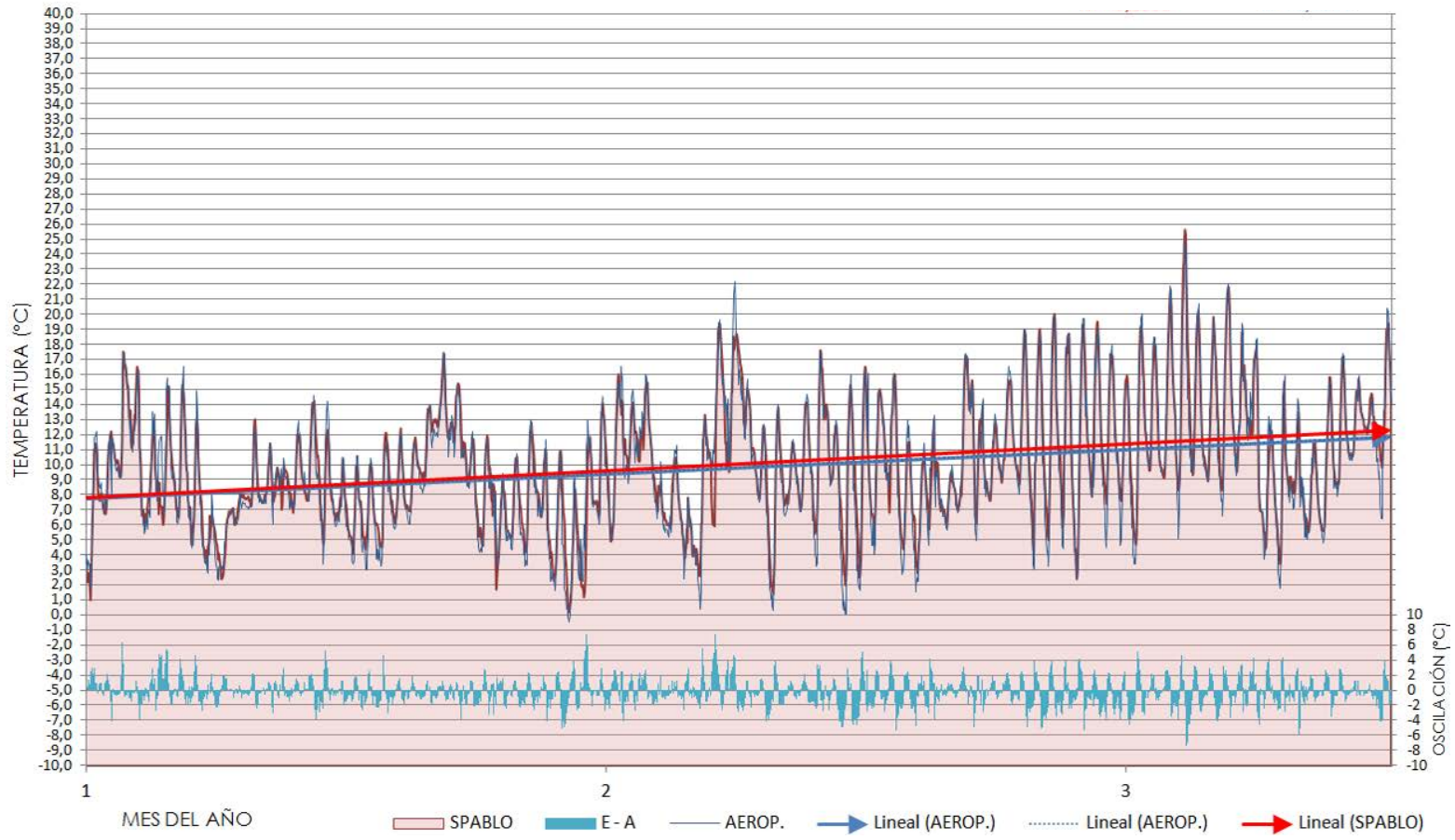

8-126 GRÁFICA COMPARADA DE LAS SERIES TÉRMICAS EN LA ESTACIÓN DE ZARAGOZA Y EN EL EDIFICIO DE LA CALLE SAN PABLO, EN ZARAGOZA DURANTE LOS MESES DE ENERO, FEBRERO Y MARZO DEL AÑO 2014. (AEMET y elaboración propia) 


\section{Series mensuales}

Los meses, por si mismos, no agrupan series térmicas homogéneas, como sucede en otras unidades temporales formadas arbitrariamente por un conjunto de días, pero si manifiestan tendencias de evolución.

En el caso del mes de enero, por ejemplo, la tendencia de la temperatura es a deprimirse, aunque tan ligeramente que podríamos considerar prácticamente se mantiene, con una también ligera inclinación en la estación meteorológica urbana a reducir menos la temperatura.

TEMPERATURA EN ESTACIONES METEOROLÓGICAS LOCALES AEMET-EDIFICIO ZARAGOZA. ENERO 2014

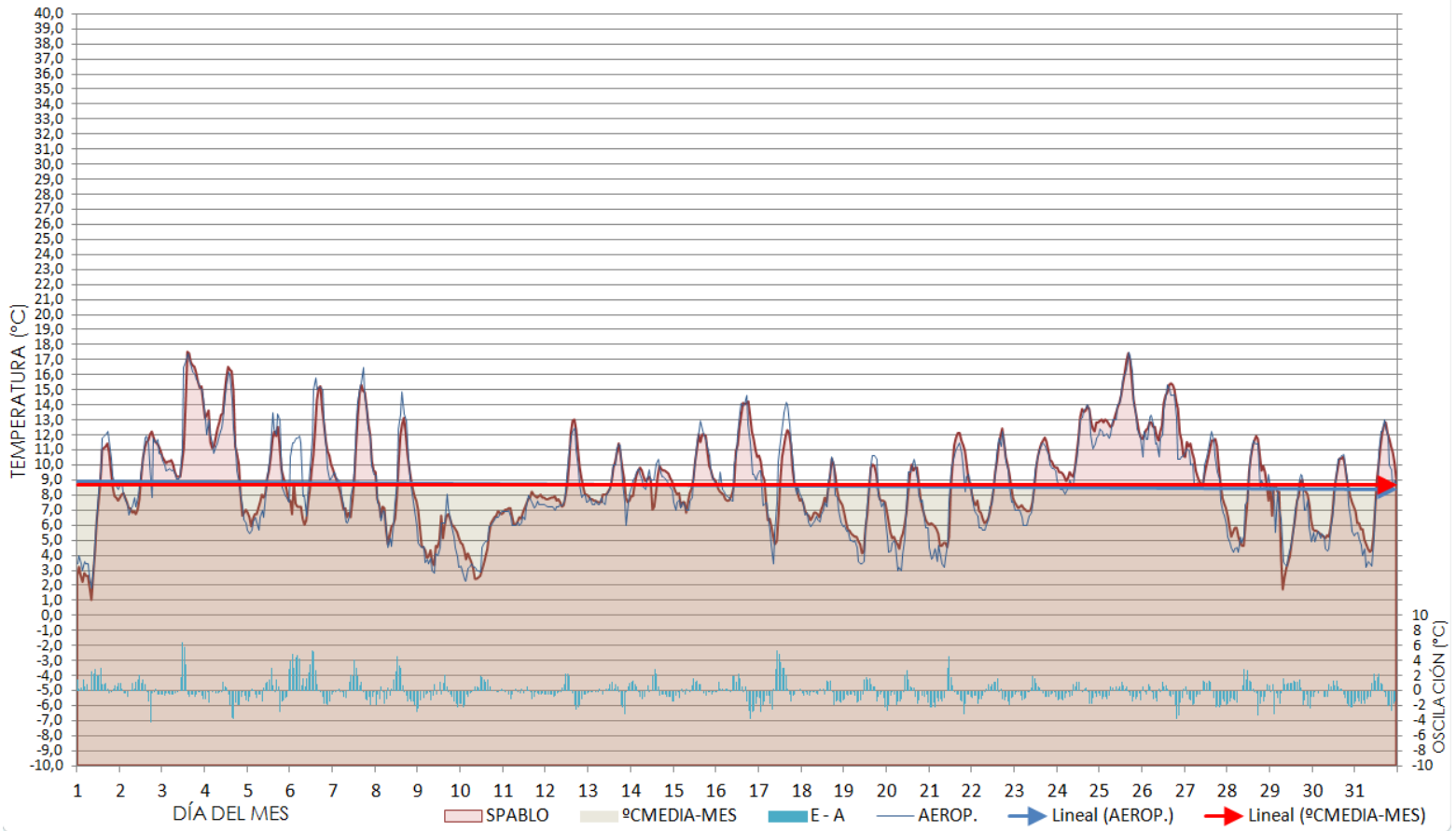

8-127 GRÁFICA COMPARADA DE LAS SERIES TÉRMICAS EN LA ESTACIÓN DE ZARAGOZA Y EN EL EDIFICIO DE LA CALLE SAN PABLO, EN ZARAGOZA DURANTE EL MES DE ENERO DEL AÑO 2014. (AEMET Y ELABORACIÓN PROPIA) 
D. Series de varios días que mantienen su tendencia

Dentro de las secuencias térmicas se encuentra una sucesión de días en los que las temperaturas crecen decrecen o se mantienen, ya sea en términos de máximas, mínimas, medianas o promedios.

En ellos puede observarse la evolución comparada diaria en función de su situación en la serie y de las magnitudes absolutas y relativas con respecto al resto de los valores de la serie.

Así, por ejemplo, en la gráfica de los días 10 a 25 de enero puede observarse, a pesar de que las máximas y mínimas diarias no siempre corresponden al observatorio de referencia o al urbano, la tendencia a que suban ligeramente más las temperaturas en la estación urbana, fundamentalmente por no alcanzar casi nunca las temperaturas mínimas absolutas diarias que pueden observarse en el observatorio de referencia en el Aeropuerto de Zaragoza, cuando las noches son más templadas pueden alcanzarse en ellos las mínimas diarias.

En cuanto a las máximas absolutas diarias pueden registrase en cualquiera de las dos estaciones, estando muy usualmente vinculadas estas máximas en las estaciones urbanas a la existencia de menores oscilaciones térmicas.

Puede observarse cómo la temperatura asciende muy a menudo antes en la estación del Aeropuerto, prácticamente hasta alcanzar el valor absoluto, a partir de lo cual este se observa un descenso más lento de la temperatura en la estación urbana que inicia el ascenso casi siempre ligeramente después de que suceda en la estación de referencia del Aeropuerto.

También en este periodo en la estación urbana la temperatura sube más rápidamente.

La evolución de las temperaturas en la estación urbana es más suave, y cuando se producen alteraciones más bruscas como es la subida o bajada rápida de la temperatura media o de las temperaturas horarias, se registran con mayor intensidad en el observatorio de referencia en el Aeropuerto, fuera por tanto de la ciudad, que en el observatorio urbano.

Se puede concluir que las estaciones meteorológicas urbanas manifiestan una mayor inercia que les hace tender a no alcanzar las temperaturas mínimas y a retrasar la consecución de las máximas, así como que en periodos de tendencia de temperatura ascendente las estaciones instaladas fuera de las zonas urbanizadas lo hacen a más velocidad. 
TEMPERATURA EN ESTACIONES METEOROLÓGICAS LOCALES AEMET-EDIFICIO

ZARAGOZA. 10 ENERO a 25 ENERO 2014

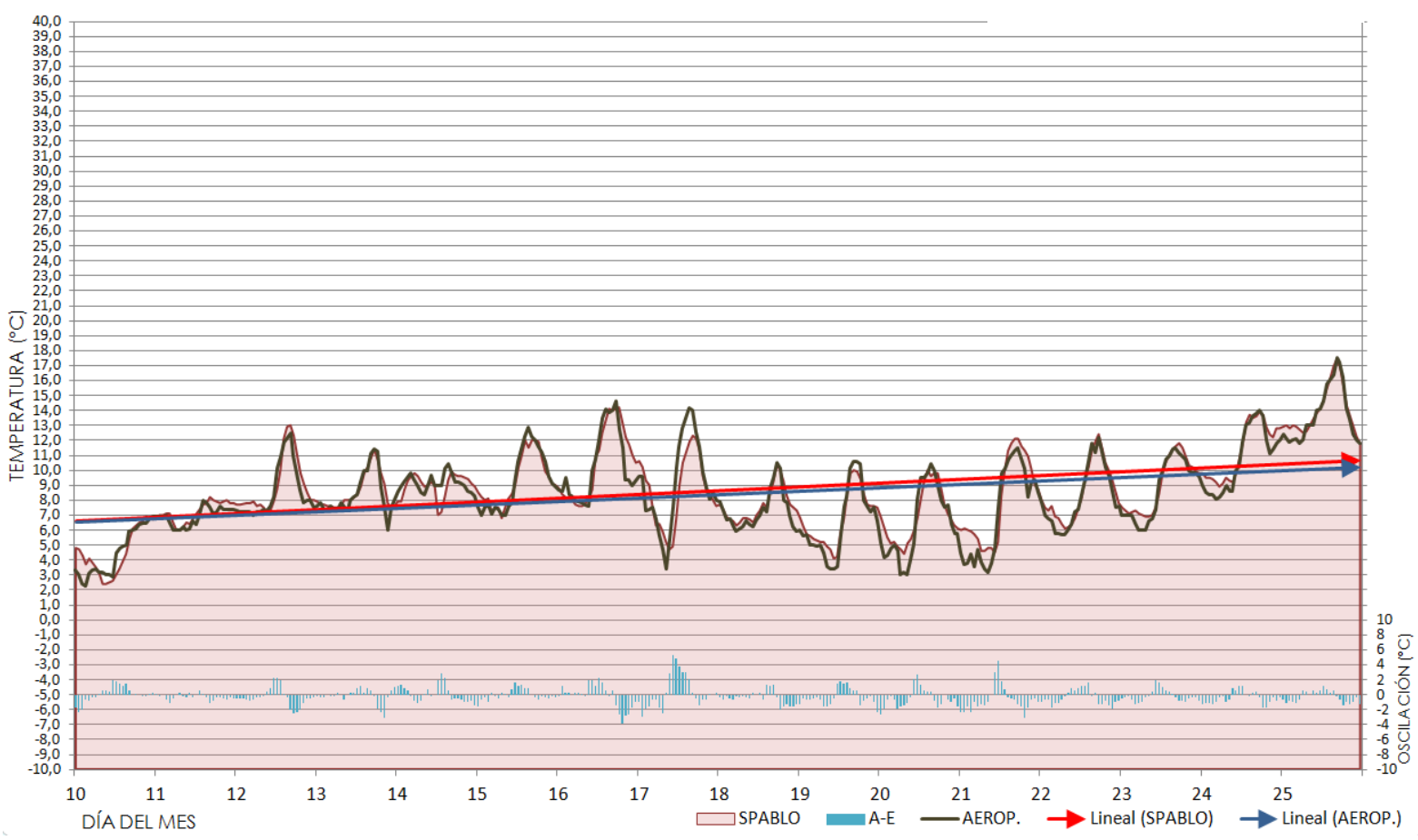

8-128 GRÁFICA COMPARADA DE LAS SERIES TÉRMICAS EN LA ESTACIÓN DE ZARAGOZA Y EN EL EDIFICIO DE LA CALLE SAN PABLO, EN ZARAGOZA DURANTE LOS DÍAS 10 AL 25 DE ENERO DEL AÑO 2014. (AEMET Y elaboración propia)

Observaciones similares pueden realizarse en los periodos en que las temperaturas tienden a descender, pues mientras la mínimas absolutas diarias se registran en la estación de referencia en el Aeropuerto de Zaragoza, las máximas no tienen una localización tan clara. La subida de las temperaturas a su vez se retrasa en las estaciones urbanas donde la tendencia es a descender más lentamente. 
TEMPERATURA EN ESTACIONES METEOROLÓGICAS LOCALES AEMET-EDIFICIO ZARAGOZA. 24 ENERO a 3 FEBRERO 2014

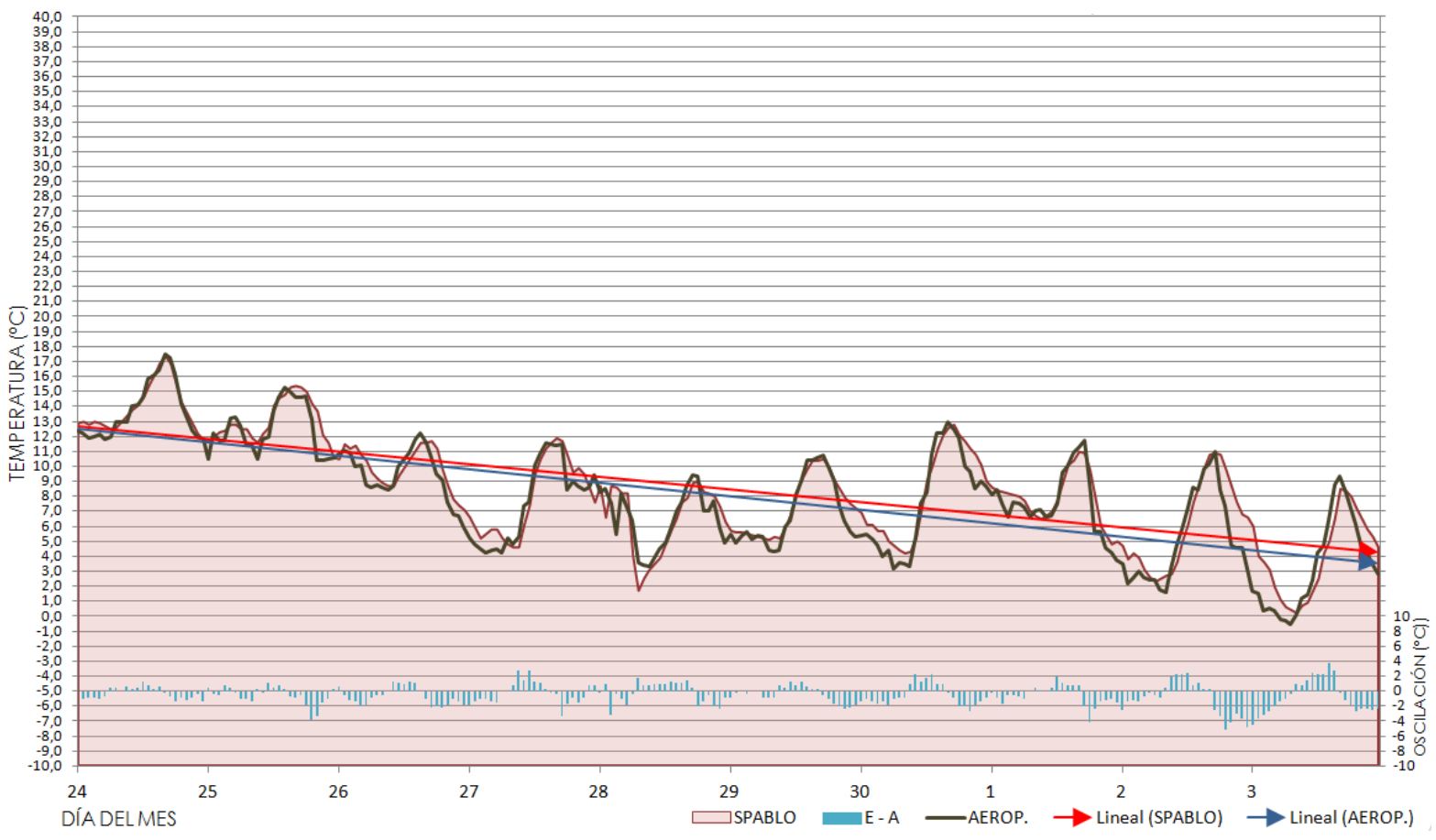

8-129 GRÁFICA COMPARADA DE LAS SERIES TÉRMICAS EN LA ESTACIÓN DE ZARAGOZA Y EN EL EDIFICIO DE LA CALLE SAN PABLO, EN ZARAGOZA DURANTE LOS DÍAS 24 DE ENERO AL 3 DE FEBRERO DEL AÑO 2014. (AEMET Y elaboración propia) 
En periodos de temperaturas ascendentes, cuando los días registran una baja oscilación térmica y en aquéllos en que las condiciones meteorológicas alteran la tendencia ondulatoria de la sucesión de temperaturas diarias provocando discontinuidades, bajadas o subidas repentinas, ya sea por la acción del viento, los meteoros o la ocultación solar, las diferencias de velocidad de calentamiento se amortiguan o anulan.

TEMPERATURA EN ESTACIONES METEOROLÓGICAS LOCALES AEMET-EDIFICIO

ZARAGOZA. 3 FEBRERO a 8 FEBRERO 2014

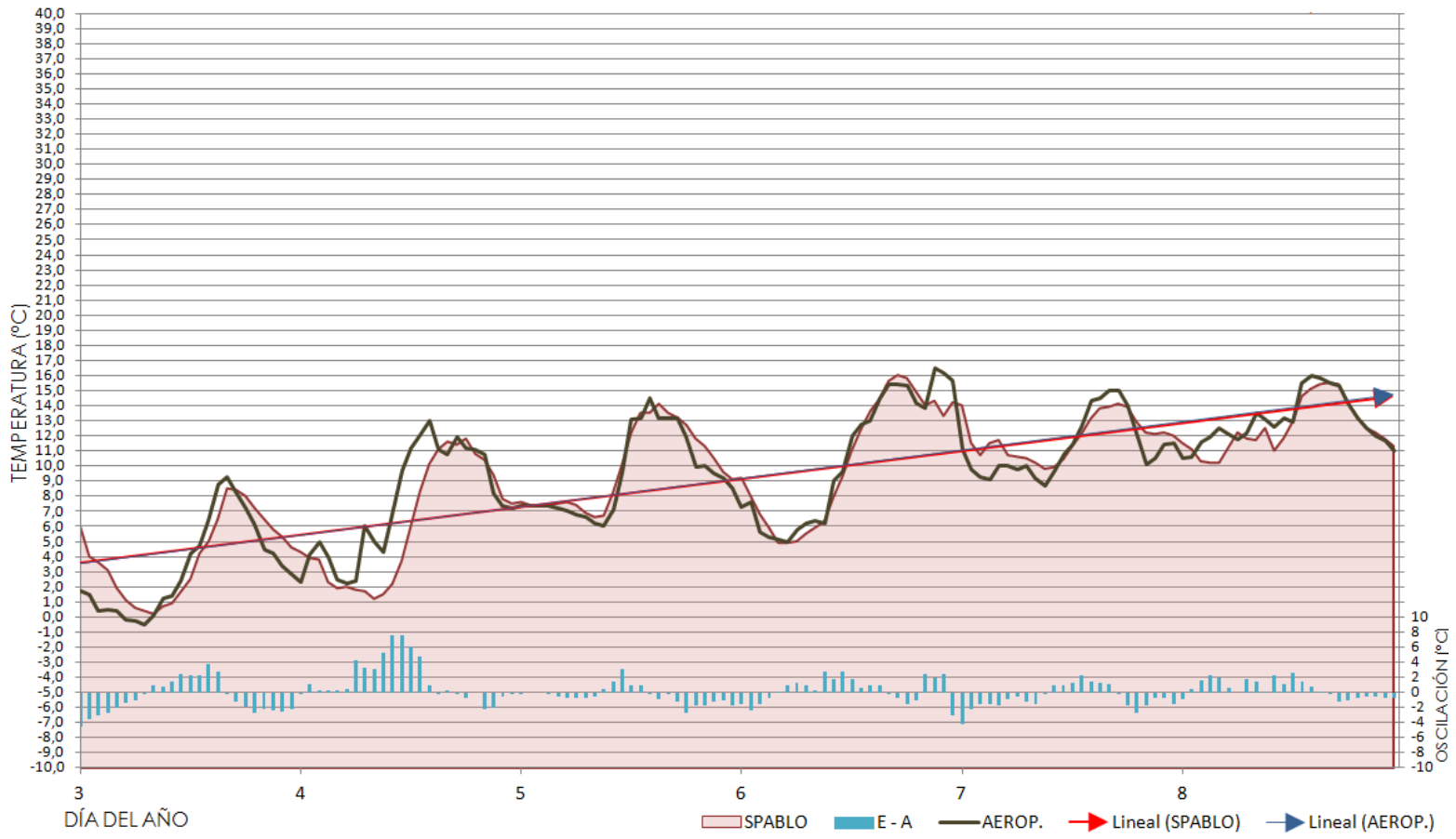

8-130 GRÁFICA COMPARADA DE LAS SERIES TÉRMICAS EN LA ESTACIÓN DE ZARAGOZA Y EN EL EDIFICIO DE LA CALLE SAN PABLO, EN ZARAGOZA DURANTE LOS DÍAS 3 AL 8 DE FEBRERO DEL AÑO 2014. (AEMET Y elaboración propia) 
TEMPERATURA EN ESTACIONES METEOROLÓGICAS LOCALES AEMET-EDIFICIO

ZARAGOZA. 03 ABRIL a 06 ABRIL 2014

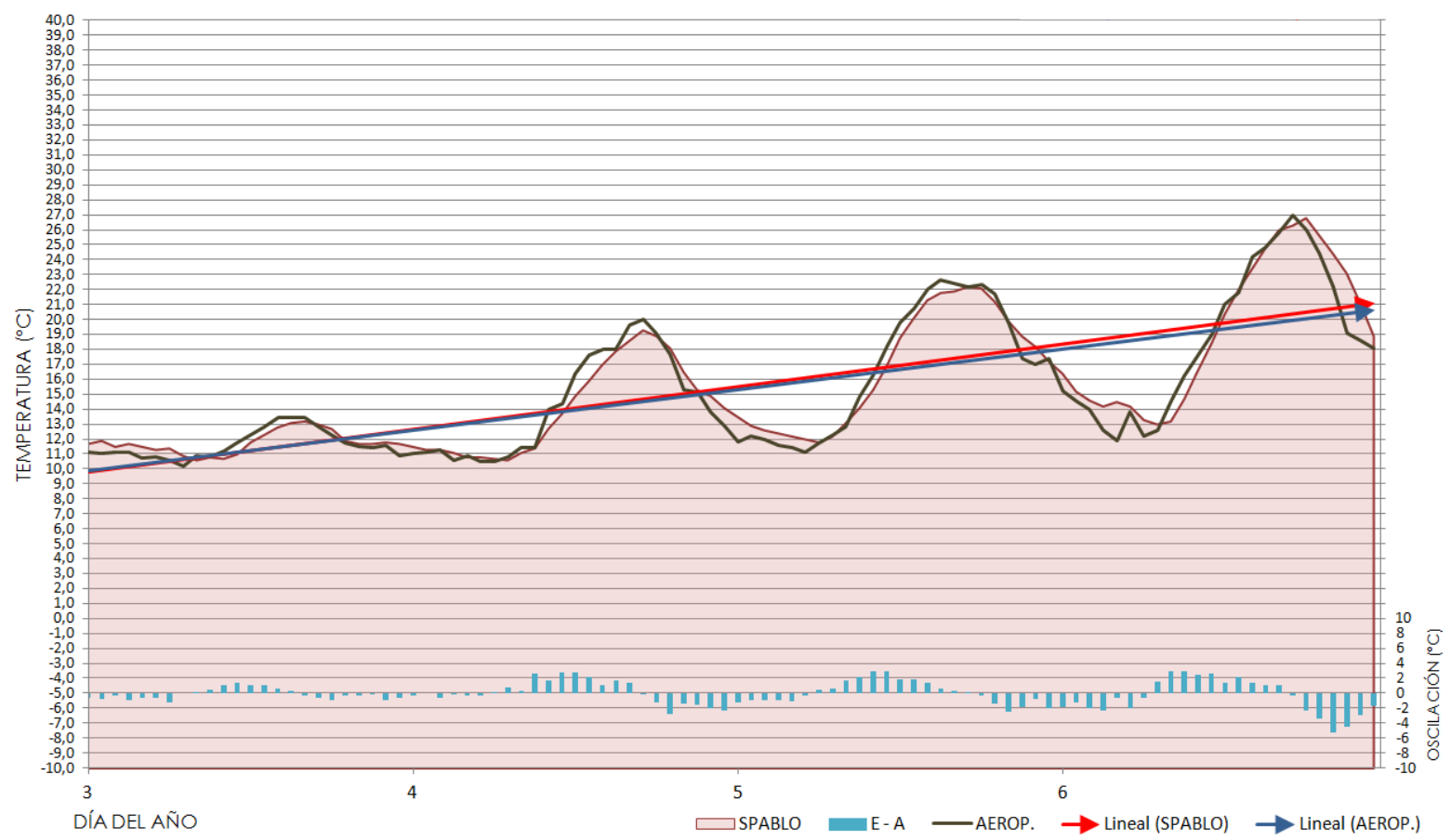

8-131 GRÁFICA COMPARADA DE LAS SERIES TÉRMICAS EN LA ESTACIÓN DE ZARAGOZA Y EN EL EDIFICIO DE LA CALLE SAN PABLO, EN ZARAGOZA DURANTE LOS DÍAS 03 AL 06 DE ABRIL DEL AÑO 2014. (AEMET y elaboración propia)

La velocidad de calentamiento en la estación de referencia fuera de la ciudad es mayor, lo que parece abundar en la dirección de una mayor inercia térmica en la instalada en el interior del núcleo urbano que se resiste a cambiar la velocidad e intensidad del ciclo de temperaturas diarias.

Algo similar sucede en los periodos en los que se registran descensos de temperatura y se producen alteraciones en la secuencia normal de temperaturas diarias. 
TEMPERATURA EN ESTACIONES METEOROLÓGICAS LOCALES AEMET-EDIFICIO

ZARAGOZA. 8 FEBRERO a 11 FEBRERO 2014

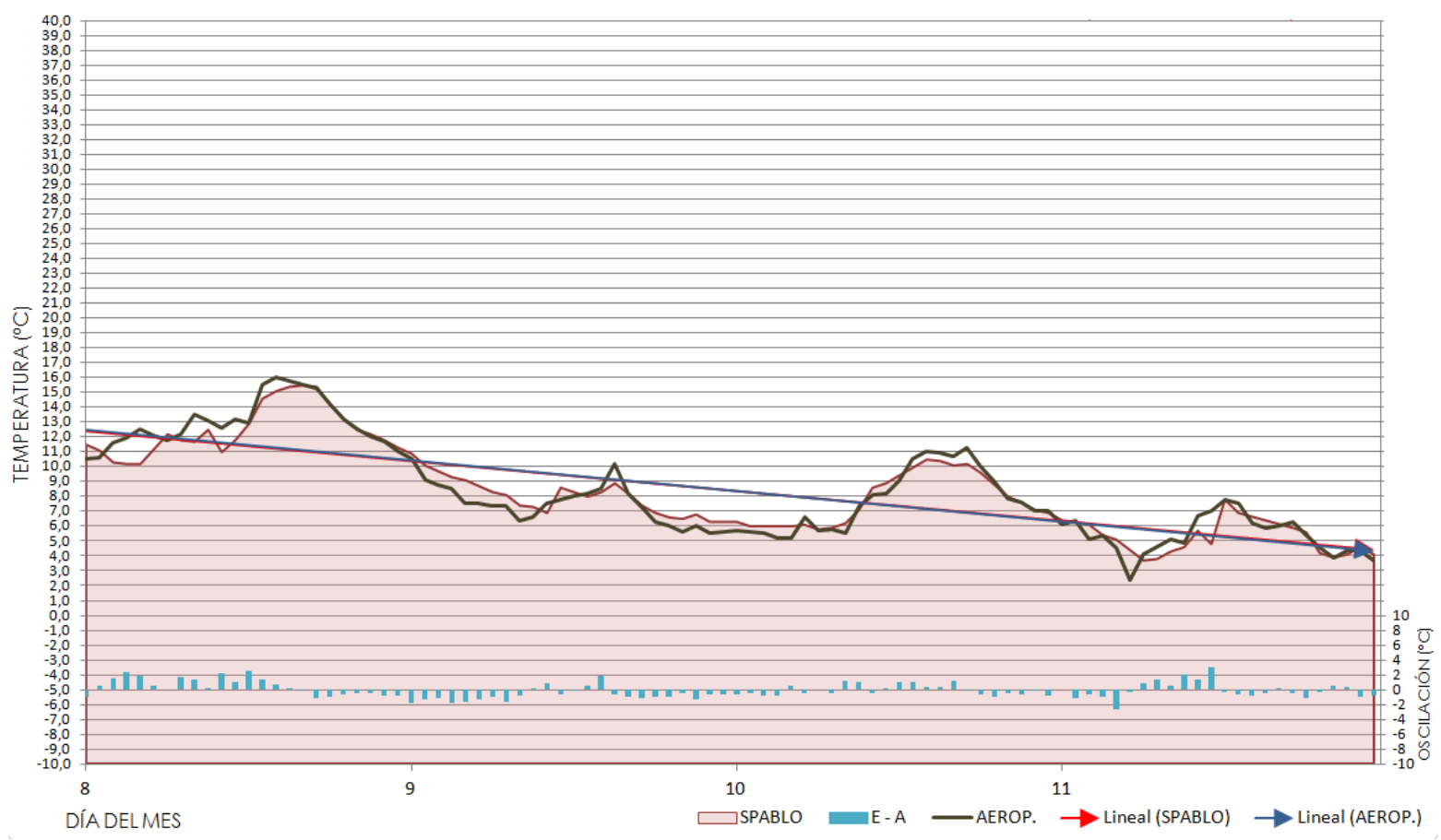

8-132 GRÁFICA COMPARADA DE LAS SERIES TÉRMICAS EN LA ESTACIÓN DE ZARAGOZA Y EN EL EDIFICIO DE LA CALLE SAN PABLO, EN ZARAGOZA DURANTE LOS DÍAS 8 AL 11 DE FEBRERO DEL AÑO 2014. (AEMET Y elaboración propia)

También puede observarse este hecho en secuencias térmicas de periodos más templados.

TEMPERATURA EN ESTACIONES METEOROLÓGICAS LOCALES AEMET-EDIFICIO

ZARAGOZA.01 ABRIL a 03 ABRIL 2014

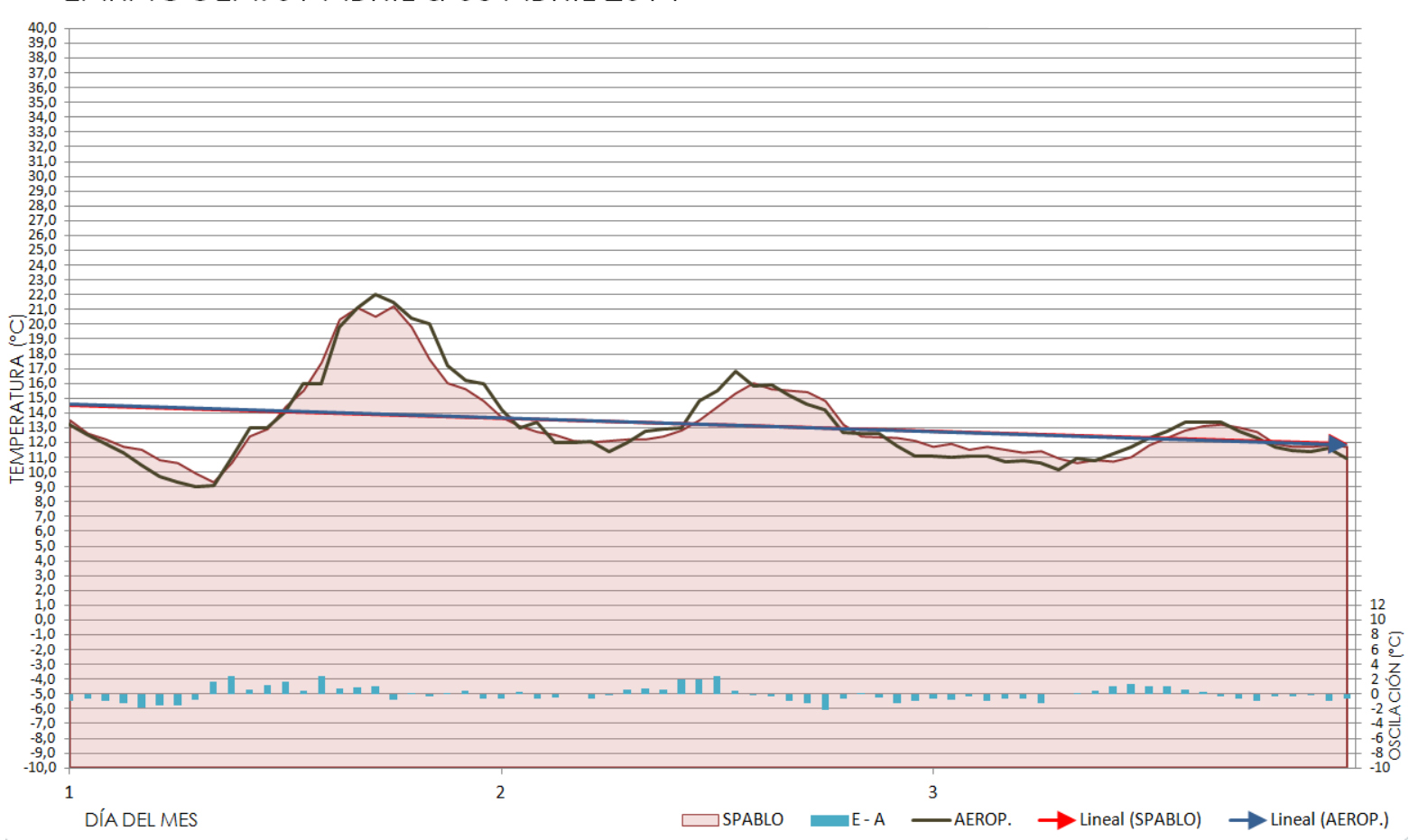

8-133 GRÁFICA COMPARADA DE LAS SERIES TÉRMICAS EN LA ESTACIÓN DE ZARAGOZA Y EN EL EDIFICIO DE LA CALLE SAN PABLO, EN ZARAGOZA DURANTE LOS DÍAS 1 AL 3 DE ABRIL DEL AÑO 2014. (AEMET y elaboración propia) 
Por otra parte es importante la constatación de que estaciones meteorológicas próximas aportan valores de temperatura diferentes a los de la estación situada en el edificio. 
Las series térmicas empleadas se han registrado en la localidad de Zaragoza, considerando el conjunto edificado de referencia. Dispone fachadas con orientación sur y norte y edificios contiguos al este y al oeste. Se encuentra en una zona urbana y muy construidas donde el viario y los edificios se encuentran próximos o contiguos y hay poca influencia de grandes zonas abiertas o de factores geográficos que puedan afectar singularmente a los edificios, a pesar de estar situado en una ciudad de tamaño medio y con grandes accidentes geográficos.

Como estudio de caso para observar esta relación se emplean las series térmicas obtenidas en la estación meteorológica del Aeropuerto de Zaragoza, perteneciente a la red nacional de AEMET, y de los equipos situados en un edificio interior a la trama urbana de Zaragoza en la calle S. Pablo y en la calle B. Boggiero, durante los años 2012, 2013 y 2014. (FIG 8-134 a 138)

Para su observación se han medido los valores higrotérmicos en distintas ubicaciones comparándolas con las condiciones en alguna estación meteorológica de referencia.

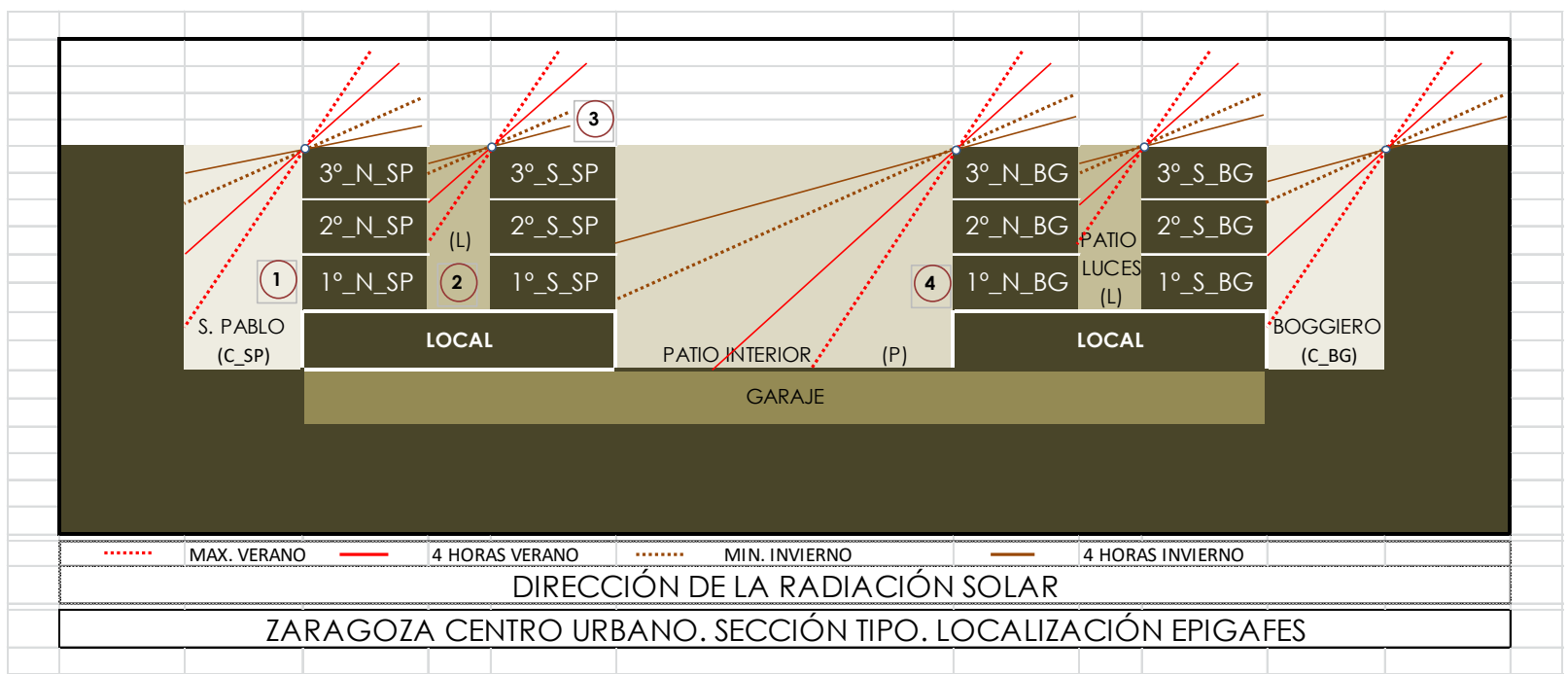

8-134 POSICIÓN DE LOS PUNTO DE MEDICIÓN DE LAS SERIES TÉRMICAS JUNTO AL EDIFICIO (Elaboración propia) 


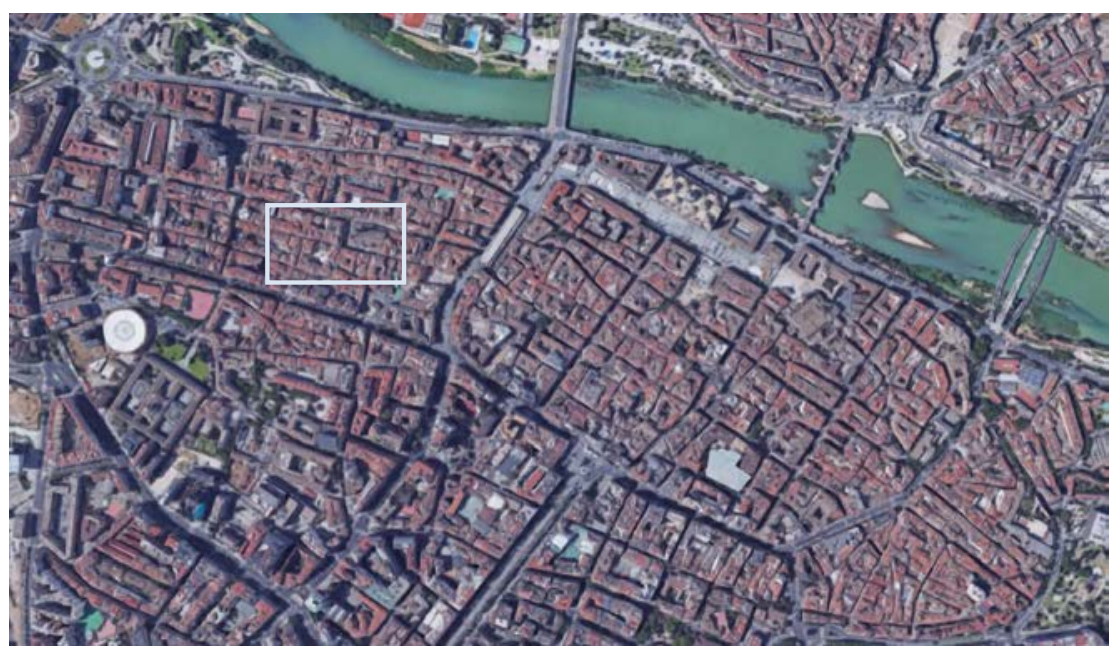

FIG 8-135 LOCALIZACIÓN EN LA CIUDAD DE LA ZONA DE TRABAJO (Google Maps y elaboración propia)

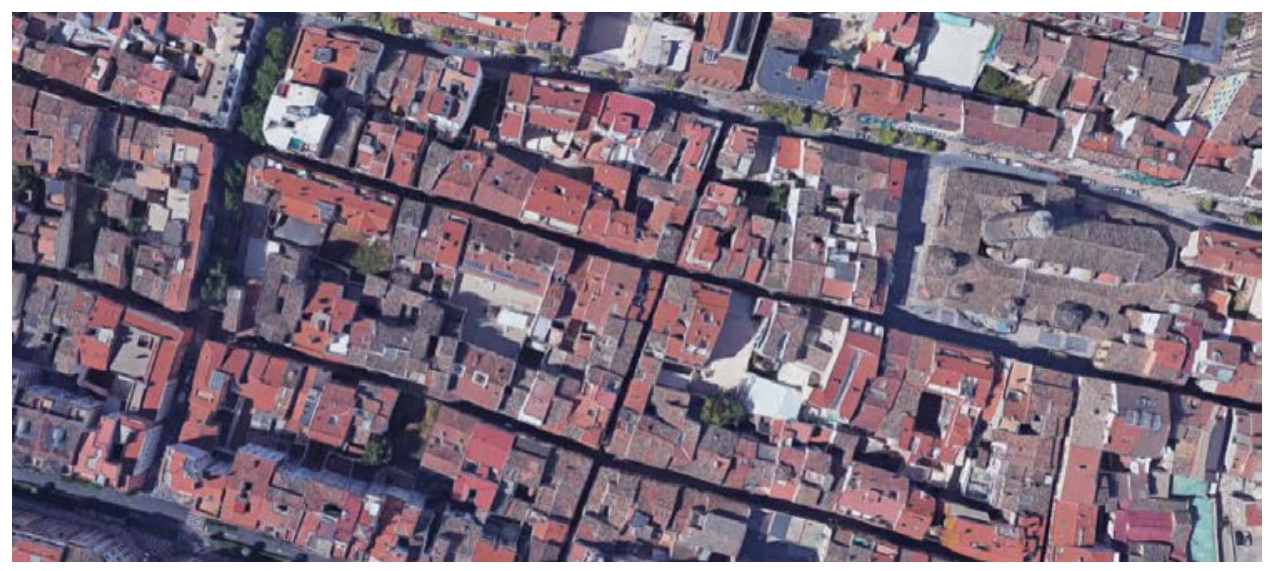

FIG 8-136 LOCALIZACIÓN URBANA DE LA ZONA DE TRABAJO (Google Maps y elaboración propia)
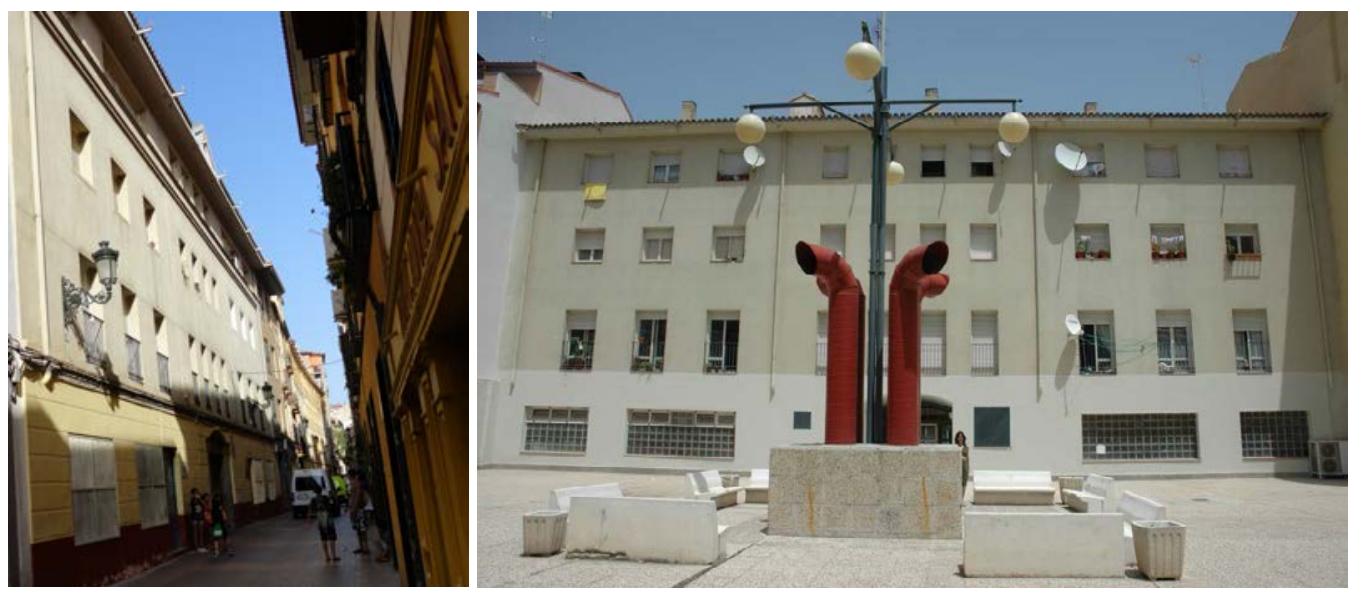

FIG 8-137 FACHADA NORTE A CALLE S. PABLO Y SUR AL PATIO INTERIOR (Elaboración propia) 

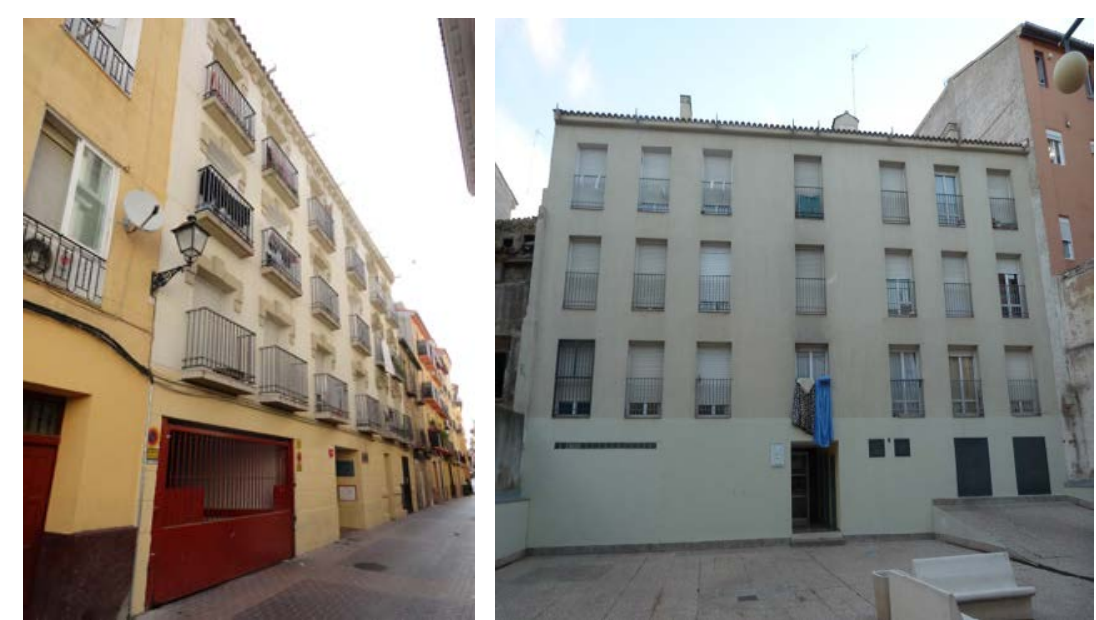

FIG 8-138 FACHADA SUR A CALLE B. BOGGIERO Y NORTE AL PATIO INTERIOR (Elaboración propia).

El edificio, está construido con estructura de hormigón armado, fachadas de color claro, con dos hojas cerámicas y cámara de aire aislada y con carpintería de madera. La cubierta es de inclinada de teja con cámara ventilada. Se concentra la toma de datos en las plantas $1^{a}, 2^{a}$ y $3^{a}$, al situarse en la planta baja locales o cuartos técnicos no habitables. 
8.7.1 PATIO DE LUCES INTERIOR AL EDIFICIO Y ESTACIÓN METEOROLÓGICA DE AEROPUERTO.

Para su observación se han medido los valores higrotérmicos en distintas ubicaciones comparándolas con las condiciones en alguna estación meteorológica de referencia.

Estos valores permiten observar diferencias como las recogidas en la tabla adjunta durante un año.

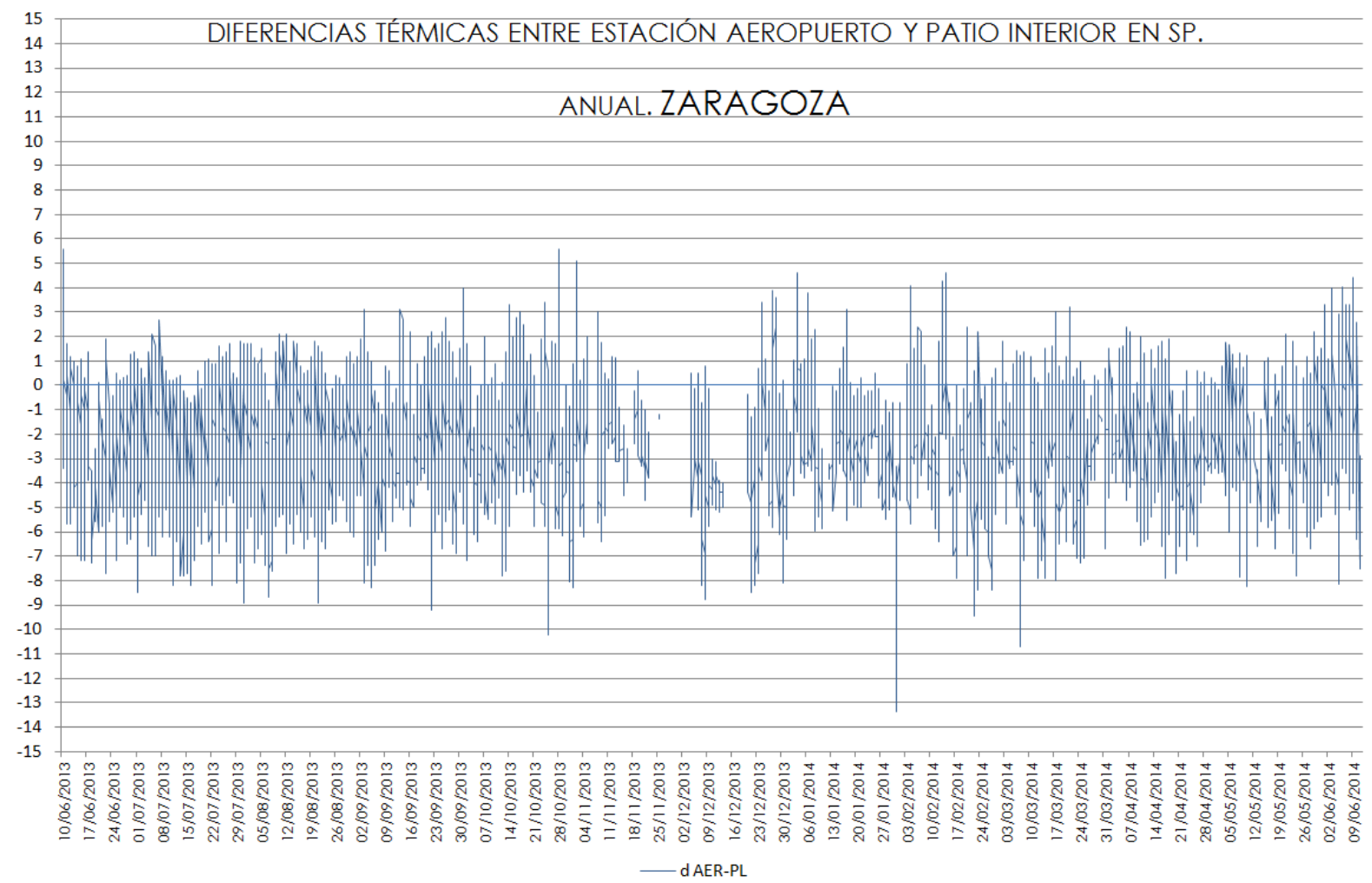

8-139 GRÁFICA COMPARADA DE LAS DIFERENCIAS ENTRE LAS TEMPERATURAS HORARIAS ENTRE LAS ESTACIONES DE ZARAGOZA-AEROPUERTO Y PATIO INTERIOR EN S. PABLO, DESDE JUNIO DE 2013 A JUNIO DE 2014. (AEMET Y elaboración propia)

La serie obtenida manifiesta una gran dispersión en los valores observados aunque puede observarse cómo casi siempre es ligeramente más alta la temperatura en las zonas exteriores más protegidas por el edificio, siendo puntualmente mucho mayor que la temperatura en las zonas exteriores.

Se puede concluir que ocasionalmente las temperaturas son menores, aunque con valores extremos menos acusados, en el patio de luces, si bien no se observa un patrón claro para este comportamiento.

La oscilación térmica en el patio de luces es muy inferior a las del resto de las localizaciones, la temperatura que alcanza la zona sur del patio interior es mayor que el resto $y$, en general, las temperaturas son menores en la estación meteorológica de referencia. 


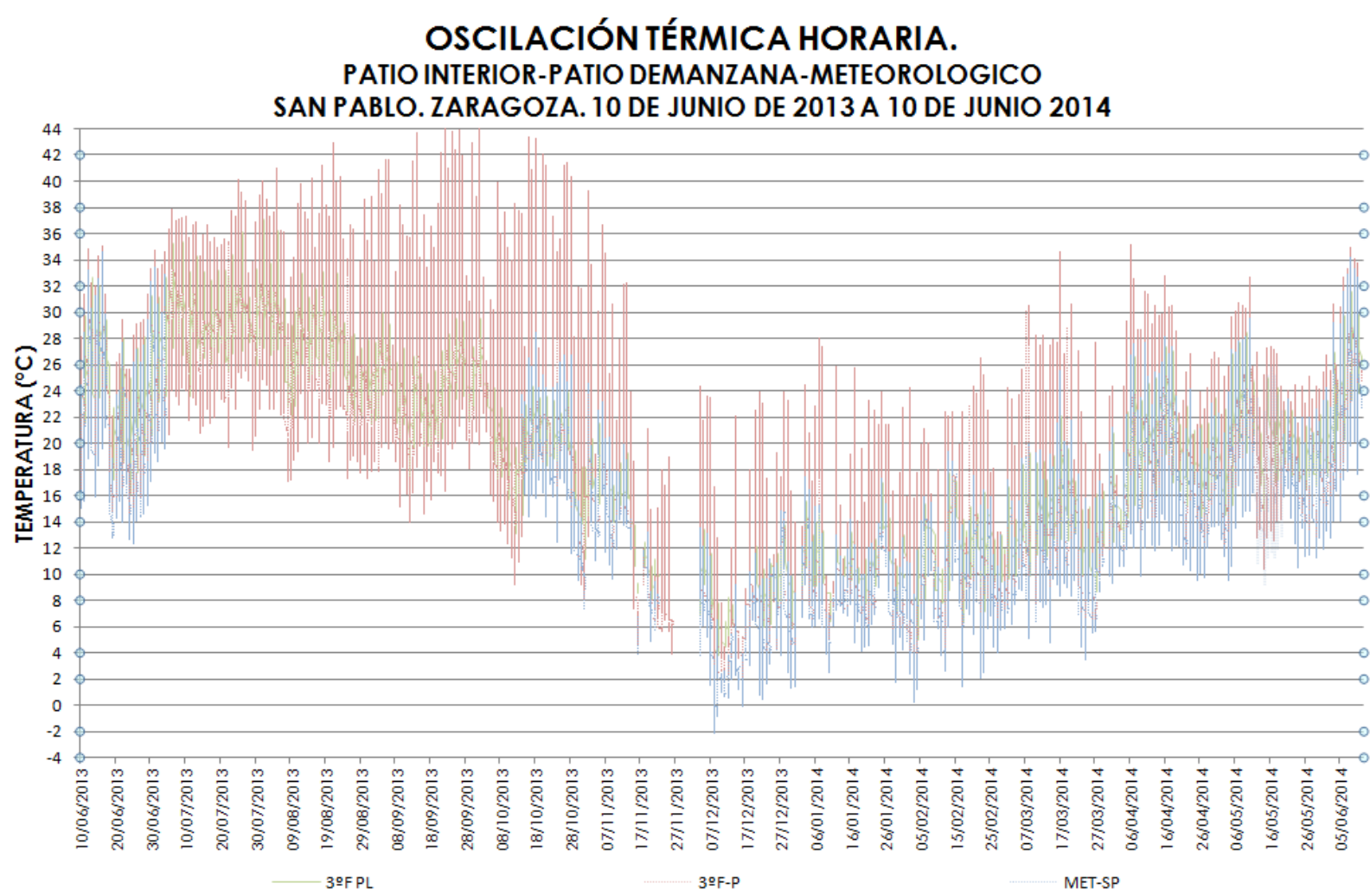

8-140 GRÁFICA COMPARADA DE LAS OSCILACIONES TÉRMICAS EN LAS ESTACIONES DE ZARAGOZA-AEROPUERTO Y PATIO INTERIOR EN S. PABLO, DESDE JUNIO DE 2013 A JUNIO DE 2014. (AEMET y elaboración propia)

Para relacionar las series térmicas obtenidas en el entorno próximo del edificio y la temperatura que se registra en las estaciones meteorológicas se ha considerado de utilidad analizar series parciales relacionadas con secuencias en las que la temperatura ambiente fluctúa manteniendo su tendencia o tiene claras tendencias ascendentes 0 descendentes, identificando las singularidades que frecuentemente no tienen reflejo en las secuencias de valores medios. 


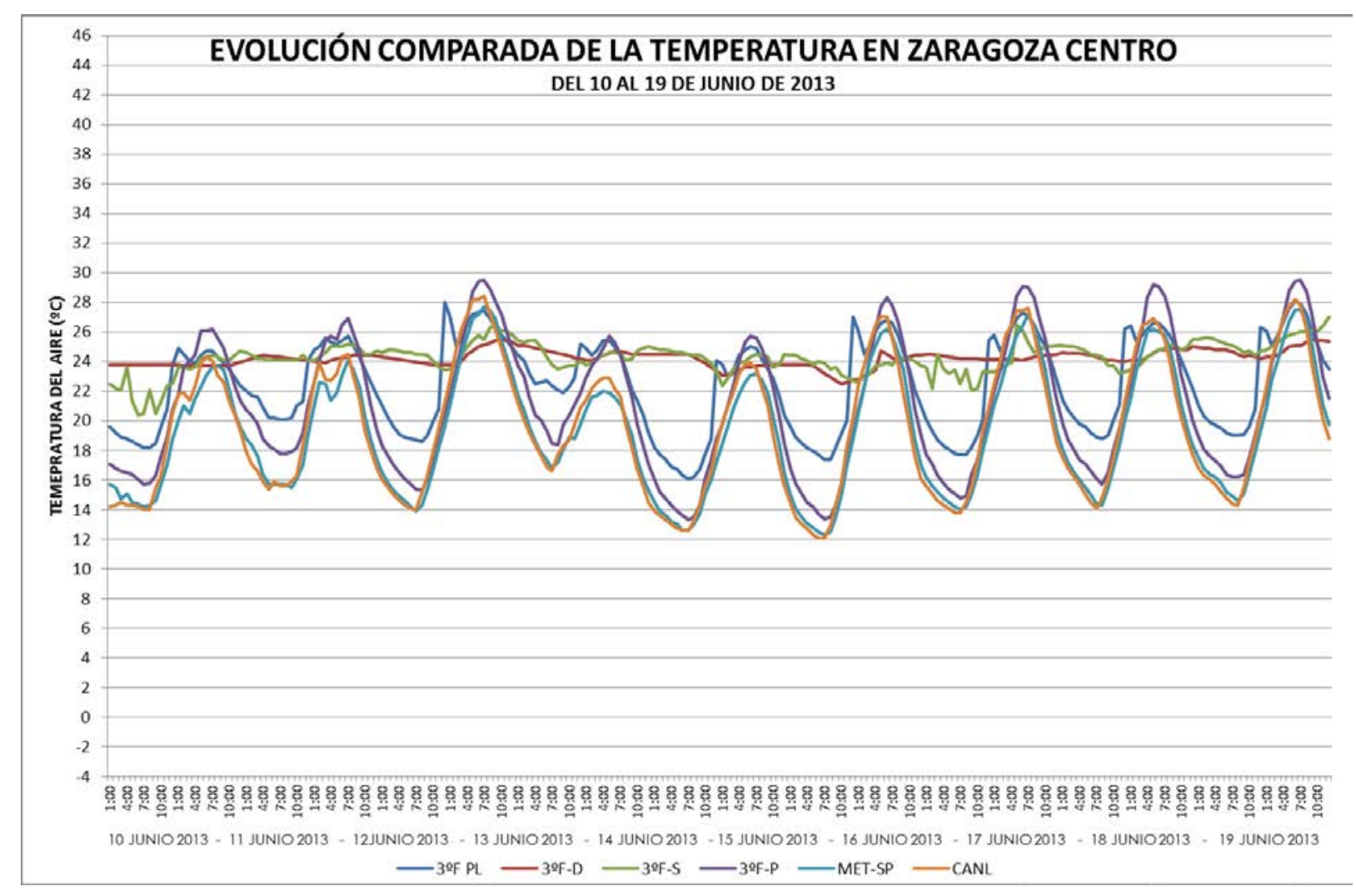

FIG 8-141 EVOLUCIÓN COMPARADA DE LA TEMPERATURA EN ZARAGOZA CENTRO EN EL INTERIOR Y EL EXTERIOR DE UN EDIFICIO DEL 10 AL 19 DE JUNIO DE 2013 (Elaboración propia)

Puede observarse la amortiguación de las temperaturas interiores con respecto a las exteriores. 
B. Evolución de la temperatura entre los días 20 y 29 de junio de 2013

C.

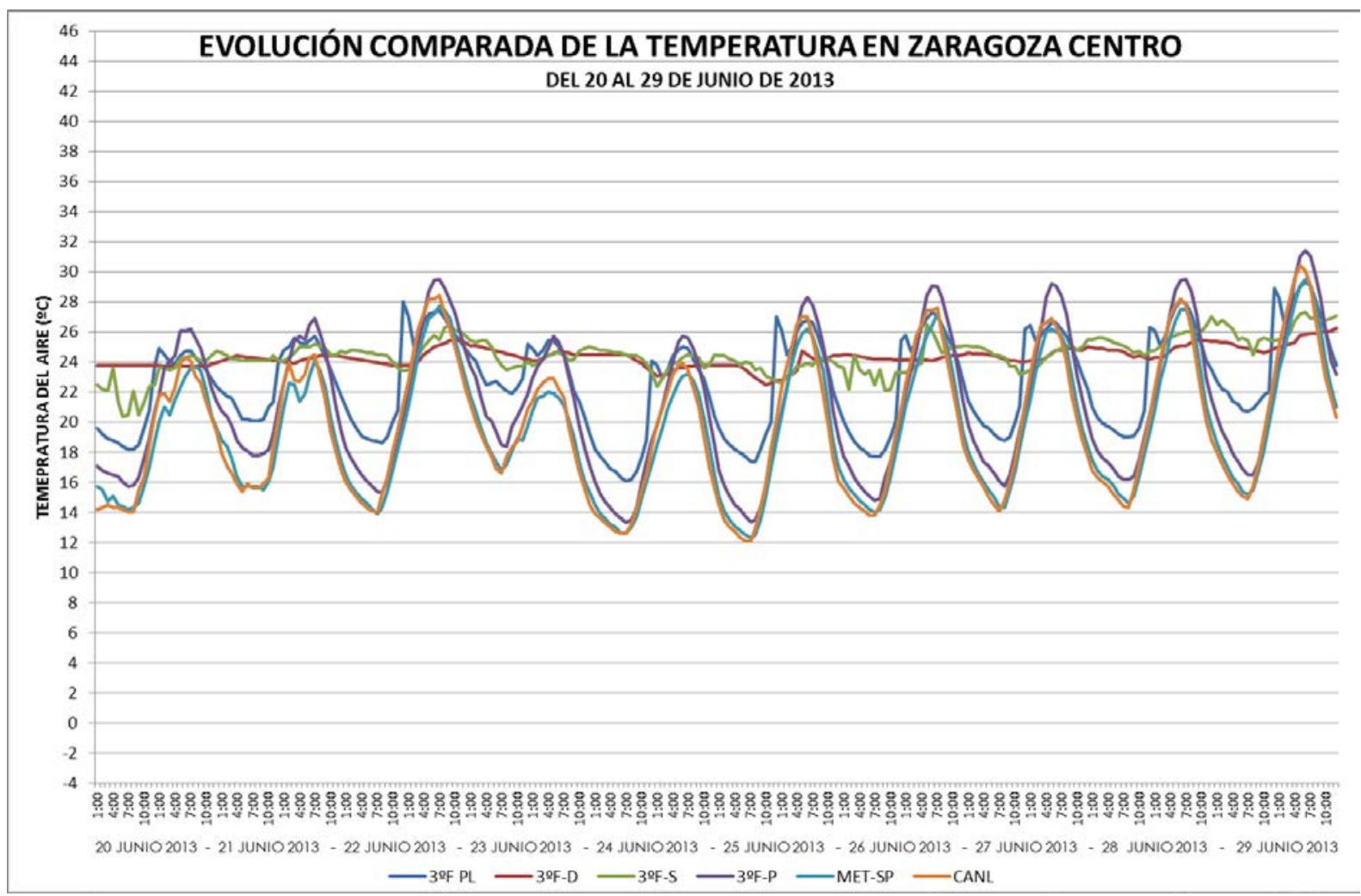

FIG 8-142 EVOLUCIÓN COMPARADA DE LA TEMPERATURA EN ZARAGOZA CENTRO DEL 20 AL 30 DE JUNIO DE 2013 (Elaboración propia) 
D. Evolución de la temperatura del 01 al 09 de julio de 2013

E.
VER ANEXO 09:

REGISTROS MICROCLIMA DE PROXIMIDAD

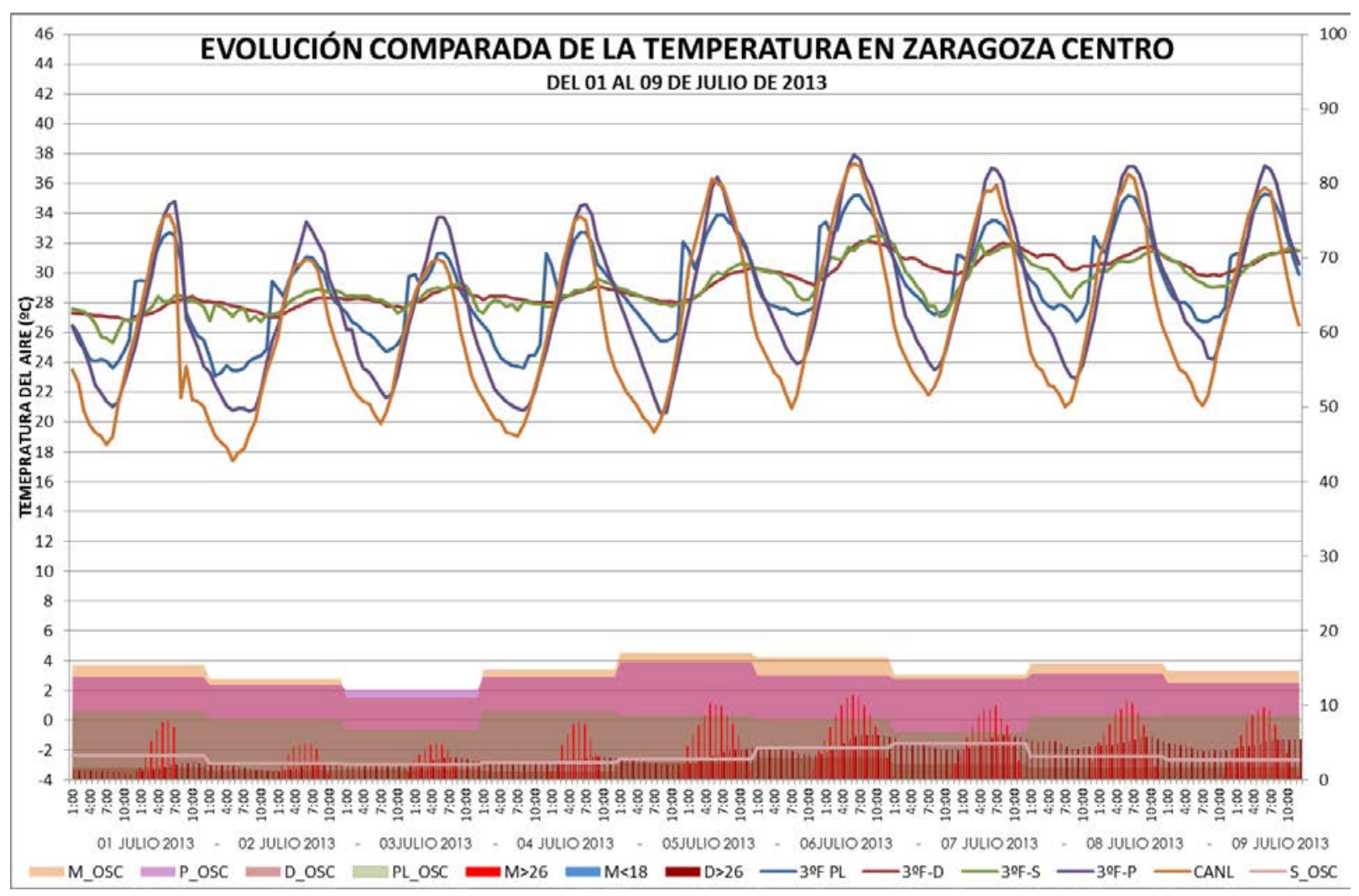

FIG 8-143 EVOLUCIÓN COMPARADA DE LA TEMPERATURA EN ZARAGOZA CENTRO DEL 1 AL 9 DE JULIO DE 2013 (Elaboración propia) 


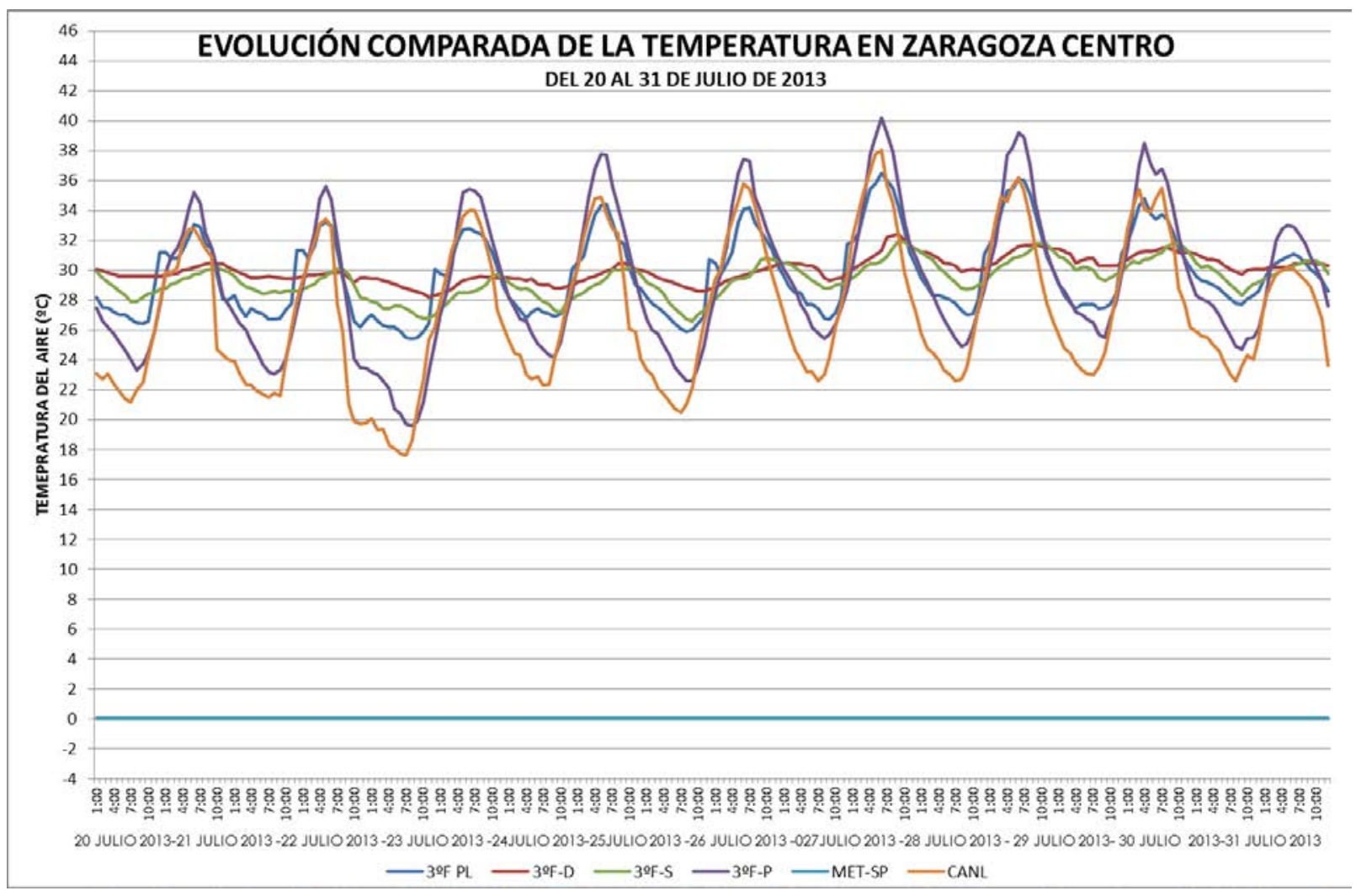

FIG 8-144 EVOLUCIÓN COMPARADA DE LA TEMPERATURA EN ZARAGOZA CENTRO DEL 20 AL 31 DE JULIO (Elaboración propia)

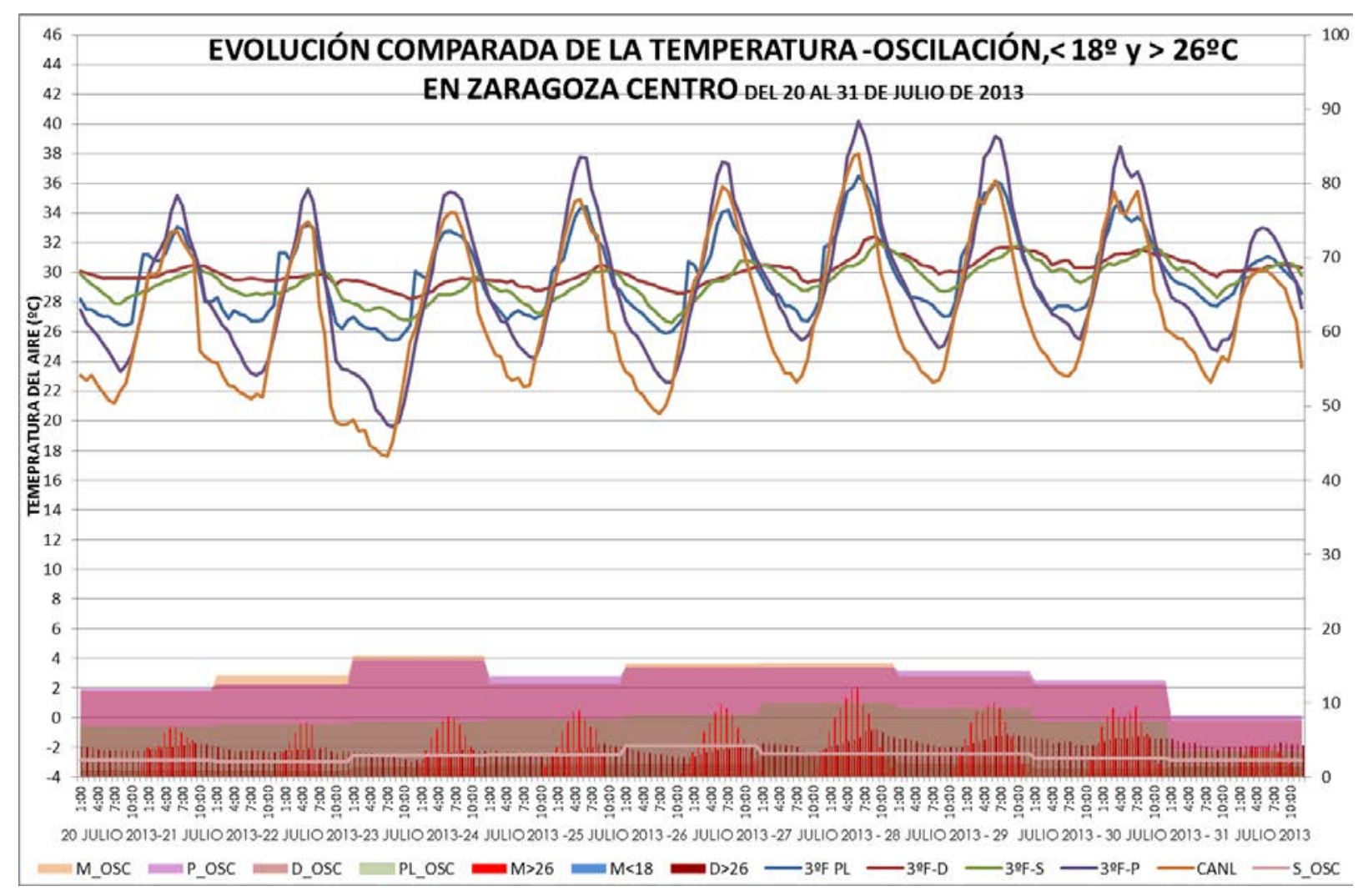

FIG 8-145 EVOLUCIÓN COMPARADA DE LA TEMPERATURA EN ZARAGOZA CENTRO DEL 20 AL 31 DE JULIO (Elaboración propia) 


\begin{tabular}{|c|c|c|c|c|c|}
\hline 10-19/JULIO 2013 & 3ㅇF PL & 3F-D & 3ㅇF-S & 3F-P & CANL \\
\hline TEMPERATURA MÁXIMA & 36,5 & 32,4 & 31,9 & 40,2 & 38 \\
\hline EMPERATURA MÍNIMA & 25,4 & 28,2 & 26 & 19,4 & 17,6 \\
\hline JSCILACIÓN MÁXIMA & 9,8 & 3,1 & 4,2 & 15,8 & 17,4 \\
\hline OSCILACIÓN MÍNIMA & 3,4 & 0,8 & 2 & 8,3 & 7,6 \\
\hline OSCILACIÓN MEDIA & 7,982 & 1,602 & 3,155 & 14,39 & 14,91 \\
\hline TOTAL GRADOS $<26^{\circ} \mathrm{C}$ & 1062 & 1145 & 913,4 & 1072 & 777 \\
\hline № DE HORAS <26으 & 279 & 288 & 287 & 194 & 150 \\
\hline$\%$ HORAS $<26$ @ C & $106 \%$ & $109 \%$ & $109 \%$ & $73 \%$ & $57 \%$ \\
\hline TOTAL GRADOS $>18 \stackrel{\circ}{\circ}$ & 0 & 0 & 0 & 0 & 0,9 \\
\hline № DE HORAS >18 ㄷ C & 0 & 0 & 0 & 0 & 3 \\
\hline$\%$ HORAS $>18 \stackrel{\circ}{ } \mathrm{C}$ & $0 \%$ & $0 \%$ & $0 \%$ & $0 \%$ & $1 \%$ \\
\hline
\end{tabular}

8-146 TABLA DE TEMPERATURAS EN ZARAGOZA CENTRO DEL 20-31 JULIO 2013 (Elaboración propia)

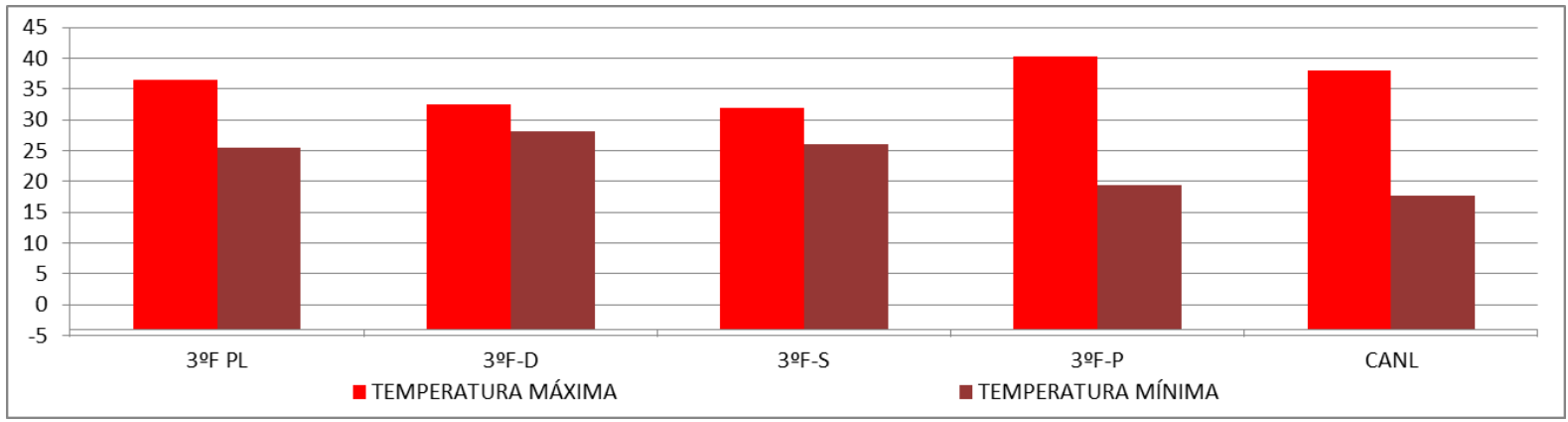

FIG 8-147 RELACION ENTRE LAS TEMPERATURAS MÁXIMAS Y MÍNIMAS EN LAS DISTINTAS LOCALIZACIONES EN ZARAGOZA CENTRO ENTRE EL 20 Y EL 31 DE JULIO DE 2013 (Elaboración propia) 
FIG 8-148 GRÁFICA DEL NÚMERO Y LA PROPORCIÓN DE HORAS CÁLIDAS $\left(>26^{\circ} \mathrm{C}\right.$ ) EN ZARAGOZA CENTRO DEL 20 AL 31 DE JULIO DE 2013. (Elaboración propia)

FIG 8-149 GRÁFICA DE LAS OSICILACIONES MÁXIMAS, MÍNIMAS Y MEDIAS EN ZARAGOZA CENTRO ENTRE EL $20 \mathrm{Y}$ EL 31 DE JULIO DE 2013 (Elaboración propia)
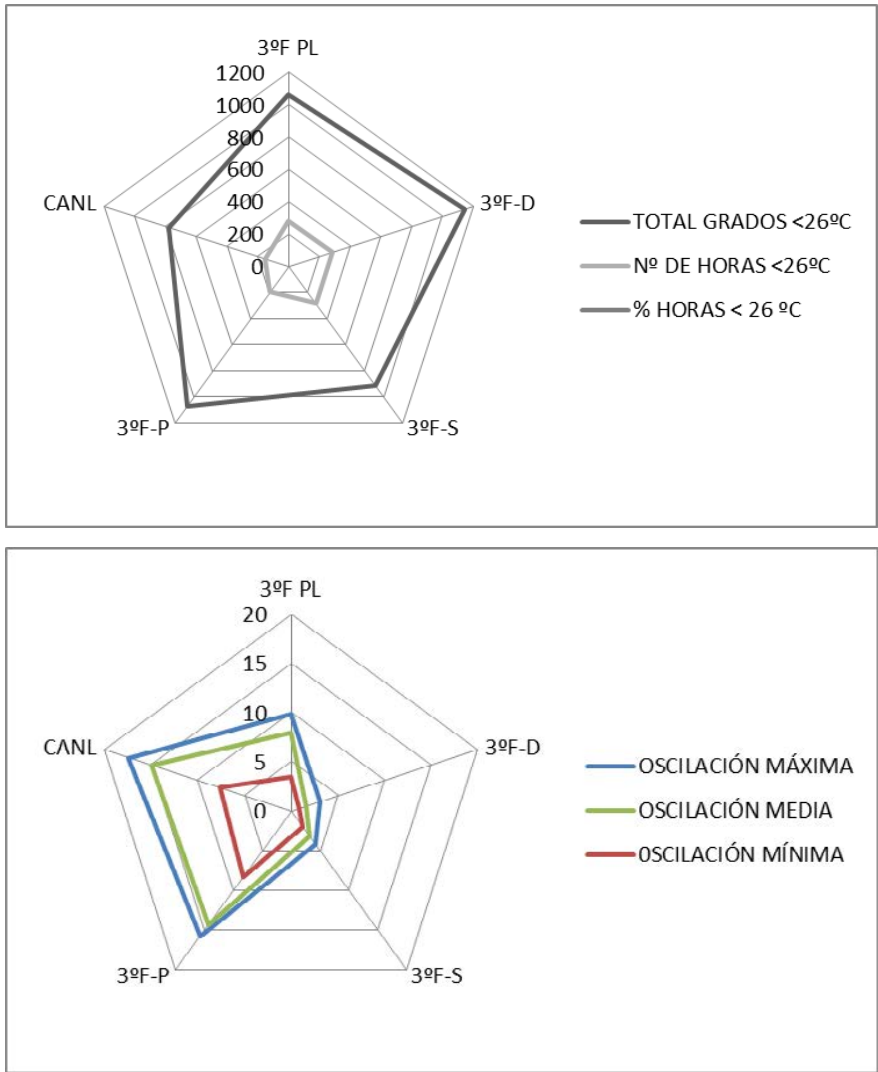


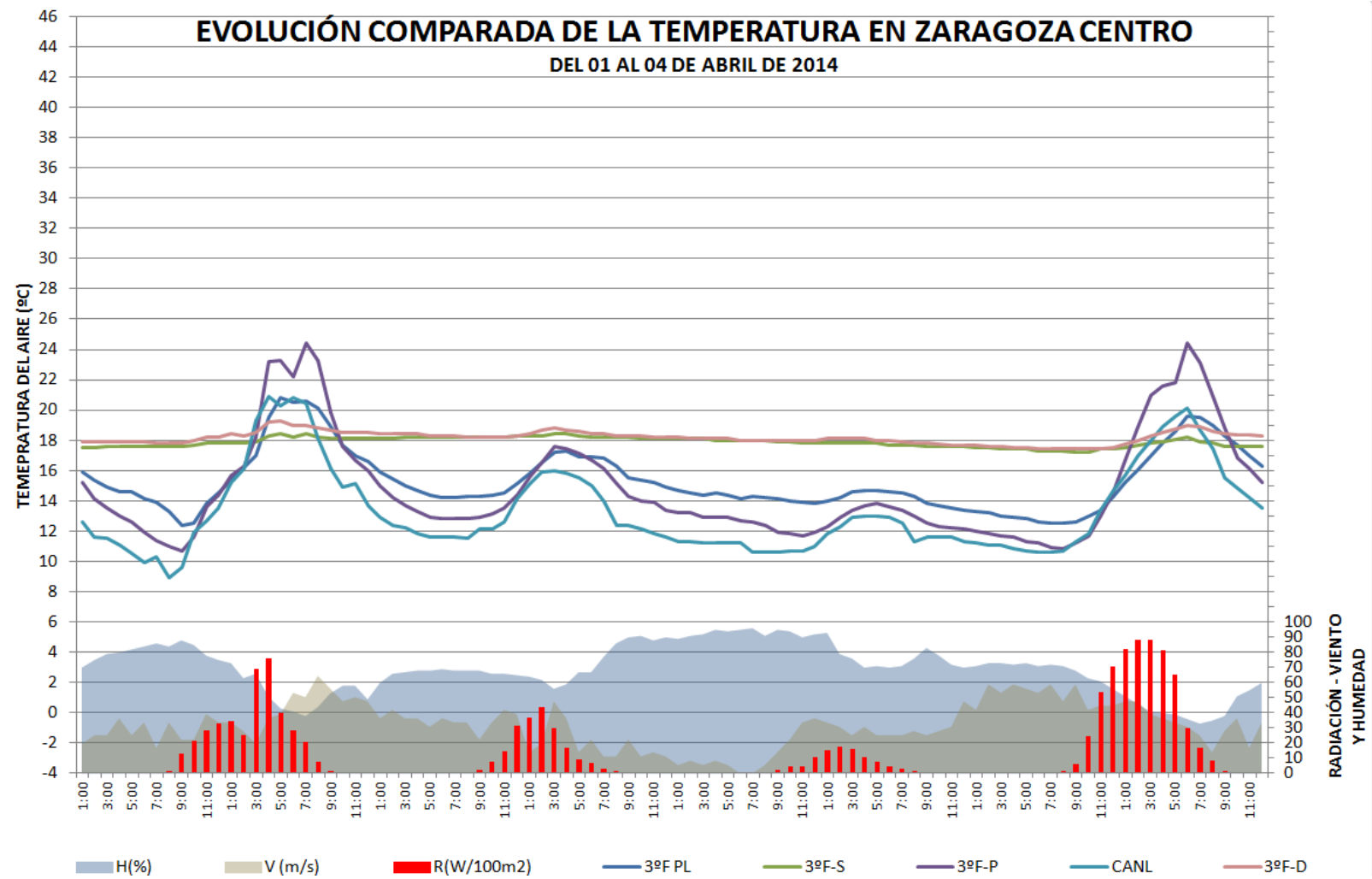

8-150 SECUENCIA DE LA EVOLUCIÓN TÉRMICA EN PERIODO DE TRANSICIÓN DEL PERIODO FRÍO AL CÁLIDO, DEL 1 AL 4 DE ABRIL DE 2014 INCLUYENDO VIENTO, RADIACIÓN Y HUMEDAD (Elaboración propia)

Cuando se comprueba la evolución de las series térmicas en la proximidad de la edificación se pueden observar diferencias significativas en los valores mínimos, en los cuatiles, en los valores máximos y en los promedios.

Se han realizado mediciones de temperatura en la ciudad de Zaragoza, en concreto en el patio de luces del edificio de referencia a la altura de su última planta y en el paramento con orientación este. Se trata de un patio interior de aproximadamente 5 metros de lado

Estos registros se han comparado con los obtenidos en una estación meteorológica situada en la cubierta del mismo edificio. 
Las diferencias entre los valores mínimos observados son de $7,8^{\circ} \mathrm{C}$ menos en el exterior, que pasan a ser de $3,8^{\circ} \mathrm{C}$ en el segundo cuartil mientras que en el 3er. cuartil se invierten las temperaturas siendo más altas en al abrigo del edificio. Las temperaturas máximas absolutas sólo manifiestan diferencias muy pequeñas del entorno de $0,6^{\circ} \mathrm{C}$.

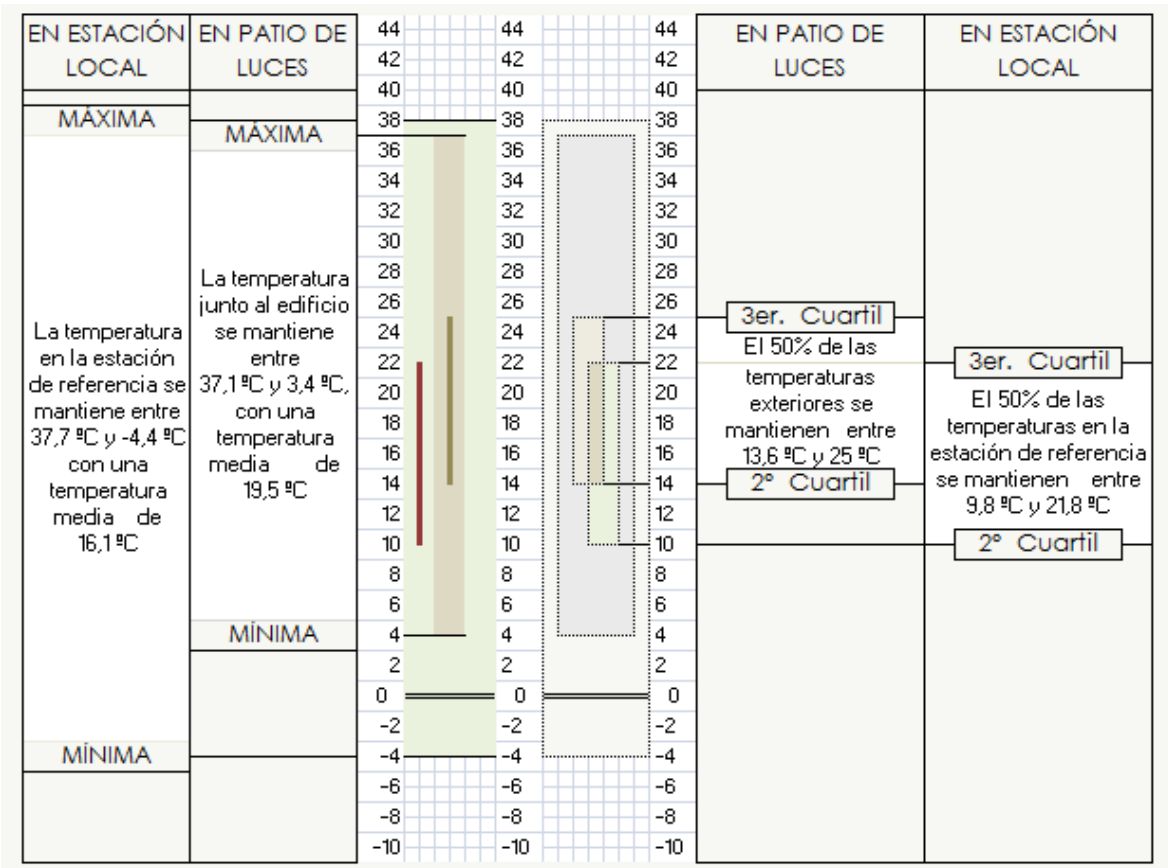

VER ANEXO 09:

REGISTROS MICROCLIMA DE PROXIMIDAD

VER ANEXO11

TENTATIVA CLASIFICACIÓN EN FRANJAS DE HOMOGÉNEIDAD TÉRMICA

8-151 ESQUEMA COMPARADO DE LA EVOLUCIÓN DE LAS MEDIAS DIARIAS DE LAS TEMPERATURAS EN UNA ESTACIÓN METEOROLÓGICA Y EN UN PATIO INTERIOR DE UN EDIFICIO EN LA CALLE S. PABLO DE ZARAGOZA (Elaboración propia). 


\subsubsection{ESCALA TEMPORAL PLURIANUAL}

VER ANEXO11

Se ha elegido establecer una franja de valores climáticos probables para ser considerados en la estimación de la respuesta de la edificación, prestando atención a las efemérides climáticas.

En los lugares estudiados se dispone de datos comparables de los últimos treinta o cincuenta años, aunque se considera suficiente disponer de series de diez años para estimar el comportamiento de la edificación frente al clima.

Las series climáticas anuales denotan una gran discontinuidad que hace imposible el establecimiento de pautas aunque se buscan correlaciones y se han desarrollado muchos modelos, no son precisas para la estimación del comportamiento de la edificación.

Para analizar la respuesta de los edificios frente al clima se sigue el siguiente procedimiento:

A. Evolución temporal de los valores climáticos

Se observa la desviación entre los valores medios en periodos plurianuales, de 3, 5 y 10 años, mensuales y por periodos significativos como para un rango de valores que permitan establecer la capacidad de reacción del edificio considerado.

B. Evolución anual

Se realiza un estudio comparado de los valores climáticos registrados en varios años para establecer los rangos útiles a las simulaciones:

- TEMPERATURA (Media, máxima y mínima)

- RADIACION

- VIENTO

- HUMEDAD RELATIVA Y PLUVIOMETRÍA

C. Evolución de los valores climáticos en periodos afines

La evolución de los valores climáticos en cada uno de los meses carece de las condiciones para ser considerada en una posterior comparación entre periodos. Las diferentes secuencias detectadas en el estado del clima no comparten, mensualmente, ni tendencias ni valores, pudiéndose encontrar secuencias temporales más afines sin estar ubicadas en fechas similares.

Aunque ocasionalmente se han empleado, en el presente estudio sólo se han recogido a efectos de establecer una cronología de series térmicas afines,

Como se ha indicado anteriormente los periodos anuales o plurianuales permiten estimar los consumos o las demandas y diseñar equipos y sistemas. Se ha observado que la aclimatación en periodos menores exige considerar las condiciones particulares
TENTATIVA CLASIFICACIÓN EN FRANJAS DE HOMOGÉNEIDAD TÉRMICA 
de estos periodos y los valores medios o ponderados no son de mucha utilidad.

Por ello se han realizado las estimaciones y las validaciones en periodos más cortos, de entre 3 y 10 días, en los que se han estimado los periodos con secuencias climáticas que provocan en el edificio diferentes respuestas y exigen diferentes compensaciones higrotérmicas para alcanzar condiciones de bienestar.

Así analizados por tanto los valores obtenidos serán útiles para la descripción del correspondiente microclima de proximidad y para conocer así la respuesta de los espacios interiores.

Para esto último también podrían considerarse diferentes patrones de uso, como pueden ser los periodos festivos o laborables o aquéllos en los que hay personas enfermas, con diferentes horarios o simplemente ausentes, pero que no se abordan explícitamente aquí.

La validación de estos periodos se encuentra en la dificultad de establecer qué hace similares entre sí estos periodos y buscar a lo largo del año aquellos periodos que se asemejan entre sí, independientemente de su ubicación en el calendario.

Para ello se han buscado periodos comparables a lo largo del año que, aunque no coinciden en fechas, sí lo hacen en unos valores que los hacen similares y por tanto útiles para el objeto del presente estudio. Para conformar dichas secuencias se deben considerar:
VER ANEXO 09:

REGISTROS MICROCLIMA DE PROXIMIDAD

VER ANEXO1 1

TENTATIVA CLASIFICACIÓN EN FRANJAS DE HOMOGÉNEIDAD TÉRMICA

\author{
MÁXIMAS TEMPERATURAS ANUALES \\ MÍNIMAS TEMPERATURAS ANUALES \\ TEMPERATURAS ANUALES MEDIAS \\ TEMPERATURAS CALIDAS EVOLUCIONANDO A TEMPERATURAS MÁS FRIAS \\ TEMPERATURAS FRÍAS EVOLUCIONANDO A TEMPERATURAS TAMBIÉN FRÍAS \\ TEMPERATURAS CALIDAS EVOLUCIONANDO A TEMPERATURAS CÁLIDAS \\ TEMPERATURAS FRIAS EVOLUCIONANDO A TEMPERATURAS CÁLIDAS \\ TEMPERATURAS CONFORTABLES EVOLUCIONANDO A TEMPERATURAS MÁS CÁLIDAS \\ TEMPERATURAS CONFORTABLES EVOLUCIONANDO A TEMPERATURAS MÁS CÁLIDAS
}


C1. Estudio de caso: Zaragoza, centro urbano

Para definir los periodos temporales significativos, es decir los que representan mejor la totalidad del año climatológico aplicados a una localización concreta y en relación a su influencia en la termodinámica del edificio, se han comparado los valores meteorológicos con obtenidos en interiores del edificio, en zonas en las que no existen aportaciones ni sustracciones de calor por medio de la climatización artificial, es decir, sin aportes de energía.

En este caso se ha considerado que la evolución de los valores climáticos se producirá por la influencia de los sistemas pasivos inherentes al edificio como son, entre otros, la radiación incidente y la emitida, la inercia térmica del sistema, los intercambios por convección en las envolventes o los intercambios por conducción con el resto de los edificios o el terreno.

La comparación entre estos valores permite observar algunas correlaciones entre las temperaturas obtenidas en una estación meteorológica y en el entorno próximo del edificio.

Comparando los valores de temperatura obtenidos en distintos microclimas de proximidad con los registrados en la estación situada en el edificio observamos que su evolución sigue patrones comunes, con retardos y amortiguaciones específicas para cada localización.
VER ANEXO 09:

REGISTROS MICROCLIMA DE PROXIMIDAD

VER ANEXO11

TENTATIVA CLASIFICACIÓN EN FRANJAS DE HOMOGÉNEIDAD TÉRMICA

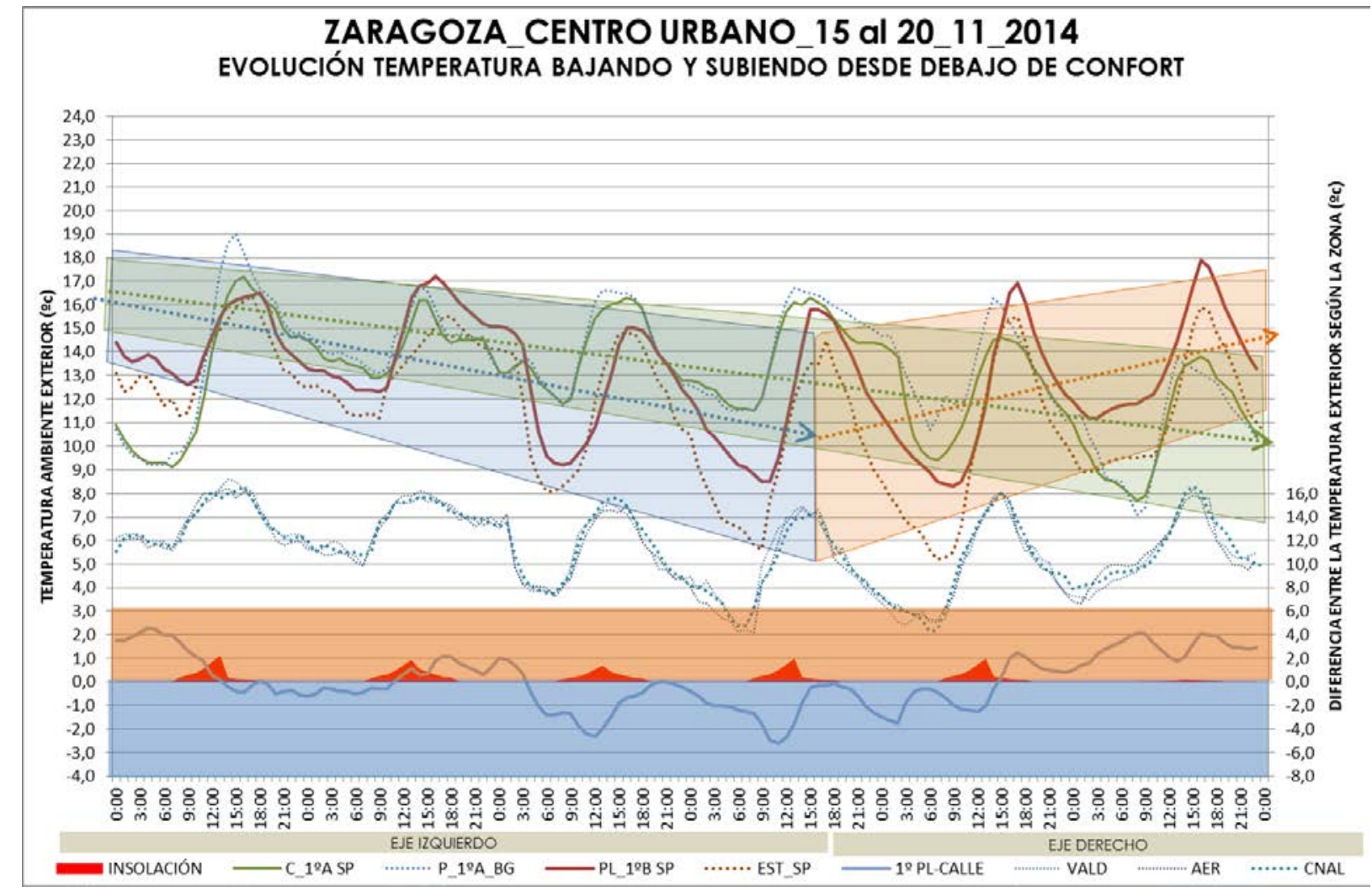

8-152 GRÁFICA COMPARADA DE LA EVOLUCIÓN TÉRMICA EN UNA ESTACION METEOROLÓGICA LOCAL Y UNA DE REFERENCIA EN ZARAGOZA ENTRE LOS DÍAS 15 AL 20 DE NOVIEMBRE DE 2014. (Elaboración propia) 


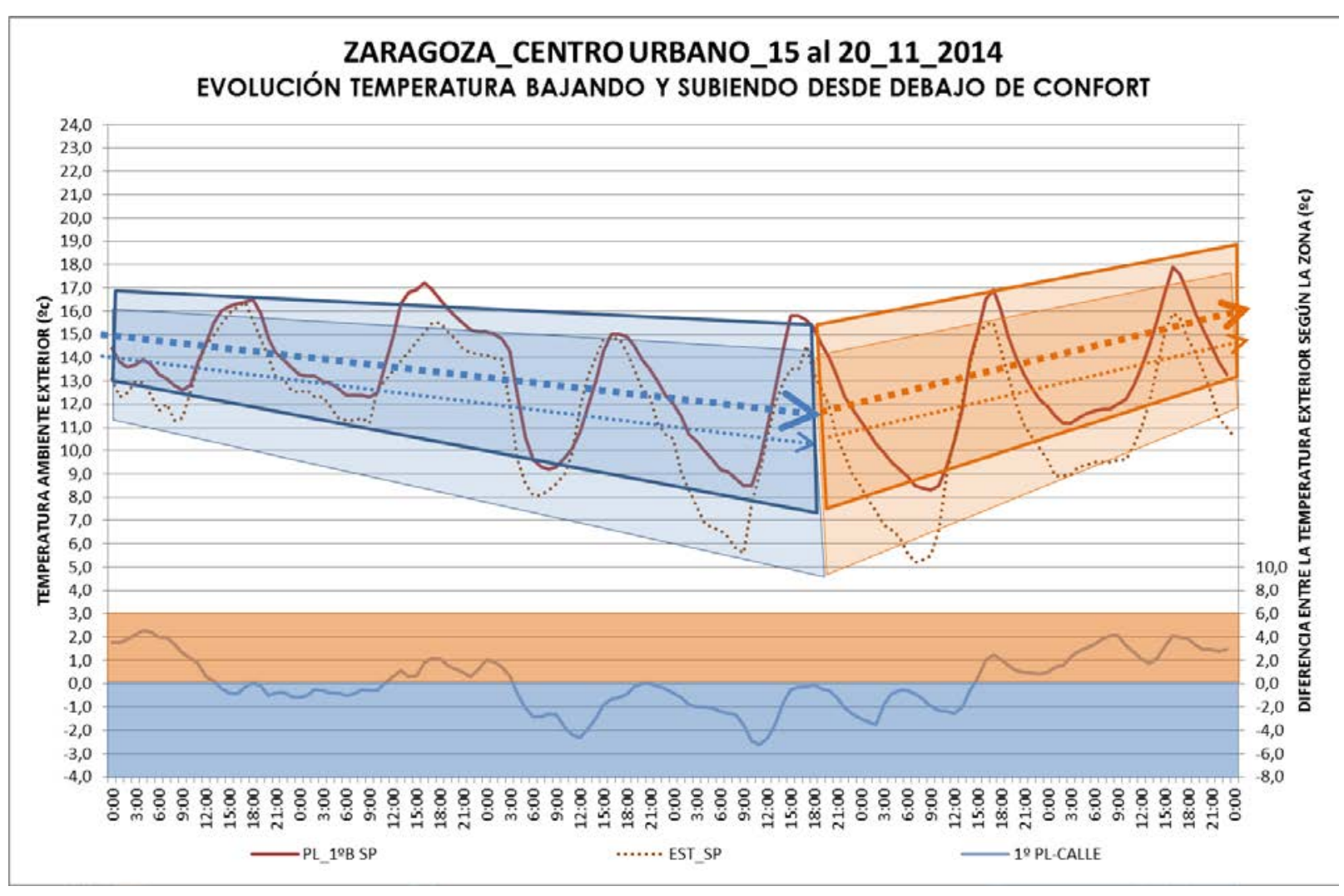

8-153 GRÁFICA COMPARADA DE LA EVOLUCIÓN TÉRMICA EN UNA ESTACION METEOROLÓGICA LOCAL Y UNA DE REFERENCIA EN ZARAGOZA ENTRE LOS DÍAS 15 AL 20 DE NOVIEMBRE DE 2014. (Elaboración propia) 
Comparando las temperaturas en distintos microclimas de proximidad observamos:
VER ANEXO 09:

REGISTROS MICROCLIMA DE PROXIMIDAD

VER ANEXO11

TENTATIVA CLASIFICACIÓN

EN FRANJAS DE

HOMOGÉNEIDAD TÉRMICA

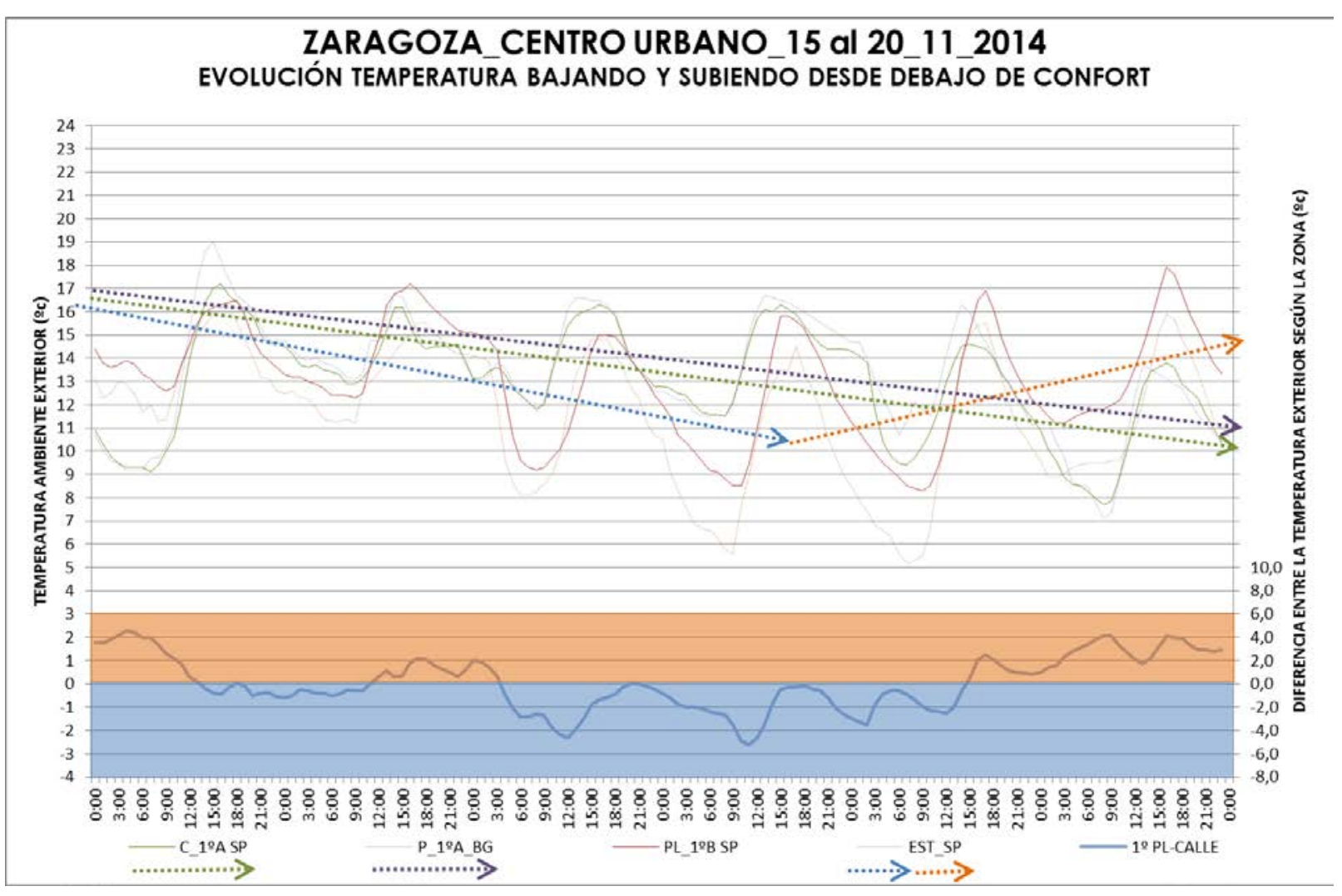

8-154 GRÁFICA COMPARADA DE LA EVOLUCIÓN TÉRMICA EN UNA ESTACION METEOROLÓGICA LOCAL Y UNA DE REFERENCIA EN ZARAGOZA ENTRE LOS DÍAS 15 AL 20 DE NOVIEMBRE DE 2014. (Elaboración propia) 
El resultado son unas diferencias de temperatura entre los espacios afectados por estos microclimas de proximidad y la estación ubicada en el propio edificio, y ello según un patrón que dista mucho de ser homogéneo.

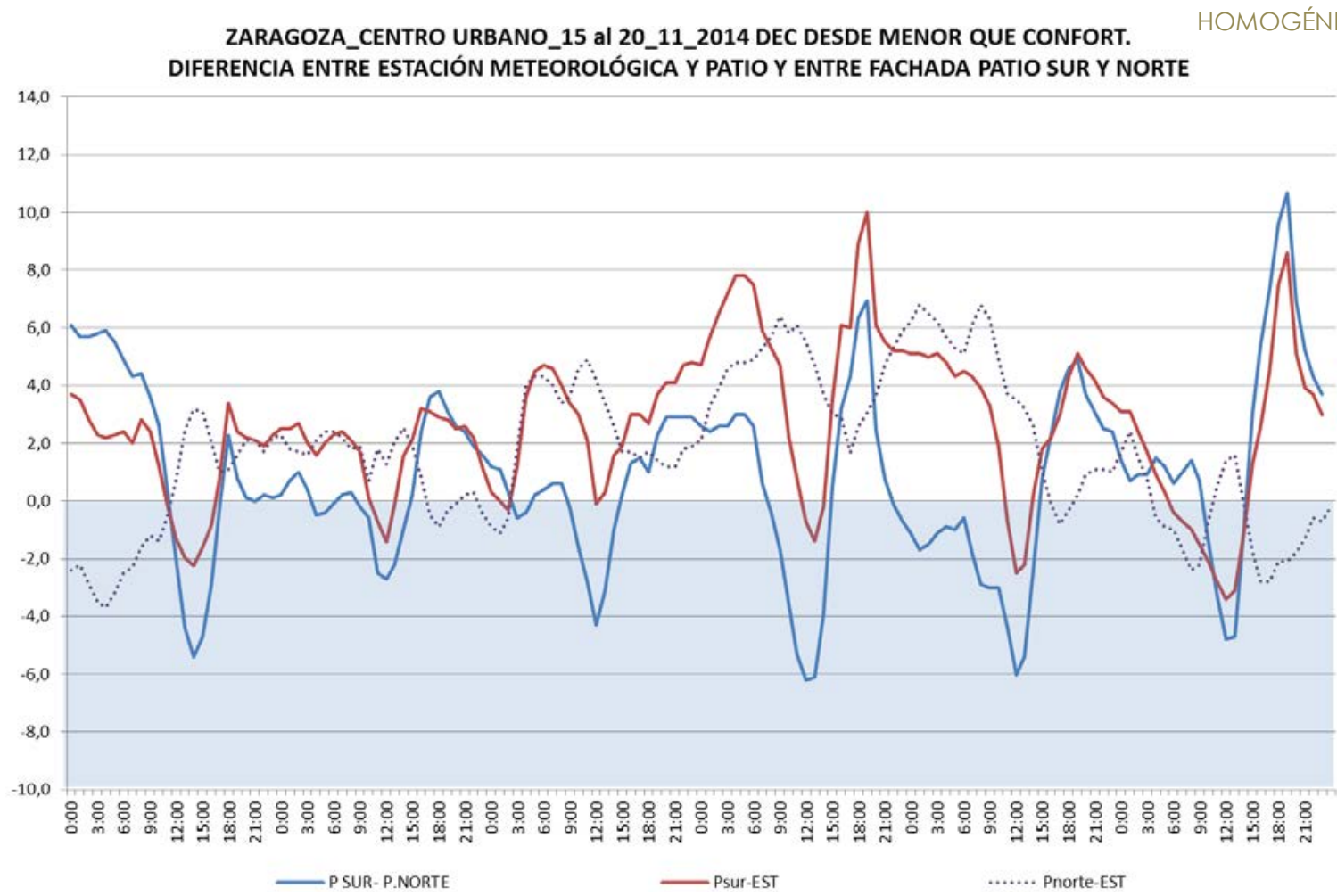

FIG 8-155 GRÁFICA COMPARADA DE LA EVOLUCIÓN TÉRMICA EN UNA ESTACION METEOROLÓGICA LOCAL Y UNA DE REFERENCIA EN ZARAGOZA ENTRE LOS DÍAS 15 AL 20 DE NOVIEMBRE DE 2014. (Elaboración propia)

\section{ZARAGOZA_CENTROURBANO_15 al 20_11_2014 EVOLUCIÓN TEMPERATURA BAJANDO Y SUBIENDO DESDE DEBAJO DE CONFORT}

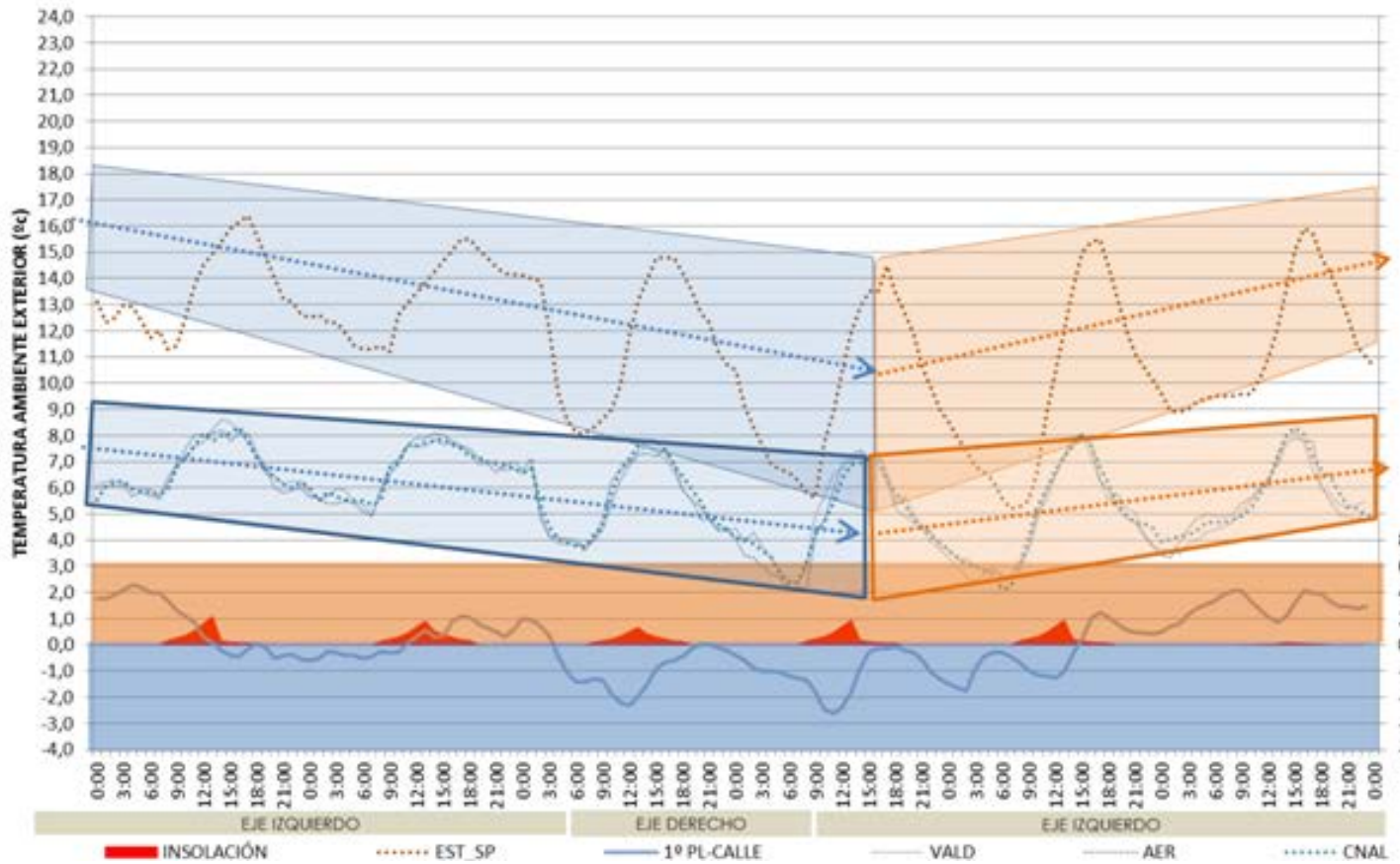

8-156 GRÁFICA COMPARADA DE LA EVOLUCIÓN TÉRMICA EN UNA ESTACION METEOROLÓGICA LOCAL Y UNA DE REFERENCIA EN ZARAGOZA ENTRE LOS DÍAS 15 AL 20 DE NOVIEMBRE DE 2014. (Elaboración propia) 
C2. Estudio de caso: comparación entre las mediciones en el entorno del edificio

Las temperaturas en el entorno del edificio manifiestan, según este análisis, una evolución diferente según sea su orientación, altura y situación con respecto a la edificación, como puede ser, por ejemplo, que se trate de una calle, un patio de manzana o un patio de luces.

Se considerará que estos valores diferentes se corresponden con diversos microclimas de proximidad generados en el entorno del edificio.

C3. Evaluación de la temperatura al bajar o subir en relación a la de confort.

Se observa un distinto patrón en la evolución de los valores de temperatura obtenidos a un cambio general del tiempo atmosférico cuando éste provoca el inicio de una subida y asciende desde una temperatura por debajo de la considerada de confort pero sin llegar a ella.
VER ANEXO 09:

REGISTROS MICROCLIMA DE PROXIMIDAD

VER ANEXO11

TENTATIVA CLASIFICACIÓN EN FRANJAS DE HOMOGÉNEIDAD TÉRMICA

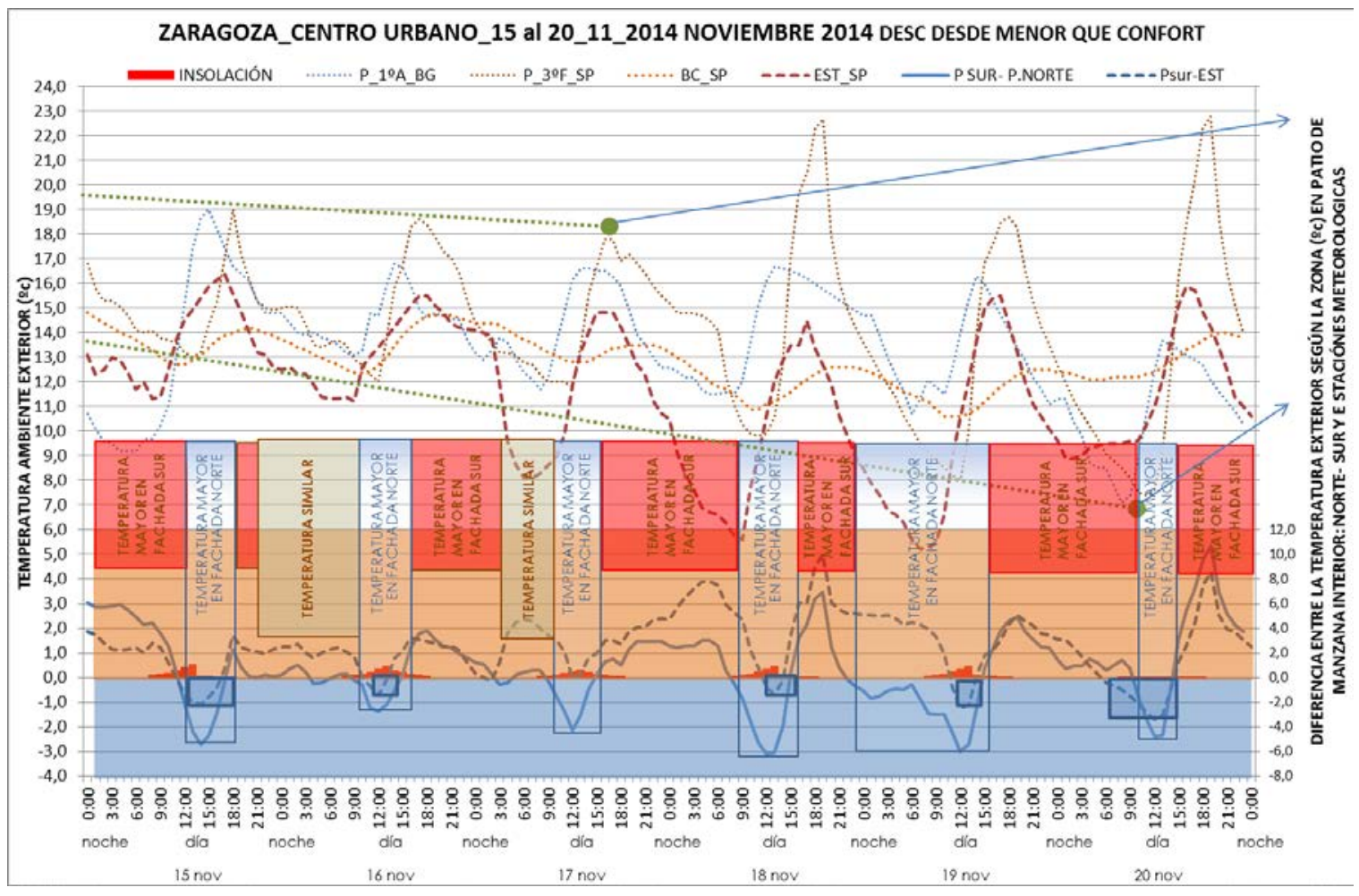

8-157 GRÁFICA COMPARADA DE LA EVOLUCIÓN TÉRMICA EN UNA ESTACION METEOROLÓGICA LOCAL Y UNA DE REFERENCIA EN ZARAGOZA ENTRE LOS DÍAS 15 AL 20 DE NOVIEMBRE DE 2014. (Elaboración propia) 
Los datos recopilados y la agregación de los análisis realizados tienen una influencia muy diversa en la edificación por lo que, previamente a las conclusiones, se considera la repercusión en la aclimatación del espacio edificado de los valores climáticos estudiados.

En primer lugar se ponen en contexto los distintos parámetros utilizados en la definición del clima local, básicamente radiación, viento, humedad y temperatura.

La legislación de obligado cumplimiento en edificación en España y los climas de referencia que la complementan y su ámbito de uso en la prescripción arquitectónica se incluyen en otro epígrafe. 


\subsection{CLIMA REGISTRADO EN ESTACIONES METEOROLÓGICAS}

Los datos registrados en las estaciones meteorológicas próximas a los edificios son una valiosa fuente de información para su diseño y operación.

\subsubsection{SECUENCIAS DE 30 AÑOS (1973-2012)}

Las secuencias de 30 años o más deben ser consideradas demasiado largas a efectos de edificación, habida cuenta de la es una duración próxima a la vida útil media estimada para los edificios residenciales sin que se imponga en este plazo una actualización significativa.

Sin embargo, para los periodos de recurrencia del clima local es un periodo muy corto, por lo que los valores obtenidos deben ser considerados con prudencia, tanto más cuanto los edificios, una vez construidos, exigen grandes inversiones para realizar remodelaciones de gran calado desde el punto de vista de su climatización, como puede observarse actualmente con la actualización exigida para un menor consumo energético o, por ejemplo, como ya sucedió a finales de la década de los setenta con otra previsible crisis energética global.

Para analizar las consideraciones realizadas se han localizado las observaciones en la zona climática D3 y, dentro de ella, en las ciudades de Madrid y Zaragoza.

Las temperaturas medias observadas en Zaragoza reflejan un ligero aumento tanto en los valores medios como en los mínimos y los máximos y aunque las varianzas no indican una correlación que pueda considerarse infalible si indican una tendencia muy clara.

Se ha optado por no hacer proyecciones con la evolución de las temperaturas ya que las razones que la motivan pueden ser muy variadas y no estar causadas directamente por un cambio del clima local y sí , por ejemplo, influida por cambios urbanos, como pueden ser el incremento en el tráfico, una distinta pavimentación, el aumento del volumen edificado o la expansión de las zonas urbanizadas.

Tampoco parece que haya ninguna razón para suponer que las modificaciones en las temperaturas actuales se alterarán a corto plazo de un modo sustantivo, lo hace que la consideración de periodos más cortos para establecer los valores climáticos, aun con la pérdida de amplitud, puede ajustarse bastante bien a los promedios actuales.

La más que evidente modificación climática actual y el eventual calentamiento que previsiblemente pueden tener lugar en las zonas objeto de estudio se considera, en definitiva, un efecto a medio plazo, de menos importancia absoluta que las correcciones provocadas por la implantación de los edificios en su tiempo de amortización efectiva. 
Los edificios deben adaptarse, especialmente en Zaragoza, a largos periodos con ocultación solar, específicamente debido a las frecuentes nieblas.

Aun así, puede tener que prescindir de la acción de la radiación solar directa para la climatización durante el 50\% del tiempo.

Las precipitaciones por su parte no muestran grandes diferencias en sus valores medios anuales y será preciso atender a su distribución a lo largo del año para considerar su colaboración con el confort interior.

La importancia en el balance térmico del edificio de las condiciones climáticas observadas indican que las posibilidad de disipación de energía por convección en Zaragoza son mayores por lo que aumenta la importancia de los sistemas constructivos que regulen la ventilación en el entorno del edificio, como puede ser la vegetación, y en el interior, como pueden ser la disposición, maniobrabilidad y dimensión de las ventanas.

Compatibilizar el uso de espacios abiertos del edificio con velocidades del viento mayores de $1 \mathrm{~m} / \mathrm{s}$ requiere una reflexión, ya que, si bien no está considerado en las condiciones de confort convencionales, resulta una práctica local muy apreciable para periodos cálidos.

Por otra parte, altas velocidades del viento en periodos fríos o templados provocan sensaciones térmicas de disconfort, haciendo muy importante la consideración de protecciones ante el viento tanto de las envolventes como de los espacios semi-exteriores o de transición de los edificios.

Siendo importantes estas consideraciones en cualquier localización, en Zaragoza, por sus particulares condiciones climáticas, se exacerba su utilidad.

\subsubsection{SECUENCIAS DECENALES}

Las gran amplitud de las temperaturas registradas a lo largo de la década observada, probablemente similar a cualquier otra, con valores superiores a $25^{\circ} \mathrm{C}$ en los periodos cálidos y a $20^{\circ} \mathrm{C}$ en los periodos fríos, no tienen un reflejo real en ninguna secuencia térmica registrada, pero pone de manifiesto la necesidad de dotar los edificios de la capacidad de conseguir condiciones interiores confortables.

Los registros en periodos más cortos, sean de un año, de varios días o incluso de un sólo día, en los que pueden observarse saltos térmicos mucho menores serán los que representen mejor las condiciones de entorno térmico a las que realmente se tendrá que enfrentar la edificación.

Es importante dejar constancia de que las diferencias entre los valores promedio de los climas de referencia y los valores anuales realmente registrados manifiestan la inexactitud de los resultados de las estimaciones basadas en los primeros. 
En el caso de los valores promedio aportan un valor próximo al real, pero suavizan la secuencia térmica, ofreciendo una imagen más homogénea de la que realmente se produce.

Dado que el edificio permite ser diseñado para que, por ejemplo, a través de la ventilación, la captación solar o la inercia térmica de sus componentes, pueda responder selectivamente a las temperaturas exteriores no confortables, retrasando su traslado al interior y amortiguando su influencia, al igual que, en sentido contrario, pueda incorporar al interior la temperatura exterior cuando ésta es susceptible de mejorar las condiciones de confort.

Las series térmicas sintéticas, por su parte, ofrecen una imagen del entorno térmico que, entendido en su totalidad, permite la estimación de las demandas globales en un determinado edificio. Si sus valores globales están por encima de los que se producen realmente en los periodos cálidos, como parece quedar patente en las observaciones realizadas, el edificio estará sometido a unas temperaturas mayores que penalizarán aún más y no necesariamente de un modo lineal, el empleo de estrategias de diseño y constructivas que potencien la captación solar, como pueden ser las superficies de vidrio expuestas directamente a la acción del sol.

La estimación a partir de temperaturas más bajas de las reales en periodos fríos afectaría negativamente al rendimiento de los equipos y estrategias que potencien la captación solar o la introducción de calor en el edificio por cualquier otro medio. Especialmente en el caso en que basen su funcionamiento en optimizar su rendimiento en condiciones más extremas, como puede ser el caso de las calderas de condensación. Ésta pérdida de rendimiento tampoco sería lineal.

La adecuación del edificio a las series térmicas reales en cada momento, punto a punto, exige considerar una casuística que sea representativa de las situaciones que pueden van a producirse, independientemente de que completen o no una serie anual.

El análisis a través de rangos muestra las necesidades en función de la capacidad del edificio de amortiguar o retrasar la acción térmica del ambiente exterior.

Se considera deseable que los edificios mantengan condiciones de confort interiores cuando las temperaturas exteriores estén comprendidas entre $26^{\circ} \mathrm{C}$ y $16^{\circ} \mathrm{C}$ y, aunque éstas se mantengan a lo largo del tiempo. Para ello sería necesario que los edificios, por ejemplo, contemplen la posibilidad de disipar el exceso de calor mediante ventilación cruzada, evitando las ganancias de calor solar no deseado y reduciendo las ganancias internas, sin tener que acudir a sistemas específicos dependientes de la energía artificial.

Igualmente si las temperaturas no bajan de $16^{\circ} \mathrm{C}$ las necesidades térmicas para alcanzar temperaturas de confort se pueden satisfacer mediante, por ejemplo, las ganancias internas, las aportaciones solares o evitando las pérdidas térmicas no deseadas 
mediante intercambio de aire $O$ la transmitancia de las envolventes.

El uso de rangos de temperaturas para las que el edificio responde adecuadamente por sí mismo se adapta mejor a la realidad a la hora de determinar las temperaturas de confort como valores de consigna para la evaluación de la comodidad térmica.

De este modo se reducen considerablemente las demandas y, lo que es más importante, los periodos en que es necesario la aportación o disipación de energía mediante sistemas o estrategias artificiales específicas.

El conocimiento previo de estos periodos influye notablemente en el rendimiento de los sistemas e invita a reconsiderar el diseño la edificación, sumando la información de los periodos de uso y las necesidades térmicas en función de la actividad, lo que no afecta a toda la vida útil del edificio sino sólo a una fracción de ésta.

Planteado en estos términos puede afirmarse que los costes que implica la edificación en todo su ciclo de vida, ya se rentabilizan en un tiempo de uso efectivo y estos periodos sin uso repercuten a su vez en los costes del mantenimiento del confort mediante la aportación o la disipación de energía. 


\subsection{ESTACIONES METEOROLÓGICAS URBANAS}

Los rasgos del clima que pueden percibirse mediante la observación de las diferencias entre los registros obtenidos en las estaciones meteorológicas próximas y en otras situadas en la misma región o zona climática serían un indicador de la diferencia que habría entre los valores de la estación meteorológica más próxima al edificio objeto de estudio, los de su entorno y los valores registrados en éste.

Es importante observar que en el estudio de caso considerado los valores registrados están ubicados en un pequeño radio, de no más de $5 \mathrm{~km}$.

Las diferencias observadas entre las secuencias térmicas de las estaciones meteorológicas de referencia y las urbanas, pueden encontrar una explicación en la existencia de un entramado edificado que ofrece mucha superficie al medioambiente,

La naturaleza de los materiales con los que se construyen las ciudades aporta mucha masa térmica al conjunto, pudiendo ser ésta la razón de las diferencias puntuales no lineales observadas.

En general, las variaciones encontradas en las series térmicas obtenidas en estaciones meteorológicas instaladas fuera de los núcleos urbanos y empleadas en la estimación de las condiciones climáticas y en los análisis de flujos térmicos en las edificaciones, ofrecen valores poco significativos en general; observándose las mayores diferencias en los valores mínimos diarios y absolutos. 


\subsection{PARÁMETROS CLIMÁTICOS Y EDIFICACIÓN}

Los distintos parámetros climáticos tienen una influencia muy diferente en la edificación por lo que se abordan por separado los componentes del clima que se han considerado.

\section{A. El viento}

La velocidad del viento influye mucho en la rapidez con que se trasfiere el calor desde el edificio al ambiente, fundamentalmente por convección, al renovarse frecuentemente el aire en contacto con los paramentos. También la capacidad de aportar calor al edificio se acelera con la velocidad de ataque del viento cuando la temperatura del aire es superior a aquéllos por lo que es muy importante considerar este parámetro climático en el intercambio energético del edificio con el ambiente.

En definitiva la velocidad del viento aumenta su efecto sobre los edificios actúa sobre el edificio cuando su dirección incide sobre los paramentos y no se han interpuesto obstáculos a esta acción. En la práctica este efecto es más notorio en las plantas altas de los edificios, en las zonas de periferia urbana, laderas orientadas hacia el viento, o lugares elevados y en los valles, vaguadas o calles orientadas en la dirección de los vientos dominantes y, por contra, se aminora en las plantas bajas, las calles urbanas ortogonales a la dirección del viento y cuando existen protecciones al viento ya sea por la orientación, por la clinometría o por la presencia de masas vegetales.

Por otra parte la forma de los edificios favorece o dificulta la acción del viento sobre ellos, observándose la disminución de la velocidad cuando se aumenta el rozamiento 0 se disponen elementos construidos que desvíen su acción.

Se considera por tanto que la acción del viento ( $F v)$, tiene un fuerte componente de diseño, ordenación urbana, orientación y exposición, de forma que la incidencia sobre los edificios de su velocidad y dirección será parte de los valores climáticos analizables y estará afectada por un coeficiente (Cv), específico que, aún siendo casi siempre inferior a la unidad, puede superarla al potenciarse con el diseño y la orientación.

En conclusión, el viento, con sus componentes de velocidad y dirección, es un parámetro con una gran variabilidad local, por lo que, al no contemplarlo, los datos aportados por cualquier clima de referencia no representarán con exactitud todas las características climáticas existentes en la ubicación de los edificios.

Cuando la velocidad del viento supera un régimen muy estrecho de valores, más de $1 \mathrm{~m} / \mathrm{s}$, se considera fuera de los rangos de confort para cualquier actividad y sólo algunas permiten valores mayores. Es imprescindible la modulación del viento para lograr las condiciones de confort, en un ejercicio muy difícil pero necesario para la arquitectura bioclimática al tener que compaginar la capacidad de controlar la entrada de aire y su velocidad, pero no 
podemos obviar su colaboración con el logro dl bienestarinterior de los edificios.

La velocidad del viento cuando su dirección incide sobre las envolventes es un factor determinante para poner a prueba la estanqueidad de la construcción, por lo que se convierte en un indicador de la calidad de la construcción, tanto más relevante cuanto peor sea ésta aunque resulta indiferente cuando la construcción y su ejecución son las apropiadas.

Las zonas muy expuestas al viento provocan un mayor intercambio de calor en las envolventes acelerando las transferencias y los tiempos necesarios para igualar las temperaturas interiores a las exteriores. Dado que las temperaturas exteriores son, la mayor parte del año, inferiores a las que pueden considerarse confortables, se considera que este intercambio dificulta la consecución de condiciones de confort interiores en los periodos fríos.

El viento se considera, en definitiva, un parámetro significativo para realizar correcciones a las condiciones de confort interior cuya influencia está necesariamente condicionada por la arquitectura y su construcción y muy especialmente por su capacidad de regulación.

Una mejor información sobre las condiciones de viento locales y la capacidad de regulación son determinantes para valorar su influencia sobre el confort interior.

B. La radiación solar

La radiación solar sobre una superficie horizontal es determinante en edificación, tanto para la obtención de energía gratuita en los edificios cuando éstos la demandan, como para incrementar el disconfort por excesivo calor.

Su valor es relativamente predecible en cada localidad en función de la latitud y el periodo del día y del año, existiendo mucha información y herramientas informáticas que permiten determinarlo con precisión.

La meteorología reduce estos valores que estando afectados por la situación geográfica, por la presencia de nieblas, por la nubosidad y por otros factores medioambientales. La localización y las ocultaciones influyen en el tiempo de recepción de la radiación, en función de la pendiente y la orientación del terreno, de la línea de horizonte y de, por ejemplo, las obstrucciones vegetales o edificadas.

Al igual que sucede con el viento, la influencia en el flujo térmico, en este caso, la capacidad de obtención de ganancias solares como aportaciones de energía a los edificios, depende tanto de las condiciones climáticas como de la exposición al sol del edificio.

La capacidad real de captación de energía en núcleos urbanos está muy limitada en las orientaciones norte, en las plantas bajas, en las calles estrechas o en las calles orientadas norte-sur, mientras 
que es alta en las cubiertas, en las orientaciones sur, y en las plantas altas, en definitiva en las zonas sin obstrucciones.

La altitud solar en el horizonte en las latitudes de la península ibérica, hace que durante el verano la radiación solar sea más vertical e inicie su recorrido desde el NE al NW, siendo su amplitud mayor de $90^{\circ}$, mientras que en invierno la altitud es menor y la amplitud menor de $180^{\circ} \mathrm{C}$ en el horizonte. La geometría y la orientación de los edificios puede eludir el soleamiento en verano y potenciar el de invierno, si las obstrucciones lo permiten, especialmente en la orientación sur y en las distribuciones arquitectónicas de los huecos y espacios interiores haciendo posible el soleamiento de las estancias orientadas al norte.

En definitiva, un diseño que tenga en cuenta la posición del sol y las posibilidades de captar o evitar la radiación en función de las demandas de energía interiores del edificio puede modificar sustancialmente la influencia de la radiación incidente.

Del mismo modo, los materiales que son irradiados manifiestan una respuesta muy diferente si son traslúcidos, transparentes u opacos, en función de su conductividad y su capacidad térmica y de su disposición transversal, como en la configuración de la epidermis de la envolvente. Es especialmente notable el incremento del calor provocado por la radiación interior cuando los materiales reflejan o retienen la radiación térmica y cuando las envolventes evitan la salida de la radiación.

En conclusión, la radiación incidente sobre planos horizontales tiene una significada importancia en el incremento de la temperatura tanto en las envolventes como en el interior acudiendo a la opacidad de las superficies irradiadas oa elementos traslúcidos, siendo lógicamente mayor su incidencia cuando las temperaturas son mayores.

Su aplicación a la edificación es bimodal puesto que, en periodos fríos permite incrementar la temperatura interior colaborando a un mayor confort mientras que en periodos cálidos la aleja de las condiciones de bienestar.

La exposición de los edificios a la radiación solar incidente está muy condicionada por su geometría, la disposición de los huecos y por las obstrucciones. Las condiciones urbanas para la captación solar son en general buenas en la cubierta y en las plantas superiores de las fachadas orientadas al sur. Esta posibilidad de insolación está muy condicionada por la altura relativa de los edificios circundantes, por su orientación y por la anchura del viario y los espacios libres adyacentes. (LUXÁN, 2009).

El control de la exposición a la radiación solar es fundamental para mejorar la colaboración con el confort por lo que la regulación de la arquitectura y la disposición de los componentes es determinante.

El carácter predecible de la posición solar permite la simulación y el diseño que sólo se vería afectado por la circunstancial ocultación solar. Existe una estimación muy precisa de la máxima 
captación y es previsible también la afección de las ocultaciones por los valores estadísticos registrados.

Se considera, por tanto, que la acción de la radiación solar $\left(F_{R}\right)$ sobre los edificios, tiene un fuerte componente de diseño arquitectónico y constructivo, ordenación urbana, orientación y exposición, de forma que la incidencia de su intensidad y dirección será sólo una parte de la que se podría aplicar a las ganancias térmicas y estará afectada por un coeficiente $\left(C_{R}\right)$, específico que, aún siendo casi siempre inferior a la unidad, puede potenciarse con el diseño y la orientación para superar este valor, normalmente por mecanismos de reflexión o de cambio de longitud de onda.

En definitiva tanto el viento como la radiación en su efecto sobre las edificaciones dependen de la exposición y del control ejercidos sobre ellos por la arquitectura y por los sistemas pasivos y activos incorporados $y$, con ellos, de su capacidad de reacción frente a las condiciones de su entorno.

Se considera que ambos parámetros climáticos son acciones intermitentes que dependen de la exposición por lo que su efecto debe ser considerado complementario a los de la temperatura y la humedad que actúan permanentemente sobre el edificio.

\section{La humedad relativa}

La humedad relativa se mantiene en valores muy próximos a los confortables durante casi todo el año, por lo que no se puede considerar como un factor crítico en el clima templado de la península ibérica, especialmente por la amortiguación que en el interior del edificio se produce de las diferencias existentes entre la noche y el día.

En cualquier caso, la adopción de medidas de conservación de la humedad en periodos cálidos regulando o evitando la ventilación con aire caliente y seco y la reducción de la humedad interior mediante el aumento de la temperatura y el control de las infiltraciones son prácticas comunes en la gestión de los espacios interiores y sus envolventes.

Cuando el control de la humedad es importante para alcanzar unas condiciones confortables es precisa la aportación o detracción del agua del aire. Esta modificación de la humedad relativa puede realizarse mediante el diseño de los espacios exteriores para que aporten soleamiento (solanas) o sombreado (umbrías), o en el diseño de las envolventes disponiendo espacios sombreados previos a la entrada del aire seco y caliente al edificio y espacios soleados y protegidos previos a la entrada del aire frio y húmedo mediante la inclusión de materiales o elementos que aporten humedad o que la detraigan del ambiente o mediante la disposición de equipos más o menos complejos.

Por otra parte, en nuestra zona de estudio, la humedad relativa ambiental se mantiene casi todo el tiempo en valores aceptables, mientras que la humedad interior está más relacionada con las modificaciones bruscas de temperatura. En los periodos fríos la temperatura interior es muy superior a la exterior lo que supone una

REPERCUSIÓN DEL VIENTO Y LA RADIACIÓN SOLAR 
menor humedad relativa provocando ambientes más secos, como se ha podido comprobar. Los incrementos de humedad interior no se deben a la humedad relativa exterior, sino a la evapotranspiración de los residentes y a la producción de vapor interior en cocinas o baños.

En los periodos cálidos, la bajada de la temperatura incrementa la humedad ambiente y puede producir condensaciones y malos olores, aunque no se ha podido corroborar en las localidades estudiadas.

La temperatura y la humedad están muy relacionadas entre sí, produciéndose las humedades relativas menores con las mayores temperaturas y viceversa.

Se considera por tanto que la acción de la humedad solar $\left(F_{H}\right)$, tiene un fuerte componente de diseño arquitectónico y constructivo, ordenación urbana, gestión del intercambio de aire con el exterior, orientación y exposición, de forma que la incidencia sobre el edificio de la humedad relativa del aire exterior sólo afectará al interior según un coeficiente $\left(\mathrm{C}_{H}\right)$ específico que, aún siendo casi siempre inferior a la unidad, puede potenciarse con el diseño y la orientación hasta llegar a superarlo.

D. La temperatura

El flujo de calor se establecerá en función de la diferencia de temperatura $\left(\mathrm{T}_{e}-\mathrm{T}_{\mathrm{i}}\right.$ ) y de la concurrencia de parámetros que definan la conductividad y la capacidad térmica de las envolventes y los elementos interiores según un coeficiente $C_{\text {T. }}$ La temperatura ambiental de bulbo seco que es utilizada en la determinación del bienestar térmico permite la integración de otros factores como la humedad, la radiación y la velocidad y temperatura del aire 0 los paramentos circundantes en temperaturas medidas en distintas condiciones como la temperatura de bulbo húmedo o la temperatura de globo y o temperaturas sintéticas formadas a partir de varios parámetros como la sensación térmica o la temperatura operativa, expresadas en grados centígrados y describiendo todas ellas aspectos del confort térmico.

E. Acción conjunta de los factores climáticos

La aplicación de los distintos factores que formalizan los climas sintéticos prestacionales, aún teniendo un efecto combinado, pueden segregarse en acciones independientes que constituyen en su conjunto la influencia del clima sobre el edificio ( $\left.F_{C}\right)$ de los distintos componentes descritos:

$$
F C=f(V, R, H, T)=f(f(C V, F V), f(C R, F R), f(C H, F H), f(C T, T e-T i))
$$

Estas consideraciones permiten hacer determinaciones independientes para cada uno de los factores, siendo la 
temperatura el más significativo y el que mejor nos puede dar una imagen de las diferencias entre los diversos climas sintéticos prestacionales y las variaciones en grados-hora.

El interés de analizar los años climáticos en valores de grados-hora y enperiodos de superación de los umbrales en grados-hora son un indicador de la demanda de energía que se precisa para alcanzar condiciones confortables en el interior del edificio. Los periodos en que se demandará energía para alcanzar estas condiciones confortables es un indicador de consumo, entre otras razones al reducirse con el tiempo las pérdidas de arranque y parada de los sistemas y las pérdidas por transporte 0 infiltraciones 0 por precalentamiento de los sistemas y construcciones.

La influencia del edificio en las temperaturas de confort alcanzadas en él, en los umbrales en los que la temperatura ambiente exterior provoca una temperatura interior fuera de los rangos de bienestar es muy alta en cifras de consumo y demanda.

Se observa cómo las temperaturas máximas medias diarias son siempre menores en las estaciones situadas más alejadas del núcleo urbano, si bien en valores pocas veces mayores de $1^{\circ} \mathrm{C}$.

El estudio de la evolución local de las temperaturas más altas merece un estudio singular ya que muestran mayores variaciones. 


\subsection{ESCALA TEMPORAL}

La escala temporal de las series térmicas para la comprobación de la respuesta del edificio al clima es convencionalmente de un año, lo que permite que se vean representadas todas las estaciones y muchas secuencias térmicas.

Estas series ofrecen una imagen de la demanda estimada con valores más o menos medios para un ciclo anual. Dependiendo del criterio que se siga para su elaboración se conseguirá que esta demanda puede ser más o menos ajustada a los valores climáticos máximos o medios de una determinada zona.

La comprobación de situaciones singulares, poco representativas estadísticamente, no queda dentro de los objetivos de las secuencias climáticas que se han consultado por lo que se considera que hay un vacio de información sobre estos periodos que permita la estimación del desempeño energético y la operación en los edificios cuando se producen estos estados climáticos.

Por otra parte, el tipo de edificio también influye en esta consideración al haberse observado que la velocidad de su respuesta difiere en función de sus características, siendo necesario, por ejemplo, que una bajada súbita de temperatura se produzca por más tiempo para afectar a un edificio de alta capacidad térmica.

La definición de estas secuencias habrá de considerar la franja térmica en la que se encuentran los valores máximos y mínimos, así como la tendencia y la duración de la secuencia.

\subsubsection{FRANJAS DE HOMOGENEIDAD TÉRMICA ANUALES}

Se han denominado franjas de homogeneidad térmica anuales a los periodos en los que se cumplen unas determinadas condiciones de temperaturas máximas, mínimas y de oscilación térmica o que se enmarcan entre unos determinados percentiles.

Las comprobaciones se han realizado para las condiciones en las estaciones meteorológicas de referencia durante un periodo de 10 años y analizando su correspondencia con los climas de referencia y las secuencias térmicas medidas en las estaciones situadas junto a los edificios y en los equipos situados en el entorno próximo del edificio.

Las duraciones de los periodos son diferentes en estas ubicaciones aunque se pueden observar patrones comunes.

Se ha considerado que, para su uso en edificación, no es adecuado hablar sólo de periodos cálidos (verano) y fríos (invierno) sino que también deben considerarse los periodos de

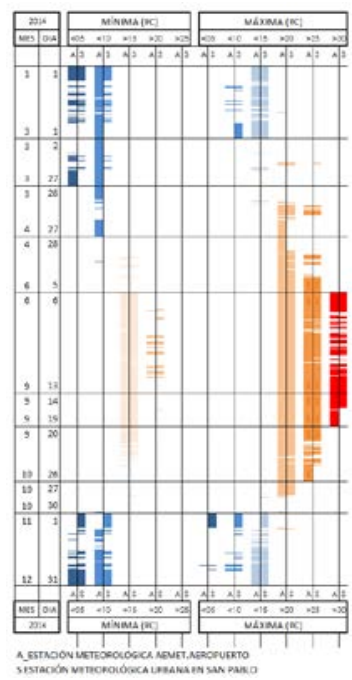
transición y subdividir los fríos y cálidos en función de su intensidad. 
Así, se propone una división en función de las temperaturas medias, siempre relativas al clima en cada lugar. En este caso las cifras se corresponden a Zaragoza, en los siguientes periodos:

1. Muy fríos

2. Fríos

3. Templados fríos

4. Templados

5. Cálidos

6. Muy Cálidos
Valores medios menores de $5^{\circ} \mathrm{C}$, ocasionalmente

Valores medios entre $5^{\circ} \mathrm{C}$ y $9^{\circ} \mathrm{C}$, predominantemente.

Valores medios entre $10^{\circ} \mathrm{C}$ y $15^{\circ} \mathrm{C}$, predominantemente.

Valores medios entre $16^{\circ} \mathrm{C}$ y $20^{\circ} \mathrm{C}$, predominantemente.

Valores medios mayores de $20^{\circ} \mathrm{C}$, predominantemente.

Valores medios mayores de $24^{\circ} \mathrm{C}$, ocasionalmente

En los periodos de transición se pueden distinguir dos subgrupos, cuando las temperaturas son ascendentes en su ciclo anual y cuando son descendentes.

Se considera que predomina una temperatura media cuando está presente en más del $80 \%$ de los días consecutivos de la serie considerada.

\subsubsection{SECUENCIAS DE COMPROBACIÓN}

A falta de un patrón global directo que permita asignar a una estación un valor deducido del obtenido por las otras dos, y antes de incorporar otros parámetros que influyen en la temperatura, se hace preciso estudiar periodos más cortos para establecer patrones más reales.

Se propone para cada uno de estos periodos emplear tres series de comprobación que recoja las mínimas absolutas, los valores más probables y las series de evolución hacia el periodo siguiente, para el periodo 1 las máximas absolutas, los valores más probables y las series de evolución desde el periodo anterior, y para el resto de los periodos los valores de evolución hacia el periodo anterior y siguiente y los valores más probables.

Como muestra de esta forma de observar la evolución térmica se aporta el gráfico correspondiente al periodo que va del 10-06-2013 al 20-10-2013 en Zaragoza, con valores periódicos discontinuos tomados en los días 10, 20 y 30. 


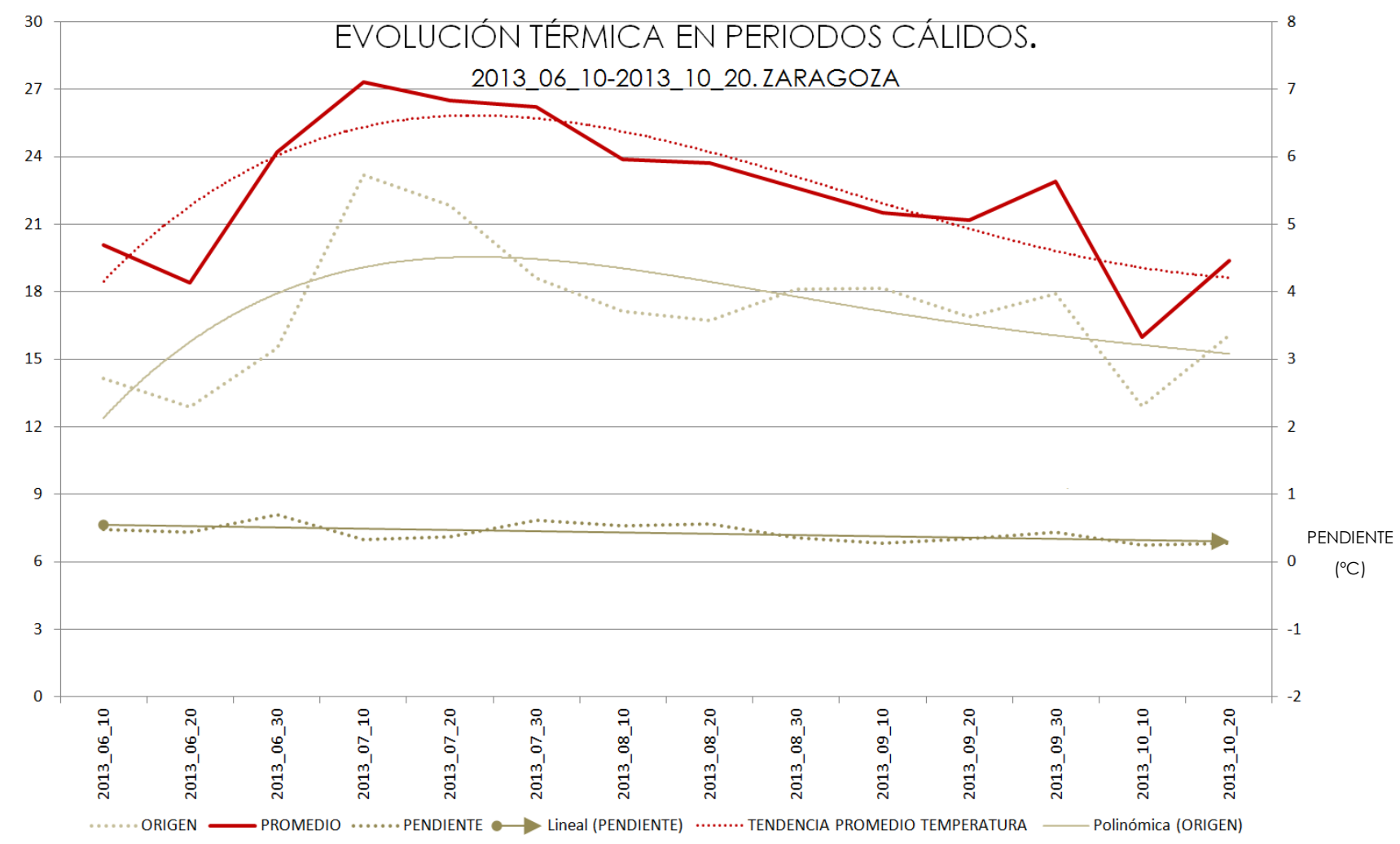

9-1 GRÁFICA DE VALORES DISCONTÍNUOS DE MEDIAS DIARIAS EN ZARAGOZA EN EL PERIODO CÁLIDO ENTRE 10-06-2013 Y 20-10-2013 (AEMET y elaboración propia)

Puede observarse temperaturas superiores a $18^{\circ} \mathrm{C}$ de media diaria, con un máximo de media diaria poco mayor de $27^{\circ} \mathrm{C}$ en el mes de julio y con un descenso progresivo que ralentiza su pendiente a mediados de noviembre.

Se han analizado con más detalle los datos registrados entre el $10 / 6 / 2013$ y el 10/6/2014 en Zaragoza y la media de las diferencias máximas está entre $-3,5^{\circ} \mathrm{C}$ y $3,7^{\circ} \mathrm{C}$, con valores medios muy poco significativos.

Los valores medios arrojan unas diferencias menores de $0,5^{\circ} \mathrm{C}$, muy similar a la diferencias observadas en las temperaturas máximas. Las temperaturas mínimas registradas manifiestan diferencias más significativas, próximas a los $2^{\circ} \mathrm{C}$.

El análisis de las diferencias entre los valores del $2^{\circ}$ y $3 e r$ c cuartil en distintas estaciones está en el entorno de los $0,5^{\circ} \mathrm{C}$.

Las series estudiadas no justifican multiplicar los puntos de observación para aproximarlos a las zonas de estudio.

El análisis de la evolución diaria de las temperaturas en transición desde los periodos cálidos a los más fríos permite observar que a éstos periodos fríos se llega tras una bajada continua con duraciones cortas en los que las temperaturas son mayores o menores a la tendencia. Esta conclusión permite mantener el argumento de la importancia de las estrategias que potencien la amortiguación de las condiciones exteriores cuando son menores que la tendencia y el incremento simultáneo de la captación de energías gratuitas. Estas soluciones deben ser compatibles con el aprovechamiento de los periodos con descensos de temperatura 
menores buscando una transferencia de las temperaturas exteriores al interior del edificio con la menor amortiguación posible.

Del mismo modo se produce la transición desde los periodos más fríos a los más cálidos, lo que sugiere facilitar la aplicación de estrategias pasivas que incrementen la amortiguación cuando las temperaturas exteriores superan a las de confort y favoreciendo la aplicación rápida de los incrementos térmicos al edificio en caso contrario. 


\subsubsection{DURACIÓN DE LAS SECUENCIAS DE COMPROBACIÓN}

Se ha optado por secuencias tan largas como sean eficaces en los edificios de alta capacidad térmica en los que se ha comprobado la respuesta interior, en definitiva series que comprendan más de 3 días, y menos de 7 días.
VER ANEXO:

TENTATIVA CLASIFICACIÓN EN FRANJAS DE HOMOGÉNEIDAD TÉRMICA

2014

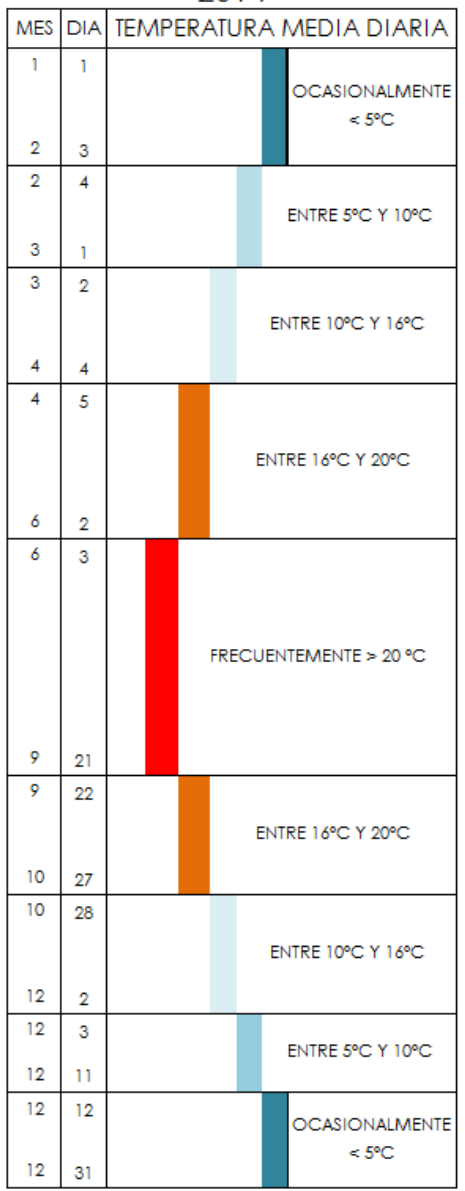

9-2 ESQUEMA DE FRANJAS DE HOMOGENEIDA TÉRMICA A LAS QUE CORRESPONDEN RESPUESTAS SIGNIFICATIVAS DEL EDIFICIO DURANTE EL AÑO 2014 EN ZARAGOZA (AEMET y elaboración propia)

\section{PERIODOS HOMOGÉNEOS}

La observación de las temperaturas induce a la segregación en periodos que faciliten la comparación del clima en distintas localidades y que permitan analizar la relación entre los edificios y el clima donde se inscriben. Con estos objetivos son frecuentes las agrupaciones de las temperaturas en periodos anuales, estacionales, trimestrales o mensuales.

El clima mediterráneo continental en el que se ubican las zonas climáticas descritas en el Código Técnico de la Edificación (CTE) como D3, si se atiende a una distribución que considere principalmente la respuesta de la edificación, tpresenta una duración que, por lo general, reduce los periodos de transición, mantiene los periodos cálidos e incrementa los fríos, con respecto a las distribuciones estacionales. 
La distribución anual tiene la ventaja de recoger un ciclo completo, por lo que sus resúmenes estadísticos, aportan valores significativos para estudios de consumo acumulado y estimado o de rendimientos anuales de equipos y sistemas. Los periodos trimestrales o mensuales permiten comparaciones coyunturales poco significativas.

El gráfico adjunto recoge esta circunstancia $y$, si se consideran como muy cálidos los días con medias diarias superiores a $20^{\circ} \mathrm{C}$, nos indica que se produjeron durante el año 2014 desde el día 3 de junio, frente al hipotético inicio del verano el 21 de junio, y que concluyeron el 21 de septiembre, con el comienzo del otoño.

Si se considera que una temperatura ambiente media diaria por debajo de $16^{\circ} \mathrm{C}$ exige frecuentemente en edificación la necesidad de aportar energía calorífica para alcanzar el confort, el periodo frío se habría extendido hasta el 4 de abril y se habría reiniciado el 28 de noviembre.

Los periodos de transición de 27 días hacia el periodo cálido y de 15 días hacia el periodo frío, mucho menores que la duración de las estaciones, tradicionalmente asociadas a esta transición, cómo son la primavera y el otoño, durante el año 2014, que puede considerarse un año cálido dentro de la serie histórica considerada, lo que permite deducir que el conocimiento local de a duración estimada de estos periodos y de su variabilidad es de gran interés para estimar los recursos con los que hay que dotar al edificio para conseguir condiciones confortables interiores en una localización determinada.
VER ANEXO:

TENTATIVA CLASIFICACIÓN EN FRANJAS DE HOMOGÉNEIDAD TÉRMICA 


\subsection{CONFORT ADAPTATIVO}

La aplicación del concepto de confort adaptativo a los valores registrados en las estaciones de referencia para una localidad permite la obtención de valores aplicados a cada localidad.

En el caso de Zaragoza, puede constatarse cómo los valores obtenidos a partir de los registros obtenidos de dos de las estaciones meteorológicas de referencia son muy similares, lo que viene a confirmar que la estación meteorológica de referencia considerada no será demasiado importante, siempre que se encuentre en las proximidades del edificio a evaluar.

Las temperaturas en periodos fríos se mantienen parecidas entre sí y casi nunca se diferencian más de $0,5^{\circ} \mathrm{C}$ en valores que oscilen entre los $22^{\circ} \mathrm{C}$ y los $17^{\circ} \mathrm{C}$.

En los periodos cálidos los valores se mantienen en una franja más estrecha, entre $27,5^{\circ} \mathrm{C}$ y poco más de $26^{\circ} \mathrm{C}$.

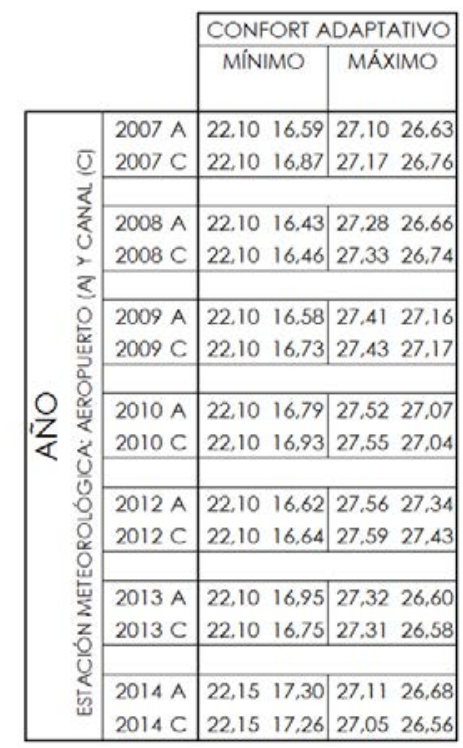

9-3 CUADRO COMPARATIVO DE LAS TEMPERATURAS DE CONFORT ADAPTATIVO A PARTIR DE LAS TEMPERATURAS REGISTRADAS EN LAS ESTACIONES METEOROLÓGICAS DE CANAL Y AEROPUERTO DE ZARAGOZA DESDE EL AÑO 2007 AL 2014 (Elaboración propia) 


\subsection{CLIMA EN LA LEGISLACIÓN PARA EDIFICACIÓN}

La legislación emplea la climatología como criterio de prescripción y de evaluación del desempeño energético del edificio y, dentro de este contexto, su capacidad para influir en las soluciones arquitectónicas es muy alta.

Los climas de referencia que acompañan a la normativa como documentos de apoyo tienen varias versiones que pueden ser aplicadas a una determinada localidad.

La elección de los criterios para comparar los climas se ha realizado teniendo en cuenta su relevancia para la aclimatación del edificio, buscando simplificar su análisis.

La comparación de todos los factores que definen un clima sintético prestacional, resulta muy compleja. Para su simplificación hasta niveles fácilmente operativos se han realizado las consideraciones independientes en cada uno de los parámetros que los definen, para concluir que será la temperatura el criterio elegido para caracterizar los diferentes climas, siendo las variaciones en grados-hora un indicador fiable para dar una imagen de las diferentes secuencias climáticas consideradas.

Por otra parte la legislación también limita la demanda estimada, en las condiciones previstas por ella en función de la tipología. De la observación de la regulación se deduce que el fraccionamiento de las promociones y las viviendas adosadas o aisladas permite un mayor límite a la demanda energética, por lo que la proliferación de viviendas adosadas o aisladas empeora el balance global de ahorro energético emprendido por la normativa en cumplimiento de las directivas. La importancia otorgada al ahorro en la vivienda en bloque contrasta con la laxitud en la vivienda individual cuyo consumo es mucho mayor por cada unidad cualquiera que sea el clima en que se ubique.

Un planteamiento responsable de la praxis arquitectónica debe atender con más rigor a la reducción de la demanda real, mejorando el conocimiento del clima y haciéndolo en todos los contextos, lo que será beneficioso para el usuario, en su día a día y en las muy probables condiciones futuras, para la comunidad, al reducir su consumo energético local, y para los ecosistemas a nivel global al reducir la presión sobre éstos.

Se puede concluir que el uso generalizado de los climas de referencia para la estimación de la respuesta de los edificios frente al clima y para la prescripción de su diseño y sus componentes, aun siendo muy operativa y simplificando mucho los procesos, no se ajusta a las condiciones climáticas reales que pueden percibirse en un determinado lugar durante toda la vida útil del edificio.

Puede observarse también cómo la limitación impuesta para calefacción se relaja para la refrigeración pues, si bien las cuantías son menores, también lo son los meses afectados por esta necesidad de disipación de energía excedente, siendo significativo que en las zonas más frías, incluso en verano se
CLIMAS DE REFERENCIA

LIMITACIÓN DE LA DEMANDA ESTIMADA. 
acepten consumos de refrigeración similares al resto, cuando la experiencia local ha permitido identificar estrategias constructivas y de diseño que evitarían su uso, actualmente masivo y descontrolado. d

Por otra parte la legislación estima unos perfiles de uso determinados que sería conveniente ajustar a la realidad, permitiendo así acompasar ajustar las temperaturas de consigna a las que ciertamente se necesitan, con una notable reducción de demanda.

Como es sabido, la renuncia a temperaturas interiores óptimas durante un número limitado de horas en el interior de los edificios, que además pueden ser horas de no ocupación, permite reducir de forma considerable el consumo de energía de las instalaciones y por tanto el coste asociado a las mismas. Cap. 5. Guía técnica de condiciones climáticas exteriores de proyecto 2010 ATECYR. IDAE 


\subsection{INFLUENCIA DEL EDIFICIO}

La influencia de las secuencias térmicas en el diseño y la operación de la edificación dependerá, de las condiciones del entorno y de las cualidades de ésta.

Siguiendo las directrices empleadas habitualmente por la legislación se ha considerado que la amortiguación de temperatura en el edificio está en función de su capacidad térmica y de la estanqueidad y la conductividad de sus envolventes. Además se considera que la temperatura interior es muy sensible a la exposición de las envolventes al viento y a la captación solar directa, tanto en las zonas opacas como, especialmente, en sus aberturas.

El esquema conceptual empleado se puede expresar como:

1. La temperatura exterior influye en la temperatura interior amortiguándose en función de la capacidad aislante de la envolvente $\left(C_{A}\right)$.

2. La temperatura exterior influye en la temperatura interior amortiguándose en función de la capacidad térmica de los componentes interiores del edificio $\left(\mathrm{C}_{1}\right)$.

3. La temperatura exterior influye en la temperatura interior en menor medida cuando la estanqueidad es mayor ( $\left.C_{E}\right)$

3. La exposición de las envolventes permite una mayor disipación de energía $\left(\mathrm{C}_{\mathrm{v}}\right)$

4. La captación solar incrementa la temperatura con respecto a la del ambiente, especialmente en los periodos soleados (Cs)

Lo que podría expresarse en la siguiente relación:

Flujo energético $=C\left(f\left(C_{A}, C_{1}, C_{E}, C_{V}, C_{S}\right)\right) *\left(T_{E}-T_{1}\right)$.

Siendo
$T_{E}$
Temperatura exterior
$\mathrm{T}_{1}$
Temperatura interior
C
Coeficiente asociado al tipo de edificio y su exposición. $f\left(\mathrm{C}_{\mathrm{A}}, \mathrm{C}_{1}, \mathrm{CE}, \mathrm{CV}_{V}, \mathrm{C}_{s}\right)$.

Se han descrito varios tipos de edificios y exposiciones que permitan establecer la importancia para cada uno de ellos de la diferencia entre la temperatura interior y exterior, puesto que todos los coeficientes son susceptibles de variar a lo largo del ciclo de uso convencional del edificio. 
En todos ellos influye la composición física de los edificios, ya sea por la configuración de los espacios y sus envolventes, muy evidente en el caso de la estanqueidad o la capacidad aislante de sus huecos, o por la disposición de ocultaciones o parapetos artificiales o naturales, así como lógicamente por las condiciones climáticas

En definitiva todos los coeficientes están muy condicionados por el diseño y por la operación durante el uso de los edificios, pudiéndose anular o potenciar su influencia en la climatización interior, lo que permite que pueda segregarse el estudio de sus aportaciones a los edificios y, cuantificándolas individualmente, establecer su influencia aplicándoles consideraciones climáticas y de diseño simultáneamente.

Las diferentes combinaciones de estas cualidades en un edificio tienen una influencia muy significativa en la escala temporal de los análisis que será preciso realizar para comprobar la influencia de las condiciones climáticas en la climatización interior.

Los ciclos día-noche son apropiados para establecer la evolución de las temperaturas interiores cuando las estanqueidades, la capacidad térmica y el aislamiento son bajos, mientras que bajos niveles de exposición, capacidad térmica, aislamiento y estanqueidad alta exigirán análisis transitorios de plazos mucho más largos para conocer las condiciones higrotérmicas interiores instantáneas. 


\section{CONCLUSIONES}

Las conclusiones, aunque se sinteticen en este apartado, se desarrollan a lo largo del documento y se han incluido en las consideraciones realizadas en el análisis de los datos obtenidos y, muy especialmente, en la discusión desarrollada en el capítulo anterior.

Las observaciones realizadas, sin embargo, permiten afirmar que existen diferencias significativas entre las series de temperaturas susceptibles de ser consideradas en la simulación energética de los espacios que formalizan los edificios, por lo que sería necesario considerar cuál o cuáles serían las más apropiadas para cada objetivo que pudiese plantearse.

Por ejemplo, en una primera aproximación se propone la elaboración de series térmicas con máximas y mínimas absolutas para estimar cuál será la capacidad de respuesta frente a las condiciones extremas a las que habrán de enfrentarse los edificios en su vida útil, así como el uso de los climas de referencia para obtener un orden de magnitud de los consumos energéticos globales que se pueden esperar durante su uso.

Sería de gran utilidad indicar para cada serie de referencia utilizada alguna medida de dispersión, si lo que se pretende es obtener un rango de consumos o de temperaturas de respuesta del edificio considerado.

Se enuncian conclusiones independientes en relación a los periodos utilizados en estas series, las localizaciones empleadas como fuentes para los valores recogidos en ellas y la respuesta frente a las temperaturas exteriores de los espacios definidos por el edificio en cuestión, en función de su posición relativa a éste.

Las síntesis de las conclusiones se hace en apartados en un orden similar al seguido en los capítulos precedentes.

Posteriormente se ordenan a su vez en consideraciones relativas a aspectos temporales, espaciales y de reacción del edificio.

Se desglosan en:

TEMPORALES

ESPACIALES

DE REACCIÓN 


\subsection{CONSIDERACIÓN TEMPORAL}

Las series térmicas con una duración de varias décadas recomendadas para los estudios climáticos no son las más apropiadas para los estudios en edificación, por lo que se recomiendan periodos de estudio decenales lo más recientes posibles, dada la fuerte evolución al alza observada en los registros estudiados.

Las series estudiadas y la velocidad de transferencia térmica observada para unas condiciones térmicas exteriores conocidas y las temperaturas interiores que responden a ellas, sin aportación ni disipación de energía mediante equipos o sistemas térmicos, sugieren que los intervalos horarios son apropiados para el análisis de las condiciones interiores, siendo la repercusión de los valores térmicos exteriores a la temperatura ambiental interior muy diferente en su desfase y amortiguación en función del periodo del año considerado.

Por el contrario, cuando se dispone de equipos de climatización y se pretende comprobar las rampas de calentamiento o las evolución de la temperatura interior para mantenerla dentro de las temperaturas de consigna, es necesario emplear periodos de registro de menor duración. Por tanto, si se pretende analizar la respuesta del edificio cuando dispone de equipos o sistemas de climatización los intervalos que se proponen son, para edificios de construcción convencional, de 15 minutos.

Aunque menores, también se observan diferencias importantes cuando se emplean sistemas de disipación o aportación de calor naturales muy eficientes en periodos de fuertes alternancias climáticas como puede ser, si se dispone de grandes superficies acristaladas al sur, las provocadas por la sucesión de periodos de soleamiento directo y los de ocultación severa por el efecto de las nubes, las nieblas o por la presencia de lluvias o nieve o, si se cuenta con ventilación natural cruzada, cuando se producen frecuentes cambios en la velocidad del viento en periodos en los que la temperatura del aire exterior es muy diferente a la del interior.

Así, el análisis de la temperatura interior cuando no se dispone de sistemas de climatización permite asegurar que cuando la temperatura exterior asciende en sus medias diarias la temperatura interior se aproxima cada vez más a los valores climáticos máximos, alcanzándolos varias fechas más tarde y que cuando las temperaturas exteriores medias descienden la temperatura interior evoluciona hacia los valores mínimos, alcanzando su valor más bajo varias fechas después que éste se produzca en el exterior.

Este amortiguamiento está condicionado principalmentepor la exposición a fuentes que aporten o disipen energía, por la masa térmica interior del edificio, por el uso y por la capacidad de operación de los sistemas móviles que afectan a la exposición.
DURACIÓN DE LAS SERIES HISTÓRICAS DE REFERENCIA

INTERVALOS EN LOS REGISTROS 
La operación real y la definición de las cualidades higrotérmicas de los edificios deberán ser estimadas a partir de secuencias climáticas significativas de recurrencia variable, que describan con mayor precisión cualquiera de las condiciones climáticas que podrían producirse durante la vida útil del edificio.

La exigencia legal de limitar el consumo energético de energía primaria no renovable (CTE-HEO), que debe justificarse en la fase de proyecto previamente a la autorización para edificar en España, se ve comprometida por la posible aplicación de diversos climas sintéticos a una zona determinada. En la práctica esto permite obtener valores diferentes de demanda estimada para un mismo edificio, en función del clima sintético empleado, cuando se han de ratificar las estimaciones una vez construido.

Dentro de un zona climática y considerando diversas bases de datos pueden observarse importantes diferencias entre las bases de datos reconocidas para caracterizar el clima. El análisis mediante grados-hora, de los climas sintéticos considerados arroja diferencias muy significativas, como se comprueba en el amplio análisis muestral realizado en Zaragoza, dentro de la zona climática D3.

La estimación más sencilla de la respuesta de los edificios debe realizarse mediante el análisis de ciclos diarios que sean suficientemente significativos. Para ello se propone la definición de días sintéticos que describan, en su conjunto, las condiciones térmicas a las que se verá sometido el edificio. Los parámetros que han de ser tenido en cuenta para su elaboración son la temperatura media, la oscilación térmica diaria, la tendencia diaria y la temperatura media en los días precedentes.

La diferencia entre periodos cálidos y periodos fríos, al igual que ya se recoge en la legislación, se ha observado significativa por lo que se propone la agrupación de los días sintéticos en series independientes para cada uno de estos periodos. También se propone la elaboración de series específicas para los periodos de transición desde periodos cálidos a periodos fríos y viceversa. 


\subsection{CONSIDERACIÓN ESPACIAL}

Las clasificaciones espaciales consideradas en las regulaciones existentes presentan unas condiciones climáticas muy diferentes para áreas, ciudades o regiones incluidas dentro de una misma zona climática y pueden resultar útiles para caracterizar las condiciones climáticas que ayuden a establecer las condiciones mínimas que deben cumplir los edificios y sus sistemas para garantizar unas prestaciones adecuadas a sus usuarios.

Diseñados para zonas muy amplias los climas sintéticos evidencian diferencias significativas al ser aplicados a una localidad concreta, por lo que no describen con precisión el entorno climático de los edificios ni de cada uno de los espacios que lo forman para una correcta simulación de las condiciones de bienestar en cada momento.

Los valores de los parámetros característicos que se emplean para definir las clasificaciones climáticas y los climas de referencia se localizan en los lugares donde éstos se obtienen con una mayor precisión (estaciones meteorológicas) y no son adecuados para describir las condiciones en el entorno próximo al edificio, como se comprueba en el trabajo de campo realizado.

Estas diferencias son mayores cuando las estaciones meteorológicas están en un entorno diferente del que afecta a los edificios, algo muy habitual puesto que la agregación de edificios y construcciones constituye en sí misma un entorno específico definido por la densidad urbana, la posición relativa con respecto al perímetro, las dimensiones del núcleo urbano, la densidad de la edificación, el flujo de vehículos con motores térmicos y la proporción de suelo construido, la posición relativa con respecto a los vientos dominantes y su exposición a ellos, la latitud, la altitud, la orientación y su exposición al sol y a los meteoros hídricos, como la lluvia la nieve, la escarcha el granizo o la helada, y su relación con otros factores climáticos pasivos significativos, como son las masas de agua o la morfología del terreno.

La observación del entorno próximo al edificio y de su microclima de proximidad ha permitido determinar, para los casos de estudio, diferencias que aconsejan afectar el microclima en que se encuentra el edificio por los factores que determinan su microclima de proximidad, como son la orientación y la naturaleza de sus paramentos y su exposición específica al sol y al viento y a los meteoros hídricos.

Se evidencia la necesidad de conocer con mayor precisión las condiciones meteorológicas en general y térmicas en particular en el entorno próximo de los edificios.

La relación de causalidad en la correlación entre las series térmicas observadas en los estadios climáticos estudiados, desde el clima regional al microclima de proximidad, no ha podido ser encontrada, siendo necesario realizar más observaciones y, probablemente, modificar el modelo de análisis para encontrar resultados relevantes. 
Aún así se han constatado localmente estas correlaciones y se deducen algunas líneas generales de su determinación, asociando sus variaciones a la orientación y exposición. Otros factores, como son por ejemplo la densidad, la caracterización constructiva o las acciones de corrección de la exposición, no se contemplan siendo una interesante iniciativa para futuras investigaciones. 


\subsection{CONSIDERACIÓN DEL POTENCIAL DE MEJORA}

Según se ha comentado la respuesta de los edificios al clima está condicionada por sus cualidades y sus sistemas. En los casos de estudio analizados se ha observado que se produce una amortiguación y un desfase de las temperaturas interiores con diferente intensidad en función de factores como la inercia térmica, la orientación, el tipo y tamaño de los huecos o las operaciones de regulación para las que el edificio está capacitado.

La exposición a la radiación han demostrado ser un factor determinante para las temperaturas y humedades interiores, por lo que cuando se realice la estimación del estado higrotérmico interior deben considerarse las posibilidades de recepción y regulación de la radiación solar directa.

La exposición al viento y su intensidad han demostrado también que afectan al enfriamiento o calentamiento de los edificios y al aumento o disminución de las temperaturas interiores.

La humedad no ha sido un parámetro determinante en los casos estudiados y no se tienen evidencias de que su influencia la consecución de condiciones de bienestar interior se deban a las condiciones climáticas, por lo que se estima que los procedimientos de climatización interior pueden estar en el origen de las fuertes alteraciones en la humedad relativa interior que se manifiestan en la literatura consultada.

Puede considerarse que los edificios responden al clima según sus características y que los factores temporales están amortiguados o potenciados en función de ellas. Esto influye en los intervalos a considerar ante las operaciones de simulación o registro y en la importancia relativa que tienen las fluctuaciones térmicas, muy frecuentes en los cambios de tendencia térmica y muy significativas en los periodos fríos y cálidos a lo largo del año térmico.

Las condiciones térmicas se modifican en el interior de los edificios en función de la disponibilidad de recursos de disipación o acumulación de temperatura, mediante sistemas que no requieren la aportación de energía (pasivos), y mediante otros que si precisan esta aportación (activos).

El acceso a la radiación solar, o a la ventilación natural, la posibilidad de incrementar la humedad o las grandes masas térmicas, permiten aproximar el ambiente térmico local a las condiciones de comodidad térmicas requeridas por los usuarios de los edificios.

Un mejor conocimiento de la respuesta del edificio al clima (reactividad), y la forma en la que la operación de sus sistemas pasivos afecta a su balance higrotérmico.

La estimación de medias horarias, diarias o en secuencias de 3, 5 o 10 días para establecer los valores climáticos de cálculo modifica significativamente los valores máximos, mínimos y las oscilaciones 
térmicas, por lo que será necesario considerar estas secuencias en función de la inercia térmica del edificio y su exposición.

Esto se pone de manifiesto en una oscilación térmica diaria menor en el interior de los edificios que en las estaciones meteorológicas de referencia, que también se refleja en los resultados aportados por los sistemas de simulación digital empleados. 


\section{LÍNEAS FUTURAS DE INVESTIGACIÓN}

El objetivo último que se propone de mejorar el conocimiento del clima en aras a obtener un mejor desempeño en la capacidad de aclimatación de los edificios es sólo una parte inicial de un propósito más complejo. Su propósito será servir de apoyo para encadenar diversas líneas de investigación, desde un mejor conocimiento del entorno hasta la prescripción, operación y evaluación de la respuesta de los edificios.

La puesta en común de los resultados parciales obtenidos ha permitido que se reciban sugerencias que no siempre ha sido posible incorporar a este documento y que han abierto interrogantes que son, en sí mismos, una nueva línea de actividad.

El método de trabajo ha consistido en el análisis de muestras y series discontinuas en el tiempo en lugares significativos por lo que, para describir completamente una zona climática o una región geográfica, será necesaria una ampliación de los ámbitos temporales y geográficos y de los tipos de edificios considerados y sus agrupaciones. Serán estudios posteriores, realizados mediante la extensión sistemática del procedimiento desarrollado, los que deban ratificar y establecer con más precisión los rangos y límites de las consideraciones recogidas en estas conclusiones.

Las consideraciones espaciales realizadas pueden ampliarse a localizaciones donde cambien parámetros antrópicos como son, por ejemplo, la densidad, la caracterización constructiva o las acciones de corrección de la exposición, no se contemplan siendo una interesante iniciativa para futuras investigaciones.

Como dejan patente las conclusiones el esfuerzo para determinar una relación de causalidad en la correlación entre las series térmicas observadas en los estadios climáticos estudiados, desde el clima regional al microclima de proximidad, exige realizar más observaciones y, probablemente, modificar el modelo de análisis para encontrar resultados relevantes.

En este sentido se esquematizan distintas líneas futuras de investigación que, en algún caso, ya han sido iniciadas pero que su desarrollo o extensión no permite incorporar ahora. Entre ellas pueden citarse:

- La Influencia del cambio climático en las condiciones de contorno del edificio durante su vida útil.

- La ddeterminación de los balances termodinámicos entre espacios cerrados y semi-cerrados en el edificio.

- Establecer la relación entre el clima de proximidad y las condiciones de bienestar interior. Para este fin las acciones térmicas sobre el edificio deben ser completadas con la capacidad de captación de energía solar y de disipación, como sucede por medio de procesos convectivos o evaporativos.

- Correlacionar los valores climáticos en estaciones meteorológicas y los que se observan en el entorno próximo del edificio y, aplicando factores como la densidad, la caracterización constructiva o las acciones de corrección de la exposición, definir 
la existencia de anomalías climáticas provocadas por las zonas edificadas. Estudiando el microclima de proximidad en entornos de isla térmica.

- Empleo de series de Fourier para la formación de las secuencias climáticas que describen el clima a emplear en la simulación del comportamiento de la edificación.

- Introducir otros componentes del clima, como la humedad, la velocidad del viento o la radiación, en los estudios.

- Extender el estudio climático a otras regiones climáticas.

- Realizar una aplicación sistemática de los climas de proximidad a edificaciones en diversas regiones climáticas mediante sistemas digitales de simulación y validar sus resultados mediante registros climáticos realizados en los edificios. En esta línea ya se han iniciado los trabajos en Madrid (España), San José (Costa Rica) y en Vilnus (Lituania).

- Emplear el conocimiento adquirido para un mejor conocimiento de la respuesta del edificio al clima (reactividad), y la forma en la que la operación de sus sistemas pasivos afecta a su balance higrotérmico. 


\section{ANEXOS}

Se aportan dentro del texto los anexos vinculados a su redacción y lectura como es la bibliografía, la tabla de ilustraciones y un breve glosario.

Fuera del texto se aportan anexos que lo complementan y no se han considerado imprescindibles para seguir los argumentos desarrollados. Cuando estos anexos están muy vinculados al texto o pueden servir de apoyo a la lectura se ha incluido una referencia al margen. Cuando afectan al conjunto del texto de un modo menos específico se han denominado con el epígrafe que prioritariamente complementan.

Los anexos aportados fuera del texto por considerar que su inclusión dificulta una lectura lineal del texto, pero que pueden ser importantes para complementar los que en él se recoge, son:

\begin{tabular}{|c|c|}
\hline DESCRIPCIÓN & CITADO EN \\
\hline \multirow[t]{2}{*}{01 BALANCE TERMODINÁMICO MEDIANTE ENERGY PLUS Y DESIGNBUILDER 1} & 1.0 \\
\hline & 6.7 \\
\hline \multirow[t]{2}{*}{02 BALANCE TERMODINÁMICO MEDIANTE ENERGY PLUS Y DESIGNBUILDER 2} & 1.0 \\
\hline & 6.7 \\
\hline 03 EQUIPOS DE TOMA DE DATOS & 4.1 \\
\hline \multirow[t]{2}{*}{04 EDIFICIO CALLE SAN PABLO. ZARAGOZA } & 6.6 \\
\hline & $8 . .7$ \\
\hline \multirow[t]{3}{*}{05 DESCRIPCIÓN CLIMAS DE REFERENCIA PARA LA ZONA CLIMÁTICA D3 } & 7.1 \\
\hline & $7.1 .1^{\mathrm{a}}$ y $\mathrm{B}$ \\
\hline & 8.1 \\
\hline \multirow[t]{2}{*}{06 REGISTROS EN ESTACIONES METEOROLÓGICAS DE ZARAGOZAI } & $7.2,4$. \\
\hline & $8.2,3$ \\
\hline \multirow[t]{2}{*}{07 REGISTROS EN ESTACIONES METEOROLÓGICAS DE ZARAGOZA2 } & $7.2 ., 5$ \\
\hline & $8.2,3$ \\
\hline 08 DESCRIPCIÓN ESTACIONES METEOROLÓGICAS LOCALES & $7.3,5$ \\
\hline \multirow[t]{2}{*}{09 REGISTROS MICROCLIMA DE PROXIMIDAD } & 7.6 \\
\hline & $8.1,7$ \\
\hline $\begin{array}{l}10 \text { COMPARADOR DIARIO ENTRE ESTACIONES METEOROLÓGICAS. } \\
\text { GRÁFICAS }\end{array}$ & 8.3 .3 \\
\hline $\begin{array}{l}11 \text { DESCRIPCIÓN DEL CLIMA. INDICADOR ELEMENTAL DE LA DURACIÓN Y } \\
\text { MAGNITUD DE PERIODOS CÁLIDOS, FRÍOS Y TEMPLADOS }\end{array}$ & 8.4 .4 \\
\hline 12 TENTATIVA CLASIFICACIÓN EN FRANJAS DE HOMOGÉNEIDAD TÉRMICA & $8.5,8$ \\
\hline
\end{tabular}




\subsection{BIBLIOGRAFÍA}

AEMET, 2011 VVAA Atlas Climático Ibérico, Agencia Estatal de Meteorología. Ministerio de Medio Ambiente y Medio Rural y Marino. Instituto de Meteorología de Portugal, 2011

ALBERTI, 1485 Leon Battista Alberti De re aedificatoria, Florencia(1485) que puede consultarse en http://commons. wikimedia.org/w/index.php?title=File:Alberti = De re aedificatoria, 1541.djuvepage $=7$

ALMARZA, 2007 Almarza, C. La Climatología en los organismos oficiales, en La Climatología española. Pasado, presente y futuro. Ed. José María Cuadrat y Javier Martín Vide. Zaragoza: Prensas Universitarias de Zaragoza, 2007. 574 p. Textos en castellano e inglés. ISBN: 978-84-7733-886-4.

ALONSO, 2007 Alonso, S., Cuxart J., Caselles, V. La gestión de los Planes Nacionales de Investigación sobre el Clima en España, en La Climatología española. Pasado, presente y futuro. Ed. José María Cuadrat y Javier Martín Vide. Zaragoza: Prensas Universitarias de Zaragoza, 2007. 574 p. Textos en castellano e inglés. ISBN: 978-84-7733-886-4.

ANGELOLONI, 2013 Angeloni, Patricia N. - Caram, Gladis A. de Prause, Juan 2013. Utilización de dos temperaturas base para el cálculo de grados-día. Cátedra de Climatología y Fenología Agrícolas - Facultad de Ciencias AgrariasUNNE. Corrientes - Argentina.

ARIZMENDI, 2002 Manual de Aislamiento de los Edificios, Arizmendi, L.J., Hernando, R. y otros. Consejo Superior de Arquitectos de España, 2002 376p. Pag 1.17-18

BRENES, Brenes, A., Saborío, V.F. Elementos de climatología, su aplicación directa a Costa Rica. Editorial Universidad estatal a distancia.

BRUGGER, 2013 Brugger, K., and F. Rubel, 2013: Characterizing the species composition of European Culicoides vectors by means of the Köppen-Geiger climate classification. Parasites \& Vectors, 6:33. EN http://koeppen-geiger.vu-wien.ac.at/

CIEMAT, 1989 Clima, Lugar y Arquitectura"1989, Pag 33

CONSTABLE, 1988Constable,G.A. y A.J.Shaw. 1988. Temperature requirements for cotton. Agfacts P5.3.5. (en ANGELONI, P.N. et all, 2013)

COPEN, 1999 Copen. y Max Sorre GIL, Tratado de Climatología. citado en pag 5. Climatología Básica. Gil Olcina, A. y Olcina Cantos, J Ariel. Barcelona 1999

Van Hann, citado en pag. 3

CORBUSIER, 1853) Le Corbusier. Building an entire new city in India, Chandigarh. 1853)

COSTANZA, 1999 Costanza, R., Cumberland, J., Daly, H., Goodland, R., Norgaard, R. Introducción a la Economía Ecológica AENOR 1999 (1997)

COUMOU, 2012 Coumou, D., Robinson, A. Rahmstorf, S. Record monthlytemperature extremes, en clima presente y en condiciones de cambio climático, en $8^{a}$ Conferencia internacional AEC 2012

CREUS, 2007 Creus, J., Peña, J.L., Barriendos, M., González, P., Moreno, A., Sancho, C. Valero, B., Pérez A., Saz, M.A., Constante, A. 
Los estudios de Paleoclimatología en España., en La Climatología española. Pasado, presente y futuro. Ed. José María Cuadrat y Javier Martín Vide. Zaragoza: Prensas Universitarias de Zaragoza, 2007. 574 p. Textos en castellano e inglés. ISBN: 978-84-7733-886-4.

CROISET, 1976 Humedad y Temperatura en los edificios. Croiset, M. Editores Técnicos Asociados S.A. (1975) 1976

CUADRAT, 2004 Cuadrat, J.M. Pita, M.F. Climatología $4^{a}$ edicion $\left(1^{\circ}\right.$ edición 2004)Cátedra Geografía, 2006, 504 p.

CUADRAT, 2007 José María Cuadrat y Javier Martín Vide. La Climatología española. Pasado, presente y futuro. Ed. José María Cuadrat y Javier Martín Vide. Zaragoza: Prensas Universitarias de Zaragoza, 2007. 574 p. Textos en castellano e inglés. ISBN: 978-84-7733-886-4.

CUADRAT, 2007b Cuadrat, J.M., Pérez, A. Climatología Regional, en La Climatología española. Pasado, presente y futuro. Ed. José María Cuadrat y Javier Martín Vide. Zaragoza: Prensas Universitarias de Zaragoza, 2007. 574 p. Textos en castellano e inglés. ISBN: 978-84-7733-886-4.

DINES, 1917 Dines, W.H. The heat Balance of the atmosphere. Quarterly Journal of the Royal Meteorological Society, Volumen 43, Issue 182 pages 151-158, april 1917

DYRBøL, 20102010 ACEEE Summer Study on Energy Efficiency in Buildings 2010 ACEEE Summer Study on Energy Efficiency in Buildings $8-126$ a 140 European Directive on the Energy Performance of Buildings: Energy Policies in Europe Examples of Best Practice Susanne Dyrbøl, Rockwool International A/S Kirsten Engelund Thomsen, Danish Building Research Institute (SBi) Trine Albaek, Danfoss A/S

DO 2000/84 Directiva Europea 2000/84/CE del Parlamento Europeo y del Consejo, de 19 de enero de 2001, que estableció que se seguirá aplicando el horario de verano establecido en Real Decreto 236/2002, de 1 de marzo, por el que se establece el horario de verano Directiva 2000/84/CE (O $7 / 3 / 1940$ ) Orden de 7 de marzo de 1949 sobre adelanto de la hora legal en 60 minutos a partir del 16 de los corrientes.

ESTRELA, 2012 Estrela, T., Impactos del cambio climático en los recursos hídricos: herramientas de modelización, en F. Fernández García, E. Galán Gallego, R. Cañada Torrecilla (Eds.Clima, ciudad y ecosistemas) Publicaciones de la Asociación Española de Climatología (AEC), 2012, Serie B, $n^{\circ} 5$. Ediciones del Serbal, Madrid, 175 pp.

EU, 2011 Eduardo Maldonado Concerted Action EPBD Coordinator Implementing the Energy Performance of the buildings directive (EPBD) European Unión, 2011 contract IEE/CA/07/333 (pag. II-5)

FERNÁNDEZ, 1996 Fernández García, F. Manual de Climatología Aplicada Editorial Síntesis 1996

FERNÁNDEZ, 2012F. Fernández García, E. Galán Gallego, R. Cañada Torrecilla (Eds.Clima, ciudad y ecosistemas) Publicaciones de la Asociación Española de Climatología (AEC), 2012, Serie $B, n^{\circ} 5$. Ediciones del Serbal, Madrid, $175 \mathrm{pp}$.

FERNÁNDEZ, 2012b Fernández, R. La modelización del sistema climático a escala regional. Teleconexiones y simulaciones regionales del clima, en F. Fernández García, E. Galán Gallego, R. Cañada Torrecilla (Eds.Clima, ciudad y ecosistemas) Publicaciones de la Asociación 
Española de Climatología (AEC), 2012, Serie B, $n^{\circ} 5$. Ediciones del Serbal, Madrid, 175 pp.

FIZ, 2010 Fiz F. Pérez y Roberta Boscolo Editores: CLIMA EN ESPAÑA: PASADO, PRESENTE Y FUTURO Informe de evaluación del cambio climático regional RED TEMÁTICA CLIVAR-ESPAÑA Enero 2010

FOMENTO, 2013 Ministerio de Fomento. Documento descriptivo climas de referencia. Ministerio de Fomento. Septiembre 2013.

FRICH, 2002 Frich, P., Alexander, L.V., Della-Marta, P., Gleason, B., Haylock, M., Klein Tank, A.M. and Peterson, T. (2002), Observed coherent changes in climatic extremes during the second half of the twentieth century, Clim. Res., 19(3), 193-212.

FUENTES, 2009 Víctor Armando Fuentes Freixanet GRADOS-DÍA EN ARQUITECTURA 2009

GALÁN, 2007 Galán, E., Cañada, M.R., La investigación en Climatología Aplicada (1970-2005), en La Climatología española. Pasado, presente y futuro. Ed. José María Cuadrat y Javier Martín Vide. Zaragoza: Prensas Universitarias de Zaragoza, 2007. 574 p. Textos en castellano e inglés. ISBN: 978-847733-886-4.

GÁMEZ, M.M., 2008 Gámez Mejías, Manuel Miguel, Origen, evolución y futuro de la determinación normativa de la hora legal en España y la Unión Europea. Revista de Administración Pública ISSN: 0034-7639, núm. 177, Madrid, septiembrediciembre (2008), págs. 377-417

GARABATOS, 1991 Garabatos,M. 1991. Temas de Agrometeorología. Tomo 2 : 120-122 (en ANGELONI, P.N. et all, 2013)

GARCÍA, 1983 Garcia Arroyo, A. et all. Bases para el diseño solar pasivo. CSIC-IETCC; 1983.

GARCIA, 2013 GARCÍA-HOOGHUIS, Informes de la Construcción Vol. 65, 531, 2013 p. 289-300.

GARCÍA-HOOGHUIS, 2013

Informes de la Construcción Vol. 65, 531, 289-300, julioseptiembre 2013 ISSN: 0020-0883 elSSN: 1988-3234 doi: 10.3989/ic.12.017 Modelos de transposición de las Directivas 2002/91/CE y 2010/31/UE "Energy Performance Building Directive" en los Estados miembros de la UE.

Consecuencias e implicaciones, A. Garcia-Hooghuis, F. J. Neila

GIDEON, 1996 GIDEON S. GOLANY URBAN DESIGN MORPHOLOGY AND THERMAL PERFORMANCE Atmospheric Environment Vol. 30, No. 3, pp. 45-65, 1996

GIVONI, 1969 Givoni B, A. Man, Climate and Architecture. Elsevier Architectural Science Series. Editor Henry J. Cowan.

GIVONI, 1994 Givoni. Passive and low energy cooling of buildings. Van Nostrand Reinhold, and International Thonson Publishing Company.

GIL, 1999 Gil Olcina, A. y Olcina Cantos, J Climatología Básica. Ariel. Barcelona 1999

GOLDREICH, 1995 YAIR GOLDREICH. URBAN CLIMATE STUDIES IN ISRAEL-A REVIEW*Atmospheric Environment Vol. 29, No. 4, pp. 467-478, 1995

GUTIÉRREZ, Gutiérrez Rubio, D. \& Riesco Martín, J. et all. Breve guía el sistema de notificación de observaciones atmosféricas singulares SINOBAS. AEMET CONSULTADO EN LA VERSIÓNDIGITAL EN 
http://www.aemet.es/documentos/es/conocermas/publicaciones/Sino bas/Guia_fenomenos_sinobas.pdf por última vez el 19/02/2015.

HEEGER, Hegger, M. Arquitectura Solar. Pag.23-24:

HERNÁNDEZ, 2012 Hernández, E.M., García, J.A., Palenzuela, J.E., Belda F. Ejercicio de homogeneización y lleno de series diarias de temperatura máxima, mediante el uso de CLIMATOL. Delegación Territorial de AEMET en Murcia, en $8^{\mathrm{a}}$ Conferencia internacional AEC 2012

HONGIL, 2005 Hongli Fana, David J. Sailorb, Modeling the impacts of anthropogenic heating on the urban climate of Philadelphia: a comparison of implementations in two PBL schemes Atmospheric Environment 39 (2005) 73-84

IDAE, 2009 IDAE et all. Condiciones de aceptación de procedimientos alternativos a LIDER y CALENER. Anexos. Ministerio de Vivienda, Ministerio de Industria, Energía y Turismo. IDAE. Mayo 2009

IDAE, 2015 IDAE et all. Condiciones técnicas de los procedimientos para la evaluación de la eficiencia energética de los edificios. Ministerio de Fomento, Ministerio de Industria, Energía y Turismo. IDAE. Versión 02 julio 2015

IPCC, 2015 Informe (AR4) del Panel Intergubernamental de Expertos para el Cambio Climático (IPCC)

JANSA, 1969 Jansá Guardiola, José María. Curso de climatología. Instituto Nacional de Meteorología1969445 p., XVIII h. de map. pleg

JENSEN, 2007B Jensen et al, 2007 Data flows in calculated and measured building energy certification rating.

JENSEN, 2007C Jensen, O.M., Hansen, M.T. Thomsen, K.E. Wittchen, K.B. Development of a 2nd generation energy certificate scheme- Danish experience ECEE summer study 2007, Nice, France

KALNAY, 1996 KALNAY, E et all The NCEP/NCAR 40-Year reanaliysis projets.Bulletin of the American Meteorological Society. Vol. 77, n 3 March 1996 pages 437-471

KOPPEN, 1884 Köppen, W., 1884: Die Wärmezonen der Erde, nach der Daver der heissen, gemässigten und kalten Zeit und nach der Wirkung der Wärme auf die organische Welt betrachtet (The thermal zones of the Earth according to the duration of hot, moderate and cold periods and of the impact of heat on the organic world). Meteorol. Z., 1, 215-226. maphttp://koeppen-geiger.vuwien.ac.at/koeppen.htm CONSULTADO 11 DIC 2016)

L 11/2007 Ley 11/2007, de 22 de junio, de acceso electrónico de los ciudadanos a los servicios públicos.

LASHOF, 1989 Lashof, D.A. The dynamic greenhouse - Feedback processes that may influence future concentrations of atmospheric trace gases and climatic change, Climate Change, número 14 (3) En informe de expertos cambio climático, 1992 p. XXXIV

LANDSBERG, $1950 \quad$ Landsberg (Ladsberg, H." CLimate and Planning of Settlements" "Microclimatic Research in Relation to Building Construction" 1950

LÓPEZ, 1997 López de Asiaín, J., Gónzalez, R., Cabeza, J.M., de Luxan, M., Celis, F., da Casa, F., Echevarria, E., de Villota, I. Arquitectura y Clima en Andalucía. Manual de Diseño. -Junta de Andalucía/Dirección General de Arquitectura y Vivienda. 1997 
LÓPEZ, 2007 López, J.A., Luna, J., Chazarra, A., Métodos y técnicas en Climatología, en La Climatología española. Pasado, presente y futuro. Ed. José María Cuadrat y Javier Martín Vide. Zaragoza: Prensas Universitarias de Zaragoza, 2007. 574 p. Textos en castellano e inglés. ISBN: 978-84-7733-8864.

LOPEZ DE LA FRANCA, 2012

López de la Franca, N., Sánchez, E., Domínguez, M. (2012), Seasons length and onset changes from an ensemble of regional climate models over the Iberian Peninsula for future climate conditions, Theoretical and Applied Climatology

LOPEZ DE LA FRANCA, 2012b

López de la Franca, N., Sánchez, E., Domínguez, M., Cambios en la duración de las estaciones sobre la península ibérica para el clima presente y condiciones de cambio climático a partir de un conjunto de modelos regionales de clima (ENSEMBLES) en $8^{a}$ Conferencia internacional AEC 2012

LORENTE, 1939 Lorente, J.M. Meteorología Biblioteca de iniciación cultural Editorial Labor $2^{a}$ edición 1939 (1930)

LOZANO, 1578 Francisco de LOZANO LOS DIEZ LIBROS DE ARQUITECTURA de León Battista Alberti, Madrid 1582

LUXÁN,2013 De Luxán, $M$, et all "Habitar sostenible" Centro de publicaciones de la Secretaria General Técnica del Ministerio de Fomento. Madrid, 1013

LUXÁN, 2005c De Luxán, M. de, M. Vázquez, R. Tendero, G. Gómez, E. Román y M. Barbero. ESTUDIO DE LAS POSIBILIDADES DE ACTUACIÓN CON CRITERIOS DE SOSTENIBILIDAD EN LA REHABILITACIÓN DE VIVIENDAS EN EL CENTRO DE MADRID. Convenio entre la Empresa Municipal de la Vivienda del Ayuntamiento de Madrid, y la Fundación General de la Universidad Politécnica de Madrid.

LUXAN, 2009 M. De Luxan, M. Vázquez, G. Gómez, E. Román y M. Barbero Actuaciones con criterios de sostenibilidad en la rehabilitación de viviendas en el centro de Madrid APLICACIÓN PARA LOS BARRIOSDE HORTALEZA, JACINTO BENAVENTE, LAVAPIES, CHAMBERÍ, JUSTICIA, SOL, TETUÁN, PALOS DE MOGUER, ARGANZUELA, Y AREAS DE SALAMANCA Y GOYA Convenio de la Fundación General de la Universidad Politécnica de Madrid con la Empresa Municipal de la Vivienda y Suelo Área de Gobierno de Urbanismo y Vivienda Ayuntamiento de Madrid. Madrid, junio 2009

MANABE, 1961 Manabe, S. On the radiative equilibrium and heat balance of he atmosphere.. Monthly Weather Review Volumen 89, Número 12 páginas 503-532. Diciembr 1961

MARTí, 2007 Martí, A., Grimalt, M., Dorta, P., La Climatología en el ámbito académico, en La Climatología española. Pasado, presente y futuro. Ed. José María Cuadrat y Javier Martín Vide. Zaragoza: Prensas Universitarias de Zaragoza, 2007. 574 p. Textos en castellano e inglés. ISBN: 978-847733-886-4.

MARTILLI, 2012 Martilli, A. Modelización del clima urbano a mesoescala, en F. Fernández García, E. Galán Gallego, R. Cañada Torrecilla (Eds.Clima, ciudad y ecosistemas) Publicaciones de la Asociación Española de Climatología (AEC), 2012, Serie $B, n^{\circ}$ 5. Ediciones del Serbal, Madrid, 175 pp. 
MARTíN, 1999 Martín Vide, J. Fundamentos de climatología analítica, Editorial Síntesis 1999, 160p.

MARTíN, 2007 Javier Martín, J. Ensayo sobre la historia reciente de la investigación climatológica en España, en La Climatología española. Pasado, presente y futuro. Ed. José María Cuadrat y Javier Martín Vide. Zaragoza: Prensas Universitarias de Zaragoza, 2007. 574 p. Textos en castellano e inglés. ISBN: 978-84-7733-886-4.

MARTíN, 2012 Martín, J. Patrones espaciales de la precipitación en España: problemas conceptuales, en F. Fernández García, E. Galán Gallego, R. Cañada Torrecilla (Eds.Clima, ciudad y ecosistemas) Publicaciones de la Asociación Española de Climatología (AEC), 2012, Serie B, $n^{\circ} 5$. Ediciones del Serbal, Madrid, $175 \mathrm{pp}$.

MORENO, 2007 Moreno, M.C., Climatología Urbana, en La Climatología española. Pasado, presente y futuro. Ed. José María Cuadrat y Javier Martín Vide. Zaragoza: Prensas Universitarias de Zaragoza, 2007. 574 p. Textos en castellano e inglés. ISBN: 978-84-7733-886-4.

MORENO, 2012 Moreno, C. Cambio climático y espacios urbanos, en F. Fernández García, E. Galán Gallego, R. Cañada Torrecilla (Eds.Clima, ciudad y ecosistemas) Publicaciones de la Asociación Española de Climatología (AEC), 2012, Serie B, $\mathrm{n}^{\circ}$ 5. Ediciones del Serbal, Madrid, $175 \mathrm{pp}$.

NEILA, 1999 Neila González, J. Diseño de ambientes exteriores. Instituto Juan de Herrera. 1999

NEILA, 2004 NEILA GONZÁLEZ, J. ARQUITECTURA BIOCLIMÁTICA en un entorno sostenible MUNILA-LEIRA, 2004

OLCINA, 2007 Olcina, J. La investigación sobre riesgos climáticos en España: retos de futuro, en La Climatología española. Pasado, presente y futuro. Ed. José María Cuadrat y Javier Martín Vide. Zaragoza: Prensas Universitarias de Zaragoza, 2007. 574 p. Textos en castellano e inglés. ISBN: 978-847733-886-4.

OLGYAY, 1998 Olgyay, V. Arquitectura y Clima -Editorial Gustavo Gili 1998 (1963)

ORTIZ, 1797 LOS cuatro libros de arquitectura de andres paladio, vicentino traducidos e ilustrados con notas por don Joseph francisco Ortiz y Sanz. Imprenta Real Madrid, 1797

OOASTERHIUS,1998 Oosterhius,D. 1998. Fisiologia do algodoeiro. Informacões Agronomicas. № 81:3-5. (en ANGELONI, P.N. et all, 2013)

PALOMARES, 2009 Palomares Calderón, Manuel. Los primeros pasos de la AEMET hace 120 años" en la edición para 2009 del Calendario Meteorológico.

PAGE, 1976 Page, J. K. Application of building climatology to the problems of housing and building for human settlements. World Meteorological Organization. TECHNICAL NOTE No. 150Ginebra, 1976

PICATOSTE, 2012 Picatoste, J.R., Gutiérrez, A., Evaluación de los impactos, vulnerabilidad y adaptación al cambio climático en España, en F. Fernández García, E. Galán Gallego, R. Cañada Torrecilla (Eds.Clima, ciudad y ecosistemas) Publicaciones de la Asociación Española de Climatología (AEC), 2012, Serie B, $n^{\circ}$ 5. Ediciones del Serbal, Madrid, 175 pp. 
PALLADIO, 1570 |I Quattro Libri dell' Architettura (1570) Andrea Palladio accessible

https://archive.org/stream/iquattrolibridel01 pall\#page/28/mode/2up última consulta 9_02_2015

PITA, 2007 Pita, M.F. Horizontes y retos de la ciencia climática, en La Climatología española. Pasado, presente y futuro. Ed. José María Cuadrat y Javier Martín Vide. Zaragoza: Prensas Universitarias de Zaragoza, 2007. 574 p. Textos en castellano e inglés. ISBN: 978-84-7733-886-4.

PLANESAS, 2013 Planesas, P. La hora oficial en España y sus cambios. Observatorio Astronómico Nacional Instituto Geográfico Nacional - Ministerio de Fomento Anuario del Observatorio Astronómico de Madrid para el año 2013 (IGN).

PTOLOMEO, SII Ptolomeo, Claudio. Geographia, (probablemente basada en otra anterior de Marino de Tiro)

RASILLA, 2007 Rasilla, F., García, J.C. La Climatología Sinóptica en España, en La Climatología española. Pasado, presente y futuro. Ed. José María Cuadrat y Javier Martín Vide. Zaragoza: Prensas Universitarias de Zaragoza, 2007. 574 p. Textos en castellano e inglés. ISBN: 978-84-7733-886-4.

RASO, 2012 Raso, J.M., Clima y salud humana: impactos del cambio climático, en F. Fernández García, E. Galán Gallego, R. Cañada Torrecilla (Eds.Clima, ciudad y ecosistemas) Publicaciones de la Asociación Española de Climatología (AEC), 2012, Serie B, $n^{\circ}$ 5. Ediciones del Serbal, Madrid, 175 PP.

RD 236/2002 REAL DECRETO 236/2002, de 1 de marzo, por el que se establece la hora de verano.

RD 1671/2009 Real Decreto 1671/2009, de 6 de noviembre de 2009

RODRÍG UEZ, 2007Rodríguez, C., Brunet, Varia bilidad y Cambio Climático, en La Climatología española. Pasado, presente y futuro. Ed. José Mańa Cuadrat y Javier Martín Vide. Zaragoza: Prensas Universitarias de Zaragoza, 2007. 574 p. Textos en castellano e inglés. ISBN: 978-84-7733-886-4.SANCHEZ, 2002 Sánchez de la Flor, Francisco José. Tesis doctoral: Modificaciones microclimáticas inducidas por el entorno del edificio y su influencia sobre las demandas energeticas de acondicionamiento. Director Álvarez Domínguez, Servando. Universidad de Sevilla, 2002

SANCHEZ, 2012 Sánchez, E., López de la Franca, N., Domínguez, M., Romera, R. Gaertner, M.A., Gallardo, C., De Castro, M. Modelización regional de periodos secos sobre la península ibérica en clima presente y en condiciones de cambio climático, en $8^{a}$ Conferencia internacional AEC 2012

SERRA, 2002 Serra, R. Arquitectura y Climas. GG Básicos - 2002 (1999)

SOBRINO, 2012 Sobrino, J.A., Oltra-Carrión, R. La campaña DESIREX en Madrid. Determinación de la isla de calor, en F. Fernández García, E. Galán Gallego, R. Cañada Torrecilla (Eds.Clima, ciudad y ecosistemas) Publicaciones de la Asociación Española de Climatología (AEC), 2012, Serie B, $\mathrm{n}^{\circ}$ 5. Ediciones del Serbal, Madrid, 175 pp.

SZOKOLAY, 2004 Szokolay, Steven. (2004) Introduction to Architectural Science: The Basis of Sustainable Design ElsevierArchitectural Press. Great Britain. p. 32 (en FUENTES, 2004)

TAYLOR, 2013 Taylor, I. How near is nearly zero? CIBSE Journal May 2013 Londres 
TENDERO, 2010 Tendero Caballero, Ricardo y Garcia de Viedma, Maria (2010). Edificación para un desarrollo sostenible: una actividad modal. "Informes de la construccion revista de informacion tecnica", v. 63 (n. 521); pp. 75-87. ISSN 00200883.

UPPALA, 2005 UPPALA, S.M., et allThe ERA-40 re-analysis. QUARTERLY JOURNALOF THEROYAL METEOROLOGICAL SOCIETY VOI. 131 OCTOBER 2005 Part B No. 612 Q. J. R. Meteorol. Soc. (2005), 131, pp. 2961-3012

VOLKEN, Volken, E. and S. Brönnimann, editores The thermal zones of the Earth according to the duration of hot, moderate and cold periods and of the impact of heat on the organic world, Meteorol. Z., 1, 215-226 (translated and edited by. Meteorol. Z., 20, 351-360. CONSULTADO 11 DIC 2016)

VOOGT, 2002 Voogt, J. 2002. Urban Heat Island. In Munn, T. (ed.) Encyclopedia of Global Environmental Change, Vol. 3. Chichester: John Wiley and Sons

VVAA, ,1989 VVAA, Arquitectura solar para climas cálidos.

PVGIS (c) Comunidades europeas, 2001-2012

VVAA, DISTRIBUCIÓN DE LA RADIACION SOLAR. Aprovechamiento de la luz natural en la iluminación de edificios. VVAA. IDAE. Pag. 15-16

VVAA, 2003 Geografía de España. Climatología: Elementos del clima, 2003

VVAA, 2009 The global annual mean Earth's energy budget for the March 2000 - May 2004 period (W m-2). The broad arrows indicate the schematic flow of energy in proportion to their importance. - From Trenberth et al., 2009.

VVAA, 2011 Atlas Climático Ibérico, Agencia Estatal de Meteorología. Ministerio de Medio Ambiente y Medio Rural y Marino. Instituto de Meteorología de Portugal, 2011

WONG, 2008 Eva Wong, E. et all. (2008) Reducing Urban Heat Islands: Compendium of Strategies Climate Protection Partnership Division in the U.S. Environmental Protection Agency's Office of Atmospheric Programs.

SOROOSHIAN, 2014 S. Sorooshian, R.G. Lawford, P. Tr y, W. Rossow, J. Roads, J. Polcher, G. Sommeria, R. Schiffer Water and energy cycles GEWEX Phase II (2003-2013) emphasizes the full exploitation of the understanding and tools from Phase I (1990-2002), http://www.gewex.org/

TREWIN, 2007 Trewin, Blair C. The Role of Climatological Nomals in a Changing Climate WCDMP-No. 61 WMO-TD No. 1377 World Meteorological Organization. World Climate Data and Monitoring Programme Geneva,2007

YAÑEZ, 1982 Yañez, G. Energía Solar, edific ación y clima I. MOPU, 1982. Madrid, 


\subsection{TABLA DE ILUSTRACIONES}

FIG 1-1 BALANCE TERRESTRE DE FLUJOS ENERGÉtICOS MEDIOS (Wm-2)

(Elaboración propia, según distintos autores)

FIG 1-2 BALANCE EMISIVO EN FUNCIÓN LA NATURALEZA DE LA SUPERFICIE TERRESTRE FASULLO, J. T.. \& TRENBERTH, K, E. (2008) "The Annual Cycle of the Energy Budget. Part I: Global Mean and Land-Ocean Exchanges", Journal of Climate, vol. 21, pp. fig 3

FIG 4-1 Secuencia de diseño de edificios en relación con su adaptación al clima

FIG 4-2 Secuencia de diseño de sistemas formados por edificios y equipos para su adaptación al clima

FIG 4-3 Secuencia de operación del edifico y los equipos durante su vida útil

FIG 4-4 ESQUEMA DE MEDIOS A TRAVÉS DE LOS QUE SE TRANSFIERE EL CALOR

DE LA ATMÓSFERA AL CUERPO HUMANO (Elaboración propia)

FIG 5-1 ESQUEMA DE MEDIOS A TRAVÉS DE LOS QUE SE TRANSFIERE EL CALOR

DE LA ATMÓSFERA AL CUERPO HUMANO (Elaboración propia)

FIG 5-2 ESQUEMA DE LAS ESCALAS TEMPORALES PARA VALORES DE

TEMPERATURA SIGNIFICATIVOS (Elaboración propia)

FIG 5-3 Gráfico para establecer la humedad relativa a partir de las temperaturas de bulbo seco y de rocío

FIG 5-4 DISTRIBUCIÓN DE LA RADIACION SOLAR. VVAA. IDAE. Pag. 15-16

FIG 5-5 IRRADIANCIA GLOBAL ACUMULADA (kW/m2) Y POR HORA (W/ m2) PARA ZARAGOZA DEL 1 AL 4 DE ENERO DEL AÑO 2013 (AEMET y Elaboración propia)

FIG 5-6 ZONAS CLIMÁTICAS. APÉNDICE B. TABLA B1 (CTE DB-HE MF, 2013) 52

FIG 5-7 Comparación entre los sistemas "informados y "operacionales para la certificación energética de edificios. (Jensen, 2007 y elaboración propia)

FIG 5-8 Esquema de la relación entre los climas y su aplicación en diferentes ámbitos espaciales. Balance termodinámico y Parámetros térmicos. (Elaboración propia)

FIG 5-9 Esquema de la relación entre los climas y las temperaturas que aportan (Elaboración propia)

FIG 5-10 EJEMPLO DE LIMITACIONES TÉRMICAS DE CONFORT ADAPTATIVO APLICADO CONDICIONES HIGROTÉRMICAS ADECUADAS PARA EL INTERIOR DE LOS EDIFICIOS. DIAGRAMAS DE CONFORT 
FIG 5-11 EJEMPLO DE LA ESQUEMA DE LA DISTRIBUCIÓN TEMPORAL DE LAS TEMPERATURAS DE CONFORT ADAPTATIVO CON LAS TEMPERATURAS MÁXIMAS MÍNIMAS Y MEDIAS EN EL AEROPUERTO DE ZARAGOZA (Elaboración propia)

FIG 6-1 Relación entre temperatura e irradiación, con zona de bienestar convencional para ZARAGOZA. (Elaboración propia partir de los datos de PGVIS, 2012)

6-2 RELACIÓN ENTRE LOS PERIODOS HORARIOS DEL DÍA Y LA ASIGNACIÓN DE TEMPERATURAS A CADA PERIODO EN LOS CLIMAS DE REFERENCIA Y EN LOS ARCHIVOS DE AEMET. (ELABORACIÓN PROPIA)

FIG 6-3 ESQUEMA DE LA SECUENCIA DE PRELACIÓN EN LAS REGULACIONES PARA EDIFICACIÓN (ELABORACIÓN PROPIA) 102

FIG 6-4 DEMANDA ENERGÉTICA MÁXIMA PERMITIDA EN EL CTE SEGÚN LA ZONA CLIMÁTICA DE INVIERNO Y LA SUPERFICIE DEL EDIFICIO (CTE HEO, APARTADO 2.2.1 Y ELABORACIÓN PROPIA) 103

FIG 6-5 DEMANDA ENERGÉTICA MÁXIMA PERMITIDA EN EL CTE PARA CALEFACCIÓN SEGÚN LA ZONA CLIMÁTICA DE INVIERNO Y LA SUPERFICIE DEL EDIFICIO (CTE HE1, APARTADO 2.2.1.1 Y ELABORACIÓN PROPIA) 105

6-6 RELACIÓN ENTRE LA DEMANDA ENERGÉTICA MÁXIMA PERMITIDA Y LA DEMANDA MÁXIMA PERMITIDA PARA CALEFACCIÓN EN EL CTE SEGÚN LA ZONA CLIMÁTICA DE INVIERNO Y LA SUPERFICIE DEL EDIFICIO (CTE HEl, APARTADO 2.2.1.1 Y ELABORACIÓN PROPIA) 106

FIG 6-7 TRANSMITANCIA LÍMITE EN EL EDIFICIO DE REFERENCIA PARA LA SIMULACIÓN DE DEMANDA MEDIANTE LA HERRAMIENTA PROPUESTA POR EL CTE. (CTE HEl, APENNDICE D2 Y ELABORACIÓN PROPIA) 108

FIG 6-8 REDUCCIÓN DE LA TRANSMITANCIA LÍMITE EN EL EDIFICIO DE REFERENCIA PARA LA SIMULACIÓN DE DEMANDA MEDIANTE LA HERRAMIENTA PROPUESTA POR EL CTE. (CTE HE1, APENDICE D2 Y ELABORACIÓN PROPIA)

FIG 6-9 TRANSMITANCIA SUGERIDA PARA PREDIMENSIONADO. (CTE HEl, APENDICE D2 Y ELABORACIÓN PROPIA)

FIG 6-10 REDUCCIÓN DE LA TRANSMITANCIA SUGERIDA PARA PREDIMENSIONADO (CTE HEl, APENDICE D2 Y ELABORACIÓN PROPIA) 110

6-11 DISTRIBUCIÓN GEOGRÁFICA DE LAS REGIONES CLIMÁTICAS POR MUNICIPIOS.(http://www.gasparnoguera.com/wp-content/uploads/2015/03/map_web.jpg http://www.cmbburgos.es/images/2010031 1_014252.jpg y elaboración propia)

6-12 ZONAS CLIMÁTICAS DE INVIERNO Y SCI (CTE Y elaboración propia)

6-13 EJEMPLO DE DETERMINACIONES DE LOS GRADOS DIA EN BASE $20^{\circ} \mathrm{C}$ EN MESES FRIOS (UTILIDAD "On line" WWW.DEGREEDAYS.NET Y ELABORACIÓN PROPIA)

6-14 ZONAS CLIMÁTICAS DE VERANO Y SCV (CTE y elaboración propia)

6-15 EJEMPLO DE DETERMNACIONES DE LOS GRADOS DIA EN BASE $20^{\circ} \mathrm{C}$ EN MESES CÁLIDOS (UTILIDAD "On line" WWW.DEGREEDAYS.NET Y ELABORACIÓN PROPIA) 
6-16 EJEMPLO DE LAS CUATRO PRIMERAS LÍNEAS DE UN ARCHIVO (.met) (DOCUMENTO DESCRIPTIVO DE CLIMAS DE REFERENCIA Y ELABORACIÓN PROPIA)

FIG 6-17 Cuadro comparado del tiempo en horas en que las temperaturas de los climas de referencia superan el umbral de $18^{\circ} \mathrm{C}$ en Madrid. (elaboración propia a partir de CTE)

FIG 6-18 Cuadro comparado de $\operatorname{los}^{\circ} \mathrm{C}$ que superan un umbral de $18^{\circ} \mathrm{C}$ en Madrid. (elaboración propia a partir de CTE)

FIG 6-19 Cuadro comparado del tiempo en horas en que las temperaturas de los climas de referencia no superan el umbral de $0^{\circ} \mathrm{C}$ en Madrid. (elaboración propia a partir de CTE)

FIG 6-20 Cuadro comparado de $\operatorname{los}^{\circ} \mathrm{C}$ que no superan un umbral de $0^{\circ} \mathrm{C}$ en Madrid. (elaboración propia a partir de CTE)

7-1 EJEMPLO DE LAS PRIMERAS LÍNEAS DE LA TABLA DE CÁLCULO (.xIs)) DEL CLIMA DE REFERENCIA PARA LA ZONA CLIMÁTICA D3 (elaboración propia)

7-2 EJEMPLO DE LAS PRIMERAS LÍNEAS DE LA TABLA DE CÁLCULO (.xIs) DE LAS TEMPERATURAS PARA EL CLIMA DE REFERENCIA (Elaboración propia)

7-3 TABLAS RESUMEN DE LA FRACCIÓN DE TEMPERATURAS: HORARIAS, MEDIAS, MÁXIMAS Y MÍNIMAS POR RANGO EN \% Y HORAS (Elaboración propia)

7-4 TABLAS RESUMEN DE PERCENTILES (Elaboración propia)

7-5 GRÁFICA ANUAL DE TEMPERATURAS HORARIAS Y OSCILACIONES TÉRMICAS PARA CLIMA DE REFERENCIA DE LA ZONA CLIMÁTICA D3 (ELABORACIÓN PROPIA)

7-6 GRÁFICA ANUAL DE TEMPERATURAS HORARIAS Y DE LAS MEDIAS CADA 3 DÍAS Y OSCILACIONES TÉRMICAS PARA CLIMA DE REFERENCIA DE LA ZONA CLIMÁTICA D3 (Elaboración propia)

7-7 GRÁFICA ANUAL DE TEMPERATURAS MEDIAS HORARIAS CADA 3 DÍAS Y OSCILACIONES TÉRMICAS PARA CLIMA DE REFERENCIA DE LA ZONA CLIMÁTICA D3 (Elaboración propia)

7-9 GRAFICA MENSUAL DE VALORES HORARIOS TIPO (MES DE SEPTIEMBRE) PARA LA ZONA CLIMÁTICA D3, SEGÚN CTE, INDICANDO LA RADIACIÓN TOTAL, VELOCIDAD DEL VIENTO Y LA HUMEDAD RELATIVA (ELABORACIÓN PROPIA)

7-10 GRAFICA MENSUAL DE VALORES HORARIOS TIPO (MES DE SEPTIEMBRE) PARA LA ZONA CLIMÁTICA D3, SEGÚN CTE, INDICANDO LA RADIACIÓN TOTAL, VELOCIDAD DEL VIENTO Y LA HUMEDAD RELATIVA Y LA CURVA DE REGRESIÓN DE LA SECUENCIA TÉRMICA (ELABORACIÓN PROPIA)

7-11 GRAFICA MENSUAL DE VALORES HORARIOS TIPO (MES DE SEPTIEMBRE) PARA LA ZONA CLIMÁTICA D3, SEGÚN CTE, INDICANDO LA RADIACIÓN TOTAL, VELOCIDAD DEL VIENTO Y LA HUMEDAD RELATIVA, Y LAS TEMPERATURAS MEDIAS DIÁRIAS (ELABORACIÓN PROPIA) 
TOTAL, VELOCIDAD DEL VIENTO Y LA HUMEDAD RELATIVA Y ALGUNAS SECUENCIAS ASCENDENTES Y RESCENDENTES REPRESENTATIVAS (ELABORACIÓN PROPIA)

7-13 GRAFICA MENSUAL DE VALORES HORARIOS TIPO (MES DE SEPTIEMBRE) PARA LA ZONA CLIMÁTICA D3, SEGÚN CTE, INDICANDO LA RADIACIÓN TOTAL, VELOCIDAD DEL VIENTO Y LA HUMEDAD RELATIVA Y ALGUNAS SECUENCIAS REPRESENTATIVAS DONDE LAS TEMPERATURAS SE MANTIENEN (ELABORACIÓN PROPIA) 143

7-14 GRAFICA SEMANAL DE VALORES HORARIOS TIPO (1-7 DE SEPTIEMBRE) PARA LA ZONA CLIMÁTICA D3, SEGÚN CTE, INDICANDO LA RADIACIÓN TOTAL, VELOCIDAD DEL VIENTO Y LA HUMEDAD RELATIVA (ELABORACIÓN PROPIA)

7-15 GRAFICA SEMANAL DE VALORES HORARIOS TIPO (8-14 DE SEPTIEMBRE) PARA LA ZONA CLIMÁTICA D3, SEGÚN CTE, INDICANDO LA RADIACIÓN TOTAL, VELOCIDAD DEL VIENTO Y LA HUMEDAD RELATIVA (ELABORACIÓN PROPIA)

7-15 TABLAS RESUMEN DE HUMEDADES RELATIVAS MEDIAS, MÁXIMAS, MÍNIMAS, OSCILACIONES TÉRMICAS Y SUPERACIÓN DE UMBRALES (Elaboración propia)

7-17 GRÁFICO DE LA EVOLUCIÓN ANUAL DE LAS HUMEDADES RELATIVAS HORARIAS Y LAS OSCILACIONES DIARIAS (Elaboración propia)

7-18 GRAFICA ANUAL DE RADIACIÓN DIARIA CON CURVA DE REGRESIÓN Y RADIACIÓN HORARIA DIFUSA Y DIRECTA (Elaboración propia)

7-19 TABLAS DE RADIACIÓN MÁXIMA DIARIA Y RADIACIÓN TOTAL DIARIA SEGREGADA POR RANGOS EXPRESADA EN PORCENTAJE Y No DE DÍAS (Elaboración propia)

7-19 GRAFICA ANUAL DE VELOCIDADES DEL VIENTO HORARIA EN m/s (Elaboración propia)

7-21 GRÁFICA ANUAL DE VELOCIDADES MÁXIMAS, MEDIAS Y MÍNIMAS DIARIAS EXPRESADAS EN m/s (Elaboración propia)

7-21 TABLA DE LA PROPORCIÓN EN POCENTAJE Y HORAS DE LAS CALMAS PRODUCIDAS, VELOCIDAD DEL VIENTO MÁXIMA, MÍNIMA Y MEDIA Y OSCILACIÓN DIARIA EN LA VELOCIDAD DEL VIENTO(Elaboración propia) 150

7-22 TABLA DE LA PROPORCIÓN EN POCENTAJES Y HORAS DE LAS VELOCIDADES DEL VIENTO SEGREGADOS POR RANGOS (Elaboración propia)

7-25 CUADRO CON LA PROPORCIÓN DE DIRECCIONES DEL VIENTO TOTALES ANUALES EN NEGRO, EN ROJO LA PROPORCIÓN DE HORAS FRÍAS $\left(<16^{\circ} \mathrm{C}\right), \mathrm{Y}$ EN AZUL EN HORAS CÁLIDAS $\left(>26^{\circ} \mathrm{C}\right)$. RECUADADA LA DIRECCIÓN DE MENOR VIENTO EN HORAS FRÍAS Y MAYOR EN HORAS CALIENTES (Elaboración propia)

7-24 ROSA DE LOS VIENTOS ANUAL EN NEGRO LOS VALORES TOTALES, EN ROJO EN HORAS FRIAS $\left(<16^{\circ} \mathrm{C}\right)$ Y EN HORAS CÁLIDAS $\left(>26^{\circ} \mathrm{C}\right)$ DISTRIBUIDAS EN LAS 8 DIRECCIONES PRINCIPALES (Elaboración propia) 
7-23 GRÁFICA ANUAL DE VELOCIDAD DEL VIENTO Y DIRECCIÓN

(Elaboración propia)

7-26 TABLA DESCRIPTIVA DE LOS PARÁMETROS RECOGIDOS EN LA GRÁFICA CONDICIONES CLIMÁTICAS ANUALES PARA EL PERIODO 1973-2012 (AEMET Y elaboración propia)

7-27 GRÁFICA DE CONDICIONES CLIMÁTICAS ANUALES PARA EL PERIODO

1973-2012 EN EL AEROPUERTO DE ZARAGOZA (AEMET y elaboración propia)

7-28 GRÁFICA DE VALORES MEDIOS DIARIOS Y VALORES MÁXIMOS, MÍNIMOS

Y PROMEDIO REGISTRADOS DURANTE LA DÉCADA 2005-2014 EN ZARAGOZA

AEROPUERTO (AEMET y elaboración propia) 154

7-29 GRÁFICA DE VALORES PROMEDIO DIARIOS DE LA DÉCADA 2015-2014

EN ZARAGOZA AEROPUERTO (AEMET y elaboración propia) 155

7-30 GRÁFICOS DE VALORES MÁXIMOS Y MÍNIMAS DIARIAS PROMEDIO EN EL PERIODO 2005 A 2014 EN EL AEROPUERTO DE ZARAGOZA (AEMET Y elaboración propia)

7-31 GRÁFICA DE VALORES PROMEDIOS DIARIOS DURANTE EL AÑO 2014, COMPARADO CON LOS VALORES PROMEDIO DE LA DÉCADA 2005-2014 EN ZARAGOZA AEROPUERTO (AEMET y elaboración propia)

7-32 GRÁFICA DE VALORES MÁXIMOS, MEDIANAS, PROMEDIO Y MÍNIMAS DIARIAS DESDE 15/10 AL 31/5 EN LA DÉCADA 2005-2014 EN ZARAGOZA AEROPUERTO (AEMET y elaboración propia)

7-33 GRÁFICA DE VALORES MÁXIMOS, MEDIANAS, PROMEDIO Y MÍNIMAS DIARIAS DESDE 15/04 AL 14/10 EN LA DÉCADA 2005-2014 EN ZARAGOZA AEROPUERTO (AEMET y elaboración propia) 158

7-34 GRÁFICA DE VALORES MÁXIMOS, MEDIANAS, PROMEDIO Y MÍNIMAS DIARIAS EN ENERO EN LA DÉCADA 2005-2014 EN ZARAGOZA AEROPUERTO (AEMET y elaboración propia)

7-35 GRÁFICA DE VALORES MÁXIMOS, MEDIANAS, PROMEDIO Y MÍNIMAS DIARIAS EN ENERO EN LA DÉCADA 2005-2014 EN ZARAGOZA AEROPUERTO (AEMET y elaboración propia)

7-36 GRÁFICA DE VALORES PROMEDIO DIARIAS EN ENERO EN LA DÉCADA 2005-2014 EN ZARAGOZA AEROPUERTO (AEMET y elaboración propia)

7-37 GRÁFICA DE VALORES PROMEDIO DIARIAS EN ENERO EN LA DÉCADA 2005-2014 EN ZARAGOZA AEROPUERTO (AEMET y elaboración propia)

7-36 HORAS Y GRADOS-HORA EN QUE ES PRECISO DISIPAR O APORTAR ENERGÍA PARA ALCANZAR DIVERSAS TEMPERATURAS DE REFERENCIA DURANTE EL AÑO 2014 EN ZARAGOZA AEROPUERTO (AEMET y elaboración propia)

7-37 HORAS Y GRADOS-HORA SOBRE Y BAJO 0C EN LA DÉCADA 2005 A 2014 EN ZARAGOZA AEROPUERTO (AEMET y elaboración propia)

7-38 HORAS Y GRADOS-HORA EN QUE ES PRECISO DISIPAR ENERGÍA PARA ALCANZAR DIVERSAS TEMPERATURAS DE REFERENCIA DURANTE LA DÉCADA 2005-2014 EN ZARAGOZA AEROPUERTO (AEMET y elaboración propia) 
7-39 HORAS Y GRADOS-HORA EN QUE ES PRECISO APORTAR ENERGÍA PARA ALCANZAR DIVERSAS TEMPERATURAS DE REFERENCIA DURANTE LA DÉCADA 2005-2014 EN ZARAGOZA AEROPUERTO (AEMET y elaboración propia) 163

7-40 UBICACIÓN DE LAS ESTACIONES METEOROLÓGICAS DE REFERENCIA EN ZARAGOZA (google. maps y elaboración propia) 164

7-41 UBICACIÓN DE LAS ESTACIONES METEOROLÓGICAS DE REFERENCIA EN ZARAGOZA SOBRE CARTOGRAFÍA 1:50000 (ign.es/iberpix2/visor Y elaboración propia)

7-42 DATOS DE DESCRIPTIVOS Y UBICACIÓN DE LA ESTACIÓN METEOROLÓGICA DE AEROPUERTO EN ZARAGOZA (AEMET, google maps Y elaboración propia) 166

7-43 GRÁFICA DE LA EVOLUCION DE LA TEMPERATURA DURANTE UN CICLO ANUAL (DE 10 DE JUNIO DE 2013 A 10 DE JUNIO DE 2014) EN LA ESTACIÓN METEOROLÓGICA DE AEROPUERTO EN ZARAGOZA. (AEMET Y elaboración propia)

7-44 DATOS DE DESCRIPTIVOS Y UBICACIÓN DE LA ESTACIÓN METEOROLÓGICA DE CANAL EN ZARAGOZA (AEMET, google maps y elaboración propia)

7-45 GRÁFICA DE LA EVOLUCION DE LA TEMPERATURA DURANTE UN CICLO ANUAL (DE 10 DE JUNIO DE 2013 A 10 DE JUNIO DE 2014) EN LA ESTACIÓN METEOROLÓGICA DE CANAL EN ZARAGOZA. (AEMET y elaboración propia)

7-46 DATOS DE DESCRIPTIVOS Y UBICACIÓN DE LA ESTACIÓN METEOROLÓGICA DE VALDESPARTERA EN ZARAGOZA (AEMET, google maps Y ELABORACIÓN PROPIA)

7-47 GRÁFICA DE LA EVOLUCION DE LA TEMPERATURA DURANTE UN CICLO ANUAL (DE 10 DE JUNIO DE 2013 A 10 DE JUNIO DE 2014) EN LA ESTACIÓN METEOROLÓGICA DE VALDESPARTERA EN ZARAGOZA. (AEMET Y elaboración propia)

7-49 GRÁFICA ACUMULADA ANUAL DE TEMPERATURAS HORARIAS EN LAS ESTACIONES DE REFERENCIA DE ZARAGOZA (10/06/2013-10/06/2014) (AEMET y elaboración propia)

7-48 GRÁFICAS ANUALES DE TEMPERATURAS HORARIAS EN LAS ESTACIONES DE REFERENCIA DE ZARAGOZA (10/06/2013-10/06/2014) (AEMET Y elaboración propia) .

7-50 GRÁFICA DE LA DISTRIBUCIÓN ANUAL DE LAS TEMPERATURAS MÁXIMAS, MEDIAS Y MÁXIMAS DIÁRIAS Y OSCILACIONES TÉRMICAS DIARIAS PARA LA ZONA CLIMÁTICA D3 (CTE y elaboración propia)

7-51 GRÁFICA DE LA DISTRIBUCIÓN ANUAL DE LAS TEMPERATURAS PROMEDIO DIÁRIAS Y OSCILACIONES TÉRMICAS DIARIAS PARA LA ZONA CLIMÁTICA D3 Y EL PROMEDIO DE LA DÉCADA 2005 Y 2014 (CTE, AEMET Y elaboración propia)

7-52 CUADRO COMPARADO EN ${ }^{\circ} \mathrm{C}-$ HORA $Y$ EN HORAS DE LAS SUPERACIONES DE LAS TEMPERATURAS DE REFERENCIA EN EL PROMEDIO DE LA DÉCADA 2005-2014 Y LOS CLIMAS PROPUSTOS EN EL CTE Y EL RITE PARA LA ZONA CLIMÁTICA D3 Y EL CLIMA PROPUESTO POR EL RITE PARA ZARAGOZA (AEMET, RITE, CTE y elaboración propia) 
7-53 CUADRO COMPARADO EN ${ }^{\circ} \mathrm{C}-\mathrm{HORA} Y$ EN HORAS DE LAS SUPERACIONES DE LAS TEMPERATURAS DE REFERENCIA EN EL PROMEDIO DE LA DÉCADA 2005-2014 Y LOS CLIMAS PROPUSTOS EN EL CTE Y EL RITE PARA LA ZONA CLIMÁTICA D3 Y EL CLIMA PROPUESTO POR EL RITE PARA ZARAGOZA (AEMET, RITE, CTE y elaboración propia)

7-54 CUADRO COMPARADO LOS ${ }^{\circ} \mathrm{C}-\mathrm{HORA}$ NECSARIOS PARA ALCANZAR LOS ${ }^{\circ} \mathrm{C}$ DESDE EMPERATURAS INFERIORES O SUPERIORES EN EL PROMEDIO DE LA DÉCADA 2005-2014 Y LOS CLIMAS PROPUSTOS EN EL CTE Y EL RITE PARA LA ZONA CLIMÁTICA D3 Y EL CLIMA PROPUESTO POR EL RITE PARA ZARAGOZA (AEMET, RITE, CTE y elaboración propia)

7-55 FOTO AÉREA CON LA UBICACIÓN DE LA ESTACIÓN URBANA EN ZARAGOZA Y LA ESTACIÓN DEL AEROPUERTO DE ZARAGOZA (IBERPIX2 Y elaboración propia)

7-56 FOTO AÉREA CON LA UBICACIÓN DE LA ESTACIÓN URBANA EN ZARAGOZA (GOOGLE y elaboración propia)

7-59 GRÁFICA COMPARADA DE TEMPERATURAS MEDIAS DARIAS Y OSCILACIONES TÉRMICAS EN LA ESTACIÓN DE ZARAGOZA-AEROPUERTO DURANTE EL AÑO 2014. (AEMET y elaboración propia)

7-60 GRÁFICA COMPARADA DE TEMPERATURAS MEDIAS DARIAS Y DIFERENCIAS ENTRE ESTACIONES DE SAN PABLO Y LA ESTACIÓN DE ZARAGOZA-AEROPUERTO DURANTE EL AÑO 2014. (AEMET y elaboración propia)

7-61 GRÁFICA DE LAS MEDIAS DIARIAS EN LA ESTACIÓN DE ZARAGOZAAEROPUERTO DURANTE EL AÑO 2014 Y LAS MEDIANAS CADA 3-6 y 9 DÍAS (AEMET y elaboración propia)

7-62 GRÁFICA DE LAS MEDIAS CADA 3 DÍAS EN LA ESTACIÓN DE ZARAGOZAAEROPUERTO Y EN S. PABLO DURANTE EL AÑO 2014 (AEMET y elaboración propia)

7-63 GRÁFICA DE LAS MEDIAS CADA 9 DÍAS EN LA ESTACIÓN DE ZARAGOZAAEROPUERTO Y EN S. PABLO DURANTE EL AÑO 2014 (AEMET y elaboración propia)

7-64 GRÁFICA COMPARADA DE LAS SERIES TÉRMICAS EN LA ESTACIÓN DE ZARAGOZA Y EN EL EDIFICIO DE LA CALLE SAN PABLO, EN ZARAGOZA DURANTE ENERO-FEBRERO Y MARZO DEL AÑO 2014. (AEMET y elaboración propia)

7-65 GRÁFICA DE LA SERIE TÉRMICA HORARIA EN LA ESTACIÓN DE ZARAGOZA-AEROPUERTO DURANTE EL MES DE ENERO DEL AÑO 2014(AEMET y elaboración propia)

7-66 GRÁFICA COMPARADA DE LAS SERIES TÉRMICAS EN LA ESTACIÓN DE ZARAGOZA Y EN EL EDIFICIO DE LA CALLE SAN PABLO, EN ZARAGOZA DURANTE EL MES DE ENERO DEL AÑO 2014. (AEMET y elaboración propia) 183

7-67 GRÁFICA COMPARADA DE LAS SERIES TÉRMICAS MEDIAS DIARIAS REGISTRADAS EN LA ESTACIÓN DE ZARAGOZA Y LAS MEDIAS CADA 9 DÍAS, DURANTE EL MES DE ENERO DEL AÑO 2014. (AEMET y elaboración propia) 184 
7-68 GRÁFICA ANUAL DESGLOSADA EN ZONAS HOMOGÉNEAS EN LA EVOLUCIÓN DE LA MEDIANA DE SU TEMPERATURAS DIARIAS DURANTE EL AÑO 2014 (AEMET y elaboración propia) 185

7-69 GRÁFICA DE MEDIA DIARIA EN LAS ESTACIONES DE ZARAGOZAAEROPUERTO Y SAN PABLO DESDE EL 1 DE ENERO AL 4 DE ABRIL DEL AÑO 2014(AEMET y elaboración propia) 186

7-70 GRÁFICA DE MEDIA DIARIA EN LAS ESTACIONES DE ZARAGOZAAEROPUERTO Y SAN PABLO DESDE EL 1 DE ENERO AL 3 DE FEBRERO DEL AÑO 2014(AEMET y elaboración propia)

7-71 GRÁFICA DE MEDIA DIARIA EN LAS ESTACIONES DE ZARAGOZAAEROPUERTO Y SAN PABLO DESDE EL 1 DE ENERO AL 3 DE FEBRERO DEL AÑO 2014(AEMET y elaboración propia) ... 188

7-72 GRÁFICA COMPARADA DE LAS SERIES TÉRMICAS EN LA ESTACIÓN DE ZARAGOZA Y EN EL EDIFICIO DE LA CALLE SAN PABLO, EN ZARAGOZA ENTRE LOS DÍAS 10 Y 19 DE ENERO EL AÑO 2014. (AEMET y elaboración propia

7-73 GRÁFICA DE MEDIA DIARIA EN LAS ESTACIONES DE ZARAGOZAAEROPUERTO Y SAN PABLO DESDE EL 3 DE FEBRERO AL 4 DE ABRIL DEL AÑO 2014(AEMET y elaboración propia)

7-74 GRÁFICA DE LA EVOLUCIÓN DE LA TEMPERATURAS DIARIAS DESDE EL 10 DE JUNIO DE 2013 AL 10 DE JUNIO DE 2014 EN UN PATIO INTERIOR DEL EDIFICIO SITUADO EN CALLE S. PABLO DE ZARAGOZA (Elaboración propia)..

7-75 GRÁFICA DE LA EVOLUCIÓN DE LA TEMPERATURAS MEDIAS MÁXIMAS Y MÍNIMAS DIARIAS DESDE EL 10 DE JUNIO DE 2013 AL 10 DE JUNIO DE 2014 EN UN PATIO INTERIOR DEL EDIFICIO SITUADO EN CALLE S. PABLO DE ZARAGOZA (Elaboración propia)

7-76 GRÁFICA DE LA OSCILACIÓN TÉRMICA DESDE EL 10 DE JUNIO DE 2013 AL 10 DE JUNIO DE 2014 EN UN PATIO INTERIOR DEL EDIFICIO SITUADO EN CALLE S. PABLO DE ZARAGOZA (Elaboración propia)

7-77 GRÁFICO ANUAL DE DIFERENCIAS ENTRE LA TEMPERATURA EN ESTACIÓN METEOROLÓGICA DEL AEROPUERTO DE ZARAGOZA Y EN EL PATIO INTERIOR DEL EDIFICIO DEMOSTRADOR (Elaboración propia) ..... 194

7-78 GRÁFICA DE DIFERENCIAS TÉRMICAS ENTRE LA ESTACIÓN METEOROLÓGICA DEL AEROPUERTO DE ZARAGOZA Y EL PATIO DE LUCES DEL EDIFICIO DEMOSTRADOR. (Elaboración propia)

7-79 COMPARACIÓN DIARIA ENTRE LAS TEMPERATURAS EN LA ESTACIÓN DE REFERENCIA Y EL PATIO DE LUCES DE EDIFICIO EN CALLE SAN PABLO. PERIODO CÁLIDO. PATRÓN DE USO. (Elaboración propia)

7-80 COMPARACIÓN DIARIA ENTRE LAS TEMPERATURAS EN LA ESTACIÓN DE REFERENCIA Y EL PATIO DE LUCES DE EDIFICIO EN CALLE SAN PABLO. PERIODO CÁLIDO. LEYENDAS DESCRIPTIVAS. (Elaboración propia)

7-81 COMPARACIÓN DIARIA ENTRE LAS TEMPERATURAS EN LA ESTACIÓN DE REFERENCIA Y EL PATIO DE LUCES DE EDIFICIO EN CALLE SAN PABLO. PERIODO CÁLIDO. MÁXIMOS Y MINIMOS. (Elaboración propia) 
7-82 COMPARACIÓN DIARIA ENTRE LAS TEMPERATURAS EN LA ESTACIÓN DE REFERENCIA Y EL PATIO DE LUCES DE EDIFICIO EN CALLE SAN PABLO. PERIODO CÁLIDO DIFERENCIAS ENTRE TEMPERATURAS. (Elaboración propia)

7-79 COMPARACIÓN DIARIA ENTRE LAS TEMPERATURAS EN LA ESTACIÓN DE REFERENCIA Y EL PATIO DE LUCES DE EDIFICIO EN CALLE SAN PABLO. PERIODO CÁLIDO PERIODOS Y MAGNITUDES SINGULARES. (Elaboración propia)

8-1 TABLA RESUMEN DE LAS DIFERENCIAS DE DISTINTOS CLIMAS DE REFERENCIA EN GRADOS-HORA PARA DISTINTOS RANGOS DE TEMPERATURA. (Varias fuentes y elaboración propia) 205

8-2 GRÁFICA COMPARADA EN GRADOS HORA PARA DIVERSOS CLIMAS SINTÉTICOS APLICABLES A LA ZONA CLIMÁTICA D3 PARA DIVERSOS RANGOS DE TEMPERATURA INTERIOR. (Elaboración propia) 206

8-3 GRÁFICA COMPARADA EN GRADOS HORA PARA DIVERSOS CLIMAS SINTÉTICOS APLICABLES A LA ZONA CLIMÁTICA D3 PARA DIVERSOS RANGOS DE TEMPERATURA INTERIOR.(Elaboración propia)

8-4 CUADRO COMPARATIVO DE TEMPERATURAS MÁXIMAS Y MÍNIMAS ABSOLUTAS Y DE VALORES MEDIOS DE MÁXIMAS, MEDIAS Y MÍNIMAS (Varias fuentes y elaboración propia)

8-5 CUADRO COMPARATIVO DE OSCILACIONES TÉRMICAS MEDIAS, MÁXIMAS Y MÍNIMAS (Varias fuentes y elaboración propia)

8-6 CUADRO COMPARATIVO DEL TIEMPO EN HORAS EN QUE LAS TEMPERATURAS OCUPAN RANGOS DE MENORES DE $0^{\circ} \mathrm{C}$, ENTRE $0^{\circ} \mathrm{C} Y 10^{\circ} \mathrm{C}$, ENTRE $10^{\circ} \mathrm{C}$ Y $20 \%$ Y MAYORES DE $30^{\circ} \mathrm{C}$. (Varias fuentes y elaboración propia)

8-7 CUADRO COMPARADO DE LAS TEMPERATURAS MEDIAS DIARIAS POR RANGOS DE MENORES DE $0^{\circ} \mathrm{C}$, ENTRE $0^{\circ} \mathrm{C} Y 10^{\circ} \mathrm{C}$, ENTRE $10^{\circ} \mathrm{C}$ Y $20 \%$ Y MAYORES DE $30^{\circ} \mathrm{C}$. (Varias fuentes y elaboración propia)

8-8 CUADRO COMPARATIVO DE LAS TEMPERATURAS MÁXIMAS DIARIAS POR RANGOS DE MENORES DE $0^{\circ} \mathrm{C}$, ENTRE $0^{\circ} \mathrm{C} Y 10^{\circ} \mathrm{C}$, ENTRE $10^{\circ} \mathrm{C}$ Y $20 \%$ Y MAYORES DE $30^{\circ} \mathrm{C}$. (Varias fuentes y elaboración propia)

8-9 CUADRO COMPARATIVO DE LAS TEMPERATURAS MÍNIMAS DIARIAS POR RANGOS DE MENORES DE $0^{\circ} \mathrm{C}$, ENTRE $0^{\circ} \mathrm{C} Y 10^{\circ} \mathrm{C}$, ENTRE $10^{\circ} \mathrm{C}$ Y $20 \%$ Y MAYORES DE $30^{\circ} \mathrm{C}$. (Varias fuentes y elaboración propia) .....

8-10 CUADRO COMPADO DE PERIODOS EN HORAS EN QUE LAS HUMEDADES RELATIVAS HORARIAS ESTÁN DISTRIBUIDAS EN RANGOS DE MENORES DE 20\%, ENTRE 20 Y 40\%, ENTRE 40\% Y 60\% Y MAYORES DEL 80\% (Varias fuentes Y elaboración propia)

8-11 CUADRO DE RADIACIÓN TOTAL INCIDENTE SOBRE PLANO HORIZONTAL EN VALOR ABSOLUTO Y EN PORCENTAJE CON RESPECTO A LA RECOGIDA EN EL CTE PARA LA ZONA CLIMÁTICA D3 (Varias fuentes y elaboración propia)

8-12 CUADRO RESUMEN DE RADIACIÓN MÁXIMA DIARIA SOBRE PLANO HORIZONTAL DISTRIBUIDA LOS RANGOS $<250 \mathrm{~W} / \mathrm{m} 2$, ENTRE 250 y $500 \mathrm{~W} / \mathrm{m} 2$, ENTRE 500 y $750 \mathrm{~W} / \mathrm{m} 2$, ENTRE 750 y $1000 \mathrm{~W} / \mathrm{m} 2$ Y > $1000 \mathrm{~W} / \mathrm{m} 2$. (Varias fuentes y elaboración pública) 
8-13 CUADRO RESUMEN DE RADIACIÓN TOTAL SOLAR DIARIA SOBRE PLANO HORIZONTAL DISTRIBUIDA LOS RANGOS $<2,00 \mathrm{~kW} / \mathrm{m} 2$, ENTRE 2,00 y 4,00 $\mathrm{KW} / \mathrm{m} 2$, ENTRE 4,00 y $6,00 \mathrm{KW} / \mathrm{m} 2$, ENTRE 6,00 y $8,00 \mathrm{KW} / \mathrm{m} 2$ Y > 8,00 KW/m2. (Varias fuentes y elaboración propia)

8-14 CUADRO RESUMEN DE LA VELOCIDAD DEL VIENTO DISTRIBUIDA POR

RANGOS (Varias fuentes y elaboración propia)

8-15 CUADRO CON ALGUNOS PARÁMETROS DE VELOCIDAD DEL VIENTO

COMPARADOS (Varias fuentes y elaboración propia)

8-16 VALORES PROMEDIOS DIARIOS DURANTE EL AÑO 2014, COMPARADO CON LOS VALORES PROMEDIO DE LA DÉCADA 2015-2014 EN ZARAGOZA AEROPUERTO (AEMET y elaboración propia)

8-17 CUADRO ANALÍTICO DE ${ }^{\circ} \mathrm{C}-H O R A$ Y PERIODO EN HORAS EN QUE LA TEMPERATURA ES MAYOR DE $26^{\circ} \mathrm{C}$ EN LA DÉCADA 2004-2014 EN ZARAGOZAAEROPUERTO (AEMET y elaboración propia)

8-18 GRADOS-HORA MAYORES DE $26^{\circ} \mathrm{C}$ EN LA DÉCADA 2004-2014 EN ZARAGOZA AEROPUERTO (AEMET Y ELABORACIÓN PROPIA)

8-19 GRADOS-HORA MAYORES DE 22C EN LA DÉCADA 2004-2014 EN ZARAGOZA AEROPUERTO (AEMET y elaboración propia)

8-20 GRADOS-HORA MAYORES DE 20 C EN LA DÉCADA 2004-2014 EN

ZARAGOZA AEROPUERTO (AEMET y elaboración propia)

8-21 GRADOS-HORA MENORES DE 20C EN LA DÉCADA 2004-2014 EN ZARAGOZA AEROPUERTO (AEMET y elaboración propia)

8-22 GRADOS-HORA MENORES DE $18^{\circ} \mathrm{C}$ EN LA DÉCADA 2004-2014 EN

ZARAGOZA AEROPUERTO (AEMET y elaboración propia)

8-23 GRADOS-HORA MENORES DE $16^{\circ} \mathrm{C}$ EN LA DÉCADA 2004-2014 EN

ZARAGOZA AEROPUERTO (AEMET y elaboración propia)

8-24 GRADOS-HORA MENORES DE $14^{\circ} \mathrm{C}$ EN LA DÉCADA 2004-2014 EN ZARAGOZA AEROPUERTO (AEMET y elaboración propia) 228

8-25 GRADOS-HORA MENORES DE $10^{\circ} \mathrm{C}$ EN LA DÉCADA 2004-2014 EN ZARAGOZA AEROPUERTO (AEMET y elaboración propia)

8-26 GRADOS-HORA MENORES DE $10^{\circ} \mathrm{C}$ EN LA DÉCADA 2004-2014 EN ZARAGOZA AEROPUERTO (AEMET y elaboración propia)

8-27 GRADOS-HORA MENORES DE $16^{\circ} \mathrm{C}$ Y MAYORES DE $26^{\circ} \mathrm{C}$ EN LA DÉCADA 2004-2014 EN ZARAGOZA AEROPUERTO (AEMET y elaboración propia)

8-28 HORAS CON TEMPERATURAS MENORES DE $16^{\circ} \mathrm{C}$ Y MAYORES DE $26^{\circ} \mathrm{C}$ EN LA DÉCADA 2004-2014 EN ZARAGOZA AEROPUERTO (AEMET y elaboración propia)

8-29 HORAS Y GRADOS-HORA EN QUE ES PRECISO APORTAR ENERGÍA PARA ALCANZAR DIVERSAS TEMPERATURAS DE REFERENCIA DURANTE LA DÉCADA 2005-2014 EN ZARAGOZA AEROPUERTO (AEMET y elaboración propia) 
8-30 HORAS Y GRADOS-HORA EN QUE ES PRECISO DISIPAR ENERGÍA PARA ALCANZAR DIVERSAS TEMPERATURAS DE REFERENCIA DURANTE LA DÉCADA 2005-2014 EN ZARAGOZA AEROPUERTO (AEMET y elaboración propia)

8-31 HORAS Y GRADOS-HORA EN QUE ES PRECISO APORTAR ENERGÍA PARA ALCANZAR DIVERSAS TEMPERATURAS DE REFERENCIA DURANTE LA DÉCADA 2005-2014 EN LOS PERIODOS EN QUE ES POSIBLE UNA EVENTUAL CAPTACIÓN SOLAR EN ZARAGOZA AEROPUERTO (AEMET y elaboración propia)

8-32 HORAS Y GRADOS-HORA EN QUE ES PRECISO DISIPAR ENERGÍA PARA ALCANZAR DIVERSAS TEMPERATURAS DE REFERENCIA DURANTE LA DÉCADA 2005-2014 EN LOS PERIODOS EN QUE ES POSIBLE UNA EVENTUAL CAPTACIÓN SOLAR EN ZARAGOZA AEROPUERTO (AEMET y elaboración propia)

8-33 HORAS Y GRADOS-HORA EN QUE ES PRECISO APORTAR ENERGÍA PARA ALCANZAR DIVERSAS TEMPERATURAS DE REFERENCIA DURANTE LA DÉCADA 2005-2014 EN LOS PERIODOS EN QUE NO ES POSIBLE UNA EVENTUAL CAPTACIÓN SOLAR EN ZARAGOZA AEROPUERTO (AEMET y elaboración propia)

8-34 HORAS Y GRADOS-HORA EN QUE ES PRECISO DISIPAR ENERGÍA PARA ALCANZAR DIVERSAS TEMPERATURAS DE REFERENCIA DURANTE LA DÉCADA 2005-2014 EN LOS PERIODOS EN QUE NO ES POSIBLE UNA EVENTUAL CAPTACIÓN SOLAR EN ZARAGOZA AEROPUERTO (AEMET y elaboración propia)

8-35 CUADROS CON LA MEDIA DE LAS ESTACIONES METEOROLÓGICAS DE CANAL, VALDESPARTERA Y AEROPUERTO DE GRADOS-HORA EN BASE 20/20 Y EN GRADOS-HORA EN BASE16/16 EN PERIODOS FRÍOS Y EN BASE 26/26 EN PERIODOS CÁLIDOS Y DE LOS PERIODOS EN HORAS EN QUE SE PRODUCEN LA SUPERACIÓN DE ESTOS UMBRALES. ZARAGOZA. 2014 (AEMET Y elaboración propia) .

8-36 CUADRO DE DIFERENCIA ANUAL CUANDO LA TEMPERATURA ES MENOR DE $20^{\circ} \mathrm{C}$ DURANTE LOS PERIODOS FRÍOS (DE OCTUBRE A MAYO) Y MAYOR DE $20^{\circ} \mathrm{C}$ DURANTE LOS PERIODOS CÁLIDOS (DE JUNIO A SEPTIEMBRE) EN GRADOS-HORA ENTRE LOS VALORES MEDIOS Y LOS REGISTRADOS EN LA ESTACIÓN METEOROLÓGICA DE CANAL (AEMET y elaboración propia)

8-37 CUADRO DE DIFERENCIA ANUAL CUANDO LA TEMPERATURA ES MENOR DE $16^{\circ} \mathrm{C}$ DURANTE LOS PERIODOS FRÍOS (DE OCTUBRE A MAYO) Y MAYOR DE $26^{\circ} \mathrm{C}$ DURANTE LOS PERIODOS CÁLIDOS (DE JUNIO A SEPTIEMBRE) EN GRADOS-HORA ENTRE LOS VALORES MEDIOS Y LOS REGISTRADOS EN LA ESTACIÓN METEOROLÓGICA DE CANAL (AEMET y elaboración propia) 238

8-38 CUADRO DE DIFERENCIA ANUAL CUANDO LA TEMPERATURA ES MENOR DE $16^{\circ} \mathrm{C}$ (HORAS FRIAS) Y MAYOR DE $26^{\circ} \mathrm{C}$ (HORAS CÁLIDAS) EN GRADOSHORA ENTRE LOS VALORES MEDIOS Y LOS REGISTRADOS EN LA ESTACIÓN METEOROLÓGICA DE CANAL (ELABORACIÓN PROPIA) ....

8-39 CUADRO DE DIFERENCIA ANUAL CUANDO LA TEMPERATURA ES MENOR DE $20^{\circ} \mathrm{C}$ DURANTE LOS PERIODOS FRÍOS (DE OCTUBRE A MAYO) Y MAYOR DE $20^{\circ} \mathrm{C}$ DURANTE LOS PERIODOS CÁLIDOS (DE JUNIO A SEPTIEMBRE) EN GRADOS-HORA ENTRE LOS VALORES MEDIOS Y LOS REGISTRADOS EN LA ESTACIÓN METEOROLÓGICA DE VALDESPARTERA (AEMET y elaboración propia) 
8-40 CUADRO DE DIFERENCIA ANUAL CUANDO LA TEMPERATURA ES MENOR DE $16^{\circ} \mathrm{C}$ DURANTE LOS PERIODOS FRÍOS (DE OCTUBRE A MAYO) Y MAYOR DE $26^{\circ} \mathrm{C}$ DURANTE LOS PERIODOS CÁLIDOS (DE JUNIO A SEPTIEMBRE) EN GRADOS-HORA ENTRE LOS VALORES MEDIOS Y LOS REGISTRADOS EN LA ESTACIÓN METEOROLÓGICA DE VALDESPARTERA (AEMET y elaboración propia)

8-41 CUADRO DE DIFERENCIA ANUAL CUANDO LA TEMPERATURA ES MENOR DE $16^{\circ} \mathrm{C}$ (HORAS FRIAS) Y MAYOR DE $26^{\circ} \mathrm{C}$ (HORAS CÁLIDAS) EN GRADOSHORA ENTRE LOS VALORES MEDIOS Y LOS REGISTRADOS EN LA ESTACIÓN METEOROLÓGICA DE VALDESPARTERA (AEMET y elaboración propia)

8-42 CUADRO DE DIFERENCIA ANUAL CUANDO LA TEMPERATURA ES MENOR DE $20^{\circ} \mathrm{C}$ DURANTE LOS PERIODOS FRÍOS (DE OCTUBRE A MAYO) Y MAYOR DE $20^{\circ} \mathrm{C}$ DURANTE LOS PERIODOS CÁLIDOS (DE JUNIO A SEPTIEMBRE) EN GRADOS-HORA ENTRE LOS VALORES MEDIOS Y LOS REGISTRADOS EN LA ESTACIÓN METEOROLÓGICA DE AEROPUERTO (AEMET y elaboración propia) .

8-43 CUADRO DE DIFERENCIA ANUAL CUANDO LA TEMPERATURA ES MENOR DE $16^{\circ} \mathrm{C}$ DURANTE LOS PERIODOS FRÍOS (DE OCTUBRE A MAYO) Y MAYOR DE $26^{\circ} \mathrm{C}$ DURANTE LOS PERIODOS CÁLIDOS (DE JUNIO A SEPTIEMBRE) EN GRADOS-HORA ENTRE LOS VALORES MEDIOS Y LOS REGISTRADOS EN LA ESTACIÓN METEOROLÓGICA DE AEROPUERTO (AEMET y elaboración propia)

8-44 CUADRO DE DIFERENCIA ANUAL CUANDO LA TEMPERATURA ES MENOR DE $16^{\circ} \mathrm{C}$ (HORAS FRIAS) Y MAYOR DE $26^{\circ} \mathrm{C}$ (HORAS CÁLIDAS) EN GRADOSHORA ENTRE LOS VALORES MEDIOS Y LOS REGISTRADOS EN LA ESTACIÓN METEOROLÓGICA DE AEROPUERTO (AEMET y elaboración propia)

8-45 CUADRO COMPARATIVO ENTRE LAS ESTACIONES METEOROLÓGICAS DE CANAL (C) Y DEL AEROPUERTO (A) DE ZARAGOZA DESDE EL AÑO 2007 AL 2014 (AEMET y elaboración propia)

8-46 CUADRO COMPARATIVO DE TEMPERATURAS MEDIAS ANUALES REPRESENTIVAS EN LA DECADA 2005-2014 ZARAGOZA. AEROPUERTO. (AEMET y elaboración propia)

8-47 CUADRO DE PERCENTILES Y MÁXIMOS Y MÍNIMOS ABSOLUTOS DE LAS DIFERENCIAS DE LAS TEMPERATURAS HORARIAS ENTRE LOS VALORES MEDIOS DE LAS ESTACIONES METEOROLÓGICAS DE CANAL, VALDESPARTERA Y AEROPUERTO DE ZARAGOZA Y LA ESTACIÓN METEOROLÓGICA DE CANAL, DURANTE EL AÑO 2014 (AEMET y elaboración propia)

8-48 GRAFICA ANUAL DE LAS DIFERENCIAS DE LAS TEMPERATURAS HORARIAS ENTRE LOS VALORES MEDIOS DE LAS ESTACIONES METEOROLÓGICAS DE CANAL, VALDESPARTERA Y AEROPUERTO DE ZARAGOZA Y LA ESTACIÓN METEOROLÓGICA DE CANAL, DURANTE EL AÑO 2014 (AEMET y elaboración propia)

8-49 CUADRO DE PERCENTILES Y MÁXIMOS Y MÍNIMOS ABSOLUTOS DE LAS DIFERENCIAS DE LAS TEMPERATURAS HORARIAS ENTRE LOS VALORES MEDIOS DE LAS ESTACIONES METEOROLÓGICAS DE CANAL, VALDESPARTERA Y AEROPUERTO DE ZARAGOZA Y LA ESTACIÓN METEOROLÓGICA DE VALDESPARTERA, DURANTE EL AÑO 2014 (AEMET y elaboración propia)

8-50 GRAFICA ANUAL DE LAS DIFERENCIAS DE LAS TEMPERATURAS HORARIAS ENTRE LOS VALORES MEDIOS DE LAS ESTACIONES METEOROLÓGICAS DE CANAL, VALDESPARTERA Y AEROPUERTO DE ZARAGOZA Y LA ESTACIÓN 
METEOROLÓGICA DE VALDESPARTERA, DURANTE EL AÑO 2014 (AEMET y elaboración propia)

8-51 CUADRO DE PERCENTILES Y MÁXIMOS Y MÍNIMOS ABSOLUTOS DE LAS DIFERENCIAS DE LAS TEMPERATURAS HORARIAS ENTRE LOS VALORES MEDIOS DE LAS ESTACIONES METEOROLÓGICAS DE CANAL, VALDESPARTERA Y AEROPUERTO DE ZARAGOZA Y LA ESTACIÓN METEOROLÓGICA DEL AEROPUERTO, DURANTE EL AÑO 2014 (AEMET y elaboración propia)

8-52 GRAFICA ANUAL DE LAS DIFERENCIAS DE LAS TEMPERATURAS HORARIAS ENTRE LOS VALORES MEDIOS DE LAS ESTACIONES METEOROLÓGICAS DE CANAL, VALDESPARTERA Y AEROPUERTO DE ZARAGOZA Y LA ESTACIÓN METEOROLÓGICA DEL AEROPUERTO, DURANTE EL AÑO 2014 (AEMET Y elaboración propia)

8-53 GRÁFICA ANUAL DE TEMPERATURAS MEDIAS DIARIAS EN LAS ESTACIONES DE REFERENCIA EN ZARAGOZA (10/06/2013-10/06/2014) (AEMET y elaboración propia)

8-54 GRÁFICA ANUAL DE TEMPERATURAS HORARIAS EN LAS ESTACIONES DE REFERENCIA EN ZARAGOZA (10/06/2013-10/06/2014) (AEMET y elaboración propia)

8-55 CUADRO COMPARATIVO DE TEMPERATURAS MÍNIMAS, MEDIAS, MÁXIMAS EN LAS ESTACIONES METEOROLÓGICAS DE CANAL,VALDESPARTERA Y AEROPUERTO DE ZARAGOZA 10-06-2013 A 10-062014 (AEMET y elaboración propia) 253

8-56 CUADRO COMPARATIVO DEL $2^{\circ}$ Y 3ER. EN LAS ESTACIONES METEOROLÓGICAS DE CANAL,VALDESPARTERA Y AEROPUERTO DE ZARAGOZA 10-06-2013 A 10-06-2014 (AEMET y elaboración propia) 253

8-57 GRAFICA ANUAL DE LAS DIFERENCIAS DE LAS TEMPERATURAS HORARIAS ENTRE LOS VALORES MEDIOS DE LAS ESTACIONES METEOROLÓGICAS DE CANAL, VALDESPARTERA Y AEROPUERTO DE ZARAGOZA DE 10/06/2013 A 10/06/2014 (AEMET y elaboración propia)

8-58 CUADRO CON LA COMPARACIÓN DE LOS VALORES MEDIOS, MÁXIMOS Y MÍNIMOS DIARIOS ENTRE LAS TRES ESTACIONES DE REFERENCIA EN ZARAGOZA. AÑO 2014 (AEMET y elaboración propia)

8-59 CUADRO CON LA COMPARACIÓN DE LAS DIFERENCIAS ENTRE LAS ESTACIONES DE REFERENCIA EN ZARAGOZA DURANTE EL AÑO 2014 (AEMET Y elaboración propia)

8-60 GRÁFICA DE LAS TEMPERATURAS MÁXIMAS, MÍNIMAS Y MEDIAS DIARIAS EN LA ESTACIÓN METEOROLÓGICA DE CANAL EN ZARAGOZA, DURANTE EL AÑO 2014 (AEMET y elaboración propia)

8-61 CUADRO DE LAS TEMPERATURAS ABSOLUTAS Y MEDIAS DIARIAS EN LA ESTACIÓN METEOROLÓGICA DE CANAL EN ZARAGOZA, DURANTE EL AÑO 2014 (AEMET y elaboración propia)

8-62 CUADRO DE LAS DIFERENCIAS EN LAS TEMPERATURAS DIARIAS ENTRE LOS VALORES MEDIOS DE LAS ESTACIONES METEOROLÓGICAS DE CANAL, VALDESPARTERA Y AEROPUERTO DE ZARAGOZA Y LA ESTACIÓN METEOROLÓGICA DE CANAL, DURANTE EL AÑO 2014. (AEMET y elaboración propia) 
8-63 GRÁFICA DE LAS TEMPERATURAS MÁXIMAS, MÍNIMAS Y MEDIAS DIARIAS EN LA ESTACIÓN METEOROLÓGICA DE VALDESPARTERA EN ZARAGOZA, DURANTE EL AÑO 2014 (AEMET y elaboración propia) 258

8-64 CUADRO DE LAS TEMPERATURAS ABSOLUTAS Y MEDIAS DIARIAS EN LA ESTACIÓN METEOROLÓGICA DE AEROPUERTO DE ZARAGOZA, DURANTE EL AÑO 2014 (AEMET y elaboración propia) 258

8-65 CUADRO DE LAS DIFERENCIAS EN LAS TEMPERATURAS DIARIAS ENTRE LOS VALORES MEDIOS DE LAS ESTACIONES METEOROLÓGICAS DE CANAL, VALDESPARTERA Y AEROPUERTO DE ZARAGOZA Y LA ESTACIÓN METEOROLÓGICA DE VALDESPARTERA, DURANTE EL AÑO 2014 (AEMET Y elaboración propia)

8-66 GRÁFICA DE LAS TEMPERATURAS MÁXIMAS, MÍNIMAS Y MEDIAS DIARIAS EN LA ESTACIÓN METEOROLÓGICA DE AEROPUERTO EN ZARAGOZA, DURANTE EL AÑO 2014 (AEMET y elaboración propia)

8-67 CUADRO DE LAS TEMPERATURAS ABSOLUTAS Y MEDIAS DIARIAS EN LA ESTACIÓN METEOROLÓGICA DE AEROPUERTO DE ZARAGOZA, DURANTE EL AÑO 2014 (AEMET y elaboración propia)

8-68 CUADRO DE LAS DIFERENCIAS EN LAS TEMPERATURAS DIARIAS ENTRE LOS VALORES MEDIOS DE LAS ESTACIONES METEOROLÓGICAS DE CANAL, VALDESPARTERA Y AEROPUERTO DE ZARAGOZA Y LA ESTACIÓN METEOROLÓGICA DE AEROPUERTO, DURANTE EL AÑO 2014 (AEMET Y elaboración propia)

8-69 GRÁFICA DIARIA COMPARADA DE TEMPERATURAS HORARIAS DEL DÍA 01/04/2014. EN CANAL Y AEROPUERTO. ZARAGOZA. (AEMET y elaboración propia)

8-70 GRÁFICA DIARIA COMPARADA DE TEMPERATURAS HORARIAS DEL DÍA 01/07/2014. EN CANAL Y AEROPUERTO. ZARAGOZA. (AEMET y elaboración propia)

8-71 GRÁFICA DIARIA COMPARADA DE TEMPERATURAS HORARIAS DEL DÍA 10/02/2014. EN CANAL Y AEROPUERTO. ZARAGOZA. (AEMET y elaboración propia)

8-72 GRÁFICA DIARIA COMPARADA DE TEMPERATURAS HORARIAS DEL DÍA 17/05/2014. EN CANAL Y AEROPUERTO. ZARAGOZA. (AEMET y elaboración propia)

8-73 GRÁFICA DIARIA COMPARADA DE TEMPERATURAS HORARIAS DEL DÍA 29/08/2014. EN CANAL Y AEROPUERTO. ZARAGOZA. (AEMET y elaboración propia)

8-74 GRÁFICA DIARIA COMPARADA DE TEMPERATURAS HORARIAS DEL DÍA 09/06/2014. EN CANAL Y AEROPUERTO. ZARAGOZA. (AEMET y elaboración propia)

8-75 GRÁFICA DIARIA COMPARADA DE TEMPERATURAS HORARIAS DEL DÍA 21/012/2014. EN CANAL Y AEROPUERTO. ZARAGOZA. (AEMET y elaboración propia)

8-76 GRÁFICA DIARIA COMPARADA DE TEMPERATURAS HORARIAS DEL DÍA 21/012/2014. EN VALDESPARTERA Y AEROPUERTO. ZARAGOZA. (AEMET Y elaboración propia) 
8-77 GRÁFICA DIARIA COMPARADA DE TEMPERATURAS HORARIAS DEL DÍA 01/01/2014. EN CANAL Y VALDESPARTERA. ZARAGOZA. (AEMET Y elaboración propia)

8-78 GRÁFICA DIARIA COMPARADA DE TEMPERATURAS HORARIAS DEL DÍA 01/01/2014. EN CANAL Y AEROPUERTO. ZARAGOZA. (AEMET y elaboración propia)

8-79 GRÁFICA DIARIA COMPARADA DE TEMPERATURAS HORARIAS DEL DÍA 01/01/2014. EN VALDESPARTERA Y AEROPUERTO. ZARAGOZA. (AEMET Y elaboración propia)

8-80 GRÁFICA DIARIA COMPARADA DE TEMPERATURAS HORARIAS DEL DÍA 01/01/2014. EN AEROPUERTO Y VALDESPARTERA. ZARAGOZA. (AEMET Y elaboración propia)

8-81 GRÁFICA DIARIA COMPARADA DE TEMPERATURAS HORARIAS DEL DÍA 01/03/2014. EN AEROPUERTO Y VALDESPARTERA. ZARAGOZA. (AEMET Y elaboración propia)

8-82 GRÁFICA DIARIA COMPARADA DE TEMPERATURAS HORARIAS DEL DÍA 23/02/2014. EN AEROPUERTO Y VALDESPARTERA. ZARAGOZA. (AEMET Y elaboración propia)

8-83 GRÁFICA DIARIA COMPARADA DE TEMPERATURAS HORARIAS DEL DÍA 14/02/2014. EN AEROPUERTO Y VALDESPARTERA. ZARAGOZA. (AEMET Y elaboración propia)

8-84 GRÁFICA DIARIA COMPARADA DE TEMPERATURAS HORARIAS DEL DÍA 21/12/2014. EN CANAL Y VALDESPARTERA. ZARAGOZA. (AEMET Y elaboración propia)

8-85 GRÁFICA DIARIA COMPARADA DE TEMPERATURAS HORARIAS DEL DÍA 04/02/2014. EN CANAL Y VALDESPARTERA. ZARAGOZA. (AEMET Y elaboración propia)

8-86 GRÁFICA COMPARATIVA DE LOS PERIODOS CON TEMPERATURAS INFERIORES A $16^{\circ} \mathrm{C}$ (NECESIDAD DE CALOR), SUPERIORES A $26^{\circ} \mathrm{C}$ (NECESIDAD DE FRÍO) Y EL PERIODO CON TEMPERATURAS ENTRE $16^{\circ} \mathrm{C}$ Y $26 \mathrm{C}$, EN LAS ESTACIONES METEOROLOGICAS DE CANAL Y AEROPUERTO EN ZARAGOZA DESDE EL AÑO 2007 AL 2014 (AEMET y elaboración propia)

8-87 GRÁFICA COMPARATIVA DE LAS TEMPERATURAS DE CONFORT ADAPTATIVO APOYADO EN LOS VALORES DE TEMPERATURA DE LAS ESTACIONES METEOROLOGICAS DE CANAL Y AEROPUERTO EN ZARAGOZA DESDE EL AÑO 2007 AL 2014 (AEMET y elaboración propia)

8-88 GRÁFICA COMPARATIVA DE LAS TEMPERATURAS MEDIAS ANUALES DE LAS ESTACIONES METEOROLOGICAS DE CANAL Y AEROPUERTO EN ZARAGOZA DESDE EL AÑO 2007 AL 2014 (AEMET y elaboración propia)

8-89 GRÁFICA COMPARATIVA DE LOS PERIODOS CON TEMPERATURAS INFERIORES A $16^{\circ} \mathrm{C}$ (NECESIDAD DE CALOR), SUPERIORES A $26^{\circ} \mathrm{C}$ (NECESIDAD DE FRÍO) Y EL PERIODO CON TEMPERATURAS ENTRE $16^{\circ} \mathrm{C}$ Y $26 \mathrm{C}$, EN LAS ESTACIONES METEOROLOGICAS DE CANAL Y AEROPUERTO EN ZARAGOZA DESDE EL AÑO 2007 AL 2014 (AEMET y elaboración propia) 
ESTACIONES METEOROLOGICAS DE REFERENCIA DE CANAL, VALDESPARTERA Y AEROPUERTO EN ZARAGOZA DURANTE EL AÑO 2014 (AEMET y elaboración propia)

8-91 CUADRO COMPARATIVO DE LAS DIFERENCIAS CON RESPECTO A LOS VALORES MEDIOS REGISTRADOS EN LAS ESTACIONES METEOROLOGICAS DE REFERENCIA DE CANAL, VALDESPARTERA Y AEROPUERTO EN ZARAGOZA Y CADA UNA DE ELLAS DURANTE EL AÑO 2014 (AEMET y elaboración propia)

8-92 GRÁFICA DE LAS MEDIAS DIARIAS EN LA ESTACIÓN DE ZARAGOZAAEROPUERTO DURANTE EL AÑO 2014 Y LAS MEDIANAS CADA 3-6 y 9 DÍAS (AEMET y elaboración propia)

8-93 GRÁFICA DE LAS MEDIAS CADA 3 DÍAS EN LA ESTACIÓN DE ZARAGOZAAEROPUERTO Y EN S. PABLO DURANTE EL AÑO 2014 (AEMET y elaboración propia)

8-94 GRÁFICA DE LAS MEDIAS CADA 9 DÍAS EN LA ESTACIÓN DE ZARAGOZAAEROPUERTO Y EN S. PABLO DURANTE EL AÑO 2014 (AEMET y elaboración propia)

8-95 GRÁFICA DE LA SERIE TÉRMICA HORARIA EN LA ESTACIÓN DE ZARAGOZA-AEROPUERTO DURANTE EL MES DE ENERO DEL AÑO 2014(AEMET y elaboración propia)

8-96 GRÁFICA ANUAL DESGLOSADA EN ZONAS HOMOGÉNEAS EN LA EVOLUCIÓN DE LA MEDIANA DE SU TEMPERATRUAS DIARIAS DURANTE EL AÑO 2014 (AEMET y elaboración propia) 284

8-97 GRÁFICA DE LA SERIE TÉRMICA HORARIA EN LA ESTACIÓN DE ZARAGOZA-AEROPUERTO DURANTE EL MES DE ENERO DEL AÑO 2014 CON RETARDO EN ALCANZAE LOS VALORES MÁXIMOS EN MEIDAS CADA 9 DÍAS (AEMET y elaboración propia) 285

8-98 GRÁFICA DE TEMPERATURAS MÁXIMAS, MEDIAS Y MÍNIMAS DE LAS TEMPERATURAS PROMEDIO DIARIAS DURANTE LA DÉCADA 2005-2014 EN ZARAGOZA AEROPUERTO COMPARADA CON LA TEMPERATURA PROMEDIO DIARIA DEL CLIMA ADOPTADO POR CTE PARA LA ZONA CLIMÁTICA D3 (AEMET, CTE y elaboración propia)

8-99 GRÁFICA DE TEMPERATURAS MÁXIMAS, MEDIAS Y MÍNIMAS DE LAS MÁXIMAS DIARIAS DURANTE LA DÉCADA 2005-2014 EN ZARAGOZA AEROPUERTO COMPARADA CON LA TEMPERATURA MÁXIMA DIARIA DEL CIMA ADOPTADO POR CTE PARA LA ZONA CLIMÁTICA D3 (AEMET, CTE Y elaboración propia)

8-100 GRÁFICA DE TEMPERATURAS MÁXIMAS, MEDIAS Y MÍNIMAS DE LAS MÁXIMAS DIARIAS DURANTE LA DÉCADA 2005-2014 EN ZARAGOZA AEROPUERTO COMPARADA CON LA TEMPERATURA MÁXIMA DIARIA DEL CIMA ADOPTADO POR CTE PARA LA ZONA CLIMÁTICA D3 (AEMET, CTE Y elaboración propia)

8-101 GRÁFICA DE TEMPERATURAS MÁXIMAS, MEDIAS Y MÍNIMAS DE LAS MÁXIMAS DIARIAS DURANTE LA DÉCADA 2005-2014 EN ZARAGOZA AEROPUERTO COMPARADA CON LA TEMPERATURA MÁXIMA DIARIA DEL CLIMA ADOPTADO POR CTE PARA LA ZONA CLIMÁTICA D3 (AEMET, CTE Y elaboración propia) 
8-102 VALORES MEDIOS DE LAS TEMPERATURAS MÁXIMAS, MEDIAS Y MÍNIMAS EN ZARAGOZA EN LA DECADA 2015-2014 (AEMET y elaboración propia)

8-103 VALORES EN GRADOS HORA DE LOS CUARTILES DE LAS TEMPERATURAS EN LA DÉCADA 2005 A 2014 Y EN LOS CLIMAS DE REFERENCIA PARA LA ZONA D3 Y PARA ZARAGOZA (CTE, RITE, AEMET y elaboración propia)

8-104 GRÁFICA DECENAL DE CUARTILES EN ZARAGOZA (AEMET y elaboración propia)

8-105 GRÁFICA DE GRADOS HORA QUE SUPERAN LOS $26^{\circ} \mathrm{C}$ (A DISIPAR, NO ALCANZAN LOS $16^{\circ} \mathrm{C}$ (A CALEFACTAR) Y QUEDAN ENTRE AMBOS (AEMET Y elaboración propia)

8-106 GRÁFICA COMPARADA CON LOS VALORES DE TIEMPO EN QUE LA TEMPERATURA ES MAYOR DE $26^{\circ} \mathrm{C}$ (PERIODO CÁLIDO) EN ZARAGOZA EN LA DECADA DE 2005 A 2014. (AEMET y elaboración propia).

8-103 GRÁFICA COMPARADA CON LOS VALORES DE GRADOS-HORA SOBRE $26^{\circ} \mathrm{C}$ (PERIODO CÁLIDO) EN ZARAGOZA EN LA DECADA DE 2005 A 2014. (AEMET Y ELABORACIÓN PROPIA).

8-108 GRÁFICA COMPARADA CON LOS VALORES DE TIEMPO EN QUE LA TEMPERATURA ES MENOR DE $16^{\circ} \mathrm{C}$ (PERIODO CÁLIDO) EN ZARAGOZA EN LA DECADA DE 2005 A 2014. (AEMET y elaboración propia).

8-109 GRÁFICA COMPARADA CON LOS VALORES DE GRADOS-HORA BAJO $16^{\circ} \mathrm{C}$ (PERIODO CÁlIDO) EN ZARAGOZA EN LA DECADA DE 2005 A 2014. (AEMET y elaboración propia).

8-110 GRÁFICA COMPARADA CON LAS TEMPERATURAS MÁXIMAS ABSOLUTAS ANUALES EN ZARAGOZA EN LA DECADA DE 2005 A 2014 (AEMET y elaboración propia).

8-111 GRÁFICA COMPARADA CON LAS TEMPERATURAS MÍNIMAS ABSOLUTAS ANUALES EN ZARAGOZA EN LA DECADA DE 2005 A 2014. (AEMET y elaboración propia).

8-112 GRÁFICA COMPARADA CON LAS TEMPERATURA MEDIANA ANUAL EN ZARAGOZA EN LA DECADA DE 2005 A 2014. (AEMET y elaboración propia).....

8-113 GRÁFICA COMPARADA CON LAS TEMPERATURA DEL PRIMER CUARTIL ANUAL EN ZARAGOZA EN LA DECADA DE 2005 A 2014. (AEMET Y elaboración propia).

8-114 GRÁFICA COMPARADA CON LAS TEMPERATURA DEL SEGUNDO CUARTIL ANUAL EN ZARAGOZA EN LA DECADA DE 2005 A 2014. (AEMET Y elaboración propia).

8-115 GRÁFICA COMPARADA CON LAS TEMPERATURA DEL CUARTO CUARTIL ANUAL EN ZARAGOZA EN LA DECADA DE 2005 A 2014. (AEMET Y elaboración propia).

8-116 GRÁFICA COMPARADA CON LAS TEMPERATURA DEL CUARTO CUARTIL ANUAL EN ZARAGOZA EN LA DECADA DE 2005 A 2014. (AEMET Y elaboración propia). 
8-117 GRÁFICA ANUAL CONJUNTA DE GRADOS-HORA POR ENCIMA DE $26^{\circ} \mathrm{C}$ Y MENORES DE $16^{\circ} \mathrm{C}$ EN LA DÉCADA DE 2005 A 2014 EN ZARAGOZA (AEMET y elaboración propia). 303

8-118 GRÁFICA ANUAL CONJUNTA DE PERIODOS CON TEMPERATURA POR ENCIMA DE $26^{\circ} \mathrm{C}$ Y MENOR DE $16^{\circ} \mathrm{C}$ EN LA DÉCADA DE 2005 A 2014 EN ZARAGOZA (AEMET y elaboración propia). 303

8-119 SERIE DE TEMPERATURAS MEDIAS ANUALES (1961-2014) INFORME CLIMÁTICO DEL AÑO 2014. (AEMET) 304

8-120 PROMEDIO DE LOS PERIODOS EN QUE LA TEMPERATURA ES INFERIOR A $16^{\circ} \mathrm{C}$, (PERIODO FRÍO), Y SUPERIOR A $26^{\circ} \mathrm{C}$ (PERIODO CÁLIDO) Y ESTÁ ENTRE AMBAS (PERIODO TEMPLADO) (AEMET y elaboración propia) 304

8-121 COMPARACIÓN DE UMBRALES PARA TEMPERATURAS MÍNIMAS Y MÁXIMAS REGISTRADAS EN LA ESTACIÓN DE REFERENCIA EN EL AEROPUERTO DE ZARAGOZA Y EN LA SITUADA EN LA CALLE S. PABLO DE ZARAGOZA DURANTE EL AÑO 2014 (AEMET y elaboración propia) 306

8-122 GRÁFICA DE MEDIA DIARIA EN LAS ESTACIONES DE ZARAGOZAAEROPUERTO Y SAN PABLO DESDE EL 1 DE ENERO AL 4 DE ABRIL DEL AÑO 2014(AEMET y elaboración propia)

8-123 GRÁFICA DE MEDIA DIARIA EN LAS ESTACIONES DE ZARAGOZAAEROPUERTO Y SAN PABLO DESDE EL 1 DE ENERO AL 3 DE FEBRERO DEL AÑO 2014(AEMET y elaboración propia) 307

8-124 GRÁFICA DE MEDIA DIARIA EN LAS ESTACIONES DE ZARAGOZAAEROPUERTO Y SAN PABLO DESDE EL 3 DE FEBRERO AL 4 DE ABRIL DEL AÑO 2014(AEMET y elaboración propia) 308

8-125 GRÁFICA DE MEDIA DIARIA EN LAS ESTACIONES DE ZARAGOZAAEROPUERTO Y SAN PABLO DESDE EL 1 DE ENERO AL 3 DE FEBRERO DEL AÑO 2014(AEMET y elaboración propia) 308

8-126 GRÁFICA COMPARADA DE LAS SERIES TÉRMICAS EN LA ESTACIÓN DE ZARAGOZA Y EN EL EDIFICIO DE LA CALLE SAN PABLO, EN ZARAGOZA DURANTE LOS MESES DE ENERO, FEBRERO Y MARZO DEL AÑO 2014. (AEMET Y elaboración propia)

8-124 GRÁFICA COMPARADA DE LAS SERIES TÉRMICAS EN LA ESTACIÓN DE ZARAGOZA Y EN EL EDIFICIO DE LA CALLE SAN PABLO, EN ZARAGOZA DURANTE EL MES DE ENERO DEL AÑO 2014. (AEMET Y ELABORACIÓN PROPIA)

8-128 GRÁFICA COMPARADA DE LAS SERIES TÉRMICAS EN LA ESTACIÓN DE ZARAGOZA Y EN EL EDIFICIO DE LA CALLE SAN PABLO, EN ZARAGOZA DURANTE LOS DÍAS 10 AL 25 DE ENERO DEL AÑO 2014. (AEMET y elaboración propia)

8-129 GRÁFICA COMPARADA DE LAS SERIES TÉRMICAS EN LA ESTACIÓN DE ZARAGOZA Y EN EL EDIFICIO DE LA CALLE SAN PABLO, EN ZARAGOZA DURANTE LOS DÍAS 24 DE ENERO AL 3 DE FEBRERO DEL AÑO 2014. (AEMET Y elaboración propia) 
8-131 GRÁFICA COMPARADA DE LAS SERIES TÉRMICAS EN LA ESTACIÓN DE ZARAGOZA Y EN EL EDIFICIO DE LA CALLE SAN PABLO, EN ZARAGOZA DURANTE LOS DÍAS 03 AL 06 DE ABRIL DEL AÑO 2014. (AEMET y elaboración propia)

8-132 GRÁFICA COMPARADA DE LAS SERIES TÉRMICAS EN LA ESTACIÓN DE ZARAGOZA Y EN EL EDIFICIO DE LA CALLE SAN PABLO, EN ZARAGOZA DURANTE LOS DÍAS 8 AL 11 DE FEBRERO DEL AÑO 2014. (AEMET Y elaboración propia)

8-133 GRÁFICA COMPARADA DE LAS SERIES TÉRMICAS EN LA ESTACIÓN DE ZARAGOZA Y EN EL EDIFICIO DE LA CALLE SAN PABLO, EN ZARAGOZA DURANTE LOS DÍAS 1 AL 3 DE ABRIL DEL AÑO 2014. (AEMET y elaboración propia)

8-134 POSICIÓN DE LOS PUNTO DE MEDICIÓN DE LAS SERIES TÉRMICAS JUNTO AL EDIFICIO (Elaboración propia)

FIG 8-135 LOCALIZACIÓN EN LA CIUDAD DE LA ZONA DE TRABAJO (Google Maps y elaboración propia)

FIG 8-136 LOCALIZACIÓN URBANA DE LA ZONA DE TRABAJO (Google Maps y elaboración propia)

FIG 8-137 FACHADA NORTE A CALLE S. PABLO Y SUR AL PATIO INTERIOR (Elaboración propia)

FIG 8-138 FACHADA SUR A CALLE B. BOGGIERO Y NORTE AL PATIO INTERIOR (Elaboración propia).

8-139 GRÁFICA COMPARADA DE LAS DIFERENCIAS ENTRE LAS TEMPERATURAS HORARIAS ENTRE LAS ESTACIONES DE ZARAGOZAAEROPUERTO Y PATIO INTERIOR EN S. PABLO, DESDE JUNIO DE 2013 A JUNIO DE 2014. (AEMET y elaboración propia)

8-140 GRÁFICA COMPARADA DE LAS OSCILACIONES TÉRMICAS EN LAS ESTACIONES DE ZARAGOZA-AEROPUERTO Y PATIO INTERIOR EN S. PABLO, DESDE JUNIO DE 2013 A JUNIO DE 2014. (AEMET y elaboración propia)

FIG 8-141 EVOLUCIÓN COMPARADA DE LA TEMPERATURA EN ZARAGOZA CENTRO EN EL INTERIOR Y EL EXTERIOR DE UN EDIFICIO DEL 10 AL 19 DE JUNIO DE 2013 (Elaboración propia)

FIG 8-142 EVOLUCIÓN COMPARADA DE LA TEMPERATURA EN ZARAGOZA CENTRO DEL 20 AL 30 DE JUNIO DE 2013 (Elaboración propia)

FIG 8-143 EVOLUCIÓN COMPARADA DE LA TEMPERATURA EN ZARAGOZA CENTRO DEL 1 AL 9 DE JULIO DE 2013 (Elaboración propia)

FIG 8-144 EVOLUCIÓN COMPARADA DE LA TEMPERATURA EN ZARAGOZA

CENTRO DEL 20 AL 31 DE JULIO (Elaboración propia)

FIG 8-145 EVOLUCIÓN COMPARADA DE LA TEMPERATURA EN ZARAGOZA

CENTRO DEL 20 AL 31 DE JULIO (Elaboración propia) 
FIG 8-147 RELACION ENTRE LAS TEMPERATURAS MÁXIMAS Y MÍNIMAS EN LAS DISTINTAS LOCALIZACIONES EN ZARAGOZA CENTRO ENTRE EL 20 Y EL 31 DE JULIO DE 2013 (Elaboración propia)

FIG 8-148 GRÁFICA DEL NÚMERO Y LA PROPORCIÓN DE HORAS CÁLIDAS (> $26^{\circ} \mathrm{C}$ ) EN ZARAGOZA CENTRO DEL 20 AL 31 DE JULIO DE 2013. (Elaboración propia)

FIG 8-149 GRÁFICA DE LAS OSICILACIONES MÁXIMAS, MÍNIMAS Y MEDIAS EN ZARAGOZA CENTRO ENTRE EL 20 Y EL 31 DE JULIO DE 2013 (Elaboración propia)

8-150 SECUENCIA DE LA EVOLUCIÓN TÉRMICA EN PERIODO DE TRANSICIÓN DEL PERIODO FRÍO AL CÁLIDO, DEL 1 AL 4 DE ABRIL DE 2014 INCLUYENDO VIENTO, RADIACIÓN Y HUMEDAD (Elaboración propia)

8-151 ESQUEMA COMPARADO DE LA EVOLUCIÓN DE LAS MEDIAS DIARIAS DE LAS TEMPERATURAS EN UNA ESTACIÓN METEOROLÓGICA Y EN UN PATIO INTERIOR DE UN EDIFICIO EN LA CALLE S. PABLO DE ZARAGOZA (Elaboración propia).

8-152 GRÁFICA COMPARADA DE LA EVOLUCIÓN TÉRMICA EN UNA ESTACION METEOROLÓGICA LOCAL Y UNA DE REFERENCIA EN ZARAGOZA ENTRE LOS DÍAS 15 AL 20 DE NOVIEMBRE DE 2014. (Elaboración propia) 335

8-153 GRÁFICA COMPARADA DE LA EVOLUCIÓN TÉRMICA EN UNA ESTACION METEOROLÓGICA LOCAL Y UNA DE REFERENCIA EN ZARAGOZA ENTRE LOS DÍAS 15 AL 20 DE NOVIEMBRE DE 2014. (Elaboración propia) 336

8-154 GRÁFICA COMPARADA DE LA EVOLUCIÓN TÉRMICA EN UNA ESTACION METEOROLÓGICA LOCAL Y UNA DE REFERENCIA EN ZARAGOZA ENTRE LOS DÍAS 15 AL 20 DE NOVIEMBRE DE 2014. (Elaboración propia)

FIG 8-155 GRÁFICA COMPARADA DE LA EVOLUCIÓN TÉRMICA EN UNA ESTACION METEOROLÓGICA LOCAL Y UNA DE REFERENCIA EN ZARAGOZA ENTRE LOS DÍAS 15 AL 20 DE NOVIEMBRE DE 2014. (Elaboración propia)

8-156 GRÁFICA COMPARADA DE LA EVOLUCIÓN TÉRMICA EN UNA ESTACION METEOROLÓGICA LOCAL Y UNA DE REFERENCIA EN ZARAGOZA ENTRE LOS DÍAS 15 AL 20 DE NOVIEMBRE DE 2014. (Elaboración propia) 338

8-157 GRÁFICA COMPARADA DE LA EVOLUCIÓN TÉRMICA EN UNA ESTACION METEOROLÓGICA LOCAL Y UNA DE REFERENCIA EN ZARAGOZA ENTRE LOS DÍAS 15 AL 20 DE NOVIEMBRE DE 2014. (Elaboración propia) 339

9-1 GRÁFICA DE VALORES DISCONTÍNUOS DE MEDIAS DIARIAS EN ZARAGOZA EN EL PERIODO CÁLIDO ENTRE 10-06-2013 Y 20-10-2013 (AEMET Y elaboración propia) 354

9-2 ESQUEMA DE FRANJAS DE HOMOGENEIDA TÉRMICA A LAS QUE CORRESPONDEN RESPUESTAS SIGNIFICATIVAS DEL EDIFICIO DURANTE EL AÑO 2014 EN ZARAGOZA (AEMET y elaboración propia)

9-3 CUADRO COMPARATIVO DE LAS TEMPERATURAS DE CONFORT ADAPTATIVO A PARTIR DE LAS TEMPERATURAS REGISTRADAS EN LAS 
ESTACIONES METEOROLÓGICAS DE CANAL Y AEROPUERTO DE ZARAGOZA

DESDE EL AÑO 2007 AL 2014 (Elaboración propia) 358 


\subsection{GLOSARIO}

Clima Sucesión habitual de estados de tiempo, en un determinado lugar o un área geográfica.

"La palabra clima procede del griego "Klima" que designaba una zona de la Tierra limitada por dos latitudes, que estaba asociada a la inclinación de los rayos solares $y$, por extensión, a las caracteństicas meteorológicas predominantes. El clima corresponde a una síntesis del tiempo atmosférico, en que el estado de tiempo atmosférico se refiere al conjunto de las condic iones meteorológicas, en un momento dado y en un lugar concreto.

En la definición más común, el clima se refiere a las “condiciones medias del tiempo" y más concretamente, a la descripción estadística en términos cuantitativos de la media y de la variabilidad de las magnitudes relevantes relativasa peńodos de tiempo suficientemente largos.

Así, clima, en un sentido restringido puede definirse como una "síntesis de las condiciones meteorológicas", o más concretamente, como la descripción estadística de las caractenísticas del estado del tiempo durante un penóo de tiempo desde pocos meses hasta millones de años. El peńodo clásico es de 30 años, adoptado por la OMM. Esas cantidades, designadas elementos c limátic os, suelen ser variables observadas en la superficie terrestre como la temperatura y la precipitación (Glossa ry Intergovemmental Panel on Climate Change o IPCC, 2009)

Clima, en sentido amplio, es el estado del sistema climático, que presenta una variabilidad intema en una amplia gama de escalas de tiempo y depende de factores extemos: naturales, como enupciones volcánicas, variaciones solares; antropogénicos, como alteraciones en la composición química de la atmósfera y de la superficie terrestre.

En el clima los fenómenos interesan por su duración o persistencia y por su repetición y se caracteriza n por va lores medios, variaciones y probabilidades de producirse valores extremos, en relación a los diversos elementos climáticos. Por eso, el clima se caracteriza por valores medios, máximos, mínimos, cuartiles, distribuciones de probabilidad, etc., de las magnitudes má s adec uadas para efectuar esa síntesis." (AEMET, 2011)

Clima analítico Clima sintético elaborado a partir de los valores registrados en un observatorio. Puede referirse a valores promedio, máximos, mínimos, percentilles obtenidos durante un periodo representativo, normalmente superior a 10 años.

Clima de cálculo valores climáticos que se emplean para la caracterización del clima con el que se realizarán las prescripciones técnicas y se establecerán las prestaciones a los efectos de cumplir las exigencias normativas.

Clima de referencia Clima sintético incluido en las regulaciones sectoriales, con el objetivo de representar las cualidades de una región o zona climática.

En CTE:

Valores de temperatura y radiación que se aplican a una zona climática en los que se definen las solicitaciones exteriores en términos de temperatura y radiación.

(Pag. 17-18 CTE DB-HE 2013)

Define las solicitaciones exteriores de cálculo para un año tipo a través de una serie de parámetros (†emperatura, humedad, radiación solar...), representativos de una zona climática. (Pag. 1.Documento descriptivo climas de referencia, 2013)

Clima sintético Clima conformado a partir de valores climáticos elegidos para representar cualidades significativas de una región o zona climática. 
Climatología analítica conjunto de condiciones atmosféricas que caracterizan una región (GIL, 1999. Pag. 2)

Conjunto de fenómenos que caracterizan el estado medio de la atmósfera en un punto de la corteza terrestre (GIL, 1999. Pag. 3)

Sucesión o ritmo habitual de los estados de la atmósfera sobre un punto de la corteza terrestre (GIL, 1999. Pag. 2)

Climatología dinámica. Fenómenos atmosféricos considerados a través de la mecánica de fluidos. (GIL, 1999. Pag. 3)

Climatología sinóptica Realidad climática considerada a través de la tipificación de situaciones atmosféricas (GIL, 1999. Pag. 3)

Climatología sintética o física. Descripción y explicación de los fenómenos atmosféricos a través de la mecánica de fluidos. Se nutre de la climatología dinámica y sinóptica y describe el clima como una sucesión de fenómenos interrelacionados entre sí, proceso que define el ambiente atmosférico en un lugar geográfico. (GIL, 1999. Pag. 5)

Consumo energético Energía necesaria para satisfacer la demanda energética de los servicios de calefacción, refrigeración, ACS y, en edificios de uso distinto al residencial privado, de iluminación, del edificio, teniendo en cuenta la eficiencia de los sistemas empleados. En el contexto de este documento, se expresa en términos de energía primaria y en unidades $\mathrm{kW} \cdot \mathrm{h} / \mathrm{m} 2$.año, considerada la superficie útil de los espacios habitables del edificio. HEO

\section{Datos Meteorológicos Se consideran datos meteorológicos:}

Media mensual, estacional y anual de la temperatura media.

Media mensual, estacional y anual de la temperatura máxima.

Media mensual, estacional y anual de la temperatura mínima.

Media estacional y anual del número de días con temperatura:

Mínima $\leq 0^{\circ} \mathrm{C}$ (días de helada)

Mínima $\geq 20^{\circ} \mathrm{C}$ (noches tropicales)

Máxima $\geq 25^{\circ} \mathrm{C}$ (días cálidos)

Media de precipitación total mensual y anual.

Media estacional y anual del número de días con precipitación:

$\geq 0,1 \mathrm{~mm}$

$\geq 1 \mathrm{~mm}$

$\geq 10 \mathrm{~mm}$

$\geq 30 \mathrm{~mm} "$ (AEMET, 2011)

Demanda energética Energía útil necesaria que tendrían que proporcionar los sistemas técnicos para mantener en el interior del edificio unas condiciones definidas reglamentariamente en función del uso del edificio (perfiles de uso) y de la zona climática en la que se ubique (clima de referencia). Se puede dividir en demanda energética de calefacción, de refrigeración, de agua caliente sanitaria (ACS) y de iluminación, y se expresa en $\mathrm{kW} . \mathrm{h} / \mathrm{m}^{2}$.año, considerada la superficie útil de los espacios habitables del edificio. HEO

Demanda energética del edificio de referencia Demanda energética obtenida para el edificio de referencia. Puede obtenerse para la demanda energética de calefacción, de refrigeración, conjunta de calefacción y refrigeración(o global) (que incluye la demanda de calefacción, refrigeración, ACS e iluminación). Se expresa en kW . h/m2.año, considerada la superficie útil de los espacios habitables del edificio 
Energía final Energía tal y como se utiliza en los puntos de consumo. Es la que compran los consumidores, en forma de electricidad, carburantes $u$ otros combustibles usados de forma directa.

Energía primaria Energía suministrada al edificio procedente de fuentes renovables y no renovables, que no ha sufrido ningún proceso previo de conversión o transformación. Es la energía contenida en los combustibles y otras fuentes de energía e incluye la energía necesaria para generar la energía final consumida, incluyendo las pérdidas por su transporte hasta el edificio, almacenamiento, etc.

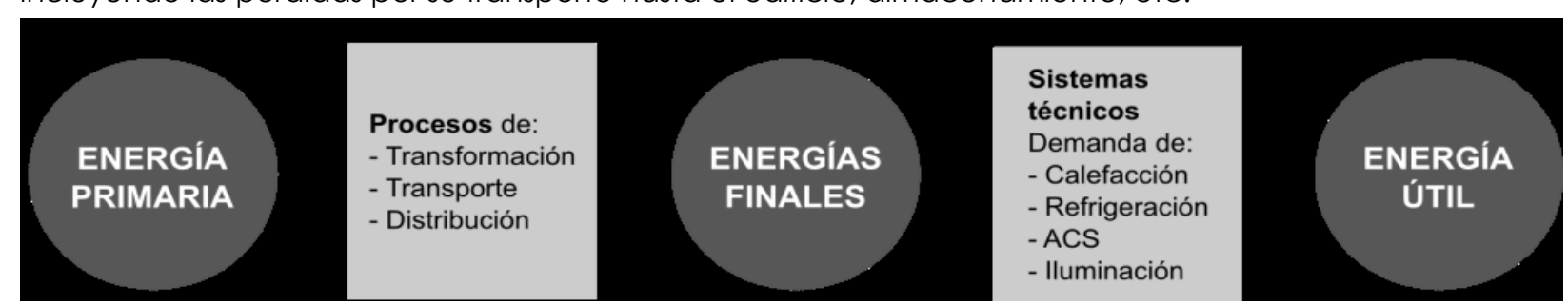

Energía primaria = Energía final + Pérdidas en transformación + Pérdidas en transporte

Grados-día. Acumulación expresada, mediante distintos procedimientos, como unidades térmicas o grados-día. La acumulación residual de grados-día considera para su determinación la temperatura base a partir de la cual se ejerce acción positiva sobre el crecimiento y desarrollo vegetal, la cual es variable para cada cultivo" (Garabatos, 1991).

Los Grados-Día (también citado como Días-Grado) es un parámetro importante a considerar para la definición de las estrategias de diseño, los requerimientos de climatización (natural o artificial) y por lo tanto la demanda de energía de una edificación. Los Grados-Día se pueden definir como los requerimientos de calentamiento o enfriamiento (en grados centígrados o Kelvin 1), necesarios para alcanzar la zona de confort, acumulados en un cierto período de tiempo (generalmente un mes, aunque podrían ser semanales, 0 incluso horarios). (FUENTES, 2013)

De esta forma se puede tener dos tipos de Grados-Día: de calentamiento o de enfriamiento. (FUENTES, 2013)

Estrictamente hablando, los Grados-Día se refieren al déficit o superávit acumulado de los 365 días del año, es decir(Szokolay, 2004):

$$
G D=\Sigma 1365\left(T-T_{\text {base }}\right)
$$

donde:

$$
\begin{aligned}
& \mathrm{GD}=\text { Grados-Día }\left({ }^{\circ} \mathrm{C}\right) \\
& \text { Tbase }=\text { Temperatura base (límite de referencia, inferior } \mathrm{O} \\
& \text { superior de confort }\left({ }^{\circ} \mathrm{C}\right) \\
& \mathrm{T}=\text { Temperatura media diaria }\left({ }^{\circ} \mathrm{C}\right)
\end{aligned}
$$

Aunque también puede analizarse de manera desagregada mes por mes:

$$
G D=\Sigma 1 n \text { (T-Tbase) }
$$

donde:

$$
\mathrm{n} \quad=\text { número de días del mes }
$$

Cuando no se cuenta con información diaria se pueden utilizar los datos mensuales de temperatura multiplicados por el número de días de mes, ya que estos datos representan el promedio de todos los días del mes. (FUENTES, 2013)

Grados-hora. Aplicación del concepto de grados día a un periodo de medición horario.

Humedad Relativa. Es la fracción de la presión de saturación que representa la presión parcial del vapor de agua en el espacio o ambiente exterior en estudio. Se tiene en cuenta en el cálculo de las condensaciones, superficiales e intersticiales en los cerramientos. (CTE-DB.HE.1, pag. 24) 
Índice Climático de Urbanidad Valor que refleja la diferencia entre distintas zonas del territorio en función de la densidad urbana y que recoge la posición relativa con respecto al perímetro, las dimensiones del núcleo urbano, la densidad de la edificación y la proporción de suelo construido.

IPPC. Grupo Intergubernamental de Expertos sobre el Cambio Climático (IPCC) en 1988. Se trata de un grupo abierto a todos los Miembros de las Naciones Unidas y de la OMM.

(http://www.ipcc.ch/home_languages_main_spanish.shtml)

La función del IPCC consiste en analizar, de forma exhaustiva, objetiva, abierta y transparente, la información científica, técnica y socioeconómica relevante para entender los elementos científicos del riesgo que supone el cambio climático provocado por las actividades humanas, sus posibles repercusiones y las posibilidades de adaptación y atenuación del mismo. El IPCC no realiza investigaciones ni controla datos relativos al clima $u$ otros parámetros pertinentes, sino que basa su evaluación principalmente en la literatura científica y técnica revisada por homólogos y publicada.

Una de las principales actividades del IPCC es hacer una evaluación periódica de los conocimientos sobre el cambio climático.

(http://es.wikipedia.org/wiki/Efecto_invernadero)

(http://www2.cgd.ucar.edu/)

(http://climate.Ilnl.gov/cssef/index.html)

(National Center for Atmospheric Research 2013 Annual Report)

(http://www.cgd.ucar.edu/cas/Topics/energybudgets.html 2014_10_14)

Meteorología. Descripción y toma de datos del tiempo atmosférico (GIL, 1999. Pag. 5)

Microclima de proximidad. Conjunto de condiciones atmosféricas modificadas por la presencia del edificio.

Prestación Objeto, componente, composición o servicio exigido por la reglamentación aplicable al edificio (CTE)

Severidad climática. La severidad climática de una localidad es el cociente entre la demanda energética de un edificio cualquiera en dicha localidad y la correspondiente al mismo edificio en una localidad de referencia. En el CTE se ha tomado Madrid como localidad de referencia, siendo, por tanto, su severidad climática la unidad. Se define una severidad climática para verano y una para invierno. (CTE-DB.HE.1, pag 25)

Solicitaciones exteriores Las solicitaciones exteriores son las acciones del clima sobre el edificio con efecto sobre su comportamiento térmico, y por tanto, sobre su demanda energética. (Pag. 17-18 CTE DB-HE 2013)

Temperaturas base Temperaturas a partir de las que la diferencia en grados con la temperatura ambiente se acumula para determinar los grados-día en un determinado periodo. También se la denomina como umbral inferior para el cálculo de los grados-día.

Temperatura de consigna Temperatura en la que se establece que debe mantenerse el interior de un espacio arquitectónico. Acepta el uso de rangos con límite superior e inferior. 
Tiempo atmosférico (Tiempo). Estado físico de la atmosfera en una localidad, o en una región, durante un período cronológico corto (minuto, día, semana, mes).

Ambiente que depara a un lugar el conjunto de condiciones atmosféricas durante un periodo relativamente corto. (GIL, 1999. Pag. 2)

Zona climática. Zona para la que se definen unas solicitaciones exteriores comunes a efectos de cálculo de la demanda energética. Se identifica mediante una letra, correspondiente a la severidad climática de invierno, y un número, correspondiente a la severidad climática de verano. (CTE DB-HE 2013, p. 12)

Se definen 12 zonas climáticas en función de las severidades climáticas de invierno (A, B, C, D, E) y verano $(1,2,3,4)$ de la localidad en cuestión. Se excluyen las combinaciones imposibles para la climatología española. (CTE-DB.HE.1, p.25) 